\title{
MUSKRAT POPULATIONS
}

1962 Winner,

Iowa State University Press Annual Award for the Most Significant New Book

by an Iowa State Faculty Member 


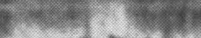

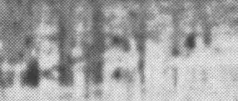

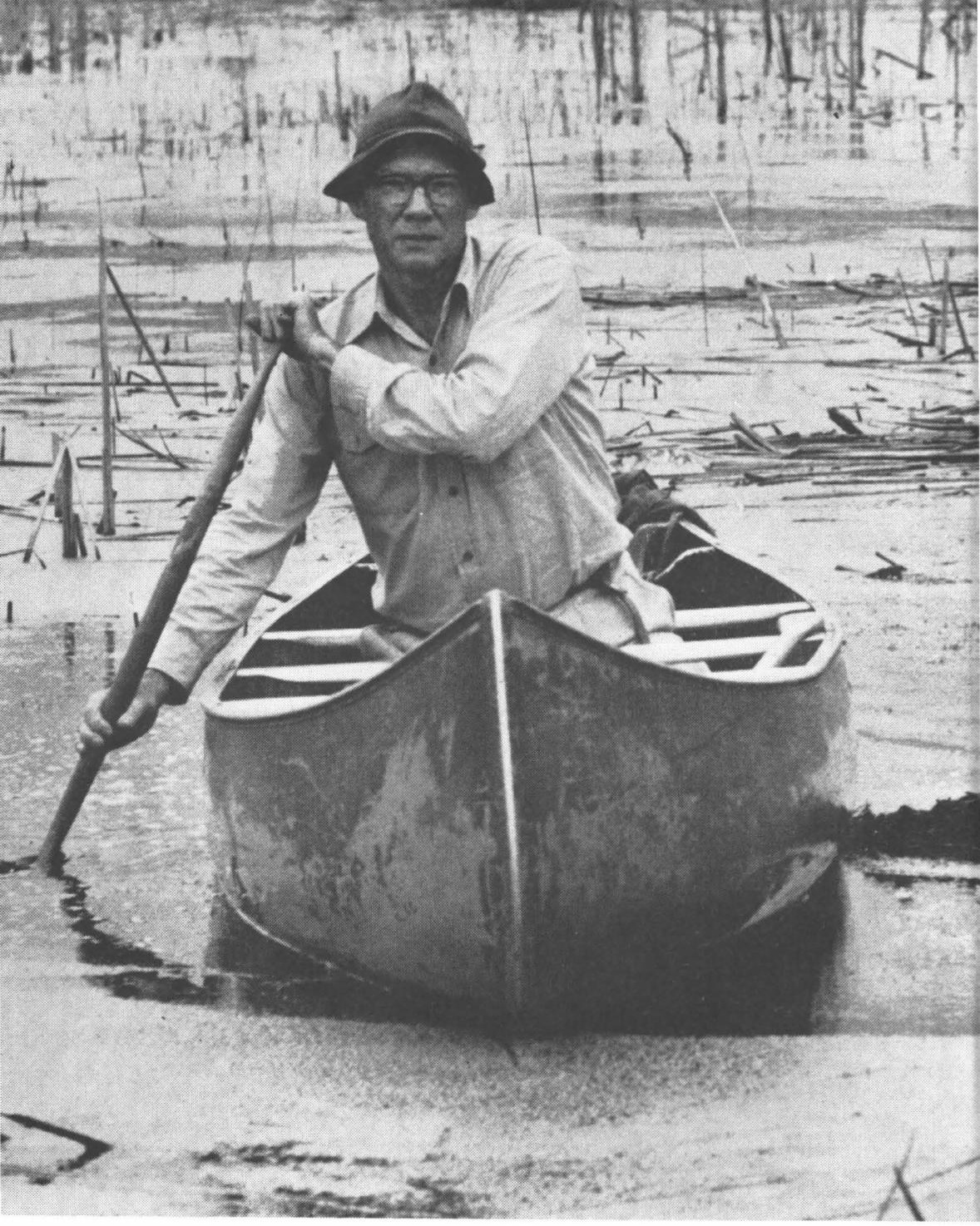

Paul L. Errington, Scientist

(C) LIFE 


\section{PAUL L. ERRINGTON}

\section{MUSKRAT POPULATIONS}

A contribution of the Iowa Cooperative Wildlife Research Unit, Ames, Iowa: Fish and Wildlife Service (United States Department of the Interior), Iowa State University, Iowa State Conservation Commission, and Wildlife Management Institute, cooperating

\section{THE IOWA STATE UNIVERSTY PRESS}

Ames, IOWA, U.S.A. 
PAUL ERRINGTON was internationally recognized for his work in the population phenomena of vertebrates, especially fur and game species, and made extensive studies in this field in North America and northern Europe. Dr. Errington was professor of zoology at Iowa State University before his death in 1962 . He became a staff member at Iowa State in 1932, the same year he received his doctorate from the Univerity of Wisconsin. Recipient of many awards, he was given the American Wildlife Conference Aldo Leopold Medal (1962), a yearly award in recognition of the highest achievement and service to wildlife conservation. He was twice honored by the Wildlife Society for outstanding wildlife publication.

He was author of more than two hundred technical and popular articles and besides this book was author of "Of Men and Marshes" and "Muskrats and Marsh Management."

In 1958-59, Dr. Errington conducted research in Europe on population dynamics of higher vertebrates, with the support of the Guggenheim and National Science Foundations and the Swedish government.

He was Fellow of the American Association for the Advancement of Science and the American Ornithologists Union, and member of the American Society of Zoologists and numerous other scientific organizations.

For the manuscript of this book, Dr. Errington, several months before his death, received the 1962 Iowa State University Press $\$ 500$ annual cash award for its selection as the most significant new book manuscript by an Iowa State University staff member submitted to the Press during the year.

Publication supported in part by grant

from National SCIEnCE Foundation

(C) 1963 by the

Iowa State University Press.

All rights reserved.

Composed and printed by the

Iowa State University Press,

Ames, Iowa, U.S.A.

Library of Congress Catalog Card Number: 63-16669 


\section{Preface}

According to most definitions, the muskrat (Ondatra zibethicussee Appendix A for taxonomy and phylogeny) can be regarded as a highly successful form of life, and, as such, it combines much of what is desirable in a subject for investigation. It is widely distributed and locally abundant over much of its native North America; and, since its artificial introduction in Eurasia during the present century, it has demonstrated its ability to acquire and to hold a vast, racially new, geographic range. It exhibits both generalized and specialized morphology, both a "down-to-earth-practicality" and psychological sensitivity, both wide and narrow ecological tolerances.

As a youth and young man, I learned something about the behavior, life history, and ecology of the muskrat in the course of 13 winters (1915-28) spent wholly or to a substantial extent as a fur trapper in Brookings and Haakon counties, South Dakota, and in Beltrami and Koochiching counties, Minnesota. Then, in 1934, in connection with regular duties at Iowa State University, I began the investigation on which this book largely is based. This research program continued through the spring of 1958 , covering a span of approximately a quarter of a century. Throughout the entire period, the program was recognized as an official activity under the Agricultural Experimental Station of Iowa State University.

My approach in the latter investigation has been conditioned in part by combinations of personal interests, experience, and opportunities for study and in part by the encouraging productiveness of certain lines of biological exploration. I have given special attention to the mortality of the muskrat and to the conditions under which mortality may or may not significantly delimit populations. I am aware of hiatuses in my researches and data and of a certain unevenness in my treatment of population dynamics of the muskrat, but mine has been so much a one-man undertaking that some things have had to be neglected or underemphasized if emphasis were to be placed on others. 
In my opinion, the chief contributions of this long-term and intensive study of free-living muskrat populations have related to manifestations of overpopulation, to territoriality and other forms of social intolerance, to adjustments during emergencies, to epizootiology in nature, to predation, and to the distinctions between intercompensatory and noncompensatory trends in rates of population gain or loss.

To supplement the intensive year-round Iowa studies, I visited representative areas of North America lying between the 35th and the 55th degrees of latitude. These out-of-state studies were chiefly during the summers of 1948 and 1949, with the help of grants from the Wildlife Management Institute and the active cooperation of the Hudson's Bay Company, the government of Manitoba, and public agencies in northwestern United States. Brief field trips outside Iowa included one to the singularly interesting muskrat-vacant swamps and streams of southern Georgia and northern Florida, as a guest of H. L. Stoddard, in April, 1929.

Finally, I took a year's leave of absence for a program of work and travel in northern Europe, 1958-59, of which the greater part was spent in the muskrat's new and probable future range in Scandinavia; this was done through the financial backing of a John Simon Guggenheim Memorial Fellowship, a National Science Foundation grant, grants-in-aid from the Swedish game research council, and cooperative arrangements with especially Lund University, the Northern Museum at Stockholm, and the Norwegian and Danish as well as Swedish governments.

In general, acknowledgments to persons who have been helpful to me in my studies of wild populations-whether by means of their published findings or in personal relations-shall be reserved for appropriate places in text or bibliography. I have been helped by many to whom I feel unable to express appreciation individually. With the passing of the years, I can no longer fully recognize, if I ever could, exactly how much I might be indebted to some people, nor can I adequately trace the origin of concepts somehow growing out of discussions with my colleagues. Perhaps my memorial article (1948b) on the late Professor Aldo Leopold of the University of Wisconsin may acknowledge part of what I owe to his good influence early in my professional career; and, in a similar way, I think of Stoddard and W. L. McAtee, both of whom were with the U.S. Biological Survey in those years.

I am very appreciative of the statistical help that I have received on the Iowa State University campus throughout the muskrat investigations, especially from Professors G. W. Snedecor and F. A. Brandner. For help with special statistical problems, I am also indebted to, among others, Doctors T. W. Horner, E. L. Kozicky, and M. L. Ferguson. 


\section{Contents}

Part 1. Introduction

1. The Muskrat: A Semiaquatic Rodent 3

2. Development and Reproduction of the Muskrat . . . . . . 32

3. Territoriality, Home Range, and Movements of the Muskrat . . . 63

Part 2. Case Histories of the Iowa

Observational Areas

4. Objectives and Techniques of Regular Observations . . . . . . 85

5. The Ruthven Marsh Area, Northwestern Iowa . . . . . . . 104

6. The Estherville Marsh Area, Northwestern Iowa . . . . . . . 125

7. The Wall Lake Area, North Central Iowa . . . . . . . . . . 151

8. The Little Wall Lake Area, Central Iowa . . . . . . . . . . 204 
9. The Goose Lake Area, Central Iowa 248

10. Central Iowa Streams and Outlying Waters: Introduction and Story City Block . . . . . . . . . 288

11. Central Iowa Stream Areas and Outlying Waters: Ames-Gilbert Block . 332

Part 3. Biogeography of the Living Forms of Muskrats

12. The Muskrat of Eastern United States and Southeastern Canada, Ondatra zibethicus zibethicus . . . . . 391

13. The Muskrats of North America Other Than Ondatra zibethicus zibethicus . . . . . . . . 421

14. The Muskrat Over the World . . 475

Part 4. Concerning Population Dynamics of THE MusKrat

15. Self-Limiting Trends and Intercompensatory Adjustments in Muskrat Populations . . . . . . . . . 489

16. Predation and Muskrat Populations . 509

17. The Muskrat and Population Cycles 522

\section{Appendices}

A. Taxonomy and Phylogeny of the Muskrat 541

B. Information on the Biotopes and Muskrat Populations of Round Lake, 194558 , Contributed by James G. Sieh . . 545

C. Calculations of the 1950 Fall Population of Muskrats at Wall Lake

D. Descriptions of Central Iowa Stream Areas and Outlying Waters . . . 550

E. Central Iowa Weather, 1932-57 . . 553

F. The Varying Fortunes of Muskrats in Eastern South Dakota, Particularly in the Oakwood-Tetonkaha Lake and Marsh Chain of Brookings County Over a Period of Nearly 30 Years 
G. Quotations from a Letter (January 28, 1949) from William P. Baldwin, Jr., in Explanation for the Absence of True Muskrats in Florida and Adjacent Georgia

H. Special Local Studies of Upper Mississippi River Muskrats

I. Kent Island (New Brunswick) Muskrats . 577

J. Concerning the Nebraska Sand Hills and Especially Sather's Muskrat Study

K. Excerpts from Glass (1952) Concerning Muskrats and Muskrat Habitat in Modern Oklahoma

L. Concerning the Exceptionally Life-Rich Marshes Along the East Side of Great Salt Lake

M. Montana Muskrats and Contagious Diseases

N. Studies of High Altitude Muskrats on and About the Beartooth Plateau, South Central Montana and Northwestern Wyoming

O. Austin W. Cameron's Notes on Localities Occupied by Ondatra obscurus in Newfoundland

P. Supplementary Information on the Hudson's Bay Company's Steeprock Lease, Manitoba

Q. Excerpts from a Paper on Muskrats at Delta, Manitoba, Presented by Peter F. Olsen at the 18th Midwest Wildlife Conference (Lansing, Michigan, December 10, 1956)

R. The Hudson's Bay Company's Cumberland Lease and the Manitoba Government's Summerberry Fur Rehabilitation Block

S. Muskrats of the Mackenzie River Delta . 612

T. Concerning Effects of Ditching on Muskrats of Tidewater Marshes, Especially Delaware 
U. Concerning Muskrat Studies on the Blackwater National Wildlife Refuge, Dorchester County, Maryland

V. The Muskrat at Mobile Bay, Alabama . 624

W. Concerning the Louisiana Muskrat in Its Main Range

$\mathrm{X}$. Concerning the Colorado Muskrat in Its New Range in Southern California

Literature Cited 
Part 1

Introduction 



\section{Chapter 1}

\section{The Muskrat: A Semiaquatic Rodent}

THE MUSKRAT'S COMMON NAME is accounted for by the odor associated with the species during the breeding season. Both sexes have special glands situated beneath the ventral skin near the external genitalia. With the enlargement of these glands, a yellowish, musky-smelling substance is secreted and deposited at stations along the routes of travel of muskrats, and at defecating posts, bases of lodges, and mud bars. Stevens and Erickson (1942) concluded that the musk oil contained a mixture of cyclopentadecanol and cycloheptadecanol and corresponding odoriferous ketones. The scent retains its properties suffciently long after exposure to air to serve effectively as an advertising medium - up to several days in intensities readily detected by the human nose and possibly for weeks under circumstances favoring retention. Grinnell, Dixon, and Linsdale (1937, p. 744) noted that dried glands kept their odor indefinitely.

\section{THE MUSKRAT IN THE WATER}

The coat of the grown muskrat may be considered waterproof under ordinary conditions. It consists of dense and silky underfur and coarser, longer, and peculiarly glossy guard hairs. The long, laterally compressed tail is rudder-like. Hind feet are modified for swimming by fringes of stiff hairs, as well as by a side-twist of the ankle joints. The much smaller fore feet are suitable for rather skillful manipulation. Ears are small and almost hidden in the fur. Eyes are also small and may protrude noticeably. Nostrils, lips, and tongue are adapted for underwater activities, and the animals have conspicuous incisor teeth with which to gnaw and transport submerged materials.

Mizelle (1935), after reviewing some of the controversial statements in the literature concerning the muskrat's manner of swimming, wrote of his experiments with presumably $O . z$. rivalicius in a concrete 
pool. His animal was clearly visible in every phase of swimming on and below the surface of the water. In neither surface nor submerged swimming did it use its fore feet, but held them motionless under chin with palms inward. (Iowa individuals, however, have been observed using the fore feet in leisurely swimming.) In surface swimming, Mizelle observed the animal propelling itself forward with alternate strokes of the hind feet. The propelling movement came chiefly from the ankle joint, but to a slight degree from the knee. Movement of the femur was imperceptible. On the forward stroke, the foot folded to facilitate its return to a forward position. Practically no undulation of the body was noted, nor was the tail used in the surface swimming, it being trailed in a straight line. In turning, the animal altered the strokes on one side or the other. The fore feet were used to assist in submergence. The estimated speed for surface swimming was one to three miles per hour, which is about the speed shown by undisturbed animals in the wild.

The strokes of the hind feet in submerged swimming were as in surface swimming except that they were made in a nearly horizontal plane instead of vertically. The tail was used vigorously as a scull at all times when the animal was under water, making lateral strokes toward the feet in the backward motion. When the muskrat was stimulated, its tail strokes became faster than the combined rates of both hind feet; but, in ordinary swimming, the tail strokes equalled the foot strokes, tending to make the animal's course a straight line. The animal turned on its course underwater in the same manner as in surface swimming.

Muskrats are capable of surprisingly swift lunges under water, as in pursuit of fishes, during fights, or when suddenly alarmed. During some fights, participants may pop out of the water with about the speed of big fishes striking at flies.

Readers interested in the anatomical basis of the muskrat's swimming movements may find detailed accounts in recent German papers. Müller (1952-53) wrote mainly about the skeleton of the animal as a whole, including some descriptions and illustrations of movements of extremities, whereas Eble (1955) devoted his corresponding paper to musculature in relation to movements of extremities.

Surface swims by muskrats living in regular residence seldom exceed a quarter of a mile, and such long swims are usually to be witnessed on the part of shore-dwelling muskrats swimming out on a lake or open marsh to feed. When swimming in rough water, the muskrats are apt to swim submerged, coming to the surface from time to time for air.

Our Iowa experiments with fur-refuges on state-owned marshes trapped by the public have shown that the setting of traps at the refuge boundaries may effectually "suck out" the muskrats for a distance of somewhat less than 200 yards into the refuge, provided that there were near the boundaries lodges or other resting places to attract swimmers. At the same time, the population living 200 yards or deeper 
in the refuge seemed to be generally unaffected by the intensity of the trapping effort outside. The fact that this depopulation of the outer zone of a refuge occurred either during the open water of late fall or in early winter after freezing over of the entire surface of the marsh is indicative of the freedom enjoyed by northern muskrats in their under-ice movements.

Trappers have reported muskrats lying submerged beneath thin ice, expelling bubbles into the water and, after intervals, drawing the bubbles in again, or lying with bubbles at the ends of their noses, alternately drawing in and letting out. I, too, have seen muskrats behaving in this way, whatever may be the explanation. The general supposition is that the expired bubble becomes oxygenated through contact with the water, and ready for reuse by the muskrat in the space of minutes, but consideration of the physical properties of gases and the few parts per million oxygen content of most natural water makes it appear most doubtful that a muskrat can get sufficient oxygen from the procedure really to benefit therefrom-except insofar as the breathing out and in may make for more efficient utilization of the oxygen already in the bubble. Or, muskrats swimming under the ice may have access to large quantities of oxygen-containing bubbles. Atmospheric air may lie between water and ice, entering through cracks caused by buckling of the ice or somehow filling in as water recedes from below. (But it should not be assumed that all bubbles under the ice contain air or oxygen from any source, for, in many cases, it is apparent that they do not.)

In underwater travels under the ice, muskrats make occasional stops at feed houses and push-ups, as well as at bubble patches, but they certainly are adapted for prolonged diving. Koppanyi and Dooley (1929), experimenting in the laboratory with reflexes inhibiting respiration in muskrats on the point of recovery from anesthesia, found that submergence apnea would result whenever the nostrils were brought in contact with the water. Manipulation of the position of the head also induced apnea. Both submergence and postural apnea were accompanied by rises in blood pressure and slowing of the heart rate.

Respiration in diving mammals has been studied particularly by Irving (1938a; 1939b; 1939). Seals, beavers, and muskrats can withstand submergence about five times as long as can land mammals. Their respiratory adjustments, though mammalian in type, are extreme and manifested, for one thing, by insensitivity to carbon dioxide. The failure of carbon dioxide as a respiratory stimulus in divers implies that it is not effective in activating the quick internal responses that mammals generally make to escape asphyxia during apnea. The respiratory adjustments of the divers do resemble those of land mammals except that the divers adjust with quantitatively greater effectiveness. When breathing of a mammal is arrested, the blood flow through the muscles decreases while increasing through the brain.

One of Irving's experimental subjects was a 600-gram muskrat 
(probably a subadult of $O$. z. macrodon), which endured submergence for 12 minutes in the laboratory. It, like other divers experimented with, relaxed muscular activity. Muscular relaxation is in itself an adjustment to avoid wasting the oxygen supply in useless struggles. In contrast with the violent struggling of a land mammal when forcibly immersed in water or prevented in any way from breathing, the muskrat accepted the situation with equanimity and waited with muscles relaxed for several minutes. It then deliberately explored means for escape, and, as in the case of other divers, did not begin violent struggling until 5 to 10 minutes had elapsed.

But diving ability in a mammal is not solely a matter of passive oxygen conservation, for a submerged diver may be quite active. A most interesting adaptation of muskrats and other diving mammals is their apparent faculty for running up an "oxygen debt," for "borrowing" oxygen from tissues outside the lungs.

Muskrats have been observed to dive longer than the 12-minute period of forced submergence of Irving's animal. Smith (1938) cited examples of two dives timed by W. A. Gibbs for a muskrat caught alive in a fish trap. It first remained down for 17 minutes, then surfaced and, becoming alarmed, dived again almost immediately, staying under for 10 minutes. It refused to dive again. Throughout the observations, the animal was in plain sight of Mr. Gibbs and could not have obtained air except while on the surface.

On several occasions, I have surprised transient muskrats in pools or streams where they had no access to existing burrows, and I have forced them (generally by touching them with a pole) to continue diving until they were exhausted enough to capture alive. A typical instance relates to a newly mature male encountered April 19, 1944, at the edge of a small oxbow pool. At my approach, it dived, reappearing in approximately 10 minutes over the spot where it had dived. I stood in the middle of the pool for a good half hour, forcing it to dive as soon as I could, each time that it came to the surface. It would lie, partly concealed, under the dead leaves on the bottom and, about a half minute before surfacing, would expel a stream of bubbles. It finally seemed unable to continue diving, though very willing to attack as it was shoved to land and held with a pole for marking.

Other muskrats may show more versatility in their efforts to escape capture. They may succeed in doing so, as through quickly digging a short, shallow burrow, and coming up under the sod of the bank above the surface of the water. A good digger working in soil of the right consistency may almost make the mud squirt through the water and may be lost from sight in a few seconds. Unquestionably, such an accomplishment has survival value for individuals pioneering in strange waters.

While submerged, the muskrat may not only be adept at digging and gnawing when having a soft medium to work with, but it may also put on some of its best displays of prowess in winter, as it cuts through frozen material. Its incisor teeth protrude ahead of the cheeks 
in a way most serviceable for underwater work and for cutting away of rootstocks of cattails, bulrushes, and reeds at the frostline under the ice. It may cut through thick lake ice from beneath (though usually choosing the thinner places or openings of cracks) or, likewise from beneath, cut away the ice of a frozen plunge hole in an unused lodge. Some of the most spectacular rehabilitation of long-frozen lodges is forced, as when a heavy winter rain or thaw floods the nearly dry tunnels in which the muskrats had previously been living under the ice somewhat away from the lodges.

Another way in which the muskrat may show adaptation for its aquatic way of life is in its respiratory tolerance for foul air inside of lodges during cold-climate winters. Over nearly all of North America where winters are sufficiently cold to seal a marsh with ice for two or three months at a stretch, muskrats may be found living in their familiar dwelling lodges in chambers having about as little fresh air as one might imagine. These lodges are not of uniformly tight construction, but the chambers of hundreds examined in early and midwinter were, to my eyes, virtually air tight above the water line. Iceshells lining the lodge chambers may be built up to a thickness of two to four inches through splashing or contact with wet bodies. While it need not be assumed that such shells provide a perfect seal, they certainly can leave few places through which air may be expected to pass very rapidly. Some of the lodge chambers, furthermore, may reek of hydrogen sulfide or other decomposition products, yet, there in the chambers, with unfrozen water at their feet, the muskrats characteristically huddle. They may huddle together, even up to a dozen or more, doubtless all but filling a chamber at times. Now. and then, an animal may dive in the plunge hole and swim off under the ice or sit or float by itself in one of the small feed houses or in the opening of the ice under a push-up or in an air space under a ridge of pressure-buckled ice; but field observations clearly show that the dwelling lodges, icelined or not, are the main day and night retreats of muskrat populations occupying the central parts of marshes as long as the water level remains well up in the plunge holes.

Huenecke, Erickson, and Marshall (1958) took air samples at weekly or biweekly intervals from individual muskrat lodges on eight Minnesota marshes, November, 1949, through March, 1950. For a total of 245 samples, the...

. . . only gas found to accumulate to any extent in muskrat houses in winter was carbon dioxide....

When the carbon dioxide accumulations were plotted by dates, there was a gradual build-up from less than 0.5 per cent in early November to a high of 5-7 per cent in early February, followed by a sharp decline to less than 0.5 per cent by mid-March. The accumulation may be related to the external snow cover and the formation of an icy shell $1 \frac{1}{2}$ inches thick on the inside of the walls of the houses. ...

The oxygen content of the air inside muskrat houses was inversely related to the carbon dioxide content. This balance is probably due to the respiratory activities of the muskrats occupying the houses. . . . 
This investigation showed that, under the conditions that existed during the winter of 1949-50, no gas accumulations in muskrat houses were found that would have been lethal to muskrats. . . No correlations were found between carbon dioxide concentrations and atmospheric temperature or precipitation.

\section{THE MUSKRAT OUT OF THE WATER}

The muskrat is awkward on land or on the surface of ice. In its own way, nevertheless, it can cover ground, walking or bounding. Differing rates of cross-country movements have been recorded during the Iowa investigations, but the following may be a fairly typical example: One thin old male, a late January wanderer, which I trailed in the snow without its awareness, covered 2,800 yards in about a half day, with several rests enroute.

The muskrat's main problem, in the event of prolonged activity away from unfrozen water, is not so much in getting around as in staying alive. As a species, it is sensitive to freezing cold. Gerstell (1942, pp. 58-59) experimentally deprived six captive $O$. z. zibethicus of food and and water until death. Two animals, which were subjected to a temperature of zero degrees Fahrenheit with a constant articificial wind of 5.8 miles per hour, survived approximately 40 hours and lost an average of 13.2 per cent of their starting weights, whereas two animals not exposed to the wind lived over 90 hours, with an average loss of 20.7 per cent. The other two, kept in still air at temperatures of 36 to 48 degrees, died after an average of 200 hours, after losing an average of 30.0 per cent of their starting weights.

An abundance of field data exists on the condition of winterwandering muskrats in Iowa, South Dakota, and northward. The first part of a muskrat's anatomy to freeze is the tail, and this may freeze solidly to within a few inches of the body without necessarily lethal consequences to the victim. The animal then chews away the frozen flesh, after which the bare tail vertebrae tend to be lost. Trappers' catches from Iowa marshes show variable numbers of adult muskrats having such stub tails. In advanced cases of freezing, still-living muskrats may be seen with eyes and toes frozen.

No field data of which I know adequately demonstrate the lengths of time that muskrats may live when exposed to given temperatures. I do know that ill-situated individuals may wander in snow or on top of the ice for a period of days at air temperatures of around 10 to 15 degrees Fahrenheit, yet suffer little more than frost-bitten tail tips, if that much, provided that they keep well nourished and avoid violence. It should be made plain that even ill-situated muskrats need not always be fully exposed to the wind and cold of a winter day. They may seek shelter in snow drifts and ice ridges or improvise nests in which to spend a few hours in weedy or rushy growths, corn shocks, and culverts, or enter badger or woodchuck holes or the root-tangles of trees.

Outside the water, a strong, full-sized muskrat, using fore feet and teeth, can penetrate a markedly resistant medium. It is not 
equipped to displace tremendous quantities of hard-frozen marsh bottom in quest of food, but it can utilize frozen food in concentrations - rootstocks of a cattail (Typha) or bulrush (Scirpus) clump if not too inaccessible, or a cache of ear-corn (Zea Mays) or tubers of duck potato (Sagittaria). In north-central waters that are very shallow at freeze-up, the last places having living fishes (such as the bullheads, Ameirus) may be the channels and entrances of muskrat habitations. When the water in these freezes, it may be packed with fishes for hungry muskrats to gnaw on, the frozen fish and encompassing icy matrix together.

During winter crises, Iowa muskrats remaining in dry marshes or stream-beds spend most of their time underground in burrows kept plugged with mud. The mud plugs quickly freeze in cold weather. When an animal living within the burrow emerges to forage outside as it generally must under such circumstances unless it has duck potatoes or corn stored inside - it has to gnaw its way out. Gnawing out of frozen burrows and lodges is done so much at will by vigorous muskrats that I can hardly conceive of muskrats being imprisoned therein to the extent of starving. They may starve but not because of inability to get out of their living quarters.

Once they find themselves outside of and separated from living quarters by frozen barriers, they may not be able to get back inside, and may die outside, only a few feet from the shelter of a subsurface retreat. Sometimes they seem unaware of the exact location of channels or chambers concealed by the ice, or they may be unable to do the necessary work while exposed to outside cold. I also think that a muskrat has far less inherent ability to gnaw downward than upward through frozen material.

On occasion, a muskrat, upon returning to its burrow after outside foraging, may find the passageway plugged from within by another occupant, and the plug frozen and indistinguishable as an entrance site. One such "locked out" individual was observed as it sat beside a small hole it had cut in a crack over the tunnel leading to its lodge. It still had 12 to 15 cubic inches of frozen mud to remove before it could enter, and it was already too lethargic from cold to keep working steadily.

An adult muskrat's powers of withstanding thirst are manifestly superior to those of a young one, but its limits of tolerance in this respect are hard to define. The very last muskrats to be found alive in the powdery peat bottoms of Iowa marshes after months of drought exposure are mainly, sometimes exclusively, adults (Errington, 1939a; 1943; Errington and Scott, 1945), so proving that these can keep alive for a protracted time on what moisture they get from dew and plant juices - that is, if they stay in holes 'or otherwise conserve the water in their bodies during hot weather. Nor are young animals, despite their much higher mortality rates during drought, without resistance to drought conditions. A food-rich bulrush of the Cheever Lake series in northern Iowa was dry from spring through the fall of 1940, 
yet its muskrat population of mid-November consisted of its three original pairs from spring and their nine successfully-reared young. At times of more acute emergencies, as on Utah and Oregon deserts, individual muskrats may stay alive long enough to travel up to 10 miles or more away from anything that might be called habitable muskrat environment. Flooding of coastal marshes by undrinkable, wind-driven salt water may result in spectacular losses of muskrats (Arthur, 1931, p. 338; Smith, 1938; Dozier, 1947a). Of these authors, Smith reported $O$. z. macrodon dying in two or three days after becoming marooned on high spots by salt water.

Against man, large birds of prey, dogs, coyotes, and medium to large sizes of flesh eaters rather generally, a muskrat surprised away from water may be in a hopeless situation unless it finds refuge in protective cover. The less powerful foxes and minks may easily kill the smaller-sized muskrats that they can seize on land, though the larger muskrats may be able to take care of themselves in the event of attacks. Much depends on the psychological attitude of an adult or subadult muskrat that is being overtaken or confronted by a mink on land or ice. If the muskrat becomes panicky and tries to escape by running, the mink may have little trouble making a kill; if the muskrat carries the fight to the mink, it stands a far better chance of defending itself. If it backs into a hole or finds some other advantageous position in which it need not present much except teeth to an adversary, a muskrat may be too formidable for a mink to care to attack. It may not have the comparatively limitless stamina, the hard-muscled toughness, and the tenacity of life that the mink has, and it rarely shows anything of a mink's faculty for directed attack; but its bite is not slow in delivery and, bite for bite, may lay open as much flesh as the bite of a mink.

Habitual transients among land-active muskrats may be further beset by a sort of occupational hazard in the form of the wounds of intraspecific strife. That muskrats can die of wounds received from their own kind is, or should be, common knowledge to anyone who might examine large numbers of those dying about the peripheries of dense or friction-ridden populations. That muskrats can continue living while severely cut up also is, or should be, common knowledge to observant trappers or outdoorsmen having much to do with the species (Seton, 1929, vol. 4, p. 597; Errington, 1939a; 1943, pp. 91621).

Selected examples of muskrats bearing strife wounds might include a drought-evicted adult female collected in September while journeying across the higher land between two marshes. It had two very severe wounds on the abdomen, just below the sternum, and these wounds and parts of liver and intestines were crawling masses of fly larvae. The animal was vigorous and making progress toward healing the wounds, though I felt at the time that it probably would have died from them. A second fall-wandering adult female had a severe, nearly healed, wound below the sternum and a wound in the region of a kidney 
through which putrid-smelling intestinal contents had penetrated. Whatever may have been its prospects for recovering, it was far from helpless when collected. Another fall transient of undetermined age and sex was seen sitting on a lake shore, resting on its elbows; one fore leg had been so mangled that it was barely hanging on; the other fore leg also had been bitten into uselessness; a two-inch gash opened the abdomen; and there were numerous fresh and healing cuts about head, neck, and hind quarters.

During the fur trapping months, many of the muskrats wandering about the countryside are those having wrung off feet to escape from steel traps. While the mortality rate of such animals is undoubtedly high (Arthur, 1931, pp. 354-55; Errington, 1943, pp. 885-86), recovery from trap injuries is by no means unusual. Warwick (1940) reported that about 10 per cent of the muskrats taken during the extermination campaign in the British Isles had previously wrung out of traps, to recover in good flesh and with cleanly healed wounds.

As long as living conditions for local muskrats are fairly good, the general run of individuals bearing severe wounds comprise doomed transients, cast-outs, or similar biological wastage. Differences in their abilities to recuperate from great physical damage may not then count very much from the racial standpoint. During crises, however, a battered - if not hungry and thirsty - group may be that part of the population upon which the natural restocking of muskrats in countywide areas may depend.

I have notes on the muskrat occupants of a food-poor intermittent stream representative of the better muskrat habitats of an immense area of western South Dakota. My December, 1924, catch of 149 pelts was badly damaged from strife wounds, with about half of the pelts showing major wounds in all stages of healing. For muskrats of the watershed - which at that time was about as habitable for them as it ever is - the rest of the winter imposed a highly selective test that eliminated before spring many more than survived. Even so, the emergencies of the winter of 1924-25 were benign for the muskrats of western South Dakota compared with the droughts of the thirties, which left hardly a muskrat alive within a 100 -mile radius of the above mentioned watershed. Surely many of the muskrats furnishing the stock for later pioneering and repopulating had to possess durability as well as luck.

\section{CHOICE OF HABITAT}

As represented by its numerous subspecies, the muskrat can adjust to a surprising geographical variety. It can adjust to environmental differences ranging from subtropical rivers and coastal marshes to arctic tundras and deltas. In North America, its subspecifically collective range is understandably delimited by mountains and semideserts of the West, by the true deserts of the Southwest, and by the almost year-round bleakness of the Far North. The reasons for its thinning out and disappearance in ecologically borderline habitat 
of northeastern United States are passably apparent. The Southeast, however, is a region of distributional mysteries, and muskrats simply do not live over a vast terrain that does not look too uncongenial for them. This will be treated at greater length farther on in the book, but the thought may be left here that many of the southeastern streams having no muskrats are similar in appearance to those of the same watershed that $d o$ have muskrats within a few hundred miles northward.

Within a given subspecific range, muskrats may be found in a diversity of habitats. O. z. zibethicus, in the Mid-West, may live in clear streams and lakes or in sewage drains, in clean- and in foul-smelling marshes and sloughs and ponds, in deep waters or in the puddles of ditches and tile flows. Northward, its range goes far into the wilderness of the Pre-Cambrian Shield south of Hudson's Bay; eastward, into the rocky streams of the upper Appalachians and the New Jersey coastal marshes; southward, into all of the Gulf States except Florida, to the edge of the subtropics. In the Great Plains, O. z. cinnamominus may live in big rivers and small, in intermittent streams and artificial reservoirs, in headwater pools and extensive marshlands. $O$. $z$. osoyoosensis of the Rocky Mountain states may live in swift, clear streams of foothills and upper plains, in irrigation ditches and seepages, in natural marshes of lowlands, in mountain valleys, in beaver pools of both low meadows and high altitude creeks, and, sometimes, in the waters of plateaus. O. z. albus, of the Mid-North, may live in typical marshes, in meandering and in fast-moving streams, in the deltas of river systems, in bogs and swamps, in places along the shores of large lakes, in parts of the subarctic tundra or Barren Grounds, and in the heterogeneity of wetlands underlain either by limestone strata or by Pre-Cambrian rock.

The above four subspecies are wide-ranging ones with which I can claim a certain personal familiarity, and, in my opinion, they are all much the same animal behavioristically. Of course, they do not maintain uniform abundance throughout the different grades of habitats occupied, but they all respond, if present, to quiet waters having either edible marsh plants or other suitable food available near by. No doubt like generalizations might apply to a fifth widely distributed subspecies, O.z. spatulatus, of the Canadian and Alaskan Northwest, as well as to some of more restricted distribution, but, as yet, I lack sufficient knowledge of them to judge.

Although water must always, in minimal amounts and within a minimal range of stability, be regarded as integral to the muskrat's way of life as a free-living species, the value of water to the muskrat is not always proportional to the quantity thereof. There can be such a thing as too much water for the muskrat's well-being, as will be discussed later in connection with effects of flooding. Or the water can be too rough, as on wave-swept open lakes, especially those of large size or situated on high plateaus subject to strong winds. Or the fluctuations in water levels may be excessive-even in the space of 
hours-not only through the occasional flash floods occurring naturally but also through human manipulation of tremendous volumes of water in river basins developed for power, transportation, or flood control. Sudden rises up to several feet above normal may be expected as a result of wind tides on some marshes lying adjacent to, and connected with, large inland lakes. For coastal marshes, storms backing up salt water may have their own distinctive consequences for muskrats and their habitats.

Or the water may be too swift, as in canyons, rapids, etc., but it is often difficult to judge exactly when water becomes too swift to be navigable by muskrats. I recall the sluiceway of a small dam on the Lower Souris marshes of North Dakota. Muskrats had been observed to be unable to swim against the current immediately above, and the rate of flow there surely was not faster than that often to be seen along practically the whole length of many mountain streams and many "white-water" stretches in the Pre-Cambrian region centering about Hudson's Bay.

The best all-around food for midwestern muskrats is cultivated ear corn; and stream-dwelling populations of the corn-belt states may conspicuously reorient themselves according to the local accessibility of corn fields (Errington, 1938; 1941a). With regard to self-propagating native foods, the muskrats of northern United States usually show the greatest responsiveness to cattails (Johnson, 1925; Errington, 194la; 1948a; Dozier, 1945; and numerous other authors). In southern coastal marshes, cattails may be considered undesirable by muskrat managers, O. z. rivalicius greatly preferring certain bulrushes, especially Scirpus olneyi (Lay, 1945; Lynch, O'Neil, and Lay, 1947; O'Neil, 1949). Bulrushes may include high-rating food plants of the more northerly marshes, as well. While inspecting muskrat habitats in Manitoba and Saskatchewan in 1948, I was reliably informed that $O$. z. albus often displayed preference toward the horsetail called "goose grass" (Equisetum fluviatile) rather than toward either cattails or bulrushes. It should be brought out that appraisals of utilization of a given food - for example, of a species of cattail - by muskrats of a region may involve many unknowns. Questions of variations in flavor or nutritive qualities may relate not only to soil, water, growing season, and the usual run of expected variables but also to taxonomic differences (Hotchkiss and Dozier, 1949).

Among other food plants that may be selectively chosen by muskrats, or that may be patently attractive enough to cause muskrats to concentrate in a part of a marsh, lake, or stream, are burreed (Sparganium), duck potato (Sagittaria), sago pondweed (Potamogeton), wild rice (Zizania), and some of the willows (Salix), and sedges (Carex), smartweeds (Polygonum), legumes, and composites. Other plants, like reed (Phragmites) and yellow water lily (Nuphar), may not appear to be particularly relished yet may be important in the lives of muskrais lacking the preferred types (Errington, 194la; Bellrose, 1950). Midwestern muskrats seem not to be very enthusiastic about flesh of lower 
vertebrates as a dietary staple, but hungry transients frequently settle in stream pools or in the vicinity of lake-shore springs having massed assemblages of fishes or frogs. These they exploit much as minks do or even subsist on the frozen fishes and frogs stored by the minks (Errington, 194la). However, the muskrat stomach does not have any special morphological adaptations for a carnivorous diet (Luppa, 1956).

Takos (1947), in his careful study of muskrat feeding in Maine, used forage ratios to express correlations between occurrences of plant remains found on feeding platforms and the relative abundance of the same species of plants in the environment. His muskrats tended to utilize the most available plant species, and he found this tendency especially marked whenever the plants occurred both in high frequencies and in dense stands. Phenological events in the life histories of the plants also had a bearing on the quantities consumed by the muskrats. Arrowheads and wild rice mature more slowly than the semiterrestrial plants and are almost always submerged in the early growing season. The sedge, Carex lacustris, was the only plant noted by Takos for which the forage ratio indicated a highly significant degree of selection during any of the growing season periods. He ascribed this disproportionate utilization to the fact that early spring floods drove many muskrats to somewhat elevated sedge-meadows where the sedge was one of the first plants to produce succulent green parts after the spring thaw.

Bellrose (1950) found that Illinois muskrats, while exhibiting a great deal of individual variation in food habits, had a marked preference for some plants, especially in winter. However, he felt that plants of high palatability may not support as many muskrats per unit of area as other foods that are less palatable but more nutritious.

In Iowa, the muskrat may show about all degrees of either indiscrimination or selectiveness in feeding and food-gathering. Individuals may have their favorite (or accustomed) shore retreats where they dig out tubers. They may have their overland routes to corn fields, apple orchards, or truck gardens. Others, especially in summer, may virtually mow the shore vegetation within easy reach of the water tree seedlings, grasses, sedges, ragweed, cocklebur, or smartweed growths, eating very nearly everything of manageable size and consistency that they may come to (Errington, 194la). In winter, even when lacking corn or rootstocks of cattails and bulrushes or other rich sources of heat and energy, muskrats at this latitude may still survive on comparatively poor cold-weather diets. If the diet is neither too harsh nor too innutritious, some solid carbohydrate or fat in combination with some flesh and green food may prevent excessive loss of weight and give the animals a chance of getting through a short winter.

The medium in which burrows must be dug influences the distribution and status of bank-dwelling muskrats when extremes of hardness or looseness are concerned. At one extreme are rocky or pebbly 
shores offering no den sites for miles except in occasional cracks or under the roots of big trees. At another, are friable shales or sands that hold the shape of burrows chiefly in proportion to the amount of binding by roots. Intermediate between the extremes are the agricultural soils and subsoils in which muskrats excavate burrows by the millions across central North America. Clay subsoils appear to be the muskrat's first choice for digging in the midwestern states. Elaborate burrow systems in firm soils, once established and favorably situated with respect to water and food, may be occupied and maintained more or less regularly for decades, even when subjected to considerable disturbance. And anything protecting burrow systems from caving or digging out by enemies may appreciably enhance the attractiveness of particular retreats for muskrats. Burrows may be dug under sturdy tree roots or boulders or fence corners, under junk piles or idle farm machinery, bridge structures, water tanks, foundations of buildings, hay stacks, wood piles, docks, wrecked boats, and so on.

In marshes, proper, heavy growths of emergent vegetation suitable for lodge-building - notably cattails and bulrushes - commonly attract muskrats, irrespective of what might be the nature of the shores. Submerged plants seldom provide building materials the equivalent of the superior emergents, though coontail (Ceratophyllum), algal growths, and other easily wadded plants may often be used in lodge construction.

The presence of other muskrats or their habitations may have an evident conditioning effect on the behavior of muskrats in search of living quarters (Errington, 1940; 1943, pp. 879-80). Muskrats are naturally attracted to places where their species lives or has lived and, within limits, tend to gather thereabout unless driven out or psychologically repelled by the residents. This may be noted especially on the more homogeneous tracts of marshes at times when populations are building up after drastic reductions. With large expanses of suitable habitat awaiting recolonizing, the marshes, lakes, and streams having vacant or underpopulated sets of lodges or burrows draw in the muskrats decidedly better than do those that are ecologically similar though lacking the lodges or burrows. Even a very old sign may have its attractions, and newcomers rebuild flattened lodges or burrows having settling or caved-in roofs. Digging of new burrows or erection of new lodges on the part of late summer and fall populations expanding into unoccupied habitat may be the forerunner of further expansion in the years to come.

Unless previously-used burrow systems remain death-traps of infectious disease, the propensity of muskrats to investigate them has its advantages for the species. Parts of streams that are generally the last to be abandoned during droughts tend to be among the ecologically superior for muskrats and at the same time well enough honeycombed with burrows to attract muskrats again after the water returns. Along Iowa drainage ditches intersecting corn fields, stored ear corn in the 
ramifications of trapped out burrows may provide an added inducement for spring newcomers to settle and breed in the better places, or in those likely to be near good sources of food year after year.

At least our north central muskrats rarely appear to be directly influenced in their choice of habitat by the presence of enemies other than intolerant or hostile members of their own kind - although they may at times avoid parts of their individual home ranges (especially on or near dry land) that they learn to regard as dangerous. It has been my observation that, if a muskrat finds available the sort of habitat having an attractive or livable combination of features, it will try to establish residence there. A wooded island in a marsh may have a family of horned owls (Bubo virginianus) and shores packed with tracks of mink and raccoon (Procyon lotor); the marsh waters may literally teem with snapping turtles (Chelydra serpentina) or with pike (Esox) or similarly carnivorous fishes; the surrounding mainland may be hunted over by more horned owls, minks, and raccoons, as well as by foxes (Vulpes), coyotes (Canis latrans), or dogs; yet, other things being satisfactory, the marsh is likely to support muskrats in abundtnce, bank- and lodge-dwellers alike.

On the other hand, old-time naturalists were prone to attribute the general scarcity or absence of muskrats in different regions to pressure of enemies, either human or subhuman. Among modern authors, Brander (1951) repeatedly emphasized the sensitivity of Finnish muskrats to disturbance or to the presence of predatory enemies.

Outright removal of entire population groups may be considered demonstrated by the results of annihilative campaigning against the muskrat as an introduced pest in the British Isles (Warwick, 1940). In parts of North America, the species may be unable to occupy otherwise livable habitat for reasons of intensive persecution (as in western irrigation districts) or utilization for food (as about Indian camps of northern wildernesses). Over-trapping for fur may, too, keep muskrat numbers locally or regionally depleted in some years, especially if the trapping is superimposed upon drought emergencies or suffered by populations already reduced through epizootics, environmental declines, or "cyclic" factors to levels from which reproductive recovery may be slow.

The favorite hypothesis of many people that the presence of alligators (Alligator mississippiensis) has kept muskrats from successfully colonizing muskrat-vacant parts of the southern states is to me unconvincing, especially in view of Lay and O'Neil's (1942) observations in Texas on the attractiveness of alligator holes to the muskrats. Giles and Childs (1949) also wrote, concerning the Sabine National Wildlife Refuge in Louisiana, that when this marshland area was first opened up in the early twenties for intensive exploitation of its fur resources, there were tremendous numbers of both alligators and muskrats.

This and related topics will be discussed later, but it may be said here that I have never recognized any evidence of subhuman predatory enemies exerting a primarily controlling influence on the muskrats of 
any wide area, anywhere in North America. What such enemies might possibly do in conjunction with emergencies or in a habitat decidedly submarginal for muskrats in the first place may not, however, be so easily dismissed. Predatory enemies would seem to be of far less importance to the population status of muskrats than would some of the nonpredaceous, as, for example, the ungulates, which through overgrazing and trampling may decidedly lower the habitability for muskrats of given marshes and streams. Anyone familiar with the properties of an ordinary midwestern sheep pasture or a lake-shore hog wallow has been introduced to ecological possibilities, from which he might go on to consider others, from denudation of vegetation by insects and plant diseases to eating of muskrat lodges by the caribou (Rangifer arcticus) of the tundra.

In generalizing, it may be said that the essentials of attractive muskrat habitats from sea level on up would include fresh to endurably brackish marshes and heavy stands of favored types of cattails, bulrushes, and other edible marsh emergents. In the absence of emergents, certain of the more nutritious submerged growths may furnish fair equivalents locally, though, as a rule, open expanses of water are not the best for muskrats. Food-rich waters would not have to be deep enough even to cover most of the marsh bottom to suffice in areas characterized by mild winters; and, in the northern states and Canada, shallow areas may be highly attractive - often fatally so in the end - for innumerable populations of muskrats during the warmer months. Muskrat marshes may range in size from those of thousands of acres down to small corners of lakes or bays, glacial potholes, seepages, wet gravel pits, and rush-lined pools in roadside ditches.

The better stream habitats are either rather well choked with vegetation or lying adjacent to cultivated grounds, notably the corn fields of the American Mid-West. Drainage ditches intersecting intensively farmed land may offer superb habitats for the species. Sluggish waters interconnecting lake chains or the oxbows or bayous of deltas and flood plains often are marshy. Swifter streams may show varying degrees of habitability in places where eddies occur or where scrub willows overhang mud banks or islands. Deep pools in the channels of intermittent streams and beaver ponds and floodings may afford passable retreats over wide areas otherwise deficient in muskrat habitats.

As we seek still lower in the scale of habitability, we find increasingly wide areas of high plains, deserts, mountains, or tundras, having fewer and fewer muskrats, and those muskrats are situated mainly in the better places, which in turn may be barely - and then not always habitable for the species. Even in what may be classed as good "muskrat country," environment that grades off into the marginal and then into the uninhabitable may be occupied with varying success and duration. In years of substantial population overflows, the animals may be encountered in a remarkable diversity of places: in barnyard feedlots, under hog pens or corn cribs, in grain shocks and 
stacks, in city basements, at mouths of tile flows, in garbage dumps, in the banks of small brooks, along rocky lake shores, in the dry and weedy borders of marshes, in badger holes of hillsides. Their establishing themselves in such places should not be construed as reflecting either choice or necessity, exclusively. Some of it is surely due to fortuitous routes of travel taken by muskrats in combination with the strong inclinations the animals have for staying alive and the aptitudes of individuals for tolerating discomfort and danger to the extent that they can stay alive.

\section{CONCERNING ORDINARY BEHAVIOR}

The literature on 24-hour activity rhythms in cricetine and murine rodents reflects differences in opinion and seemingly opposite conclusions, much of which is resolved by Calhoun's (1945) experiments with cotton rats (Sigmodon) and meadow mice (Microtus). Both of the latter have patterns of nocturnal activity that are subject to modification by meteorological or biotic changes in their environment. Calhoun noted similarities in the activity cycles of many nocturnal rodents, although each species shows patterns dependent upon innate morphological and physiological organization. Davis (1933), experimenting with the activity rhythms of Microtus, found a 2- to 4hour rhythm in feeding activities as well as a longer 24-hour rhythm having a peak following sunset. There was a higher average activity at night. Meadow mice kept in total darkness for 24 days maintained both the short and the long rhythms. Johnson (1926) experimentally reversed the normal nocturnal rhythm in deer mice (Peromyscus) through manipulation of light.

These findings would seem basically applicable to the muskrat. In my professional trapping years in South Dakota, I covered my muskrat trapline every three to five hours, day and night, for the first few days of the open season, beginning December 1. The heaviest catches were taken in late afternoon and early evening, with daybreak also being a good time for trapping. More nocturnal than diurnal, the species may nevertheless occasionally engage in general activity throughout the daylight hours, much depending upon the weather. Quiet, foggy days of autumn may stimulate activity, and, on some days of this description, a large proportion of the muskrats resident about the bay of a lake or an open tract of marsh may be simultaneously visible. Sometimes, a sunny day will bring them out, as may an impending sunset combined with glassy waters. Irregularities in 24-hour rhythms of muskrats become pronounced during periods of crisis, evictions, or movements. The animals trying to winter on drought-exposed Iowa marshes may seldom come out of their subsurface retreats to feed except as temperatures moderate in midday.

Muskrat habitations are more or less familiar to North American outdoorsmen and have been variously referred to in both technical and popular literature. They may be classed mainly as lodges or burrows, with numerous variations of each. 
Burrowing represents an elementary form of behavior in the muskrats as they lose their juvenile helplessness. At its simplest, it may consist only of crawling into or under loose vegetation. Digging or biting away of mud or vegetation may make a short burrow suitable for a temporary retreat of either young or old. Strangers passing through along a stream or following a lake shore may dig short, shallow burrows with underwater entrances and live in them from a few hours to a few days. These burrows may or may not have enlarged chambers above the water in the banks. Sometimes, the burrowing of such transients may be in dry earth, or they may enter parts of old burrow systems through holes dug in the bank. One sees much of this sort of thing about Iowa streams and marshes in April and early May at the height of the spring dispersal of population surpluses from wintering quarters.

The really complex burrow systems may be decades old, mazes of caved-in and renovated diggings, with old and new chambers at different levels, little holes and big holes, interconnected or not. They may penetrate the banks only for a couple of feet or so, in which case extensive lateral ramifications may follow the banks along the water's edge. Or, through settling of the surface of the land, the outlines of some ancient burrows may be traced almost in a straight line away from the water for 20 to 100 yards, or even farther, if they lead from the edge of a shallow slough up a low-gradient slope into the surrounding land. In extreme cases, as when the outlines of a burrow system may lead as far as 200 yards from the edge of a marsh, it would seem likely that such had resulted from gradual extensions of formerly shorter burrows as the marsh levels changed over the years rather than from the burrows remaining in use along their full lengths at any one time. Still, it is nothing uncommon in Iowa and eastern South Dakota to find currently used burrows going back 50 yards from the water, as they may radiate away from a pasture slough.

Lodge-building may be regarded as a behavioristic advance over burrowing. A lodge usually begins with a sitting place of muskrats, whether the sitting place be a floating rush raft or a mud bar or a solid foundation of almost any sort. In winter, many lodges may be put up that depend only upon the ice for support. Variations in lodge sites include boulders or piles of rocks or broken cement or dumped trash, leaning fence posts or rolls of wire out in the water, stumps and bases of trees, floating logs or boards or partly submerged wreckage of boats. A favorite place for building is the butt of an old lodge that has settled through decay and trampling by waterfowl or turtles until the whole remnant is down to or slightly below the surface of the water.

After their preliminary heaping of materials for the lodge, the muskrats usually hollow out a chamber and a passageway from beneath. The early stages of lodge-building merely provide, in effect, something to burrow into. Occasionally, the used entrances may be for a time through the side of a new structure at or above water level. 
With the chamber and one or more plunge holes hollowed out, a new lodge may remain small, ultimately to be abandoned, or it may be built upon, worked over, and occupied for years.

Big lodges (which may rise up to about six feet above the water surface) may have multiple chambers, either separate from or connected with the others. In lodges having wide bases (eight or more feet in diameter) but flat, low tops - especially those decayed to a peatlike condition - rings of chambers connected by tunnels may be found encircling a solid center. The typical chamber in a typical dwelling lodge is centrally located, having a bed a few inches above the water and two or three plunge holes leading outward through the submerged base. If the/lodge is situated on the marsh bottom, the tunnels may run through from a few feet to several yards of mud or peat before reaching open water. The simple chamber itself may be the only hollow part of the lodge above the water, or a passageway or two may lead to higher levels at which one to several separate or connected nests may occur. These nests, as well as the bed of the chamber over the plunge holes, may be lined with shredded vegetation. They are the places in which suckling young are likely to be kept. Transient animals frequently dig shallow holes for themselves for temporary refuge in the outer sides of lodges, the inner chambers of which are either inaccessible to them or "out-of-bounds" because of intolerant residents. Such blind nests may also be used with seeming regularity by some of the male consorts of females having young inside the lodges. On occasion, a litter of suckling young may even be found tucked away in an outside nest.

Not quite in the same category as typical lodges are some of the smaller ones built of fresh vegetation and in which litters may be kept in nests lying over the water. Sometimes, the nests may be roofed with solid, wet-heaped vegetation (usually of the easily-wadded types of submerged plants); sometimes the only upper covering of the young may be that furnished by the mother's body. Then, too, nests of coots or of diving ducks may sometimes be utilized, with or without alterations by the muskrats. Many young are born in these nests or on rush rafts or drifted debris, as well as in the chambers of the typical lodges or bank burrows.

Compared with lodge-building during the colder months, lodgebuilding in summer may be a rather minor activity. Old lodges may be repaired or have parts built or rebuilt to a variable extent, and sitting places and small structures may appear at almost any time during early summer and midsummer, but, from late summer on, there is a gradual increase of construction of both lodges and burrows. A great deal of this construction has been shown to be (from specimens of occupants examined) the work of subadults. Late summer lodges and burrows tend to be of the simpler designs. Then the lodges often have a chamber big enough to accommodate but a single animal, and lodges of this sort may appear by the hundreds in well-populated Iowa marshes from late July to frost. They were noted to appear about three 
weeks later, a thousand miles to the north, in the muskrat marshes of Manitoba and Saskatchewan. The first hard frosts stimulate burrowing and lodge-building alike, and, with the sealing of a marsh by thin ice, lodge-building may be conspicuously accelerated. After the ice comes, however, the medium-sized and large lodges have the capacious chambers and/multiple plunge holes typical of marsh habitations occupied by groups of animals. These are the real winter dwelling lodges, and, unless something goes wrong, the bigger they are the more muskrats (up to a dozen or so) they are likely to harbor.

Lesser structures, in considerable variety, are also more or less characteristic of frozen-over muskrat marshes. One is the small "feed house," having room for a single animal to sit or float. The feed house may grade upward in size to the smaller dwelling lodges of usual types. It may or may not have a bed and may be a mere opening in the ice under a wad of pushed-up vegetation. Although the smaller of the typical lodges are often abandoned for the bigger ones as the weather becomes colder, feed houses and push-ups may show sign of use throughout the winter - which does not necessarily mean that the same ones must be used all winter, for new ones may continually be built where muskrats are present to do the building. The relative numbers of feed houses and push-ups being built seem to reflect, among other things, the degree to which the muskrats may be crowded. Where wintering densities of the muskrats have been reduced, as by moderate trapping, survivors may rather restrict their activities to the main lodges without attempting to keep feed houses functional.

Lack of rushy building material may result in some odd structures, especially after freeze-up. On open sloughs, muskrats may push quantities of coontail or like submergents out of a hole in the ice antil a frozen column protrudes, to collapse during a thaw. They may cut a hole in the ice and build around it a thin, shell-like feed house, which, too, may collapse during a thaw. They may work on an ambitious scale and pile up a great mass of soft material (mixed with sticks, water lily rootstocks, clam shells, frozen fish, and a fair sample of the transportable items within reach) as large as a big lodge of rushes or cattails; and this may house a central basin of water as big as a wash tub - or it may be built on the same plan as an ordinary marsh lodge except on an icy foundation. Sometimes a whole string of connected feed-houses and push-ups may appear along an ice-heave or a wide crack, or about openings out from a set of bank burrows.

Food storage by muskrats may be linked with building routines to some extent. Normal storage is classifiable under two main headings: (1) the partly incidental storage of vegetation used in lining nests or for construction or repairs of habitations and (2) the obviously purposeful and selective storage of nutritious parts of plants, in particular duck potato and ear corn (Errington, 1941a). The foods stored incidentally, though commonly of only fair sustentative value compared with the better foods, may at times be quite important to wintering muskrats, irrespective of whether put away with storage 
intent or not. However, variable amounts of good foods such as bulrush rootstocks may be incorporated along with the upper parts of the plant during lodge building. Duck potatoes and ears of corn may be packed by the bushel in the chambers and ramifying blind alleys of some bank burrows. Duck potatoes may fill most of the chamber space and extensions thereof in certain marsh lodges.

Storage in marsh lodges is difficult to generalize about. I had long been aware of Eastman's (1902, pp. 239-40) description of storage of duck potatoes in lodges and had looked for evidence in thousands of lodges personally examined in Iowa and South Dakota, yet never found this sort of storage until the fall of 1948. Then, and for several years thereafter, storage of duck potatoes in lodges was found to be of general occurrence at Wall Lake, both in the shallow, muddier outlying sloughs and in some of the deeper central parts. The quantities stored varied from about a peck to more than a bushel. My view is that this represents a behavior pattern that may or may not become established locally. When it does occur, as at Wall Lake, it may be conspicuous, but, as a rule, I would say that marsh-dwelling muskrats of this region having continued access to good sources of food under the ice - or even when they do not have - seldom practice anything recognizable as deliberate storage.

In contrast with the year-around daily foraging on the part of most muskrats dependent upon foods occurring naturally in their habitats, the muskrats having access to ear corn stored in their burrows may sometimes hardly move about for weeks at a stretch in midwinter, especially when conditions outside the burrows are not conducive to foraging.

Muskrats are primarily individualists, each living for itself irrespective of the gregarious tendencies and seemingly unified acts that may be witnessed. Though the contributions of more than one muskrat to the erection of a big lodge or their concerted attack in driving out a common enemy such as a mink or a strange muskrat may have the rewards of teamwork, such acts may be more logically ascribed to a number of individuals having similar impulses and responding to them accordingly. Huddling for warmth or companionship on rush rafts or in chambers of habitations has its evident mutual attractions, and a considerable amount of what may be termed friendly behavior often may be seen during those seasons of the year when the animals are most disposed to be tolerant toward each other. The ordinary Iowa muskrat does not seem to object to physical contact or proximity of acquaintances between late summer and late winter. A couple of months in late summer and early fall represent a period of minimal friction, when intermingling of strangers in established populations is least likely to be attended by fighting. Strangers, however, may get into trouble with residents at practically any time of year, but are most likely to do so during the breeding months.

But, as individuality is always showing up, no absolute general- 
izations on social relations in muskrats are permissible. Some adults remain visibly placid in their attitudes toward neighbors, young or old, even when they themselves may be suckling young. Vicious intolerance toward their fellows may be displayed by others at all seasons. Variations in irritability may, in addition, reflect the health or comfort of individuals or may be among the apparent manifestations of that as yet inexplicable phenomenon known as the "10-year cycle," to which a separate chapter will be devoted.

Generally, despite much overlapping of movements, the foci of activity of breeding females occur 20 to 40 yards or farther apart, though I have found them closer together and know that, on rare occasions, the helpless young of two different females may even be kept in the same lodge or burrow. Visiting young are sometimes tolerated in, or in the vicinity of, nests having suckling young, but my observations indicate that they often are not tolerated, nor are the previously weaned young from the same mother. The large-scale killings of weaned young by other muskrats known to have taken place on crowded marshes have been largely traceable to attacks by suckling mothers, and the victims have included the earlier-born progeny of those same mothers as well as young intruders from elsewhere. Nor do weaned young invariably need to approach the currently suckling young to invite attack. Some observed mothers seemed to kill or try to kill any free-living youngster that came within reach, anywhere.

Hostile responses of suckling mothers toward weaned young notwithstanding, the mothers may still not be especially zealous guardians of their helpless offspring. The new-born may be left scattered around on tops of lodges and rush piles - some until they die - and suckling litters may be transferred from lodge to lodge, often in an only partly responsible manner. Litters may be split up in the course of the transfers and the component parts kept in separate nests, and it does not always follow that those left in a particular place ever will be revisited. The casual treatment by a mother muskrat of her own small young under routine living conditions is in accordance with the increasing cheapness of life on a muskrat marsh as populations build up. She seems to be satisfied if she has some of her currently suckling litter about her long enough to wean. Once weaned, the young look after themselves as well as they can.

During her whole maternal experience, the mother rarely does anything incompatible with her own living as an individual. She may stop to eat while gathering together scattered young, despite their weary complaining in the rushes near by. She takes much of her motherhood as matter-of-factly as she does anything that ordinarily comes to her life. It is the exceptional muskrat mother that makes any recognizable effort to defend the young against humans opening a lodge - though, were she herself cornered, she could be counted upon to attack anything in her own defense. Even her murders of luckless or indiscreet young (some of which I have had the fortune to witness 
at close range) show little of excitement unless it were during the approach and actual biting. After swimming away from the body of a young one that she had killed, she may as likely as not start eating.

The behavior of the male follows much the pattern of the female, to the extent that a muskrat is a muskrat. As adults, the males of the Iowa observational areas tended to be more tolerant than the females toward young during the breeding season. At other times of the year, the animals having patently bad dispositions appeared to be of one sex about as often as the other. Instances of males undertaking simple care of suckling young orphaned by deaths of females were observed in the course of intensive field studies, and it is well known that both members of a pair may work together building or remodeling a lodge - all of which conforms to accepted criteria of monogamy. Lavrov (1933a) observed that the adult males took a regular part in the rearing of the young from about the nineteenth day on to independent stages.

Sexual relations in muskrats may show sufficient promiscuity, on the part of free-living and captive animals alike, to discourage broad statements as to monogamous habits. A concept of a loose monogamy would seem most consistent with reality. Glimpses that I have had of natural mating in the species were of males being aggressive and persistent and of females being passive or coy. The females continually made some effort to avoid contact with the males, without appearing to be excited even when caught and held by the males' teeth. One female that had been mounted sixty times in seven minutes finally turned on the male and fought him off, biting him about the face.

\section{RESPONSIVENESS TO EMERGENCY CONDITIONS}

The purpose of the following will be to amplify what has just been presented about muskrat behavior, as such may be modified by the floods, droughts, cold weather, food shortages, or sociological crises to which the species may at times be subject. Some duplication of, and overlapping with, what already has been written appears unavoidable, but this is in part defensible on grounds of conveying to the reader a better idea of responses to be expected from muskrats when beset by the more urgent problems of staying alive.

Floods are part of the ecology of muskrat ranges over much of North America. The muskrats may often be affected indirectly through killing of important vegetation. Or, sudden or sustained rises in water levels may create emergencies that must be met at once. Bellrose and Brown (1941), investigating bottomland lakes of the Illinois River Valley, reported that greater differences in the abundance of muskrat houses per acre were due to changing water levels rather than to variations in type of marsh vegetation.

Bellrose and Low (1943) observed pronounced local differences in the fortunes of muskrats during flooding of Illinois River lakes in the fall of 1941. Water levels rose several feet in early October and stayed high for several weeks. On their Douglas Lake area, most of 
the river bulrushes were completely covered by up to two feet of water, and, where there had been at least 1,234 dwelling lodges the previous year, there was scarcely a lodge left. Most of the lodges rose with the flood waters, to become mere piles of floating vegetation. Many of these came apart under the buffeting waves, and the authors counted averages of over five muskrats sitting on rafts and floating lodges. Many sat in buttonbushes, and as many as eight were observed stacked, one on top of another, in crotches of large willows. On the Rice Lake area, the lodges were also demolished by waves, and the debris from wrecked lodges formed a mat of vegetation two to ten yards wide and a half mile long. Nevertheless, relatively few animals (averaging 1.1 per remnant of lodge or raft) remained exposed, for hundreds of acres of flooded bottomland timber lay behind the line of wrecked lodges, and this afforded the muskrats much better emergency refuge than at Douglas Lake.

Bellrose and Low's muskrats sought, where possible, to remain on the tops of their lodges during the flood crisis. Next, they apparently preferred floating rafts of vegetation and, last, branches of willows and buttonbush. Building and rehabilitation activities were carried on by the muskrats, and large numbers of lodges and rafts were built around the branches and limbs of trees, as well as on foundations of logs, boards, boats, and duck blinds. As the water receded, the muskrats continued to add to the bottoms of the lodges that had been built in trees at the height of the flood, until these took on the appearance of multiple-storied structures, often six feet or more in height as they were held cradled in the trees. After further recession of the water in early December left their emergency structures suspended, the Rice Lake muskrats moved out to the beds of river bulrushes and built their third set of lodges. In contrast, only a few of the Douglas Lake muskrats moved back into the center of the marsh from the levee where they had taken refuge.

If comparison of Bellrose and Low's observations be made with those recorded elsewhere, a basic similarity in responses of muskrats to floods becomes evident, more or less irrespective of geographical or subspecific differences - see, for example, photographs and text in Arthur's account of the Louisiana muskrat (1931, pp. 201, 215, 219, 297, 311-12). Muskrats of the vast wetlands of Manitoba and Saskatchewan personally observed in 1948 resorted chiefly to willow growths during high water periods, whether such meant building lodges and raising young in the willows when floods continued all spring and summer or merely sitting out a rise from a wind tide off a big lake. Iowa observations have brought out the same tendencies of flood-evicted muskrats to take refuge in fringing willows of streams, or on floating or protruding objects (Errington, 1937a). Nests on top of stumps or woven into brushy thickets may not be as satisfactory as typical marsh lodges or bank chambers, but young are kept and raised there. The flooded bases of hollow trees or cavities above the water under root-tangles may, when reinforced or built around by the musk- 
rats, be fair engineering equivalents of the usual types of lodges.

If lodges remain attached to marsh bottoms, muskrats may burrow through the tops as the water rises and then later plug the holes as the water recedes. Their behavior in bank burrows has its comparable aspects. In the burrows, the animals often dig upward until, just before the water goes over the banks, they lie in the upper parts of the openings, with heads or nostrils out of water, bobbing up and down if alarmed. If the water covers the banks, the animals of course must emerge, and then they have to do something else.

Floods in cold weather may impose terrific crises. Squaw Creek in central Iowa was in a very high flood stage in late January, 1935, and the temperature dropped nearly to 30 degrees below zero Fahrenheit. The creek valley turned into a freezing lake, affording little refuge for evicted muskrats anywhere (Errington, 1943, p. 883). The affected population was almost annihilated. Under lesser extremes, as during mild weather, the animals may survive simply by sitting in the riverbank willows. Or, if forced for a time to live about a snow-covered countryside bordering flooded stream valleys, they may improvise nests, retire to land holes and eat what they can find after the manner of ordinary winter wanderers - though subject to the dangers and discomforts that beset such wanderers. If the animals succeed in enduring a crisis without leaving their familiar locality, they stand a good chance of regaining their old quarters as the water goes down. Often, the only adjustments forced by the surface waters of winter thaws or rains are the gnawing away of more chamber space higher up in the lodges or burrows, repairing of parts of retreats exposed through melting, rehabilitation of abandoned lodges, or the erection of new lodges or feed houses on the ice - all of which muskrats may do readily under ordinary north-central conditions.

It is not clear how well muskrats may find food by diving in muddy flood waters, but the fact that so much feeding on the tender bark of trees and shrubs occurs at such times indicates that foods concealed by flood waters must be largely unavailable. Foraging by flood-evicted animals on or near land is relatively easy when green summer growths abound, though a winter or early spring fare of dead weed stalks and miscellaneous coarse organic matter may only delay starvation unless supplemented by ear corn, live roots, or other of the more nutritious foods. Sometimes, muskrats may even attempt to eat dead wood. The versatility of the species in feeding (Errington, 194la) is unquestionably of survival value during emergencies of this kind.

Bellrose and Low noted a correlation between intraspecific strife and insecurity of flood-exposed muskrats. Not only were adults observed to fight over the possession of refuge sites but kits were also frequent victims of attacking elders. And, of course, homeless and vulnerable muskrats fell prey to avian predators and other flesh eaters that were in a position to take advantage of them.

Gross dissimilarities notwithstanding, drought crises are comparable to those of floods in that they similarly upset the living routines 
and security of populations. Yet, for a species as dependent upon water as the muskrat, droughts have singular potentialities for deadliness and may force special adjustments (Errington, 1939a).

As entrances to their lodges and bank burrows become exposed by drought, muskrats usually engage in deepening operations. These may take the form of simple excavations or of complex systems of channels radiating away from lodge or burrow entrances. Accelerated digging may be noted in summer at about the time when residual puddles assume the consistency of liquid mud, and newly-constructed lodges may be of plastered mud and vegetation. In building a new lodge on exposed marsh bottom, muskrats may simply cut away the most convenient vegetation and pile it in a cleared space. The resulting structure may cover previously existing channels and burrows, but often the digging is done later as the structure is hollowed out and otherwise modified for use. Lodges may be similarly built in corn fields, except for the use of cornstalks and field debris instead of marsh plants as building material.

Digging in response to drought exposure is also stimulated in late fall by heavy frosts, even though comparatively large amounts of water may be left in the entrances. Digging at freeze-up is especially apt to take place on an extensive scale. Mud and peat may be piled at the ends and sides of ramifying channels. Wide, straight channels may be cut down through the mud, extended for yards, then used no more. Pockets and blind burrows may be dug from the surface and enlarged underground amid the rootstocks of water plants. Deepening of passageways may progress to a depth of a couple of feet below their original levels, or new sets of burrows may be dug under the old burrows as the water continues to go down. During periods of winter drought, old lodges may continue to be favorite retreats, but often the original chambers are abandoned in favor of new ones hollowed out below. The muskrats may enter and leave the dry lodges through holes at the lower edges or through tunnel openings close by.

Sinking of the frost line as winter advances may bring about droughtlike conditions under the ice even when plenty of water may be present at freeze-up. In many places between the northern lake states and the Barren Grounds about Hudson's Bay, ice accumulates to a depth of four or five feet, and late winter thicknesses up to three feet are nothing so very unusual for Dakota lakes and marshes. Less extreme thickening may cause muskrats to continue deepening the channels leading to chambers - or to excavate completely new burrows beneath the shallower ones of fall and early winter. The animals also take advantage of air spaces in stratified ice to improvise subsurface living quarters, plugging and reinforcing with mud and vegetation much as they would higher parts of burrows or lodges. Disappearance of unfrozen water beneath the ice may occur either as a result of natural drainage or human manipulation, as through the lowering of water in storage basins. Then, networks of dry or frozen or merely moist runways concealed from human view by ice or snow 
may be the sites of muskrats passing back and forth, digging and feeding and living as they can.

Muskrats may live fairly well on a marsh bottom without much unfrozen water as long as they have the protection of an ice covering overhead and an ample and accessible food supply, such as cattail or bulrush rootstocks. In sloughs dominated by water lilies, coontail, and other shallow-rooted submergents and surface plants, the food supply may become so encased in ice as to be quite unavailable to muskrats by late winter. Entire local populations may find themselves in a state of crisis within a space of days. There may be unfrozen mud underneath, but, if it contains no food to reward digging, the muskrats may be as much compelled to undertake surface foraging or wandering as those evicted outright by full exposure of the bottom through drought.

The established way of living of muskrat populations may have a pronounced bearing upon how they meet the problem of winter feeding in dry or nearly dry habitat. Such marsh-dwelling muskrats as habitually obtain their food from the marsh largely as required each day may find themselves confronted by crises exceeding their immediate adaptations if they attempt to continue their feeding routines under drought conditions. Conversely, the populations that engage in storing may winter at high densities in quarters that are restricted and nearly waterless. Much outside activity of muskrats in winter is plainly due to newcomers establishing themselves too late in the fall to make adequate preparations for cold weather. On occasion, animals are encountered living in corncribs, corn shocks, and other food-rich land retreats, but I have seldom found evidence of such animals successfully wintering in areas having rigorous winter climates.

\section{RESPONSIVENESS TO PHYSICAL ATTACK OR DISTURBANCE}

In responding to physical attack or disturbance by predators, the muskrat may show considerable geographic variation. Mention has already been made of the sensitivity to disturbance reported by Brander (1951) for muskrats in Finland. The Louisiana muskrat is said to be both more wary of traps and possible enemies inhabiting the deeper waters (Arthur, 1931, pp. 250, 286; Lynch, O'Neil, and Lay, 1947) than any muskrats that $I$ have ever observed on northern areas.

It may be remarkable what north central animals can tolerate in the way of disturbance, a good deal depending upon alternatives and psychic conditioning. Dogs may dig out burrows, minks may penetrate lodges on a large scale, horses and cattle may trample and hogs may root on muskrat marshes without visibly affecting the status of well-situated muskrats that are in a position to adjust. Nevertheless, disturbances of muskrats living under handicaps may have serious consequences.

Drought crises underlie some of the most decided reactions to disturbance that we see in the north central region. As an extreme case, mass use by livestock of remaining waterholes may be accompanied 
by so much trampling that resident muskrats leave to take their chances elsewhere, usually to embark on a brief career of lethal wandering. As another extreme case, muskrats may long persist in a dry marsh but with attachments to home ranges so tenuous that practically any disturbance - flattening of lodges by livestock, digging by predators or scavengers, opening by human investigators - causes them to leave, likewise to wander and probably to die as wanderers. After disappearance of the surface water, Iowa muskrats seldom remain on a marsh if their lodges are opened for examination, although, with favorable water levels prevailing, they might well repair their lodges overnight. It is no big job for muskrats completely to rebuild lodges if they are so disposed and have access to materials with which to do it.

Intrusions into muskrat lodges by minks may be notably subject to misinterpretation. Minks may enter through the sides and tops of occupied and unoccupied lodges alike. Openings in occupied lodges may be promptly plugged by the resident muskrats, whereas mink holes in unoccupied lodges may remain conspicuous indefinitely. It is also true that some muskrat habitations appear to be abandoned by the muskrats directly because of the activities of minks, but this need not signify any real disadvantage to the muskrats. Muskrats may abandon the less desirable lodges opened by minks much as they may abandon, of their own volition, loosely-built or shallow water structures with the coming of midwinter cold. Well-established muskrats, with a variety of alternative living places to choose from, may withdraw from some without risk. As long as their adjustments in such ways fall within the ordinary range of adaptability of the species, the muskrats do not seem to be forced to retire before the minks to the point of critical disadvantage. They can demonstrate an unquestionable ability to maintain themselves securely in the more important dwelling lodges.

Despite the general rating of the mink as the North American muskrat's supreme predatory enemy (Errington, 1943; 1946; 1954b), the two species often live in close proximity. A complex burrow system may be in use at the same time by both minks and muskrats, each species obviously being aware of the other and adjusting its living routine accordingly. Muskrats may even rear their young in lodges or burrows, of which some parts are regularly used as mink dens. In short, our north central muskrats may accept the presence of many enemies or potential enemies without undue excitement.

I have repeatedly watched muskrats approaching big snapping turtles in pools, on lodge tops, or in muddy marsh bottoms, and about all that the muskrats did for safety was to keep out of striking distance of the turtles' heads. Our Goose Lake study area had in some summers actually hundreds of snappers per acre visible at once in parts covered by shallow water, and, as far as I could see, the resident muskrats did not allow the turtles to interfere with their own way of life.

Another marsh had conspicuous numbers of northern pike in the 
midst of an ascending muskrat population in the early thirties, but I never saw the muskrats pay any particular attention to them. Great horned owls have nested near and hunted some of the best muskrat areas personally studied in the north central region without appearing to force muskrats into noticeable departures from their usual behavior patterns. On the other hand, muskrats may avoid solid land when such is diligently worked by canids.

If muskrats can be said really to hate any living things, the examples coming to my mind are all either of strange or unwelcome muskrats or of minks, either of which may be met more than half way, at least some of the time. Attacks, individually or concerted, by muskrats upon minks are among the interesting phenomena witnessed by people having the luck to be on the scene and the judgment to keep quiet. Dr. Maurice W. Provost turned over to me the following field notes taken from 6:50 to 7:15 P.M., September 10, 1941, from northwestern Iowa:

Two rats watched at dam, Mud Lake. One became engaged with a mink in the rushes; the splashing was over in 10 seconds, each animal going its way. Shortly afterwards, directly at the dam, the two animals met again. This time the muskrat lunged at the mink. In a few seconds the tussle was over and the rat was swimming away. He swam two or three yards away then turned around and again pounced on the mink. This third struggle was very short, maybe 7 seconds. The mink disappeared and was not seen again. The muskrat nonchalantly swam away.

Bruce F. Stiles, late Director of the Iowa State Conservation Commission, described (letter, May 29, 1948) another case of muskrat aggressiveness toward a mink:

On the morning of October 23, 1947 . . as I leaned motionless against a tree waiting for daylight ... I saw a mink come hopping along the low shore toward me.

About twenty feet out into the water from where I stood was . . . an accumulation of brush where the day before I had noticed two muskrats sunning themselves. As the mink reached a point opposite this brush pile, he jumped out into the water into what would be a depth of probably 3 or 4 inches. Just at this time a muskrat emerged about 3 feet from the mink and dashed toward him in a menacing manner. The mink quickly hopped to one side but continued in the water whereupon two more muskrats appeared near him.

The mink swam out into the water whereupon additional muskrats put in their appearance causing the mink to retreat with considerable haste to the shore. . . . He finally ran off down the shore in the direction from which he had first come and disappeared from my sight. Individual rats appearing and disappearing in quite rapid succession made it difficult for me to count, but I am of the opinion that there were seven muskrats involved. I did not actually see a rat come in physical contact with the mink although it is possible that they did so.

For all of the viciousness with which a grown muskrat will fight when at bay, or when bitten or seized by an enemy, attempts to break away to run or dive after receiving punishment are of common occur- 
rence. The more urgent retreats following fights with other muskrats doubtless reflect social subordination, at least in part. Allee's (1942) demonstration of the role of psychological background in the fighting prowess of laboratory mice could well be thought of in terms of muskrats. Nice's (1941) generalization in her review of vertebrate territoriality that familiarity with an area enables an animal to be dominant there may be applicable not only to intraspecific but also logically to interspecific relations where antagonists are evenly matched.

With behavior patterns in many ways well stereotyped, the muskrat is not completely an automaton. It is possibly of average intelligence among rodents, often behaving haphazardly and often, if anything unusual happens, seemingly unable to keep its mind on more than one matter at a time. But it can learn to follow safe living routines, and the critical reader should not be far wrong in regarding it as a species blessed with a certain earthy practicality valuable in meeting day-to-day problems. It can and does live by the millions and contributes to the geographic features of large areas over the earth. 


\section{Chapter 2}

\section{Development and Reproduction of}

\section{the Muskrat}

Although not aQuatic in any fishlike sense, the muskrat is enough of a water animal to make it seem appropriate that an individual's life usually begins, in a way, in the water. All recognized attempts at coitus of muskrats that I ever witnessed were in the water. Water for the animals to get into is not absolutely prerequisite to breeding, however. Ulbrich (1930, pp. 15-16) made observations in central Europe similar to mine but also noted mating on merely wet land. Breeding has taken place in dry cages of fur breeders and experimenters.

At any rate, a pregnancy may be assumed as a starting point for the discussion of development and reproduction in this chapter.

\section{ON THE YOUNG BEFORE AND AT BIRTH}

The length of gestation in the muskrat has long been a controversial subject. As far as I know, nothing has been published on preimplantation periods for the species, but the five or six days normally required by murine rats in the laboratory (Nicholas, 1947) may be something of an indication. Probably the confusing variations in so-called gestation recorded for the muskrat are in considerable part due to variations in times of implantation (Beer, 1950).

Milton S. Banks, a Michigan fur breeder, gave the gestation period as 19 to 21 days for his farm-bred muskrats (Arthur, 1931, pp. 34344); Ulbrich (1930, p. 15), a period of not quite four weeks for the muskrats of his breeding boxes in Germany. Lavrov (1933a) wrote of pregnancies lasting about 25 days for the muskrats of an experimental fur farm in the U.S.S.R. Smith (1938) recorded two pregnancies with captives in Maryland suggesting a period of 29 or 30 days.

Some Iowa field data are indicative of gestation periods. The technical difficulties of following satisfactorily the reproductive fortunes of a particular free-living mother muskrat are so substantial that only 
under certain conditions is an investigator justified in having much confidence in the results obtained; but, through intensive study of the litters born to and cared for by individually recognizable animals and marking and tracing of litters, sufficient data emerged eventually to demonstrate trends.

Of the 76 recorded intervals between births of successive litters born to 58 Iowa females, 61 intervals were of approximately a month. Only 10 of the intervals were a week or more over or under a month. I recognize that the more substantial of these variations may have been due not only to irregularities in times of implantation but also to undetected errors in estimating ages of the young when handled or, conceivably, to misidentification of mothers under field conditions. Nevertheless, Svihla (1932), working on deer mice (Peromyscus) in the laboratory, found variations that look comparable. He reported that subsequent litters in $P$. maniculatus were born 22 to 35 days after mating and, in P. leucopus, 22 to 37 days. Prolongation of the periods was associated with lactation but not with greater numbers of embryos carried, nor with sizes of adults.

Once I had expressed the thought that a 19-day interval between births of the first two litters assigned to a three-litter muskrat mother was apparently close to a true but probably atypical gestation period (Errington, 1937b). The three young of the first litter had been remarkably rapid growers, even for well-nourished members of a small family. They had attained, by the age of 19 days when what was judged to have been the second litter of their mother was born, about 30 per cent greater weight than the mean of 24 other young of like age. Moreover, these oversized young were decidedly behind a normal schedule for their size in eye-opening, pelage development, and defence behavior. I thought that the observed precocity of these young in certain respects might indicate precocity in utero and consequent earlier delivery. The possibilities of superfetation and other aberrances described by King (1913) for laboratory rats and by Sumner (1916) for Peromyscus were considered, as well as the chance that the muskrat litters born 19 days apart might have been offspring of different females. What seemed to have been two actual cases of superfetation or superfecundation are recorded in the Iowa field data, but, whenever I think of the above 19-day interval, I always return to the previously suggested explanation.

There is nothing in the latter that is inconsistent with the results of studies of estrous cycles. McLeod and Bondar (1952), in recording 136 complete estrous cycles for 10 captive $O$. z. albus in 1951, found a minimum time for completion of a cycle of only 2 days, a maximum of 22 days, and a mean of 6.1 days. The longer cycles occurred infrequently, and these authors interpreted Beer's (1950) findings of 24- to 34-day cycles in 11 females of $O$. z. zibethicus kept in an outdoor court in southern Wisconsin as possibly indicative of premature falling off of sexual activity.

The supposition that a female muskrat will not accept a male 
until she has weaned her current litter is widely held by fur breeders, whereas, in common with the females of many other prolific rodents, she may in actuality be sexually receptive very soon following parturition. At least some of the discrepancies in intervals of birth shown by captive females and by females living free on Iowa marshes would appear due to failure of the human manipulators to provide a female with a male soon enough after she had given birth to a litter. It may be judged that a given young muskrat may, from its beginning as a fertilized ovum (or as an ovum with sperms awaiting it), be carried by the mother three to four weeks or somewhat longer before being born.

Our data on still-born young are too scanty to consider statistically, if only because of the difficulties of distinguishing under field conditions between the still-born and those alive at birth but dying soon after. For a large series of laboratory rats, King (1935) reported that the still-born young comprised 1.2 per cent of the young in complete litters.

Another phenomenon affecting young muskrats is that of resorption of embryos in utero (see Dozier, 1947b, for a good example in O. z. macrodon). Warwick (1940) found single embryos resorbing in 2 of 25 pregnancies of $O$. z. zibethicus examined in the British Isles and referred to 3 cases in 98 pregnancies examined by Mehl (undated publication) in continental Europe. No effort has been made to keep full records of resorptions in the Iowa studies, but evidence thereof was noted on several occasions while "posting" dead adults during the breeding months.

At birth, the moist young weigh considerably more than after drying for a short time. What may be regarded as a typical example of $O$. z. zibethicus in northern Iowa weighed 26 grams (its attached placenta weighed 5 grams more) and measured $108 \mathrm{~mm}$. in total length; the mean weights and measurements for 7 normal litter mates that had been born a few hours earlier were 22.4 grams and $102.9 \mathrm{~mm}$. The means for 41 living young weighed and measured during the day of their birth were 21.3 grams and $100.4 \mathrm{~mm}$., with a median weight of 21 grams and a median length of $102 \mathrm{~mm}$. The smallest and largest were 16 and 28 grams and 85 and $115 \mathrm{~mm}$., respectively. Males were of slightly larger mean size than females at birth, but this difference is not believed to be significant, in view of big variations linked with size of litters.

King (1935), from her exhaustive investigations of reproduction in laboratory rats, found weight at birth to be directly correlated with the age of the mothers and inversely correlated with litter size. Other factors apparently influencing the body weight of the newborn included heredity and length of gestation, as well as internal secretions, metabolic products, body size, physical condition, and nutrition of the mother. Data tabulated by month and by season of conception indicated a seasonal cycle in birth weights. Birth weights of both sexes were at their minimum for individuals conceived in summer, with maximum weight for males coming from winter conceptions and for 
females from autumn conceptions. King also assigned some importance to distribution of embryos in the uterus, and, in this connection, Nicholas (1947) wrote of the likelihood of considerable regimentation in the development of the young rat being imposed directly upon it by the maternal physiology. While he did not regard the evidence as yet clear concerning rigidity of placental sites, he was certain that the relation of present pregnancies to previous ones reflected predilections toward special regions of the uterus.

The sex ratio obtained for new-born muskrats during the Iowa studies was 90 or 61.2 per cent males in a sample of 147; but, for the total sample of 1,954 small muskrats examined at chiefly less than two weeks of age (and including the 147 new-born), 1,057 or 54.1 per cent were males. Gashwiler (1950) found 233 or 59.4 per cent males in a Maine sample of 392 young examined at ages of 2 to 28 days. Beer and Truax (1950), in Wisconsin, found 438 or 53.4 per cent males in a sample of 820 nestling muskrats under 100 grams in weight, but they did get 192 or 58.3 per cent males in a sample of 329 nestlings weighing over 100 grams.

The new-born muskrat is blind, nearly helpless, scantily furred (almost naked), from a rich pink to a greyish or bluish coloration, and of generalized mouselike aspect, with plump body, feet of nearly equal size, and round tail. It is, at first, a hardy little creature, adapted to stay alive even when chilled almost to the point of freezing (Errington, 1937c). It is able to recover from comparatively severe wounds such as may be inflicted by accidental trampling of sharp-clawed adults or by bites of larger young. It may endure up to several days of deprivation of food before dying.

\section{THE YOUNG DURING THE FIRST MONTH AFTER BIRTH}

The young retain their natal hardiness for some days, gradually losing it as their tissues become more differentiated. One animal of about eight days was found with a forefoot that had been nearly severed possibly two or three days previously. Although the broken ends of radius and ulna were exposed and separated, the wound was healing, and, after eight more days, the leg was healed as a serviceable deformity, and the cripple's weight was 71 per cent of the mean of its litter mates. Another young maintained its normal growth rate during the healing of a $20 \mathrm{~mm}$. gash in its abdominal wall; the wound was inflicted when the animal was about three days old and it healed almost completely in five days, though it had been sufficiently deep to penetrate the body cavity.

Figs. 2.1 and 2.2 are from engravings returned by the Journal of Mammalogy after publication of a paper (Errington, 1939b) dealing in part with data on growth rates for the first month obtained from 345 members of 66 litters of $O$. z. zibethicus in Iowa. For a discussion of techniques, the reader is referred to the original publication, but some of the salient features may here be mentioned.

It may be noted from Fig. 2.1 that the weights of the largest young of 20 to 30 days were nearly twice those of the smallest healthy young 


\begin{tabular}{|c|c|c|c|c|c|c|c|c|c|c|c|c|c|c|c|c|c|c|c|c|c|c|c|c|c|c|}
\hline & $\begin{array}{l}\text { Total, incl. } \\
\text { calculated }\end{array}$ & & & & & & & & 12212 & & & & 1169 & & & & & & & & & 26 & 2118 & 181 & 312 & 10 \\
\hline & $\begin{array}{l}\text { Actually } \\
\text { weighed } \\
\text { meosured }\end{array}$ & & 43 & & 4 & $26 \mid$ & 2353 & 044 & $24 \mid 23$ & 32225 & 193 & 36 & & 192 & 716 & 524 & 417 & 13 & 15 & 6 & 5 & 8 & 7 & 8 & 5 & 2 \\
\hline $\begin{array}{l}\text { Number } \\
\text { yielding }\end{array}$ & $\begin{array}{l}\text { litters } \\
\text { data }\end{array}$ & & 10 & 12 & 15 & 18 & 2127 & 3337 & $37 \mid 38$ & 3941 & 38 & $39 \mid 3$ & 383 & 31 & 25 & & 20 & 20 & 17 & 17 & 16 & 16 & $13 \mid 1$ & 11 & 9 & 7 \\
\hline
\end{tabular}
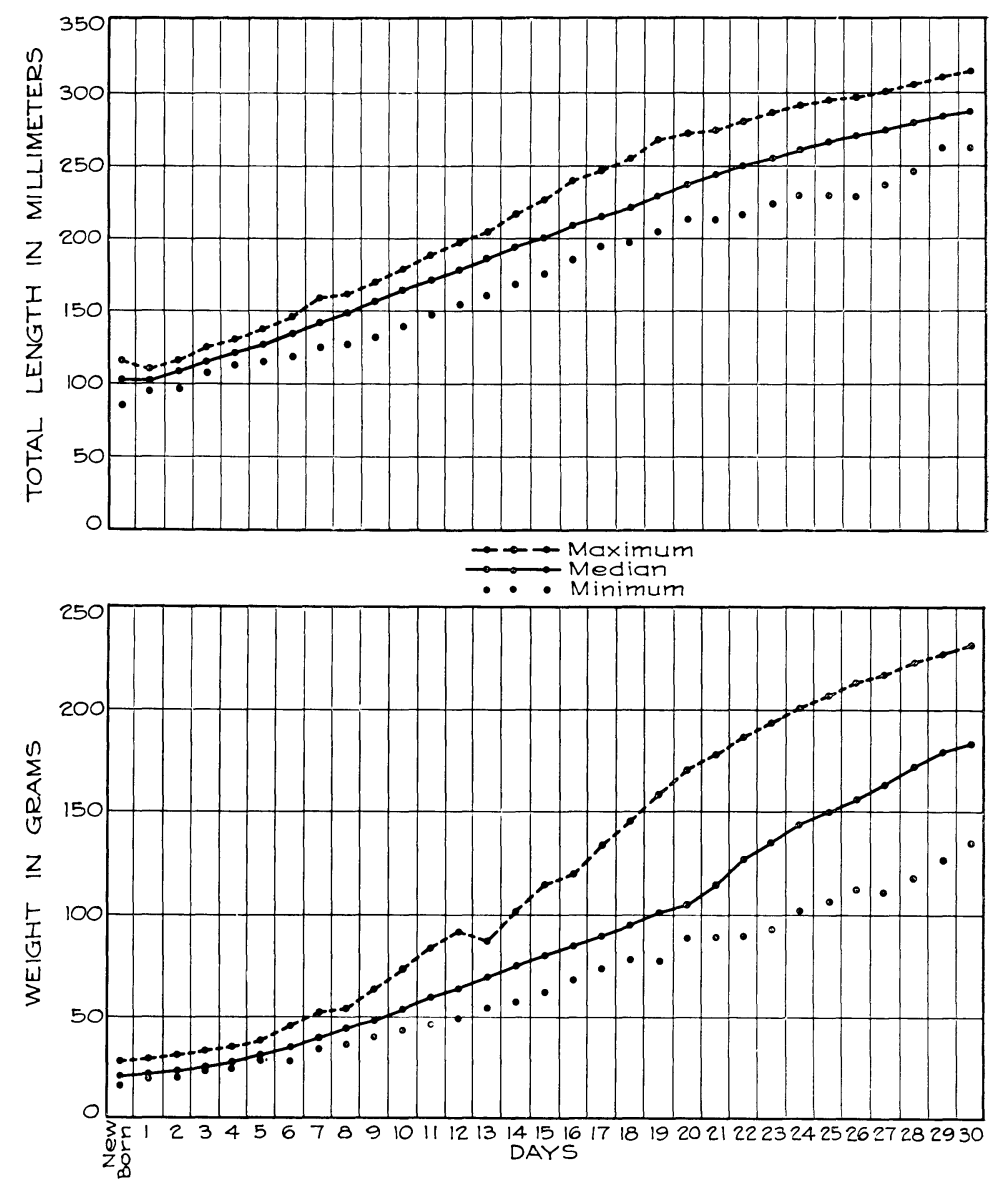

Fig. 2.1. Total length and weight curves of young muskrats from birth to 30 days. (After Errington, 1939b - Journal of Mammalogy.)

of comparable ages and that there were also material differences in maximum and minimum lengths. While many animals appeared to be simply large or small for their ages, the varying growth rates of others were seemingly influenced by nutritional differences. Young that were the sole members of litters were particularly apt to be chubby. Fig. 2.2 shows that overfed young had weight advantages over the others chiefly during the third week. (Weights and measurements of $382 \mathrm{~W}$ isconsin muskrats handled by Dorney and Rusch (1953) between the ages of one and 30 days ran somewhat higher than those for our Iowa specimens.) 


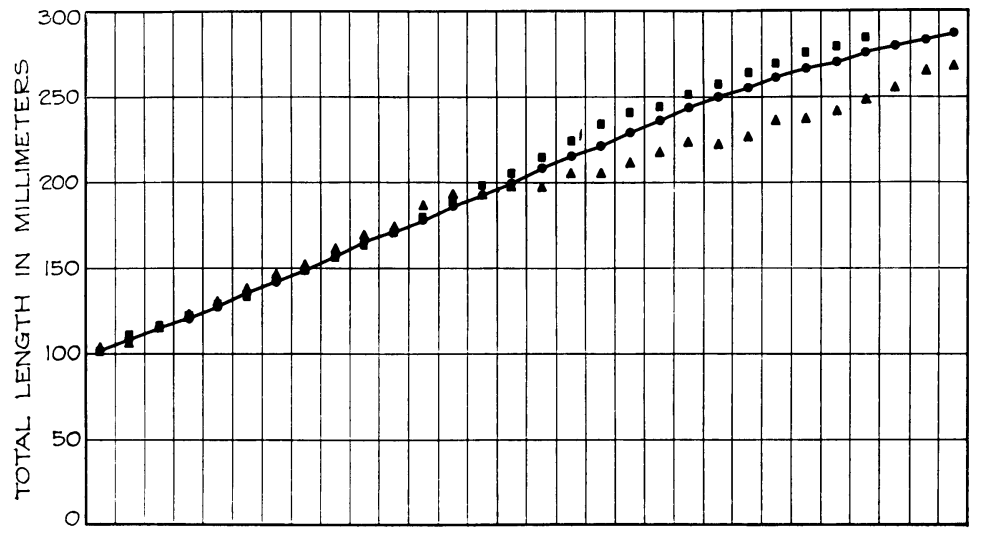

- - Composite from growth curves of 28 overfed young.

$\rightarrow$ Median based on early growth data from 345 young.

$200 \Delta \Delta \Delta$ Composite from growth curves of 13 slightly underfed young.

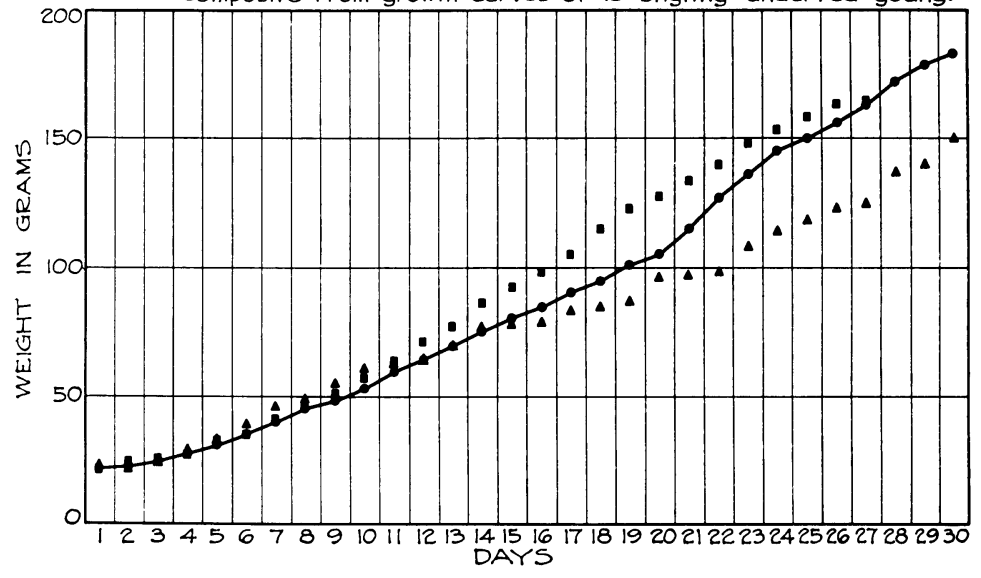

Fig. 2.2. Total length and weight curves of overfed and underfed young muskrats. (After Errington, 1939b - Journal of Mammalogy.)

When about five days old, the young, while feeding, may cling to their mother's nipples with sufficient strength to be pulled into the water if she hurriedly plunges. Some may sink, but most float with nostrils submerged, and submergence apnea upon wetting seems to occur much as described by Koppanyi and Dooley (1929) for grown muskrats. With rapidly developing pelage, the young are covered by a coarse-appearing, gray-brown coat toward the end of the first week. By the beginning of the second week, they are still blind but able to scramble more or less actively about the nest. Animals experimented with at 10 days floated with nostrils above water, swam blindly up to and clambered out on low floating objects and the landings of plunge holes in lodges.

Most young are able to dive with facility immediately before eyeopening and may leave a lodge that is being examined and head across surrounding open water. Eye-opening was recorded for 36 litters and occurred at from 12 to 20 days, commonly between 14 and 16 days. 
Smith (1938) found eye-opening at 11 to 15 days in pen-reared $O . z$. macrodon in Maryland.

At about two weeks, the pelage changes to a softer and more wooly texture and becomes a mouse-gray color; this change either precedes or follows eye-opening. During their first two weeks of life, 48 individuals studied showed a mean increase in proportion of tail length to total length from 27.4 per cent to 32.4 per cent. Young growing with unusal rapidity often were backward both in eye-opening and in pelage changes and seemed less excitable in temperament. Many undersized young were otherwise precocious and responded more viciously to handling. Animals displaying ill temper before eyeopening may be sufferers from disease or physiological deficiencies, but much normal variation may be seen.

At three weeks, the majority of young are suckling but gaining in independence. The more precocious are difficult to capture by hand, as they bob up and down or stay submerged for considerable intervals in the plunge holes of their lodges or leave the lodges to swim and dive outside. If pursued, they are apt to conceal themselves for minutes at a time under the vegetation of the marsh bottom. If not further disturbed, the usual reaction of such animals is to swim or float with head out of water or to climb partially out on convenient objects. They may, within the next few minutes, become sufficiently anxious or uncomfortable to complain quite audibly, thus perhaps attracting the attention of adults. One such young swam and floated in open water for 45 minutes before it was rescued, nearly drowned, by hand.

Diving and swimming ability at this stage may be illustrated by observations on a 23-day young. It had been in the water near its home lodge for some minutes before an attempt was made to read its tag number and obtain growth rate data. Pursued by means of a canoe, it dived and wedged itself, imperfectly concealed, under the vegetation of the marsh bottom, where it remained submerged for at least three minutes and 20 seconds; after about five seconds on the surface, it dived to stay down for 35 seconds; and after another fivesecond rest, it went under for two minutes and 45 seconds. It was then captured, though in condition to have continued diving.

Weaning is, in most cases, accomplished early in the fourth week. The young of the slowest growing litters studied were typically selfsustaining by the end of their first 30 days. An accelerated period of growth beginning about the twentieth day (see median weight curve of Fig. 2.1) coincided generally with the time that the young began foraging for themselves. Smith (1938) found, for his pen-raised $O$. z. macrodon, that 15- or 16-day suckling periods were more common, but, in view of the fact that the mean size of Smith's pen-born litters was only three, it may be wondered if such a small litter size may have had some bearing upon the earliness with which many of his experimentally propagated young were weaned.

For the Iowa young, growth rates of approximately half of the large 
litters were noticeably retarded several days before weaning, for the apparent reason that their mothers' milk was insufficient. This is exemplified by Fig. 2.2, in which the weight and length curves of the slightly underfed young leveled off after the second week, but these young showed little departure from normal in eye-opening, pelage change, activity, and response to handling. Weaning was usually late toward the end of the fourth week - among the underfed young and was followed by an acceleration of growth as they became self-sustaining. At least some of such underfed young subsequently reached normal size.

While undersized young may show more alertness and activity than may many larger young of the same age, the larger may become independent earlier. In litters having young of slightly unequal sizes, the larger members may already be swimming and feeding outside before their smaller litter mates show inclinations to leave the lodge. Transition periods between developmental stages may be so short that a previously docile animal may be transformed into a wild biter in the space of 24 hours.

The muskrat nearing the end of its first month may be thought of as an independent enterprise in a very modest way. It still has far greater potentialities than ability for taking care of itself. It may still need the warmth that it can get from huddling wih older young or with adults - usually with adult males or adults of mixed sexes that are through breeding.

Individuals of this age-class may die of pneumonia or apparently of chilling if long exposed to rainy weather - indeed, they seem to show far less tolerance of exposure than do the nearly poikilothermic new-born. They may, when their wet fur is plastered to their bodies, attract egg-laying by myiasis-producing flies, the larvae of which are quick to enter wounds or natural openings. Because of their cartilaginous bones, tender skins and musculature, and bulging viscera, they can not withstand much violence. A solid bite by an older muskrat may crush head or shoulders, sever the tail, lay open a lung or a kidney or a hip bone, or bring intestines tumbling forth from an abdominal wound. I have never known an animal of a recently weaned size to recover from more than a superficial cut, in contrast with the remarkable durability observed in young injured during their first week.

However, the month-old muskrat has made gains over its earlier helplessness. For its size, it is a willing fighter when attacked or cornered, itself able to slash through flesh. It is also approaching a stage of decidedly greater resistance to that skin disease of local deadliness to young muskrats caused by Trichophyton mentagrophytes (Robin) Blanchard, one of the "ring-worm" fungi (Errington, 1942b).

\section{THE YOUNG DURING THE SECOND MONTH AFTER BIRTH}

Our Iowa growth data on young aged between 31 and 60 days are too limited to plot in curves. Nine specimens of animals at 31 days, six at 32 days, six at 33 days, seven at 34 days, four at 35 days, and 
one at 36 days showed a mean increase in weight from 197 to 215 grams and an increase in length from 295 to $305 \mathrm{~mm}$. Two young of 41 days averaged 275 grams and $387 \mathrm{~mm}$. Three specimens collected toward the very last of their second month averaged 462 grams and $406 \mathrm{~mm}$. Dorney and Rusch (1953) listed 25 Horicon, Wisconsin, young of between 31 and 59 days of age, and their data show means of 198 grams for 10 specimens for the 31- to 39-day periods, of 270 grams for 10 specimens for the 40- to 49-day period, and of 362 grams for five specimens for the 50- to 59-day period.

The tails of our Iowa young, which show only slight lateral flattening at the beginning of the second month, become much flattened in the following weeks. The proportion of tail length to total length for nine of the larger specimens averaged about 40 per cent.

Much variation in pelage coloration may be observed for young muskrats in the course of their second month. The coats of many take on a rich brownish cast between the fourth and sixth weeks, whereas those of others retain their general leaden coloration for many weeks longer, especially, it seems, if living in dense, shady vegetation.

During the first half of their second month, the young, if driven from a lodge, usually swim underwater for about 50 feet, to hide among rushes or to lie under rafts of vegetation with only eyes and nostrils exposed. If alarmed while swimming on the surface or sitting on floating material, the young of recently independent ages often enter lodges through small openings previously dug into the sides above the water level. As a rule, the young are comparatively unwary up to their fifth or sixth weeks, though seldom permitting close approach unless asleep or cautiously stalked.

Later, the young become so adept at underwater swimming that they may habitually go from lodge to lodge without necessarily coming to the surface. On one occasion, I had an excellent opportunity to watch members of a litter of young known to be about 50 days of age. These young were swimming submerged and undisturbed in the vicinity of the large, high lodge in which they lived and on which I stood. The water was clear and smooth, the light was just right, and the young conducted themselves naturally. They swam with a leisurely, sprawling motion, using both forefeet and hindfeet. Their routes appeared to be casually explorative, very crooked, and were underwater for minutes at a time. Fig. 2.3 shows the course of an individual swimming submerged for an estimated total of nearly 60 yards in irregular loops and circles. During its submerged swimming, it investigated many bottom objects.

When weaned, the young may either remain in the lodges or burrows in which they are reared or establish themselves in other quarters 10 to 50 yards or farther away. Their behavior in this respect depends upon their opportunities and necessities and particularly upon the toleration their mothers show them at times when later litters are being cared for.

Some degree of fighting involving the young may be expected in 


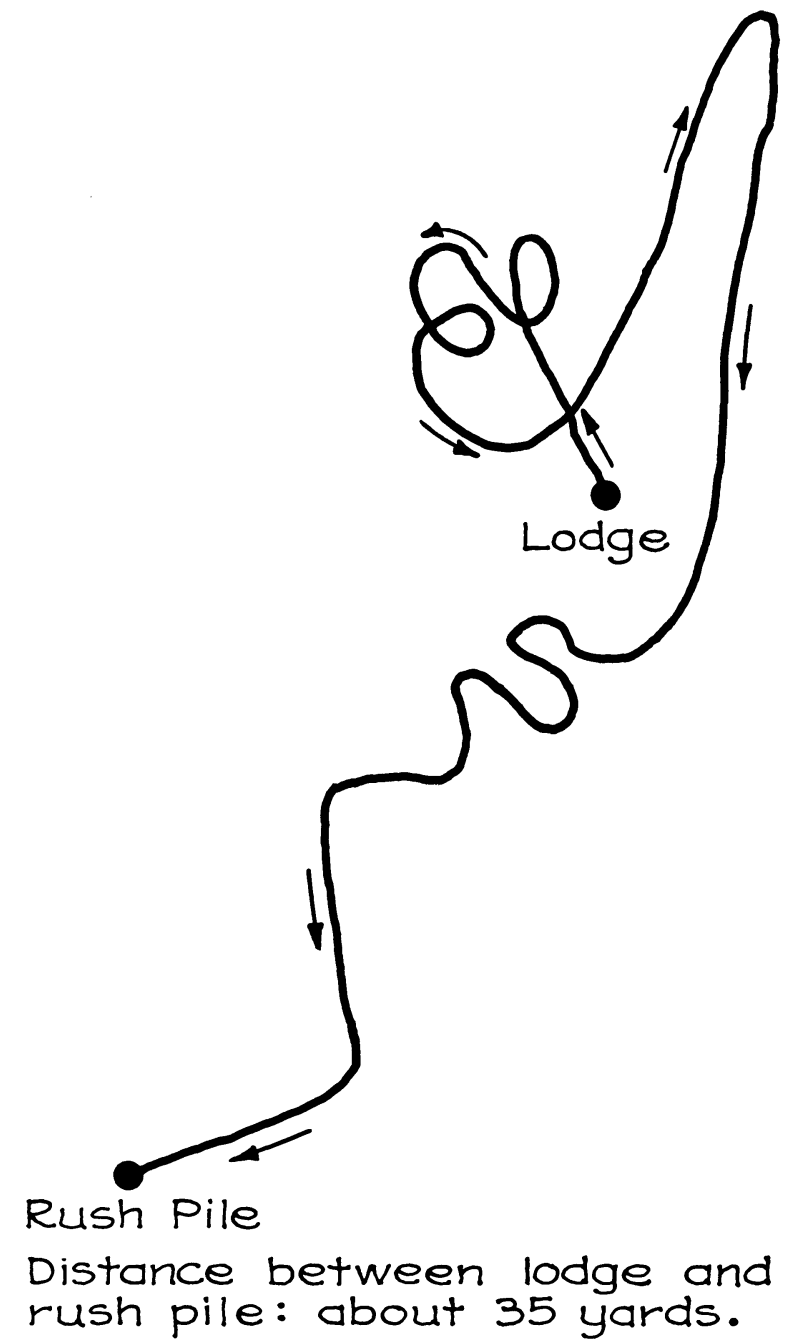

Fig. 2.3. Route taken by undisturbed muskrat of about 50 days of age while swimming entirely submerged. (After Errington, 1939b - Journal of Mammalogy.)

practically all muskrat populations. Attacks may be mostly by adults upon young of early swimming sizes; but, toward the end of their second month, the young are themselves sufficiently grown to inflict dangerous wounds on each other. Young in their second month may also feed on the bodies of other muskrats, and some of this feeding may represent direct predation, in particular when animals less than a week old are eaten. This may explain some of the violence with which mother muskrats may drive weaned young from the vicinity of newborn or helpless litters. Older young, however, are often seen entering or leaving lodges containing suckling litters, and, in overpopulated 
habitats, they are practically forced into continued close association with their own or neighboring families, whether or not their presence is tolerated.

Insofar as few young muskrats on Iowa marshes do much in the way of constructing or repairing habitations before the age of four months, the living quarters of young in their second month tend to be in lodges, old lodge butts, rush piles, or miscellaneous mats or heaps or floating vegetation in or near parental home ranges. These young may do a great deal of burrowing through the sides and bases of lodges. Sometimes large, sound lodges may be riddled with holes and tunnels, but the most conspicuous evidence of burrowing is typically to be seen about smaller, less permanent lodges and in the tops of flat remnants rising just over the water. Individual nests of post-weaning sizes of young may be hollowed out in almost any heap of debris. Bank-dwelling young of streams behave similarly except that they seek refuge more in the ramifications of burrows. Longestablished, strategic burrow systems may be complex (Errington, 1937a; 1943, p. 813) with blind-alley retreats or criss-crossing tunnels both deep in the banks and opening along the water fronts.

A two-months muskrat stands a good chance of continuing to live for many months, as long as environmental conditions are favorable always assuming that it does not succumb to disease. As long as it is in a position to use its normal faculties for escaping, it is not much in danger from the predatory faunas characteristic of our northcentral region. But, it is still not a rugged creature, and, sharp incisors notwithstanding, its main defense is to keep from getting caught.

In the event of a drought exposure or other emergency leaving it badly situated, it may not last long. Practically any medium-sized avian and mammalian predators will exploit drought-exposed young muskrats while they can. On the Iowa study areas, the usual exploiter is the mink (Mustela vison), which obviously responds to increased availability of muskrat prey as opportunities permit (Errington, 1943; $1954 \mathrm{~b})$. Nor are the prospects for survival of a two-months muskrat away from water great in the absence of animate enemies. It cannot endure much thirst and it does not seem to thrive on a harsh diet of dry-land plants.

\section{THE THIRD AND FOURTH MONTHS, INCLUDING "KIT" STAGES}

"Kit" muskrats taken by north central trappers in fall and winter are young animals, the small, thin pelts of which have little value on the fur market. The identity of the "kit" has long been a subject of conflicting opinions (Johnson, 1925, pp. 229-36), but the animals so designated by trappers and fur buyers in the regions of my familiarity correspond in weight, length, and sexual development to midsummer young of 70 to 90 days. In Iowa, this means that the "kits" taken from the usual opening of the trapping season on November 10 up to mid-December are the young that were born in August or later. 
Sixteen of our Iowa specimens were handled at known ages of between 62 and 104 days. Two were young of 62 days averaging 402 grams and $367 \mathrm{~mm}$. in total length; four, between 70 and 77 days, 451 grams and $439 \mathrm{~mm}$.; four, between 89 and 93 days, 499 grams and $473 \mathrm{~mm}$.; four, at 97 and 98 days, 759 grams and $513 \mathrm{~mm}$.; and two, at 104 days, 883 grams and $509 \mathrm{~mm}$. The proportion of tail length to total length for nine specimens of between 90 and 104 days averaged 41.5 per cent.

Dorney and Rusch (1953) tabulated the weights of 107 animals from Horicon, Wisconsin, aged 60 to 129 days. Following are the means for the two sexes combined: 364 grams for five specimens for the 60- to 69-day period; 536 grams for six specimens for the 70to 79-day period; 535 grams for 10 specimens for the 80- to 89-day period; 644 grams for five specimens for the 90- to 99-day period; 758 grams for 23 specimens for the 100- to 109-day period; 835 grams for 33 specimens for the 110- to 119-day period; and 818 grams for 25 specimens for the 120- to 129-day period.

The time of change from "kit" to adult-like pelage varies considerably with individuals. An adult-like, November-trapped animal of only 567 grams weight and $452 \mathrm{~mm}$. total length is listed in my notes, and animals of similar appearance under 615 grams and 465 $\mathrm{mm}$. are of frequent occurrence. On the other hand, a specimen as large as 733 grams and $490 \mathrm{~mm}$. is described as "turning."

In its daily life, almost any muskrat that is strong enough to get around is able to do more or less digging, and those of "kit" sizes are fairly adept diggers. A little more advanced behavior pattern is required for the construction or maintenance of lodges or the repairing of burrows caved in through disuse, trampled by livestock, or dug into by predators. The larger "kits" may be thought of as being on the verge of living as adults do. Indeed, they are then at the age at which a very few begin to breed.

In escaping and defending themselves against vertebrate enemies, the "kits" need all of the advantages that favorable living conditions may confer. When anything goes wrong, as during drought exposures or evictions from familiar habitats, the "kits" usually suffer heavier losses in proportion to numbers than do the older animals. I have long noticed that, when a mink does succeed in taking a healthy muskrat from an obviously secure wintering population, the victim is often a "kit." At times when hardly any other muskrats may be dying, "kits" may now and then be found about a marsh dead or severely injured from miscellaneous types of violence. Not only are the "kits" weakbacked, soft-fleshed, big and tender around the middle, and with a thorax easily crushed or penetrated, but they also seem a bit more uncertain in their escape and defense reactions - perhaps a little slower both to dodge and to fight - and not quite as strong biters as the more fully grown. Whatever may be the exact reasons, they are among the more conspicuous targets for abuse by the ill-tempered or aggressive of their better-equipped fellows. 
But the "kits," too, are interested in staying alive, and what tolerance of adverse living conditions they may have suffices to carry them through many emergencies of moderate intensity or duration. Of course, with luck, a given "kit" or group of "kits" might not necessarily be fatally vulnerable even during a generally cataclysmic crisis, and young may occasionally be found surviving the majority of adults on a dried-up marsh (Errington, 1943, p. 901).

\section{THE FIFTH TO EIGHTH MONTHS OR SUBADULT STAGE}

Growth and developmental data were obtained on 40 muskrats marked on central and northern Iowa marshes while very young and recovered at ages from five to seven and one-half months. Of these, eight specimens of five to five and one-half months averaged 798 grams and $507 \mathrm{~mm}$.; 19 specimens of six to six and one-half months averaged 940 grams and $547 \mathrm{~mm}$.; 11 specimens of around seven months averaged 918 grams and $540 \mathrm{~mm}$.; and two specimens of around seven and one-half months averaged 841 grams and $535 \mathrm{~mm}$.

The Horicon, Wisconsin, weights of Dorney and Rusch (1953) for 424 marked animals handled at 130 to 199 days of age give a far more complete picture of subadult trends than do our Iowa data. Their mean weights for the sexes combined: 862 grams for 52 specimens for the 130- to 139-day period; 906 grams for 67 specimens for the 140- to 149-day period; 1,002 grams for 59 specimens for the 150- to 159-day period; 1,029 grams for 69 specimens for the 160- to 169-day period; 1,032 grams for 93 specimens for the 170- to 179-day period; 1,073 grams for 67 specimens for the 180- to 189-day period; and 1,101 grams for 17 specimens for the 190- to 199-day period.

Dorney and Rusch also plotted separately their weight data on 309 male and 247 female muskrats handled at 31 to 199 days of age.

The resulting curves, as well as tabulated data, show slower growth rates for the females after about the first two months, and this trend continues throughout the later age-groupings. The more limited data from Iowa specimens line up similarly, the females having a decidedly slower growth between weaning age and their own sexual maturity. For Round Lake, northwest Iowa, the mean weight of 20 young males caught in early November, 1936, was 781 grams, compared with 707 grams for 24 females; in December, five young males averaged 840 grams and three females averaged 773 grams. The mean total lengths of the 20 males and 24 females for November were 507 and $489 \mathrm{~mm}$., respectively; for 53 young males and 35 females for December, 531 and $526 \mathrm{~mm}$. Total lengths of young Round Lake animals taken in December, 1937, averaged $525 \mathrm{~mm}$. for 94 males and $512 \mathrm{~mm}$. for 70 females; in December, 1938, they averaged $530 \mathrm{~mm}$. for 88 males and $512 \mathrm{~mm}$. for 79 females. Measurements of young muskrats trapped by the public in central Iowa in November, 1937 and 1938, illustrate the same trend: 52 males averaged $537 \mathrm{~mm}$. and 47 females averaged 521 $\mathrm{mm}$.

These larger mean sizes attained by immature Round Lake males 
in late fall and early winter do not seem attributable to earlier dates of birth. For April and May, 1935-38, 57.2 per cent of 222 young for which times of birth were determined on the marsh were males; for June, 55.8 per cent of 267 young were males; and, for July and August, so were 56.1 per cent of 41 young. The corresponding November and December sex ratios from the same marsh averaged 54.9 per cent males for 584 young of the year.

Grimm (1941), from the data kept on 232 adults and subadults in Pennsylvania, found that the mean weight for young males was 2.37 pounds, while that for the young females was only 1.77 pounds. In Ohio, Anderson (1947), after listing the frequency distribution of weights of 1,146 muskrats by two-ounce classes, concluded that a larger proportion of young males of his study area reached the two-pound class by March than was the case with females.

The physiological researches of Bogart, Sperling, Barnes, and Asdell (1940) on females of the laboratory rat suggest that this lag in growth may be due to inhibiting estrogens and that the inhibitor may be removed later, as through pregnancy or the formation of corpora lutea. They favored the latter possibility and cited Slonaker (1929) as having shown that a similar stimulus to growth is found in pseudopregnancy.

In considering the usefulness of the Dorney and Rusch curves for estimating approximate ages of unmarked animals on the basis of size, one should not lose sight of the reality of the variations to be expected in populations and individuals. Pronounced variations in sizes of subadults may be ascribed to food differences, alone. Corn-fed Iowa muskrats of six to eight months often are as large as their less well-fed fellows that are a year older, though such corn-fed young may be hardly farther advanced in sexual development than evident "kits." Alexander (1951) found, in a population sample of 140 winter-caught muskrats from New York, that the variance in weight due to age was only slightly greater than the variance in individuals.

Only one marked Iowa animal was recovered as a subadult after having been reared up to the age of five months in a patently foodpoor habitat; it weighed 642 grams. Four specimens most nearly comparable in age and fullness of alimentary tract, but taken from ordinarily good habitat, averaged 767 grams. The growth rates reported by Lavrov (1933a) for four semicapitve muskrats handled at intervals on a Russian fur farm were much lower than those of our free-living Iowa and Wisconsin young, averaging less than 500 grams at around four months of age.

As winter brings evidence of gradual sexual awakening in muskrat populations, the influence of food on development of the subadults becomes clearer. The testes of 195 young males examined from our Round Lake study area in November and December, 1936-38, averaged $8.1 \times 5.0 \times 3.7 \mathrm{~mm}$., with the testes of 14 individuals reaching or exceeding $10 \mathrm{~mm}$. in length and the greatest testis measurement being $12.0 \times 9.0 \times 5.0 \mathrm{~mm}$. Most of these specimens were caught during the first week of December and none later than the middle of that month. 
In 1939, we obtained 97 young males during the last few days of December, and, of these, 63 or 65 per cent had testes reaching or exceeding $10 \mathrm{~mm}$. in length, and 28 or 29 per cent had testes reaching or exceeding $12 \mathrm{~mm}$. in length. For the latter 28, the testis measurements averaged $13.9 \times 8.0 \times 5.7 \mathrm{~mm}$., with the sizes of the two largest sets of testes being $18.0 \times 12.0 \times 7.5$ and $17.0 \times 11.0 \times 8.0 \mathrm{~mm}$. Cheever Lake, a marsh about 15 miles from Round Lake, had a food supply noticeably inferior to that of Round Lake (but not really a very poor one) in 1939; of 46 young male muskrats taken for examination during the first week of January, 1940, only five or 11 per cent had testes that were $10 \mathrm{~mm}$. or more in length, and their largest testis measured $11.0 \times 6.5 \times 5.5 \mathrm{~mm}$. The testes of the Cheever Lake sample were then, by early January, in about the same stage of advancement shown by the better-fed Round Lake animals a month earlier.

It should be indicated that little change in testis size occurs during the months of juvenile quiescence of the Iowa muskrats. For 11 "kit" males, the measurements averaged $7.5 \times 4.9 \times 3.4 \mathrm{~mm}$., or essentially the same as the mean of $7.3 \times 4.6 \times 3.6 \mathrm{~mm}$. obtained for five males posted at ages between 40 and 60 days. For the females, the uteri are small and the uterine walls so thin as to be almost transparent throughout "kit" and subadult stages unless precocious sexual activity occurs.

There are several papers on priming, moults, and fur structure in muskrats (Gunn, 1933; Kellogg, 1946; Shanks, 1948; and others). With a few conspicuous exceptions, fall-trapped young of the year from. north central United States have a distinctive priming pattern, usually leaving a skunklike set of two light stripes against the dark background of the dorsal part of the pelt, whereas the pelt pattern of an adult tends to be irregular and blotchy. The few exceptions can be confusing nevertheless: On one occasion, I was delighted to obtain what I thought was a second-year tagged animal, only to find it to be an exceptionally large 185-day young with a thick pelt having a typically adult priming pattern. In general, late fall and early winter pelts of adults appear more "prime" than those of the young and are more likely to be scarred. All pelts of precociously breeding young females that I have examined were retaining their juvenile priming patterns until at least early December.

According to notes dated the winter of 1921-22 and relating to about 320 muskrats caught personally for fur in Brookings County, South Dakota, the pelts from the Big Sioux River became prime about a month later than the pelts from the Oakwood and Tetonkaha marshes. This difference seems attributable to the richer food of the marsh muskrats compared with that of the muskrats of the Big Sioux River, the diets of which ran prominently to frogs and bivalves. Pelts from poorly-fed animals of open water lakes were also behind the priming schedule of muskrat pelts from marshes - well demonstrated by the condition of nearly 200 marsh and lake muskrats trapped in the Tetonkaha area during the winter of $1922-23$ and by about 130 
more trapped in December, 1923. Finally, my 149 muskrat pelts for December, 1924, from creek-bed pools of Haakon County, western South Dakota, were of very inferior quality. This was in part due to wounds resulting from much fighting among the muskrats themselves, but the pools had also been short of food (Errington, 1939a).

To consider next the sex ratios of the subadults: Most of the total of 11,313 young of the year recorded for Iowa trappers' catches, 193657 , were subadults, and, of these 6,368 or 56.3 per cent were males. As an over-all ratio for the larger young animals, this differs from the over-all 54.1 per cent males shown by the 1,954 small young that were sexed, but, when the more strictly comparable data were considered, the difference became less. Some 3,635 young of the year were examined in fall and early winter from areas on which 1.123 small young had been sexed during preceding summers: the series for the large young contained 2,019 or 55.5 per cent males. compared with 630 or 56.1 per cent males in the series for the small young. From outside of Iowa, Sooter (1946) recorded 653 or 56.5 per cent males in a series of 1,155 sub-adults taken December 1, 1943, to February 28, 1944, from Tule Lake, California; McCann (1944), 239 or 57.0 per cent males in 412 young of the year that were trapped from December 1 to 21,1941 , in Minnesota; Hargrave (1950a), 304 or 56.4 per cent males in 539 young taken in North Dakota, December, 1949; Beer and Truax (1950), 10,784 or 57.3 per cent males in 18,832 fall immatures from Wisconsin, 1946-48; Gashwiler (1950), 402 or 59.0 per cent males in 681 November-trapped Maine subadults, 1945-48.

Gould and Kreeger (1948), in their study of skulls of $O$. z. rivalicius at advanced ages, referred to age changes in the muskrat as appearing to be continuous. The skull increases in weight and density, and the molar teeth undergo progressive changes throughout life. Among the other respects in which subadults grade off into adults, the bodies of the adults show a sturdiness seldom found in the younger. The maturing animals become more formidable, can give and take more punishment, and the psychological boldness that well-situated muskrats gain with maturity is tempered by an increase in what may be called discretion.

\section{ON THE MUSKRAT AS AN ADULT}

Most Iowa examples of $O$. z. zibethicus examined at known or approximately known ages weighed around 1,100 grams ( $22 / 5$ pounds) and measured around $550 \mathrm{~mm}$. (215/8 inches), tip to tip, by the end of their first year. Weights between 1,250 and 1,300 grams are believed to be fairly representative of animals approaching the end of their second year.

The famous Bergmann Rule holds that, among the geographic races of a warm-blooded species, the races living in the colder climates are generally of larger body sizes than the races living in the warmer (Rensch, 1938). The phenomenon seems to have its foundation in the fact that, while the volume of a body increases to the third power, its 
surface increases only to the second power. Hence the larger body, having proportionally less surface, will better resist loss of heat.

There are exceptions to the Bergmann Rule, including, as Hesse, Allee, and Schmidt (1951, p. 465) indicate, burrowing mammals, which can withdraw from the cold; and, for this reason, no one should be surprised to find the muskrat conforming poorly. The muskrat's normal winter habitations have unfrozen water in their plunge holes, whether these be in central United States or within the Arctic Circle. To a muskrat not exposed to it, the terrific outside cold of the northern high plains or the Canadian tundra need not be felt any more than mere freezing weather in Maryland or Missouri, though intensity of cold and length of winter may introduce other variables.

What is generally the largest muskrat of all, macrodon, may be called a southern form for it lives in Maryland, Virginia, and North Carolina. The small muskrat, zalophus, lives in the Arctic northwest, as does the fairly large spatulatus, but these two are subject to dissimilar climatic conditions. (The reader should not be confused by published reference to spatulatus as a small muskrat, for, from a recent series of specimens, Fuller (1951) rated it similar in size to zibethicus.) The small muskrat, albus, lives in the region west of Hudson's Bay. The smallest adult muskrats of which I know are those of the Barren Grounds near York Factory, Manitoba. I was informed by G. W. Malaher, Director of the Game and Fisheries Branch of the Manitoba Government, that these may attain sexual maturity and reproduce when no larger than ordinary "kits," or at around half the normal size of adults (in conversation, August, 1948); considering the lateness and shortness of the breeding season to be expected at a latitude of 57 degrees, these small-sized breeders could hardly have been precocious young from the same calendar year. Until otherwise demonstrated, they may be regarded as locally stunted members of $O$. z. albus living at an inhospitable edge of muskrat range.

Four (occipitalis, osoyoosensis, zibethicus, and aquilonius) of the six forms living in northern United States and southern Canada are muskrats of large or fairly large body size. The other two, cinnamominus and obscurus are smaller animals, of which cinnamominus in its northern range lives in what can be an exceedingly severe winter climate. Two (mergens and goldmani) of the five southwestern muskrats are medium-sized to fairly large, whereas pallidus, bernardi, and ripensis are small or very small. In the Gulf Coast marshes, rivalicius is distinctly smaller than zibethicus at the nearly adjacent southern extreme of the latter's range.

A most impressive linkage of sizes of muskrats with food differences is afforded by Dozier's (1945) data on 2,152 males and 1,767 females of O. z. zibethicus trapped early in 1944 from the Montezuma National Wildlife Refuge in New York. Weights were taken to the nearest quarter pound, and, for the males, the mean was three and five-eighths pounds (1,644 grams), for the females three and five-sixteenths pounds (1,503 grams), and, for the whole series, three and a half pounds 
(1,588 grams). The largest individual muskrat of the same subspecies that I weighed during the Iowa investigations was a male of 1,586 grams - about the same as the mean for the whole Montezuma series.

Dozier described his Montezuma series of zibethicus as outweighing macrodon by an average of a pound and as being distinctly larger in measurements, having a stockier, heavy-set appearance, a much wider tail (up to one and three-sixteenths inches in width), and a more docile disposition. Except for the specimens from one tract, the Montezuma series was very fat. The pelts of some of the larger animals weighed as much as 17 ounces before fleshing, with three ounces of the weight being due to fat. For some, the total fat removed from skin and body weighed as much as eight ounces, but the skins were still exceptionally thick and tough, and the fur was dense and long. The specimens from a pool having a water level too high for optimum food conditions for muskrats averaged at least a third less in weight than those living in the more food-rich places.

Alexander and Radway (1951) followed up Dozier's study on the Montezuma Refuge and appraised yearly differences in mean sizes in terms of sex and age ratios, time of trapping, and status of habitats. The weights given for comparison were: 3.24 pounds for 1943; 3.44 for 1944; 3.08 for 1945; 3.04 for 1946; 3.16 for 1947; 2.84 for 1948; 3.04 for 1950; and 3.01 for 1951. A general decline of most of the most of the habitats was noted in 1948, whereas the heaviest trapping of 1943, 1944, and 1947 was done in food-rich habitats.

In comparing the size variations of widely-distributed zibethicus over its native range, Dozier's very fat Montezuma series should perhaps be ignored. Alexander and Radway evidently considered that about three pounds should be a more typical weight for muskrats wintering on the Refuge.

Anderson (1947) obtained a mean of 2.33 pounds for 1,146 springtrapped but rather lean Ohio specimens, which he felt were similar in appearance to Dozier's leaner ones from Montezuma. Baumgartner and Bellrose (1943) examined a series of 318 adults from two Illinois lakes and 66 more from Michigan; the Illinois specimens averaged 2.7 pounds and those from Michigan, 2.3 pounds. Seamans' (1941, p. 21) mean for 150 spring-trapped Vermont muskrats was 2.66 pounds; Grimm's (1941), for 567 winter-trapped in Pennsylvania was 2.37 pounds.

It may be seen that most of the samples of weight data on adults of $O$. z. zibethicus come from the northeastern quarter of the United States or from, roughly, near the middle of the subspecific range. For the South, Freeman (1945) stated that the mean weight of adults of this subspecies in Mississippi was 2.1 pounds. He did not give the number of specimens in his sample, and, on the basis of criteria on his page 31, I suspect that his series included large subadults.

The normal life span of the muskrat is only suggested by the data at hand. Gould and Kreeger (1948) cited a personal communication from $\mathrm{O}^{\prime} \mathrm{Neil}$ to the effect that a marked specimen of $O$. $z$. rivalicius 
was recovered three years after its release as a young adult. Harold Mathiak, of the Wisconsin Conservation Commission, told me (December, 1957) of recovering a tagged Horicon Marsh muskrat at the age of 1,302 days, or over three and a half years. Tsygankov (1955) concluded, on the basis of tooth structure, that muskrats may live to the age of four years.

Good leads as to longevity of muskrats are afforded by the dying of muskrats from apparent old age on two Iowa marshes. From the case histories of the Iowa observational areas, it may be fairly well established that most of the aged muskrats dying on a noticeable scale at Little Wall Lake throughout the summer and fall of 1944 must have been young animals of 1941. At Wall Lake, the many old ones dying on a fur-refuge tract during the fall and winter of 1946-47 could hardly have been animals born prior to 1943 . On both marshes, the natural mortality that seemed traceable to old age figures out as occurring at ages of around three to four years. These old muskrats were mostly emaciated but, if filled out for their frames, would have fitted well into the 1,200- to 1,300-gram weight class. My record Iowa specimen of 1,586 grams was, when collected in midsummer, a male obviously in old age - my guess of its age would be at least four years. One scarred old male at another place attracted attention by its unsteady actions and permitted itself to be struck by a canoe paddle. It was not very thin, yet was smaller than many young animals after their first summer's growth, weighing 913 grams for its total length of 541 $\mathrm{mm}$.

There is strong evidence of differential sex mortality among the adults. Of the 2,132 adults examined in the trappers' catches from the Iowa obseravtional areas in fall and early winter, 1936-57, 988 or 46.3 per cent were males, and, for some good samples, the percentages of males among the full adults were considerably lower. Data on sex and age ratios published by various authors on large series of American specimens - McCann (1944) in Minnesota, Sooter (1946) at Tule Lake in California, Beer and Truax (1950) in Wisconsin, and Hargrave (1950a) in North Dakota - show that 3,052 or 50.0 per cent of 6,106 adults were males, compared with 15,858 or 55.8 per cent males in an over-all sample of 28,422 trapped carcasses. Only Hargrave's series of 2,243 showed approximately the same sex ratios in the adults (59.8 per cent males in 326) as in the general popualtion (59.1 per cent). The smaller proportions of males among the adults as compared with the young probably reflect as much as anything the greater conspicuousness and vulnerability of surplus and transient adult males during the breeding months (Errington, 1940; 1943, especially pp. 83343).

In any treatment of sex ratios in trapped miskrats, questions as to the validity of the samples should always be considered. Sexually active males may be easy to take selectively as long as any sort of surplusage remains. Much variation is shown by local samples, however, and possibly the best procedure would be to see what we get by com- 
bining the data in the literature on muskrats harvested in fall and early winter and under conditions most likely to bring out the true sex ratios in the respective populations. My tally, as of 1954 and including unpublished Iowa data as well as those summarized by North American workers elsewhere: 55.4 per cent males in samples totaling 62,635 muskrats. But neither did the average lot of specimens known to have been trapped in late winter and spring show appreciably greater preponderance of males: 54.6 per cent in samples totaling 93,947 muskrats.

I make no claims as to the completeness of my sex ratio tabulations, for more figures are being acquired or published all the time. Nor do I think, in view of the dozens of authors who have published on muskrat sex ratios, that a title-by-title listing of this literature would be justified in this book. Without getting into wearisome involvements, an interested reader might consult the following papers, which summarize a great deal of what has been published on muskrat sex ratios in North America: Dozier and Allen (1942), Dozier, Markley, and Llewellyn (1948), Beer and Truax (1950), and Alexander and Radway $(1951)$.

From the latter and miscellaneous sources, I have arrived at an over-all ratio of 55.0 per cent males in a grand total of 165,954 North American muskrats trapped for fur; and surely, for general purposes, 55 per cent males to 45 per cent females may be regarded as the sex ratio for grown-up muskrats, irrespective of wide local differences to be expected from time to time. Hoffmann $(1952 ; 1958)$ reported the same ratio on the basis of a tremendous amount of German data.

\section{THE BREEDING MONTHS}

Dixon (1922) wrote of muskrats in the Imperial Valley of California breeding in every month of the year, with the bulk of the young being born between February 15 and October 30. In Louisiana, Svihla and Svihla (1931) similarly found young muskrats or embryos in every month of the year, but they reported the heaviest breeding from November through April. Winter breeding is likewise indicated by Lay's (1945) data from Texas marshes; this author obtained only occasional records between April and October. O'Neil (1949, p. 60), on the basis of five years (1940-45) of work on Louisiana muskrats, determined that November and March were the months of the greatest sexual activity and July and August the months of the least.

From histological studies of reproductive tracts of 222 male and 340 female adult muskrats from Maryland, Forbes (1942) concluded that spermatogenesis began in the middle of December and ovulation in the middle of February, also that gonadal activity of both sexes terminated in late October. Previously, Forbes and Enders (1940) had suggested that the first ovulatory cycle in the annual breeding season of the Maryland muskrat generally began early in February and ended before the middle of March, after which a second ovulatory cycle came around. 
In southern Wisconsin, Beer (1950) took daily vaginal smears from captive, live-trapped muskrats and followed through 11 complete estrous cycles. He obtained a mean of 28.7 days per cycle, with a variation of 24 to 34 days. The estimated birth dates for the first litters that he handled were April 28 for 1946, May 5 for 1947, and April 20 for 1948. Not many litters were found until after May 15, and only a few after the first week of July. It may be that, for reasons of the lineup of Beer's period of research with years of a cyclic low (Errington, 1954a; 1957), the breeding span he recorded may have been near the minimum for his region. His much longer mean for estrous cycles, compared with that of 6.1 days recorded by McLeod and Bondar (1952) might be thus explainable, for the latter authors felt that the longer cycles might have been due to premature falling off of sexual activity. Beer did find one young, trapped November 3, 1946, having an estimated birth date of about the middle of September; and he had a reliable trapper's report of small embryos in a female taken during late February.

From the embryos reported upon by Smith (1938), I would judge that the main breeding season in Maryland is one to three weeks earlier than in central Iowa and three to five weeks earlier than in the northwestern part of this state. The earliest breeding record that we have for central and southern Iowa dates to late February, 1943. Not only did field signs toward the end of a several-day period of springlike weather, February 22 and 23, reveal evidences of mating, but what proved to be a bred female was picked up by a conservation officer from a highway near Creston on February 28. It seems unlikely that even highly favorable diets and living conditions would advance the actual time of early coitus among Iowa muskrats appreciably earlier than that recorded for 1943.

So far as late breeding of muskrats in Iowa is concerned, $I$ have an unverified trapper's report of very small young found near Ruthven in northwest Iowa in December, 1936. I am inclined to consider this as probably true, though occurrences of this sort must be most exceptional at the latitude of Iowa, and trappers may mistake for young muskrats the meadow mice and other rodents that rather frequently live in muskrat retreats even in winter. (Once, upon opening a central Iowa lodge in late winter, I was startled by what looked like a recently weaned young muskrat sticking its head out of a plunge hole, only to see that it was a Norway rat.)

Glen C. Sanderson, then Game Biologist of the Iowa State Conservation Commission, found two young muskrats with eyes barely open on October 21, 1949, in Jones County, east central Iowa. The total length of a specimen was $234 \mathrm{~mm}$., which would indicate that they were probably born during the first week of October" (letter, December 18, 1949). One of the "kits" trapped at Wall Lake in late November, 1951, had a total length of only $340 \mathrm{~mm}$., which should make its date of birth about the middle of October; and, in midNovember, 1953, 18 specimens of similar size or smaller were found in the total of 90 "kits" handled from the same marsh. 
Two of our Iowa adult males taken in late November of the early fifties were in breeding condition, with testes measuring $19 \times 14 \times 12$ and $22 \times 17 \times 14 \mathrm{~mm}$. Considering the long periods of sexual activity of females noted by McLeod and Bondar (1952) for O. z. albus - as late as mid-August, if not later, even in Manitoba - it would seem quite possible that an Iowa litter might rarely be sired in winter.

McLeod and Bondar found the earliest date of birth of several hundred Manitoba litters to be May 11. Their observations show that a pronounced upsurge of production of young is normally to be expected on marshes of southern and central Manitoba following May 20. The exact time varies with the time of breakup of the ice. Following the first upsurge in rate of arrival of the season's litters, the rate drops very low, to be followed by another but smaller upsurge coming almost a month after the first. After about another month, a third but still smaller upsurge comes and, following this, an almost negligible fourth. The interpretation is that some of the first females to breed mate again to produce second litters about a month after their first and that a progressively diminishing proportion then produce third and fourth litters at about monthly intervals. An occasional four-litter female should not be unexpected at southern or central Manitoba latitudes, with successive litters born in late May, late June, late July, and late August. In opening a limited number of lodges at random in the Saskatchewan River marshes in 1948, I found two litters with birth dates assignable to late July and, on Netley Marsh south of Lake Winnipeg, a dead female with fetuses due about midAugust. McLeod and Bondar reported an exceptionally late litter born on September 20, 1950, on Delta Marsh, and it was near here that Provincial Conservation officer William Newman had observed a litter of probably September-born young in a partly-exposed bank nest when ice was on the water in October (conversation, August, 1948).

We actually have obtained field data during the breeding months on times of birth of nearly 1,000 litters in central and northern Iowa, but, due to the fact that the quantitative studies for 1950-52 were restricted to the first half of the breeding season, only 745 of these litters (those recorded, 1935-49) are reliable indicators of seasonal distribution. Data on seasonal distribution of Iowa litters were also obtained through estimating ages of placental scars in the uteri of muskrats trapped during late fall and early winter fur seasons or found dead.

It was not until after the postmortem examination of two particularly informative adult females of known age in the fall of 1939 that I attempted to count and differentiate into sets the placental scars visible in the uteri of fall-trapped females. In 1940 and 1941, I made some preliminary trials at dating sets of scars, and then, from 1942 on, such dating was made a part of routine examinations.

This method is much less exact than that of dating litters handled or seen in the field throughout the annual breeding span of the muskrats. Dating of placental scars months after their respective pregnancies is of course more dependent upon personal judgment. Indeed, the reli- 
ability of placental scars as indicators of breeding history frequently has been challenged, and reliability does vary with the species of mammal being worked with, as well as with the time of year in relation to the breeding season. For muskrats breeding more or less in all months of the year, or with much seasonal irregularity, I would consider placental scar counts to be of limited utility, much as Davis and Emlen (1948) found for two species of Rattus in Maryland and Texas. But, for northern muskrats in which the annual breeding season is essentially restricted to a block of months, fall and early winter specimens yield far more satisfactory data. Even so, the fading of the older sets of placental scars may make counts in Iowa specimens unreliable after about the end of the calendar year.

The possibility is further recognized that, even in Iowa fall specimens, some of the placental scars assigned to early spring may have been laid down the previous year. Spring and summer specimens occasionally show a gradual fading of scars that could not have been laid down during the current breeding season. Generally, the later the scars are laid down during a breeding season, the more accurately they may be dated from the uteri of fall and winter specimens, and the better they agree in chronology with the field data on times of birth of litters.

Table 2.1 compares our Iowa data on times of birth, as arrived at by the two methods on the same areas over the same years of study, 1940-49. It may be judged that I had a tendency to overestimate the ages of early-season placental scars in fall-trapped specimens and to date the midsummer scars a little too late. This is something that I tried to correct in examining specimen series of later years.

Although other authors besides McLeod and Bondar presented data indicating mean intervals of about a month between breeding peaks (Dorney and Rusch, 1953), our Iowa data on birth dates of muskrat litters show no over-all peaks and troughs indentifiable with the births of successive litters (Table 2.2). The times of birth of the 745 litters examined in the field during entire breeding seasons (Table 2.2, left)

\section{TABLE 2.1}

Comparison of Data on Birth Months of Iowa Muskrat Litters According to Two Methods of Study Used on the Same Areas During the Same Years, 1940-49

\begin{tabular}{|c|c|c|c|}
\hline $\begin{array}{l}\text { Month of } \\
\text { Birth }\end{array}$ & $\begin{array}{l}\text { Data from } 360 \\
\text { litters examined } \\
\text { in the field during } \\
\text { entire breeding } \\
\text { seasons }\end{array}$ & $\begin{array}{l}\text { Data from } 890 \\
\text { litters having } \\
\text { birth dates esti- } \\
\text { mated from } \\
\text { placental scars }\end{array}$ & $\begin{array}{l}\text { For the total of } \\
1,250 \text { data samples } \\
\text { from both litters } \\
\text { and placental scars } \\
\text { used in combination }\end{array}$ \\
\hline March & 1 or $0.3 \%$ & 6 or $0.7 \%$ & 7 or $0.6 \%$ \\
\hline April & . 41 or $11.4 \%$ & 169 or $19.0 \%$ & 210 or $16.8 \%$ \\
\hline May. & . 142 or $39.4 \%$ & 267 or $30.0 \%$ & 409 or $32.7 \%$ \\
\hline June & 134 or $37.2 \%$ & 250 or $28.1 \%$ & 384 or $30.7 \%$ \\
\hline July .. & 24 or $6.7 \%$ & 151 or $16.9 \%$ & 175 or $14.0 \%$ \\
\hline August ... & 17 or $4.7 \%$ & 45 or $5.1 \%$ & 62 or $5.0 \%$ \\
\hline September & . $\quad 1$ or $0.3 \%$ & 2 or $0.2 \%$ & 3 or $0.2 \%$ \\
\hline
\end{tabular}


TABLE 2.2

Seasonal Distribution of Birth Months of Muskrat Litters in Central and NORTHERN IOWA

\begin{tabular}{|c|c|c|c|}
\hline $\begin{array}{l}\text { Month of } \\
\text { Birth }\end{array}$ & $\begin{array}{l}\text { For } 745 \text { litters } \\
\text { examined in the } \\
\text { field during the } \\
\text { entire breeding } \\
\text { season (restricted } \\
\text { to } 1935-49-\text { see text) }\end{array}$ & $\begin{array}{c}\text { For } 2,179 \text { litters } \\
\text { having birth dates } \\
\text { estimated from } \\
\text { placental scars } \\
\text { during fall and } \\
\text { winter months, } \\
1940-57\end{array}$ & $\begin{array}{l}\text { For the total of } \\
3,209 \text { litters for } \\
\text { which times of } \\
\text { birth were recorded } \\
\text { from all sources, } \\
1935-57\end{array}$ \\
\hline March & 1 or $0.1 \%$ & 6 or $0.3 \%$ & 10 or $0.3 \%$ \\
\hline April & 86 or $11.6 \%$ & 315 or $14.5 \%$ & 448 or $14.0 \%$ \\
\hline May & 259 or $34.8 \%$ & 566 or $26.0 \%$ & 983 or $30.6 \%$ \\
\hline June & 277 or $37.2 \%$ & 582 or $26.7 \%$ & 918 or $28.6 \%$ \\
\hline July & 89 or $11.9 \%$ & 460 or $21.2 \%$ & 558 or $17.4 \%$ \\
\hline August ... & . 32 or $4.3 \%$ & 232 or $10.6 \%$ & 272 or $8.5 \%$ \\
\hline September & 1 or $0.1 \%$ & 17 or $0.8 \%$ & 19 or $0.6 \%$ \\
\hline October. & . $\quad-$ & 1 or $0.05 \%$ & 1 or $0.03 \%$ \\
\hline
\end{tabular}

may be regrouped according to half-month periods: One litter was born in the second half of March; 11 litters in the first half of April; 75, in the second half of April; 132, in the first half of May; 127, in the second half of May; 165, in the first half of June; 112, in the second half of June; 62 , in the first half of July; 27, in the second half of July; 21, in the first half of August; 11, in the second half of August; and one, in the first half of September.

Furthermore, examination of hundreds of spring and early summer victims of quick-acting epizootic disease on central Iowa marshes disclosed nothing of monthly peaks and intervals in times of birth of litters. Some of the female victims were pregnant in early April; many young females of the previous years - even large-sized females - were still showing no evidence of sexual maturity by mid-May or later; and considerable numbers did not reach breeding condition before the middle of June. All of these variations could be seen on the same marsh in the same year. Irrespective of how the species begins its annual breeding on marshes having late melting dates for ice cover, the Iowa muskrats seem to begin breeding when they are individually ready, late winter to early fall.

The reader may wonder how much the differences in percentages shown by the middle columns of Table 2.2 may be due to differences in methods. I cannot answer positively except to say that the percentages of litters born in August and later actually were higher during the years when the chief reliance was placed upon placental scars as a source of data. Prior to 1950, the Iowa investigations had furnished little evidence of young females breeding during the calendar year of their birth, though they may have been adult-like in external appearance at the age of three and a half to four months, or by midsummer. On the basis of data from placental scars alone, only 0.6 per cent of 841 litters for the 1940-49 period were assignable to precociously breeding young - which period also included some years of our best data 
TABLE 2.3

Precocious Breeding, (in Calfndar Year of Birth) in Iowa Muskrats, 1936-57

\begin{tabular}{|c|c|c|c|}
\hline Year & $\begin{array}{l}\text { Number of } \\
\text { young females } \\
\text { examined }\end{array}$ & $\begin{array}{l}\text { Number of } \\
\text { sample con- } \\
\text { ceiving young }\end{array}$ & $\begin{array}{l}\text { Per cent of } \\
\text { sample con- } \\
\text { ceiving young }\end{array}$ \\
\hline 1936 & 57 & 0 & $0.0 \%$ \\
\hline 1937 & $\ldots \ldots 108$ & 0 & $0.0 \%$ \\
\hline 1938 & $\ldots \ldots \quad 96$ & 0 & $0.0 \%$ \\
\hline 1939 & $\ldots \ldots \quad 95$ & 0 & $0.0 \%$ \\
\hline 1940 & $\ldots \ldots 217$ & 0 & $0.0 \%$ \\
\hline 1941 & .... 119 & 1 & $0.8 \%$ \\
\hline 1942 & $\ldots \ldots 164$ & 2 & $1.2 \%$ \\
\hline 1943 & $\ldots \ldots 505$ & $\bar{l}$ & $0.2 \%$ \\
\hline 1944 & 627 & 0 & $0.0 \%$ \\
\hline 1945 & $\ldots \ldots 222$ & 0 & $0.0 \%$ \\
\hline 1946 & $\ldots \ldots \ldots 175$ & 0 & $0.0 \%$ \\
\hline 1947 & $\ldots \ldots \quad 49$ & 0 & $0.0 \%$ \\
\hline 1948 & $\ldots \ldots \ldots 143$ & 1 & $0.7 \%$ \\
\hline 1949 & $\ldots \ldots \ldots 135$ & 0 & $0.0 \%$ \\
\hline 1950 & $\ldots \ldots 4436$ & 23 & $5.3 \%$ \\
\hline 1951 & $\ldots \ldots 590$ & 18 & $3.1 \%$ \\
\hline 1952 & $\ldots \ldots 405$ & 8 & $2.0 \%$ \\
\hline 1953 & $\ldots \ldots 345$ & 12 & $3.5 \%$ \\
\hline 1954 & ..... 132 & 7 & $5.3 \%$ \\
\hline 1955 & $\ldots \ldots \quad 40$ & 1 & $2.5 \%$ \\
\hline 1956 & $\ldots \ldots 125$ & 0 & $0.0 \%$ \\
\hline 1957 & $\ldots \ldots \quad 98$ & 2 & $2.0 \%$ \\
\hline Totals & $\ldots 4,883$ & 76 & $1.6 \%$ \\
\hline
\end{tabular}

obtained from handling litters in nests. But the big increase in precocious breeding from 1950 through 1954 (see Table 2.3) resulted in 6.4 per cent of 1,075 litters being assignable to precocious young, thus weighting the tabulated data from placental scars with late-born litters.

Warwick (1940), from examining muskrats taken the year around in the British Isles, came to much the same conclusion that I had in the early years of the Iowa studies. Even when young animals of the year were larger than currently breeding adults, the gonads of such young remained quite undeveloped in proportion to body size until after the breeding season was over. I had, nevertheless, long suspected that the young of four months or so could breed if living in a climate conducive to breeding in all months, as in the southern states. This is substantiated by O'Neil (1949, p. 60) for Louisiana. Hoffmann (1952) tabulated data on 1,665 pregnant adult muskrats and 152 pregnant young. Two of his pregnancies in young animals were found in June specimens, 13 in July, 56 in August, 60 in September, 16 in October, and 5 in November. For the years 1952-55, he tabulated 176 additional pregnancies of young females, including 76 for September, 24 for October, 9 for November, and 7 for December (Hoffmann, 1958).

The possibility should be considered that the nearly continuous daylight of Arctic and subarctic summers might accelerate sexual development in nature somewhat as laboratory investigators have done 
in changing the sexual cycles of mammals and birds through experimental manipulations of lighting (Bissonnette, 1936, 1938; Bissonnette and Csech, 1937; Rowan, 1938), but the extreme shortness of such northern summers would seem to impose some rather strict limitations. My feeling is that the previously mentioned breeding of "kit"sized muskrats near York Factory, Manitoba, represented activities of stunted adults rather than of very young individuals. After all, the studies of Fuller (1951) in the Athabasca-Peace Delta and of McLeod and Bondar (1952) in central Manitoba showed that the initial mating of a breeding season tended to occur when the ice went out. Where the earliest young are born in late May or later, and winter begins in September, there can hardly be many opportunities for precocious breeding, however long may be the daylight periods. And such studies of reproduction that have been carried on with muskrats of northern Canada do show a rapid slackening of breeding by midsummer. Stevens (1953) wrote that the testes of the Mackenzie Delta muskrats decreased rapidly in volume after most females had been bred and by mid-August were reduced to half of their June size.

\section{NUMBER OF LITTERS PER FEMALE PER YEAR}

O'Neil (1949, p. 60) estimated that an adult female muskrat produced five to six litters per year on the Louisiana coastal marshes and considered a female evidently capable of seven to eight litters in a year. At the opposite extreme of our continent, Stevens (1953) summarized evidence that yearling females of the Mackenzie Delta may have only one litter, coming mainly in late June, whereas the secondyear females may have two, the latter coming mainly in early and mid-June and in July. He also noted evidence of a few August litters, which could represent third litters. Fuller (1951), while recognizing the rare possibility of a third litter in the Athabasca-Peace Delta, concluded that nearly every female would have two litters in a breeding season. This two-litter pattern, with possibiliies of three- or even fourlitter exceptions, seems to be indicated not only by McLeod and Bondar's Manitoba data but also by the studies of many investigators in northern United States - see Gashwiler's (1950) data for northern Maine. Shanks and Arthur's (1952) finding that the female muskrats of Missouri farm ponds produced but a single litter may be appraised as reflecting the conditions under which the animals lived rather than any inherently low reproductive potential. In Nebraska, Sather (1958) found that $O . z$. cinnamominus of his study area had one to four litters during the breeding season, with a mean of 2.6 for the seasons of $1949-51$.

The earlier data on seasonal breeding performances of individual females on Iowa marshlands were all obtained through handling and dating of litters born. Times of birth of single-season litters were recorded with more or less satisfaction for 76 marsh-dwelling females judged to have been kept track of individually. One-litter females comprised 17 or 22.4 per cent of these 76 : three animals having single 
litters in May, eleven in June, and three in July. Of the others, 43 or 56.6 per cent were two-litter females for the breeding seasons concerned, 14 or 18.4 per cent were three-litter females, and two or 2.6 per cent were four-litter females. The mean for these was slightly over two litters, and the mean for the 51 adult females for which breeding fortunes could be individually followed with greatest assurance was slightly less than two litters. However, these particular data probably show an atypical preponderance of one-litter and two-litter females, coming as they did largely during a cyclic low (Errington, 1954a).

No litters either known or suspected to have been born to precocious young females in the calendar year of their own births were handled on our Iowa areas during the breeding months. Circumstantial evidence of adult females not conceiving young during a breeding season was found from time to time, but nonbreeding during a given breeding season was best demonstrated later by the condition of the uteri of fully adult females examined in connection with the fall trapping.

Of 931 adult females in the trapped samples from central and northern Iowa, 1941-57, 104 or 11.2 per cent had no placental scars indicating conceptions during their last breeding season. Seventy-two or 8.5 per cent conceived only one litter for the season - most of these litters having birth dates assignable to April, May, June, and, to a lesser extent, July. This poor breeding was almost always associated with animals living in comparative isolation - lone occupants of cattail or bulrush islands or pregnant females moving in to establish residence in some remote corner of a marsh or in a roadside ditch.

Adult females judged from placental scars to have had two litters in their last breeding season totaled 197 or 21.2 per cent; three litters, 320 or 34.4 per cent; four litters, 231 or 24.8 per cent; and five litters, 3 or 0.3 per cent. The data for all fully adult females (including nonbreeders) averaged out at 2.54 litters for their last spring and summer of life and at 2.87 litters for 824 adult females having productive and traceable breeding histories.

No evidence is at hand showing how many litters a given Iowa female may conceive during her life span under free-living conditions - probably rarely more than eight or nine, even when breeding begins precociously.

Pronounced differences in the color and size of the placental scars suggested occasional failures to conceive at expected times. Ordinarily, the more uniform gradations in appearance of sets of placental scars in Iowa fall specimens gave little cause to suspect irregularities in conception and birth of litters, and, for working purposes, intervals of about a month between litters balance out about right. In view of the variations in reproductive performances of the living females studied throughout the breeding season, it is not surprising that the seasonal distribution of litters estimated from placental scars does not correspond exactly with the distribution shown by the best field data; rather, the extent that they do correspond is in itself indicative. Only 
three of the 197 two-litter females appeared to have had intervals longer than approximately a month between births, but 24 or 7.5 per cent of the 320 three-litter females had intervals between births judged to have been substantially longer than a month and so did nine or 3.9 per cent of the 231 four-litter females.

The first positive proof of precocious breeding in Iowa was found in 1950. A marked female born in May gave birth to a litter of five young assigned to the following August. Four Iowa specimens from 1941-43 and one from 1948 may now be classed as young-bearing precocious breeders on the basis of hindsight. Most of the precocious breeding known to have occurred on the Iowa observational areas was in the 1950-54 period, and only one of the 68 specimens of young females that had thus participated was judged to have had more than a small single late litter each - two litters in this exceptional case. It may be suspected, from the June-to-December length of the breeding season shown for the young muskrats of Hoffmann's (1952; 1958) samples, that a larger percentage of the precocious breeders among the German populations may conceive more than one litter during their year of birth than was the case in Iowa, where the dates of births estimated from placental scars of this class of mothers fell within a period extending only from late July into September. The six largest litters of Hoffmann's (1952) young females (three of eight and three of nine) were carried in October and November, which would seem to suggest prior breeding histories.

\section{NUMBER OF YOUNG PER LITTER}

It is apparent that the size of litters in the muskrat may vary with the subspecies in addition to other factors. Samples totaling 1,393 pregnant females of $O . z$. rivalicius given by Arthur (1931, p. 218), Svihla and Svihla (1931), Lay (1945), Freeman (1945), and O'Neil $(1949$, p. 59) show a size range of one to nine embryos and a mean of 3.7. Of these samples from the coastal marshes of Louisiana, Mississippi, and Texas, those obtained by Lay in Texas, 1939-44, ran the highest in embryo counts, averaging 4.2 for 68 pregnancies.

For O. z. macrodon of the Maryland marshes, Smith (1938) reported a mean of three young for 27 litters born in experimental pens, but this small size should be considered atypical. His data from pregnancies in free-living animals, in combination with those of Harris (1952), give a mean of 4.0 for 105 pregnancies. Harris, furthermore, obtained good counts of placental scars from adult females, averaging 8.9 per uterus, which could be consistent with either two or three small litters of sizes fairly similar to those of $O$. $z$. rivalicius.

Except for $O . z$. zibethicus, few data have been published on litter sizes of northern muskrats. McLeod (1948) found litters of $O$. z. albus in Manitoba ranging in size from one to 12, with means of 5.0 for first litters of the season and 5.6 for second litters. In Nebraska, Sather's (1953) means for litters of nestling young of O. z. cinnamominus were 6.0 and 6.5 for 1950 and 1951, respectively, and, for litters 
represented by placental scars, 6.7, 6.8, and 7.1 for the winters of 1949$50,1950-51$, and 1951-52. His precocious females averaged 4.9, 5.0, and 4.5 placental scars for the three winters.

Although the muskrats that are now established in Europe are probably not completely pure $O$. z. zibethicus, that is the subspecies to which the European muskrats may be most confidently assigned. Ahrens (1921) and later Ulbrich (1930, pp. 15-16) wrote of 6 to 8 young being produced at a time. The mean number of embryos in 25 pregnancies examined by Warwick (1940) in the British Isles was 7.0. For comparison, he combined Ulbrich's records from central Europe with those of S. Mehl, obtaining a mean of 6.9 embryos for 94 pregnancies. From examination of thousands of muskrats taken in connection with control operations in the Netherlands, chiefly 1947-52, van Koersveld (1953) reported pregnancies averaging 5.8 embryos, compared with 7.1 in Germany. The 1,665 pregnancies in Hoffmann's (1952) German series of adult muskrats, 1940-49, averaged 6.8 embryos, with a range of 1 to 14 . He (1958) obtained the same mean from a later series of 1,294 specimens. The mean size of 328 litters carried by young breeders was 5.2, with a range of 1 to 10 (tabulated data from Hoffmann [1952; 1958 ] combined).

At the southern fringe of its range in North America, O. z. zibethicus seems to have about the same litter size as $O$. z. rivalicius, though recorded samples are few. Freeman (1945) examined two pregnant females in February in northern Mississippi and found three embryos in one and four in the other. Beshears and Haugen (1953) handled four litters averaging four young in east-central Alabama. They also counted a mean of 12.7 placental scars in 10 uteri, which they considered indicative of a mean production of three litters per year per female.

I know that a tremendous amount of data on litter sizes exists from long-term investigations of $O$. z. zibethicus in northern United States outside of Iowa, but definite facts thereon are hard to find in the literature. In 1946, Beer and Truax (1950) obtained a mean of 6.3 young in $15 \mathrm{~W}$ isconsin litters "considered to be complete"; in 1947, 6.8 in 17 litters; and, in 1948, 8.0 in 44 litters. This gives a mean of 7.4 for their total of 76 litters handled.

The Iowa data from complete litters in nests and embryos carried during pregnancies are most nearly comparable with the data on placental counts for the 1935-48 period. For this period, we have means of 6.78 young in 188 complete litters and 6.94 placental scars per set in 1,075 differentiated sets. Considering that some resorption of embryos occurs in the uterus - noticed in Europe by Mehl in 3 out of 98 pregnancies and by Warwick in 2 of 25 - and that occasionally a young animal must be lost between birth and time of first handling in the nest, these general means from the litters and from placental scars are in good agreement. It should be explained that not all of the many placental scars in the uterus of an ordinary Iowa female may be 
assigned to specific litters, even though the totals may be counted and divided by the number of litters conceived during a breeding season.

There is practically a traditional belief in both North America and Europe that early spring litters average smaller than those conceived during the main breeding season. Our most accurate Iowa data on birth dates are for 237 litters, and, for these, the following mean sizes of litters born (or due, in the case of embryos) per half-month period may be presented: 5.8 young for 4 litters for the second half of April; 7.4 for 58 litters for the first half of May; 7.3 for 50 litters for the second half of May; 6.5 for 43 litters for the first half of June; 6.5 for 37 litters for the second half of June; 6.6 for 25 litters for the first half of July; 6.5 for 13 litters for the second half of July. Seven August litters averaged 7.2. At times, successive litters born to a female may be of equal or similar sizes, or they may be either larger or smaller. Among our more reliable samples: a litter of seven followed by a litter of two and then by one of seven; nine young followed by five; seven followed by five; four by six; six by five; six by seven; seven by eight; five by nine; eight by ten; and ten by seven.

Variations in mean sizes of Iowa litters occurred according to both locality and year. The most pronounced of these variations appear to be linked with the "10-year game cycle" (Errington, 1954a; 1957). Certain lesser differences reflect the influence of habitat differences, especially during years of acute population crises and food shortages.

Table 2.4 illustrates the annual variations in litter sizes born to or conceived by fully adult muskrats living on or near the Iowa study areas. Something more in the way of formal statistical treatment for the year-series, 1935-52, is shown elsewhere (Eerrington, 1954a).

The 1950-54 period of notably precocious breeding on the part of Iowa females during the calendar year of birth yielded data on the sizes of 69 litters thus conceived. Their over-all mean was 5.3, with the following frequencies: 2 litters of three young, 10 of four, 30 of five, 19 of six, 6 of seven, and 2 of eight. If the data on litters conceived by precocious females for this period be lumped with the data from adult females, the mean sizes of the litters recorded would be lowered from 8.0 in 224 litters to 7.7 in 247 litters in 1950; from 8.2 in 322 litters to 8.0 in 340 litters in 1951; from 8.0 in 199 litters to 7.9 in 207 litters in 1952; from 7.4 in 219 litters to 7.3 in 231 litters in 1953; from 7.2 in 79 litters to 7.0 in 87 litters in 1954.

Apportioning of the litter data of adult muskrats for calendar years into groups corresponding to cyclic phases is not wholly satisfactory. Evidence from various sources suggests that significant shifts in phase may have occurred within the span of some of the breeding seasons (Errington, 1954a; 1957). In other cases, it is most difficult to say just when a shift may be dated. Some of the line-ups of groups of years look interesting, however, and these may here be introduced, pending further discussions of cyclic phenomena in later chapters.

For the year-group, 1935-37, which I have been designating the 
TABLE 2.4

Mean Sizes of Litters Born To or Conceived by Adult Iowa Muskrats, 1935-57

\begin{tabular}{|c|c|c|}
\hline Year & $\begin{array}{c}\text { Number of } \\
\text { litters in } \\
\text { sample }\end{array}$ & $\begin{array}{c}\text { Mean numbers of young per } \\
\text { litter and } 95 \% \text { confidence } \\
\text { intervals for the population } \\
\text { means }\end{array}$ \\
\hline 1935 & 78 & $6.64 \pm 0.44$ \\
\hline 1936 & 43 & $6.42 \pm 0.57$ \\
\hline 1937 & $\ldots$ & $7.29 \pm 1.48$ \\
\hline 1938 & 34 & $6.53 \pm 0.55$ \\
\hline 1939 & 13 & $7.00 \pm 0.35$ \\
\hline 1940 & 86 & $7.38 \pm 0.27$ \\
\hline 1941 & 53 & $8.19 \pm 0.46$ \\
\hline 1942 & 73 & $8.41 \pm 0.28$ \\
\hline 1943 & 295 & $7.91 \pm 0.16$ \\
\hline 1944 & 367 & $6.95 \pm 0.12$ \\
\hline 1945 & 108 & $6.91 \pm 0.22$ \\
\hline 1946 & 65 & $6.40 \pm 0.41$ \\
\hline 1947 & 26 & $7.73 \pm 0.57$ \\
\hline 1948 & 92 & $7.30 \pm 0.25$ \\
\hline 1949 & 86 & $8.09 \pm 0.30$ \\
\hline 1950 & 224 & $7.95 \pm 0.24$ \\
\hline 1951 & 322 & $8.17 \pm 0.15$ \\
\hline 1952 & 199 & $8.01 \pm 0.22$ \\
\hline 1953 & 219 & $7.45 \pm 0.17$ \\
\hline 1954 & 79 & $7.20 \pm 0.30$ \\
\hline 1955 & 74 & $7.12 \pm 0.30$ \\
\hline 1956 & 113 & $6.35 \pm 0.22$ \\
\hline 1957 & 73 & $7.58 \pm 0.34$ \\
\hline Totals & $\ldots \quad 2,729$ & $7.50 \pm 0.06$ \\
\hline
\end{tabular}

chronological cyclic low, the mean size of samples totaling 128 litters of adult muskrats is 6.6 ; for 1938-40, the transition upgrade, 7.1 for 133 litters; for 1941-42, the cyclic high, 8.3 for 126 litters; for 1943-44, the transition downgrade, 7.4 for 662 litters; for 1945-47, the cyclic low, 6.8 for 199 litters; for 1948-50, the transition upgrade, 7.8 for 402 litters; for 1951-52, the cyclic high, 8.1 for 521 litters; for 1953-54, the transition downgrade, 7.4 for 298 litters; and for 1955-57, the cyclic low, 6.9 for 260 litters. 


\section{Chapter 3}

\section{Territoriality, Home Range, and \\ Movements of the Muskrat}

MOBILITY AND TENDENCIES toward fixed residence naturally have an important bearing on the daily life of a species as well as on the strength and effectiveness of its pioneering thrusts. On the whole, these phases of behavior have been better studied in birds than in mammals (Nice, 1941; Errington, 1946); but, among mammals, small rodents have become the subjects of a related literature that is already so large as to make a review of even the findings on the muskrat's nearest relatives among the microtines impractical for this chapter.

Most modern studies of free-living small rodents emphasize the limited sizes of areas comprising individual home ranges, although wider movements may be forced by emergencies or population pressures. The great overflows of the Scandinavian lemming (Lemmus lemmus) are surely in remarkable contrast with the habits of those members of the same species that maintain themselves in nearly sedentary residence about as other mouselike rodents do (Elton, 1942, pp. 226-30; Wildhagen, 1952).

\section{BACKGROUND OF DATA FROM MARKED MUSKRATS}

During the summers of 1935 and 1936, 463 muskrats were experimentally marked with serially numbered alumninum tags, and the salient results were tabulated (Errington and Errington, 1937) ; 122 of these tags yielded data of some sort. Of 214 young similarly tagged from 1937 to 1943 (including 23 also toe-clipped) and of 65 that were toe-clipped only, 18 were again handled or heard of at intervals sufficient to be informative (Errington, 1944). From 1944 to 1952, 788 more young were tagged and 9 adults or subadults toe-clipped; and, of these, 34 of the tagged and 3 of the toe-clipped were later recovered or studied further. To sum up, we have "returns" on 177 of a total of 1,539 animals thus far marked in central and northwestern Iowa. Data 
were likewise obtained on the behavior of 6 individuals that were recognizable without question (though they had not been deliberately marked) as well as on many other individuals that were distinguishable in life on the basis of their isolated residences, their appearance and idiosyncracies, and the responsibility that they showed in their care of marked litters.

Specific records of movements at stages of early independence were obtained for 36 of the marked young, and only 3 of the records were for distances exceeding 50 yards from the lodges where the tagging had been done: 2 at 60 yards and 1 at about 125 yards. One partial albino was seen in company with mixed young and adults on July 13, 1935 , and on several days thereafter, finally to die in emaciated condition 200 yards distant at an estimated age of two months. In the case of the albino, the unusual movement could well have been due to the animal's illness.

The muskrats marked while very young and recovered as subadults, months afterward, showed some differences in mobility that varied according to their circumstances. Some could not have moved far without inviting trouble from other muskrats. Three individuals, living in natal localities bounded on all sides either by unfavorable habitat or by home ranges or territories occupied by other family groups, were tagged and released in May and June, 1936; these were all taken in the following November and December at a mean distance of 70 yards from the tagging sites. On an overcrowded marsh, an undernourished one tagged on June 22, 1944, was taken near the same place on November 10.

The following marked young muskrats, although not subject to any special hazards of intraspecific strife, had drought conditions to contend with. One, toe-clipped and released on May 30, 1940, was trapped about November 20 in the same locality, after drought crises in both summer and fall. Another was probably killed by a great horned owl (Bubo virginianus) during a drought exposure; it had been tagged on May 23, 1947, on a part of a marsh that went dry, and its remains were found on top of a lodge 70 yards nearer water. Four of another litter tagged on May 23, 1947, died within a few days of each other in mid-September; of these four, three died at a lodge about 20 yards from the site of tagging - one from hemorrhagic disease and two (likely diseased also) from attack by a dog. The fourth died of disease but on the shore of another marsh three miles away, probably a couple of days after leaving its natal locality. One other marked subadult, living in the drought-exposed corner of a marsh in 1936, evidently wandered away in late summer and fall, to be trapped in November along a drainage ditch four miles away.

Thirty-eight tagged animals recovered as subadults were residents of relatively underpopulated marshy habitats or of a linear or elongated type of home range that usually permits greater freedom of movement without trespassing on the property rights of other muskrats. Ten tagged during the breeding seasons of 1935 and 1936 
were recovered at a mean distance of 270 yards; three, in 1938, at a mean distance of 410 yards. Then, in 1943, one animal was recovered from its natal locality, and six others (all members of a single litter) were trapped more or less together in a small area, 100 to 150 yards from the site of tagging. Of 18 tagged, 1950-52, 13 were trapped in the fall in the vicinities of their spring and early summer tagging sites; two about 200 yards distant; one at 260 yards; and the last two, at estimated distances of 825 and 1,000 yards.

Records for individuals tagged while young and retaken when well into their second calendar year of life show both continued local residence and substantially greater movements. As an extreme case, an animal aged between 500 and 550 days was killed in early winter 193637 in a farmer's hog house 21 miles from its birthplace. Three tagged as young animals on a wildlife refuge, May and June, 1936, were trapped on neighboring marshes in November, 1937, from two and a quarter to three and a quarter miles from their sites of tagging. Other tagged muskrats were said to have been similarly caught, but the trappers did not report them for fear that possession might have been construed as evidence of poaching on the refuge; these muskrats, according to the "grapevine," were also caught within a four-mile radius of where tagged. (It should be mentioned that muskrats leaving this refuge would be unlikely to find attractive bodies of water much nearer than those at which the above were finally trapped.)

Among the older muskrats remaining on fair-sized marshes on which they had been born and marked, a storm or disease victim was found on April 25, 1937, in the central vegetation and about 800 yards from its tagging site of May 27, 1936; it was judged, from what scavengers had left, to have been a sexually active male. Two mature females, tagged as young in 1938, were recovered in late December, 1939, at about 375 and 950 yards from their birthplaces; and, of the two, the one moving the farthest had passed through its first breeding season without conceiving, whereas the other had placental scars of three litters. Another mature female, tagged as a young one in May, 1950, was trapped very near its tagging site in late November, 1951. An adult male died of disease, April 29, 1952, about 640 yards from where, at the age of 13 days, it had been tagged on May 17, 1950.

A second partial albino young for which we have field records was born about June 14, 1936, and, when last handled on June 30, was somewhat undersized, though the sole member of a litter. On April 25, 1937, a rather small - for that time of year - partial albino was seen very close to the above site, in company with an adult of normal appearance. No other examples of albinism were seen on the marsh in 1936 and 1937, so the observations for those years doubtless related to the same individual. In the summer of 1938, a lodge traceable to what could hardly have been other than this same partial albino (a female) was erected about 450 yards from the old home range; and, in this lodge, the third litter of the season (seven born on August 16) included two partial albino young. 
Manifest albinism is rare among our north-central muskrats, and all four cases that I have seen and handled were from one marsh (Round Lake) during the years 1935-38. At least 1935, 1936, and 1938 were years of such intensive field studies that the likelihood of other partial albino young being present but escaping notice would seem to be remote. Hence the peculiar coloration of these young should afford a means of recognition even when they could not be approached sufficiently close to permit reading of tag numbers.

Data on the movements of a stump-footed muskrat illustrate the tendency for solitary individuals to spend a few days in a given area before moving on. The animal left its distinctive tracks along a little less than a mile of a creek during the night of March 24, 1939; from then to March 29 it confined its activities to about a third of a mile of stream border, mostly within the stretch covered on the night of March 24. It was still around by April 10, but no sign of it could be found thereafter, irrespective of careful and repeated search in five sections of land upstream and two sections downstream.

An example of late winter and early spring fidelity to a home range was accidentally obtained in 1943 . On February 4, I wished to destroy a covered nest that had been built on the ice of a flooded ditch, in order to learn from its subsequent repair or lack of repair whether a muskrat still lived in it. The nest was out of my reach from solid ground, so I scattered it with two light charges of number five shot from a .410 shotgun, taking off part of the top with the first charge as a warning to any possible occupant. By the time of my next visit, February 8 , the nest had been rebuilt, and signs of an animal clearly in residence were seen on February 23. On March 14, an unbred female was found killed by a dog on the ditch bank at this same site, and the victim had as a marker a single number five shot imbedded under a healed wound on the skin of its back.

On April 19, 1944, a newly-mature male was captured uninjured as a transient, toe-clipped, and experimentally released at a pool nearly three miles away. At the time, the pool was muskrat-vacant, but muskrats had lived there until trapped out in the fall of 1943, and a set of burrows remained in attractive condition for muskrats. The toeclipped transient was put directly into a partly-covered chamber of a burrow, and ear corn was dropped in after it to give it some incentive for staying. Its distinctive tracks were laid down in this vicinity until about the middle of July, after which the burrow appeared to have been abandoned.

Two other toe-clipped animals yielding data were precariously situated small subadults living in a newly excavated and foodless gravel pit pool lying adjacent to a creek. These probable litter mates moved into the gravel pit in the fall of 1947 and were first noticed foraging in a corn field on November 16. One or the other of them left the gravel pit in quest of food at such times as the weather moderated, but with poorer success as snow and ice accumulated in the corn field. By mid-February, 1948, both were extremely weak and 
underweight when handled, and one was partly blind. One was found dead on February 19, with a good representation of liver lesions from hemorrhagic disease. The partly blind one outlived the other; its tracks were seen on February 23, though it probably died soon after.

The stream-side activities of a big yellow adult were traceable for several months during the drought of 1937. In late August and early September, there were other muskrats living within a half mile of the burrow system occupied by the big one, but, even then, the signs of this animal were becoming characteristic. By mid-September, the creek bed was devoid of other muskrats for a straight-line distance of about 1,200 yards downstream, and, by the end of the month, an equal distance upstream. By late October, a three-mile stretch was depopulated of all known muskrats except the big one. A few days after the trapping season opened on November 10, no known muskrats except the big one occupied a stretch of more than seven miles of the creek. This elimination of other animals through drought and fur trapping greatly simplified the problem of identifying the remaining muskrat, not only from its tracks and its appearance when seen but also from its general behavior and feeding routines. Moreover, field conditions were most favorable for repeated observations.

The big yellow one had been first fairly well recognized as an individual in late August, 1937. Though living in a set of dry burrows and raiding the adjacent corn field, it was beginning to travel back and forth between its burrows and a large pool about 200 yards upstream. From September 5 to 15, the animal used the burrows, raided the corn field from the same place as before, and commuted upstream. The animal retired to the upstream pool shortly after September 22, to raid the corn field from there, over a new route. Water returned to cover the creek bed in mid-October, but the muskrat worked out from its upstream quarters until late November, when it returned to its old burrows and renovated them. From November 30 to March 3, 1938, all foraging and other activities were centered about the old burrows. By March 19, the spring dispersal was underway, and no further sign indicating the presence of this animal was seen.

Elsewhere in Iowa, Snead (1950) carried on an extremely detailed marking and retrapping study of muskrats of all ages on the Mississippi River near Lansing. (See also Appendix H.) I know of no published break-down of his findings. I do know, however, from conversation with him, that his muskrats tended to live in very restricted home ranges, about like those of central and northwestern Iowa. This is also the impression that I have concerning the unpublished tagging data of Dr. James R. Beer for a marsh near Madison, Wisconsin.

The program of live-trapping and tagging of muskrats at Horicon Marsh by the Wisconsin Conservation Department included littertagging of 4,158 young muskrats (Mathiak and Linde, 1954). Of 149 young animals litter-tagged in 1949 on a 95-acre refuge area, three (members of the same litter) were trapped in November just outside of the refuge line. Five were taken as animals wandering on the ice, in- 
cluding two still wandering within the refuge boundaries. No first-year recoveries from 154 litter-tagged young were reported from trapping outside the refuge in 1950. Trapping in the refuge itself in the fall of 1951 and the spring of 1952 accounted for 30 of 106 litter-tagged in the summer of 1951. Six of the total of 409 litter-tagged on the refuge were taken in their second year, off the refuge, but mostly within a half mile of the boundary; probably most of the six were animals that had left the refuge during the spring dispersal following their year of birth.

In his study of muskrats tagged on a part of Horicon Marsh that had been ditched experimentally as part of a management project, Mathiak (1953) found most distances between sites of tagging and sites of recovery to be less than 400 feet. Of 49 winter recoveries of animals tagged in the fall of 1951, 27 were taken at sites of previous live-trapping. However, he recorded three members of one litter trapped over a mile away, while no members of that litter were trapped in the experimental ditches. He found little evidence of more than local movements in 1949 and 1950, when the muskrat densities were relatively low, but, in the spring of 1952, with a greater residual population in the ditches, greater movement away from the ditches occurred. In early April, 1952, five muskrats were trapped at probable average distances of over a mile from the ditches where they had been originally tagged.

This author also found a relation between amount of movement and the distance that experimental ditches were spaced apart. Of 14 recoveries of animals tagged, 1949-51, in ditches 400 feet apart, 12 were taken within 300 feet of tagging sites and two within 700 feet. Of 43 from ditches that were 200 feet apart, 35 were taken within 200 feet of tagging sites, 7 more within 400 feet, and one within 600 feet. Of 49 from ditches 100 feet apart, 37 were taken within 200 feet, 6 within 400 feet, 5 more at distances between 410 and 800 feet, and one between 1,310 and 1,400 feet. Then, of 53 from ditches only 50 feet apart, 25 were taken within 200 feet, 10 within 600 feet, and 8 more at distances between 710 and 1,800 feet.

Dorney and Rusch (1953) found that, of 348 young marked during the breeding season of 1950, 56 were recovered during the early November trapping, including 38 from within 300 feet of where marked. In some cases, part or all of a litter appeared to have moved as a group to a new fall location. Dorney and Rusch plotted the recovery points of 31 members of 15 litters showing movements exceeding 300 feet from their original lodges, and 12 of these members had moved at least 1,000 feet. Field observations in combination with the marking data suggested that the wider movements could be explained in terms of the attractiveness of a part of the marsh that was occupied by a thinly-distributed resident population.

On the Sand Lake National Wildlife Refuge in northeastern South Dakota, Aldous (1947) obtained data from recaptures of 367 marked muskrats of different ages. Some of the travels of his animals were 
accounted for by movements from bank burrows to lodges. About 70 per cent of the recoveries (mostly in the winter following the summer tagging) were under 55 yards, or within the limits of the daily feeding radius. About 20 per cent were from 60 to 165 yards, and the other recoveries were strung out to about a half mile, with one being at 1,100 yards.

Sather (1958) carried on an intensive two-year (1949-51) tagging and trapping study of the muskrats of a Nebraska sandhill marsh. In his marking and retrapping of hundreds of animals, he found summer, fall, and most winter movements confined to a radius of less than 100 yards of the marking sites. He also found, after the spring dispersal, that the adult females were more likely to maintain their original home ranges than were the males.

In the course of a Missouri study of pond and stream muskrats, Shanks and Arthur (1952) live-trapped, marked, and released 183 animals (103 in 1946, 69 in 1947, and 11 in 1948). These were retaken a total of 298 times. Only 15 of the retakes gave records of wandering beyond the limits of the original home ranges, and, among these, 11 were movements from one pond to another (a maximum distance of a half mile), one from a pond to a stream (a distance of at least two miles), and one from a pond to a pool in an intermittent stream. Muskrat populations were comparatively stable during summer and winter, with periods of movement occurring primarily in spring and fall.

Of 40 ponds visited by Shanks and Arthur in the summer of 1946, 12 contained resident adult muskrats with young; but, after the fall dispersal, only three ponds contained resident adults with their young, one pond contained an adult female and a young male, each of five ponds contained a young male and a young female, and each of two ponds contained a young female. All of the three ponds holding both adults and young into the winter months were more than two acres in area.

Williams (1950) live-trapped 84 previously marked muskrats on Gray's Lake, southeastern Idaho, in the summer and fall of 1949. Two individuals were recovered 200 yards from their sites of marking, and 63 within 50 yards. Eighteen of the marked animals were taken by fur trappers during the spring of 1950, all from the same parts of the marsh where the animals had been marked eight or nine months earlier.

In Maine, Takos (1944) reported that all of nine immature muskrats captured two or more times (a total of 28 captures) were taken within 100 feet of the original site of capture. All together, he banded 107 of mixed ages, of which 40 were recaptured a total of 184 times. His records for 11 adults captured five or more times during summer and early fall gave maximum distances from original trapping sites of up to 265 feet, mostly within a 100 -foot radius. The most complete data he obtained were for an adult male, taken 28 times between April 20 and August 7, 1941. It was first captured near the periphery of its range, and the greatest straight-line distance between captures 
was 260 feet. Another adult male showed the maximum distance between points of capture -570 feet away on the morning following the previous handling. But several other adults of both sexes showed similar tendencies to range widely.

Some pronounced differences in movements of muskrats were reported for southern Ontario by Wragg (1955) on the basis of data from marking 62 adults and 28 young in nests. His data on a total of 41 recoveries involving 30 individuals were chiefly from animals marked between May and October, 1947, and taken by fur trappers in the springs of 1948 and - to a lesser extent - 1949. Fifteen of 24 recaptures made after an interval of five to 10 months (including the periods of fall and spring activity) were at distances less than 100 yards from marking sites. Nine animals were taken outside of the home marsh (175 acres), and 5 of these traveled over a mile: one of the latter was found frozen in a hole in a creek bank two and a quarter miles away. The second, marked as a "kit" in July, was taken in poor condition the following spring along a small stony creek three miles away. The third was also trapped along a creek, over a mile from the banding site. The fourth was a huge female killed by a dog in winter along a railway track over a mile from the marsh. The fifth was taken eight miles away.

Only three of Wragg's 28 young that were marked in nests were recovered in the following spring - one 175 yards, one 500 yards, and the other three miles away. A female live-trapped along a creek bank on October 24 was recaptured two days later 100 yards distant and then killed at the latter place five months later. In October, an adult male and an adult female were taken and banded on successive nights on a small lodge just being constructed; the female was captured the following spring 150 feet from this lodge, but the male was a half mile upstream.

The author noted that the nine animals leaving the marsh left an excellent environment having a population that was well below normal. In most cases, recoveries of these animals were made in less favorable places, and some of the animals were then in poorer condition than the muskrats remaining at the home marsh. Movements tended to be along water courses, but some unbanded muskrats that were frozen out of lodges in shallow water were found wandering over the ice and adjacent land or dead in the snow.

From June, 1947, and up to March, 1948, Stevens (1953) captured, marked, and released 303 muskrats (including 217 young) in the Mackenzie delta of the Canadian Northwest Territories. After at least three months, he recovered 89 marked animals in the three acres where most of the marking had been done. Fur trappers recovered 10 more, one of which had traveled four miles in the period between summer and spring, another a half mile from where first trapped and marked, and the remaining eight did not appear to have moved any appreciable distance after marking.

The Athabasca-Peace delta is another area of northwest Canada 
known for its muskrats, and here Fuller (1951) marked 168 during the summer of 1947. He detected no large scale fall movements among his marked animals - nothing over 100 feet.

\section{TRENDS OF EVIDENCE SHOWN BY FIELD DATA ON TERRITORIALITY AND HOME RANGE OF THE MUSKRAT}

Territoriality (or defence of specific parts of a home range against trespassers) may be regarded as a valid phenomenon in muskrat populations, though among muskrats there are nowhere near the rigidities to be seen in the territorial behavior of some birds. The boundaries of muskrat territories are not marked by definite lines, the crossing of which by individuals living outside invariably provokes resistance on the part of defenders witnessing the trespassing. In fact, it has long been plain that adult muskrats may cut corners or approach rather closely the lodges and burrow systems comprising territorial foci of their neighbors and even that, on occasion, several adults may have undisputed access to retreats containing suckling young. I have seen as many as four adults simultaneously using one medium-sized lodge and sitting and swimming near each other without hostile displays at the height of the breeding season when young were being cared for within the lodge.

Yet, during the breeding season in particular, the females can be, and usually are, noticeably intolerant toward trespassers, and the place defended may be substantially larger than the near vicinity of a litter of young. Tracts of stream edge, lake shore, or marsh that are recognizable as territorial units may be up to hundreds or thousands of yards apart in sparsely occupied habitats; but, at higher densities, the territories show much compressibility, down to the point where they may be separated by distances of only 20 to 40 yards. Differences in territorial tolerance of muskrats may be regarded as a resultant of opportunities, individual dispositions, the impacts of physiological and environmental variations, social conditioning, and the tensions of unknown nature associated with what we call cyclic lows or periodic depression phases. During cyclic low phases, breeding densities the equivalents of between two and three pairs per acre on first-class muskrat marshes have been observed to show fully as much evidence of intraspecific strife and like manifestations of overpopulation as have densities of 8 to 10 pairs per acre living on comparable marshes during favorable cyclic phases (Errington, 1954a; 1957).

Tendencies toward equalization of distances between territorial foci are often best illustrated when more or less homogeneous tracts of inviting marshland are being repopulated by newcomers during springs following drastic overtrapping or annihilative losses from drought or disease, or at times when large expanses of new habitat may for any reason become available to muskrats for colonization. The data from area case histories indicate that muskrats may be little influenced in their establishment of breeding territories by the presence of other territories existing more than 200 or 300 yards away. As popu- 
lation densities rise, territorial spacing may become increasingly a matter of compromises until the limits of tolerance of territoryjealous populations are reached.

Territorial foci may be expected to shift to a varying extent in the course of the breeding season. Such shifts may be pronounced just before young are born, when pregnant females and associated males may display indecision as to where they wish to establish residence. Much of the Round Lake study area had a general marsh population less than a pair per two acres in April and early May, 1936, yet temporary aggregations up to five pairs per acre were noted on tracts that proved to be almost muskrat-vacant later in the summer. Some territorial adjustment may also take place in response to receding waters or to disturbance by livestock of shore-zone territories. Often the females may transfer their young from lodge to lodge or "resettle" locally without detected cause other than their impulses to do so.

I have never been able to note any decided territorial intolerance on the part of the male member of a breeding pair. Males as well as females may be individually vicious and may attack other animals coming within reach, but observed males seemed much more likely to tolerate the presence of acquaintances or of inoffensive strangers and were far safer company than the adult females for weaned young.

Both sexes and all ages displayed tendencies to frequent certain parts of home ranges with which they were obviously familiar. The sizes of these home ranges for animals having opportunities for unimpeded movements varied from perhaps 60 to 80 yards in diameter for newly-weaned young and up to about a half mile for adults working underpopulated shores or toward the centers of bodies of water. When breeding populations were high and territories having intolerant females were closely spaced, the home ranges were correspondingiy smaller and more circumscribed, but a certain amount of passing back and forth by local residents took place in the interterritorial avenues without conspicuous friction. A resident could often be seen approaching to recognize another resident, to turn back when satisfied. Strangers attempting to cut through well-occupied blocks of marsh were, however, likely to be beset by attackers all along the route. Sometimes a luckless transient could be watched over several hundreds of yards of its course, attacked by residents wherever it went. Home ranges of resident muskrats were almost synonymous with territories from the standpoint of these strangers, insofar as their presence was little if at all tolerated anywhere within the tracts regularly frequented by residents. It made a difference what animals belonged and what did not.

Territorial adjustments in response to environmental pressures readily take place if the muskrats are in a position to move without effective hindrance in directions in which they may find better living conditions. On underpopulated parts of lakes and marshes, movements of given family groups have been traced for total distances of nearly a half mile in the course of a month or so. Other contempo- 
raneous groups having their movements blocked by either physical barriers or occupied territories of other muskrats have remained where they were, often despite severe losses and pyramiding crises for the survivors. But, territorial blockades do not necessarily prevent animals from breaking free as wanderers, to die or keep alive as they can amid the hazards of wandering.

Successful territorial adjustments that I have closely observed did not start with bold departures from burrows or lodges. There would be preliminary movements along a favored route in the direction of a prospective new site, from a relatively few yards to 35 to 100 yards or even farther distant. The main connecting trail might be quite beaten before a new lodge or set of lodges would be built and the old lodges finally abandoned. Then, if, for example, the new site threatened to dry up, the process of extension would be repeated - assuming that the muskrats in their local explorations found new accessible sites having greater attractiveness for them. If lacking further alternatives, they typically stayed where they found themselves after the last feasible move until the crisis passed or progressed to the point of mortality or eviction. This often meant that females living on drought-shrinking marshes gave birth to and raised successive litters at increasing distances from their original territories.

Adjustments in home ranges have the fundamental aspects of territorial adjustments except that they are less influenced by the jealousies of females caring for unweaned young. Free extensions, whether of territories or of home ranges, in response to drought tend to be centripetal, from shallower or disappearing waters to the deeper waters in lakes and marshes; but, where gradients vary and deeper parts are irregularly distributed, explorative trails may angle off in many directions. In drying streams, most home range adjustments are from pool to pool in the stream bed.

\section{THE SPRING DISPERSAL OF MUSKRATS}

Pronounced movements of muskrats may occur in any month in a warm or temperate climate, but, in the north-central region in which my work has been centered, they have been most evident in spring and fall.

The spring dispersal may more properly be regarded as an adjustment phenomenon than the manifestation of an inherent urge to travel. The initial activities of most Iowa muskrats after the ice goes out may show explorative tendencies, and, if the animals find prospective territorial sites close by their old wintering quarters, they are apt to settle there. Sometimes only very minor proportions of muskrat populations abandon the lodges or burrows in which they have wintered, to wander in strange places. The adjustments that then occur tend to be restricted to familiar grounds or to within a few hundred yards of familiar grounds. Populations wintering at fairly low densities in good environment during favorable cyclic phases seem most disposed to remain in the same locality. Participants in wider movements 
may follow lake or marsh shores or watercourses, but, in the event of their becoming lost (as in fields or pastures, tundra or desert, or city streets), they may go practically anywhere as long as they stay alive.

The changes in social relationships between midwinter and spring, which culminate in animals either withdrawing from or being forced out of the lodges or burrows where they had previously lived together with their fellows, are basically associated with sexual awakening. However, the sexual chronology of Iowa muskrats engaging in spring dispersal may be most variable. Some of those first dispersing are precociously maturing young. Others are old animals not anywhere near breeding condition, or perhaps even senile. At the height of the dispersal, large numbers of cross-country travelers may be perceptibly behind schedule in sexual advancement.

It has by now become rather clear that the participants in the earlier stages of the spring dispersal are likely to be certain individuals. Activities on the snow or ice during late winter thaws may often be visible symptoms of unrest or insecurity, especially when some recurring external signs may be seen in the same places after each thaw and in places where the majority of muskrats appear well-situated. In central Iowa, these active animals may be killed by minks or canids, and, after predation has eliminated them as individuals, the signs of further surface activities may correspondingly diminish. When this occurs, scant evidence of wandering or of habitual transients may be seen in the locality with the coming of spring, even though the number of locally resident muskrats may not look perceptibly diminished. On the other hand, if many of such individuals showing restless tendencies in late winter do not happen to draw attention of formidable predators, and thus survive until spring, sore and harassed transients may be encountered abundantly about shore zones and the countryside. Evidently, at least a minor proportion of an ordinary wintering population of muskrats may be assigned well in advance of the dispersal to the less pleasant roles therein.

An effort has been made to examine substantial numbers of muskrats traveling overland in spring outside of what could logically be regarded as their radii of familiarity. The total of 137 of such specimens that I handled in Iowa includes not only those personally collected or found dead but also 33 (mainly traffic victims) sent in by personnel of the State Conservation Commission.

Of the 137, the earliest known spring wanderer was a newly mature, newly-bred female struck by an automobile in the very last days of February. For the first week of March, 2 specimens were available: an old male and an old female, both strife-torn and in poor condition. For the second week of March, there were 4 specimens, one each of immature and newly-mature individuals of both sexes. Then, for the second half of March, with the spring dispersal really on, there were 35 specimens more or less satisfactorily grouped as 3 immature females, 20 males and 4 females maturing to newly mature, and 7 old males and one old female. As a rule, the March specimens were fairly free of strife wounds, though some individuals - proportionally more old 
animals than young - were badly chewed up. Neither the old nor newly-mature muskrats were doing much breeding, but 3 of 6 newly mature females for March had corpora lutea.

For the first half of April, 31 specimens consisted of 3 immature males, 12 males and 7 females judged to have been maturing or newly mature, and 7 old males and 2 old females. Of 32 specimens for the second half of the month, one was an immature female, 13 males and 2 females were classed as maturing or newly mature, 10 males and 2 females were old ones, and 4 males were not satisfactorily aged but were probably newly mature. Many of the wandering animals became strife-torn as the month passed, notably the males congregating about the edges of densely populated marshes or those leaving such marshes. On the other hand, newcomers to underpopulated habitats, even those arriving well after the middle of April, were almost wound-free.

The females still moving from mid-April on were, like the males, with or without strife wounds, depending largely on local circumstances. One newly-pregnant young animal was severely bitten all over its body, and so was another female that was maturing but unbred.

There were 31 May specimens of wanderers: an immature male and an immature female, 12 males and a single female classed as maturing and newly mature, 7 old males and 4 old females, and 4 males and one female that were not satisfactorily aged but were probably newly mature. A single specimen of a wanderer for mid-June was an old, battered female. None of 4 mid-May newcomers ( 2 old males, a newly mature male, and a probably newly mature though unbred female) to an almost unpopulated marsh was strife-torn a week later; but, except for this lot and a couple of other individuals, the May collection represented the most patent of biological leftovers, with intraspecific wounds of all degrees of severity, healed, healing, and fresh. The newly-mature female had had a litter of young prior to May 27, but, by that date, she herself was footloose and bitten. In similar condition were 2 old females, one pregnant as of May 19 and another having on May 29 the placental scars of $t w o$ earlier litters of that spring.

Warwick (1940), in his study of muskrats introduced in the British Isles, considered that only a small portion of a total population participated in the spring migration. Although the most striking instances of movement were on the part of isolated males, the muskrats sometimes traveled in pairs or in larger groups. A cited example was of a migrant party that evidently traveled to the headwaters of a stream, then over the divide to another stream, down which it passed to colonize a lake.

Recognized late spring transients on the Iowa study areas tended to occupy narrow strips separating wet marsh from cultivated or pastured land, to live in places having variable amounts of food and cover, in dry land holes, under stumps, logs, and drift, in remnants of abandoned muskrat habitations, and in flimsy nests built on shore or a short distance out in the water. Individually distinguishable transients were known to stay in temporary retreats from a few hours to several days.

The mortality that late spring transients suffered from wounds, 
predators, and motor traffic may be said to have been sex-selective mainly to the extent that wandering males outnumbered wandering females at this time of year. This seemed not only to reflect the tèndency of females (mated or not) to settle down and live more safely but also, in part, the usual preponderance of males in the wintering population.

Spring and summer wanderers frequent central Iowa streams with less disturbance and greater safety than do wanderers about the lakes and marshes - apparently because such socially unwelcome animals are able to spend the warmer months living more or less alone in outof-the-way pools, brooks, and drainage flows.

The onset of the year's breeding may be counted upon to intensify frictions and intolerances, whether departure results from voluntary withdrawal or from eviction by dominant animals electing to establish breeding territories of their own in or about wintering quarters once shared with others. Beer and Meyer (1951) reported for Wisconsin muskrats a very definite connection between time of year and reproductive physiology and behavior patterns. The greatest amount of movement was during the rapid growth of the reproductive tracts and the period of high gonadotropic activity of the pituitary; the greatest amount of fighting, when the reproductive tract was at its maximum weight.

Sprugel (1951) examined known dispersai dates of central Iowa muskrats with reference to weather records for the decade 1938-47. He concluded that an average temperature of 32 degrees Fahrenheit, or above, for three consecutive days after the animals reached the proper stage of receptiveness was enough to initiate the movement generally in the last days of February or early March-but that marked rises in temperature for particular days did not appear to be enough. Inhibitory effects of ice or snow were evident, and movements, though once begun, usually ceased for the duration of later periods of colder weather. The spring dispersal could be expected to reach its maximum two to three weeks after beginning, or in late March or early April.

Repopulation of previously muskrat-vacant habitats afforded good opportunities for studying these movements in Iowa. It could be seen that newcomers usually first worked about a strange area and then settled in a place that appealed to them, especially one having an old lodge or burrow system or an attractive food supply. Sometimes a single animal settled in a territory and was later joined by a mate. Sometimes, residence of lone but pregnant females was established shortly before birth of a litter. Sometimes, for the period of their wandering along the peripheries of occupied territories, battered pregnant females behaved essentially as did the males that more characteristically made up the biological surplus of the spring and early-summer population. However, most participants in spring dispersals would be settled in breeding territories within a month or a month and a half after the initial movements began.

Spring dispersal of Iowa stream-dwellers may or may not be associ- 
ated with floods. Flooding during the winter months may introduce serious if not lethal complications, but, unless the animals are already disposed to move from wintering quarters, they try to sit out the floods and return. Similar behavior may prevail when settled muskrats are flooded out during the breeding season. The detailed observations made by Sprugel in June, 1947, when a creek was in high flood three separate times, indicated a great deal of fidelity toward their home ranges on the part of residents forced to seek refuge some hundreds of yards away from their stream-bank burrows - even when the burrows were obliterated by silt and the configuration of the watercourse was changed.

But, for those muskrats that are, by early spring, physiologically and psychologically ready to move, a flood may be just the thing to start them, and so may a thaw that removes the ice or snow. Dispersal along ice-free central Iowa streams generally got underway almost a month earlier than about the slow-thawing farm ponds and marshes. Yet, there was evidence that population tensions mounted in the marshes in much the same manner as in the stream habitats where events were less obscured by ice and snow (Errington, 1943, p. 923).

A preliminary discussion of numbers of muskrats involved in the annual spring dispersals has been published (Errington, 1940), but the reader wishing more exact information had best consult the case histories of the observational areas given later in this book. Naturally, the volume of a dispersal depends to some degree on its sources. From some marshes having high wintering populations, spring migrants may pour along the principal watercourses or wander over surrounding lands by the thousands. Or, following a killing drought or a winter of drastic trapping, there may be practically no overland spring movements to restock suitable but muskrat-vacant habitats lying away from streams or lake and marsh chains.

In the southern coastal states (where the Louisiana subspecies $O$. z. rivalicius breeds the year around but especially during the cooler months), what may be called spring dispersal begins considerably earlier than in the north-central region. Freeman (1945) wrote that the emigration of this subspecies in Mississippi begins in January and lasts for about six weeks, coinciding with what is considered the most active breeding season. In Texas, Lay (1945) regularly found muskrat tracks in cow trails a mile from the nearest marsh, and several hundred muskrats were taken by hunters with dogs in one winter from a beach a mile away from the marshes. One muskrat was found in March, 1944, in the Big Thicket, forty miles from the nearest muskrat marsh.

\section{POSTBREEDING AND AUTUMNAL MOVEMENT}

Postbreeding abandonment of familiar habitat should be distinguished from gradual and orderly modification of home ranges, such as centripetal extensions from shore zones as water recedes in dry, hot weather. It may be expected to take place in all years and in all places where there are free-living muskrats.

Late August through September may be particularly a time for 
abandonment of habitats in central Iowa. The animals involved may consist disproportionately of the immature - young of six weeks to subadults of four or five months - but also may include adults. There may be random movements of solitary muskrats, sudden appearances of several animals at once in retreats that are miles from places known to have been occupied earlier, or even truly mass migrations.

The subject of footloose mass movements by summer and fall muskrat populations is one that I feel reluctant to discuss. Like their more celebrated possible counterparts in the Scandinavian lemming (Elton, 1942; Kalela, 1949; Wildhagen, 1952), there is much about them concerning which very little is known. Those that $I$ have witnessed personally, or had described for me by other observers, seemed to have had their inception either in deteriorating environmental conditions or in tensions associated with top-heavy populations, or in combinations of the two resulting in acute situations necessitating some kind of relief. The best examples I ever saw were in the summer of 1944, at the time of a population crisis aggravated by the dying of the principal food plants of a marsh. The behavior of mass-moving animals observed both in wet areas and on land suggests that they may have a tendency toward gregariousness when lost or uneasy - especially at seasons of minimal friction, after the breeding is over, yet before the time of tightening social relations that becomes apparent with the approach of winter. Furthermore, even when great movements of animals consist of individuals or small groups trickling through or away from an area, muskrats often display inclinations to go where muskrats have gone ahead of them, whether this is by following packed trails or simply by following scent across open spaces.

The stimulus of the chronological cyclic low warrants mention here. Within the span of the Iowa muskrat investigations, three such depression phases are believed to have occurred, centering about 1936 $37,1946-47$, and $1956-57$.

The biological manifestations of the first and third lows were in part obscured by drought conditions on many of the Iowa observational areas, but those of the second low were not. So far as can be judged from currently available evidence, the acute period of the latter low in central Iowa began in the summer of 1946 and continued well into the spring of 1947. Not only did we have an explosive dispersal in the spring of 1947 that spread the muskrat populations widely, but the late summer and early fall of 1946 had also been notable for cross-country movements having no ordinary explanation. Neither were the muskrats then overly abundant nor did food and water conditions look anything but favorable. The muskrats, however, were killed on highways in conspicuous numbers, and strange animals were known to have moved into some marshes by the hundreds.

Beer and Meyer (1951), in their study of the endocrinology and behavior of Wisconsin muskrats, noted a minor surge in both fighting and movement during the fall that could be correlated with physiolog- 
ical conditions. Adrenal weights then reached their maximum, and there was a minor increase in pituitary weights.

Normal population adjustments in late summer and early fall may involve large numbers of muskrats within a half-mile, or somewhat larger, radius when underpopulated or muskrat-vacant though habitable environment exists in places that explorative animals are likely to find. Some tracts of marshes and streams may be unproductive in terms of young muskrats actually born and reared there, yet, through postbreeding adjustments, may be amply stocked with the species by fall.

In late years, the behavior of stream-dwelling muskrats in central Iowa has changed greatly. Prior to the mid-forties, the majority of these muskrats maintained themselves in year-round residence. They habitually stored ear corn in their burrows and often wintered well on this choice food despite low water conditons. Then a series of summer and fall droughts beginning about 1947 was marked by pronounced movements and by a virtual loss of the local corn-storing tradition. The old habits were not restored during 1951 and 1954, when water levels were again favorable for muskrats. By the mid-fifties, a new and distinctive pattern was becoming clear. Groups of watercourses became almost completely depopulated in late summer, through movements along stream channels. The consequently very low wintering populations were then followed by more or less repopulation of the streams with breeding animals during the spring dispersal, good to excellent reproductive success, and, once again, nearly complete depopulation in late summer.

\section{NONSEASONAL AND EMERGENCY MOVEMENTS OF MUSKRATS}

Home range adjustment and footloose wandering can occur at any season over the muskrat's range in North America, although northward little evidence of winter movement may be seen. Northern animals may well want to move then, but they cannot endure very low temperatures. Hence, whether they starve or freeze in their protected retreats, they tend to avoid exposure to intensely cold outside air. Successful adjustments of home ranges may be made under the ice and are usually manifested by new lodges appearing farther and farther from those earlier occupied. Often strings of small to mediumsized lodges reach out from shallow shore zones toward the deeper water of lakes and sloughs having much submerged vegetation.

When the sinking frost-line seals the subsurface food supply of a population of muskrats, the entire living population may come out on top of the ice. Wandering may take place without much reference to old home ranges except insofar as strangers invading lodges may be fought off by the resident animals. Movements under such conditions (also when remnant populations do their desperate best to winter in a dry marsh) may be either directed or random. If much randomness is apparent, there is also likely to be considerable wandering over outlying lands. 
In discussing over-utilization of habitats by muskrats, Lynch, O'Neil, and Lay (1947) traced the sequences of events observed during the abandonment of Texas marshlands and expressed the view that something akin to mass psychology may operate. At any rate, muskrats living in parts of marshes that are relatively little damaged often join in the general exodus of animals from severely eaten-out parts.

Drought exposures have been the apparent stimulus to most of the irregular movements of muskrats studied in Iowa and neighboring states as well as in the West and North. It is here classed as nonseasonal, though its frequent coincidence with the post breeding movements and the period of minimal friction of late summer and early fall may be decidedly a source of confusion. It may even occur in the months of the spring dispersal if for any reason spring rains are deficient. And, in the fall, it may combine with the onset of winter to launch hundreds and thousands of muskrats into their troubled drifting.

One of the few permissible generalizations concerning abandonment of familiar home ranges as a result of drought is that, regardless of the time of year, some muskrats leave and some do not. Old animals are likely to stay in their homesteads the longest - in some cases for several months after the disappearance of surface water. However, at least a few young of the original residents may often remain in a dry marsh after the population reaches a remnant stage, although the very last animals able to keep alive are almost exclusively tough old adults. But adults of both sexes, from the newly mature to the aged, do comprise part of the population first leaving a dry marsh. Specimens collected or found dead on highways away from marshes in the earlier stages of droughts tend to have more intraspecific strife wounds if they are adults, so it may be that as a rule adults must feel more incentive to move than must the immature.

In my experience, sudden mass abandonment of drying marshes is an unusual phenomenon but it can occur. One of the best examples of which I have personal knowledge (Errington, 1943, pp. 859 and 864-65) appeared to result from drought and food shortage operating in conjunction. When the last six acres of the food-poor center of a northwest Iowa marsh went dry on the unseasonably hot day of October 22, 1940, the concentrated population remnant of possibly around 200 muskrats left the marsh and its vicinity either during or immediately after the final exposure of the central marsh bottom.

The regularity with which the shallows of some western marshes go dry from midsummer to fall imparts a certain regularity to droughtevictions of muskrat populations. Cartwright (1944) regarded drying of the potholes and shallower marshes in midsummer as a normal occurrence over much of the agricultural region of the Canadian prairie provinces, and perhaps as much may be said for the marshy areas of north-central United States. As concerns responses of the muskrats, I have often seen characteristically beaten trails leading a half mile or more from the drying to wetter sections of many large 
north-central marshes. So may one think of the gradual midsummer exposure of hundreds of square miles of alkali flats along the northeast corner of Great Salt Lake, northern Utah, and of the muskrat trails, miles long, extending from the drying far-out bulrush shallows to the flowing streams and wet impoundments nearer shore.

But wherever they try to live in the drying marshes with which I am familiar, the behavior of the muskrats is conditioned by social intolerances and by opportunities for individual adjustments, and the rules they follow individually remain partly of their own making. Here, again, some move and some stay.

A high incidence of trap cripples among wandering muskrats has long been apparent in the Iowa studies during or following the trapping season (Errington, 1943, pp. 886-87). Their handicaps presumably incite their uninjured fellows to turn upon them. It also may be suspected that their irritability from suffering may make them unpopular in places where otherwise they might be tolerated. Sufferers from disease may also be especially prone to wander, perhaps to find solitude for a time in a corn shock, a tile opening, or a bank hole near a lake side. 



\section{Part 2}

Case Histories of the Iowa Observational Areas 



\section{Chapter 4}

\section{Objectives and Techniques of Regular Observations}

THE PROBLEMS INVOLVED in researches in population dynamics can not be approached through any single scientific discipline. Some problems may be investigated in the laboratory through experimental manipulations, as has been illustrated by numerous publications of Pearl, Chapman, Allee, Gause, Park, and their colleagues and students, among others. Even these primarily laboratory investigators used the more reliable field literature in supplementing and orienting their own work. Park $(1939 ; 1941)$, in particular, urged better integration of field and laboratory studies, and so have Nicholson (1954) and Andrewartha and Birch (1954). Raymond Pearl, himself a great pioneering experimenter with laboratory populations, remarked in one of his last papers (1937) upon the natural equivalents of longterm experiments afforded by populations existing under widely differing circumstances.

I have emphasized field studies. Of the field problems within my experience, some were amenable to experimentation and some were not; and, if they were not, the closest equivalents to experiments were sought.

The Iowa observational areas, the case histories of which follow this chapter, were selected because they were workable and representative. Year-to-year studies were begun on each area, with the intention of continuing them as long as they were feasible and satisfactorily productive of data bearing upon the problems considered. The overall objective behind the field program was to learn as much as possible about muskrat populations.

The density factor, rated decades ago by Pearl and Parker (1922) as of outstanding population significance, had proved to be so important in my earlier field studies of the bobwhite quail (Errington, $1941 \mathrm{~b} ; 1945)$ that the muskrat studies were likewise directed to investi- 
gate this factor as it applied to muskrat populations. Throughout the years, routine acquisition of annual statistics on muskrat populations of each Iowa observational area was the job of first priority. Special studies of responses of muskrats to droughts or other emergencies, as well as studies of epizootics, predation, intraspecific strife, and movements, were worked in wherever timely and possible.

\section{ON FIELD STUdies AND THE "READING OF SIGN"}

Relatively few of my field observations in the routine studies of muskrat populations consisted of observing directly the animals themselves. The living habits of muskrats are such that they spend most of their time out of sight of human eyes, concealed in habitations or under cover of water, ice, vegetation, or darkness. Even during weather promoting large-scale diurnal activity in places where visibility may be good, more animals may remain in lodge or bank retreats at a given time than come out in view. One may gather excellent data for the duration of weeks-long crises and seldom see a living muskrat.

A certain amount of mapping, blocking off sample areas, and recording changes in land use, weather conditions, and food-coverwater relationships for the various areas was done, along with other work fundamental to an ecological study. The earlier years of the investigations were those in which the most detailed mapping and recording systems were tried, then gradually discontinued or modified with increasing experience. The earlier extremes in intensive work involved, for examples, efforts to mark, number, and note for a full year the histories of 271 sites of muskrat activity along several miles of small streams (Errington, 1937a); to map in scale the muskrat habitations of a 450-acre marsh and to follow the fortunes of these habitations throughout the breeding months (Errington, 1937b); and to measure muskrat exploitation of the relished corn in fields bordering a half mile of drainage ditch (Errington, 1938).

With experience, as the feasibility of short-cuts in gathering the more conventional ecological data became demonstrated, emphases in detailed studies were shifted considerably toward mapping the spread of epizootics, the examination of large population samples, the tracing of mortality during crises, the search for truly limiting factors. Systems of large-size sample areas were found to be advantageous in both marsh and stream work.

The mainstay of my field observations on the muskrat was "reading of sign," that is, studying the meaning of tracks and trails, of diggings and cuttings and heapings, of food debris and droppings, of miscellaneous traces, of blood, fur, wounds, and carcasses. Information thus obtained was used in conjunction with quantitative indices from specimen material.

To be effective, such observations must be specifically directed to the extent that they produce pertinent data without undue waste of time and effort on trivialities, yet they must permit the scouting needed to discover unexpected happenings. A planned program may be weak- 
ened by errors of judgment or oversights, as may be illustrated by my own early neglect of placental scars as supplementary evidence on breeding. I also failed to recognize the lesions of the hemorrhagic disease until 1943 and certain of the most dramatic implications of the disease until still later. Nor are distinctions between values of facts always easy to make, nor, for that matter, distinctions between what are facts and what may only appear to be facts.

In describing the season-to-season routine work on the central Iowa observational areas, I shall begin, for convenience, with midwinter, after fur trapping by the public is over. At the latitude of central Iowa, midwinter "reading of sign" of muskrats must usually be limited in scope. Flashlight and mirror combinations and some other gadgets for looking under water or ice were tried, as were some tricks in taking - advantage of muskrat psychology. It was possible to learn about the contents of deep bank burrows through inducing the animals to plug breaches with movable items that they found within - nest linings, food debris, and bones along with the sticks, stones, and mud. Excavations with axe, pick, spade, or hay knife were especially revealing at some times. On occasion, a dog or a woodchuck obligingly dug out a burrow chamber, spreading out to view a collection of items. Mostly, the informative winter signs were those on the surface of the land, ice, snow, or lodges, and part of the significance of the signs depended upon what was not to be seen. Scarcity of external tracks about an Iowa marsh where a substantial population of muskrats is known to be wintering may be an indication that the animals are getting along well; and the converse almost inevitably is an indication of something being wrong, at least with regard to the individuals engaging in much outside activity in cold weather. Particular efforts were made to locate and study mortality victims while they were still relatively fresh and intact.

Incidences of muskrat remains in mink scats were useful indicators of security or of crisis in the lives of the muskrats (Errington, 1943; 1954b). Minks tended to frequent the habitats that were the more food-rich for them, which in Iowa were usually the marshes rather than the streams, so it was about the marshes that the mink scats commonly (not always) were picked up in greatest quantities.

Concerning the hundreds of muskrats examined as winter mortality victims, whether killed or fed upon by the minks or not, the following may be said: They included trap cripples, with stumps from the wringing-off inflamed or cleanly healed. Victims' bodies were free of other wounds or with all parts bitten by other muskrats. Victims were found as fragmentary remains but with partly bare tail vertebrae from which the once-frozen flesh had been gnawed in life. They were individuals attaining sexual maturity and corresponding restlessness ahead of schedule. They were those breaking out of lodges or at the edge of the ice, to die outside of old or new injuries, hunger, exposure, disease, or by direct attack of mink, fox, dog, or other predator finding them at a disadvantage. 
Specimens examined singly often did not reveal anything diagnostic, but, if adequate series were obtained, the story behind any largescale winter-killing usually became clear. This was especially true in the case of epizootics, which often depleted local populations without leaving many external signs, or left the evidence so obscured by the scavenging of minks that casual observers easily mistook it for evidence of simple predation. When die-offs were in progress, the bodies of the dead sometimes greatly exceeded the abilities of the local scavengers, which included not only minks and foxes but also cannibalistic muskrats, to find and consume them, and it was then possible to obtain variable quantities of fresh and intact specimens for study.

Although activities of muskrats on top of the ice or in the snow may suggest trouble, indirect evidence of well-being on the part of a wintering population may include some signs visible from above. Fresh plugs of vegetation in cracks in the ice either near or away from lodges or burrows, repairs of maintained retreats damaged by mink intrusions or by cave-ins during thaws, the presence of fresh frost on parts of a lodge, of thin ice or open water in front of lodge or burrow entrances - all of these sorts of signs afford an index as to how the muskrats are getting along. If the ice is clear and not too thick, the animals may be seen swimming, or their droppings and food particles be noted beneath. And, if sample lodges are opened at intervals for inspection, much may be learned from their internal appearance, particularly toward mid- or late winter.

The evidence obtained through cutting into lodges or the ice over burrow systems should be interpreted in terms of the level of water beneath the ice. If the under-ice spaces are well filled with water, the retreats of the muskrats are accordingly restricted to the higher parts of lodges or burrow-chambers. On the other hand, if the water beneath the ice recedes, leaving extensive air spaces, the animals may withdraw to the lower parts of burrows, to the very bottoms of the lodges, or may be living almost anywhere under the ice in the vicinity of their lodges and burrows.

Partial melting of the ice during thaws of late winter or early spring affords opportunities for learning about subsurface adjustments. The melting may expose details of main burrow systems deepened by the muskrats as the winter progressed. So may be exposed the retreats under ice heaves, hollows and nests in snow drifts, feeding and dropping signs, latrines and left-over food items of minks, concentration sites of desperate fishes. A rich medley of revelations may be dated backward by one knowing something about weathering processes, about rates of discoloration, softening, and decay of organic material at ice water temperatures, and about time intervals between major changes in air temperature, storms, and other events useful for dating.

The winter's dead muskrats often may be retrieved in quantity soon after the ice goes out, sometimes refrigerated in lodges having interiors that remain partly frozen, but more often as the dead float on the surface of the water. These floaters may be so rotten as to lose 
hair and appendages, but their viscera may still be sufficiently intact to show distinguishable disease lesions in a fair proportion of the cases. A most workable technique is the approximate dating of winter losses on the basis of sexual advancement of specimens at times of death.

Despite the usual irregularities in daytime visibility of muskrats, the break-up of the ice may provide opportunities for rather satisfactory censusing on occasion, by direct enumeration of local muskrat populations surviving the winter. The efficacy of the method varies largely with the weather, the hour of day, and the habitat. I have found it best for use on central parts of marshes on a still, warm day. At the right place and time, an observer may count virtually all of the muskrats of a sample tract just before the main spring dispersal begins.

Subsequent to the main spring dispersal in the north-central states, or beginning about the last of April or - preferably - early May when settling for the breeding season is pretty much accomplished, territories were blocked off and counted on the basis of foci of activity. This was done fairly well in Iowa until late June or early July, when the activities of the half-grown or larger young of the season obscured the original territorial foci. Under special circumstances - as in 1942 and 1944, when recurring floods drowned almost all of the young born until the middle of June along central Iowa streams - territorial calculations were continued into August. Where sparse numbers of muskrats lived in extensive tracts of good habitat, the distribution of the breeding territories could be apparent even by late fall or winter, but the farther one leaves the breeding months behind the greater becomes the chance for error.

After the routine territorial checks were finished or comfortably under way, more time was given to other and often far more interesting phases of the field researches. Then, and for the duration of the summer and early fall, about the only strictly routine work was collecting and examining scats or pellets of minks, foxes, and horned owls (sometimes of raccoons and other predators or scavengers). Areas were visited frequently enough to record evidence of any unusual mortality of adults, of movements, of the onset of epizootics.

Some of the procedures followed will be self-evident from the case histories of the observational areas to be presented in this section of the book, or from the papers on tagging (Errington and Errington, 1937; Errington, 1944) or those dealing with restricted aspects of the investigations (for examples, see Errington, 1937b; 1938; 1939b; 194la; 1942b; 1954b; Errington and Scott, 1945).

Late summer and early fall almost always has been one of the slackest periods from the standpoint of the Iowa muskrat investigations. Not only were field observations then hindered by wider distribution and greater abundance of signs and profusion of vegetation, but, under normal conditions, not much usually happened to the muskrats at that time. Despite home range adjustments and often wholesale trespassing by "kits" and subadults, intraspecific relations 
tended to be rather peaceful. Now and then, animals died from miscellaneous agencies, which could be hard to trace because of the rapidity of putrefactive changes. (In contrast with the state of those dying during the cooler months, hot-weather mortality victims may be fresh-appearing externally yet with viscera too far advanced in decay to be diagnostically revealing.) The best post-mortems have indicated that most of the dead adults of this season were victims of old age and that most of the dead young were those having accidental mishaps befalling them, including drownings. Representations of muskrats in predator diets were commonly light, or quite lacking, except in the event of something like a drought or an epizootic. A great deal of the field work of this time of year fell in the category of patrolling, to watch for departures from the ordinary.

Field studies of muskrat populations also have been about as difficult to conduct on a quantitative basis in late fall as in early fall or late summer. Nevertheless, as the first frosts came on, the productivity of investigations in proportion to effort often increased decidedly. Epizootics have had a way of starting up about the first of October in Iowa, and, in their spectacular forms, have swept a section of marsh in a couple of weeks. When this sort of die-off occurred, not only did it provide opportunities to study epizootiological sequences in detail, but the dead of lodge-dwelling populations were at times almost completely retrievable for counting and examination. Thus samples were obtained from which much was learned about densities, sex and age compositions, and breeding histories (from placental scars of adult females).

It may also be possible actually to census the muskrats living in representative tracts of shallows dominated by duck potato. If the water is low enough, and the tops of the plants have wilted enough to leave surrounding water and mud flats clearly visible, sample lodges may be systematically dug out, and the resident muskrats forced out to be counted. The same technique may be used for census-sampling of populations living away from bank burrows in almost any body of very shallow water not covered by emergent vegetation. In making these counts, care must be taken to choose typical large, small, and intermediate sizes of lodges, to expose all chambers and passageways above the water or to trample down the parts where muskrats might be hiding with nostrils in the air. Enough time (a minimum of 15 minutes) should be allowed for submerged animals to use up the oxygen in their bodies and emerge. Of course, any technique involving so much disturbance should be used only sparingly and for good reason.

Summer droughts may or may not be broken by late fall, and long dry Indian summers may be superimposed upon them with lethal consequences for muskrats. When muskrats suffer emergencies in late fall, the manifestations may be impressive. By then, the period of minimal friction has terminated, and strangers may expect to meet with hostility if they venture into places held by property-conscious resi- 
dents. Whether eviction from, or abandonment of, deteriorating habitat be gradual or sudden, the homeless ones wander or gather about marsh edges or lake shores. Details concerning such aggregates of unfortunates may be both interesting and informative. An observer may witness threat displays and fights between newcomers and residents. He may record the post-mortem condition of animals found dead or dying. He may compare collected samples of transients and residents. He may study predation by minks, canids, and birds of prey, and study the circumstances favoring capture or escape of the muskrats.

Ephemeral snows afforded opportunities to trace travel routes of wanderers along the lake and marsh shores - including sick animals leaving their old home ranges to go off and die. The bodies of the dead retained freshness for a day or two if lying in cold water, and liver lesions and some types of intestinal lesions could be made out surprisingly long after the bodies softened and became fungus-grown.

Much of the efficacy of reading signs in very late fall naturally depends upon what remains to be seen after freeze-up. When freeze-up comes with a storm that leaves rough or snow-covered ice over lake and marsh, the handicaps of winter observational work may prevent doing a great deal except examining mink scats, watching for tracks of surface-active muskrats, push-ups of vegetation or debris, and openings in the ice.

Freeze-ups characterized by days or weeks of clear ice may afford exceptional opportunities to learn about muskrat populations. Under the right conditions, muskrats can be driven out of lodges or burrows by stamping and minimal counts of them obtained as they swim away under the ice. Such counts, if carefully made with possibilities of error in mind, may comprise fair to good sampling. Food habits of the muskrats may often be followed closely through under-ice observations, and correlations made with availability or lack of availability of different kinds of foods. One may study the respective feeding trends of the established residents and of the late-comers, transients, or unpopular individuals that live by themselves - as in newly-improvised nests, in short or shallow burrows, in hollows in submerged logs, or in the spaces under overturned boats.

Where muskrat diets run to animal food (as is particularly likely when freeze-up occurs during low-water stages of streams), the bones and scales of fishes, frog eggs, clam shells, and bloody smears may be conspicuous about openings in the ice or about landings above the water. Often the principal signs under stream ice relate to caches of grass or ear corn, to diggings for roots in the banks, and to places about driftwood jams and riffles where items of interest (not excepting dead bodies of muskrats) may accumulate.

Muskrats dead of epizootics may be visible through clear ice in the vicinity of lodges or the entrances of burrows, and these may be easily retrieved for examination. And there is always the occasional dead one about any well-populated marsh. It may be a victim of age or strife or gunshot wounds. It may have little discernibly wrong with 
it. Or, it may show hemorrhagic lesions - maybe and maybe not the forerunner of a deadly epizootic. Or, during epizootics, the fresh bubble signs from muskrat activities may simply cease appearing over the passageways.

In reading bubble signs, bubbles signifying muskrat activities must not be confused with gas bubbles that happen to rise from the bottom and line up in misleading bunches under the ice over burrow entrances and passageways. Distinguishing between the sources of bubbles under the ice is neither always easy nor wholly satisfactory even for an experienced field man, but this is certainly one of the techniques in which experience counts. Nor should an investigator overlook the possibilities that some populations may have storage habits - relieving them of the necessity of much foraging away from their food-packed chambers in lodges or burrows. The foods most frequently stored on the Iowa areas have been ear corn and duck potatoes.

Another first-priority job in the gathering of routine data from the Iowa observational areas has been the examination of specimens taken from the populations in late fall and early winter. This has been an outstanding source of statistics on placental scars, sex and age ratios, incidence of "kits" and evident wanderers in a population, and of other quantitative data.

Used discreetly, and with awareness of what they do not show, such specimens may provide the best means of piecing together what may be lacking in an adequate picture of a population's reproductive history. If adult mortality and movements in or out of the observational area are negligible (or reasonably well appraised), sex and age ratios that are prorated from the number of breeding territories previously arrived at for late spring and early summer may serve as the principal basis for calculating late fall densities. Pro rata computations may be risky, however, if complicated by unappraised variables, as those introduced by droughts, epizootics, and movements.

The best Iowa series of fall specimens came from carcasses of muskrats trapped by the public for fur from November 10 through December. During these months, the placental scars from the last breeding season may be counted and fairly satisfactorily aged, and the differences in gonadal development of old animals and of young of that year may be readily distinguished. I have examined as many as a thousand specimens from an Iowa marsh in a single trapping season, and cooperating trappers have made available for study many lots totaling hundreds of specimens in each lot. Many specimen series are of course smaller, but, if these represent (as they sometimes do) practically entire population groups, they have their own distinctive values.

When adequate series of fall specimens were not available for age ratios, or when emergencies or movements invalidated calculations of fall populations from age ratios, estimates from signs were at- 
tempted. At very low densities confined to restricted habitats - those existing in the last stages of a lethal drought, for example - this method may give acceptable results, particularly in places where most of the remnant individuals occupying certain retreats are sooner or later found dead or otherwise accounted for. At higher densities, the technical difficulties of making good estimates may mount up, and subjective criteria must more and more be resorted to.

My own procedure in estimating numbers of muskrats from signs has been to consider the signs about each lodge or burrow system, then think back to my trapping experience and estimate that I could have expected to catch at least so many muskrats and no more than so many at a particular place. The two figures would be put down in my field notes. Then, I would put a check mark beside the figure that I considered nearest to the truth. In arriving at an estimate for the whole marsh or stretch of stream, I would add up the minima and maxima to get the range of estimates and, finally, in a separate column, add up the checked figures. The latter would be as close as I felt able to come to the true population through estimates.

\section{MOSTLY ABOUT LABORATORY TECHNIQUES}

Apart from experiments employing the muskrat as a laboratory subject, a large part of the laboratory work done on the species comes under the heading of the post-mortem examinations introduced in preceding paragraphs. The fact that many post-mortems are actually conducted out of doors, along a lake shore, or at some other site of finding specimens, should not alter their classification as laboratory work.

Figures 4.1-3 illustrate typical uteri and testes of adult muskrats and of young of the year, as in Iowa specimens taken about December 1. In Figure 4.1, the fatty material usually associated with the testes is shown; in Figure 4.2, the testes of adults (bottom) and young (two upper rows) have been dissected out. The testes depicted have all dried slightly after exposure to the air, but those of adults tend to be somewhat wrinkled, anyway, as well as more darkened than the turgid flesh- or cream-colored testes of the young. As winter progresses, the size range of subadult testes overlaps more and more that of the adults, until, by late January, this has lost much of its reliability as a criterion.

From Figure 4.3, it may be seen that the uteri of females born during the year (right and middle) are small and thin-walled, rather like cellophane in appearance. The uterus on the left had placental scars but they are indistinguishable in the photograph. I am sure that any uterus as enlarged and as thickened as this one denotes passage through a breeding season, whether showing placental scars or not. Figure 4.4 gives a better view of placental scars. Occasionally, a uterus intermediate in size and thickness (usually without placental scars but sometimes with) may be hard to classify, but, as a rule, the 


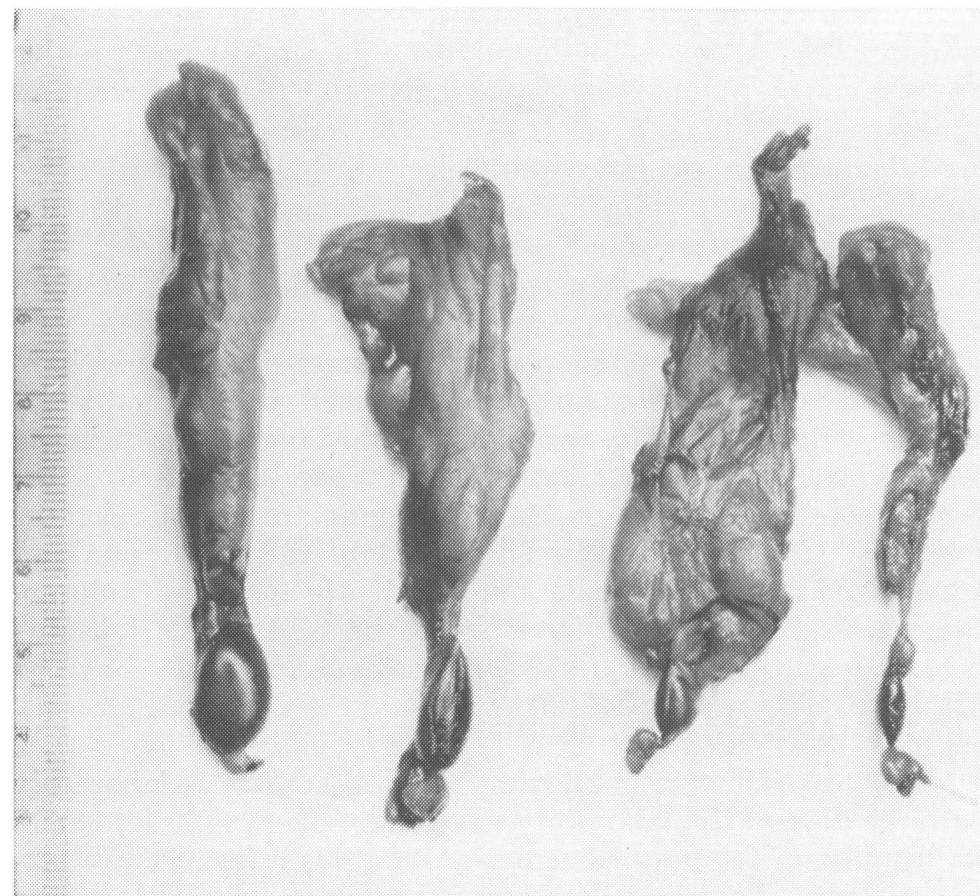

Fig. 4.1. Testes and associated fatty material of fall-trapped lowa muskrats. The two specimens nearest the scale on the left illustrate the appearance of adult testes, as compared with those of the young on the right.

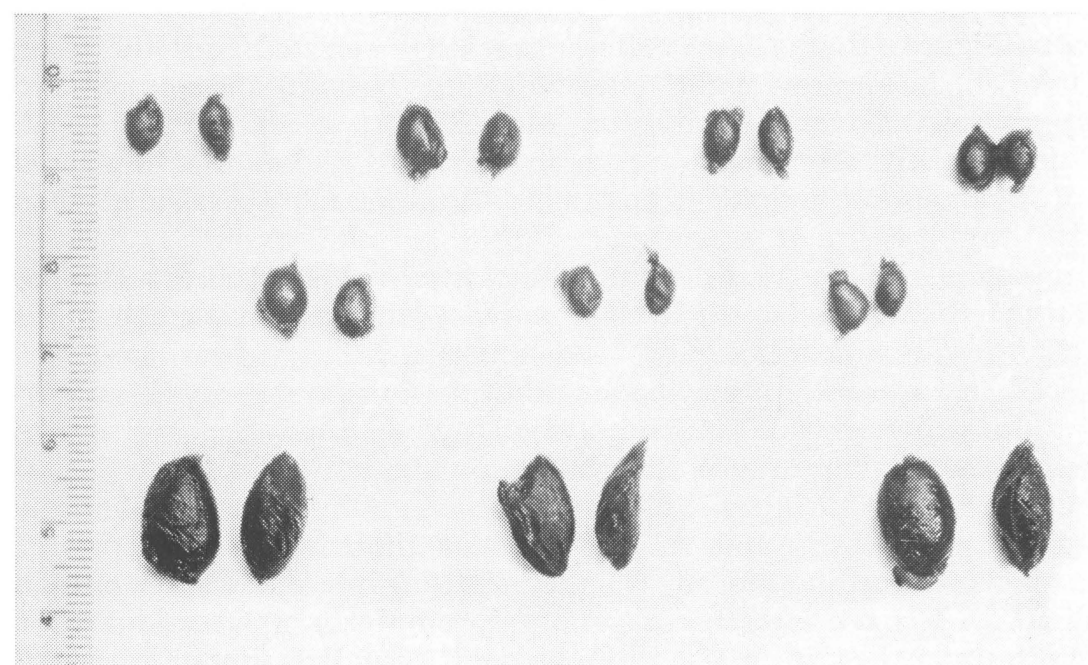

Fig. 4.2. Testes of adult (bottom row) and young (two upper rows) of falltrapped lowa muskrats as they appear when dissected out of their associated fatty material. 
categories are easy to separate for fall and winter specimens, and questionable specimens may be checked by tooth characters (Sather, 1954). Then, too, females may be more satisfactorily aged than males as the breeding season approaches, for uterine enlargement takes place late. Some investigators having access only to spring-trapped carcasses have ignored the males and tried to obtain age ratios of population samples from females alone.

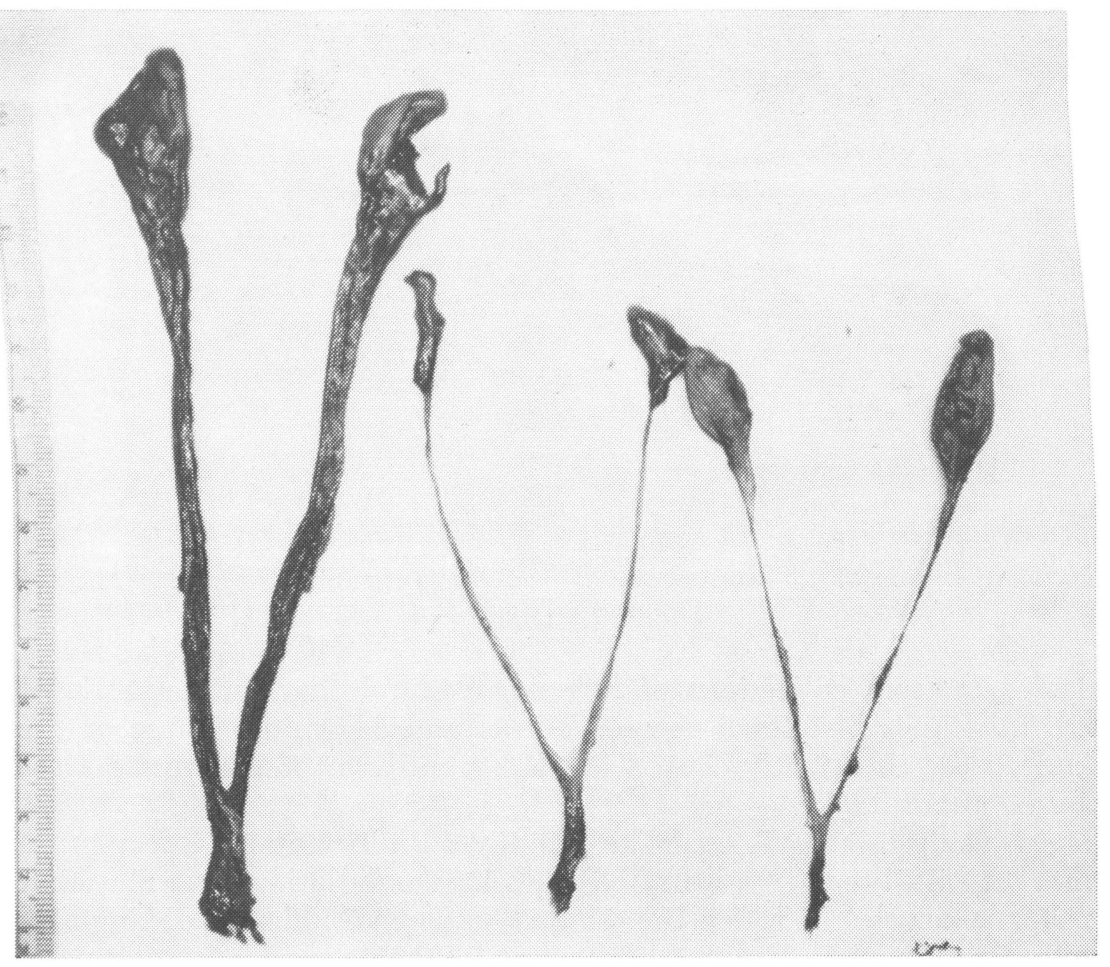

Fig. 4.3. Uteri of adult and young fall-trapped lowa muskrats. Note the enlarged and thickened uterus of the adult (left, nearest the scale) compared with the two thin-walled small uteri of the young in the middle and right of the picture.

There are substantial potentialities for error in attempting age classification of adult and the larger sizes of muskrats on the basis of size and pelage differences. Some of my trapper friends have been astonished to see the undeveloped testes and uteri that could be demonstrated in large, adult-looking carcasses. A tagged young male had testes measuring only $8 \times 5 \times 4 \mathrm{~mm}$. when recovered as a specimen at the known age of 185 days, although in size, pelage, and priming pattern it was mistaken for a second-year adult when first handled. Shanks (1948), in testing a pelt-primeness method for obtaining age- 


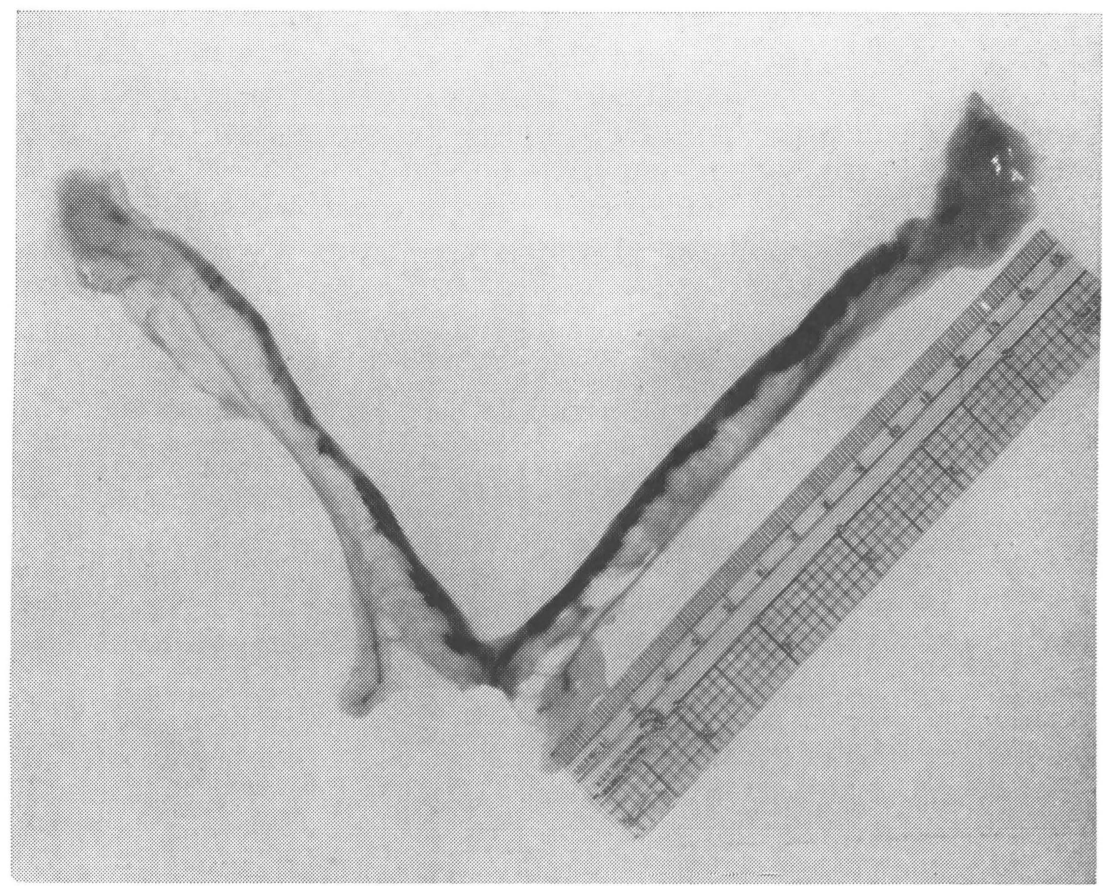

Fig. 4.4. Uterus of fall-trapped lowa muskrat illustrating the appearance of placental scars.

class data from collections of raw skins, found that, in a sample of 69 individuals of known age (15 adults and 54 young), three of the adults were incorrectly classed as young and two of the young were classed as adults.

In using placental scars to obtain supplementary information on a season's breeding history of a muskrat population, one may find perfect examples in which the season's sets remain clearly distinguishable. Or, one may find uteri in which bloody residues have run together, or in which traces of the scars of the previous year's breeding may be mixed with scars of the current year. I doubt that one may reliably count or age the scars in the uteri of north-central females taken much after early winter, but, for November and December specimens, the scars in fresh uteri may be aged with passible satisfaction on the basis of size and color. A bright, bluish-black scar two or three millimeters in diameter signifies a late litter, as of August or perhaps late July; and gradation in the shrinking and fading of the earlier scars may commonly be noted without much difficulty until one has to consider the very earliest of the season or those of the year before. Faintness and a light brown coloration may suggest scars of more than one year of age, especially if only a few of them are visible and those are irregularly distributed along the uterus. 
At times when post-mortem changes make it hard to separate the scars into age classes, some section of a uterine horn may be in relatively better condition than the uterus as a whole. An observer may then be able to note in that section the pattern shown with respect to numbers and ages of distinguishable litters. The best examples show the scars of given ages lined up in sequences: In two-litter females, a two-by-two line-up, with noticeable intervals of unstained uterus between the groupings; in three- and four-litter females, the scars of successive litters may become progressively fainter or clearer, according to the order in which they may be followed. Thus, in fourlitter females, the repetitively grouped scars may appear as one bright, one less bright, one still less bright, one rather dim, then one bright again. Most inconveniently, not all of the uteri of adult females, even when examined in fall and early winter, furnish the best of examples, and some scars may be close together or take on a fused appearance. I do not know whether two placental attachments of a breeding season ever occur at the identical site but doubt that this may very often be the case.

Counting placental scars in atypical or partly decomposed specimens may require blocking off and estimating the numbers in clouded or bloody tracts, prorating from counts obtainable from comparable lengths of the uterus having the most clearly visible scars. Ordinarily, the uncountable scars are localized in strings short enough to reduce likelihood for error. It is important to avoid mistaking for separate placental scars the little dark marks from other causes, including parenthesis-like ones often to be seen enclosing the site of the real scar itself.

In learning what I have about working with placental scars, I found the literature of little direct help past the point of very general information, or as it specifically treated animals other than muskrats. Most helpful was the preliminary advice (letter, January 30, 1940) received from Dr. H. W. Mossman, of the University of Wisconsin, an anatomist of long experience with the reproductive tracts of rodents. My technique is chiefly the resultant of discussions and correspondence with colleagues, of limited microscopic examinations, of macroscopic post-mortems of hundreds of adult females distributed chronologically over the calendar year, of the guidance afforded by some highly informative tagged animals, and of detailed field records on reproduction in populations from which fall and winter series of specimens were taken.

Use of placental scars had value chiefly in following seasonal trends in the breeding fortunes of local populations, in checking up on the representativeness of given series of field data, and in obtaining otherwise unobtainable information on reproductive histories, especially as such were influenced by emergencies. Placental scars should, whenever possible, be considered in conjunction with field data and always with proper awareness of their technical deficiencies. 
Pathological material may offer a big diversity of problems for any investigator who is not a pathologist. Any specimens showing extraordinary lesions should be taken to a competent pathologist, preferably in the freshest and most undisturbed condition possible. In dead muskrats coming to hand in the north central region, it was of great practical importance to look for wounds or for evidence of the hemorrhagic disease.

Victims of minks are commonly found bitten about the neck. In many cases, injuries to the nervous system appear to be the direct cause of death, although wounds involving important blood vessels and muscles are often seen. The teeth of the attacking minks do not necessarily penetrate the skin in all places that are bitten, even when extensive damage to underlying tissues may result. Canids are likely to "mouth" and shake their prey, breaking the spinal column or such large bones as the innominates and leaving big blood clots in such a region as the kidneys. Their teeth often do not penetrate the muskrat's skin unless they eat the victim. Raptorial birds leave talon marks on muskrat prey and tend to start eating at head or neck; when scavenging on a cold carcass, they may feed on almost any part where meat is easily accessible. Wounds of intraspecific strife on muskrats are of slashing types; they may be superficial or sufficiently deep to expose a hip bone, a kidney, or other viscera, or to cut clear through the musculature of a leg; they may occur anywhere on the muskrat's body, but especially on the parts that an animal exposes while either facing or retreating from an assailant.

Amputations represent mostly trap-crippling, "wring-offs" of feet after leg bones have been broken or disjointed by the snapping of the trap jaws or by the struggling of victims in nondrowning sets. Usually, they are the result of frenzied twisting of the weaker forelegs, with occasionally some biting, and are a common cause of mortality from infection, loss of blood, and, likely, shock. Great abscesses may be found associated with "wring-offs" or with strife wounds, but sometimes they have no evident connection with any wounds, and they may occur in the body cavity singly or in multiple form.

Old age, undernourishment, freezing of eyes and appendages, shot wounds, accidents, miscellaneous ailments, and other factors bringing about the death of an animal, or contributing thereto, may leave more or less recognizable manifestations. Nevertheless, many die for undetermined reasons, and an investigator should reconcile himself to putting down many queries in his notes.

The hemorrhagic disease is of such deadliness to muskrats on so many occasions that all persons conducting post-mortems should always watch for anything resembling its lesions. Necrotic foci on the liver are among the most suggestive lesions, even though they do not invariably signify the hemorrhagic disease. (They could be due to infections with the Pasteurella and Salmonella genera of bacteria - exemplified by tularemia and mouse typhoid - or to some other infec- 


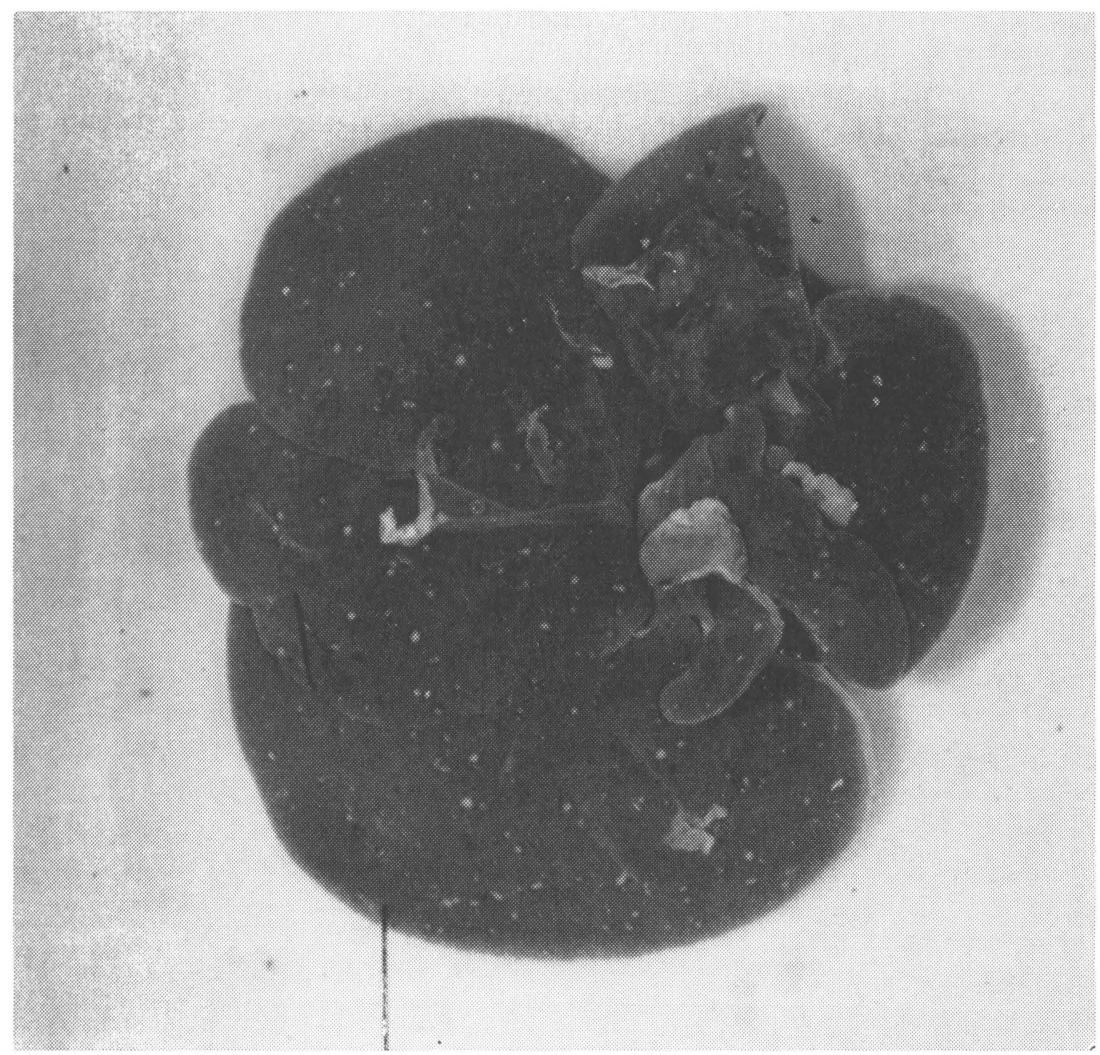

Fig. 4.5. Muskrat liver, illustrating numerous lesions of the hemorrhagic disease.

tious or irritating agency.) Hemorrhages may take place about anywhere in the muskrat's body, the more extensive tending to be localized in lungs, intestines, and kidneys. Figures 4.5, 4.6, and 4.7 illustrate, in addition to the tularemia-like liver lesions, hemorrhages involving cecum and large intestine in one case and small intestine and rectum in the other.

The manifestations of the disease in Iowa victims are of three main types: liver necrosis, intestinal hemorrhages, and lung hemorrhages. In a particular victim, the severity of each type tends to be rather inverse to the severity of the other two types. Thus, a specimen showing a very heavily spotted liver may show moderate to no hemorrhaging in intestines and lungs. A specimen with few if any liver lesions may have tremendous purplish blotches over the cecum or a dull-red coloration of a length of its small intestine. A specimen with indistinguishable liver or intestinal lesions may have lungs filled with solid clots of blood. All intergradations between the above 


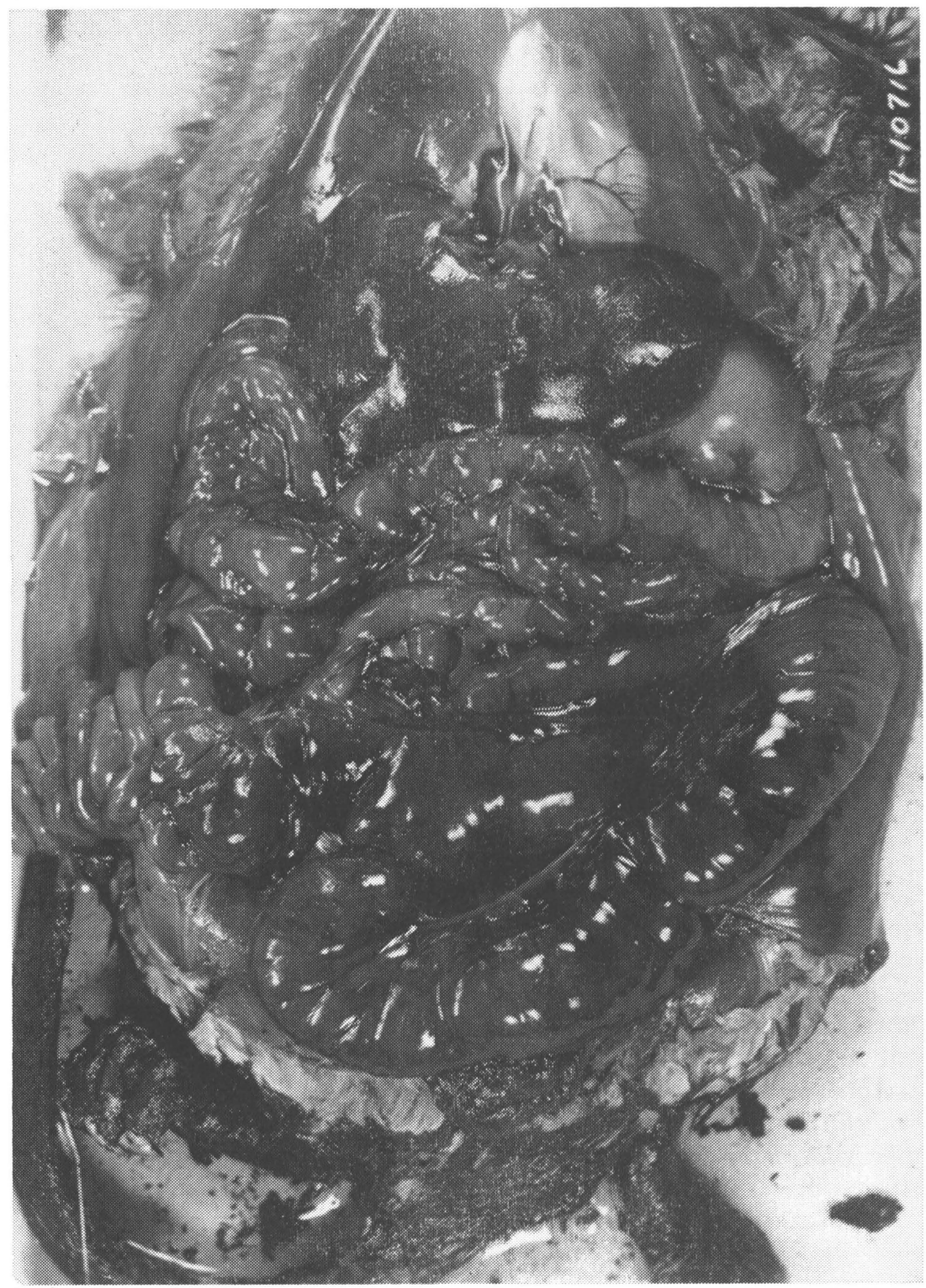

Fig. 4.6. Specimen of muskrat dying from the hemorrhagic disease, illustrating liver lesions (small light spots) and hemorrhages involving cecum and large intestine. 
extremes may be found, but the field studies of epizootics reveal that one type may dominate for protracted periods. External bleeding from mouth or anus of a muskrat found dead should always arouse an observer's suspicions, but these are not invariable accompaniments of disease hemorrhages.

The commonest syndrome in Iowa is entero-hepatic, with fair numbers of liver lesions and moderate intestinal hemorrhages. With this syndrome, about eight days elapse between time of exposure and death. There may be recoveries, and liver-spotting may be noted in individual specimens taken months after known die-offs. Then, there is a syndrome characterized by massive intestinal hemorrhages from which the victims apparently bleed to death before liver lesions have a chance to appear. The pneumonic type can be spectacularly lethal in its operation when dominating an epizootic.

For all of the skinning of hemorrhagic victims that trappers do without taking any antiseptic precautions and without suffering any known ill effects, I feel afraid of the disease and certainly would advocate that anyone having occasion to handle such muskrats do so with discretion. My practice is to avoid touching suspected material directly with my hands and to avoid letting any object that may later be touched come in contact with such material. Or, if contact cannot feasibly be avoided, or if the material is touched accidentally, a disinfectant of proven value should be applied.

I may here express appreciation to Dr. E. A. Benbrook, of the Department of Veterinary Pathology at Iowa State University, not only for personally conducting the strategic post-mortems of muskrats in the beginning years of our studies of the hemorrhagic disease, but, particularly, for the very helpful demonstrations and advice given me whenever I brought to him my problems in diagnosis and epizootiology. I have also received strategic help from other Iowa State University staff members in connection with the disease studies, particularly from Doctors Paul C. Bennett and Howard L. Hamilton.

Food habits investigations are among those classifiable as laboratory work, and, in connection with the Iowa cooperative research program, my colleagues and I have analyzed large quantities of scats and pellets of predatory vertebrates, including around 5,000 from each of minks, foxes, and great horned owls. Considerable work in laboratory and field was also done with muskrat droppings and stomach contents.

The more detailed analyses require a tremendous amount of preparation, adequate reference collections, and the cooperation of taxonomic specialists. My own effective background in this may be said to have begun at Washington, D. C., in the spring of 1929, with a course in museum methods directed by Dr. Paul Bartsch, in which I spent three half-days a week for a semester studying skeletons and skins of North American vertebrates at the U.S. National Museum. In the actual researches that followed, I have received a great deal of highly technical help from the Division of Food Habits Research of the 


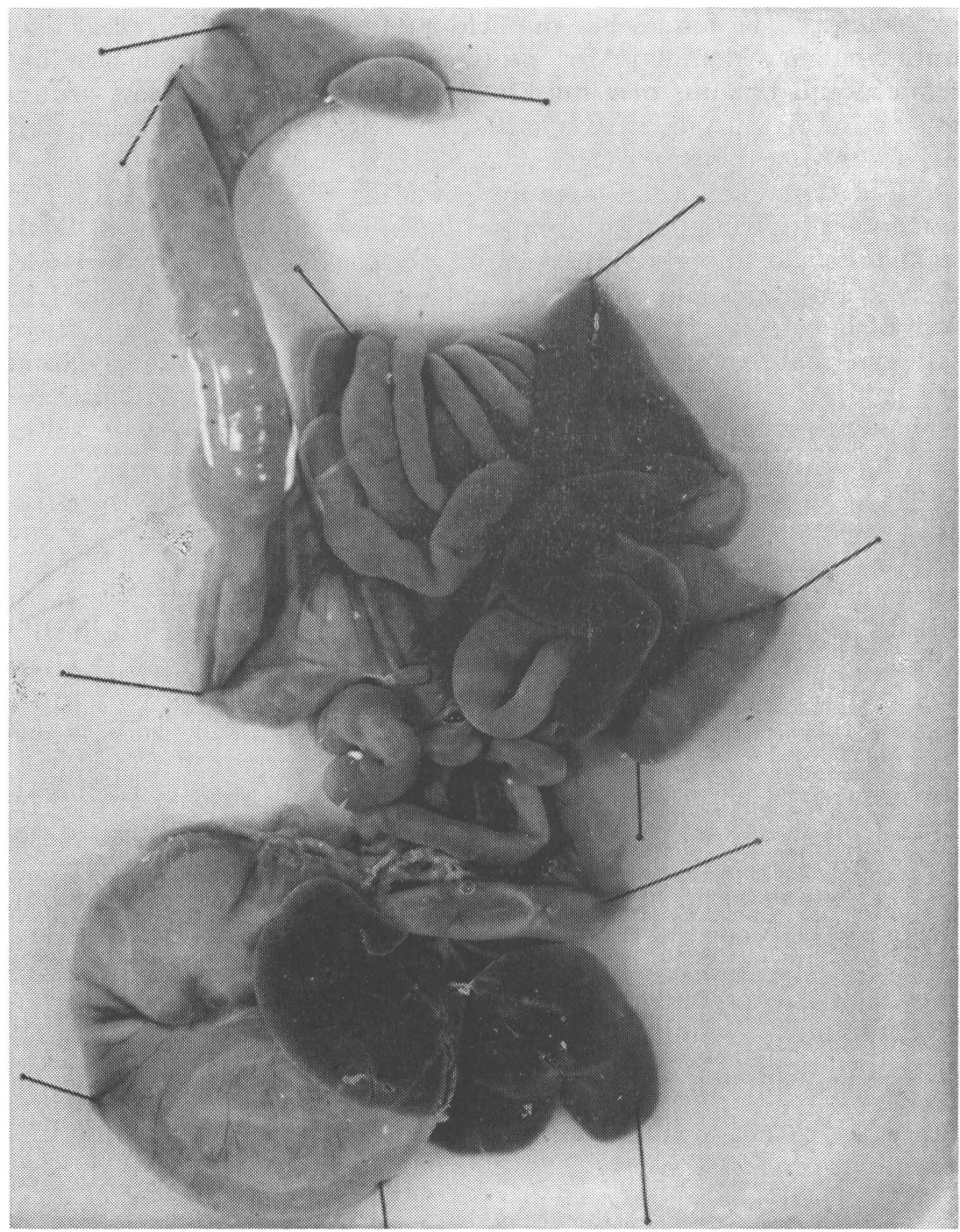

Fig. 4.7. Viscera from a muskrat dying from the hemorrhagic disease, illustrating liver lesions (the numerous small light spots) and hemorrhages involving small intestine and rectum.

former U. S. Biological Survey, first under the administration of W. L. McAtee and, later, under that of Dr. Clarence Cottam. In the laboratories of Iowa State University, much of the work on food habits was done cooperatively with Kenneth Krumm, Mrs. Ruth Dudgeon Adams, Dr. Logan J. Bennett, Dr. and Mrs. F. N. Hamerstrom, Jr., and Dr. Thomas G. Scott. Dr. H. H. Knight helped with invertebrate identifications.

About 20,000 additional mink scats were looked over in the field 
for muskrat remains, only, but this did not present the technical problems of the detailed food habits investigations. It is not overly difficult for a person familiar with muskrat morphology to recognize remains of the species in a mink scat. The fur is most useful as a diagnostic item, and, when dry and fluffed out, may be readily distinguished at a glance by a practised analyst, except when the victim is a very young individual. Both guard hair and underfur are distinctive in muskrats of "kit" size and larger, and, with experience, I felt entitled to guess at age classes from the appearance of the fur. Ends of long bones, pieces of skull, teeth, toe-nails and tail vertebrae were especially worth sorting out for identification. 


\section{Chapter 5}

\section{The Ruthven Marsh Area,}

Northwestern Iowa

The salient features of the marshes of Clay and Palo Alto counties comprising the Ruthven study area have been described by recent authors (Bennett, 1938; Hayden, 1943; Low, 1945; Provost, 1948); and the locations of the principal bodies of water in relation to each other are shown in Figure 5.1, reproduced from Hayden's map.

Although most of my work on muskrats was centered on a stateowned wildlife refuge, 450-acre Round Lake, data of supplementary value were obtained elsewhere in the vicinity. Next to Round Lake, the best-studied areas included about 300 acres of Mud Lake owned by the Mud Lake Fur Farm and the potholes of a 392-acre state-owned tract known as Dewey's Pasture.

\section{THE YEARS OF PRELIMINARY INVESTIGATIONS, 1932-34}

My experience with the Ruthven marshes began in the summer of 1932. The muskrat was not at that time one of the species being systematically studied under the Iowa wildlife research program, but it did draw attention because of its relation to waterfowl habitat. During the summer of 1934, when intensive field work on the muskrats was initiated, I accomplished little more than to lay groundwork for the detailed studies of the years to follow. However, information furnished by Dr. Logan J. Bennett (letter, April 1, 1938) and Joe Kautzky, Jr. (letter, March 23, 1938) helped a great deal in piecing together the Mud Lake picture for the years preceding and following my own studies on that marsh.

\section{Mud Lake}

By 1932, when Bennett began his waterfowl researches at Mud Lake, the marsh had regained a satisfactory water level after having gone dry in 1931. He estimated a 1932 fall population of about 200 muskrats, which would appear to have resulted from a spring population of about 20 pairs. 


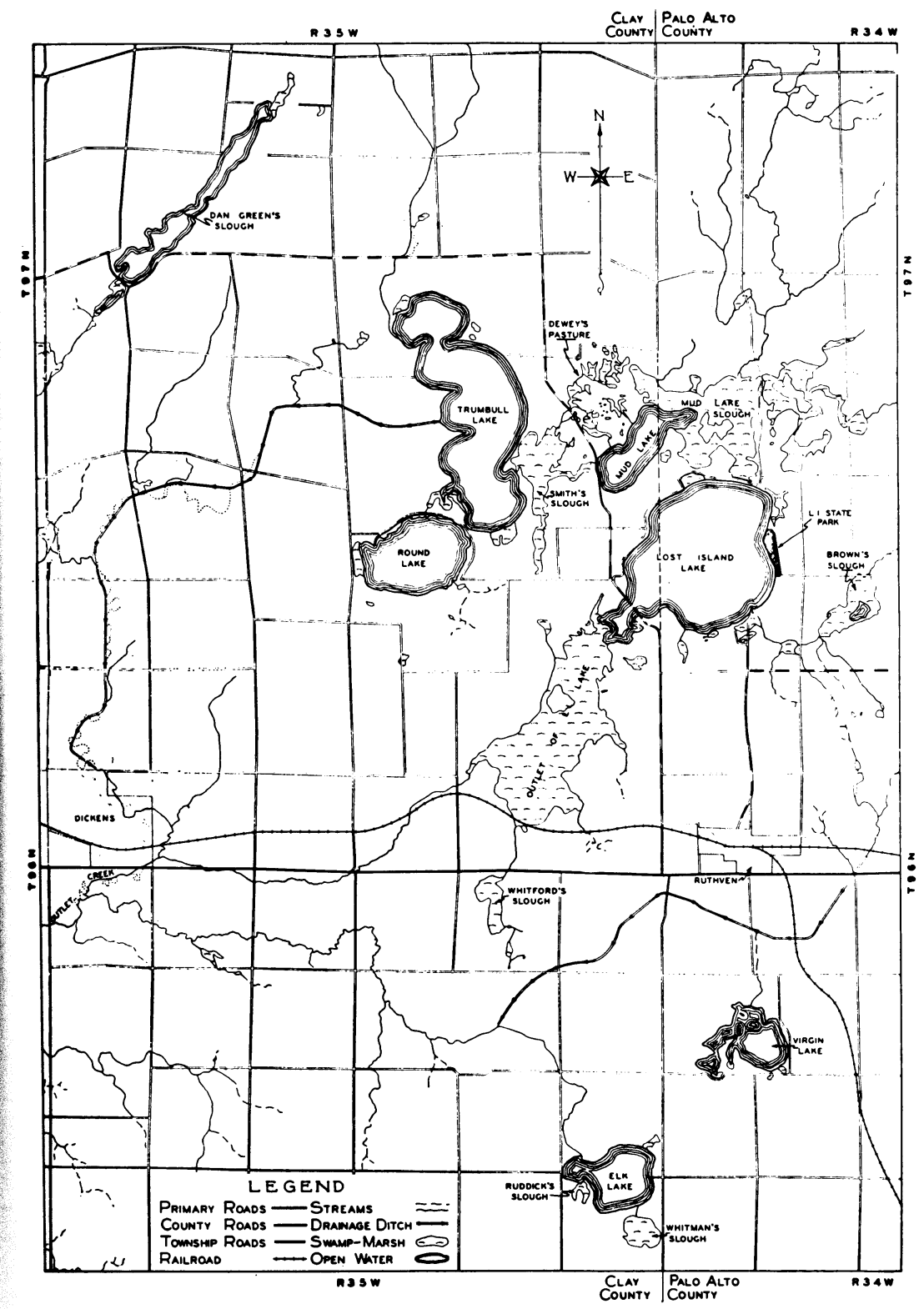

Fig. 5.1. Map of Ruthven area, northwestern lowa. (After Hayden, 1943.)

From my own observations, I would think that the equivalent of about 100 pairs should be close to the breeding population at Mud Lake in 1933. Bennett estimated the fall population at about 1,500 , a likely figure following a 100-pair breeding population on a foodrich 300-acre tract. Minks were abundant, and four females with young were recorded for the marsh during the summer. Only one of 
93 May to August mink scats contained muskrat remains, but other evidence was found of fairly heavy local feeding upon young muskrats.

No legal muskrat trapping was done at Mud Lake during the fall and winter of 1933-34. By midwinter, a zone essentially unoccupied by muskrats extended out about 150 yards from shore. The shallowwater muskrats had, by then, either withdrawn to bank burrows or congregated in the deeper marsh. This zone of abandonment had hundreds of lodges and feed houses. Although most of them showed unrepaired mink borings, slight evidence of muskrat mortality was found except in one tract. There, 46 of 58 winter mink scats from lodge latrines contained muskrat remains. This high incidence was ascribed to vulnerability of muskrats trying to winter under difficult conditions, but it could have represented instead the responsiveness of minks to a local die-off from the hemorrhagic disease (Errington, $1954 \mathrm{~b})$. The wintering population of minks was estimated at between 8 and 12.

The breeding population of Mud Lake for the spring of 1934 was originally recorded as the equivalent of about 400 pairs, but I would now say that about 1,000 animals (including unmated males) should have been closer to the truth. There were many manifestations of crowding in the summer months, with conspicuous groups of mixedage muskrats to be seen on lodge butts and rush rafts. Dead young muskrats were frequently noticed at the dens of two female minks having young about the marsh, but remains of muskrats were found in only three of the 64 mink scats examined for the period of June through September. The 1934 fall population of muskrats at Mud Lake was calculated at between 3,200 and 3,400, of which 2,528 to 2,790 were reported trapped. (The figures on trapping catches varied with the source of information.) At any rate, the muskrats were abundant for the habitat and probably comprised an overpopulation, even if this were judged solely on the basis of the extensive "mowing" of emergent vegetation that occurred in late summer.

\section{Round Lake}

Neither data nor estimates are available for Round Lake for 1932, but, in 1933, I worked to a considerable extent on this marsh. The general breeding-season signs in 1933 were similar to those of 1936, when an adult population the equivalent of 80 pairs was actually determined. The 1933 fall signs, however, were indicative of a much higher density than in 1936 and were more conspicuous than those shown by known populations of between 500 and 750 in the falls of 1937 and 1938. The 1933 fall density was therefore estimated at about 800 .

Two female minks reared families about the marsh in 1933, and a third female was found killed by another mink. Mink predation upon the muskrats was obviously light: two of 126 mink scats for June, July, and August contained muskrat remains. There is reason 
to think that a moderate population of muskrats lived securely in good habitat.

In 1934, Round Lake showed such evidences of overpopulation as "mowing" of emergent vegetation on a large scale. The breeding population for this year was considered a little lower than one accurately determined for 1939, which would make it about the equivalent of 180 pairs for 1934. The fall population for 1939 also affords an index that might be applied to 1934. After certain emergency losses had taken place, the fall population for 1939 was determined at less than 1,300. Insofar as habitat conditions for rather similar breeding populations had been considerably better in 1934 than in 1939 , it may be judged that the fall population may have been correspondingly higher in 1934. I would say that the 1934 population should have been possibly 200 muskrats higher, or a total of about 1,500 .

Three female minks with young lived around the marsh, and substantial quantities of muskrat remains were seen in the fecal deposits outside the mink dens, though no exact figures as to incidence of muskrat remains in the mink scats are at hand for June and July, the months of greatest vulnerability of the young muskrats. Two of 37 mink scats for September contained muskrat remains.

The muskrats wintering 1934-35 were not subjected to legal trapping but did suffer illegal exploitation through spearing. Remains of 14 dying in winter and early spring were found.

\section{INTENSIVE STUDIES OF OVERPOPULATIONS, 1935}

I spent the most of the daylight hours from May through July and part of August, 1935, on Mud and Round lakes. For all of the intensiveness of particular phases of the studies, methods for determining total populations for the marshes had yet to be well worked out, and figures for the over-all spring and fall densities had to be determined by less satisfactory means.

\section{Mud Lake}

At Mud Lake, a 1935 breeding density the equivalent of 0.65 pair per lodge was arrived at through close watches in sample areas. This applied to a total of 546 lodges would give 355 pairs (or adult females), and, following sex ratio data currently available from the vicinity, a total of about 750 adults, as of late spring. The latter does not have the value of a census figure, but I am unable to improve upon it. My feeling is that there were higher breeding densities in the observational samples than indicated but that error from this source could be offset by the existence of some local groups of sparsely populated lodges, especially in two shallow bays. A 1935 fall population of about 2,300 at Mud Lake would appear consistent with a reported trapping catch of 1,900 .

A program of experimental tagging of young muskrats was begun at Mud Lake (Errington and Errington, 1937), and 129 young in 30 
litters were thus marked from May 25 to June 23, 1935. The techniques first tried had serious shortcomings, but the tags stayed on well enough to establish the identity of certain litters (especially litters of which parts were kept in separate nests). A single tagged animal was taken as a subadult by a trapper in the fall.

Of 54 litters handled from one to five times during the period of May 17 to June 23, when the studies were centered on Mud Lake, 24 litters judged to have been complete averaged 6.9 young at very early ages. Nine samples of litters alive at about one week averaged 6.8 young; 21 samples at about two weeks, 5.9 young; 10 samples, two and one-half to three weeks, 6.6 young; and nine samples, three and one-half to four weeks, 4.2 young. The sharp decrease in mean size coincided with relaxation of parental care and with freer ranging by the young.

Diagnosed mortality from natural causes suffered by the above litters was almost entirely due to drowning and to attacks by other muskrats. Five of a litter of at least eight 23-day young and two of a litter of four 27-day young were drowned during a cold rain (Errington, 1937c). Among the victims of chiefly intraspecific strife, one litter having five young at 25 days was annihilated within the next fortnight; another of five at 18 days lost two within the next two days.

Elsewhere on the marsh, the collapse of about a third of the emergent vegetation in late spring and early summer left many muskrats vulnerable to horned owls. Prior to this crisis, no muskrat remains were found in 209 horned owl pellets gathered from the woods about Mud Lake from early spring, 1933, to early spring, 1935, despite a higher population of muskrats in 1934 than in 1935. After the failure of so much of the marsh cover, one of 43 pellets from March 31 to May 16, 1935, contained remains of young muskrats; five of 16 pellets from May 17 to June 1 contained muskrat remains (young animals in four and an adult in the other); and eight of 12 pellets from June 2 to July 15 contained remains of 11 recognized individual young and an adult (Errington, Hamerstrom, and Hamerstrom, 1940). Only one family of young minks was known to frequent Mud Lake in 1935; nothing is recorded of its food habits.

\section{Round Lake}

The most reliable direct counts of muskrats obtained at Round Lake in 1935 under conditions of good visibility gave 94 adults per 50 lodges, or a breeding density of 1.88 per lodge, as of early May. The total adult population for this season for the total of 286 lodges (excluding feed houses) may be computed pro rata at 538, plus 9 known bank dwellers, or about 547 adults. Using the same sex ratio (52.8 per cent males) as for Mud Lake, we would get 289 males to 258 females. A revised estimate gave about 650 adults, including about 310 females.

Verl ("Jack") Black, an expert trapper with experience on some well-populated Iowa marshes, told me that he estimated a population 
of about 2,000 when looking over Round Lake in the fall of 1935. I have no record of my own final estimate of the time but know that Black's was hundreds of animals higher, and I now feel that his was the more nearly correct. My considered view is that the actual 1935 fall population for the marsh was around 1,700, insofar as it was apparently (judging from the comparable sign) a few hundreds higher than a 1939 population that was determined to have been a little below 1,300 .

Two hundred and ten young muskrats in 63 litters were tagged experimentally at Round Lake from June 25 to July 22, 1935. Of these young, 27 were tagged in the middle of July by means of an improved technique; the other tagging was sometimes efficacious, sometimes not. Forty-nine of the 210 tagged young yielded data of some sort.

Special efforts were made to keep track of the tagged animals as long as possible. One study in the northeast part of Round Lake entailed daily examination of all lodges, feeding places, and litters of young on a tract of 15.8 acres for 19 consecutive days, July 6 to 24 . Other sample tracts were closely observed for lesser periods of time, including 9.3 acres in northwest Round Lake, from July 16 to 22.

The northeast sample tract of 15.8 acres and the northwest one of 9.3 acres were selected for the most intensive studies because they had the heaviest breeding densities on the marsh - the equivalents of 22 and 15 pairs, respectively, as ultimately determined. In terms of muskrats per acre, these breeding densities do not look impressive as maxima, but in actuality they constituted, because of the mediocre quality of the existing habitat for muskrats, what I now regard as some of the top-heaviest overpopulations that I ever studied.

The reproductive fortunes of the 22 adult females and associated males of the 15.8-acre study area of northeastern Round Lake were not accurately measured prior to July 6 . The field notes for the period of intensive study indicated a minimum of 48 large young that by then had been weaned and established in the area as free-living individuals. Of these 48 , four were found dead, leaving a minimum of 44 that might be regarded as having good chances for survival. Sixteen large young, which were referred to in the notes but not counted in the above total because of possible duplications, could have included additional individuals. It is still more likely that a number of other large young were sufficiently wary and able as divers to keep out of sight at the times of the daily visits.

Limited movements of free-ranging young across the boundaries of the northeast study area were known to have occurred. While no outside records were obtained on 8 tagged animals that reached ages of independence within the area, 7 outsiders were recorded short distances inside. Six of the latter had been tagged considerably less than 100 yards from the places where later seen, but the seventh (an ailing albino) was found dead 200 yards from its original quarters.

Of a total of 73 young closely studied on the northeast area during the 19-day period in July, only 11 were judged on fair evidence to 
have been reared. A loss of 16 may be more or less chargeable to human disturbance or tagging, but, even allowing for this, a "natural" mortality of 46 of 62 is still extremely high. A fungus skin disease due to Trichophyton mentagrophytes (Errington, 1942b) and intraspecific attacks were the major agencies of loss.

One litter of five 13-day young was bitten to death by an adult on circumstantial evidence, by a female about to give birth to a litter of her own. The lodge was remodeled, the dead young covered up therein, and, on about the following day, a new litter was born to the nearest adult female (other than the mother of the murdered young) living in the vicinity. This had all the appearances of aggressive action to gain possession of what had been at the time the best habitation in the neighborhood. Three days after the killing, I leveled the lodge in search of the buried young, following which a new lodge containing the very young litter was built up 45 yards away.

Another lodge just outside the 15.8-acre northeast area was apparently taken over and rebuilt by adults other than the rightful possessors, on the day after the destruction of a litter of 8 young of four days. In this instance, the killing was done not as an act of parental competition but by cannibalistic young of the litter preceding the litter destroyed. Another litter of 7 new-born young did not last as long, the young cannibals having well cleaned it up by the day after its birth.

Equally deadly to the victims, if reflecting less viciousness, was the rebuilding of a lodge by a mother that brought her own young to it after covering with debris the then-living abandoned young of a litter belonging there. Also, the eating of some very small young by larger young followed the abandonment and death of half of a split litter of 8 ; the other 4 of the litter were well attended in a lodge 60 yards away.

The hazards awaiting weaned young trying to live under crowded conditions are illustrated by data on intraspecific attacks in and about the 15.8-acre area. An animal slightly less than two months of age was found sitting on a rush raft, so dazed from head wounds that it was easily caught by hand; after tagging and release, it was seen two and one-half hours later, still sitting and still dazed. The biggest and most vigorous young of one tagged litter was found dying at 31 days, its tail bitten through and nearly severed at the base. One of about 40 days was found dead in a lodge, hindquarters slashed. Two suspected strife victims of between 50 and 60 days were seen rotting in the water.

The total productivity of the northeast 15.8 acres may be calculated as the 11 young believed to have grown to independent ages during the July period of intensive study, plus the 44 of older ages having good chances for survival, plus the unknown number of older ones that were reared without being recorded. Possibly, the number of the latter might fairly well offset the number of the others that died in late summer or early fall after having been last observed. At any rate, a local increase totaling 55 young for the equivalent of 22 
pairs would seem, under the circumstances, about what might have been expected.

The northwest sample area of 9.3 acres having the equivalent of 15 breeding pairs was partly surrounded by wide expanses of open range, into which the weaned young usually succeeded in moving before being tempted to prey upon helpless litters or getting into trouble with their elders. Except for one young that recovered from slight wounds inflicted by another young, no victims of intraspecific attack were found in the area during the intensive study, nor during nine visits made before or after this period. In fact, only two dead young were found in here: one drowned and the other dead from what looked like a light accidental blow to its nose.

There were 10 helpless litters being cared for in the 16 lodges of the northwest sample area, with much splitting and shifting of litters taking place. Members of one litter of 14 days were found distributed in four adjacent lodges. As this happened to be the situation at the time of the first inspection of the area in nine days, it could hardly have resulted from human disturbance. In one instance, a new-born litter was moved into a lodge very shortly after the lodge was vacated by a mother moving her 16-day litter to the next lodge, 55 yards distant. Two members of another new-born litter were found, placentae still attached, 45 yards from the lodge containing their 7 litter mates. It was apparent that much intermingling of adults occurred, but, with the larger young "out from under foot," the overlapping of territories did not promote anywhere nearly the friction observed in the northeast area.

The northwest area was unquestionably a very productive one for Round Lake in 1935. An early checkup on May 5 revealed seven litters of small young in 24 lodges lying within or just outside the area. Breeding also continued late, litters being born July 29, August 5, and August 24.

I find it most difficult, if only because of the variety and complexity of situations existing at Round Lake in 1935, to generalize accurately on the fortunes and responses of the muskrats of that marsh for that year. Yet, so many equivalents of experiments were set up through the operation of natural factors that attempts at generalizations should be particularly in order.

Eight dead adults and 77 dead or dying young were individually referred to in the notes for the middle and latter parts of the summer of 1935, and, of these dead, the young of course represent but a small fraction of the numbers dying. Of the litters handled, 6.9 per cent were infected and virtually wiped out by Trichophyton (Errington, 1942b). Seldom were more than one or two young actually found dead of whole litters patently dying from the fungus skin disease or found dead among the helpless litters being preyed upon by large young muskrats. Most losses were indicated by final disappearance of the young. Decomposition, settling to the bottom of the marsh, burial under the piles of vegetation manipulated by muskrats, and scavenging (especially by partly grown muskrats and by the small painted 
turtles, Chrysemys picta bellii), all served to obliterate remains of dead young quite rapidly.

Among the more informative specimens were three of four newborn young dead of exposure on a flooded nest; a breast-slashed young of about five weeks on a deep-water rush pile occupied by two adults; an unweaned young of 20 days backed into a blind chamber in a lodge and twice bitten through the head by an adult; and two young of 16 days killed in a shore-zone lodge by a mink, one bitten through the head and the other through the shoulders.

For comparative purposes, Round Lake may be divided roughly into east and west halves for the spring and summer of 1935. There were no mink dens with young along the shore of the east half (which was mainly bounded by a graveled road, much frequented by dogs), but along the quieter west shore were no fewer than five female minks with their families. Until the breaking up of the mink families, only an occasional big mink (of the size of an adult male) worked around the east shore. The two halves had rather similar numbers of occupied muskrat burrows and, considered broadly, were also somewhat alike in topography and vegetation.

Mink predation upon the young muskrats was as pronounced in the west half as it was negligible in the east half. Mink scats could be seen literally by the quart about the latrines of the rearing dens, and the weathering muskrat fur stood out in heaps. Samples totaling 114 mink scats were gathered from May to August, 1935, and 41 of these contained muskrat remains - an exceedingly high incidence for the warm-weather months during a period of no serious environmental emergencies.

The losses from skin disease were likewise heavier in the west half, and this also had a bearing upon the severity of the mink predation suffered (Errington, 1943). But, disease and mink predation notwithstanding, the mean fall densities looked about the same on most of the comparable subdivisions of the marsh that had been either minkhunted or practically mink-free. One exception was noted: on 20 acres of marsh where the summer mink pressure had been most severe, the fall population was probably lower by two or three muskrats per acre than the 10- to 15-per acre densities estimated for adjacent parts of the marsh.

The data from the two halves of Round Lake for 1935 revealed other evidences of intercompensations or automatic adjustments in rates of loss and gain. On the east half, where losses from agencies other than intraspecific strife had not been great, breeding had ceased by midsummer. This half had a number of conspicuous aggregations of mixed ages of young throughout July. Thirteen were caught and tagged on one old lodge butt alone, and many others on this butt escaped capture. Five additional gathering sites of miscellaneous groups of adults and young were mentioned in the field notes, mostly in the northeast study area.

The sexual states of adult males collected for specimens while in close association with such mixed groups suggest that the continued 
proximity of large numbers of young may have affected the psychology, hence the physiology, of the males and thus brought about an early sexual quiescence. One of two adult males collected on June 27 and two of three collected on July 25 and 26 from the densely populated tracts of the east half had testes that were much reduced in size, whereas four specimens of adult males collected between June 25 and July 28 from the less populated west half were in normal breeding condition. Breeding continued through August in the west half.

In those parts of the marsh where continued late breeding was prominent, the basic stimulus may be identified with a relative lack of population tension. Nearly all of the late-summer litters (or commonly the third or fourth of the season for individual females) were born on sections of the marsh where either the known early summer mortality of the young had been highest or where lessened tension may be ascribed to unimpeded movements of young outward into relatively underpopulated parts of the marsh. Appreciably fewer young of active sizes were intimately associated with adult animals in the long-producing west half than in the east half, where breeding ceased so early.

In the east half, and especially in the northeast study area, it was many weeks before the majority of the weaned young had access to any livable quarters except those in the midst of population aggregates dominated by short-tempered adults. Here, the weaned young, having but limited opportunities for movement away from the area, lived warily as unpopular trespassers, the survivors among them contributing to prevailing population tensions as well as drawing attacks from their elders.

In late summer, the harassed muskrats of the northeast study area were living in what had been the most food-rich part of Round Lake until midsummer. It was doubtless not a matter of chance that so many adults had wedged in their breeding territories where the vegetation had then been most attractive to them. The behavioristic manifestations of the resident adults may therefore be regarded as a resultant of (1) a greater tolerance of crowding induced by an originally superior food supply and of (2) the heightened tensions following both overuse and natural deterioration of important tracts of the habitat available to them, plus (3) irritations because of the presence of weaned young while new litters continued to be born, and plus (4), conceivably, the psycho-physiological influence of an impending cyclic low (Errington, 1954a; 1957).

Cover conditions had been generally backward on the marsh up to the last week of June, with bulrushes sparse and reeds only about two and one-half feet out of the water. By the end of the first week of July, emergent vegetation had made much better growth, especially in the center, and muskrat lodges were being built at an accelerated rate. By the middle of July, it was becoming more and more apparent that fair-sized young were moving deeper into the marsh where the newly emergent vegetation was thicker.

One particularly substantial drift of young was from the outer- 
most edges of the northeast study area and from an area immediately to the north, where emergent stands died or were cut down by the muskrats to such an extent that the bulk of the muskrat population situated within 200 yards of shore almost had to move. By August 3, most of the animals engaged in this adjustment were living in heavier, previously unoccupied rushy growths 300 to 400 yards from shore. No evidence of foot-loose abandonment of home ranges was noted in connection with the drifting toward deeper parts of the marsh. The drift was of the nature of mass extensions of ranges into marsh that was essentially virgin habitat.

Rather similar drifting of young occurred during the summer from the northwest study area, which had avenues of travel to deep water vegetation on three sides. At the same time, there was very little sign of activity in west-central Round Lake out from the places having the characteristically heavy losses of young through predation and disease.

\section{INTENSIVE STUDIES DURING THE DROUGHT EMERGENCY AND APPARENT CYCLIC LOW OF 1936}

Dissociation of variables linked with drought, heat, disease, and the little-understood phenomenon called the "10-year cycle" is admittedly hard to do. Drought had a big part in the wholesale reduction of muskrats that occurred in Iowa and in states to the north and west in 1936. Directly and indirectly, it was responsible for the loss of millions of muskrats. It all but wiped out the species over countywide areas in the western half of the north central region.

I long attributed primarily to the 1936 drought the lowest net rates of gain (either in relation to density or not) observed for both the Round Lake and Mud Lake populations. Yet, the data looked upon from the perspective of recent years show that only a small proportion of the Round Lake residents could have been seriously affected by drought between the spring and fall of 1936. There the food, cover, and water conditions remained well within known limits of comfort and tolerance of at least the lodge-dwelling muskrats. At Mud Lake, the situation differed in degree, with drought being a more important factor on the east third than on any sizable tract at Round Lake, but a summer gain surely depressed below 100 per cent may not be convincingly explained more than partly in terms of drought.

The summer of 1936 was hot, but, if it be argued that excessive temperatures (up to 117 degrees Fahrenheit and often day after day above 100 degrees) may have accelerated mortality or damped reproduction, similar statements could be made of the summer of 1934, when rates of net population gain figured out in the vicinity of 300 per cent for both marshes - and these latter gains appeared to have reflected considerable density-depression as well.

Further discussion of the possible operation of the cyclic mechanism in 1936 had best be reserved until later in the book, after the various kinds and shades of evidence have been assembled, winnowed, 
and appraised. That something special happened may nonetheless be recognized, something not to be dismissed in ordinary terms of weather, habitat, or epizootiology.

\section{Mud Lake and Dewey's Pasture}

About 100 of the 300 acres of marsh controlled by the Mud Lake Fur Farm were dry by the fall of 1936, and only 40 of the dry 100 acres still had living muskrats. The season's catch was 501 muskrats (letter, Joe Kautsky, Jr., March 23, 1938), of which 42 were reported taken from dry marsh (letter, John Garlisch, November 17, 1936). Virtually the entire population was caught, which would figure out at a November density close to 460 muskrats on the 200 acres of wet marsh. The fall population of 2.3 animals per acre for the wet marsh apparently had not been significantly affected by the drought. On a pro rata basis, a reduction of the dry marsh population to less than one-half muskrat per acre would mean a net lowering of the Mud Lake population by almost 200 .

The mistake should not be made of thinking that the greater numbers of muskrats trapped on the wetter 200 acres might simply have reflected immigration from the part drying up in summer and fall. The territories or home ranges had been packed together in such a way as to have permitted little free movement, and, in the dry marsh, well-used home ranges had been consistently occupied despite more favorable food and water conditions in the wetter but already occupied parts of the marsh. Only a very small proportion of the animals trapped in the better grades of habitats showed the wounds and poor flesh indicative of trespassers, whereas all of six muskrats from the dry eastern end that I examined on November 11 were thin and chewed up. The principal trapper, Verl ("Jack") Black, judged that 90 per cent of the muskrat pelts taken from the dry marsh were damaged (letter, November 16, 1936).

The 1936 spring breeding density for Mud Lake cannot be figured out with better than fair satisfaction, but sufficient work was done to judge (1) that the population of adult females of the dry but still occupied 40-acre tract had suffered only moderate reduction through drought up to the trapping, (2) that, on the basis of specimens examined, possibly 18 of the 42 muskrats trapped on the dry 40 acres were adult females, and (3) that these dry 40 acres had an original population more or less representative of the holdings of the Mud Lake Fur Farm. After making allowance for some drought loss of adult females on the 40 -acre sample, the evidence would suggest the equivalents of between 160 and 200 pairs - probably nearer the former - as the spring population for the total of 300 acres of the Mud Lake Fur Farm.

Lying north of and adjacent to Mud Lake, the 392-acre state-owned waterfowl breeding grounds known as Dewey's Pasture had slightly over 100 acres in marshy potholes. The 1936 breeding population of muskrats was estimated on the basis of summer signs as the equiv- 
alent of 20 pairs. The potholes went dry from June to August, with vulnerability of the muskrats to minks becoming critical just after disappearance of the surface waters. No muskrat remains were seen in about 200 mink scats dated to June and early July, but 20 of 27 scats deposited from the middle of July to early October did contain muskrat remains. However, all of 4 dead young muskrats found could have died from causes other than mink predation, and one had been eaten upon by another muskrat. There was also evidence of much outright abandonment of the dry potholes in late July - though fairly substantial remnants occupied some old quarters for weeks afterward. The remnant animals included not only formidable, property conscious adults but also individuals seen to be immature, diseased, and otherwise handicapped. The last resident muskrat in Dewey's Pasture was apparently killed by a mink early in October.

\section{Round Lake}

Much illegal spearing of muskrats through the lodges had taken place on Round Lake during the winter of 1935-36. The field notes for a visit of May 13, 1936, suggest disease losses, as well. Two neighboring east-side lodges had winter mink latrines on them, and all of about 90 scats contained muskrat remains, which is the sort of thing one sees following a local epizootic. On May 23, a recently dead adult was found in one of the lodges near the winter mink latrines, further suggesting the continuation of a local epizootic. In the south central part, an adult male was found floating on June 17 and adult females on June 24 and 27, all sufficiently fresh to show what was then noted as visceral inflammation.

The entire marsh was kept under intensive observation during the 1936 breeding season, with the objective of obtaining data on as many as possible of the muskrat litters born. Not all of the season's litters actually were handled, but thorough inspections of mapped and numbered lodges (in which the majority of the litters were regularly quartered) were made at about weekly intervals, or as often as full circuits could be made.

A breeding population the equivalent of 80 pairs was determined from, among other data, the location of litters. This, considering the evidence of surplus adult males, should mean a total of about 170 adults present, as of the middle of May.

Mink predation on adults was conspicuous in April and May, but the brunt was borne by shore-dwelling transients. Eighteen carcasses of victims were found, and those for which sex was ascertained were males having many wounds received from other muskrats. Sixty-one of 106 mink scats deposited in April and May contained remains of adult muskrats. By June, the surplus males had been eliminated, and the incidence of muskrat remains in the scats dropped to 7 in 84 .

The total of 120 litters accounted for at Round Lake in 1936 should be revised upward. The best procedure in trying to arrive at valid figures as to the actual number born would seem through pro 
rata calculations. The breeding histories of 51 of the adult females were followed with reasonable confidence in the completeness of the data obtained on the numbers of litters born to them during the breeding season. The remaining 29 of the total of 80 adult females could well have given birth to and reared undetected litters in bank burrows. Of the 51 adult females most satisfactorily kept track of, 2 were classed as nonbreeders, 13 as one-litter females (including 3 that died before the possibility of further conceptions), 23 as two-litter females, 11 as three-litter females (including one dying while pregnant for the third time), and 2 as four-litter females. If these 51 and their total of 100 litters be accepted as representative for Round Lake in 1936, then the grand total of litters would be 157. The mean size of 43 complete litters was 6.3 , which would give a grand total of about 990 young born.

Four of the original 80 adult females were accounted for as having died during the breeding season. It is possible that some of the 13 unsexed adults found dead between late spring and fall also had been females, or that other adults (including females) had died without my knowledge, especially when concealed in bank burrows. Perhaps about 70 adult females were surviving by fall.

It did seem that, after the elimination of surplus males through minks and strife in April and May, most adults lived securely until the water level of the marsh went down in July and exposed some of the bank burrows. As a rule, the occupants of the banks withdrew safely to deeper water, but 7 of the 8 adults believed to have been living in the exposed burrows of a 300-yard stretch of shore were apparently killed by minks, and lesser losses were detected in two other places. Thirty-four of about 160 mink scats collected for this period from the 300-yard exposed stretch contained remains of muskrats, mostly of adults.

Considerable movement of muskrats about the countryside was induced by drought in late summer and fall, but there was no reason to think that the relatively well-situated Round Lake population participated in it to any significant extent - least of all the resident adult females, which are always among the more reluctant to give up established home ranges as long as living conditions are tolerable.

A late fall sample of 175 residents (taken as specimens for the investigation by Verl Black, Roy Walrod, and myself) consisted of 18 adult males, 29 adult females, 72 young males, and 56 young females. (Six other specimens collected at this time were easily recognizable as wanderers from their poor and battered physical condition.) On the basis of the above ratios, a total living population of about 70 resident adult females should have been associated with about 45 adult males, 175 young males, and 135 young females, or a grand total of about 425 resident muskrats at Round Lake, as of November, 1936. The removal of 175 specimens would have left about 250 of the resident population to enter the winter. If any wanderers became established, they were present in but negligible numbers. 
It may be seen that the total of about 310 young of the year calculated for the 1936 fall population would comprise less than a third of the calculated number of young that had been born. By far the greater part of such a decline should have been due to mortality, for the tagging of 123 young in 52 litters gave evidence that few young had left the marsh. Of 13 young muskrats tagged on Round Lake during the summer of 1936 and recovered in the following fall and early winter, only one evidently took to wandering. It was trapped at a drainage ditch about four miles from its birthplace.

The causes of mortality of 90 young were well ascertained. Fifty-one were, directly or indirectly, victims of the skin disease previously mentioned, but this sample surely is much overweighted, even considering that 12 per cent of the litters were infected. It was true that infections of the skin disease proved to be invariably fatal to victims showing gross manifestations before the age of two weeks, and that few litter members escaped if the disease appeared among them at such an early age (Errington, 1942b); also that, as infection in a litter could be recognized days before any actual dying, the mere disappearance of animals thus ailing could be interpreted as evidence of their deaths. But the five of the ninety that were found dead from strife wounds probably did not represent a proportionate amount of those dying through this agency - especially near two rather crowded shore zones occupied by some patently intolerant adults.

Three female minks had young in dens about Round Lake in 1936, and also present was a huge male (sometimes observed at close quarters in its favorite retreat) that specialized on the transient male muskrats frequenting the shore in the spring. The killing of 8 young muskrats, including a litter of 6 small ones, was specifically traced to the minks. Only 3 of 153 mink scats for May and June contained muskrat remains, and these remains were of the above litter of 6 . After drought had exposed the shallower parts of Round Lake in July, 47 of 194 mink scats contained muskrat remains. For August through September, with the passing of the period of greatest drought vulnerability, no muskrat remains were found in 76 mink scats. For late fall, when some ingress of drought-evicted muskrats from other places occurred, 4 of 21 mink scats contained muskrat remains.

By late September, most of the lodges were within 50 to 150 yards of shore, and, even in the central part, the heaviest concentrations were within 300 yards of shore. The total of habitable lodges was something over 175. A month later, the mud margin extended about 200 yards out in the marsh, and, by freeze-up in early November, the maximum depth of water was about a foot and a half.

\section{THE INTERMITTENT STUDIES OF 1937}

In 1937, I was too busy in central Iowa to make more than occasional visits to the Ruthven area; hence the time spent there was largely devoted to obtaining data illustrating population trends. For information contributed by others, particular thanks are due to Dan Nichols of the State Conservation Commission and to Dr. Clarence A. Sooter, then of Iowa State College. 


\section{Mud Lake}

At Mud Lake Fur Farm, John Garlisch, the caretaker, told me that, in 1937, he saw only one muskrat there up to April 27. Considerable repopulation occurred later in the spring, bringing the Mud Lake breeding population up to an estimated equivalent of about 17 pairs. A 1937 fall catch of 130 (letter, Joe Kautzky, Jr., March 23, 1938), plus an estimated 30 escaping the trapping at Mud Lake, would indicate a fair amount of ingress of breeding animals.

\section{Round Lake}

Despite a low water level and freezing to the bottom over much if not all of Round Lake in the winter of 1936-37, the survival rate of the muskrats appeared to have been quite high. Indeed, the usual habits of the muskrats living in channels and air spaces under the ice rather than in the lodges at such times gave them good protection from illegal spearing. (The main violators of the refuge were apprehended with nine muskrats in possession. They were said to have tried again, but, after spearing only three in three nights, concluded that there were not any muskrats left.) But living conditions for some of the wintering muskrats were unfavorable, and some wandering was observed. Muskrat remains were found in all of eight winter mink scats examined.

Mink-eaten bodies of $\mathbf{5}$ muskrats were found in late April, and these seemed to have been typical transients. Thirty-six of 114 mink scats for this month contained muskrat remains. Ten other winter and spring dead were found, of which the deaths of 7 were originally ascribed to drowning during a windstorm. That diagnosis may have been faulty, for, despite the absence of references in the field notes to recognized lesions, the general evidence suggested that a local epizootic may have killed the occupants of a reed patch, the lodges of which later disintegrated through wave action.

Conditions on Round Lake were favorable for direct observations in the last week of April, 1937, and a census figure the equivalent of 86 pairs, or about 185 adults, is believed to have been accurate for the time. However, the spring dispersal was by no means over, and Round Lake was the likeliest source of the muskrats moving into Mud Lake, for more were known to have survived at Round Lake than elsewhere in the Ruthven area. Then, too, three of the animals tagged in 1936 at Round Lake were taken by trappers at Mud Lake and a neighboring marsh in the fall of 1937. Several other tagged muskrats were, according to "grapevine," caught during the same fall within a four-mile radius of Round Lake.

From tagging results, the early-summer distribution of lodges observed by Sooter (I have his notes and a map dated June 26, 1937), and information pieced together on location of used burrow systems, it may be estimated that the equivalent of 52 pairs - or approximately 60 per cent of the late April population - remained on the marsh. The fewness of visits to Round Lake in this year are hardly conducive to accuracy in calculating adult mortality, but, unless disease did un- 
detected killing of adults, such mortality would appear to have been considerably lighter in 1937 than in 1936. Remains of only 2 dead adults could be assigned to the summer of 1937. For lack of more definite information, we may assume a spring to fall loss of a couple of adult females, thus reducing their number to the vicinity of 50 .

In early winter, 1937, C. C. Lille and L. D. Wright of the State Conservation Commission trapped 208 specimens from Round Lake in connection with the investigations: 20 adult males, 24 adult females, 94 young males, and 70 young females.

This sample, because of the moderation of the trapping done in particular areas, is thought to have been overweighted with selectively taken adults, for the reason that a greater proportion of the fully adult members of a muskrat population may be caught in the first few days of trapping. We have data from Iowa samples totaling 3,720 fall-trapped muskrats that are both representative of practically total populations and informative concerning times of trapping of their component lots; these samples show a mean ratio of 3.61 young per adult in the early-caught lots, compared with a mean ratio of 4.43 young per adult in the over-all populations. Instead of the recorded ratio of 3.73 young per adult in the Round Lake specimens trapped in 1937, we may then, calculating from proportions, arrive at a ratio of 4.58 young per adult as being more nearly representative of the actual Round Lake population for that year.

The use of 50 surviving adult females as a basis for calculating the 1937 fall population from the sex and age ratios would give a total adult population of 92 , including 42 males. With the corrected ratio of 4.58 young per adult, the number of young of the year would figure out as near 420 and the total population at near 515. The trapping by the Conservation Commission should have left about 300 muskrats to enter the winter of 1937-38.

Mink predation upon the Round Lake muskrats was clearly light in 1937 after the elimination of the vulnerable spring transients. No muskrat remains were found in about 86 mink scats deposited from May to August, nor in 81 fall scats. Three female minks with their young lived along the shore, close to the retreats of the majority of the resident muskrats.

Following the spring dispersal, the Round Lake muskrats of 1937 lived principally in lodges near shore or in bank burrows. Water levels were high not only in the spring but also throughout the summer. No important late-summer drifting of muskrats toward the center of the marsh took place, though the central vegetation remained in attractive condition and was only somewhat less dense than in 1935 and 1936, when centripetal movements had been conspicuous.

\section{INTENSIVE STUDIES AT ROUND LAKE OF A MODERATELY LOW-DENSITY POPULATION LIVING IN FAIRLY GOOD HABTAT, 1938}

The evidence indicates that the muskrats were well-situated on Round Lake during the winter of 1937-38. Though minks ate several 
muskrats in the traps of the state trappers, the general population of muskrats seemed to have been secure. None of 160 winter mink scats contained muskrat remains. For the spring months, 1938, one of 124 mink scats contained muskrat remains, and a single body of a mink victim was found, a male lying on shore.

A settled breeding population the equivalent of 64 pairs or about 150 adults was arrived at. Because of the low population, favorable conditions for observation, and the intensive nature of the work, this figure is regarded as being nearly exact.

Tagging was resumed, after lapsing in 1937, and 128 tags were placed on members of 26 litters between May 16 and July 7, 1938, principally to establish the identity of key litters in studies of growth rates and development (Errington, 1944).

Lille and Wright took 206 specimens for examination from Round Lake in December, 1938. The sites of trapping of all specimens were carefully mapped for purposes of the investigation by Horace L. Poole. Excluding two wanderers, 204 specimens consisted of 18 adult males, 20 adult females, 88 young males, and 78 young females. This sample, like that for 1937, is undoubtedly overweighted with selectively taken adults, as different parts of the marsh were subjected to only a single day of trapping. If calculations on the same proportional bases as in 1937 be applied to the 1938 data, the 1938 age ratio should be 5.36 young per adult, instead of the 4.37 young per adult in the actual series of 204 specimens.

The losses of adults during the summer were remarkably low. Only one dead (a male dying from wounds of intraspecific strife) was found. Three adult males were collected for specimens. For practical purposes, it may be assumed that about 62 adult females were still alive by late fall. On this basis, pro rata calculations would give a total resident population of 118 adults and - using the recalculated ratio of 5.36 young per adult -632 young of the year, or a grand total of 750 .

Sixteen young were shot for specimens during the summer, and a seventeenth escaped with probable fatal wounds. Of 62 other young known to have died, 32 were victims of the fungus skin disease; 12 of abandonment or other deficiencies in parental care; 5 of drowning, chiefly during a cloudburst; 3 of mink predation; and 8 of miscellaneous or unknown causes, probably including undiagnosed disease. In 1938, the incidence of litters infected with Trichophyton was a trifle higher (12.2 per cent) than in 1936.

Among the victims of undiagnosed disease was a subadult found floating on the water, still warm with body heat, with nothing demonstrably wrong with it except thoracic congestion. This, I now suspect, represented the pneumonic syndrome of the then unrecognized hemorrhagic disease.

Most of the intraspecific strife, cannibalistic feeding, desertions, and behavioristic irregularities of the year occurred in the northwest corner, the most heavily populated part of the marsh. Numerous young went ashore here-presumably as a result of intraspecific 
tensions, as this sort of thing did not often happen with well-situuated Iowa marsh populations. This was where the known mink predation took place.

Signs of only one female mink with her young could be found at Round Lake in the summer of 1938. The 3 mink-killed young muskrats were recently weaned; remains were found in 8 of 160 mink scats deposited in June and July. Five of 89 scats for August contained muskrat remains, and these remains were of approximately halfgrown animals. Four representations of muskrats in 35 September and October scats included remains of at least 2 individuals that were adult-like in appearance.

Water levels were well maintained throughout the 1938 breeding season. Perhaps the emergent vegetation over the marsh as a whole was somewhat less abundant than in the earlier years of the study, but general environmental conditions were not greatly dissimilar to what they had been each year following 1933, with the exception of the low water stages of 1936. Local changes could be noticed, for example, in the continued deterioration of the heavy stand of cattails of the east side, but this was partly offset by the extension of cattail tracts in the north center and northwest corner and the washing out of some of the reed clumps was accompanied by thickening growths of bulrushes.

\section{INTERMITTENT STUDIES AT ROUND LAKE DURING A YEAR OF FALL DROUGHT, 1939}

Little information may be extracted from the notes concerning the 1938-39 wintering of the muskrats at Round Lake. Minks were scarce; muskrat remains were found in one of 13 scats. In March and April, 1939, two mink victims were handled, both representative of the several transient muskrats seen to be living in flimsy nests along the shore. One transient muskrat, collected for examination, was a typical wandering male with painful-looking strife wounds. Three of 19 spring mink scats contained muskrat remains.

A good checkup of the breeding population, May 8 to 10, gave the equivalent of an even 200 pairs, or a total of about 425 adults. Because of the initiation of intensive studies at Cheever Lake (Chapter 6), visits to Round Lake were inadequate to trace mortality in detail. Apparently, only a solitary mink was regularly present in the summer; muskrat remains were found in 4 of 150 scats deposited in June and July and in none of 92 from September.

The year was characterized by a prolonged, dry Indian summer, turning into locally acute drought. Water levels in late fall and early winter were not as low at Round Lake in 1939 as they had been in 1936, but the population adjustments and mortality reflected drought crises far more spectacularly in 1939.

Lille, Wright, and Verl Black took 195 specimens (exclusive of six current wanderers) for examination in December: 16 adult males, 14 adult females, 96 young males, and 69 young females. The trapping 
was sufficiently intense in given tracts of marsh to yield a good cross section of the population living there; nevertheless, the age ratio was distorted by differential mortality of adults during the drought.

Offspring of the shallow-zone adults had tended to migrate centripetally and to establish themselves securely in deep-water habitats during the late-summer period of minimal friction, whereas the old animals had remained in residence along the exposed marsh borders until late fall. Then, when these old ones had finally relinquished their property rights and tried to make adjustments, it had been too late for them. They had been fought off by animals already resident in the better habitats, and they had suffered severe losses from intraspecific strife and from the special hazards of wanderers at this time of year.

Ninety-three of the original breeding territories had been wellsituated with respect to the drought, and, in these, the survival of adults had been high. In the shallow zone, most of the adults of the other 107 original territories ultimately had died or departed from the lake after having produced their season's young. Using 93 as the remaining and more or less centrally located population of adult females in combination with the sex and age ratios obtained from the trapping, we would get a corresponding number of about 106 adult males and about 1,080 young of the year, the latter being the offspring of both central and peripheral breeders. The grand total of about 1,280 arrived at for the marsh seemed to be in keeping with the external signs shown by an almost exclusively lodge-dwelling population in December.

\section{CONCLUDING COMMENTS ON THE ROUND LAKE STUDIES}

My real work in the Ruthven area terminated with a few brief visits in the course of 1940-41. In those years, the general trends of muskrat populations and muskrat habitat were both downward.

In midwinter, 1939-40, poachers violated the Round Lake refuge and drastically exploited the muskrats. It would be a good guess that many hundreds of muskrats were speared or trapped illegally, and the 1940 spring population was obviously much reduced - down to an estimated equivalent of 60 pairs or about 143 adults. The midsummer water level was similar to what it had been in most previous years of my studies, but, by late fall, it was considerably lower, exposing much of the shore zone. For unknown reasons, the emergent vegetation became much reduced (especially the central stands of bulrush and cattail), although the reed clumps appeared to be little changed, and the southeast corner had the best stand of bulrushes in years. The late fall population of muskrats was rather restricted to 225 medium-small lodges (194 actually counted, the balance estimated for inaccessible parts). These lodges were of the sort that, judged from my trapping experience, might have yielded an average of 3 muskrats each. On this basis, an estimate of about 675 muskrats as the fall population was made. 
Something happened to the Round Lake muskrats during the winter of 1940-41 - just what is not at all clear. B. I. Severson of the State Conservation Commission reported that he knew of only 15 muskrats having been speared there (Taylor W. Huston, letter, March 4, 1941). The famous "Armistice Day Blizzard" was said to have destroyed many of the lodges, but I have no way of knowing how deadly this event was for the muskrats. Bodies of $3 \mathrm{mink}$ victims were found on a spring inspection trip, and 7 of 15 mink scats contained muskrat remains. My estimate of the 1941 breeding population was the equivalent of between 25 and 30 pairs, probably about 55 adults.

Water levels fluctuated considerably at Round Lake from spring to fall, 1941, yet not enough to bring about any known crises for the muskrats. In general, emergent vegetation continued to be less dense and less widely distributed than in the early years of the study, being especially sparse in the deeper parts of the north half. No muskrat remains were seen in about 200 summer mink scats. By late fall, the visible signs indicated a low population, estimated at about 175 .

I visited the Ruthven area in late June, 1958, and found that the marshes on which my intensive work had been done in the thirties were dry and conspicuously grown over with cattails. James G. Sieh, of the Iowa State Conservation Commission, kindly summarized for me (letter and inclosures of July 9, 1958) the information he obtained from Round Lake after discontinuation of my work there, and this material is excerpted in Appendix B. 


\section{Chapter 6}

\section{The Estherville Marsh Area, Northwestern Iowa}

The Estherville area of Emmet and Dickinson counties somewhat resembles the Ruthven area, which lies to the south. It has, for agricultural Iowa, a considerable variety of glacial lakes, marshes, and sloughs. The Estherville area, too, was first observed personally in 1932, though I did not systematically work it until 1939, when it largely superseded the Ruthven area as a major site for intensive investigations of marsh-dwelling muskrats in northwestern Iowa. After 1940, I visited the area only at long intervals (once to three times a year), but infrequency of inspections was in large part offset by the cooperation given by E. M. Wogen, then of the State Conservation Commission, who made special efforts to obtain specimens and information for the study. I also received much help and information from the C. A. Barnes family who lived next to Cheever Lake - the series of marshes on which my intensive studies were mainly centered.

The 282 acres of state-owned property known as Cheever Lake was once divided, in a treatment of mink predation upon its muskrat occupants, into the Main, Northwest, and Northeast marshes (Errington, 1943). For purposes of the present chapter, further subdivision and the inclusion of certain outlying wetlands is desirable because of the complexity of the population data obtained for 1939. This was a year of complications imposed by a summer and fall drought upon heavy populations of muskrats.

In Figure 6.1, the once-designated Main Marsh may be subdivided into Central Marsh and Southeast Marsh, which are adjacent bodies. Central Marsh is the largest and deepest of the whole Cheever Lake series, totaling about 180 acres characteristically covered by thin to moderate stands of hardstem bulrush (Scirpus acutus) and with parts of its numerous bays grown heavily to cattails, wild rice, sedges, reeds, and yellow water lilies. Southeast Marsh, perhaps 15 acres in area, 


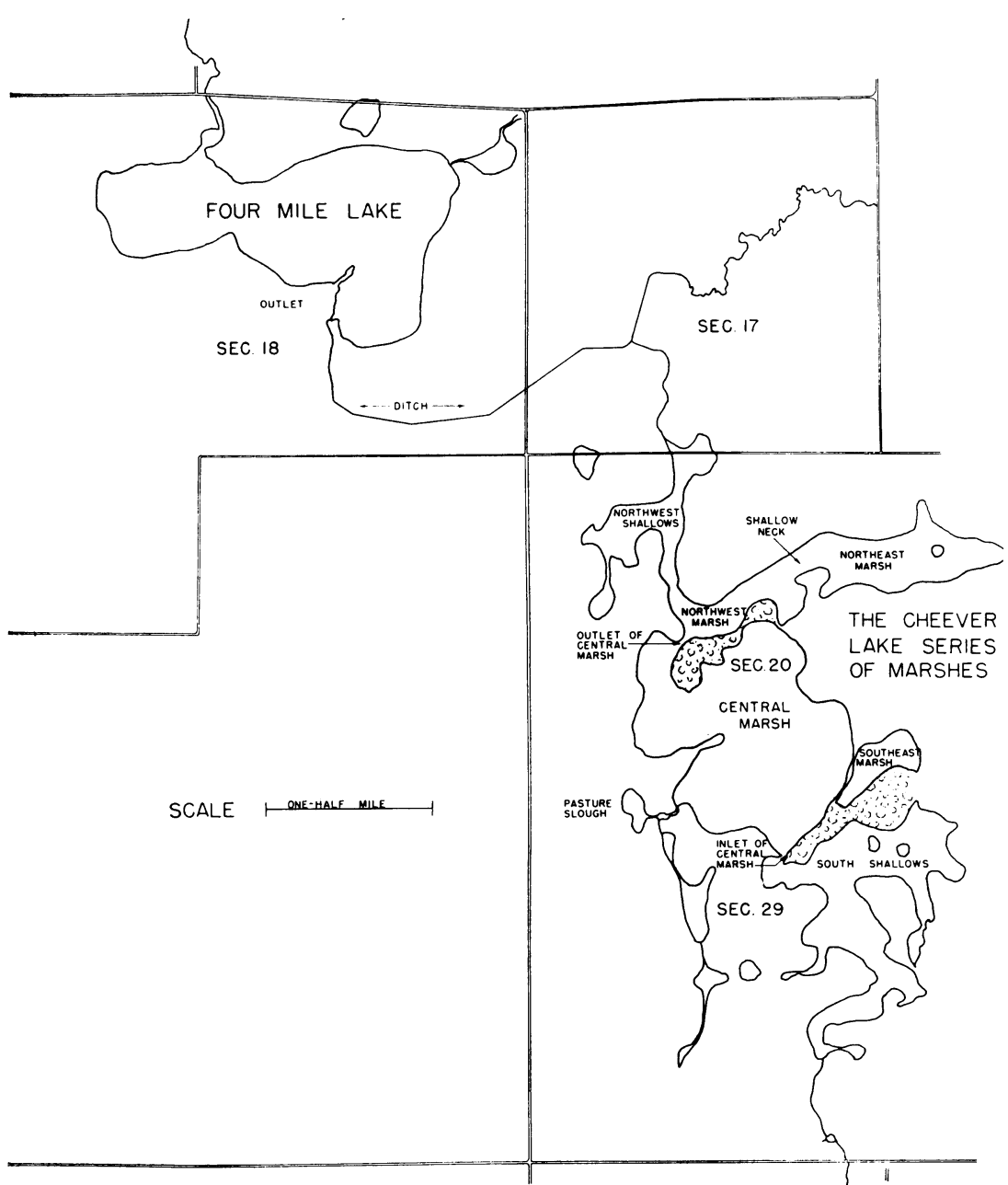

Fig. 6.1. Map of Cheever Lake and Four-Mile Lake and associated wetlands, near Estherville, northwestern lowa.

is shallow, with an irregular open-water center and heavy marginal growths of cattail and burreed; it is separated from Central Marsh by a narrow strip of land, which is in part an ice-ridge. To the south of both Southeast Marsh and Central Marsh, and connected to the latter, is a 67-acre tract, partly in private ownership and partly stateowned; it may be referred to as the South Shallows. West of Central Marsh and separated from it by a few hundreds of yards of cultivated land and pasture is a small pasture slough. Northwest Marsh, of about 29 acres, is connected to the northwest corner of Central Marsh by the outlet channel from the latter; it is mostly quite shallow, lined by cattail, bulrush, sedge, and burreed fringes. Northeast Marsh is separated from a northeast lobe of Northwest Marsh by a neck that 
soon goes dry as the water level recedes; it is about 44 acres in area, long and narrow in shape, and with burreed, cattail, and other marshy emergents surrounding an open-water center. Another marsh, Northwest Shallows, privately owned and 30 acres in area, extends to the west and northwest of the state holdings and is connected during high water with a northwest lobe of Northwest Marsh; it usually has excellent food resources for muskrats in its cattail and bulrush growths but is among the first to go dry in the Cheever Lake series of marshes.

Water levels of the Cheever Lake series varied much from year to year, from complete drought exposure to the maximum permitted by natural drainage in wet seasons. Stands of wild rice bordering Central Marsh varied as water levels changed, and species of Scirpus gained and lost dominance locally over the years. It could be seen that, prior to 1939, stands of river bulrush (Scirpus fluviatilis) grew and declined in the centers of Northwest and Northeast marshes and in shallow water at the north end of Central Marsh.

Most of Cheever Lake was a wildlife refuge in the early years of the study, only the southernmost part being open, in season, to hunting and trapping by the public. In 1942, the entire state-owned area was reclassified as Public Shooting Grounds, and all of this was likewise subject to legal trapping except on temporary fur-refuge units.

Cheever Lake in its aggregate of marshes has long been known as a muskrat marsh. It had sufficiently heavy populations in 1935 to incite agitation for opening the refuge to trapping and to cause the State Conservation Commission to suggest that investigations of the muskrats be conducted there. The muskrats did not actually build up without suffering human exploitation, for the refuge - situated in a four-section block of land, away from roads - was much violated by spearers, if not trappers, operating at night. At any rate, it had a great many muskrats for years.

Four-Mile Lake, 219 acres of state-owned Public Shooting Ground situated about a mile and a half northwest of the Cheever Lake series, was kept under limited observation as a check area. Occasional visits also were made to the High Lake and Mud Lake chain of waters east of Wallingford and to some in the vicinity of Spirit Lake, as well as to other wetlands within a radius of about 20 miles of Cheever Lake.

\section{THE INTENSIVE STUDIES OF 1939 IN THE CHEeVER LAKE SERIES OF MARSHES}

Following dispersal from wintering quarters in March and early April, 1939, the young-producing spring population of the Cheever Lake series of marshes was recorded as the equivalent of 332 pairs on 380 acres: 48 pairs on South Shallows, 28 on Southeast Marsh, one on the pasture slough, 16 on Northwest Shallows, 69 on Northeast Marsh, 41 on Northwest Marsh, and 129 on Central Marsh. Data on numbers of locally resident adult females not producing young in 1939 are lacking, but, if we assume that these comprised 5 per cent of the total - a figure not out of line with data obtained elsewhere - we would 
get a total of 347 adult females, or, in round numbers, about 350 . Applying a ratio of 55 per cent males, we would get a total of about 430 of that sex. The total adult population, as of the time of establishment of breeding territories, would then be about 780 .

Carcasses of four adult muskrats dying between late March and late April were found, all in shore zones. One of these could have been a victim of the hemorrhagic disease worked with in later years but not specifically identified as early as 1939. The written description of this specimen now suggests visceral hemorrhages. Two of the other three had the appearance of transients killed by minks, and eight of twenty-one contemporaneous mink scats contained muskrat remains. The local mink population was quite low: a female with her family of young and possibly one or two adult males.

The most intensive field work was begun on July 15, by which time the water levels were low. The shallower parts showed much territorial adjustment, extension or modification of home ranges, and some outright abandonment or depopulation of given tracts through mink predation upon drought-exposed family groups.

A maximum postbreeding population of about 4,200 adults and young was estimated on the basis of the Cheever Lake data at hand, as of the middle of June. Of 62 litters for which the times of birth were recorded, 3 were born in the first half of April; 9, second half of April; 10, first half of May; 9, second half of May; 22, first half of June; 6 , second half of June; 1, first half of July; and 2, second half of July.

By late fall, truly resident muskrats remained on the partly wet Central Marsh and, to a lesser extent, on the dry Northeast and Northwest marshes. Wanderers at times discovered and lived in abandoned lodges and burrow systems of dry marshes, but these may be ignored in population computations. The 1939 fall summaries arrived at for the three still-occupied marshes were about 1,680 muskrats for Central Marsh and about 53 and 32 for the Northeast and Northwest marshes, respectively, or a grand total of about 1,765.

The main marshy components of the Cheever Lake series are grouped for convenience of treatment.

\section{South Shallows and Southeast Marsh}

Only four acres of the South Shallows remained covered with water on July 23. The wet tract lay south and southeast of the inlet to the south end of Central Marsh and had five functional territories. Farther to the east and south, the marsh bottom had been so long exposed that five former breeding territories were completely depopulated and 20 others were recognizably near abandonment. About half, then, of the original 48 territories of the South Shallows were already lost or seriously impaired. Mortality was noted in five places. The specimens examined were of young of one month to two and a half months of age and dead since before the middle of July.

Late July brought an intensification of the drought crisis here. 
Decided changes in the amount of water in sight were recorded even in the space of days, July 23 to 27 . August rains (including one rain of four and a half inches) reflooded most of the marsh bottom by the end of that month, but the bottom was wholly exposed again before October.

An inspection on September 29 revealed that many wanderers were living in South Shallows from 200 yards to a half mile from the inlet of Central Marsh - most signs being light, superficial, and distributed with little reference to given lodges - most being, in fact, in dense vegetation along shore. A few animals were digging and heaping dry vegetation as if they intended to stay. Nearer the inlet were two wellmaintained lodges and heavy general signs. An estimated 20 muskrats lived here at this time. Evidence was also seen of somewhat more muskrats living out in the adjacent south part of Central Marsh than could logically be accounted for in terms of Central Marsh territories and the young produced there.

At this time, nearly all of the muskrats scattered over the dry South Shallows were adults, as were a number of wanderers congregated along a quarter mile of the south shore of Central Marsh, on both sides of the inlet. A considerable proportion of the young from several South Shallows territories near the inlet evidently succeeded in establishing themselves between late July and the middle of September in the deeper waters of Central Marsh lying a convenient distance to the north; and these seemed to be about all of the muskrats of the South Shallows escaping the lethal consequences of the drought.

By the last of October, the signs of both wanderers and residents were much reduced in South Shallows, and there were fewer wanderers trying to live along the south shore of Central Marsh. A passageway through the dry inlet continued to be well-beaten, however. The single dead animal examined was of an adult male, bitten under a kidney by another muskrat. Seven of 11 contemporaneous mink scats contained muskrat remains. By November 18, practically all of the living muskrats of South Shallows were localized and "dug in" about 200 yards southeast of the inlet. Scattered wanderers remained alive until the cold weather of January, 1940, or later. Spring thaws exposed muskrat nests and tunnels in roadside snowdrifts nearly a mile to the south.

The pasture slough with the lone territory (which lay northwest of South Shallows and west of the southwest corner of Central Marsh) dried up early in the summer, but it had living young as late as early July. It was in the last stages of abandonment on July 23 - though abandonment may have been due as much to trampling of lodges by livestock as to the drought exposure, itself.

The situation at Southeast Marsh was rather like that of South Shallows, except that the drought crisis came later in the summer. All of the 28 original territories of Southeast Marsh were functional in mid-July, though many were by then partly drought-exposed. This resulted in considerable local readjustment and some known mortal- 
ity. A newly-weaned young muskrat found on shore was a mink victim, and a single mink scat contained muskrat remains. By late July, evidence could be seen of a substantial drift of both adults and young from the west side of Southeast Marsh for distances up to 300 yards into the adjacent waters of Central Marsh. By late August, the movement became quite pronounced, and, by the first of November, scarcely any muskrats were left as residents along the west side of Southeast Marsh.

Studies of the above movements were made in some detail. Eight family groups living in Southeast Marsh along or near the strip of land separating that part from Central Marsh included in their original home ranges the adjacent stretch of Central Marsh. This left them in a position to move considerable distances into Central Marsh without trespassing. Apart from this transfer of family groups, numerous young from 13 other Southeast Marsh territories lying within about 200 yards of Central Marsh moved into the latter from late July to early September - mostly in late July as the water receded.

Some adults of the 200-yard zone lying nearest to Central Marsh did not extend their home ranges into the latter. These animals, plus animals of all ages living in Southeast Marsh outside of the 200-yard zone next to Central Marsh, were living by late August and September much where they had been in early and midsummer, except that they mostly abandoned the lodges in favor of trails, nests, and burrows in the dense vegetation fringing the banks.

A strife-torn live adult was seen hiding in the vegetation between Southeast and Central marshes on July 29. A probable mink victim of about five weeks of age was found August 28, and five of six fresh and recent mink scats contained muskrat remains. Despite their patent vulnerability, many of the Southeast Marsh muskrats maintained themselves in their original home ranges and territories for weeks after the disappearance of the surface water. As late as September 29, the numbers still alive farther than 200 yards from Central Marsh were judged from signs to be but slightly fewer than the numbers surviving August there.

The further decline of Southeast Marsh muskrats occurring in October represented little successful re-establishment elsewhere. There were in November passage trails across the marsh to the shore of Central Marsh and typical evidence of last-stage occupancy in places where muskrat signs had been conspicuous in September. On November 1, an animal was witnessed making a 140-yard journey across the mud bottom of the center of Southeast Marsh. A freshly dead adult male was found lying on its stomach, its back covered with muskratinflicted wounds and muskrat feces. The ultimate depopulation of Southeast Marsh took place, as in the South Shallows, with winterkilling or departure of the last wretched wanderers.

\section{Northwest Shallows, Northeast Marsh, and Northwest Marsh}

The heaviest drought losses by midsummer on the Cheever Lake series occurred in Northwest Shallows, dry since late May. A note of 
July 16 describes the massing of most of the living animals (nearly all adults or of adult sizes, the remnant population of 16 original territories) in perhaps five acres of dense burreed and bulrush at the extreme west edge of the marsh. The animals were living in a food-rich place crisscrossed by trails; they improvised nests for shelter where convenient; and they were largely independent of the lodges formerly used. In the center of Northwest Shallows, a single territory continued to be maintained, and four lodges near by (one having a dead adult outside) showed limited use. The whole east half of Northwest Shallows, or that nearest a dry channel leading to one lobe of Northwest Marsh, was muskrat-vacant. The channel itself had only old signs, as if many animals had moved out weeks earlier. On July 23, a six-weeks young, which could have come from the Northwest Shallows as logically as from anywhere, was seen flattened at a road intersection about a quarter of a mile to the northwest.

By the last of August, massing in the west half of Northwest Shallows was no longer apparent, but muskrats did live in certain old lodges and in some lodges newly constructed on the dry marsh bed. The signs suggested transients more than persistent residents, as individuals stayed about a given lodge for but a few days at a time. By the last of September, what were probably the true remnants of the Northwest Shallows population were hundreds of yards to the south, massed at the edge of the then dry lobe of Northwest Marsh, nearest the channel constituting the natural passageway between the two marshes. The signs of these massed animals were restricted (as earlier they had been in the west half of Northwest Shallows) to dense vegetation furnishing cover as well as food.

In Northwest Shallows, an old male was found dead on September 29. The signs indicated that it was a transient that got into trouble with the single other muskrat present. From November to midwinter, the muskrats of which signs could be seen on occasion were evidently wanderers. Before spring, Northwest Shallows ceased to be the habitat of living muskrats.

Northeast Marsh originally had 69 territories in 1939. It became, in effect, partly isolated sociologically as the drought crisis progressed. Territories of the elongated marsh tended to be distributed near shore, side by side, in a way permitting extensions toward the deeper center without undue trespassing on property rights of animals occupying the neighboring territories. In contrast, the territories of a shallow bay abutting the junction between Northeast Marsh and Northwest Marsh tended to be circular in form and packed into a dense block of burreeds and bulrushes. No considerable movement on the marsh bottom was here possible without crossing territorial boundaries. The occupants generally stayed where they were, in a sense imprisoned and enduring far more drought exposure without readjustment than did their more freely-moving fellows living to the east. The jammedtogether territories (twenty-one in all and, except for those bordering the open water, localized in no more than five or six acres of vegetation) formed an evident obstacle to either footloose movements or to 
orderly extensions of home ranges from the west end of Northeast Marsh to the adjoining lobe of Northwest Marsh. That the muskrats were crowded is illustrated by my witnessing, on July 28, thirteen muskrats (an adult, a subadult of about three and a half months, six young of about three months, and five young of about seven weeks) leaving a loosely constructed small lodge when it was opened for examination.

The muskrats resident in the crowded junction were not droughtexposed for as long as were those of the shallow east end of Northeast Marsh, and they had access to equally good if not better growths of food plants. Nevertheless, primarily because of their population tensions and fewness of alternatives of action, they were subject to greater crisis at given stages of the drought.

In Northeast Marsh away from the crowded junction, one territory was abandoned without compensating extensions or adjustments, and three others were badly deteriorated, as of July 20-21. In the junction, itself, opportunistic minks cleaned out an exposed territory and heavily raided three neighboring ones. Six victims between six and 10 weeks of age were found in the drought-exposed lodges. An earlyJuly lot of 28 mink scats from the wetter parts of the marsh contained no muskrat remains, compared with representations of this prey in 11 of 46 scats deposited mainly in the drying junction. From the middle of to late July, 20 of 40 scats from or near the junction contained muskrat remains.

What seemed to be massing of Northeast Marsh animals east of the territorial blockage at the junction was observed as early as July 28. The August rains relieved the crisis at the junction temporarily, and, on August 28, the population there looked much as it had a month before. Eight of 17 mink scats for August contained muskrat remains, mostly denoting close scavenging by the minks - large quantities of bone splinters, tail bones, muddy fur, and debris in the scats. The vulnerability of the occupants of the junction did not appear to be as acute as it had been in late July.

By September 28, the junction was again drought-exposed. An adult female was found dead in a sitting position, too putrid to reveal cause of death; it was thought at the time to have been a strife victim. A subadult partly eaten by a mink was found just west of the junction. Eight of fifteen September mink scats contained muskrat remains.

The muskrats were not at this time wholly comfortable in the more favorable parts of Northeast Marsh - an adult male was found dead with muskrat-inflicted wounds - but these parts showed a great deal of evidence of residents "digging in" rather than attempting to move out. Of course, there was some cross-country movement out of here as well as from other drought-exposed places. Farmers living on surrounding land told of encountering muskrats everywhere in the fields. Territory-by-territory estimates totaled 53 resident muskrats for Northeast Marsh, as of September 28. By November 1, the situation was little changed so far as the dug-in residents were concerned, 
except that winter was approaching. One of three fresh and recent mink scats contained remains of a small "kit" muskrat. By November 19, there may have been somewhat fewer muskrats than on November 1 , but surely the losses in the interim had not been heavy.

In early January, 1940, it was seen that poachers were violating the dry Northeast Marsh. They dug out some of the best lodges and left no muskrats alive in about half of the area of the marsh. Two animals found dead were a subadult dying of strife wounds and an adult female killed by a mink. C. C. Lille and L. D. Wright (State Conservation Commission) and I took seventeen muskrats as specimens from still-occupied habitats: four adult males, four adult females, seven young males, and two young females. Four of these specimens had fresh or recent strife wounds, and five others had older healed wounds. The animals ranged in condition from thin to fairly fat, with the majority being lean but in good shape and having fed upon shoots and rootstocks of burreed. The adult females had countable placental scars for the 1939 breeding season. From these, it could be seen that two of the animals had conceived two litters each and that the other two had conceived three litters each.

The evidence suggesed that about a half-dozen muskrats survived the winter of 1939-40 on Northeast Marsh.

The drought chronology of Northwest Marsh was similar to that observed for Northeast Marsh, but Northwest Marsh had decidedly the poorer food supply over most of its area. Hence, its 41 original breeding territories were rather restricted to a fringe of cattail, burreed, bulrush, sedge, iris, cordgrass, and the like. As this border zone became drought-exposed, the muskrats had the alternative of erecting lodges for living quarters in the deeper water of the center (where little food except duckweed was obtainable) or remaining in their drying burrows and lodges closer to the good food. Many muskrats moved into the wetter parts to live but "commuted" to feed near shore.

It happened that the deepest part (and one of the richer from the standpoint of food) of Northwest Marsh lay adjacent to the junction with Northeast Marsh, and a certain converging of local muskrats here further reinforced the barrier to through passage presented by the close-packed territories of the Northeast Marsh on that side of the junction. This converging was a response of muskrats originally living in well-defined territories of the surrounding shore zone. As the population worked toward the central water, territorial boundaries coalesced until they were no longer perceptible, and the center became essentially common range. Even so, the muskrats establishing themselves nearer the center (the equivalents of 16 families) comprised something of a sociological unit, the members of which displayed tolerance toward each other's presence and activities. On the other hand, there was no reason to think that any significant numbers of outsiders were tolerated, except perhaps some young moving in from late July to September.

Massing of former residents of Northwest Shallows in the connec. 
ting lobe of Northwest Marsh also appeared due in part to an abundance of local animals (the equivalents of seven families) in residence in the outer edge of this lobe. This outer edge had a dense cattail growth and, accordingly, some of the most attractive food on the marsh. The outlet from Central Marsh had a still more extensive cattail growth with muskrats (the equivalents of four families) in it, but these muskrats were not especially crowded - although it was true that two of the Central Marsh territories discouraged the passage of strangers through the outlet until Sepember.

When, in late September, the outlet territories lost their identity, movements without effective impediment took place over common trails from the south part of Northwest Marsh to the edge of Central Marsh lying to the south. And when there was a backwash of the transients massed about the outlet of Central Marsh, large numbers congregated in the outlet cattails and in the adjacent cattail growths of Northwest Marsh.

The most conspicuous July and August losses at Northwest Marsh were noted in or near the crowded junction with Northeast Marsh and may be identified with the general crisis there. Two long-exposed lodges were dug out and their occupants collected, July 28: two adult females and four young aged from five to about ten weeks.

Another site of losses was in the shallow cattail-grown part of Northwest Marsh between the outlet from Central Marsh and the channel leading to Northwest Shallows. A mink-killed young less than a month old was found in mid-July and six of seven mink scats contained muskrat remains. The respite afforded by the August rains was such that, by the end of that month, the muskrats were living in the cattails much as they had been a month before - except for the massed transients from the Northwest Shallows. The transients somehow disappeared, probably to engage in cross-country wandering. The less populated sides of the marsh, with their inferior food supply, also had muskrats in late August about as they had in late July.

September brought the real changes. By its end, the animals originally blocking movement through the junction of Northwest Marsh with Northeast Marsh had largely abandoned the junction, though by late August the blockade had looked stronger than ever. Following this partial abandonment, the signs of seemingly footloose individuals appeared in increasing quantities for a time, and this was observed in many places about once-abandoned lodges and burrows for the whole length of Northwest Marsh. The disintegration of so many territorial boundaries and the pouring of massed transients through the junction was traced back to about the middle of September. Contemporaneously, the territories of the outlet either broke down or were bypassed (evidences of both were noted), and the massed muskrats overflowed into and about adjacent Central Marsh, to the accompaniment of clashes with the residents.

During the month of October, the greater proportion of those muskrats invading Central Marsh via its outlet withdrew to the 
heavy cattails of the outlet and the south and southwest edges of Northwest Marsh. Not only were the residents of the invaded part of Central Marsh savagely intolerant, but the yellow waterlily and miscellaneous shore growths of that place were also less attractive than the food supply remaining for muskrats in Northwest Marsh, lack of surface water in Northwest Marsh notwithstanding.

Little that could be called peace existed for the Northwest Marsh muskrats after early September. They were drought-exposed, minkhunted, and strife-torn. Mortality noted for September and October included four adults and three young, of which one young was a mink victim. Four of five mink scats contained muskrat remains. Feeding upon an adult or subadult by another muskrat was revealed by muskrat scats made up of muskrat fur. Two muskrat specimens were collected: a young female in good condition and without wounds and a wandering adult female having abdominal strife wounds infested with maggots.

A population estimate of about 32 was made for Northwest Marsh on September 28, and, except for the backwash of transients from the outlet of Central Marsh, the numbers of animals staying there seemed not to change importantly in November and December. Two specimens collected in January were adult males, one in fair shape and without wounds and the other thin and strife-torn. The backwash of transients disappeared, presumably to wander cross-country and to spread along the shores of Central Marsh.

Later in the winter, all the muskrats of Northwest Marsh either died or left.

\section{Central Marsh}

With its deeper water and a fair food supply and its location in the midst of outlying drought-exposed marshlands, Central Marsh attracted many newcomers during the late summer and fall crises. As previously indicated, however, it was not exactly a haven for the needy, and desperate strangers were greeted by teeth of the residents. Residents died, too, as the drought worsened. Indeed, the numbers of residents dying or leaving far exceeded the numbers of muskrats successfully coming in to establish themselves.

By mid-July, two territories of the original 129 had been depopulated without compensating gain elsewhere, and many others showed deterioration, adjustments, and movements from drying to wetter parts of the same territories or home ranges. Along the southeast shore, a row of territories extended into both Central Marsh and Southeast Marsh from the strip of land separating the two. As was also brought out earlier, movements by the occupants of eight territories took place here without apparent difficulty, from drying Southeast Marsh into wetter Central Marsh; and the latter marsh absorbed most of the young reared in 13 other Southeast Marsh territories. The territories here and along most of the shore zone of Central Marsh were of the elongate type extending from bank burrows out into the marsh, side 
by side; they permitted much more freedom of movement as the shallow parts became drought-exposed than did territories of the circular type that were crowded together.

The Central Marsh circular territories that were close enough together to impede deep water adjustments were chiefly at the northwest corner next to the outlet leading to Northwest Marsh and in a shallow tract a few hundred yards east of the outlet. These not only imposed problems upon those muskrats trying to live in circumscribed home ranges but also discouraged movements of the fall transients massed in or about the outlet.

As exemplifying what might be expected of an elongate territory, there were, in mid-July, dry and abandoned lodges on an exposed mud flat 80 yards from the water's edge, and, 100 yards out in the water, a nest used by the family group. Temporary structures were strung out in between. Trail signs between the abandoned lodges and the new nest reflected the gradual, unimpeded changing of living quarters in response to exposure of the shore zone. Feeding and other activities of adults and young continued to be noted along this trail for some time after the major adjustments were over.

In contrast, two blocked-off territories in the dry outlet had evident family groups that stayed where they were despite long drought exposure, living in barely moist burrows or in nests in the vegetation, digging in the powdery bottoms and fighting the newcomers from Northwest Marsh. These occupants of the dry outlet held recognizable territories until they, in the second half of September, either left as wanderers themselves or were overrun by the animals massing to the north.

In a shallow tract east of the outlet, a stretch of about 600 yards of poor shore-zone habitat crowded with muskrats (27 territories) was separated from superior deep-water habitat (lying 300 to 400 yards out from shore) by 11 strong, well-used territories. Immediately to the east of the crowded stretch there were no blocking territories between shore and deep-water bulrushes, and here the occupants of 4 shore territories patently "commuted" distances of 200 to 300 yards out to the richer feeding grounds.

The maximum summer population of Main Marsh must have been around 3,000 muskrats of all ages. Considering the numbers involved, nothing very exceptional happened to this population until July. It had some of the troubles attendant upon high densities, manifested in part by slackening of breeding in June. A single runty young that looked like a sufferer from the deadly Trichophyton skin disease (see Chapter 5) was observed on July 17. On July 22, while opening a few deep water lodges, I found a young of weaning size dead from unknown cause. Another dead, this one of about five weeks, had a muskrat-slashed face. These samples of data suggest much adjustment mortality taking place unobserved before the beginning of the intensive studies in the middle of July. By then, aggregations of adults and mixed sizes of young could be seen on rush rafts, similar to those 
seen late in or after the breeding seasons during the high-density years at Round Lake.

Of two adult males collected from deep water, July 18-19, one was becoming sexually quiescent. Of three adult females collected, one had not conceived in 1939, one had had its last young early in the summer, and one had had its last young probably about the middle of June.

A shore territory in late stages of abandonment was dug out July 25 and its population remnant collected: an adult male and two young of about seven weeks. A young mink victim was found near shore. Two other dead muskrats were found in dry lodges, including a recognized adult. Remains of a young muskrat were found in a horned owl pellet, though the local horned owl diets were running almost entirely to marsh birds.

Away from the southeast shore and the route of ingress of muskrats from Southeast Marsh, young muskrats were known to drift into Central Marsh during late July, August, and the first half of September, chiefly via the natural inlet and outlet. The young thus attracted to the deeper waters in substantial numbers were essentially the offspring from a total of 35 breeding territories of South Shallows and Northwest Marsh that were situated within 200 yards of Central Marsh.

Late summer movements of young animals about drying territories situated farther than 200 yards from Central Marsh appeared to be more random, with an unmeasured but probably minor ingress into Central Marsh occurring in connection with cross-country wandering.

The August rains had the effect of prolonging the late July status. of the Central Marsh muskrats until about the middle of September. Adjustments within shallow water territories were noted, many young animals (whether locally reared or not) moving toward the central bulrushes, there to sit around on floating nests. In one place, the muskrats that had stationed themselves from between 150 and 200 yards from shore in late July moved several hundreds of yards deeper into the marsh during August. Large-scale remodeling of lodges and bank burrows was also carried on while the benign living conditions of August prevailed.

A local population crisis resulting from the heavy southward invasion of drought-evicted muskrats via the outlet was at its height by late September. On the evening of September 27, around 30 muskrats per acre were counted in the five acres of Central Marsh lying nearest the outlet. This might be judged a top-heavy concentration of adults and subadults anywhere, the more so here because of shortage of good food and because of acute population tensions. The peripheries of the marsh, where residents and invaders most frequently met, were scenes of continuous conflict - sometimes fights could be seen simultaneously in different places.

In this tract, the signs indicated that the resident animals tended 
to avoid the shore which was practically taken over by the invaders for several hundreds of yards on both sides of the outlet. This rather characterized the behavior of residents even when the better food was on shore. Insofar as it was restricted to the stretches of shore dominated by strangers, it may logically be interpreted as the behavior of animals desiring to stay out of trouble.

The unhappiness of the invaders is evinced by their withdrawal in October from the most congested and strife-ridden shore of Central Marsh, back through the outlet into Northwest Marsh. However, many transients still continued living along the shore of the northwest corner of Central Marsh well into November. Four of five specimens collected from this group, November 18-19, were battered adults. In the fall, the corn fields lying northwest of the marsh had conspicuous numbers of wandering muskrats that might be attributed in large part to the backwash from the outlet.

Further indications of the troubles of the mainly shore-dwelling invaders were the following: 12 individuals found dead here from late August to November 19 included at least 6 adults and were mostly victims of intraspecific strife. Two of the 12 died in ways that now suggest the hemorrhagic disease. Two subadults were killed by minks, and 22 of 40 contemporaneously deposited mink scats contained muskrat remains. And much traveling of muskrats on the ice of late fall was noted.

Adults resident on Central Marsh by late fall were the occupants of 112 summer territories that either remained functional throughout the drought or were restored by the adjustments at the southeast part. Of 75 residents taken for specimens in early January, 1940, by Lille, Wright, and myself, 4 were adult males, 5 adult females, 44 young males, and 22 young females. The ratio of 13.2 young per surviving female included immigrant as well as locally-reared young. The statistical adequacy of such a small sample might be questioned, but it probably is fairly representative, judging from our other data on sex and age ratios from northwest Iowa marshes similarly affected by the 1939 drought.

The ratios from the 75 trapped residents applied to 112 territories would give early winter figures of 112 adult females, 90 adult males, and 1,478 young, or a total of 1,680 muskrats entering the winter. This figure was derived without reference to transients and nonbreeding females.

Computations of the number of young immigrating to Central Marsh and successfully establishing themselves may be attempted. Ten July specimens dug out of drought-exposed lodges - just before the late-summer centripetal drifting of young occurred - were an adult male, 2 adult females, and 7 large young, or in the ratio of 3.5 young per adult female. There were 71 dried-up territories $(23$ about Central Marsh itself, 25 in Northwest Marsh, 13 in Northeast Marsh, and 10 in South Shallows) from which the young moved centripetally into the deeper water of Central Marsh without being accompanied by 
the adults. The 3.5:1 ratio used as an indication of the young that were present to move from each of the 71 dry territories (leaving the adults behind to die, or later to wander and then probably to die, anyway) would give a value of about 250 young in this category. The 250 subtracted from the total of 1,478 young calculated to be fall residents would leave about 1,230 young reared in the 112 successful territories of Central Marsh.

Returns, for effort expended, of the specimen trapping in January, 1940, were sufficiently poor to show that the Central Marsh population had been greatly reduced by illegal spearing known to have been carried on prior to our trapping; and it may be doubted that more than 100 animals wintered. Living conditions for these were only fair over most of the marsh, for the water levels seldom exceeded a foot and a half at freeze-up - though few signs were seen of any except evident transients being forced to come out on the ice. Most of the truly resident animals had access to bulrush rootstocks under the ice and to bullheads massed in the channels of the lodges. Twenty-seven of 66 examined stomachs of January-trapped specimens contained fish remains, in addition to bulrush material (Errington, 194la). The Central Marsh specimens were in good flesh, but the high incidence of animal matter in their diet suggests that they were not finding easy feeding, and, in sexual development, they were about a month behind the specimens from the more food-rich Round Lake.

\section{SUPPLEMENTARY OBSERVATIONS IN THE ESTHERVILLE AREA DURING THE 1939 DROUGHT}

Four-Mile Lake had a thick border of cattails and bulrushes and a 1939 breeding density the equivalent of about a pair per 50 yards of shore zone. With no territories near the open water center, this figures out as about 100 territories for the marsh. By November, conditions looked bad because of low water, and wanderers could be seen sitting or running on the ice, but nearly all of the original territories were still occupied. The data suggest an average productivity of about 5 young per original territory, with some 200 adults remaining alive up to freeze-up and later. The total fall population of about 700 was sharply reduced by winter-kill and poaching - the legal trapping season having been kept closed to protect the drought-handicapped muskrats.

The plight of late fall and early winter wanderers was particularly illustrated by data obtained east of Wallingford, from the open water Mud Lake and High Lake. The shores of these lakes were gathering grounds for luckless adult muskrats leaving their dry territories too late in the season for successful re-establishment of living quarters elsewhere. Dr. Jessop B. Low, then of Iowa State College, noted similar behavior on the part of muskrats about open water Lost Island Lake and Trumbull Lake, near Ruthven. On the whole, such muskrats were thin and battered, living in improvised nests on shore or in holes in the ground. As cold weather came on, they died in con- 
spicuous numbers from strife wounds, mink and canid predation, hunger, and exposure. Traffic victims were commonly to be seen on the main highways of the counties having many lakes and marshes.

About Mud Lake and High Lake east of Wallingford, the shoredwelling transients were as opportunistic and indiscriminate in their feeding as one might have expected for desperate animals (Errington, 1941a). They preyed upon sluggish bullheads and Bell's painted turtles in the shallow waters over the beaches and ate away the flesh from exposed parts of the fish and turtles frozen in the ice. Frogs and clams were also utilized as available, but the most available food consisted of population-stunted bullheads, present about the lake margins in thousands, alive and dead, and fed upon accordingly by whatever hungry creatures, muskrats included, could take advantage of them.

As concerns the hungry transient muskrats of the shores, any advantages that they found there must be judged to have been oniy ephemeral, for they suffered near-annihilative mortality before the weather became really cold.

\section{THE EMERGENCY YEAR OF 1940 IN THE ESTHERVILLE AREA}

A survey, May 1-2, 1940, of the Cheever Lake series showed 50 well-used sets of burrows and maintained lodges that could be classed as breeding territories. All were on Central Marsh, no sign of regular use being apparent on the dry or nearly dry South and Northwest Shallows, nor on the Northeast, Northwest, and Southeast marshes. Eight dead muskrats, representing winter and spring mortality, were found: four (including a winter wanderer with a frozen tail) that had been partly eaten by minks, a male and a female dead possibly from disease, and two specimens that were too putrid to suggest cause of death. Eight of 32 mink scats contained muskrat remains.

On July 17-18, there were 34 plainly recognizable territories on Central Marsh and three in Northeast Marsh. Three others in Southeast Marsh showed signs of abandonment after having been established in late spring and early summer. At this time the marshes were drier than they ever had been in 1939, and the remnants of surface water of Central Marsh continued to shrink, to disappear completely in October.

The occupants of the three Northeast Marsh territories got along comparatively well in a dry but food-rich habitat. By October 22, after about four months of drought-exposure, signs of what could be identified as the corresponding three family groups were still distinguishable, localized as they were in widely separated places. This entire population was trapped for examination in November by Morris Hardman of the State Conservation Commission: three adult males, three adult females, five young males, and four young females. The adult females had an average of two early-season sets of 1940 placental scars averaging six scars to a set. In view of the relative isolation of these territories and the lack of passage signs leading to or away from them, the Northeast Marsh population was considered 
to have been self-contained. Successful rearing of a fourth of the young conceived, or an average of three per adult female or breeding territory, may be indicative of what to expect in the north-central region when excellence of food resources may partly offset the disadvantages of an all but waterless habitat. A single July mink scat found in Northeast Marsh contained remains of a large, young muskrat. No other mortality was noted here, and the fifteen trapped specimens were in good flesh and without strife wounds.

The wetter though ecologically unfavorable Central Marsh was the scene of mounting crisis for the muskrats from midsummer to winter. Maximum postbreeding densities, as of late July, were estimated at about 400 adults and young. The local mink population was a female with her young, plus a very few adult males.

There probably was considerable loss from the hemorrhagic disease on Central Marsh, and late summer and early fall carcasses of three adults and two subadults may, without certainty, be thus assigned. A drought-exposed muskrat family suffered severely from the minks in early July, which accounted for most of the seven muskrat representations in 128 mink scats from July. No muskrat remains were found in 114 August scats, though the water level gradually went down throughout the month. Up to September, the general muskrat population responded safely to the drought by moving centripetally toward the wetter parts of the marsh. In September, several badly-situated family groups were severely preyed upon by the minks, but only two of a sample of 43 contemporaneous mink scats contained muskrat remains.

By October 21, approximately 40 used lodges on Central Marsh were concentrated in a wet area of less than six acres. This concentration appeared to follow an orderly adjustment within old territorial boundaries. Successive stages in the centripetal movement of family groups could readily be traced through lodges and nests built farther and farther out, over total distances up to a quarter mile in some cases. At the last stage of occupancy, the used lodges were in the apexes of territories shaped like long equilateral triangles extending back to the dry shore zone and its old lodges and burrows. The surface water disappeared on October 22, and the muskrats abandoned the marsh. Mass movements were also noted at about this time from marshes of similar status in the vicinities of Spirit Lake and Wallingford.

Just before the muskrats abandoned Central Marsh in October, drought-exposed and concentrated groups suffered very heavy mink predation. Of 98 mink scats examined in October, 23 contained muskrat remains. Heavy rains during the last few days of the month brought the water up to about the level of late summer, and living conditions for muskrats looked greatly improved, but, except for fewer than a dozen evident transients, freeze-up found no muskrats remaining on the marsh. None of $18 \mathrm{mink}$ scats for November contained muskrat remains, but three possible mink victims among the land- 
active transients were recorded. Four more transients were taken for specimens: an adult male, two adult females, and one young male. The adult females (origin unknown) had two 1940 sets of placental scars each, averaging 8.5 scars per set. An occasional transient continued circulating about the marsh and adjacent fields until early winter. By January, the depopulation of the entire Cheever Lake series of its muskrats was complete.

Neighboring Four-Mile Lake had in 1940 about 30 breeding territories, of which seven were abandoned by mid-July. The drought affected the Four-Mile muskrats less severely than those of the wetter Central Marsh of Cheever Lake. About 12 of the original territories at Four-Mile Lake were still functional on October 23 when the drought reached its greatest intensity. The fall population was calculated at about 60 animals or slightly less than the number of adults present in the spring. So far as I could determine, the marsh was minkless all summer and fall. By December, the rushes in most parts occupied by muskrats were well drifted over with snow, thus giving the animals substantial protection from cold.

Wogen obtained for examination a series of 12 specimens taken by trappers in November from Mud Lake and High Lake, east of Wallingford, where conditions were rather typical of drying northwest Iowa lakes and marshes. All except one of these specimens were thin animals, mostly shore-dwelling transients. Six of the 12 were adults, of which 2 were females. One of the adult females had 11 placental scars in two sets dating back to early in the 1940 breeding season; the second had 23 placental scars in three 1940 sets.

\section{THE EARLY YEARS OF POPULATION RECOVERY OF MUSKRATS IN THE ESTHERVILLE AREA, 1941 AND 1942}

The 1941 breeding population at Cheever Lake was of immigrant animals, exclusively, insofar as no muskrats survived the preceding winter on that series of marshes. It amounted to the equivalent of seven pairs, all localized in Central Marsh. The marsh levels were well restored by winter precipitation and remained in good condition for muskrats until midsummer, a dry spring notwithstanding.

Following another long period of more or less dry weather, a heavy rain in mid-September brought up the water to cover about two-thirds of Central Marsh. The other Cheever Lake marshes still had bottoms exposed except for puddles. The near exposure of Central Marsh in late summer did not appear to result in any particular complications for the low population of muskrats resident. By late November, some mortality was apparent. A subadult victim of a mink was seen. An adult male, in poor condition and likely a transient, was probably a mink victim, also. Four of 19 fall and early winter mink scats contained muskrat remains.

The evidence (chiefly from the 1942 spring census) indicates that about 65 muskrats wintered at Cheever Lake, 1941-42, and that the 1941 fall population may have been about 70 . 
Four-Mile Lake was less affected by dry weather than Cheever Lake, and its combination of food and water was favorable for muskrats throughout most of 1941 . The breeding population was the equivalent of 19 pairs, or about 45 individuals. Trappers took during the open season a known total of about 140 muskrats, of which the carcasses of 81 were examined: 5 adult males, 9 adult females, 40 young males, and 27 young females. The 9 females included one that had not conceived young in 1941, 3 that had a single litter each, 3 that had two litters each, and 2 that had three litters each. From the available sex and age ratios and the reported trappers' catches, the fall population for Four-Mile Lake may be calculated as about 160, of which most of those surviving the trapping also survived the winter of $1941-42$.

Wogen (letter, March 14, 1942) reported that all of the muskrat lodges on Cheever Lake and approximately half of those on FourMile Lake showed unrepaired mink borings. This did not appear to have any particularly lethal significance to the muskrats, for the survival of the wintering muskrats was very good. At Cheever Lake, the strongest possibility is that the muskrats simply abandoned their lodges and retired to bank burrows- which, in view of the location of their lodges (mostly within 150 yards from shore, and usually much closer), they could easily have done.

In 1942, heavy spring and early summer rains brought the water of the Estherville marshes up to high levels. At the same time, Cheever and Four-Mile lakes had their most attractive stands of vegetation which at Cheever Lake meant chiefly more and thicker bulrushes in the shallow north parts of Central Marsh. On the other hand, High and Mud lakes and associated waters east of Wallingford showed deterioration from the point of view of the muskrats.

On Cheever Lake, a 1942 breeding population the equivalent of about 35 pairs (about 75 adults) lived mainly in Central Marsh and in lodges built the previous fall fairly well out in the water. The few bank territories also were in places that showed use late in 1941. A total of 491 muskrats was reported trapped by the public in the late fall of 1942, of which the carcasses of 191 were collected and sent to me by Wogen. This sample consisted of 12 adult males, 11 adult females, 93 young males, and 75 young females. A fall density of about 660 may be calculated, assuming that adult losses had been immaterial (as they seemed to have been) during the breeding season and that no great amount of movement took place into or away from the marshes. Farmers noticed muskrats appearing in September in Northeast Marsh, but this is regarded as merely an adjustment within the Cheever Lake series.

Of the 11 Cheever Lake adult females examined for placental scars, one had not conceived in 1942; 2 had conceived single litters each; 3, two litters each; 3, three litters each; and 2, four litters each. The seasonal chronology of the above 25 sets of placental scars: 10 in spring and early summer, 10 in midsummer, and 5 in late summer. 
The 1942 data on breeding densities at Four-Mile Lake are too inferior to permit satisfactory expression numerically. From the sparseness of signs (of only three territories) seen during an inspection of a half-mile of the best shore zone on June 12, and the wintering figure of about 20 previously calculated, an estimate surely not much in excess of the equivalent of 10 pairs may be made. But the trapping catch for late fall, 1942, was reported to Wogen as 429! A sample of 93 carcasses was sent to me for examination: 6 adult males, 7 adult females, 45 young males, and 34 young females.

Unlike the appraised situation at Cheever Lake in 1942, a heavy late summer and fall movement of mixed-age animals is believed to have taken place into Four-Mile Lake, via its outlet, from a drainage ditch near by, to bring the pre-trapping population up to between 700 and 800 , probably nearer the former. Whether they were born and reared on the marsh or not, the 80 specimens of young included 9 or 11.3 per cent "kits" or probable August young. And, whatever its origin, the sample of 7 adult females included 2 that had conceived a single 1942 litter each; 2, three litters each; and 3, four litters each. Of the 20 sets of placental scars, nine were assigned to spring and early summer; six, to midsummer; and five, to late summer.

Similarities in the 1942 data from Cheever and Four-Mile lakes may lead one to ask whether there may not have been substantial though undetected ingress into Cheever Lake in late summer and fall, as well as that indicated for Four-Mile Lake. Probably there was undetected movement into Cheever Lake from its environs. However, Cheever Lake was more out of the usual routes of travel of muskrats leaving the ditches. Then, again, the spring densities, as recorded, were not nearly so much out of line with the trapping season catches at Cheever Lake as at Four-Mile Lake.

\section{THE HIGH-DENSITY YEAR OF 1943}

The spring of 1943 was one of exceptionally high breeding densities, not only in the good habitats of Cheever and Four-Mile lakes, but also in the food-poor waters of the High Lake-Mud Lake series where the animals were practically restricted to the banks. In the latter series, samples of lake shores looked over in May had functional territories distributed at about 100 -yard intervals.

The Cheever Lake breeding densities recorded for the spring of 1943 were only about half those of the first high-density year studied, 1939 , and amounted to a total equivalent of 180 pairs. These were distributed as follows: 27 on South Shallows, 7 on Southeast Marsh, 15 on Northeast Marsh, 23 on Northwest Marsh, 8 on Northwest Shallows, and 100 on Central Marsh. This, on the basis of 55 per cent males shown by the 1942-43 trapped specimens, would give a total of about 400 adult muskrats. The population appeared to be secure, for, in walking the shores in late May, I found no remains of spring transients, and none of 13 fresh and recent scats from a large mink coniained muskrat remains. 
Plans for an experimental fur-refuge system were worked out with Wogen, and three areas were designated as those to be closed to trapping in the fall. One was about fifteen acres in area in the Northeast Marsh, selected as having the best combination of water and food for wintering muskrats. Another of approximately the same size was set up in the deeper part of Central Marsh. The third, of about twelve acres, included the south part of Central Marsh and the north, or deepest, part of the South Shallows.

The 533 trapped carcasses that Wogen sent me from Cheever Lake in November, 1943, consisted of 32 adult males, 34 adult females, 292 young males, and 175 young females. Wogen and I thought that the summer losses of settled adult females had been negligible; hence, the age and sex ratios of fall are applied without correction to the figure of 180 territories obtained for the spring. This, prorated, would give 180 adult females, 169 adult males, and about 2,414 young of the year, or a total of about 2,763 for the November pre-trapping population.

The reported catch was 2,352, and Wogen (letter, February 5, 1944) did not believe that a night of poaching on one of the refuge tracts could have resulted in the illegal taking of more than 25 to 30 muskrats. The number surviving the trapping at Cheever Lake appeared to be in the vicinity of 400 .

The uterus was lost from one of the adult female specimens. Of the other 33, 3 had not conceived during the 1943 breeding season; 3 had conceived a single litter each; 11, two litters each; 12, three litters each; and 4, four litters each. The seasonal chronology of 77 sets of placental scars: 39 for spring and early summer, 30 for midsummer, and 8 for late summer. Thirty-one "kits" (August-born or later) were listed among the 467 young of the year, or 6.6 per cent of the total, compared with 4 or 5.2 per cent of the placental sets assigned to August.

Four-Mile Lake had in 1943 a breeding population the equivalent of 165 pairs, or (using the 55.4 per cent of males found for the 1942-43 carcasses) a total of about 370 adults. As at Cheever Lake, summer conditions were favorable at Four-Mile Lake, and no mortality was recorded. A fur-refuge of about 70 acres was set up at FourMile Lake and enclosed a sizable part of the best wintering habitat.

Thirty-four young in five litters were tagged on Four-Mile Lake in 1943 (Errington, 1944). Seven were recovered during the trapping, including six members of a litter taken as subadults living close together 100 to 150 yards from where they had been tagged.

Wogen accounted for a minimum of 1,815 muskrats taken in the 1943-44 trapping at Four-Mile Lake and sent me 308 carcasses: 22 each of adult males and adult females, 164 young males, and 100 young females. These ratios used without corrections for the 165 territories recorded during the breeding census would give an early November figure of 330 adults and 1,980 young of the year, or a calculated total of 2,310. A population of between 400 and 450 surviving the trapping 
should be as much in keeping with the evidence as any computed figure.

Four of the 22 adult females examined from the Four-Mile Lake catch had not conceived during 1943; 5 had conceived one litter each; one, two litters; 6 , three litters each; and 6 , four litters each. The 49 litters were chronologically distributed as 15 for spring and early summer, 28 for midsummer, and 6 for late summer. The 6 for late summer were assigned to August, and the 12.2 per cent of the total that they represent may be compared with 24 or 9.1 per cent "kits" or August young in the sample of young of the year.

Environmental conditions for muskrats at Four-Mile Lake were substantially improved in 1943 through moderate flooding of heavily vegetated shallows. At Cheever Lake, there was similar improvement, but the proportion of the marsh thus affected was decidedly less than at Four-Mile Lake. To a considerable extent, the rise in water level at Four-Mile Lake actually created a new habitat, at the same time leaving unimpaired, if not improved, the habitat previously occupied up to (or near) capacity by the muskrats.

\section{THE BEGINNING OF A POPULATION DECLINE, 1944}

Continuing high water was accompanied by some changes in the Estherville marshes. Twelve-Mile Lake, a formerly densely-grown marsh lying south of Cheever Lake, lost its emergent vegetation almost completely. Cheever Lake was less affected than Four-Mile Lake, the latter of which showed considerable thinning of emergents and, especially, loss of cattails. Four-Mile Lake, however, remained in good condition for muskrats until the failure of a dam in the summer brought about the equivalent of a drought emergency.

The 1943-44 fur-refuge experiments at Cheever and Four-Mile lakes were instrumental in protecting and wintering a reasonably satisfactory stock of muskrats. The two small refuge tracts at Central Marsh appeared to function somewhat better than the one at Northeast Marsh because their location and the bank-dwelling habits of many of their muskrats decreased the likelihood of excessive exploitation by legal trapping at their boundaries. The larger refuge at FourMile Lake had a long trapped boundary on one side, but the animals living in its east half were secure from the trapping. So far as our knowledge goes, the survivors of the trapping season on the refuge tracts wintered with slight loss. On the other hand, the 1943-44 trapping was almost annihilative on those parts of both marshes open to legal exploitation.

By mid-June, 1944, the equivalent of 272 breeding pairs could be distinguished at Cheever Lake: 70 on South Shallows, 21 on Southeast Marsh, 55 on Northeast Marsh, 32 on Northwest Marsh, and 94 on Central Marsh. Because of the attractive 1944 condition of Northeast Marsh and South Shallows, and the unlikeliness of many muskrats surviving in them the winter before, it is believed that these marshes drew considerable numbers of muskrats from outside the 
Cheever Lake series during the spring dispersal. Such newcomers presumably came from the well-populated east end of Four-Mile Lake as well as from local creeks and ditches. Using the 1943-44 sex ratio of 60.8 per cent males, the spring breeding population may be calculated at about 700 adults.

Four-Mile Lake had a "settled" breeding population in 1944 of the equivalent of 142 pairs, or possibly about 100 animals fewer than the number judged to have wintered. The sex ratio of 60.4 per cent males in the Four-Mile Lake catch for 1943-44 applied to 142 territories would give a breeding season figure of about 360 adults.

Mortality during the summer and early fall months was conspicuous at Four-Mile Lake even before the partial drying of the marsh. At Cheever Lake, losses through intraspecific attack and unknown causes were noticeable by June, but the marshes there did not appreciably deteriorate until fall. According to Wogen, much lateseason shifting - attributable to local food shortages - took place. Animals massed in the then-attractive Northwest Shallows and in a string of rich sloughs extending several hundreds of yards northward.

Wogen sent me November-trapped samples of 190 carcasses from Cheever Lake and 225 from Four-Mile Lake. The Cheever Lake carcasses consisted of 11 adult males, 16 adult females, 89 young males, and 74 young females; those for Four-Mile Lake, of 23 adult males, 18 adult females, 103 young males, and 82 young females. No adult females in either collection passed through the 1944 breeding season without conceiving. Of those for Cheever Lake, 7 conceived two litters each; 5 , three litters each; and 4, four litters each. For Four-Mile Lake, 6 conceived two litters each; 8, three litters each; and 4, four litters each. The 45 Cheever Lake sets of scars were dated: 20 for spring and early summer, 22 for midsummer, and 3 for late summer. The 52 sets of scars from Four-Mile Lake: 16 for spring and early summer, 31 for midsummer, and 5 for late summer.

No information on the total 1944-45 trappers' catches from these marshes is at hand, and any estimates as to fall populations must be prorated from spring densities and the specimen data. This might not be so difficult for Cheever Lake, where the chief adverse factor seemed to be the mounting population density. Allowance for a likely spring to fall reduction of about 10 per cent of the adult females should leave about 245 of the spring-resident females still present by November. Using the sex and age ratios of the carcasses, a fall population of about 413 adults and 1,871 young, or a round-number total of about 2,300, can then be calculated.

From the distribution of the 1944 breeding territories at Four-Mile Lake, I would judge that at least 44 were hazardously situated with respect to the crisis following loss of most of the surface water. It is probable that the spring to fall losses of adult females cut the original 142 down to about 90 and that the sample of young included the increase from both functional and lost territories. The November 
population would then figure out at 205 adults and 920 young, or a total of 1,125 .

The fur-refuge tracts at Cheever Lake afforded muskrats better wintering in 1944-45 than did the nearly dry refuge at Four-Mile Lake, but the Cheever Lake refuges were still much less efficacious than they had been in 1943-44. The refuge of Northeast Marsh, which qualitatively was in excellent condition for muskrats in 1944-45, proved too small for the most advantageous results. At Central Marsh, the bulrushes and other emergents deteriorated in apparent consequence of high water.

\section{THE ACCELERATION OF A POPULATION DECLINE, 1945}

By late May, 1945, it could be seen that the formerly outstanding muskrat marshlands of the Cheever Lake series were deteriorating to the extent of becoming rather open water lakes and sloughs. Privately owned, low-lying pastures, which normally were too dry to afford livable muskrat habitat, now became lush marshes in their turn. The status of Northwest Shallows changed in practically a single growing season from a muskrat-vacant tract of lowland to the most populous muskrat marsh in the neighborhood.

This ecological drama, with its local variations, occurred not only in the glaciated lake areas of central and northwest Iowa but also throughout the eastern Dakotas and western Minnesota northward far into south central Canada. In the Estherville area, only Four-Mile Lake, among those inspected annually, escaped the major changes introduced by the wet years, and it was subject to changes of the opposite sort after its dam failed in 1944. As of late May, 1945, it had water over most but not all of its bottom.

The 1945 breeding density at Cheever Lake totaled the equivalent of 67 pairs: 8 on South Shallows, 6 on Southeast Marsh, 17 on Northeast Marsh, 4 on Northwest Marsh, 13 on Northwest Shallows, and 19 on Central Marsh. Application of the ratio of 52.6 per cent males shown by the 1944-45 catches would give a total adult population of about 140. At Four-Mile Lake, the equivalent of 44 pairs was recorded, which, with the 1944-45 ratio of 55.6 per cent males, would figure out at about 100 adults.

Following the environmental extremes imposed by high water in the Estherville area, the summer and fall of 1945 brought a severe drought. Wogen informed me that all except Central Marsh at Cheever Lake went dry. He was unable to obtain specimens from Four-Mile Lake, which was so muddy at the opening of the trapping season on November 10 that the trappers quit.

Of 228 trapped carcasses from Cheever Lake (mostly from Central Marsh, where the drought-concentrated population was exploited), 13 were adult males, 13 adult females, 112 young males, and 90 young females. The ratio of 15.5 young per adult female certainly reflects centripetal movements of young more than it does the mean productivity of breeding females at Central Marsh. It may be judged, from the spring location of the territories, that those of Northeast 
Marsh, Northwest Marsh, and Northwest Shallows probably lost most of their adults during the drought crisis. This would leave 33 or approximately half of the initial spring population of Cheever Lake females alive and present in the fall of 1945 . Actually, it may be expected that a few of the adult females of the drought-exposed territories did get over to Central Marsh to stay there and also that a few of those resident at or near Central Marsh did die or leave. The sex and age ratios of the trapped carcasses prorated from 33 adult females would give 66 adults and 512 young of the year, or a total of about 580 muskrats for the fall population.

Of the 13 adult females, one did not conceive in 1945; 2 conceived a single litter each; 2, two litters each; 5 , three litters each; and 3, four litters each. The chronology of the scars (nineteen sets assigned to early summer, twelve sets to midsummer, and only two sets to late summer) parallels the tightening of the drought emergency.

No satisfactory basis exists for assigning a numerical value to the 1945 fall population at Four-Mile Lake. In view of the drought exposure and the fact that people intending to trap became discouraged even before starting, there could hardly have been more than 100 muskrats remaining by November. The survival for the winter of 1945-46 must have been negligible, in contrast with which fair numbers got through the winter on a fur refuge of about 30 acres established in the east part of Central Marsh at Cheever Lake.

\section{THE LOW-DENSITY YEARS, 1946-49}

High water conditions again prevailed in the marshes of the Estherville area by the spring of 1946. Estimates of breeding territories or the equivalent of pairs for Cheever Lake totaled 38 as of early June: 2 on South Shallows, 3 on Southeast Marsh, 8 on Northeast Marsh, 3 on Northwest Marsh, and 22 on Central Marsh. The 1945-46 ratio of 54.8 per cent males would give a total of about 85 adults. At this time, I could find evidence of only two functional breeding territories on Four-Mile Lake, but some others were probably overlooked. Nevertheless, the density surely was very low - perhaps the equivalent of a half-dozen pairs or about 15 adults.

Cheever and Four-Mile lakes were closed to trapping in the fall of 1946, so no trap carcasses were available for examination. Conservation Officer Ralph Lemke told me that there were about 60 lodges of medium to large sizes on Cheever Lake during the fall and winter of 1946-47. At 5 muskrats per lodge, the total fall population of Cheever Lake may be estimated at about 300. For Four-Mile Lake, I would estimate the fall population at between 40 and 50 .

By early summer, 1947, the Cheever Lake population was still more reduced. My estimate was the equivalent of 10 pairs, or perhaps 25 adults. At Four-Mile Lake, the population seemed higher: the equivalent of about 15 pairs, or perhaps 40 adults.

The trapping season on muskrats was closed for the fall and winter of 1947-48 over nearly all of Iowa. At Cheever Lake, the water was low in the fall, with only about two and a half feet remaining in the 
deepest parts of Central Marsh. Lemke made an estimate of some hundreds of lodges and feed houses on the wet marsh, and a farmer living nearby counted about 100 large-sized lodges there. As nearly as I could find out, almost no muskrats wintered on dry Four-Mile Lake in 1947-48, nor anywhere in the neighborhood of Cheever Lake except on Central Marsh itself.

Northwest Iowa marshes had unusually few signs of muskrats in late May, 1948, even compared with the preceding two years. At Cheever Lake, a check of breeding territories of two-thirds of Central Marsh on May 28, 1948, gave the equivalent of 16 pairs. Prorated, this would give 24 pairs for the whole of Central Marsh. Not many muskrats seemed to live elsewhere on the Cheever Lake series, and I think that an allowance of another dozen would be ample. The breeding population could then be estimated at perhaps 70 adults.

Lemke said that most of the Central Marsh lodges of winter were taken out by the ice in the spring and that many muskrats were then seen on shore. Whether this resulted in any appreciable population crisis may not well be judged.

The hemorrhagic disease may be suspected of being at least partially responsible for the continued unfavorable status of many muskrat populations of northwestern Iowa and northward and northwestward. Prior to 1948, no victims from this region were positively recognized, but, on May 28, two were found dead along the northwest shore of Central Marsh at Cheever Lake, of which the one in freshest condition showed typical lesions.

During another inspection trip in late September, 1948, many muskrat signs were seen about the Cheever Lake marshes, but they were irregularly enough distributed to suggest summer disease losses. A muskrat-vacant, 100-yard stretch of shore zone still could be seen where the clearly diagnosed disease victim had been found four months before. The fall population for Central Marsh was calculated with fair satisfaction at a little over 500. An allowance of another 100 muskrats for Northeast and Northwest marshes might be permissible, which would bring the Cheever Lake grand total for the fall of 1948 up to about 600 .

Water and vegetation looked favorable for muskrats at Four-Mile Lake during brief visits on May 28, September 28, and October 1, 1948, but this marsh appeared to have been devoid of the animals at these times.

In early summer, 1949, Cheever Lake and Four-Mile Lake were in attractive condition for muskrats but practically unoccupied. On June 6, the east half of Central Marsh at Cheever Lake was checked over, and a single functional territory was found there. I doubt that a dozen adult muskrats were alive on the whole Cheever Lake series. I made no further inspections of the Cheever Lake area after midautumn, 1949. Central Marsh at Cheever Lake and Four-Mile Lake were then in good condition, but the muskrat was still barely represented as a species. 


\section{Chapter 7}

\section{The Wall Lake Area,}

\section{North Central Iowa}

WaLL LAKE (Figure 7.1) is a state-owned glacial marsh of nearly 1,000 acres in Wright County, north of Blairsburg and southeast of Clarion. It is a public shooting ground open to fur trapping in season, unless specifically closed, wholly or partly, by official administrative order.

It varies in aspect from dry expanses of cattails, rushes, reeds, grasses, farm weeds, and bare bottoms to extensive blocks of open water interspersed with emergent vegetation. Unevenness of the bottom is manifested at times by low islands (of which some are grown to brush and trees), by wet channels and projections of higher ground, by shallows grading off into adjacent pastures or ending abruptly with ice-ridges, by timbered shores or reedy jungles enclosing lakelike bays. Some parts have sandy beaches and protruding boulders; others, peat deposits or deep mud.

The diversity of the muskrat habitat presented in most years would require subdividing for purposes of detailed reference, but, for general treatment, a few broad statements may suffice. The deeper tracts are in the south and southeast parts and in a series of three sloughs and connecting channels extending mostly north and south along the east central side. The shallower tracts comprise the north half of the marsh, some pastured shallows lying to the northeast, and sizable acreages in the south center and the southwest corner.

Over the years of my studies at Wall Lake, I received special help from personnel of the State Conservation Commission, especially Harry E. Rector, H. E. Colby, Walter W. Trusell, James G. Sieh, W. E. Ayers, and Paul E. Leaverton. The following trappers include those giving special cooperation: Verl ("Jack") Black, R. E. Kautsky, O. R. Sands, Walter Sampson, Harold Kaster, Hobart Abbott, E. A. Johnson, Robert Mosiman, Torkell Hill, Garry Hunter, and Charles and LeRoy Inks. 


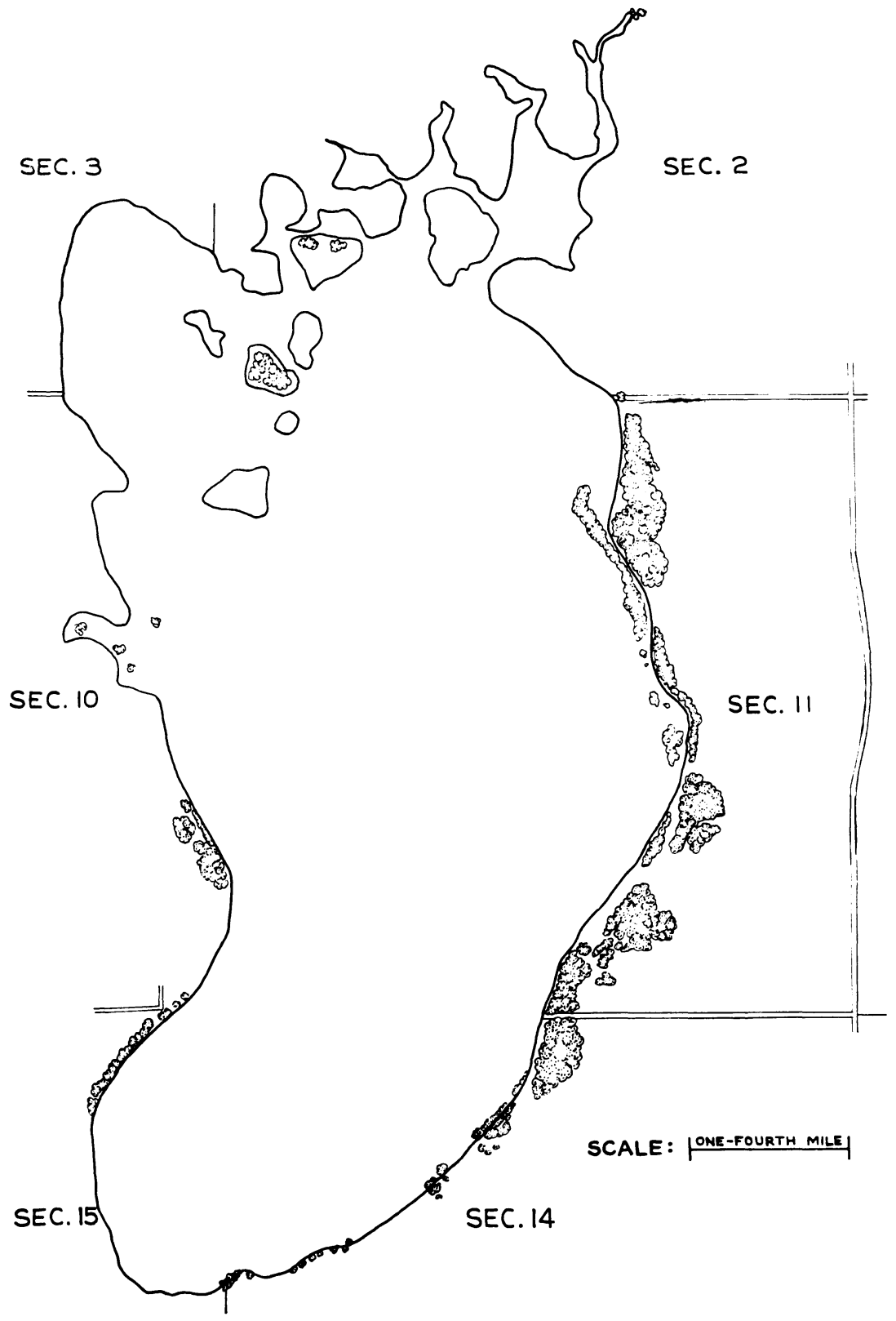

Fig. 7.1. Map of Wall Lake, north of Blairsburg, north central lowa. 


\section{THE LOW WATER YEAR OF 1939}

My first systematic inspection of Wall Lake was made in mid-May, 1939, at which time only the deeper parts of the marsh were covered with water -24 acres in the southeast and a 10-acre strip along the east side. Presumably, the marsh was then in the early stages of recovery after the droughts of 1934, 1936, and 1937.

A census of breeding territories, made in early June, 1939, gave the equivalent of 11 pairs for the 24-acre tract and of two more pairs in three acres lying to the northeast. Later calculations gave 6 more pairs for the 7 acres of sloughs and channels extending northward to the end of the wet marsh. This adds up to the equivalent of 19 pairs or, using the previous winter's sex ratio of 51.0 per cent males shown by trapping catches, a breeding-season total of about 40 adults.

During the summer, the water of Wall Lake went down to about a foot and a half in the deepest places, but the vegetation here (especially broad-leaved cattails) became extremely heavy, and the localized muskrats thrived. By late October, the water was somewhat deeper over the wet tracts than in late summer. The late fall and early winter population was carefully estimated at about 280 on the basis of comparable known populations elsewhere. The wettest 15 acres of the 24-acre tract had about 12 per acre or a total of 210, including ingress animals such as those from two dried-out pasture sloughs to the south. For the 10 acres of east-side wet marsh, the fall population was estimated at between 65 and 70 , probably nearer the latter figure.

Between the middle of the fall and early winter, the muskrats of the 10-acre series of sloughs and channels responded to the combination of dense vegetation and low water by building hundreds of lodges. These were of all sizes, with or without chambers, mud-plastered or not. After a hard freeze on the night of November 26, a very small proportion showed current use. There were in fact about five lodges to every muskrat of the 10 acres, with only certain lodges showing good to excellent signs.

By the middle of December, a crisis began to develop in the eastside shallows. The water had gone down so much in the preceding weeks that, even in the wetter parts, the lodges were surrounded by exposed frozen mud. By the end of the month, the muskrats of the drier parts were tracking about in the snow, and dogs from a farm yard as well as minks were interested in them. Bloody signs of intraspecific strife were sometimes conspicuous. Some muskrats living in mud lodges on open mud flats revealed their presence by muddy pushups outlining subsurface channels but did not come out on top; it is now suspected that they had stores of duck potato. Five dead were found during the winter (of which at least 4 were fed upon by minks), and 14 of 46 mink scats contained muskrat remains. With the coming of spring, an estimated 18 to 20 muskrats were surviving here.

The population of the 24-acre tract of wet marsh wintered securely, though 9 acres of the shallower periphery were abandoned by residents withdrawing to the deeper 15 acres. All signs of external activity dur- 
ing cold weather appeared to be that of wanderers (chiefly from depopulated parts of the east-side sloughs, a half mile or more distant), which characteristically frequented the abandoned lodges of the shallows. About 190 of 210 established residents evidently wintered, despite the presence of at least a half-dozen minks working the muskrat-occupied area. The minks dug into the lodges throughout the winter, but the muskrats maintained their best living quarters and as a rule left unrepaired only those of lesser importance. It was also apparent that even big minks (doubtless including some experienced in preying upon drought-vulnerable and wandering muskrats) were not inclined to enter certain of the lodges harboring large numbers of muskrats.

\section{THE DROUGHT CRISES OF 1940 AND 1941}

The parts and acreages of Wall Lake occupied by muskrats in the late spring of 1940 were the same as those occupied in 1939. In 1940, however, the breeding population was greater. Well after the spring dispersal, late-May checkups gave the equivalents of 11 pairs on the 10-acre east-side series of sloughs and of 30 to 35 on the wetter 24 acres. This would give a total of 41 to 46 pairs, probably nearer the latter, or a grand total of around 100 adults.

The muskrats of both deep marsh and shallows got along well through the first three weeks of June. Four of 30 mink scats for early May contained muskrat remains (probably all of the same animal), whereas no muskrat remains were found in 106 mink scats from late May and June. The maximum number of young muskrats present at any one time was estimated at between 500 and 700 . Sixty-one young in 15 litters were marked, but only one was subsequently recovered as a subadult - that one in its natal locality.

By June 20 , the bottom of about half of the 34 acres occupied by muskrats was exposed. Friction was observed among adult muskrats on one of the drier tracts, and the drought situation was becoming critical for many residents, although the species. was not, as yet, suffering unusual mortality. Minks were frequenting mainly the deeper parts of the marsh, where they lived almost entirely upon coots. Red foxes, however, were displaying interest in two sets of shallow-water lodges - still limiting their explorations to areas of bottom sufficiently firm to prevent their feet from sinking more than an inch into the mud.

Despite a three-inch rain on the night of June 22, the drought emergency for the Wall Lake muskrats rapidly grew worse. Before the end of June, a calculated 30 to 50 muskrats (about three young to each adult) were foraging in the vegetation near drought-exposed lodges. During July, the habitats of between 50 and 200 muskrats dried out. By early August, the water level was so low that a muskrat population of possibly 250 (about two young to each adult) was exposed.

The responsiveness of the foxes (a family group) was spectacular (Errington, 1943; Errington and Scott, 1945; Scott, 1947). By the end 
of July, the foxes had caught practically all the young muskrats on at least 20 acres of marsh. From late June to mid-August, 69 of 73 fox scats contained remains of young muskrats, mostly of animals between two and three months of age. No evidence was seen of foxes catching adult muskrats.

Track signs of the fox family indicated a definite system of maneuvers, with some foxes stationing themselves beside the trails between muskrat lodges and feeding grounds, while other foxes circled about. The effectiveness of the system may have resulted not so much from conscious teamwork as from the astuteness of old foxes in waiting near places where alarmed young muskrats would be likely to run. At one time, the foxes were working so close to the edge of the receding water that they sank two or three inches in the mud, but they did no digging into muskrat-occupied habitations.

Minks seemingly avoided the places that were intensively hunted by the foxes and were not known to kill muskrats in any place where water remained in lodge entrances. The minks did hunt in a dry part that was not exploited by the foxes, and four of eight mink scats from there contained remains of the same age classes of muskrats as the fox victims. Elsewhere on the marsh, seven of 27 mink scats for July contained muskrat remains, including three representations of adult muskrats.

Rains in early August reflooded the tract on which most of the living muskrats were concentrated, and the foxes discontinued their hunting on the marsh. There were still a few drought-evicted muskrats on surrounding land, and 3 of 17 fox scats and 6 of 31 mink scats from August and September contained muskrat remains. The bottom was fully exposed again by mid-October, but the foxes did not return.

The known catch during near-annihilative public trapping in November was 197 . Of the sample of 105 trap carcasses that I examined, 14 were adult males, 22 adult females, 35 young males, and 34 young females. Seven of the 69 young were of "kit" sizes, and at least 3 and perhaps as many as 5 of the 22 females showed late-season sets of placental scars and thus evidence of some resumption of breeding with the temporary relief from the drought in early August. Early litters only were recorded for 6 of the 22 adult females. The mean number of 1940 placental scars per adult female was 19.2.

After the trapping ceased, a very few trap cripples wandered over the frozen bottom for a time, but there is no reason to think that any muskrats survived the winter of $1940-41$ at Wall Lake. No muskrat remains were found in 145 fox scats deposited from October, 1940, to early March, 1941, nor in 4 winter mink scats.

Melting snow refilled the shallower parts of the marsh in the spring of 1941, and environmental conditions were much as they had been the year before. The marsh was naturally restocked with the equivalent of five pairs of muskrats and one unmated or nonbreeding female. During the period of muskrat movements over the countryside in March, an intact, freshly killed, maturing male muskrat was found 
at a marsh-edge fox den, and one of 194 fox scats deposited from the middle of March through April contained remains of a second muskrat.

Wall Lake dried up again in August, 1941, but the muskrats were relieved by rains after three weeks of drought exposure. The foxes did not visit the dry part of the marsh where the muskrats lived, and no muskrat remains were found in 555 scats deposited from May through August. Two of 13 mink scats dated to the drought exposure contained remains of young muskrats.

After the late August rains, the Wall Lake population suffered no detected mortality until the public trapping in December, 1941. A sample of 15 carcasses consisted of 3 adult males, 3 adult females (one unbred in 1941, one having 19 placental scars in three sets, and one having 40 scars in four sets), 6 young males, and 3 young females. Thirty-two muskrats were trapped by the public, and the signs remaining after the trapping indicated that a couple of animals escaped, perhaps to winter successfully but more likely not to.

\section{THE GENERAL POPULATION TRENDS AT WALL LAKE DURING THE RECOVERY YEARS, 1942-46}

During the gasoline rationing of the war years, I visited Wall Lake only at long intervals or incidental to travel elsewhere. The data at hand covering the period of a pronounced population ascendancy are, accordingly, incomplete but they do illustrate trends.

The water level of late June, 1942, was high enough to cover 300 to 500 acres of bottom, and the whole marsh was densely grown to cattails, bulrushes, and reeds. Muskrats were all but confined to the 34 acres comprising the only habitable parts in 1940 and 1941. A rough estimate gave the equivalent of about a dozen pairs or about 25 adults. The fall population was estimated at about 175 .

Wall Lake was closed to legal fur trapping for the fall and winter of 1942-43, but evidence was seen of violators on the marsh. No sign of external activity of muskrats was recorded in February and March, 1943. Of 24 winter mink scats deposited prior to a late February thaw, none contained muskrat remains, though minks diligently dug into the lodges. Sixteen of 49 scats deposited between late February and the middle of March did contain muskrat remains.

A checkup in late May, 1943, gave the equivalent of 16 pairs or about 35 adults - still localized (despite a higher water level than in 1942) in or near the deeper parts to which the muskrats had been restricted during the drought years of 1940 and 1941.

By winter, 1943-44, an area of about 192 acres was occupied by muskrats, and, on this, the wintering density was estimated at about 3 per acre, or a total of about 575. Many of the animals then present surely came in from the outside, as the general Iowa population in 1943 was the highest recorded during the entire research program, and much late summer and early fall adjustment was noted. Furthermore, Wall Lake was in splendid condition to attract newcomers after the 
1943 breeding season. The marsh was still kept closed to trapping in 1943-44, and this protection seemed more effective than for 1942-43.

The 1944 breeding density, as of mid-June, was judged to have been the equivalent of about a pair per acre for the above 192 acres, or about 425 adults. The summer was extremely wet, and, by early August, Wall Lake was habitable and in excellent condition for muskrats over nearly its entire area, except for the deeper parts of the south end where cattail stands died. The biggest of several open spaces was about 10 acres in area, but the ecological losses resulting from the dying of cattails were far outweighed by the flooding of hundreds of acres of heavily vegetated shallows with a foot and a half to two feet of water.

A fall estimate of about 5 per acre or a total of 450 was made for a 90 -acre fur-refuge tract set up by the Conservation Commission in the deeper and less vegetated south end of Wall Lake for the 194445 trapping season. The total trappers' catch for the rest of the marsh amounted to about 8,000. From the information available, the 1944 fall population should have been about 9,000.

In late January, 1945, after the trapping, the principal evidence of living muskrats was confined to the refuge tract, which was appraised as too small for optimum effectiveness. Minks were active in expected places, but I had to work hard to find 17 winter scats, none of which contained muskrat remains. A single dead muskrat (an apparent transient on shore, cleaned up by a probable mink) was found on a visit the last of March.

A breeding census of late June, 1945, gave the equivalent of 10 pairs on 128 acres of the more open south end of Wall Lake; and, for about 800 acres of once-shallow marsh lying to the north, the density seemed to be the equivalent of about a pair per two acres. Application of the sex ratio of 59.6 per cent males in central Iowa trappers' catches for 1944-45 (data from the population crisis at Little Wall Lake excluded) to the 410-pair total at Wall Lake would give about 1,000 adults.

The long, dry Indian summer of 1945, marked by widespread adjustments on the part of stream-dwelling muskrats in particular, doubtless resulted in Wall Lake attracting some animals from outside. In mid-October, there were about one and a half large lodges per acre for the marsh, open waters and dense vegetation averaged together.

For the 1945-46 trapping season, the Conservation Commission set up another fur refuge, this one of about 200 acres and located in east central Wall Lake. The 1945-46 catch was about 7,000. Judging from a 1946 spring population, the equivalent of about 700 pairs, the 1945 fall population should have been about the same as that of 1944, or about 9,000 .

Decided changes took place in the ecology of parts of the marsh in 1946. A cattail stand of about 40 acres in the north part of the fur refuge died out from an unknown cause. The popular opinion was 
that this was a muskrat "eat-out," but close inspection showed that substantial tracts - indeed, acres - of dead stalks hardly had a toothmark on them, and the dead barrenness of the affected parts was almost unrelieved by green plants escaping. From the standpoint of muskrat ecology, the cattail die-off was offset by a newly-thriving growth of bulrushes in the deeper south end, which had lost most of its cattails as the water reached its maximum depth in 1944.

The spring dispersal was quite general by April 2, 1946, but with the heaviest populations still living in or near the refuge tract. Of 45 fresh and recent mink scats examined, one contained muskrat remains. The single dead muskrat found was an adult male dying from intraspecific strife. Several transients were seen sitting in shore nests, mostly at the edge of parts of the marsh that had been trapped during the winter. The population density averaged slightly less than the equivalent of a pair per two acres for the north part of Wall Lake and about a pair per acre for the south part, or about 700 pairs. Application of the 1945-46 central Iowa winter ratio of 54.7 per cent males should give about 1,550 adults as the 1946 spring population of the entire marsh.

I saw dead adults in scattered places in late October and early November, 1946, but none fresh enough to examine showed lesions of the hemorrhagic disease. Early in the trapping season (beginning November 10), Kaster saw as many as four dead floating about a lodge that later proved to be in a disease focus.

The trappers' catch was about 6,000. On December 20, 1946, after the trapping was over, decided differences could be seen in the external sign visible on the trapped marsh and the current fur refuge (which was the same as that of the previous year). The muskrats were by no means cleaned out of the trapped marsh, but there were few push-ups (wads of vegetation pushed up from below by the muskrats) or lodges having about them open water or thin ice due to muskrat activities. On the other hand, there were push-ups by the hundreds on the refuge away from the boundary, and nearly all of the big lodges were surrounded either by open water or thin ice. Considerable numbers of muskrats also were sitting on the ice about the protected lodges well after the general freeze-up. The trapping eliminated animals from about 50 acres of the refuge tract, which left about 150 acres as effective refuge. On the choicer parts of the refuge, the wintering population was estimated at 20 to 25 per acre, or a total of something less than 3,000 for the whole refuge. This would give a grand total of about 9,000 for the marsh, as of late fall, or a figure similar to the fall populations for 1944 and 1945.

Winter checkups during 1946-47 afforded insight into the functioning of the fur refuge. The west central edge of the refuge was bounded by thick and more or less continuous growths of reeds, which seemed to serve as enough of an impediment to under-ice movements to prevent the muskrats within the refuge from being exploited by traps set at the boundary. Where the refuge edges were characterized 
by open water, or by interspersions of open water and clumps of sparse growths of emergent vegetation, the muskrats were eliminated for distances up to 200 to 300 yards within the refuge.

Trappers reported many wandering and dead muskrats, especially on or near the refuge. Three dead found and examined personally in late January, 1947, were aged, strife-torn individuals, showing no disease lesions. Two of these three were females, the other being of undetermined sex. Plainly, the refuge was the site of some unrest, but the majority of the animals wintering there got along with apparent comfort.

\section{THE INTENSIVE STUDIES OF 1947, A YEAR OF TENSIONS AND COMPLICATIONS AT WALL LAKE}

The 1947 breeding population was the equivalent of about 1,070 pairs, as of April 25. The 1946-47 central Iowa ratio of 52.9 per cent males shown by trap carcasses would give a total adult population of about 2,275. As late as April 11, this rather top-heavy population was still localized in the fur-refuge tract where it had wintered. Some evidence of muskrats was appearing west of the refuge, but the entire marsh southwest of the refuge was practically muskrat-vacant, even up to the refuge boundary. There were already, however, numerous transient muskrats along the south shore.

Then, an almost explosive dispersal took place in mid-April and, by April 25, the muskrat population of Wall Lake was essentially equalized over trapped and untrapped areas, alike. Only in one place - a tract of about eight acres next to the reedy barrier on the west side of the fur refuge-were the muskrats perceptibly more abundant than elsewhere on the marsh, and here the density was the equivalent of about five pairs per acre. About 145 pairs remained in the 200 acres of refuge; about 525 pairs were in 350 acres of heavy vegetation lying west and northwest of the refuge; southwest of the refuge, about 300 pairs were in 150 acres of marsh, which had been muskrat free two weeks before; and about 100 more pairs were in the south shore zone and associated deeper waters.

The above equalization of muskrat densities over Wall Lake was interpreted as a manifestation of acute unrest. Population adjustments continued: by May 7, the south shore zone and its deeper waters had the equivalent of only 25 pairs, a quarter of the 100 counted there on April 25; and the population of the 150 acres lying southwest of the refuge was reduced from the equivalent of approximately 300 pairs to very close to 150 . Coinciding with this decline in the south part of the marsh was a northward shifting into the central and north parts. The food-rich shallows of the northwest and north edges and the pasture sloughs to the northeast gradually improved in attractiveness and habitability during a wet spring and early summer, and these drew a great many muskrats from the deeper parts.

In about 300 acres of centrally located habitat, including heavy stands of emergent vegetation in the north center, the adult popu- 
lation present by late April changed little throughout May and early June. Two mink victims found on shore were likely transients of late April; no muskrat remains were found in four mink scats of early May. Of 2 adults known to die in late May, one died from undetermined cause - but probably hemorrhagic disease - beside a lodge near the place where Kaster saw the floating dead ones in the preceding November. The other was an adult female with the new breeding season's placental scars, dying in the same locality from severe intraspecific wounds.

A medium-sized male raccoon, collected for examination from the inside of a muskrat lodge in late afternoon of May 19, had teeth of a young muskrat of about three weeks amid the crayfish and avian remains in its alimentary tract. At this time, only one muskrat (of about 14 days) could be found in the neighboring lodges of a 200-yard stretch of shore zone in which at least four litters from one to four days of age had been seen on May 7 . This stretch was another place that later proved to be in an infection focus of the hemorrhagic disease. The muskrat-eating raccoon had liver lesions that Dr. E. A. Benbrook, of the Department of Veterinary Pathology at Iowa State, regarded as similar to those with which he had become familiar in his examination of diseased muskrats.

The main breeding season of muskrats came on at Wall Lake in 1947 with the comparative suddenness of the spring dispersal. Seven of the 65 litters for which we have dates of birth were born in the second half of April, chiefly in the last few days of the month; 35 in May; 11 in June; 4 in July; and 8 in August.

By late June, a great reduction in numbers of centrally located lodges had become apparent. Seven dead young of between five and six weeks of age were found about a sample of ten lodges. The cause of mortality was not determined, but it could have been hemorrhagic disease, for it was most conspicuous near one of the deadliest of infection foci of later years.

On July 8, maintained lodges were scarce in south central tracts where dozens of litters of young had been kept earlier, and only three litters of young were found, all members of which were dead or dying from unknown disease or diseases. One of the dying litters consisted of eleven very small young having bodies covered by rashlike pustules. Four of six of another litter of small young were dead, and the other two young were barely alive, but none had recognized skin lesions. Two of three in the third litter, of about six days, were dead (one was freshly dead but healthy in appearance and the other had died soon after birth); the young that was still alive was thrashing as if in misery, its body shrunken and skin generally inflamed. A putrid young of about five weeks floated near the lodge containing the last-mentioned litter.

Most of the muskrats observed in the central vegetation during July were adults living in open nests rather than in typical lodges. These adults were fairly numerous, thus suggesting that the central 
decline may have been due in large part to failure in propagation. By early August, it was seen that the losses of young in the affected area were continuing. Two dying litters of shrunken small young were found. On August 27, two of three litters of small young were found to be diseased, and five of the victims were brought in to the Veterinary Diagnostic Laboratory of Iowa State University, where they were examined by Dr. Paul C. Bennett. He reported (memoranda of September 9 and November 21, 1947) that gross lesions were confined to a very slight pneumonic condition and that a hemolytic streptococcus recovered from cultures proved to be nonpathogenic when inoculated into laboratory mice.

There were changes in the ecology of the marsh in 1947, some of which did not reach their culmination before the next year-for example, the dying of most of the river bulrushes from what looked like a virus disease. The reeds suffered from such a massive infestation of aphids that their vitality was probably lowered thereby, which may have been responsible for some of the observed dying of that plant. Many central stands of broad-leafed cattails died during the period of high water, and those remaining alive by midsummer were chiefly either in floating mats or anchored in the shallows. By fall, the open water tracts were generally larger than in 1946, the north shallows had less water and correspondingly wider margins of exposed mud, and the choice muskrat habitat was restricted to perhaps two-fifths of the marsh area.

By mid-September, a dead subadult and a young of about five weeks lay 50 yards apart near a burrow of the east side, probably hemorrhagic victims; another muskrat in decayed condition was found about 200 yards distant on October 30; and, on November 4, a mink-eaten adult female was found, together with muskrat remains in one of 10 fresh and recent mink scats. In early October, 19 fresh to fairly recent mink scats were examined along the southwest shore, of which one (a scat deposited about three weeks previously) contained remains of a young muskrat of about five weeks. Two of six summer and fall raccoon scats contained remains of very young muskrats.

Considerable midautumn mortality of "kits," or even of recently weaned young, was noted in the north half of the marsh. This was attributable in part to unusually large numbers of late young being present and in part to disease. Remains of a very young muskrat in a single mink scat dated back to early fall. Several decayed "kits" were seen floating in the north end before freeze-up. Specimens retrieved here after the ice went out in the spring of 1948, but datable to early or midfall, 1947, included two subadults and two young of five or six weeks.

The shallow northwest corner was subject to some illegal trapping in early November or possibly late October, 1947. On November 14, I found a trap with a dead muskrat in it - obviously missed by the trapper - and there were suspiciously few living muskrats in its vicinity. Except for this place, the shallows of the northwest corner 
showed from the middle of November through December the most activity of muskrats on frozen mud and thin ice over shallow water that I ever saw. Hundreds of muskrats were traveling, feeding, digging, pushing up mud plugs, and building feed houses over about 80 acres of the northwest corner. The north central and northeast shallows were sites of similar activity, though on a less extensive scale. Occasional transients or poorly situated individuals frequented the entire shore line, and there were a few out on top of the ice in deep water habitats. In the main, however, the residents of the deeper tracts did not engage in outside activities, and their signs indicated comfortable living.

Of 44 mink scats of late fall and early winter, 1947-48, from the northwest corner, two contained remains of muskrats, and these were of young animals. Bloody trails about the exposed burrows and wet holes in the frozen mud denoted intraspecific strife. The single dead muskrat found here in December was an undersized adult male with a very bad cut across the anus.

Wintering losses in the shallows of the northwest corner were not excessive, considering the circumstances and the large number of muskrats present. The fragmentary remains of eight dead were found there in January and February, 1948, and most of these had been eaten upon by minks. No muskrat remains were found in eight mink scats for late January, but eighteen of thirty-three fresh to fairly recent scats found and examined in late February did contain this item. Five more dead muskrats - all mink-eaten - were found in March, and these included a big adult, a "kit," and two small subadults. Eight mink scats dated to late winter contained no muskrat remains; but three of twenty-four scats for mid-March and ten of fifteen for late March did.

In many places where the water was only a couple of inches deep at freeze-up, the lodges were still well maintained by muskrats in early spring. Large tracts of the river bulrushes of the exposed bottom had snowdrifts over them at least during part of the winter, and the bulrush stands were often so thick that they furnished good cover as such, as well as a favored and abundant food. The readiness with which the muskrats were able to find soft mud and other material for plugging their passage holes over burrows or in the sides of lodges was also a big advantage to them. Some lodges on the mud flats were so tremendous that the central parts of their bases were unusually well protected from freezing.

Four late-winter dead found in the center and south half were two subadults and two emaciated old ones. This part of the marsh was infrequently visited by the scarce (possibly no more than two) Wall Lake minks, and the minks consequently did not find a deadly focus of the hemorrhagic disease. From the condition of the gonads of victims examined in the spring, the time of dying in this focus was dated to about January, 1948, if not somewhat earlier. The initial dying was confined to about an acre of mixed cattails and 
reeds in the north center of the marsh. After the evidently quick killing off of the muskrat population of the acre tract, the epizootic appeared to subside until spring. Nineteen of the dead specifically examined and recorded in the field notes were assigned to this original focus, and at least a half-dozen others found there were too putrid for examination.

Wall Lake, for reasons of administrative convenience, was left closed to muskrat trapping for the 1947-48 season in conformity with a closed season over most of Iowa, where muskrat populations were generally low. As a result, a locally congested population entered the winter with little known reduction from human exploitation except in those parts that had been illegally trapped in late October or early November.

Sex and age data from the victims of the epizootic of the winter and spring of 1947-48 should give the nearest equivalent of ratios from trappers' catches. Of the 117 dead muskrats eligible for comparison (excluding the dead "kits," the aged, and the otherwise handicapped that were dying from time to time), 21 males and nine females clearly had been born prior to 1947, and 57 males and 29 females were judged to have been born in 1947. One other was a 1947 young of undetermined sex, making a total of 21 adult males, 9 adult females and 87 young of the year for what should be about the same as a late fall sample for 1947.

Of the five adults of known sex found dead at Wall Lake and recorded in the field notes for 1947, four were females. The abandonment of half to three-fourths of the territories of the southern part of the marsh between the last week of April and the first week of May is not fully appraisable in terms of ultimate losses. Inasmuch as it was accompanied by a heavy pioneering drift into the fringing shallows of the north end, it probably meant increased hazards for adult females in particular, as the water receded in late summer and fall. Then, too, the lay of the land to the northeast of the marsh is such as to promote a certain amount of emigration on the part of muskrats massing there. This is the principal avenue of travel away from Wall Lake during droughts, and it might also be during highwater stages. (A big adult was seen flattened on the highway to the east on June 26, when the water level of the marsh was at or near maximum.) In other words, it is likely (though not demonstrated) that many of the animals moving northward in the course of the late April and early May adjustment, including females establishing territories, did not permanently settle within the mapped boundaries of Wall Lake. The big disparity in the sex ratio of the adult victims of a nonselective epizootic (21 males to 9 females) is, despite statistical inadequacies, further indication of heavy losses of females somewhere along the line-particularly in view of the usual preponderance of females among wintering adults.

From the collective evidence, it should not be far wrong to assume a loss of a good half of the 1947 adult females, which would 
leave a total of around 500 from which pro rata calculations might be made. Application of the available sex and age data would give a late fall or early winter population of around 6,500, a not improbable figure.

To try another approach: All of three main sources of quantitative data - predispersal enumerations after the melting of the ice in the spring, totals of dead picked up from disease-swept tracts, and counts of animals sitting around after eviction from lodges leveled during disease-control experiments-show densities of about 20 muskrats per acre wintering in superior habitat at Wall Lake, 1947-48. It would seem that similar densities entered the fall on a little over 300 acres, which would give about 6,000 , plus about 800 estimated to be living in less attractive places. This, too, would give a figure not much in excess of 6,500 as the approximate population for the marsh, as of late fall and early winter.

On the basis of an average reduction from about 20 per acre to the vicinity of 15 per acre for 80 acres in the northwest corner and minor (call it about one per acre) losses on another 135 acres of shallows, the 1947-48 wintering loss in the north half of Wall Lake may be calculated at about 535. Possibly the figure would be around 600 for the entire marsh. If this were subtracted from 6,500 about 5,900 would be the number surviving the winter.

\section{THE INTENSIVE STUDIES OF 1948: A YEAR OF SPECTACULAR LOSSES FROM THE HEMORRHAGIC DISEASE}

The first 1948 spring highway victim east of Wall Lake was noted on March 21. On this date, an inspection brought out decided contrasts in the behavior of the muskrats living in different parts of the marsh. The muskrats of the north shallows were engaging in a great amount of activity on shore. In the south shore zone with its deeper water, the resident muskrats were leaving many signs about the lodges but hardly traveling on the land at all. Quite evidently, the more comfortably situated muskrats were less disposed to move from their wintering quarters than those that had been feeling an ecological pinch for some months.

The ice melted and broke up at Wall Lake during the last few days of March, 1948. On April 9, a good checkup of the best and most heavily populated muskrat habitat of the center revealed that the animals were undispersed. At the time of the visit, they were sitting around on rush rafts and the edges of the lodges. Little change in local status of the centrally located muskrats due to dispersal was noted during seven subsequent visits up to May 3, but variable numbers of transients worked the shores. During this period, nine dead transients were found near or on shore, of which seven apparently died of intraspecific strife wounds and one of hemorrhagic disease. None of 50 mink scats for April contained muskrat remains.

Somewhere about May 5, the main dispersal of the central muskrats began. A week later, the population remaining on Wall Lake 
was well settled, except for the battered animals haunting the shores. A mid-May breeding census gave the equivalent of 529 pairs, or probably around 1,175 adults.

Wall Lake lost much emergent vegetation, particularly river bulrush stands, from the summer of 1947 to that of 1948. Three muskratvacant tracts of largely open water totaled over 500 acres, and there were other tracts similar in appearance except for their smaller sizes. To a considerable extent, the best muskrat habitats of the marsh in 1948 were irregular in outline and variable in size, occurring mostly in the shallower parts. The deep-water habitat consisted of bulrush and floating cattail clumps near the south end and some cattail and reed growths bordering deeper waters elsewhere. One of the most heavily populated tracts was a series of shallow muddy sloughs in the northeast corner, the vegetation of which was dominated by duck potatoes. River bulrushes remained abundant chiefly in the north half.

Fourteen dead muskrats were found near the east central shore in mid-April, of which the freshest 11 specimens were victims of the hemorrhagic disease. It could be seen that the 11 probably drifted to shore across a stretch of open water lying to the west. The source of the drifting dead was soon located: a 5-acre tract of bulrushes. It had floating bodies of at least 28 muskrats lying in sight on the water at the time of the first visit. The final count of 112 dying in this 5 -acre tract within a space of weeks - over 100 within a single week illustrates not only the infectiousness and virulence of the disease but also the densities of muskrats existing in limited and locally favorable habitat.

Post-mortem examinations of muskrats dying from the above epizootic and its extensions revealed a syndrome of lesions of a less common type but still one generally observed in central Iowa from late summer, 1946, through the first half of the spring of 1947. In this syndrome, the necrotic foci in the liver tended to be fewer (or entirely absent), whereas the intestinal hemorrhages tended to be more conspicuous than in the Iowa specimens studied from 1943 to the middle of 1946. In late April, the site of a different epizootic was discovered in the shallow sloughs at the northeast corner of Wall Lake. The disease syndrome of the victims here was characterized by lung hemorrhages, which left large portions of the lungs with the appearance of being almost solid clots, and by absence of apparent liver and intestinal lesions. The courses of both epizootics became complex as they progressed, as field experiments were conducted, and as muskrats entered the infected zones from the outside in connection with normal spring dispersal and establishment of breeding territories.

Through ex post facto "reading of sign," the April, 1948, die-off in the 5-acre tract was traced to the disease focus of about an acre mentioned in the discussion of 1947-48 winter mortality. This focus lay about 175 yards west of the above 5 acres. Evidence was also seen that one of the first to die in the 5 acres of river bulrushes had drifted 
across an irregular channel of open water to the edge of another tract of river bulrushes - this of 8 acres - lying to the northeast.

This second tract of bulrushes had a per-acre density of muskrats similar to or even higher than the one of 5 acres. Two freshly dead victims were found on April 14 in the vicinity of the dead one judged to have drifted over about a week before. By April 20, 14 more dead were found, and the epizootic had depopulated about half an acre of the bulrushes radiating away from the vicinity of the animal that had drifted across the channel. The saving of the rest of the population of the 8 acres of bulrushes from the epizootic may be credited to experimental control measures, i.e., designed to remove or dilute sources of infection.

About a dozen animals could be seen alive in the 5-acre tract just before the lodges were experimentally leveled on April 21. Dying continued on a much reduced scale, and the rebuilt lodges were leveled. Thereafter, the epizootic appeared to subside, and lodges rebuilt by newcomers or survivors were left undisturbed. By May 24, about three weeks after the last freshly dead muskrat was found, the equivalents of 9 breeding pairs were established.

A southward spread of the epizootic from the site of the earlywinter disease focus was manifested by animals beginning to die about April 10 in a half-mile, north-south strip of reeds surrounded by open water. Also an easterly extension of the south end of this reed strip was catching bodies drifting across a wide expanse of open water from the five acres of river bulrushes. Many of the reed-dwellers died here, April 13 to 16. At a little island of cattails, likewise in the line of drift from the nearly depopulated five acres of river bulrushes - which lay across open water about 600 yards to the northwest - at least 11 muskrats died on April 17 and 18.

Leveling of lodges in the latter sites was carried on, April 20-21, and this, with removal of the dead, seemed to suffice as a control measure - though, as a matter of fact, there had been for some weeks hardly enough muskrats left to do any dying. By late May, there were the equivalent of only five breeding pairs on about 25 acres in the reeds. At least 53 were known to die here, and, of these, 48 were found inside the lodges.

The most heavily populated part of Wall Lake was a series of river bulrush islands totaling about 35 acres (exclusive of open water) and having a pre-dispersal spring density of around 20 muskrats per acre. The north end lay a little over 200 yards south of the abovementioned reed strip and separated from it by open water and a small patch of reeds lying between. The small reed patch was depopulated of muskrats toward the last of April, but, before then, the contagion reached the 35 acres of bulrush islands and their hundreds of muskrats. Foci of infections were found at the north edge on April 22 (three freshly dead and one in dying condition at a single lodge) and on May 3 (four freshly dead close together about 150 yards from those dying April 22); but measures were promptly taken 
to prevent further spread of the disease in both cases. Whatever else happened, the massed population of the 35 acres escaped the sort of die-off suffered in the reeds, bulrushes, and cattails to the north, where the epizootic had largely run its course prior to human intervention.

West of the early-winter focus of infection, the epizootic started a mid-April advance on a new front, but chronology and the observed drift of infected bodies implicated the five acres of river bulrushes rather than, directly, the earlier focus. On this new front, the epizootic killed relatively few known muskrats and finally subsided. None of fifty late-April mink scats from a lodge contained muskrat remains. Some control work was tried here but not really enough to count. The explanation for the subsidence of the epizootic probably lies both in a scarcity of muskrats remaining alive locally (the habitat being neither very good nor heavily populated) and in warm weather lessen. ing the infectiousness of the dead through putrefaction.

The pneumonic syndrome of the hemorrhagic epizootic got a fairly late start in the spring of 1948. The first recognized victim had died about April 17, a half mile north of the northernmost limits mapped for the spring and early summer spread of the commoner or hepatic-enteritic syndromes. I suspect that the infection was introduced by a transient, as the new die-off was first noticed along a marsh edge used as a highway by considerable numbers of foot-loose individuals.

In the course of the next six weeks, at least 28 muskrats were recorded as dying from the pneumonic epizootic, and the deaths of many more were believed to have taken place out of sight and out of reach in bank burrows. Indeed, it was estimated that upwards of 100 died here up to early summer, mostly along a quarter-mile stretch of shore near the extreme northeast boundary of the marsh. Control experiments were neither attempted nor considered feasible. A certain amount of dying continued for much of the summer, and an area of several acres remained depopulated until fall.

As the weather turned warm, dead muskrats experimentally left floating on the water in easily recognizable places disappeared in a relatively few days, and it is quite to be expected that increasing proportions of the late spring victims did likewise. Moreover, the technical problems of covering the nearly half of a square mile of marsh affected by the epizootics were so substantial that some missing of dead should be taken for granted, even if they had continued to be visible indefinitely.

Neverthless, the dying occurred principally while the weather was moderately cool, and the heaviest mortality was restricted to tracts small enough to permit fairly thorough and repeated coverage. Also, systematic digging out of lodges in connection with control experiments surely did not leave any great numbers of the dead to disintegrate out of sight in lodges. I should question that more than one victim of the hepatic-enteritic epizootic was overlooked for every 
two found and recorded, which, on the basis of a recorded total of 267 , would give a total of about 400 . The addition of the approximately 100 pneumonic victims to the other 400 would give a grand total of perhaps 500 for both epizootics at Wall Lake in the first half of 1948.

The control experiments were conducted cooperatively with the State Conservation Commission, with State Trapper Walter W. Trusell and Conservation Officer H. E. Colby being the principal representatives of the Commission during the experiments. Colby also patrolled the marsh at intervals throughout the summer searching for evidence of new outbreaks. This work may be appraised as having protected several hundred muskrats from death from the disease.

The population significance of the north central die-off, on the other hand, is not to be judged merely in terms of numbers of animals dying or not dying. There was such a state of overpopulation at Wall Lake in the spring of 1948 that considerable biological wastage was entirely to be expected under the best of conditions. In short, the epizootic in this part of the marsh had the apparent effect of eliminating a surplus that stood a good chance of being lost anyway, through one agency or another.

The extent that territorial adjustments of the muskrats took up the slack left by the heaviest die-off is illustrated by the distribution and densities of the breeding population, as of late May, when the final spring census was taken over the marsh as a whole. On comparable disease-free and disease-swept parts of the attractive habitat of north central and northeastern Wall Lake, the late May breeding densities stabilized quite uniformly at the equivalent of 1.8 pairs per acre on 94 acres. A total of about 135 acres of shallows to the north, including the shallows swept by the pneumonic epizootic, had the equivalent of 1.2 pairs per acre, whereas a larger (160-acre) tract of disease-free, though ecologically similar shallows adjoining to the southwest, had the equivalent of 1.0 pair per acre. These were the only local situations permitting valid comparisons.

At the site of the pneumonic epizootic, severe local mortality in relation to the muskrat densities continued into the summer. An area of several acres remained depopulated until a late-summer and earlyfall drought induced substantial numbers of muskrats to move in from still shallower outlying parts of Wall Lake. A big movement here attained its greatest observed momentum in the first week of October. (On October 1, alone, four muskrats were seen freshly killed by traffic on U.S. highway 69 a half mile east of the edge of the droughtexposed shallows.) Many of the newcomers established themselves shortly before October 8 in the old burrows and lodges left vacant by the pneumonic epizootic. By mid-October, animals were again dying from disease at this place, although evidently nowhere else on the marsh. In this instance, however, the common hepatic-enteritic syndromes dominated, with just enough specimens revealing pneumonic or intergrading syndromes to indicate that all of the observed syndromes represented the same disease entity. 
Through working over the marsh, part by part, and obtaining local population indices by forcing muskrats out of shallow-water lodges for counting, I arrived at a late October, 1948, figure of about 4,200 . The major exodus because of drought-eviction, per se, had terminated by this time.

When the epizootic started again in the northeast focus of infection, the water surface there covered about five acres. A population of about 20 muskrats per acre or a total of about 100 was quite accurately determined. By October 23, a half acre or so was nearly depopulated, and, between then and December 1, the area depopulated was enlarged to about four acres, leaving an undiminished population on a little over an acre in the southwest end of the slough. Four disease victims were found to have died in mid-October, seven from October 20 to 23, fifteen about the first week in November, and six in midNovember. On the opening day of the trapping season, December 1, two freshly dead, evidently diseased, muskrats were seen in the southwest end, but trapping eliminated the rest of the residents before more could die. Trappers reported taking about twenty five from this southwest end, compared with four muskrats from the entire four-acre tract that had been disease-swept.

Partly connected with the slough having the northeast focus of infection, and similar to it in ecology and per-acre density of muskrats, a six-acre slough lying to the west escaped sweeping disease mortality up to the December trapping, though it did have minor and localized dying in November. The reported catch of about 50 for these six acres is patently incomplete. Post-trapping inspections showed evidence of muskrats being alive at but a single lodge.

The northeast focus of infection may be reconsidered. A freshly dead victim of intraspecific strife was seen on shore, October 23. On the same day, another unpopular one was watched as it withdrew under attack to the side of the slough. Soon thereafter, a pronounced egress was known to take place. Subtraction of the 35 recorded disease victims and the trappers' catch of about 29 from the mid-October census figure of about 100 would leave a difference of nearly 40 animals. In view of the absence of signs of muskrats surviving the trapping and the unlikeliness of much mortality being unaccounted for at this particular slough, an estimate of upwards of 30 muskrats abandoning the place after once being in established residence should be well in keeping with the facts.

The chronology of this late-October egress agreed with a detected movement of animals, including diseased ones, along the east central margin of Wall Lake. The first known disease victim - having the appearance of a transient - died along this travel route about October 23, at the water's edge. Two more battered transients died on land within the next few days. Shortly before the first of November, eight more were known to have died, and a sick one was seen on November 2 , all within a 125-yard strip of shore and fringing growths of bulrushes lying a mile S.S.E. of the fall focus of infection from which egress had been noted. 
On November 2, a freshly dead one was found a third of a mile farther south in the above shore zone. In the following two weeks, eight more were known to have died in this new place, including at least two strife-torn diseased ones dying on shore. By December 3, dead muskrats were found about a quarter mile still farther southwest along the shore, thus extending the known infected strip to nearly three-quarters of a mile. Thirteen more dying between late November and early December, 1948, were found during the 1949 spring checkup. This proved to be as far as the epizootic progressed down the southeast shore zone, although immediately to the southwest lay a narrow, 380-yard bulrush fringe having an area of about two and one-half acres in which possibly fifty, or even more, muskrats successfully wintered, trappers and disease notwithstanding.

Three muskrats dying in October were found in south central Wall Lake, but one of these had been shot by a hunter, another appeared to have died of old age, and the third was too decayed to show cause of death.

In early November, a die-off was observed to be starting at the edge of a moderately populated (around 10 muskrats per acre) 30acre tract of river bulrushes of the south center, of which the east edge was separated from the epizootic zone of the southeast shore by 150 to 250 yards of open water. The first death from the hemorrhagic disease may be traced back to about October 25, and this victim apparently touched off the partial collapse of fall and winter here to be described. Insofar as its death antedated the dying of the occupants of the shore zone lying on the opposite side of the open water and agrees more nearly in chronology with the deaths of the first-observed diseased transients along shore several hundreds of yards to the northeast, this muskrat, too, may be suspected of having been one of those leaving the fall focus of infection more than a mile to the north. It and at least a few other of the dead later found bore the strife wounds of wanderers or otherwise unpopular individuals.

During the first half of November, 69 were known to have died in the river bulrushes of the south center, and another sick one was seen. For the second half of the month and early December, 24 more dead were found. Trappers reported seeing still others in early December, but they may have picked up some of these for pelting, for I could find only one dead in the designated places after the trapping ceased.

The front of the south central die-off took the month of November to advance westward about 700 yards, or the length of an east-west belt of vegetation less than 200 yards in width. Experimental control measures (removal and dilution of sources of infection, as tried out in the spring) quite evidently checked the dying in the first-infected eastern third of the belt; but shortage of man-power available to the Conservation Commission prevented us from doing the full amount of work we felt was needed in the middle and western thirds, and the contagion kept spreading westward until freeze-up. Following the control measures conducted on November 9 on 12 acres of the 
eastern third having the severest mortality, the rate of dying fell off in a pronounced manner; but, during the last week of November, the epizootic was seen to be flaring again among the remnants of the population that earlier had escaped. The known late November mortality of 5 dead on the 12 acres may be compared with 59 known dead for the initial sweep.

Trappers working the bulrush belt of the south center soon discontinued their trapping of the disease-swept eastern third when they found how relatively scarce the animals were - about three per acre estimated on the basis of the bubble signs under new ice. As a result, more muskrats remained alive after the trapping in the part of the central bulrush belt that had been more nearly depopulated by the November epizootic than in parts where animals were only beginning to die as the trapping season opened. Following the trapping, the south central epizootic seemed to remain quiescent for a couple of months, finally killing the remnant muskrats early in February, 1949.

The chronology of the late-October, 1948, egress of diseased muskrats from the fall focus of infection in the northeast corner also agreed with hemorrhagic outbreaks in parts of Wall Lake other than those so far mentioned. About 1,100 yards S.S.W. of the fall focus, animals started dying in the last few days of October in the west center of the marsh. All of the muskrats of a 90-yard stretch of the outer edge of an extensive growth of reeds seemed to die (nine were found) by midNovember, but the epizootic was not known to have spread farther from this site by the beginning of the trapping, on December 1. The surrounding densities were moderately low, of perhaps five per acre.

The center of another die-off consisted of about two-thirds of an acre of wet, rushy shallows about a half mile northwest of the above and about 1,000 yards W.S.W. of the northeast focus of infection. It lay adjacent to a six-acre residual pocket of wet marsh in the generally drought-exposed northwest corner of Wall Lake. The per-acre density of muskrats for the combined six and two-thirds acres was estimated to be, as of mid-October, slightly in excess of the 20 per acre actually determined for the focus of infection of the northeast corner, or possibly 25 per acre.

Animals were first known to die in the tract of two-thirds of an acre toward the end of the first week of November, and this place appeared completely depopulated by the middle of the month. Only six dead were specifically recorded from here, but visibility in thick stands of river bulrush was so poor, and human travel on foot or by canoe so difficult, that many other dead could have been overlooked. Six additional muskrats dying about the same time were found within a 150-yard radius on exposed marsh bottom, but, of these, only one was fresh enough to be positively identified as a disease victim. An animal that may have been a diseased transient died in late October or early November a quarter mile to the south, but without precipitating any local die-off there.

As the trapping began, December 1, a single dead muskrat was 
discovered in the six-acre tract, at the edge of the depopulated twothirds of an acre, and another died there soon after. The epizootic looked as if it were on the way to bigger accomplishments when the trapping sharply reduced the population. Most of the few muskrats surviving the trapping appeared to die in early or midwinter. Three of eight early-winter mink scats contained muskrat remains. The tract did have a small group of muskrats - residents of a single big lodge - that successfully wintered.

Two more of what were probably disease victims died about the middle of November, some 250 yards apart, between 1,100 and 1,200 yards south of the northeast focus of infection. One died 100 yards or more from the nearest muskrat habitation; the other, in the midst of one of the heaviest muskrat populations on Wall Lake. No other deaths were noted here before the trapping season opened.

A trapper brought in and pelted two dead found in the center, north of the south central epizootic area and approximately a mile south of the northeast focus of infection. When these were posted, December 3, one was found to have hemorrhagic lesions. A third dead animal was found about a quarter mile to the west, but it was a very aged one having no lesions suggesting infectious disease. Twentysix carcasses of locally trapped animals were also examined. These represented the trapper's total catch for this part of the marsh. With the melting of the ice in the spring, 16 more disease vicims were picked up, all in early winter sexual condition, with times of death dated to between freeze-up and the beginning of the trapping in December, 1948.

Near the south central shore, almost two miles from the northeast focus of infection and a good half mile from the nearest known disease victims of the south center, a lone animal was found to have died about the first of January, 1949. The site of dying was in the disease focus first suggested by the activities of the muskrat-eating raccoon in 1947. The only other dead muskrat found so far south in Wall Lake during the 1948 dying was a trap cripple, which apparently had died of injuries.

The legal trapping catch in early winter 1948-49 figures out at around 3,000 animals. In late October, 1948, there had been indications of extremely early illegal exploitation of the muskrats of about 60 acres of river bulrush shallows in the northeast part. The toll from this was thought to have amounted to hundreds of muskrats, judging from the local distribution and densities of those remaining compared with the densities on adjoining tracts of marsh during November.

Of 298 trap carcasses and disease victims for which sex and age data were obtained for the fall of 1948, 24 were adult males, 28 adult females, 136 young males, and 110 young females. Counts of placental scars were obtained for 22 adult females, three of which had not conceived in 1948. One had conceived a single litter; 6, two litters each; 10, three litters each; and 2, four litters each. Fifty-one sets of pla- 
cental scars shown by the 22 adult females were chronologically distributed as 23 early in the breeding season, 26 in the middle of the breeding season, and 2 late in the breeding season.

The 1948 field data indicate a negligible loss of adult females between midspring and midlautumn except for about 94 trying to live on an aggregate of 96 acres of the drought-exposed north fringes. Subtraction of these from the May census figure of 529 would leave about 435 remaining alive on the marsh up to the time of the illegal trapping of the northeast corner in October. The fall and early winter sex and age data prorated would also give a remaining population of about 373 adult males and about 3,822 young of the year, or a grand total of about 4,630 muskrats. This, allowing for several hundred illegally trapped or otherwise disappearing from the bulrush shallows of the northeast corner, would agree with the late October figure of about 4,200 .

For many weeks following the legal trapping in early December, 1948, little additional evidence of mortality was detected. Between early February and the middle of March, 1949, 15 of those surviving the fall die-off and the trapping in the south center were known to have succumbed to the hemorrhagic disease in an area having a diameter of about 130 yards. This all but completed the depopulation of the 30 -acre tract of river bulrushes in the south center, bringing up to 110 the number of disease victims found there.

A big mink was attracted to the site of the February flare-up of the epizootic in the south center, and it subsisted to a considerable extent on the dead muskrats for at least five weeks. Of the locally gathered mink scats, only two of 42 deposited between freeze-up and midwinter contained muskrat remains, compared with seven of 9 for late February and early March, one of 11 for the middle of March, and none of 21 for April.

Contemporaneously with the February flare-up of the hemorrhagic disease in the south center, a similarly localized die-off started nearly a mile to the north, in the part of the marsh where the illegal trapping had been done in October and in which no disease losses had been recorded since the epizootic of the previous spring. The local density of muskrats escaping the trapping (legal or illegal) was estimated at two or three per acre. Four mink-eaten bodies were seen in an area about 100 yards in diameter. The uneaten body of a diseased wanderer lay on a lodge, and a sixth dead one was old and strife-torn but without recognized disease lesions. Muskrat remains were represented in the one mink scat examined.

In summary, the recorded number of muskrats demonstrably or presumably dying from the hemorrhagic disease on Wall Lake, late summer, 1948, through March, 1949, totaled 233, in contrast with 8 found dead chiefly from apparent old age and strife wounds. The field work was sufficiently intensive to preclude the likelihood of any large proportion of disease victims being overlooked. The overlooked victims might perhaps be estimated at about fifteen individuals for a 
depopulated quarter acre of slough lying immediately west of the northeast focus of infection, about ten for the two-thirds of an acre of wet marsh in the northwest corner, perhaps three or four more dying nearby after the trapping, a dozen or so found but not reported by trappers in the south center and along the southeast shore, and about thirty more allowed for as dying but not found on or about the rest of the marsh.

This adds up to around 300 as disease toll for the fall and winter of 1948-49. The figure is not as high as the total arrived at for the spring losses from the hepatic-enteritic and pneumonic syndromes combined, but the fall and winter disease losses were, in this case, superimposed upon losses occurring incidental to normal population adjustments instead of merely substituting for other losses.

\section{SPRING TO FALL, 1949, A PERIOD OF IMPORTANT CHANGES}

The muskrats surviving the legal trapping on Wall Lake in early December, 1948, were mostly confined to a moderately trapped area of about 25 acres of excellent habitat in the northeast center, but there was a lesser group along the southeast shore. Other than at these two places, there were a few muskrats in the disease-swept south center, and a few distributed very locally in the west center, in the northwest corner, and in the northeast shallows.

The ice was partly out of Wall Lake by March 25, 1949, by which time the winter survivors among the muskrats could be observed swimming in the open water and sitting at the edges of their lodges. Some muskrats from the southeast shore moved north to dig into the upper parts of the infected burrows of the east central shore. After an interval of about a week, these newcomers, too, began dying. Here, five were found that died of the hemorrhagic disease in the first half of April. No evidence of muskrats re-establishing themselves along the east shore north of the wintering grounds was seen until after the breeding season was over.

Six more muskrats were known to die during April or early May in the south central tract that had been disease-swept in the preceding fall, early winter, and midwinter. The rate of dying slackened in May, though the equivalent of seven breeding pairs remained within a radius of about 150 yards. The disease mortality left a number of apparently unmated animals scattered through 30 acres of bulrushes, but the picture is confused by continued ingress from the southeast shore zone and from a small tract lying to the northwest in which some successful wintering occurred.

The spring dispersal also put the equivalent of four pairs in the previously depopulated center lying just north of the disease-swept south center. These appeared to move in from either the south center or from the southeast shore via the south center. At any rate, a driftroute could be made out from the south, whereas a wide (nearly a half-mile) muskrat-vacant space lying to the north separated the newly repopulated part of the center from the wintering grounds of 
the northeast center. A single animal was found dead of hemorrhagic disease in the central tract on May 10. In mid-April, a freshly dead hemorrhagic victim was found in the well-populated northeast center, but it did not start any known die-off. Several hundreds of yards to the west, three dead muskrats were found close together, probably dying about late April, and a fourth died about the first week of May. Two mink-eaten carcasses of transients on shore- of which one died near the old focus of infection of the northeast shallows under circumstances indicating disease - were dated to about the first 10 days of April.

In addition to the total of 18 muskrats listed in the Wall Lake notes as certainly or probably dying from hemorrhagic disease in the spring of 1949, I would estimate that 20 to 30 more (exclusive of young of the season) died in and about the northeast focus of infection and on four small tracts in the central marsh. The dying from this cause subsided almost completely by early summer.

Breeding censuses, as of the middle of May, gave the equivalent of 94 pairs, or about 200 adults. The settled breeding populations clearly reflected wintering success in particular tracts of marsh. Fifteen of 21 territories or the equivalent of pairs of the south one-fifth of Wall Lake were localized in the southeast shore zone, in one of the two places where substantial numbers had wintered. To the north, in or near the disease-swept, trapped-out south center, 15 territories were established, with local sources being evident in some cases but with fair numbers of the muskrats coming across from the above southeast shore zone. In the northeast center, 43 of 54 territories were distributed within a quarter mile of the tract where wintering success had been greatest, and the occupants of the other 11 territories probably came from the same source. All of the four breeding territories listed for the northwest corner were found in the vicinity of the one known place where muskrats had wintered. Much excellent marsh away from wintering grounds had no resident muskrats up to the end of May, nor, likely, during any part of the 1949 breeding season.

Mating was inefficient among the animals of the scattered territories of the south center and adjacent parts. Of 9 adult females from here that were examined during a week of legal trapping starting December 1, 1949, 6 had not conceived young during the 1949 breeding season, and the other 3 conceived 5 litters (all early ones) among them. In addition to the 9 adult females, the late fall and early winter sample of 90 specimens from the south half of Wall Lake included 6 adult males, 39 young males, and 36 young females. The high proportion of young of the year in this sample was clearly due to a differential movement of young into the south and central tracts of marsh away from the northeast center in late summer through early fall. No August-born young were noted in the sample.

A sample of 40 carcasses was obtained from the northeast center: an adult male, 7 adult females, 14 young males, and 18 young females. The young of the year included 4 assigned to late July. Two of the 
7 adult females of this lot conceived 3 litters each in 1949, and the other 5 conceived 4 litters each. Of the total of 26 litters represented by placental scars, 6 were assigned to the middle or the latter part of July, yet none to August. The northeast center females conceived a mean of 31.3 young.

The adults of the northeast center remained much in their breeding territories throughout the summer and fall despite the southward and southwestward drift of large numbers of their season's young. This drifting was an adjustment both to worsening drought conditions in the north half of the marsh and to the reappearance of splendid growths of river bulrush over wide expanses of the center in which this species had died out during the epiphytotic of 1947. As of mid-September, the rejuvenated central stands of river bulrushes were fairly well filled up with immigrant muskrats, but about 50 acres of cattail and hardstem bulrush islands lying south of the river bulrushes of the south center and separated from them by 50 to 100 yards of open water remained practically without muskrats. However, five weeks later, there were numerous muskrats among these islands, and, by the middle of November, almost every clump of cattails or hardstem bulrushes had its lodges.

By late fall, the wet and muskrat-occupied area of Wall Lake was constricted by drought to about 295 acres, of which about 160 acres had 6 inches or more of water over the bottom. After the passing of the late summer and early fall period of minimal friction, the muskrats of the more solid blocks of partly exposed shallows were reluctant to make further adjustments because of the excessive trespassing over established home ranges that such entailed. On the other hand, late fall adjustments from shallow to deeper water in well-vegetated parts of the marsh were general where they could be accomplished unimpeded.

A subadult died in late summer, 1949, along the east central shore, which had been depopulated during the 1948 fall die-off and in which transients continued to die in the spring of 1949. During November, 7 victims of hemorrhagic disease (all subadults) were found dead here. A 140-yard stretch was left depopulated (except for a single live muskrat) by the opening of the short legal trapping season on December 1 .

Two diseased dead, dying in late October or early November, were found outside a lodge in the south center, a quarter mile southwest of the infected shore zone. On December 26, a freshly mink-bored lodge with the sign of a mink dragging a muskrat outside was seen about 110 yards from the lodge with the two dead ones. On the following day, this mink-bored lodge was dug out, and the hindquarters of a mink-eaten muskrat retrieved, but not enough remained to show whether it was diseased.

A very putrid muskrat, with time of death dated to about midOctober, was found in late December near the exact center of the marsh. In early January, a mink dragged a muskrat outside a lodge 
about 100 yards from the site of the above dead one. One other dead muskrat had been reported by a hunter in late October from the west central part of the marsh. Mink signs were moderately abundant; of 31 scats examined for late summer through December, one (deposited in late September) contained muskrat remains.

Harold Kaster's (letter, January 9, 1950) highest estimate of the total number of muskrats legally taken on Wall Lake in December, 1949, was about 700 . The trapping much reduced the occupants of all parts that were readily accessible by boat, at the same time affecting relatively little the occupants of the muddy shallows.

On the afternoon of December 7, the last day of trapping, I worked over an 18-acre sample of partly exposed shallows in the northeast center and estimated a surviving population of around 8 to 10 per acre. Similar remaining populations were estimated from the signs visible in mid-December on about 75 acres of hard-to-trap shallows extending off to the south and southwest. An allowance of 8 survivors per acre for about 90 acres would give something over 700 shallowsdwelling muskrats entering the winter. I do not think that many more than 100 escaped the trapping on the rest of the marsh. The approximately 800 survivors added to about 700 legally trapped, and with an allowance of about 50 for mortality from trap crippling, a minor amount of illegal trapping, disease, and miscellaneous losses, would give a fall population of about 1,550.

Judging from the sample data, the females of the 54 breeding territories of the northeast center conceived closed to 1,700 young and the 40 females of the rest of the marsh conceived fewer than 200 young, which would give a total of about 1,875 young conceived on the marsh in 1949. Ingress of animals from drying streams in the vicinity may be considered immaterial in 1949, probably no more than would offset the numbers abandoning the marsh. Survival rates of the young were surely high, and the survival of about 1,375 of 1,875 conceived young that would be needed to give us a total fall population of about 1,550 muskrats seems not at all out of reason.

\section{THE LATE-WINTER EMERGENCY OF 1949-50}

With around 700 muskrats living in more or less exposed shallows of Wall Lake, and week following week of sinking frostlines and winter drought, a large-scale crisis was in prospect as midwinter approached. As early as late December, the muskrats of the central shallows were simply popping out of the lodges and passage holes in the marsh bottom during a thaw, but nearly all went back in and stayed in when the weather turned cold again. In early winter, there were three places in the center and one place in the northeast center where what seemed to be individual muskrats habitually came out daily to forage in the river bulrushes. The animal active on the ice of the northeast center was a trap cripple. A mink scat deposited here about the first of January contained remains of a muskrat hind foot-indicative of close scavenging on fragmentary remains - and no 
further sign of the trap cripple was seen thereafter. On January 7 , a mink got one of three foragers that regularly came out in the central shallows. By January 16, the other two muskrats were still coming out at the expected places in the central shallows irrespective of the cold weather; similar observations were made January 19.

Rather suddenly, about January 19, the under-ice retreats of some muskrats of the central and other food-rich shallows froze dry, and four animals started engaging in cold weather surface activities for the first time known thus far in the winter. One of the four, in fact, worked on top on January 18, and, in the afternoon of January 19, left its home range as a footloose wanderer. It was tracked down and looked at near shore, about 250 yards away. Another of the four newly active ones left its lodge about noon of January 19 and, after about 60 yards of surface foraging, had the misfortune to visit a "bored" lodge harboring a mink. The mink quickly overtook it on the ice, killed it, and dragged it into the "bored" lodge.

Only 2 of a sample of 50 mink scats deposited from the first of the year up to January 19 contained muskrat remains, and one of these two was the previously mentioned scat containing the remains of the muskrat foot from the northeast center. The chief items of mink diet were meadow mice living in the drier of the muskrat lodges, small bullheads congregated in the plunge holes of some of the wetter lodges (these bullheads were exploited by resident muskrats as well), and the dead coots shot by hunters in the fall. There were at least 3 big minks and a small one regularly working the central shallows in mid-January.

On January 19, three muskrat-occupied sites totaling about 4 acres of shallows were frozen to the bottom; by January 29, the affected area was about 45 acres; by February 4, about 60 acres. Up to this time, only the muskrats of the central shallows had been suffering greatly from the freeze-out. By February 7, about 2 acres of the northeast shallows and about 20 acres of the shallows bordering the wetter south part of the marsh were likewise frozen to the extent that their muskrats were coming out. Then, on February 8, nearly 6 inches of heavy wet snow covered Wall Lake, followed in the next week by storms that left two to three or more feet of snow drifted in the reeds and bulrushes. This snow decidedly lessened the wintering crisis for the shallows-dwelling muskrats, both by stopping the descent of the frostline and by affording surface-active muskrats protection in their foraging for bulrush rootstocks on top of the ice.

During the period of most lethal exposure between January 20 and February 7, 19 mink victims were specifically recorded, and 13 of 21 mink scats contained muskrat remains. All of the above scats that did not contain muskrat remains were gathered from the northeast center where the muskrats continued to live securely. Later, from mid-February to early March, muskrat remains were found in 7 of 17 scats.

Mink predation upon exposed muskrats was often spectacular. 
One mink killed and cached four muskrats in one night and day, and signs were seen in several places of minks overtaking and killing muskrats on light snow.

The fates of two of the muskrats that ended up wandering about the deeper south part were determined. An old male died sitting in a small rush clump. Another animal with a frozen tail was killed by a mink.

The thaw of early March removed all but the larger drifts, but the melted snow restored living conditions for muskrats of the shallows to about what they had been in late December. Some muskrats continued to work about on the surface, but most remained under the ice and in the lodges. It was quite apparent during early and midMarch visits that the surviving muskrats of the central shallows were generally getting along well.

As nearly as I can figure, the total wintering losses through February among about 800 muskrats amounted to about 200, confined almost entirely to a total of about 60 acres of shallows.

There was evidence that the hemorrhagic disease killed muskrats now and then in the vicinity of the lodge in the south center where two were known to have died in the fall. A muskrat was active in the snow about 55 yards from this lodge on February 6, and the next day 2 fresh mink scats containing muskrat remains were found near by. The lodge also had on March 13 another fresh muskrat-containing mink scat and, on March 15, 3 more. The minks must have had access to at least 2 dead muskrats in here. The previously mentioned old male found dead sitting in a rush clump died 60 yards away, and the mink-eaten wanderer with the frozen tail was within 200 yards; but I doubt that they were diseased.

Between December 7 (when the one-week trapping season closed) and late winter, two big deep-water lodges were frequented by most of the surviving muskrats within a radius of about 125 yards. Minkeaten remains outside of a hole in one of the big lodges on March 10 caused me to watch this tract closely. On March 13, remains of two others (including a nearly intact one fed upon by a mink in a neighboring feed house) were found, as well as another muskrat that came out of one of the big lodges to be overtaken on the ice by a mink, killed, and cached in a snowdrift about 50 yards away. Both of the two intact or nearly intact dead muskrats - including the one actually killed on the ice by the mink - showed typical hemorrhagic lesions. On March 15, the two big lodges and fourteen lesser habitations in their vicinty were chopped apart. Five more dead were found, four in one of the big lodges and one in the other. Three dead were intact, dying from hemorrhagic disease while huddling together in one corner of a lodge chamber. This made a total of nine recorded as dying in or about the two lodges. As of mid-March, the nearest muskrats known to have been alive were in a lodge about 140 yards away. These lodges were within 225 yards of two other sites of fall and winter disease mortality. 
Elsewhere on the marsh, some imperfectly appraisable mortality took place after the crisis from freezing out had passed. Mink-eaten remains of two muskrats found near the northeast shallows were believed to have been of wanderers, but the question may be asked as to why they had been wandering. An epizootic, only suspected in mid-March, was discovered to have depopulated about four acres in this part of the northeast shallows and to have killed unknown numbers in adjacent parts. On March 10, two fresh mink victims were found in the central shallows (an intact one was emaciated but had no recognized disease lesions), and two other muskrats were engaging in outside activities. On March 13, remains corresponding to the two surface-active animals were found. Remains of three more were found on March 20. Thirteen of nineteen mink scats deposited here during the first half of March contained muskrat remains, compared with seven of sixteen scats for the south center where the minks were known to have been feeding upon disease victims.

Another possibility is one of sexual tensions forcing the beginning of the spring dispersal before the ice went out. A traffic victim was seen on U.S. highway 69 southeast of Wall Lake, March 15, and three of four males dying on the marsh itself from March 9 to 13 were in full breeding condition. In late March, a surface-active animal was collected from the northeast center, but it proved to be a fat and apparently healthy adult female. Also at the very last of the month, a pronounced but still localized dispersal took place in gradual stages from the northeast center, days before the actual break-up of the ice.

Minks were still responding to the availability of surface-active muskrats, whether the latter were vulnerable because of disease or not. Twenty-one of 42 mink scats deposited in the second half of March contained muskrat remains, including 3 of 14 scats passed after the softening of the ice and the appearance of much open water.

Slightly over 400 were judged to have survived on Wall Lake until the ice went out in 1950. This survival was all but confined to four main blocks.

One of these blocks comprised about 18 acres of muskrat-occupied shallows dominated by river bulrushes in the northeast part. It was not very successfully trapped during the short fur season. After the trapping, it had a carefully estimated population of between 145 and 180, more nearly the latter, or about 170. This block included the site of the deadly epizootic of early spring, and it is thought that about 15 muskrats per acre died on 4 clean-swept acres, plus maybe 20 or more on another 4 acres lying adjacent but less severely affected. There were some possible disease losses from 200 to several hundred yards away in other parts of the block, besides miscellaneous losses as from mink predation on ill-situated animals, winter wandering, and the like, and these may have totaled another 30 or 40 . The best evidence indicates that about 60 survived the winter on the 18 acres.

The block having the most muskrats after the trapping - estimated at between 600 and 750, more nearly the former figure, or perhaps 
about 630 - was about 75 acres of the central shallows. Losses from mortality and departure were locally severe during the winter. It had minor foci of disease between the fall of 1949 and the spring of 1950, but sweeping epizootics did not get started. Most detected mortality occurred through the agency of the mink predation upon frost-evicted muskrats already described. The greatest wintering losses were confined to a tract of about 25 acres of shallows located almost in the exact center of the marsh, which tract was all but depopulated, with an estimated mortality of about 150 . The winter and early spring losses on the other 50 acres of the central shallows amounted to about 150 muskrats more, from disease, frost-eviction, and mink predation, combined, thus bringing up the total post-trapping, pre-dispersal losses to about 300. If the early winter post-trapping estimates are nearly correct, the survival might be something over 300 for the 75 acres, but this figure is a little higher than the number actually believed to have survived. Possibly it should be about 275 .

Approximately 100 animals were considered alive elsewhere on the marsh after the trapping in December, 1949 - these being almost entirely localized in two wintering blocks in the south center. One block of about 22 acres was dominated by river bulrush (with minor growths of hardstem bulrush), but it had considerably more water than either the central or the northeast shallows. The muskrats of this block, though well-situated with respect to ordinary environmental features, were practically eliminated by hemorrhagic disease by spring. It is doubtful if more than a half dozen survived there out of a posttrapping population of perhaps 25 or 30 .

The other block consisted of a zone of about 60 acres of mainly river bulrush shallows adjacent to the deeper waters and the cattails and hardstem bulrushes of the southwest tip of Wall Lake. For the 70 or 75 muskrats present in mid-December, 1949, the winter survival was high. No post-trapping losses of consequence were detected, and it may be judged that perhaps 70 survived.

\section{SPRING TO FALL, 1950, AN EXCEPTIONALLY INFORMATIVE PERIOD}

With the rains of spring and early summer, the water level was restored almost to within a foot of the high water mark of the midforties. Large tracts of formerly dry marsh thereby became habitable and attractive for muskrats. Yet only the wintering area of the central shallows had any pronounced emigration, and to this source may be ascribed most of the Wall Lake muskrats moving more than a few hundred yards during the spring dispersal, including those leaving the marsh to wander cross-country. The main route of travel of the central muskrats, from late March through most of May, was in a southeasterly direction. Apart from the wandering (which took place early and was essentially over soon after the ice covering disappeared), the movements most closely studied were those of an orderly extension of home ranges or breeding territories into previously vacant but attractive bulrush stands - especially into a disease-swept tract and 
into what was formerly a drought-exposed stand of bulrushes immediately to the south of the central shallows. Most of the restocking traceable to the central shallows took place within a 500 -yard radius. There was practically no movement northward into the splendid habitat awaiting recolonization by muskrats in about the northern two-fifths of the marsh.

A few animals left the northeast shallows before the surface ice melted, to go to shore, but even these did not work along the shore line like real transients. Establishment of breeding territories could be quite satisfactorily traced within a radius of a quarter mile or less from known wintering quarters. From here, too, the animals worked westward, southward, and eastward but not northward. I do not know the origin of a single 1950 territory in the northwest corner of Wall Lake, 1,000 yards from the nearest place where muskrats got through the winter.

As of mid-May, 1950, the breeding population of Wall Lake was quite accurately determined as the occupants of about 131 territories, or the equivalent of at least an equal number of females plus associated males. Following the sex ratio of 46 per cent males in 139 fall and winter specimens, we would have about 243 adults. The occupied areas totaled 292 acres.

The relative shortage of males in combination with the scattered distribution of many of the territories cut down the efficiency of mating in certain territorial groups. Moreover, the dying of disproportionate numbers of adult males from hemorrhagic disease in late spring (seven of eight dead adults in sufficiently good condition to sex when found during the second half of May were males) did not remedy this unbalance. By early summer, there may not have been more than two males per three females in the adult population of muskrats on the marsh.

Except in the northeast shallows, little or no dying from hemorrhagic disease occurred between late March and late April. Then, about the time in late April when newcomers were establishing breeding territories in old foci of infection, the dying was resumed. No sweeping epizootics took place until later, but muskrats were found dead in May and early June at or near all recent disease foci. By late June, a severe die-off all but depopulated one of the best muskrat areas in the south part of the marsh. We can charge to hemorrhagic disease the loss of at least 28 and possibly as many as 35 of the 131 territories, as of early July.

Meadow mice (Microtus pennsylvanicus) proved to be an unexpectedly adverse factor from the standpoint of early productivity of muskrats at Wall Lake in 1950. This species of mouse occupied large acreages of dry or nearly dry marsh in the fall and winter of 1949-50, living in the muskrat lodges and feeding chiefly on the rootstocks of river bulrush incorporated therein. Despite conspicuous predation by minks, short-eared owls, and marsh hawks, substantial numbers remained to become real marsh dwellers as the waters rose in the spring. 
The mice of tracts having much lodged or floating vegetation - such as the northeast and the central shallows - could, by alternately running over the debris and swimming, travel about where they wished away from their retreats in the muskrat lodges. The mouse occupants of lodges situated in deep or more open water were marooned there and searched the lodges for food with a desperate intensity. In either case, the mice were for many weeks (until the marsh grew up to lush vegetation in June) dependent upon the bulrush rootstocks and what little variety of other foods they could find in a flooded habitat.

After it was noticed that the mice were thoroughly working the interiors of lodges for food, a study of possible predation by the mice upon young muskrats of helpless sizes was undertaken. Accordingly, 12 mouse-infested lodges that were kept in continued repair by adult muskrats as territorial headquarters were marked and later re-examined at appropriate intervals. Of these 12 territorial lodges having mouse occupants, all were in river bulrushes except one, which was in reeds.

It happened that half of the territorial lodges having mice were in rather open or deep water and the others were in shallows partly covered with emergent or floating vegetation. The fortunes of muskrats in rearing young in lodges containing mice were decidedly better where the lodges were in well-vegetated shallows rather than surrounded by open water. In the latter lodges, the mice usually appeared to clean out the accessible young muskrats within a few days after birth. Little or no successful rearing of muskrats occurred in the early part of the breeding season in five of the mouse-infested lodges. Some reduction in size of muskrat litters through depredations of mice is indicated by the field data from seven productive territories. Five of what were regarded as mouse-reduced litters averaged only 3.1 young at about one week of age.

A possible connection between the hemorrhagic disease and miscellaneous mortality of young muskrats may be mentioned. Apart from such obvious events as a suckling litter being left to starve after the death of the mother - resulting in the loss of one of the 61 litters handled on the marsh in 1950 - all of the intraspecific attacks known to be suffered by small young occurred in disease areas. One newborn litter was almost completely eaten by an adult muskrat that behaved in a way characteristic of a sick animal. Another litter in a disease area was lost under conditions suggesting intraspecific predation. In a third instance, a newly weaned young was bitten to death with extraordinary ferocity by a sick adult in a neighboring territory; the victim's intestines and part of its liver protruded from one side of its abdomen, more intestines from the other side, and a hind leg was bitten through and broken.

Most of the 1950 trapping at Wall Lake was done by skilled and cooperative trappers. Of the approximately 1,000 animals trapped, the carcasses of 952 were examined. Seven of 164 back-tags that had 
been placed upon young muskrats were recovered as a result of the trapping. The most interesting tagged animal was a precociously breeding female trapped at the age of 213 days practically where it had been tagged at the age of 16 days; its placental scars indicated the birth of a litter of 5 young in August, or a conception at around 3 months of age.

The ratio of 45 adult males to 79 adult females (36.3 per cent males) in the trapped sample of 952 carcasses illustrated the unbalance in favor of the females known to have existed on the marsh early in the 1950 breeding season. The over-all sex ratio was 51.2 per cent males. The sample of 828 young of the year (442 males, 386 females) contained 53.4 per cent males, compared with the 55.9 per cent males in 202 young examined soon after birth and 56.8 per cent males in 111 "kits" examined in the trappers' catches.

Of the 79 bona fide adult females (i.e., those born prior to 1950), 17 had not conceived during 1950, and 15 of the 17 were found in carcass lots totaling 447 specimens taken largely from parts of the marsh that were underpopulated in spring and early summer. On the other hand, only two of the nonbreeding adult females were found in the balance of the 505 specimens taken largely from tracts sufficiently well populated to permit efficient mating.

Other contrasts are afforded by the numbers of litters conceived by the breeding adult females living in underpopulated and well-populated tracts. Of 27 adult females that managed to breed despite a relative shortage or unavailability of males in the places where they lived, 5 (18.5 per cent) conceived a single litter each in 1950 ; $10(37.0$ per cent), two litters each; 4 (14.8 per cent), three litters each; and 8 (29.6 per cent), four litters each. Of 35 adult females that bred in a better populated marsh, only one (2.9 per cent) conceived a single litter in 1950; 8 (22.9 per cent), two litters each; 8 more, three litters each; and 18 (51.4 per cent), four litters each.

Considered in terms of litter production, the 1950 means for the underpopulated tracts were 1.64 litters for all adult females and 2.56 litters for those actually breeding; in the well-populated tracts, the means were 3.05 litters for all adult females and 3.23 litters for those breeding. Over the whole marsh, the means were 2.30 litters for all adult females and 2.94 litters for those breeding.

Of 69 litters conceived in 1950 by the sample of adult females living in the underpopulated tracts, 17 (24.6 per cent) were judged from the appearance of placental scars to have been born in April; 20 (29.0 per cent), in May; 15 (21.7 per cent), in June; 13 (18.8 per cent), in July; and 4 (5.8 per cent), in August. Of 113 litters conceived by the adult females of the well-populated tracts, the births of 17 (15.0 per cent) were thus dated to April; 24 (21.2 per cent), to May; 26 (23.0 per cent), to June; 29 (25.7 per cent), to July; 15 (13.3 per cent), to August; and 2 (1.8 per cent), to September.

For the marsh as a whole, the seasonal distribution of 182 litters conceived by adult females of the trapped sample in 1950 lined up as 
34 (18.7 per cent), in April; 44 (24.2 per cent), in May; 41 (22.5 per cent), in June; 42 (23.1 per cent), in July; 19 (10.4 per cent), in August; and 2 (1.1 per cent), in September. To get a true cross section of the season's breeding, we must add to these the single litters conceived by 22 females that were themselves born during the 1950 breeding season: five litters assigned to late July, nine to August, and eight to September. This would give a total of 204 litters conceived by the population sample examined - 34 (16.7 per cent), in April; 44 (21.6 per cent), in May; 41 (20.1 per cent), in June; 47 (23.0 per cent), in July; 28 (13.2 per cent), in August; and 10 (4.9 per cent), in September.

The precocious breeders in the underpopulated tracts conceived more young apiece than did those of the well-populated tracts (a mean of 5.7 as against 4.9 ), but the mean size of the litters conceived by bona fide adults in the underpopulated tracts was smaller (7.4 as against 8.3). For the entire marsh, the mean of placental scars counted in the uteri of fully adult females was 8.1 per litter; in the precocious young females, 5.3 per litter. At Wall Lake in 1950, the over-all mean was 7.7 for the 204 litters counted from placental scars and from 14 complete very young litters previously examined in the nests. The 14 complete young litters examined in the nests averaged 7.1 young in each, and 80 sets of placental scars of adult females trapped in approximately the same parts of the marsh where the litters had been handled during the field studies averaged 7.4 scars per set (or litter). If allowance be made for a minor amount of resorption of embryos in the uteri and for young born dead, the means from placental scars and from nest studies are in good agreement.

On the basis of field and specimen data (see Appendix C for details), the 1950 fall population was calculated at about 1,600.

\section{THE 1950 CHANGE IN STATUS OF THE HEMORRHAGIC DISEASE AT WALL LAKE}

Following the scattered dying of late spring and early summer and the deadly local epizootic of June, 1950, no evidence of mortality was personally seen on the marsh up to freeze-up, nor by skilled trappers who looked over their prospective trapping grounds in advance of the opening date. During the trapping, only two dead animals were reported as found by trappers under circumstances suggesting disease (one had died from lung and kidney hemorrhages and the other from acute intestinal hemorrhages), yet 30 or 6.7 per cent of a series of 446 trap carcasses examined for disease lesions had characteristic necrotic foci on the livers. This was a high incidence of infection for such a series of active animals taken at large, and the disease was surely of nearly general distribution over the marsh.

It is of interest that most (not all) of the animals showing conspicuous liver lesions were very young ones, in contrast with the previously noted inability of the very young to live long enough, at times of big die-offs, even to develop liver lesions.

Post-trapping checkups through December revealed no evidence 
of important losses at Wall Lake. One animal suspected of being diseased wandered about in the snow for at least a half mile and died sitting on the side of a lodge. Perhaps a week later, its frozen body was discovered by a mink, wrenched loose, and dragged away. In late December, the site of the late-spring die-off in the northeast part had two lodges lying close together that were taken over by a mink. A once disease-swept tract in the south center had three neighboring lodges also with unrepaired mink holes and showing continued mink use. This indicated the possibility of mortality of muskrats from hemorrhagic disease. Elsewhere on Wall Lake, the muskrats surviving the trapping had all appearances of getting along satisfactorily up to the end of the year.

\section{THE "GOOD YEARS" OF 1951, 1952, AND 1953 AT WALL LAKE}

By midwinter, 1950-51, nine local sites of mortality were distinguishable, of which two were sites of light losses considered incidental to deep freezing of shallows. The other seven were foci of the hemorrhagic disease, and only two of them were at sites not found during the previous year - and, at both of the latter, the losses also were light and did not continue into the summer. At one of the five old foci of infection, losses were known to have involved a few wintering animals, then to have ceased by spring. Four of the foci not only had animals dying from time to time during cold weather, but there the disease also continued to kill locally until about the middle of May, 1951. By early June, all of Wall Lake's local epizootics seemed to stop, after partially depopulating a total of about 30 acres, including about 22 acres previously known to have been disease-swept one or more times in recent years. Some further mortality probably due to disease was noted at a lodge situated within 100 yards of one of the foci: a mink was known to have eaten a newly-weaned young, and the body of another young was found floating in the water on a midsummer inspection.

Not counting young of the 1951 season, 22 dead muskrats were specifically recorded at Wall Lake between early spring and mid-May, and half of these were intact enough to examine for disease lesions. Two of the latter 11 had died from undetermined cause (old age would be as good a guess as any), and the other 9 showed diagnostic lesions. Of the 9 disease victims, 7 had the appearance of having almost beaten the disease, having livers that were heavily spotted with necrotic foci in all stages of healing. In one case, about a fourth of the volume of the liver was necrotic. In another, nearly all of the liver lesions were healing or healed except for an active lesion $4 \mathrm{~mm}$. in diameter, or about twice the diameter of the larger that are ordinarily seen. Intestinal hemorrhages were recognized in only 2 specimens, and, in one such case, the hemorrhaging was slight. One of the 2 individuals that died without building up extensive liver lesions had severe lung hemorrhages.

Comparative post-mortems on 2 adult females and their suckling litters made on the afternoon of May 18 were especially interesting. 
One female died probably in the morning of the day of the posting, but she had not been caring for her litter of 11-day (age estimated) young for some days. Five starved-looking live and one dead young were scattered about the bed of the lodge. The dead young had several liver lesions, and one of the 5 living had at least a single lesion starting to form. These young were the remnants of 11 conceived of the litter. The female had a new pregnancy of 8 embryos about $5 \mathrm{~mm}$. in diameter, and it may be conjectured that the onset of her sickness may have cut down both the size and rate of development of her second pregnancy.

The second adult female died about 18 hours before the posting, a victim of the pneumonic syndrome (though she had a few liver lesions). She did not conceive again after the birth of the litter she was suckling. She had 11 placental scars corresponding to her suckling litter, of which 7 young were found in three different places within the lodge chamber, having died an estimated 8 to 30 hours previously. The age of the one living the longest was estimated at about 10 days. While these died from hunger and neglect, 2 of the dead young had liver lesions, including one young with a heavy spotting.

Minks and other flesh-eaters responded most decidedly to the availability of muskrat flesh at three of the four foci of infection at which disease mortality continued into the summer. Three minks that were distinguishable as individuals stayed out in the center of the marsh far into the summer, subsisting for many weeks upon a diet of water birds and the diseased muskrats to be found at two of the foci. A family of raccoons similarly occupied itself about another disease focus, this one being 200 yards from shore. The fourth focus of the early summer was not discovered by mammalian flesh-eaters in time for exploitation.

Twelve of 15 muskrat carcasses found at mink retreats of the center after the ice went out were unsuitable for diagnoses; but 2 intact fresh carcasses (without a toothmark of a mink on them) and one other (of which the mink had eaten the head only) showed characteristic lesions. Two carcasses eaten upon by minks had sufficient growths of algae and water mold on tails and feet to indicate that they had been dragged to higher places after periods of floating in the water. Thirtysix of 43 mink scats deposited about the central retreats during the first half of May - the period of greatest mortality about the minkfrequented disease foci - contained muskrat remains, compared with nine of 90 deposited earlier in the year and one of 30 deposited from mid-May to mid-June. When the muskrats of the center stopped dying from disease in early summer, the minks stopped eating muskrats, though the minks remained at those places, and there were many muskrats (including young) still alive there. Moreover, when minks later moved away from the disease foci to work other central parts, they managed to continue eating water birds but had little if any luck with the muskrats - even when taking over muskrat-maintained lodges for temporary living quarters.

The details of what the family of raccoons did are not so clear. The 
raccoons leveled the lodges in an area of about six acres. It is conceivable that this family group learned to raid the nests for helpless young muskrats, but I doubt if this would have yielded them enough meat to encourage them to make a specialty of it had it not been for numerous large dead muskrats lying around. I found two dead adult muskrats that they had overlooked.

As of early May, 1951, 243 certain or highly probable breeding territories were enumerated on Wall Lake, or, following the overall early winter sex ratio of 51.2 per cent males, a total of about 500 adults. This is in good agreement with the figure of about $600 \mathrm{calcu}-$ lated to have survived the early winter trapping. After the trapping, a winter and early spring mortality of about 100 should have been quite within reason.

The spring and early summer die-off resulted in the loss of about 35 territories, including those established prior to the breeding season census of early May. An estimated 65 adults died during the period of notable mortality from late April to mid-May. Allowing for some scattered mortality from miscellaneous causes, this should have left about 425 adults on the marsh as potential breeding stock.

From midspring through the summer of 1951, Wall Lake was in a most attractive condition for muskrats - approximating its condition for the years immediately preceding 1947 - with water covering nearly all of the bottom. Seventeen of the territories for 1951 were established in the north half of the marsh, at varying distances (up to a half mile) from places occupied by muskrats during the past few years. Eight other territories were distributed along about a mile and a quarter of shore zone that had no muskrats in the winter of 1950-51, and about a half mile of this same stretch served as a refuge area for transients. About seven lone animals, thought to have been surplus males, gravitated to this place and maintained solitary nests from late April to at least the middle of May. Otherwise, the tracts having the breeding territories were the ones wintering the muskrats, though local dispersals within a 200-yard radius of wintering quarters were commonly traceable.

Territorial sites were distributed at densities of one or two per acre over the greater part of the regularly occupied marsh, with occasional aggregates of up to five territories per acre. Local growths of broad-leaved cattails were the outstanding inducements for such territorial massing.

Three of the examined lodges containing litters of young muskrats were also occupied by meadow mice, and, in one of these, the young muskrats probably were preyed upon by the mice. Only two of this muskrat litter were left at the age of about four days. One of the other two muskrat litters was reared up to weaning without detected loss from the mice, and the other still had nine young at the age of about ten days despite the presence of a mouse family.

In late summer and early fall, very localized dying occurred in two places on Wall Lake. One of these places was the earlier "bach- 
elor quarters" of the southeast shore zone. More muskrats moved in here after midsummer, and some rehabilitated a number of old burrow systems at the site of the shore-zone epizootics of the falls of 1948 and 1949. A hunter saw two sick-acting muskrats here about the middle of October, 1951; one was hardly able to move, and the other tried to attack him on shore when he went near it. One of five mink scats found here and assigned to this date contained muskrat remains, as did two of nineteen examined between late July and late August.

The second place was an area including part of one of the central disease foci of the spring and early summer. This place (of about three acres) was nearly muskrat-vacant by mid-September and had been for some weeks. Later in the fall, the vacancies filled up again, and no more evidence of dying was found until late December, when the first wintering mortality on the marsh was detected.

Extremely few dead muskrats were reported by hunters and trappers during October and November, 1951. One hunter saw three dead in the water about a lodge in one of the cattail islands of the south part. The trappers, who covered the marsh very thoroughly in connection with a week of legal trapping in late November, reported finding only four dead animals, of which the single one examined was a disease victim typical of those almost but not quite recovering. But the disease was obviously widespread; 45 or 10 per cent of 450 trap carcasses that were examined for disease lesions had necrotic areas (mostly in various stages of healing) in their livers - an astonishingly high incidence and one suggesting that most of the animals were contracting the disease in sublethal cases. The most conspicuous lesions were usually to be seen in the youngest animals, yet it was clear that these young were showing pronounced resistance, in contrast with their dying without visible lesions during the deadlier epizootics.

The trappers took, in a special trapping season applying to Wall Lake in 1951, approximately 1,850 or, at the outside, perhaps 1,900 . The 1,047 carcasses examined consisted of 58 adult males, 68 adult females, 527 young males, and 392 young females. One hundred and twenty-four or 13.5 per cent of the 921 young of the year in the sample were of "kit" sizes. Of the 394 classed as young females, 13 or 3.3 per cent were precocious breeders, each giving birth to a single litter (averaging 5.5 young or a total of 71 ) assigned to August or later. Of 67 adult females in the sample for which placental scars could be counted and aged, 8 had not conceived in 1951; 3 conceived single litters each; 8 , two litters each; 20, three litters each; 27, four litters each; and 1, five litters. The seasonal distribution of the 192 litters born to the 67 adult females may be judged from placental scars to have been 19 in April, 47 in May, 50 in June, 48 in July, 26 in August, and 2 in September.

The "Allee effect" of inefficient mating in sparsely populated areas is well-illustrated by the data in hand. Of 7 adult females taken by the trappers from isolated rush clumps, 6 did not conceive at all in 1951, whereas but 2 of 61 taken from the more populous parts failed 
to conceive. That the muskrats lived sedentary lives on this marsh during the year is demonstrated by the tagging as well as by the observational data. A female born and tagged in 1950 and 4 tagged young of the year that were recovered in the 1951 trapping were all trapped in the vicinities of where tagged. The 1951 muskrat population of Wall Lake also was isolated, out of the lines of travel of adjusting stream populations, and quite clearly self-contained.

The central parts of the marsh were the sites of remarkably high rates of survival of the young despite the continued summer residence of the minks there and early mortality in two major disease foci. A sample of 450 carcasses taken from a strip about a quarter-mile wide and a mile in length and running right through the middle in a north-south line consisted of 26 adult males, 27 adult females, 236 young males, and 161 young females. The 20 productive adult females in this lot conceived a mean of 3.15 litters and 23.8 young, or a total of 475 young. Two precocious young females each conceived a single litter of 5 , bringing up the total conceived by the sample's breeders to 485 . The 397 young of the year in the trappers' catches corresponding to the 485 conceived by the sample reflect a reproductive success of 82 per cent.

Outside of the above strip, 40 productive adult females conceived a mean of 3.15 litters and 26.8 young or a total of 1,099 young. Eleven precocious females of this other sample conceived a total of 61 young in single, late litters, thus bringing up the total conceived to 1,160 , compared with only 524 young, or 45.2 per cent, reared. For the combined sample represented by the trap carcasses, the rearing of 921 of 1,655 conceived amounts to a reproductive success of 56 per cent.

Of the 425 adults judged to have been left on the marsh after the late spring and early summer disease losses, about 230 should have been females, following the 46.0 per cent ratio of males in the sample of 126 adults taken by trappers. The sex and age data applied to an adult female population of 230 surviving the 1951 breeding season would give a calculated total fall population of about 3,530, including about 3,100 young of the year. About 203 of the 230 adult females should have been productive, averaging 3.15 litters and 25.8 young, which would give about 5,237 young conceived or born in about 639 litters, plus about 230 young in 44 litters from precocious young breeders, or a total of about 5,467 young.

The survival rate of late-born young was unusually high at Wall Lake in 1951. For the animals of the trapped samples, 28 or 14.6 per cent of the litters conceived by adult females and all of 13 litters conceived by precocious young females were assigned to August or later. This figures out at 295 or 17.8 per cent of the total of 1,655 conceived by the trapped sample during the breeding season. The rearing of 124 "kits," or 13.5 per cent of the 921 young of the year in the trapped sample, demonstrates that the late-born had nearly as good a chance in 1951 as did the early-born - quite different from what often is the case. 
The week of trapping removed only a few of the many minks frequenting Wall Lake in the fall and winter of 1951-52, and, when snow came, it was obvious that the marsh had an exceptionally heavy population of minks - perhaps the largest number in decades. One small tract studied intensively in early January had at least 3 minks that were distinguishable on the basis of tracks (including an enormous one that left, while running in firm, wet snow, an imprint of a hind foot measuring $51 \mathrm{~mm}$. in width, at maximum spread); and almost all other parts of the marsh, visited then and thereafter until spring, likewise had mink signs. My guess is that there may have been up to 20 minks, mostly large ones, wintering on or about the marsh. They gave the muskrat-occupied parts a thorough working during the entire time that an ice covering existed, and their relations to the wintering muskrats were carefully studied.

Even early in the winter, the minks were repeatedly smelling the lodges (this could be deduced from the trails running past or over the lodges) but, except for certain places, were not digging into them. Most of the mink holes then being made in the dwelling lodges were promptly repaired by the muskrat occupants. But, in late December, a centrally located tract about 150 yards by 200 yards in size (the site of the probable late summer or fall epizootic previously referred to) began showing many unrepaired mink holes, and, for about the next six weeks, minks were obviously interested in this place. The minks were similarly interested in a smaller tract about 300 yards away (also the site of an old disease focus) from about January 10 to the end of the month. Mink-eaten remains of seven muskrats were found in these two suspected foci during the above period, as were muskrat remains in seventeen of thirty-one contemporaneous mink scats. Three other victims were later found, including one with typical lesions. Away from these foci, muskrat remains occurred in one of nine mink scats deposited in the south half of Wall Lake from freeze-up to mid-February.

In early January, the minks became interested in a number of lodges in and near the old disease focus that had been so thoroughly worked over by the family of raccoons in the spring of 1951. Remains of 3 dead muskrats were found here during the next three weeks, and 4 of 17 contemporaneous mink scats contained muskrat remains. A fox also scavenged on a dead muskrat that probably died of old age; and 1 of 2 fox scats from here contained muskrat remains, compared with their absence in 34 other fox scats examined on the marsh during the winter. Two muskrats dying in the winter were found in the northeast shallows, at the site of the pneumonic epizootic of the spring of 1948. These were too putrid to show possible disease lesions. when examined, but one had suffered loss of part of its tail from freezing before it died.

The sparsely populated, food-rich, but shallow northwest corner was the site of some mortality that at first seemed to reflect restlessness of individual muskrats with the approach of the breeding season, but some dying from disease was found here later. Four different 
places were seen in mid-February where muskrats were coming out on the ice, though only the shallower of the waters froze to the bottom. A muskrat was found freshly killed and eaten upon by a mink at one of these places, and remains of a second victim were found in the same general area. Mortality of at least two more was detected in March, and dying from disease was known to have continued into May. No muskrat remains were found in 70 mink scats deposited here from late fall through January, but 10 of 14 February scats and one of 15 March scats had representations of this item.

An imperfectly dated epizootic was detected in the south center, at the site of a rather sweeping June die-off in 1950. A mink dragged a probable muskrat in the snow on January 10, 1952. On March 10. mink-eaten remains of nine muskrats were found here, and all 16 fresh and recent mink scats contained muskrat remains, as did all 5 fresh scats from the shore zone. The evidence suggests that these muskrats were dead long before the minks got to them. The mink holes were almost restricted to the sun-softened southwest sides of the lodges, and the most nearly complete carcass found on the visit of March 10 smelled strongly of decay, though the mink had freshly dug it out of a chamber regularly used by living muskrats. Of two animals known to have died in early winter, one was of a young trap cripple probably dying of its wound, and the other at least had no liver lesions. This tract (about 15 acres) included the site of a deadly epizootic after the ice went out in 1952.

Only two places were found in 1952 where spring or early summer disease mortality at Wall Lake had no evident connection with winter foci, and at neither of these two places were the losses extensive up to mid-June. Only one of the winter disease foci failed to have some spring dying as well, and this exception related to a tract having no known victims of the pneumonic syndrome of the disease.

Elsewhere on the marsh, in the spring and early summer of 1952, the pneumonic syndrome occurred to the practical exclusion of the other syndromes, to which the muskrats were currently showing a high degree of resistance. One pneumonic victim did have an enormously enlarged and necrotic spleen, and others occasionally had a few liver lesions or slight enteritis, but, on the whole, the only gross lesions to be seen in the pneumonic victims were localized in the thorax. At the site of the deadliest epizootic, the last victim showing substantial liver lesions died about April 8; of 22 victims later recorded from here, 11 were too decayed for diagnosis, but the other 11 showed the expected pneumonic lesions. Of 32 victims recorded from the other sites of continuing spring and early summer mortality, 7 were found sufficiently fresh for posting, and these all had the pneumonic lesions.

In all three cases where locally sweeping epizootics got started at Wall Lake in the spring of 1952, the dying began at sites of heavy mortality of past years, including two foci notorious for their disease losses since 1948. After these localized epizootics gained momentum, they spread about wherever contiguous muskrat populations re- 
mained to take the infection, with resulting mortality in the affected tracts of close to 90 per cent whenever the dominant syndromes switched from the hepatic-enteric to the pneumonic.

Some evidence of spring dispersal away from Wall Lake was noted in 1952, but, while the marsh population then did not appear to be quite as self-contained as during 1949, 1950, and 1951, it is doubtful that any really important movements out of - or into - this observational area took place in 1952. Many of the muskrats of the south center were evicted by violent storms washing away the less sheltered lodges; otherwise, the muskrats seemed to stay to breed in parts of their familiar home ranges of the past winter. Only the food-rich northwest corner drew any great number of animals during the spring dispersal, and the evident source of these was the north center, lying within 600 yards of the outermost places reached and settled by muskrats of the north half. The storm-evicted occupants of the south center first concentrated in the nearest heavy vegetation, then dispersed along routes that could not be traced with complete satisfaction, though many obviously moved into previously muskrat-vacant islands of cattails and bulrushes.

The field notes indicate a total of 455 breeding territories on Wall Lake, as of early May, 1952. On the basis of the sex ratio of 55.1 per cent males shown by the winter-trapped carcasses, the initial, more or less settled, breeding population figures out at about 1,035 adults, plus whatever number may have been living in or about territories overlooked in the censusing of heavily vegetated parts of the north half. Allowance for about 20 of such overlooked territories would give a total of about 475 territories, or about 1,075 adults. Few territorial concentrations exceeding two per acre were found; exceptions were four territories in a cattail clump of less than an acre, 11 in four acres, 10 in two acres, and 5 in one tract of about one-half acre. The latter had a lodge containing young of two different females.

During May, 33 territories were recorded as lost through the agency of the hemorrhagic disease. Eight more were recorded as lost in the first half of June. Thus, about 100 adults were eliminated from the 1952 breeding population, which would then leave a mid-June population of perhaps 975 adults remaining in well over 400 functional territories.

The responsiveness of minks to the disease foci at Wall Lake was, if anything, more notable in the spring and early summer of 1952 than in 1951. In 1952, no spring focus of any consequence failed to draw the attentions of minks, even when located near the center of the marsh - in fact, the evidence is that the minks stayed over from winter at these places. Whereas none of 165 mink scats gathered in May and June away from the foci contained muskrat remains, 32 of 198 scats from the foci did contain muskrat remains. For the main focus, 32 of 102 scats gathered during April (the month of severest disease mortality) contained muskrat remains. As long as the muskrats kept dying, the local minks took advantage thereof, though overlook- 
ing many dead muskrats, probably about two for every one they found after the ice went out.

After all but depopulating the 15-acre tract where the heavy dying of winter and spring occurred, the pneumonic-syndrome epizootic did about the same thing in early June in a neighboring tract of about four acres. Wide areas of muskrat-vacant marsh on three of four sides of both of these tracts seemed to prevent further spread. No evidence of dying was found after the third week of June until early fall, despite the fact that, by July, muskrats were moving into the disease-swept areas and establishing themselves there.

A breeding female that had apparently been living for many weeks in the main area of the pneumonic epizootic was taken for a specimen on June 30 . She had no recognized liver or other lesions, but the small sizes of her two pregnancies of the season ( 6 and 5 young) might suggest earlier illness. The mean size of 17 complete litters handled up to this time in 1952 was a little less than 8 .

A probable case of ringworm skin disease was seen, June 12, on a young muskrat of about 9 days in one of the bulrush islands of the southeast center. It had two large hairless patches reminiscent of the many victims of Trichophyton studied at Round Lake, 1935-38 (Chapter 5).

Of the young muskrats tagged on Wall Lake in May and June, 1952, five were turned in by trappers in the fall. Four of the five were caught close to, the fifth approximately 1,000 yards away from, sites of tagging. This was about the sort of pattern shown by the field data on movements. While it was clear that muskrats appeared in late summer and early fall in places several hundreds of yards from those having had breeding populations earlier in the year, it was just as clear that the majority of family groups tended to stay in the vicinities of their original territories of spring and early summer. Many fair-sized tracts of excellent marshy habitat remained unpopulated by fall for the obvious reason that insufficient movement occurred away from adjacent territorial sites to put muskrats into them.

The one outstanding example of population adjustment that was studied occurred on the part of a local population living adjacent to a tract of about seven acres that had been depopulated in April and May by a pneumonic epizootic. By midsummer, the habitat of the local population that escaped the epizootic had deteriorated, and the living animals simply took over the depopulated tract in gradual stages. The end result was a mass shift over distances varying from 50 to almost 300 yards, leaving, by late summer, the deteriorated habitat virtually unpopulated and the formerly disease-swept tract well refilled with muskrats.

Along the southeast shore, a burrow system at which muskrats had died at intervals since the fall of 1948 - and one of the few places where dying had been noted in the fall of 1951 - was the only site of dying discovered at Wall Lake between late June and late fall, 1952. At least one animal died here about mid-September, right where 
victims were usually found. Then, no further evidence of dying was found until November 7, when a freshly dead "kit" was found at another disease focus of limited area near the south central shore. This "kit" had lesions suggesting low resistance. From the latter focus, a very deadly epizootic was traced in the shore zone for about 130 yards to the west on November 9; the three other victims examined all had lesions suggesting low to moderate resistance. A third old disease focus, this one in the southwest center, was also known to be the site of substantial dying in early November; two dead were found here by trappers, and a large proportion of the diseased specimens caught in traps came from this general area.

Trappers' catches from Wall Lake during a 10-day open season in mid-November, 1952, amounted to more than 4,000 muskrats. The intensiveness of the fur trapping evidently prevented the late-starting fall epizootics from spreading over much of the marsh away from the disease foci.

A sample of 276 trapped carcasses believed to be representative was examined, and 10 or 3.6 per cent showed liver lesions. There were no small young among these carcasses, in contrast with the large proportions of young in the trapped carcasses showing healed or healing lesions in 1951. Moreover, the 1952 specimens of Wall Lake animals that were diseased yet still active enough to be caught in traps generally showed moderate to severe lesions, some healed-looking and some indicating that the victims were about to succumb.

It should not be assumed that the late-born young were not contracting the disease in the fall of 1952. Rather, the likelihood is that the late-born young were not staying alive long enough after contracting the disease to be caught in traps or to build up liver lesions.

Using a minimal basis of 400 productive territories and the sex and age ratios of fall (27 adult males, 19 adult females, 149 young males, and 81 young females), a pre-trapping population of 968 adults and 4,842 young, or a grand total of 5,810, may be calculated. Although this figure may be as accurate as any permitted by the data, my feeling is that the fall population actually was somewhat higher.

The sample of 19 adult females had a total of 498 placental scars in 63 litters, or a mean of 26.2 young conceived in a mean of 3.3 litters for the breeding season. One female conceived two litters in 1952; 11, three litters each; and 7, four litters each. Of the litters represented by the placental scars, the times of birth of 3 were assigned to April, 16 to May, 17 to June, 17 to July, 8 to August, and 2 to September.

No evidence was found of breeding by precocious young females at Wall Lake in 1952, though bona fide adults did plenty of late breeding. Two of the 17 "kits" found among 230 young of the year in the trapped sample were animals of about six weeks, or animals born in late September. A ratio of only 7.4 per cent "kits" among the young of the year is sufficiently in contrast with 15.9 per cent of the litters judged to have been born in corresponding months to indicate 
a disproportionate mortality of the late-born young. Part of this disproportionate mortality is attributed to greater susceptibility of lateborn young to disease.

Approximately 2,000 muskrats survived the fall trapping, of which an estimated 75 to 80 per cent entered the winter of $1952-53$ in the shallower but food-rich central and north parts of the marsh. The south part was not only more accessible to trappers using boats, but it also lost sizable acreages of food resources through natural causes.

The muskrats of the trap-thinned south part suffered light wintering losses, and these losses were all but restricted to two major disease foci. The few minks wintering here centered their attentions about these foci. Remains of 10 mink-eaten muskrats were found, and 44 of 99 mink scats contained muskrat remains.

In the north shallows, the muskrat wintering losses were possibly 100 , occurring through a combination of disease in minor foci, freezing of the shallower places to the bottom, and mink predation upon vulnerably situated animals. As the spring breeding season came on, the muskrats did a certain amount of fighting and shore-wandering, which also meant some more mink predation upon those muskrats trying to live at the greatest disadvantage. An extremely high concentration of minks - an estimated 12 to 15 - wintered here, to stay on into the spring and summer.

Of 715 mink scats deposited in the north shallows from early winter to midwinter, 203 contained muskrat remains, compared with 62 of 297 scats for late winter through the first of March and 57 of 455 scats for the second half of March. Of 23 mink-eaten muskrats noted for the north shallows for this period, only 3 were found in known disease foci, but neither is it certain that any of the other 20 were away from places where dying from hemorrhagic disease had occurred; and it may be judged that disease loss constituted about half the wintering loss of about 100. For April, 61 of 433 mink scats contained muskrat remains, but this item was not found in 167 scats for the first half of May, after both dying and shore-wandering of muskrats had largely ceased. The April exploitation was clearly linked with dying of muskrats at disease foci; of 8 dead adult muskrats examined in sufficiently fresh and intact condition to be diagnostic, 7 (including 2 partly eaten by the minks) were disease victims. The prompt letup in feeding by minks upon muskrats in late April is significant insofar as a settled muskrat population of about 1,000 adults was living securely in the north shallows, even in meadow-edge habitats that were thoroughly worked over by the numerous minks.

During late winter and early spring, 1953, raccoons dug open lodges in one of the principal disease foci of the south part of Wall Lake, and they continued visiting this tract until midspring. Two raccoons were seen asleep in the top of a lodge having a dug-out nest of young muskrats, and other nests in the vicinity were raided. Of 60 raccoon scats deposited from late March to early May, 17 contained remains of young muskrats, and the muskrat-containing scats had bones of dozens of individual young muskrats aged up to several 
weeks at time of death. Some scats were packed masses of tiny muskrat bones and teeth. This exploitation ceased in early May, and none of 23 raccoon scats deposited here from mid-May to early June contained muskrat remains. Most of the opening of muskrat lodges by raccoons in May and June occurred in a second disease focus, but none of 44 locally deposited raccoon scats contained muskrat remains.

The above raccoon-muskrat relationship appeared to be neither a simple matter of direct predation nor exploitation of disease victims. The centering of attentions of the raccoons in or about disease foci was striking - many shore-zone lodges and burrows adjoined both of the raccoon-worked foci, but the raccoons did not disturb them. Yet, much of what went on in the general areas of the disease foci did have aspects of direct predation, with the raccoons digging out nests having young muskrats; and the one thing that seemed to terminate the raccoon predation was the harrassed adult muskrats moving their territorial headquarters out into deeper water or into other places where the raccoons were unlikely to swim. Of course these territorial shifts also may have reduced the chances of family groups contracting the disease. The leg bone of a half-grown muskrat at one of the raccoon retreats suggested scavenging on a disease victim, for this size muskrat should normally be able easily to escape capture by raccoons. It may be that the raccoons learned that the foci were likely places in which to seek dead muskrats and that, while there, they got started hunting the perfectly normal but helpless smaller young muskrats in the nests.

A mid-May, 1953, total of 708 maintained territories represented about 1,900 adults. Over half of these muskrats were located in the shallower but food-rich northern third of the marsh, and, at the high water stage of spring, the shallower parts were not necessarily very shallow in terms of muskrat habitat. Two local concentrations the equivalent of 7 pairs of muskrats per acre were noted.

The shallows became drought-exposed in late summer and early fall, with extremely severe consequences to the occupants of 130 territories and less serious consequences to the occupants of another 300 , or more, territories. By mid-October, fair remnants of the original populations (consisting for the most part of large animals) were still living in the dried-out territories. (One muskrat found freshly killed by a dog was an old male.)

Population remnants could be seen at sites of old disease foci as well as elsewhere. At one of the later foci, 7 of 11 mink scats from early October contained muskrat remains, compared with 2 of 30 scats deposited a short distance away. Mortality was recorded at another disease focus, but none of 8 scats for late September or early October contained muskrat remains. The occurrence of muskrat remains in 8 of 9 scats from a long-dry place probably reflected predation upon drought-exposed muskrats; elsewhere it was remarkable how little the drought-exposed muskrats were exploited by minks except at old disease foci.

Six of about 1,000 raccoon scats hastily looked over in the dry 
tracts contained muskrat remains. All 6 were from the near vicinity of known foci, including one of the most consistently deadly on Wall Lake - the acre-sized focus in the north center, from which the main die-off, winter and spring of 1947--48, had started.

From spring through early fall, most of the old disease foci were left almost devoid of muskrats, as dying occurred about as fast as the foci were reoccupied by newcomers. The 1953 drought surely reduced the disease losses by leaving some of the worst foci so dry that they no longer held attractions for muskrats after late summer. Foci that were sites of late fall dying were those becoming refilled by readjusting animals during about the middle of the fall and were almost restricted to the south center. At these, some dead were reported by hunters and trappers as early as a month before the trapping season opened on November 10, but no epizootics really got started. With the opening of the trapping season, public trapping removed many of the dangerously situated newcomers just as they were beginning to die.

The catches of two groups of trappers included muskrats taken from the south central disease foci, and 839 carcasses of these catches (representing the first week of trapping) were examined. Of the 256 that were first caught, two animals, or fewer than 1 per cent, had a few small liver lesions. Of the 583 caught some days later, 16, or nearly 3 per cent, had liver lesions, and, of the 16 diseased livers, 8 had substantial to large numbers of lesions that were obviously getting a good start. The lesion changes would seem to indicate a build-up toward a potentially serious epizootic.

Totals of 916 carcasses of trapped muskrats were examined at Wall Lake in November, 1953: 72 adult males, 68 adult females, 468 young males, and 308 young females. Of 69 adult females examined in the fall, 8 had not conceived young in 1953; 6 had one litter each; 5 , two litters each; 27, three litters each; and 23, four litters each. The mean number of litters for the 69 adult females was 2.71 and, for the 61 breeders, 3.07. Seasonal distribution of the litters of the above adults: 22 or 12 per cent of 187 litters were assigned to April; 45 or 24 per cent to May; 48 or 26 per cent to June; 44 or 24 per cent to July; 27 or 14 per cent to August; and a single one to September.

Twelve or 3.9 per cent of the young females in the trapped sample conceived a single small (averaging 5.4 young), late (born from late July through September) litter. All together, the birth dates of 39, or 20 per cent of the sample of 199 litters yielding quantitative data, were assigned to August and September. That these late-born young did not thrive as well as the young born earlier is indicated by the occurrence of only 90, or 12 per cent, late-born animals (assigned to birth dates after July) in the 776 specimens of young of the year in the trapped carcasses. Among the 90 late-born young in the midNovember carcasses, 16 were judged to have been born less than two months previously.

Many young animals in at least the better-situated of the drying 
territories made successful adjustments after the breeding season. They were able to move into the more disease-free parts that had favorable water levels, fair to excellent food resources, and were still relatively underpopulated by muskrats. There was also considerable late breeding on the wetter two-thirds of the marsh, even in places where most of the marsh bottom was exposed except for the deepened channels about the muskrat lodges. Yet, in the latter places, the excellence of the food supply (mostly river bulrush) offset many of the disadvantages of the low water as long as plenty of surface water actually remained in the channels up to the onset of hard frosts.

Wall Lake, being outside the travel routes of muskrats adjusting to the drying of surrounding streams, had an essentially self-contained muskrat population in 1953 - that is, except for some muskrats leaving the dry north end and perhaps other shallows to wander. The calculated population of adult females still alive on the marsh by the beginning of the trapping in November was about 480 . This base, used with the ratios shown by the trap carcasses, gives a pre-trapping population of 6,480 , or, in rounder numbers, about 6,500 .

The trapping pressure was excessive on Wall Lake during the 30day open season beginning November 10, 1953. Except for the occupants of certain hard-to-get-at shallows, the muskrats were nearly cleaned out, and probably no more than 300 survived the trapping. The survivors of the trapping were further reduced by losses from disease and winter-killing. Almost annihilative mortality was noted during the winter at 4 well-known shallow-water disease foci, at which remains of 17 probable disease victims were found. There were muskrat remains in 113 of 134 scats deposited by perhaps 4 minks frequenting the disease foci, December through February. Elsewhere in the partly or completely exposed shallows - including suspected but not actually proven disease foci -19 dead muskrats were found, of which the two intact specimens were disease victims. Fourteen of 28 mink scats deposited at scattered sites contained muskrat remains.

\section{TWO YEARS OF UNDERPOPULATION, 1954 AND 1955}

The Wall Lake breeding census of mid-May, 1954, gave the figure of 52 maintained territories, representing about 130 adults. The area received enough spring rain to become a generally excellent muskrat marsh again - but with only about a tenth of the breeding stock that it could easily have accommodated.

Signs of at least a fair amount of reproduction could be noted during the summer in those few tracts in which the low breeding population tended to be distributed in clumps of territories. Away from these clumped territories, there seemed to be little or no reproduction by animals living in isolated small cattail, reed, or bulrush islands. Later, the inefficiencies of breeding as a result of too-low population densities were verified by specimen material obtained from trappers in late November.

Of approximately 500 muskrats trapped by the public in 1954, the 
carcasses of 266 were examined: 14 adult males, 24 adult females, 141 young males, and 87 young females. Nine of the 24 adult females had not conceived in 1954, but the samples were trapped from those parts of the marsh having had by far the largest numbers of isolated adult muskrats during the breeding months. Three of the 24 adult females gave birth to single litters dated to May - they probably had been pregnant when taking up residence in out-of-the-way places. Of the other 12 adult females, 6 conceived 2 litters each in 1954; 2 , three litters each; and 4, four litters each. Assigned birth dates of the 37 litters: 2 litters to April, 10 to May, 11 to June, 11 to July, and 3 to August.

Seven of the 87 young females of the trapped sample were precocious breeders, and one of these gave birth to 2 litters -5 in each litter and assigned to late July and late August. The birth dates of the other 6 litters of precocious young females were assigned to August.

The population of resident adult muskrats surviving until the fur trapping figured out at about 80 , and the number of young reared on Wall Lake in 1954 at about 675. Of these young, about 600 were born before August, and, of the late-born young reared, about 45 were - on the basis of existing ratios - born to the precociously breeding young females. The actual fall population may have been somewhat higher than the total of about 755 muskrats calculated; after allowing for overlooked territories and possible small numbers of newcomers from the outside, an estimate of about 800 may be made.

About one square mile of marsh was habitable for muskrats by late November, 1954, and, following the trapping, this area had a population of about 300 entering the winter. Only a little dying was noted in fall and early winter, this all being confined to old disease foci. One of the 266 trapped carcasses that were examined had a liver lesion suggesting the hemorrhagic disease. Of a total of about 32 ) lodges, 31 were found opened by minks between freeze-up and midDecember, and 26 of these 31 mink-opened lodges were either in or adjacent to disease foci. Even so, remains of only three probably diseased muskrats were found in this period, and none of 101 early and mid-December mink scats contained muskrat remains. As the winter progressed, the diminishing evidence of living muskrats in the vicinities of major foci indicated that epizootics were spreading under the ice on a considerable scale. An abundance of minks - estimated at between 15 and 20, probably nearer the former - worked muskratoccupied and muskrat-vacant parts alike, and these minks were most responsive to new sites of dying as the local epizootics spread away from the old foci of infection. Eighty-six of 329 winter mink scats deposited after mid-December contained muskrat remains. Only 3 specimens of 42 dead muskrats were in good enough condition to examine for lesions of the hemorrhagic disease; all three proved to be diseased, including one apparently killed by a mink while starting to hemorrhage. Probably at least twice as many muskrats died as were individually recorded in the course of the winter studies, so an esti- 
mate of about 100 dying mainly from the hemorrhagic disease would seem reasonable.

The breeding season census, as of the first half of May, 1955, gave a total of 97 functional territories. Application of the sex ratio of 58.3 per cent males obtained at Wall Lake in the preceding late fall and early winter would give a total of about 233 adults for the settled late spring population. One territory had been lost shortly before the breeding season census - presumably from disease, in view of its location in a small focus of known deadliness - but only one specimen of an animal dying from disease was found in the course of the spring. The majority of the territories were maintained in parts of the marsh considered fairly safe on the basis of their disease histories. Nevertheless, a few territories were in time established in some of the deadliest foci and were almost certainly lost, in turn.

By late fall, only about 70 acres remained covered by water, and practically the entire muskrat population was concentrated in a tract established as a state fur-refuge area. A total of 256 medium-sized and larger lodges in the wetter parts of the marsh should signify a population of about 1,200 .

Most of these muskrats got along well up to the end of December, though evidences of both disease loss and drought vulnerability were recorded. The shallow, thickly-vegetated central and north parts had a heavy population of minks - estimated at about 30 on the basis of signs - and these minks were exploiting muskrats in two places suspected of being sites of dying from hemorrhagic disease. Eleven of 29 mink scats from these two places contained muskrat remains, compared with no muskrat remains in 52 mink scats examined from other muskrat-occupied parts. At this time, there was some but not much activity of ill-situated muskrats on the surface of the ice.

\section{THE COLLAPSE OF 1956}

By late January, 1956, muskrats were active practically everywhere on the surface in the muskrat-occupied parts, to the accompaniment of much intraspecific fighting and mink predation. A freeze-out crisis reached acute stages, which continued unrelieved into March. Fifteen trails of minks dragging muskrats were noted during six inspection trips made over a six-week period. Muskrat remains were found in 92 of 100 mink scats, as well as in all 4 fox scats examined during the middle two weeks of February. (An unrecorded number of fox scats examined at random earlier in the winter had contained no muskrat remains.)

As many as five bodies of muskrats were recorded as cached in a single mink retreat in a muskrat lodge, and the source of these dead was a disease focus about 150 yards away. After the melting of the ice, three muskrat disease victims were examined at the focus itself. One of the three had recently died, and times of death of the other two were datable (on the basis of stage of sexual maturity) to the period when the minks had been active dragging muskrat bodies from this 
place. Later in the winter, it became clear that very heavy mortality from disease was occurring under the ice in some of the places that had had the most muskrats at freeze-up.

As of mid-May, the muskrat-occupied parts had a total of about 80 maintained territories representing about 200 muskrats. Some movement away from the marsh was known to have occurred in late February and early March, but most of the fall-to-spring decline of approximately 1,000 muskrats must be assigned to mortality. No accurate means of dissociating this mortality exists. The best I can do is to estimate that about 800 died of disease during the winter and that the loss of the other 200 may be charged to departure from the area and to freezing, fighting among themselves, and mink and fox predation upon ill-situated animals that got into dangerous habits of foraging on top of ice and snow.

Four of 81 mink scats examined in May contained muskrat remains, and all 4 of the muskrat-containing scats came from a place where dying from disease was suspected of continuing.

The case history of the muskrat population became truly astonishing during the summer of 1956. It is true that the marsh went dry, but drought did not account for the wholesale abandonment of territories taking place in early summer. As early as mid-June, I was seeing evidence of abandonment of once-maintained territories while water remained sufficiently deep to permit me to reach some of them by canoe. Within the next two weeks, and before the last of the surface water disappeared from the majority of territories, abandonment progressed to the point where I could, with certainty, find only 2 of the original 80 territories still being maintained. I could not trace the movements of the vanishing muskrats, nor could I find signs of many living at large in thick food-rich vegetation of the dry marsh surrounding the abandoned territories.

The tract of marsh that still had water covering the bottom shrank from 70 acres as of mid-May to about 4 acres by early September. By then it was clear that mostly adult muskrats were congregating in food-rich retreats within a 300-yard radius of the last surface water. By mid-September, all surface water was gone, at which time the remaining muskrat population was estimated at about 45, including about 20 on a couple of acres having the most conspicuous density. The total muskrat-occupied area was then about 6 acres. By late September and well into the fall thereafter, this population was maintaining itself without evidence of further loss.

I cannot account for the almost total disappearance of the Wall Lake muskrats in November or early December, 1956. The only muskrat I could find there in mid-December was collected for a specimen at the place where what was thought to be this same animal had been living alone since early fall - at the last territory clearly being maintained on the marsh. The specimen was an adult female that had conceived four litters in 1956, for which birth months estimated from placental scars were April, May, June, and August. The latter line-up 
of birth months was in excellent agreement with field data on sizes of young found in the original territory.

After a drought-exposed and muskratless spring, Wall Lake had some surface water restored - over perhaps 50 acres of bottom - by the May and June rains of 1957. A lone muskrat came into the marsh to establish itself about the second week of July, in habitat good enough to have accommodated hundreds. No further sign of this individual was traced past midsummer. Later signs indicated that a few more animals may have come in cluring late fall. As of late December, there was on the marsh one large lodge harboring a single muskrat. In another tract about a half mile distant were two close-together structures of feed-house type, freshly opened by a mink and having no current sign of living muskrats.

At the same time, the wetter parts of Wall Lake were frequented by five minks that could be individually recognized on the basis of track differences. 


\section{Chapter 8}

\section{The Little Wall Lake Area, Central Iowa}

LitTle Wall LaKe is a marsh of about 270 acres, largely state-owned and administered by the Iowa State Conservation Commission. It lies two miles south of Jewell, Hamilton County, Iowa, and three miles south of the Goose Lake to be treated in the next chapter (Fig. 8.1).

I saw Little Wall Lake for the first time shortly after coming to live in Iowa in the summer of 1932. The water level was then rather high. With its extensive stands and patches of cattails and bulrushes, the marsh looked like ideal habitat for muskrats, waterfowl, and associated animal life. Rainfall varied greatly between 1932 and 1935, but a trend toward lowered water levels and massed cattail growths did not become pronounced until 1936, when only about 100 acres remained sufficiently wet to be attractive to muskrats. A dredging program that deepened some of the marsh in 1953 actually had little effect on the parts usually occupied by muskrats.

The State Conservation Commission gave me excellent cooperation in my work at Little Wall Lake, especially in connection with furrefuge experiments; and I wish to single out Paul E. Leaverton and former Conservation Officer Kay Setchell for individual thanks. I also received valuable cooperation from trappers, including Wayne Clayton, Palmer and Dean Erickson, Lee Kramer, Keith Larson, John and Herbert Egenes, Leigh and Morris Johnson, Torkell Hill, Harley Doolittle, M. Boyd, O. Boyd, Robert Sowers, Frank Batman, Mike Olson, James Thorson, and Gary Severson.

\section{THE YEARS OF ACUTE LOCAL DROUGHTS, 1936-41}

Highly intensive work was begun at Little Wall Lake in late fall, 1936, as the imminence of a drought crisis became apparent. Notes taken in early spring were inadequate but suggest, so far as they may be relied upon, a breeding population the equivalent of 67 to 72 pairs, 


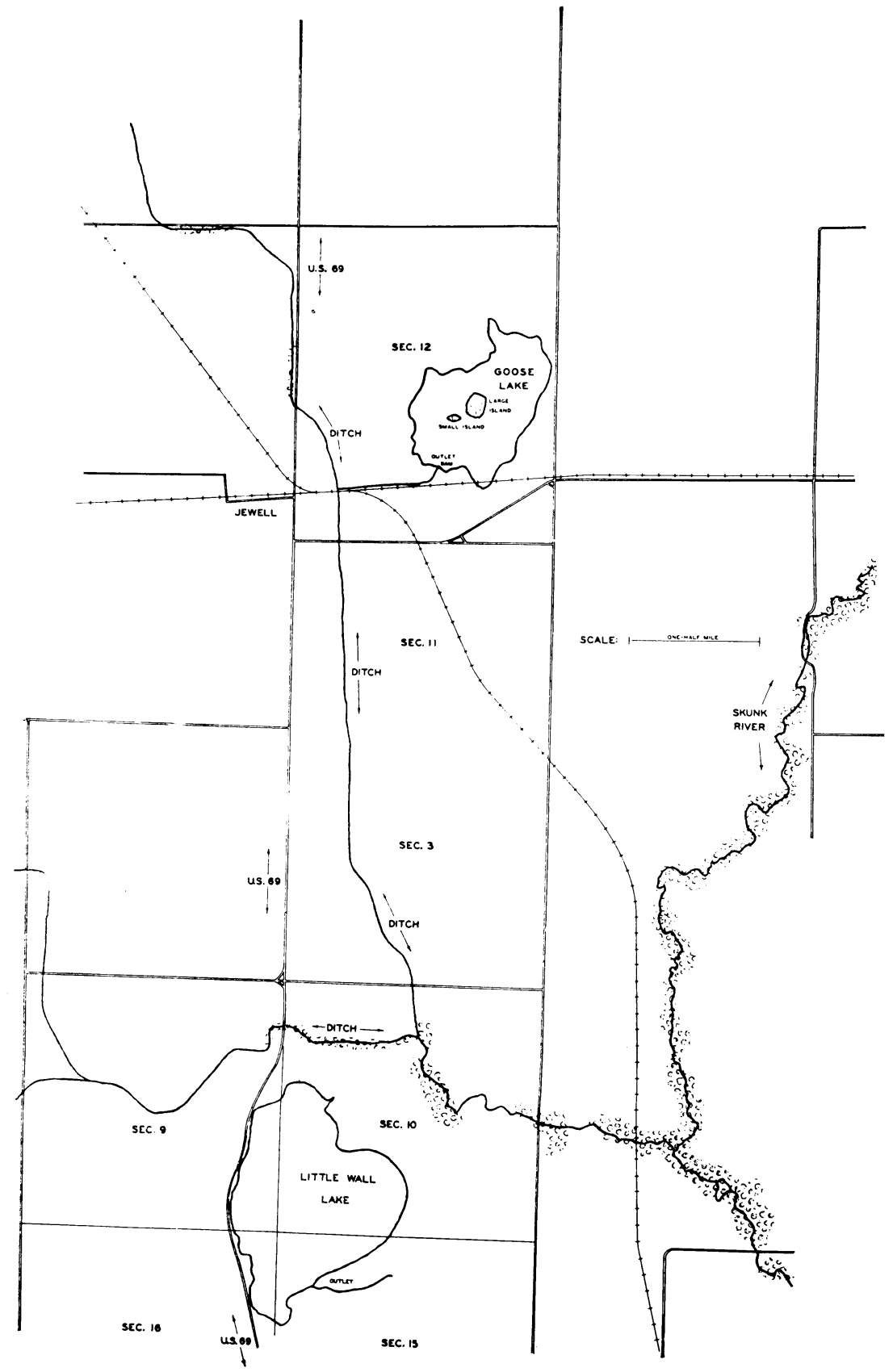

Fig. 8.1. Map of Little Wall Lake, Goose Lake, and environs, near Jewell, 
probably nearer the latter, of which 30 pairs occupied the wetter 100 acres. The muskrats were on the whole uniformly distributed over the marsh, in the shallower as well as the deeper parts. It is now suspected but not definitely known that many of these left before the spring dispersal was over.

By October 27, the bottom was exposed except for a tract of about 10 acres in the southeast corner and another of similar size in the north central part. Numerous occupied lodges could be seen, but losses obviously had been severe. The presence of five intact skeletons in an area of 1,400 square feet probably represented disease mortality earlier in the month or in late September.

On November 29, when freezing permitted a thorough checkup, practically no water was left on the surface. The muskrat population was estimated at 40 for the approximately 100-acre tract still occupied. This was done on the basis of the known trappers' catch of 42 from the 100-acre dry end of another marsh (Mud Lake, Chapter 5) that had similar signs before trapping.

The marsh bottom was solidly frozen by December 4. Muskrats gnawed out of their underground quarters to forage amid the cattails on the surface and then retired, to plug their passageways with fresh mud. As the weather became colder, the sinking of the frost line into the mud forced the muskrats to forage on the surface, often exposing their sensitive tails, feet, and eyes to air temperatures that were sometimes around zero Fahrenheit even during the warmer hours of the day. Moreover, the dead vegetation available on top of the frozen mud afforded little of the heat and energy that muskrats need for cold weather subsistence (Errington, 1941a). Certain animals obtained some protection from snowdrifts, and their survival may have been prolonged for a few weeks. No evidence of any being alive was found after February 4, 1937.

Of the late fall population, some (perhaps a dozen) were illegally trapped in December, at a time when Little Wall Lake was a wildlife refuge. Three others were collected for specimens. Thirteen dead were found during the winter, including one positive and another probable victim of outright cannibalistic predation. Muskrat remains were found in quantity in 4 of 16 stomachs and fecal deposits of the muskrats themselves and in 21 of 41 mink scats examined from the marsh between December 5 and February 23. Three muskrats were definitely known to have left during December and January, but it was undetermined whether they were residents or had previously wandered into the area.

A mink scat found February 23, 1937, contained remains of a muskrat that was probably a newcomer. About a foot of water from melting snow lay over the central bottom, and the marsh again looked fairly habitable for muskrats by March 17, with numerous unused though suitable lodges. The first indubitable sign of reoccupation was seen on March 27. As late as May 9, it was judged that there might be no more than the equivalent of two pairs on Little Wall Lake. Soon 
after, more animals came in, until by the last week of May the territorial settling seemed completed. The area of the habitable part of the marsh was now about 90 acres.

Very detailed field work in the breeding months of 1937 proved the existence of 7 females having young, together with associated males and an isolated adult, probably an unbred female. With one exception, the foci of activity of the family groups or territories were rather uniformly distributed in the shape of an irregular oval of about $500 \times 700$ yards. This arrangement was interesting in that it reflected unusual freedom of choice on the part of the immigrant muskrats. Having numerous vacant lodges and excellent food resources scattered over the wet area, the muskrats appeared to be influenced chiefly by their own densities in their selection of permanent quarters for the breeding season.

Thirteen litters were handled, and these were believed to have been all litters born on the marsh in 1937. Of these, one litter was born to each of 3 females; two litters to each of 3 females; and four litters to one female. Marking of 35 of the young by toe-clipping failed to yield information because of nearly annihilative drought losses later in the summer. The possibility of disease losses should also be considered, as a decomposing adult with what could have been hemorrhagic lesions was found floating in the water on June 2. All of the young of one of the two-litter females became emaciated and surely died. Remains of three adults eaten by minks were listed; these could have been disease victims. A bona fide mink victim was a fairly large young that took up residence in a drought-exposed lodge. Two young aged 32 days were found freshly killed by other muskrats. Two of 73 mink scats from April and May contained remains of adult muskrats; one of 19 scats from July to the middle of August contained remains of the large young from the drought-exposed lodge; there were no muskrat remains in 56 scats from September and October.

Little Wall Lake was dry by September, when evidence of activity by muskrats was seen only in the vicinity of the summer retreats. Abandonment of two former territories had occurred by late October, with no indications that their occupants stayed on the marsh. Two original territories continued to be used, and the animals of three other family groups moved into a previously vacant tract. The population remnant converged into the latter tract by November. When the legal status of the marsh was changed from a wildlife refuge to that of a public shooting ground, the remnant was completely trapped out sixteen muskrats, according to a farmer who lived nearby.

The 1938 spring repopulation of Little Wall Lake involved far fewer animals, presumably because of lower densities overwintering in surrounding streams and lessened tendencies for cross-country movements. A fresh track of a stump-footed animal was seen on, but not after, March 12. No further muskrat sign was seen up to April 5, when about eight inches of water covered the bottom in the deepest places. By April 18, the water was about as high as in the previous 
spring; by May 7, nearly the entire marsh bottom was covered. Muskrat cuttings were seen on April 28, but no fresh sign could be found on May 9, nor on May 24. No muskrat remains were found in 180 mink scats deposited from late January through April.

I was absent from central Iowa from June through August, 1938, so made no checkups of Little Wall Lake during that summer. Ex post facto evidence indicated that a female arrived in midsummer, found a mate, and gave birth to two litters in July and August. About 13 animals were in the vicinity of the natal lodge by late fall. Trapping by persons unknown to me eliminated nearly all of these. A sign of a living animal was seen during the winter of 1938-39, but, by March 4, the marsh was again depopulated.

The water level in the spring of 1939 was high, and the dense stand of cattails furnished inviting habitat for muskrats. The first recognized evidence of a muskrat appeared May 18, but no signs could be made out during careful searches in mid-July and midSeptember. By the latter time, considerable overland movement of muskrats was resulting from a drought crisis along the local streams. An animal was killed by highway traffic just west of Little Wall Lake, September 30, and, by October 18, what appeared to be a newlyarrived individual was found at a part of the marsh that had been deepened by experimental blasting (Scott and Dever, 1940); it departed within 10 days. In late October, three or four muskrats built small lodges in two parts of the approximately 10 acres of marsh then remaining habitable. By November 12, the marsh had no surface water other than a few puddles, and the muskrats had moved on, except one that stayed until early December.

By April 9, 1940, water again covered the marsh bottom, much as in the previous three springs. Two territories were established in widely separated places, one in April, the other in early summer. A single litter born in one of these territories in late May apparently died of starvation at the age of about six days, and no new sign of adult muskrats was thereafter laid down in the vicinity. My guess is that a lone female had come in pregnant and died after giving birth to the litter. Despite drying up of the marsh during the summer, the other territory had a few animals maintaining themselves through August, until rains put water in the deeper places. The last muskrats abandoned the marsh, once again dry, about the first of November. Minks did not seem to take advantage of the drought-exposed muskrats in this instance, though they generally frequented the same places that the muskrats did. None of 210 spring and summer mink scats contained muskrat remains.

The water started coming back early in the winter of 1940-41 and, by the spring of 1941, was about at the level usually to be observed. But no breedling muskrats established themselves, and the marsh was again dry between midsummer and November, 1941. What were judged to have been lone animals appeared about the middle of July in one place and in early September in another. These stayed a few weeks at most. Eighty-eight mink scats deposited mainly in September 
and October about the places used by the muskrats contained no muskrat remains.

\section{THE RECOVERY YEARS, 1942-43, AND UP TO THE SPRING OF 1944}

The water level, as of March 22, 1942, was up to, or exceeding, the maxima for the springs 1937-41. The plant successions favored by the recurrent exposures and floodings of the marsh bottom had by now culminated in a nearly solid stand of broad-leaved cattails, with scattered rushes and a few shrunken openings dominated by wild rice and yellow water lily. The marsh was in exceptionally good condition for muskrats.

On May 8, two freshly built lodges were seen, of which both were considered territorial foci. Four more territories were later established. These six territories were widely separated, three being in the wettest 100 acres of the east side and the others being in the northwest and southwest corners and the west center.

Water continued to rise on Little Wall Lake as a result of heavy summer rains, and, by early winter, a well situated (and legally protected) population was manifested by 35 large and medium-sized lodges, occupied by probably between 150 and 200 muskrats. Many of the lodges that were assiduously dug into by at least two minks were abandoned by the muskrats; many others were repeatedly plugged after the minks left them; and scarcely a lodge on the whole marsh escaped attention of the minks for more than a few weeks at a time during the winter months. Despite this close association between predators and prospective prey, no muskrat remains were found in 103 mink scats deposited from December, 1942, to mid-February, 1943, nor was other contemporary evidence seen of the minks successfully attacking the local muskrats.

Then, 153 of 208 mink scats from the last half of February to the middle of March contained muskrat remains, the calculated equivalent of up to 10 or 12 individual muskrats (see p. 923 of Errington, 1949). This period of vulnerability to the minks coincided with the beginning of the spring dispersal of stream-dwelling muskrats, though the muskrats of ice-covered Little Wall Lake showed few signs of dispersing or of outside activity. The one carcass examined was that of an old male. After the elimination by the minks of what appeared to be the vulnerable individuals, muskrat representations dropped to 5 in 69 mink scats for the second half of March. No further evidence of mink predation upon the muskrats was found during two visits in April.

The 1943 breeding density, as of May 20, was calculated at the equivalent of between 61 and 67 pairs, probably nearer the latter figure. The territories were patchily distributed - rather crowded together in places, with other places being nearly muskrat-vacant. The water level was the highest yet noted and sufficient to make the entire marsh habitable for muskrats. By June 7, growths of cattails covered the marsh so thickly that only the lodges near shore could be seen from land. A mid-August checkup showed the muskrat population to be thriving in the midst of a nearly perfect environmental combination, 
and a fall population of about 1,300 was arrived at on the basis of sample counts. Only 2 dead muskrats (both young) were found during four visits in October; one of 12 mink scats contained remains of an adult.

Legal protection of the Little Wall Lake muskrats was extended for another trapping season. Although some evidence of probable illegal activity was seen, it is doubtful that much successful poaching was done. Considerable signs of restless or transient muskrats were visible on the ice during the winter of 1943-44, and the greater part of the detected predation upon muskrats by the dozen or more minks frequenting the marsh was borne either by such individuals or by some that were patently immature. Eight of 101 mink scats examined from November to the middle of January, 1944, contained muskrat remains. Despite the extensive mink intrusions into the lodges, the muskrat population as a whole lived with much security.

For the second half of January, 27 of 49 mink scats contained muskrat remains, as did 52 of 65 scats for February, a month of obviously increasing tensions among the muskrats. On a 16-acre sample of densely populated marsh, nine places were noted where apparently different muskrats habitually worked over the surface of the ice during thaws. The sample represented about one-tenth of the marsh showing this type of sign, from which an estimate of around 90 restless muskrats may be made. For early March, one of 5 mink scats contained muskrat remains, by which time the less favored muskrats seemed to have been eliminated. The great majority of the muskrats of the marsh (perhaps 1,200) were then left comfortably and securely situated.

Particular attention was paid to responses of muskrats to the activities of the minks. By midwinter, hardly a lodge in large tracts failed to show evidence of mink intrusion, but even many of those known to be repeatedly entered were retained by the muskrats as regular dwellings. Some of the mink holes were plugged so close to the lodge chambers that from an outside view they appeared to have been unrepaired; others were plugged so neatly at the outer surfaces that, except where marked for recognition, the former locations of the holes could easily have been overlooked.

The 1944 spring dispersal of muskrats at slow-thawing Little Wall Lake did not get under way until late March, about a month later than in ice-free small streams. During the dispersal, and up to May 9,16 muskrats were found dead about the marsh, 13 being victims of highway traffic on U.S. 69, which skirts the west side. The figure arrived at for the breeding population, as of May 9, was the equivalent of 437 pairs, or about 900 adults, with a certain amount of dispersal continuing to be in progress and some surplus males still frequenting the marsh border.

\section{THE GREAT CRISIS OF 1944}

So far as it can be dated, the decline of Little Wall Lake as firstclass muskrat habitat was assured by the rise of the water to an over- 
flow level in consequence of rains on the nights of May 18 and 19, 1944. This killed the once-lush stand of broad-leaved cattails, and, with the advance of summer, Little Wall Lake took on some of the aspects of a body of open water, with little except rotting stalks of last year's cattails holding the lodges in place. The few small remaining clumps of live cattails (mostly narrow-leaved) were severely exploited by the muskrats. The high water did not wholly eliminate muskrat food from the marsh, for fairly extensive growths of hardstem bulrushes remained in the south center by July, and duckweeds, smartweeds, and submerged plants (especially coontail and bladderwort) were locally prominent. But hundreds of adults and thousands of young muskrats were confronted by an ecological crisis, of the sort illustrating what can happen in a large population of muskrats when many things go wrong.

The tragic consequences of the crisis were carefully followed through a program of intensive study. Up to June 10, breeding was progressing in a normal way in the deep-water lodges of the north and west parts, though animals were conspicuously spreading along the north and west shores. In the northeast corner and the east central part, green vegetation could hardly be found at all, and the lodges generally had an unmaintained appearance. A very few young, however, were still being born in the east central lodges as late as the third week in June, but this part was the site of lethal intraspecific strife. Ten dead young (mostly slashed by adults) and a dead adult were examined here on two visits, compared with two slashed dead young and a dead adult for a larger area of the west side. By late June, intraspecific strife was becoming more noticeable among the relatively better situated populations of the west part. Hostile displays between muskrats could be witnessed at any time of day, and slashed victims were seen dead in the water, on and in the lodges, and on rush rafts and shore.

Shortly before the midclle of July, a storm blew ashore the lodges and muskrats of the east central part. Many animals of different ages and sizes thus found themselves suddenly transplanted into a strange environment already occupied by viciously intolerant residents. Minks took advantage of young muskrats that were marooned on shore during the hours of greatest vulnerability; 16 bodies (all killed about the same time and mostly uneaten) were counted outside the den used by a mother mink and her young. Twenty-two of 149 mink scats deposited in the first half of July contained remains of young muskrats, and it could be fairly well ascertained that the eating of most of these occurred during or just after the storm. None of 25 mink scats for May and only one of 60 June scats contained muskrat remains.

Some of the displaced east central muskrats continued to live in lodges that blew ashore without disintegrating. Some displaced muskrats stayed where they could in holes and other retreats on land, or in nests on mats of drifted debris. Most of them seemed to move crosscountry eastward, over grain fields and pastures. A field of ripening 
oats had eight major trails leading into it, and, after the shocking of the oats, many muskrats lived in the shocks, to be exposed by the threshers.

Over those tracts of Little Wall Lake on which habitability for muskrats remained fair, litters continued to be born into July and August. These conclusions, which were arrived at from the field data of spring and summer, agreed well with the seasonal distribution of litters indicated by the placental scars of the adult females examined in the trappers' catches of mid-November.

Although the survival of the early litters was high, survival of the late-born was low. The latter is reflected by recovery during the trapping season of only one of 126 tagged young, the majority of which (all but a May litter of six) were born in June. The very dubious life expectancy of this age class is emphasized by the successful over-all rearing of about half of the total number of young conceived by Little Wall Lake breeding females in 1944. The high rate of survival of the early-born might naturally be expected to doom many of the late-born even under better living conditions (Errington, 1946; 1951), but, with the marsh being subject to acute and progressive damage from the standpoint of the muskrats anyway, the handicaps of the late-born were sharply increased.

Manifestations of biological unbalance grew more pronounced in midsummer, and, if anything, more so as autumn came on. By the end of July, the marsh was almost lakelike except for the bulrushes of the south center, and increasing signs of muskrat activity could be seen along shore. Not only was there much random drifting of animals shoreward but there was also some mass moving.

On August 12, around 450 muskrats of mixed sizes were concentrated in the south central bulrush tract, whereas probably fewer than 100 had worked here only a few days before. On August 14, exceptional numbers were sitting along the south shore nearest the bulrushes; by September 2, the animals of this stretch of shore almost disappeared, and the population of the bulrushes was down to about 190 .

Starting about August 21, another concentration of shore-dwellers or transients located a corn field, which they reached by crossing the busy highway, U.S. 69. An effort was made to record all traffic victims for sample 24-hour periods as long as the raiding of this corn field continued. In 20 days, 48 fresh victims were counted - as many as 12 killed in a single day - which, on a prorata basis, would total about 90 highway victims for the 38 days that the situation existed. Many other Little Wall Lake muskrats died on U.S. highway 69 throughout the summer and fall of 1944, but the above mortality fell in a special category.

The late-summer clearing of practically all of the emergent vegetation by the muskrats hardly signified, in itself, any uniformly desperate hunger crisis, for extensive growths of submerged plants remained available in many places. Nevertheless, hazardous feeding on shore continued on a large scale. Aside from some degree of undernutrition 
of the young after midsummer, the population effect of deterioration of the food supply seemed chiefly a matter of heightened intraspecific tensions. Fighting was especially prevalent in shore zones invaded by the inhabitants of lodges disintegrating through action of waves and wind.

On October 7, 121 muskrats were counted sitting out a windstorm along a quarter-mile of shore line. These included many strife-torn and bewildered transients, but many animals plainly were acquainted with each other and displayed tendencies to huddle and move in groups. After the storm, some of the shore-sitters returned to the much damaged bulrush tract of the south center and there rebuilt lodges and nests; others improvised nests on debris floating out from shore or lived in badger diggings, and the like on a hillside; probably others simply drifted along the shore line (three were marked by toe-clipping but never found again); and others moved into the damp swale comprising the outlet. Nests with muskrats in them were seen -9 adults and subadults in a single nest - in the outlet near the marsh until October 9, after which they moved about 140 yards down the outlet to establish new quarters in a hummocky bog. Some were still living in the hummocks when the trapping season opened on November 10.

From the middle of June through September, 150 dead muskrats were recorded, and it is likely that the actual mortality was considerably higher. Most of the interspecific predation upon the vulnerable shore-dwellers occurred through the agency of minks, although dogs killed some; one kill was attributed to a red-tailed hawk, and it is to be expected that red foxes living in the vicinity picked up at least a few (Errington and Scott, 1945). Muskrat remains (especially of young) were found in 42 of 112 mink scats for the second half of July.

Throughout August and September, the minks still preyed especially upon the young among the muskrats living on shore. Muskrat representations in mink droppings were in 24 of 111 for the first half of August; in 15 of 56 for the second half of August; in 16 of 61 for the first half of September; and in 15 of 41 for the second half of September. These muskrats, too, reacted according to patterns shown by transients, living in nests in the grass and in dry bank holes, excavating shallow burrows and then abandoning them, and otherwise betraying their restlessness and unfamiliarity with their surroundings. Besides suffering the usual mink predation and intraspecific strife, they were killed on a substantial scale by hunters' dogs after the hunting season for waterfowl opened on September 20. Sign of a juvenile great horned owl was found on the hilltop just south of the marsh, and evidence was seen October 8 of its scavenging upon a dead muskrat. This species of owl could be expected to take a certain advantage of vulnerably situated muskrats, though a juvenile might not be very successful as a muskrat predator (Errington, Hamerstrom, and Hamerstrom, 1940).

Close watch, meanwhile, was kept for the hemorrhagic disease, but lesions were not recognized in any of the post-mortems made of dead 
muskrats from Little Wall Lake until October, 1944. In the early part of that month, the disease appeared along the west central shore. Two probable disease victims (both decayed) were here seen floating near shore on October 6, but the first clearly diagnosed one was found on October 16. Between October 16 and 28, 21 certain and probable victims were found, all dead along 70 yards of shore at the focus of infection. From October 29 to November 2, the known zone of infection extended 840 yards north and northeast and 365 yards south of the set of burrows about which the unquestionably diseased animals were first discovered. By November 14, the zone was further extended about 50 yards to the northeast but was still largely restricted to the vicinity of the shore, despite the presence of a lodge-dwelling population less than 100 yards out in the marsh. By this time, the muskrats had been so reduced by public fur trapping that no further disease victims were found during the fall. Diligent searching produced no specimens showing the disease from outside the designated zone, but the origin of a trapped carcass having a few small liver lesions could not be traced.

The original focus of infection was, to all appearances, completely devoid of live muskrats by November 1 . Then a strong wind and waves tore some deep water lodges apart, and the occupants came to shore and established themselves in the undefended burrows. The first of these newcomers known to die of the disease was found on November 9. A dead muskrat that proved to be diseased was washed in, November 2, near a shore lodge in a place where no evidence of the disease had been seen earlier; after the muskrat was examined, on the same day, it was returned to the water and anchored as an experiment; and, on November 9, the first of the muskrats at this new place was found dead of the disease.

Altogether, 97 dead muskrats from Little Wall Lake were examined between the first of October and the beginning of the trapping season, November 10. Forty-three of these definitely or very probably had died of the epizootic disease, and undoubtedly several times as many more had died underground in the burrows. (Once, I quartered over a piece of ground trying to locate the source of an odor by nose, finally dug through the sod and unearthed the putrid animal lying toward the end of a shallow burrow.)

The disease itself now became the main factor underlying the availability of Little Wall Lake muskrats to minks. Of 32 mink scats deposited during the second half of October along the stretch of shore where the epizootic was most lethal, 17 contained muskrat remains, compared with 7 of 83 scats from disease-free shores and 6 of 72 scats from the first half of the month, prior to the outbreak stage of the disease. At the same time, the symptoms of population unbalance continued up to the trapping, with evidences of vicious strife where strangers and residents came in contact.

The recorded trappers' catch at Little Wall Lake for the 1944-45 season was 1,346 muskrats - mostly taken by three parties of trappers. 
Allowing for some muskrats caught by other or by unknown persons, it should be safe to fix the season's catch at about 1,400. On November 28 , after the muskrat trapping ceased and during a period favorable for observation through thin ice, signs of considerable numbers of muskrats could be made out in the vicinity of burrows of the northcentral and northeast shores. Possibly as many as 200 survived the trapping on the whole marsh.

Working backward from an early winter population figure of about 1,600 , I think it possible to trace the course of numbers in the muskrats from the May population of about 900 .

In a 1,000-carcass sample obtained for examination from the fur trappers at Little Wall Lake in November, 1944, there were 78 adult males, 110 adult females, 440 young males, and 372 young females. From these ratios, it may be computed that a population of 1,600 on November 10 would consist, in round numbers, of about 125 adult males and 175 adult females, or a total of 300 adults; 700 young males and 600 young females, or a total of 1,300 young. Assuming that the ingress from surrounding habitats was inconsequential-which is surely to be expected, in view of the critical situation - about 600 or two-thirds of the adults had been lost from Little Wall Lake in one way or another since May.

If the 437 May territories be accepted as the equivalent of females among 900 adults, the May to November reduction of adult males and females would figure out at about 340 and 260, respectively. Part of the differential mortality suffered by the adult males would be in keeping with that commonly taking place during the warmer months (Errington, 1943), but the known ratio of only 42 per cent males in the adults alive by fall indicates, moreover, exceptionally severe differential mortality.

In the sample of 90 adult females the uteri of which contributed data on the 1944 breeding at Little Wall Lake, 9 (10.0 per cent) had not conceived during that breeding season. Eight (8.9 per cent) had conceived one litter each; 35 (38.9 per cent), two litters each; another 35 , three litters each; and 3 (3.3 per cent), four litters each. The mean number of litters was 2.17 per adult female and 2.41 per breeding female. The recognized placental scars in 195 sets, or litters, averaged 6.68. Of the 81 breeding females in the trapped sample, 61 were judged to have given birth to their last young in June or earlier, 17 in July, and 3 in August.

The 90 adult females had totals of 761 placental scars assignable to 114 litters judged to have been born prior to the month of June and 541 scars corresponding to 81 litters born in June or later. Prorata computations from the May base of 437 females would give a figure of nearly 3,700 young conceived if not born for the high-survival part of the season. For June, the count was 407 scars in 59 sets; the females giving birth to and caring for these young suffered light enough known loss so that a 425 -female base would seem reasonable; and, using this, we get a total of over 1,900 June young conceived or born. The late 
summer losses of adults, including females, were sufficient to lower the base of adult females to about 300 for the July and August young, which, for 134 placental scars in the 90-female sample, would give a total figure of nearly 450 conceived or born. The totals for young conceived or born on Little Wall Lake during the breeding season of 1944, as thus figured, would come to about 6,060 , or in rounder numbers, about 6,000 .

The muskrats alive on the marsh at one time doubtless reached maximum numbers early in June, before losses of either adults or young became excessive. The previously indicated rearing of about half of the total numbers of young conceived would afford grounds for estimating that about 3,000 of the early young were alive and reared up to stages of relative independence by early June. To these we may add the June-born, alive as of the middle of the month, though largely doomed to be lost later - perhaps about 1,500. The July and August young may here be ignored, as their births chiefly constituted wastage in an accelerating decline. Counting about 850 adults, Little Wall Lake should have had a grand total of about 5,350 muskrats of all ages at the peak of the 1944 population.

In mid-August, conditions for study were such that quite accurate counts of lodge-dwelling populations were possible on about half of the area where lodges remained, and, on the other half, estimates were made from sample counts. The total arrived at for the lodge-dwellers was 1,240. By the end of the month, the muskrats regularly living in lodges were drastically lowered through destruction of lodges and shoreward movements, until the sample counts gave a figure scarcely in excess of 400. In early September, the lodge-dwellers were reduced to probably between 200 and 300 - then, their numbers seemed to remain rather stabilized for about a month. Further reduction resulted from storms in October and early November. Trappers' catches suggested a lodge-dwelling population of about 250 as of November 10 .

The true bank-dwellers could not be satisfactorily counted in life, though frequent attempts were made to do so by watching sample stretches of shore and adjacent water at hours of the day most conducive to muskrat activity. Except along the disease-depopulated shores, however, the numbers of animals resident in the banks were not believed to have changed a great deal between mid-August and November 10. Approximately 1,150 were taken by trappers from the bank population, which number added to about 200 bank-dwellers surviving the trapping would give a total of about 1,350. The midAugust population of bank dwellers should have been perhaps about 1,400 , plus the number of resident animals that died from epizootic disease in October and early November.

The disease victims - ignoring those scattered along lightly-affected shores-made up the equivalent of the entire bank population of about 600 yards of the very heavily populated west shore. From what is known of nearly annihilative trappers' catches along and out from stretches that had comparable densities before the epizootic, the late 
fall disease loss may be estimated at about 350 . The 350 that died from disease added to 1,400 would give a total of about 1,750 bank dwellers, as of mid-August, which added to 1,240 lodge muskrats would give a postbreeding population of about 3,000.

In recapitulation, the available figures for the Little Wall Lake population in 1944 may be listed according to certain periods: early March, about 1,200 adults; mid-April, about 1,000 adults, plus some of the earliest young; mid-June, about 5,350 of all ages, including about 850 adults; mid-August, about 3,000, including probably not more than 600 adults; November 10, about 1,600, including about 300 adults; late November, possibly 200 after the trapping.

\section{THE YEARS OF SUSPECTED CYCLIC LOW, 1945-47}

General evidence suggests that the low phase of the 10-year cycle operated in north central United States somewhere during the years 1945 to 1947 (Errington, 1954a; 1957). No attempt will be made in this chapter to discuss fully the phenomenon with respect to the muskrat; rather, the Little Wall Lake case history will be continued as a presentation of data, and the cyclic aspects thereof will be reserved for more nearly adequate treatment later. The mere fact of low densities should not necessarily be construed as evidence of cyclic depression, nor should overmuch significance be laid to epizootic disease, per se, as a mechanism.

Following the melting of the ice and disintegration of deep water lodges through wave action in the middle of March, 1945, 21 specimens of dead muskrats were retrieved. Judging from the appearance of their internal sex organs, these victims had died in late November or early December. Despite the partly decomposed state of the specimens, their viscera remained sufficiently unchanged to show disease lesions in nine, and it is likely that most of the others died from the same cause. The spring distribution of the victims and the last information obtained on the spread of the disease in November make it reasonably certain that an epizootic took place after freeze-up in the north part of the marsh, where the most muskrats survived the trapping. The muskrats of this part, however, were by no means completely eliminated by the disease during the winter.

On March 29, 1945, a recently dead specimen was found near the north shore with a bloody anus suggesting the disease, but visceral decay was too far advanced to permit clearer diagnosis.

Minks were scarce, if present at all, on Little Wall Lake in December, 1944, and early January, 1945. Toward the middle of January, coincident with a pronounced acceleration of mink movements on central Iowa observational areas generally, one mink appeared and lived in or near some muskrat burrows that had been depopulated by the epizootic in October. The frozen bodies of disease victims were apparently the principal attraction for the mink, and the only mink scat found here for this period consisted of muskrat remains. A fragmentary mink-eaten carcass also was found in a snow tunnel leading 
into one of the burrows. From late January to the middle of February, a single muskrat representation occurred in 35 mink scats.

Shortly after the middle of February, a mink - probably the abovementioned - moved into an enormous snowdrift across the lake to the northeast. On March 16, after the drift melted, four mink-eaten carcasses of muskrats were distinguished in the debris at the site, and 38 of 44 of the associated mink scats contained muskrat remains. The one carcass complete enough to indicate the status of a victim had had the end of its tail frozen off during the winter - a sure mark of a wanderer or of an otherwise ill-situated individual. Muskrat remains were found in two of $14 \mathrm{mink}$ scats deposited elsewhere about the marsh in the first half of March.

On March 19, 1945, at least a dozen muskrats were seen along the west side of Little Wall Lake, which suggests a fair winter survival, the disease loss notwithstanding. The best estimate I could make was of between 100 and 125 alive on the whole marsh, as of early April. In consequence of the spring dispersal and a sweeping epizootic getting underway in late April (after months of no detected disease losses), the population was reduced to the equivalent of eight pairs and enough extra animals to bring the total of resident muskrats up to about 20. Seven dead were found between April 23 and June 20, of which 4 were surely or probably diseased.

Young were known to have been born at only four places (including one at which the mother died), but postbreeding ingress introduced such a big variable that the significance of November data on placental scars cannot be clearly judged. Three of 11 adult females examined had conceived 3 or 4 litters each in 1945, and 2 other females had conceived 2 litters each - which should be considered along with the evidence on very poor reproductive success obtained through the 1945 field studies at Little Wall Lake. Of the other 6 adult females examined from Little Wall Lake in November, 4 had not conceived in 1945, and 2 had conceived a single late litter each - which looks more like what had been the performance of the local stock. Of 83 trapped carcasses examined, 4 were adult males, 10 adult females, 43 young males, and 26 young females.

From August to the opening of the trapping season, November 10, 8 dead were found. These included 2 old animals with multiple abscesses in their viscera but no recognized victims of the hemorrhagic disease nor of predation. No muskrat remains were found in 309 mink scats deposited between late March and the middle of August. Nor did the local muskrats suffer observed intraspecific strife even when an estimated 200 to 250 newcomers appeared at the marsh in late summer, to bring the pre-trapping population up to about 300 .

The reported trappers' catch was 184 , and an early December checkup (after the muskrat trapping and while the ice was clear enough to allow an excellent view beneath) gave the basis for population estimates of about 100. The marsh was in highly satisfactory condition for the existing muskrats, as fine growths of river bulrushes dominated the previously lakelike west half. 
The population wintered with no detected loss from December, 1945, to early March, 1946. No muskrat remains were found in 64 mink scats deposited in January and February. When the ice receded from the shore in early March, muskrats came out in all places where their presence could have been expected from the December signs. The spring signs also indicated a Little Wall Lake population in the vicinity of 100 animals.

The mink-eaten remains of an undersized muskrat were traced to about this time, and 1 of 6 similarly dated mink scats picked up nearby consisted of muskrat remains. Of 26 mink scats examined during the rest of March, none contained muskrat remains, and muskrats were seen to be getting along in a normal manner for this season, with the exception of two specimens dying about March 19 from the hemorrhagic disease. No epizootic materialized, however.

The perfect 1945-46 winter survival at Little Wall Lake contrasts with an approximately 80 per cent loss for Goose Lake (see Chapter 9). The rain and thaw, which temporarily flooded out the muskrats from their dry burrows under the ice at Goose Lake, merely deepened the water and raised the ice a few inches at Little Wall Lake. This rise was without complications for the Little Wall Lake muskrats, though both they and the Goose Lake muskrats were essentially restricted to shore zones, and were roughly comparable in per-acre densities for the tracts occupied. Seemingly about the same number of minks (three or four?) hunted the muskrat-occupied tracts of each marsh, and almost certainly individual minks visited both places. The minks also entered the water by penetrating muskrat habitations at Little Wall Lake as at Goose Lake; and, at both lakes, they had similarly convenient access to similar types of food other than muskrats. The muskrats at Little Wall Lake were patently secure, living disease-free in moderate abundance and in habitat characterized by satisfactory food, water depths, and burrow systems.

The 1946 spring population of Little Wall Lake had, by May, leveled off through dispersal to the equivalent of about 22 pairs, or about 50 adults. This number was further reduced to about 19 pairs or possibly 40 adults during the summer. Nevertheless, only 4 dead (including a five-weeks victim of a mink and a large young that someone wantonly had shot) were found from April through October. The only muskrat remains in 554 contemporaneously dated mink scats were apparently of the one five-weeks victim, represented in 5 scats.

The marsh remained in good condition for muskrats throughout summer and fall of 1946. It attracted many immigrants, as in 1945, and this ingress followed the same chronology in 1946 as in 1945. The 1946 breeding season at Little Wall Lake, however, was one of suffcient local reproduction so that a much greater proportion of the animals present by the November trapping was of resident adults and their progeny than had been the case in 1945 .

Prior to the 1946 trapping, the marsh had been divided into two parts. One part, on the west side, was a breeding stock refuge for fur animals. The other part, larger but not so well populated, was open 
to public exploitation. The total reported trappers' catch of muskrats was 227, and it is unlikely that the actual catch exceeded 250. By March 22, 1947, just before the spring dispersal began here, the signs of muskrats surviving on the trapped part became rather evident, and, from this, an estimate of about 30 animals was made on the basis of personal trapping experience. On the refuge side, the muskrat population was estimated, in a similar way, at about 345 , as of November 27 , 1946. These figures suggest an early November (pre-trapping) population of about 625 .

A sample of 140 carcasses trapped at Little Wall Lake in 1946 consisted of 8 adult males, 9 adult females, 70 young males and 53 young females. The age ratio from the sample applied to a total of 625 animals would give a fall population of about 75 adults and about 550 young. The Little Wall Lake ratio of 12.1 per cent adults differs only insignificantly from the 12.5 per cent obtained from 438 carcasses from all central Iowa sources in 1946 (28 adult males, 27 adult females, 203 young males, 175 young females, and 5 young of undetermined sex). The Little Wall Lake age ratio would give a figure of about 290 young for 40 resident adults or 330 animals all together; if this be close to the number of true residents, then it would seem that about 300 animals might represent postbreeding immigrants. The field evidence suggested that most of the newcomers established themselves in centrally located growths of bulrushes - at least a great many of them did, in places a quarter-mile or farther from any of the shore zones dominated by residents of the summer's breeding territories.

The 1946 data from placental scars suggest more irregularity in breeding among 10 adult females examined from Little Wall Lake than among 17 females examined from central Iowa streams. Four of the 10 females from Little Wall Lake either had not conceived in 1946 or had conceived but a single litter, whereas only 2 of the 17 stream females had conceived but single litters. The other 6 of the Little Wall Lake females averaged 3 litters each, and the other 15 of the stream females averaged slightly under 2.9 litters each. Of 20 litters conceived by Little Wall Lake females, 9 had been due for birth before June, as had 22 of 43 litters of stream females. Differences in the reproductive performances of the two groups of females may be ascribed in part to isolation of certain territories interfering with the mating of some of the females living at Little Wall Lake.

The detected wintering loss for 1946-47 was three animals, which doubtless does not represent all that died; but the loss was surely low, especially in view of the continued frequency of signs on the refuge tract. Of these dead, one was recognized as a victim of the hemorrhagic disease, dying about the middle of February near what had been the old west central focus of infection of October, 1944. A new epizootic slowly made headway from here as spring progressed.

Another correlation between winter feeding by minks upon muskrats locally suffering from disease was shown by the 1946-47 data from 
Little Wall Lake. No muskrat remains were found in 320 fall scats deposited before the November trapping, despite the presence of hundreds of muskrats. Neither were muskrat remains found in 47 scats deposited from the middle of January to early February. Then, the first muskrat known to have died from the disease during the winter died about the time that the first muskrat remains began to appear in the mink scats. Eight of 30 scats deposited from the middle of February to early March contained muskrat remains, and all of the muskrat-containing scats came from the site of the disease flare-up. For the middle of March to late March, only one of 33 scats contained this item; at the very end of the month, all of 6 scattered droppings were made up of muskrat remains, but this was probably associated with dispersal vulnerability more than with the disease. No muskrat remains were found in 5 April scats.

It may be mentioned that central Iowa minks had been so nearly annihilated by the 1946-47 fur trapping that untrapped Goose Lake was almost the only one of my observational areas that harbored any minks at all by January, 1947. Of the four minks that were distinguishable more or less satisfactorily on the basis of tracks or trails at Goose Lake, the biggest seemingly started visiting Little Wall Lake in early January, finally frequenting Little Wall Lake regularly after the middle of February. This big mink was most probably one of the principal exploiters of a stricken muskrat population at Goose Lake (see Chapter 9), yet its depredations upon uninfected muskrats at Little Wall Lake were surely negligible.

Between the middle of March and the fore part of July, 1947, 53 dead muskrats were examined from Little Wall Lake. Thirty-eight of these were certainly or very probably victims of the epizootic disease, 7 were transients killed by a dog near a lake-side set of farm buildings, one was found shot, and 7 (including 5 weaned young) died from undetermined causes.

Before the middle of April, the epizootic nearly depopulated about 300 yards of the shore zone having the most muskrats, possibly killing up to 100 during this time in a strip totaling about two acres in area. It was judged that most of the resident victims died out of sight in the bank burrows and were not seen. Only two lodges were situated here, and these, when opened, had three victims inside compared with one outside. Of five February and March victims the sexes of which were recorded, only two were males; then, as newcomers made up an increasing proportion of the victims in early April, the ratio of males changed to seven out of eight. Except for a corner of the marsh where victims were known to die 600 to 750 yards north of the focus of infection in mid-April, evidences of the epizootic were restricted to the vicinity of the original west central focus until late April.

Starting about the last week of April, muskrats died conspicuously in places along the northeast and southwest shores for a couple of weeks. A ratio of 11 males to 10 females in the dead would seem rep- 
resentative of the local residents. After this, a few more diseased or probably diseased dead were found: a female dying about May 18, a male on May 21, and another male about June 21. By the time that the epizootic subsided, after killing an estimated 200 muskrats, all sites where disease victims had not been found were in the south part of the marsh, and the apparently uninfected shore zone constituted roughly a third of the total muskrat-occupied periphery.

A remaining population of 29 adult females and associated males, or a total of about 60 adults, was arrived at through the field studies after the epizootic subsided, or as of late May to the middle of June. One breeding female was found dead for this period, but she had given birth to two litters before dying.

The heavy June rains of 1947 actually filled Little Wall Lake to overflowing, the water running off into the outlet over a wide flat depression. The deep-water bulrush stands covered a good half of the marsh but they seemed thinner than at midsummer, 1946. The bulrushes still comprised excellent habitat for muskrats, which, however, were making but limited use of them on July 22, when fewer than half a dozen individuals - all adults - were seen far out from shore. Even by the middle of September, relatively few muskrats were living out of convenient reach of the bank burrows.

During July, August, and early September, 1947, the survivors of the epizootic and their offspring seemed to be getting along well. Four of 587 late June to early September mink scats contained muskrat remains, one representation being of a young muskrat of about five weeks killed about early July. In this particular case, a female mink took over an isolated burrow system (the only muskrat-occupied one in the whole east shore) for her own family, and the muskrats resident there responded to the mink intrusion by excavating another set of burrows about five yards away. In their new quarters, this family group of muskrats seemed to live securely after the earlier loss of a member. The other muskrat remains were of an animal possibly two months of age judged to have been eaten in late June and two representations of an animal of three to three and one-half months, eaten in late August. Remains of an adult muskrat were also found in a raccoon scat deposited about mid-August, and a dead muskrat was found corresponding to the fecal contents. A female muskrat that had given birth to two early litters died from probable hemorrhagic disease on September 3.

The saturating rains of June were followed by a long, dry period, much of which was also very hot, but the water level of the marsh dropped only about 10 inches by August 13. On that date, a local thunderstorm brought up the level about five inches, but this gain was lost during the next four weeks. The signs continued to suggest a favorably situated population. As of September 10, no evidence of animals drifting to Little Wall Lake from outside was recognizable, though the flows of muskrat-occupied streams in the vicinity were becoming much diminished, and many of the residents at Goose Lake 
were experiencing a drought crisis accompanied by extensive readjustments and a certain amount of mortality. On September 15, one of the season's young tagged at Goose Lake was found dead of the hemorrhagic disease on the southeast shore of Little Wall Lake. Later in the fall, two recognized transients were seen working the south and west shores.

By early October, there were about 16 muskrat lodges of habitable sizes in the central bulrushes, 7 of which were clumped together in an area of about an acre lying about 60 yards out from a series of abandoned bank burrows. It was quite apparent in the latter case that the muskrats had simply withdrawn to deeper waters of their regular home ranges. A few other lodges built in shallow water were clearly associated with bank burrows. What seemed to be an infected burrow system along the west side had the aspect of having been little used and was near the site where the dead muskrat was found on September 3 , as well as near the raccoon-eaten body of mid-August. Still another possible disease victim was found near the burrow system on October 4.

There was other detected 1947 fall mortality at Little Wall Lake. Fragments of a subadult were found October 6 along the east shore, and contemporaneous remains of what looked like the same animal were found in 3 of 136 mink scats deposited from mid-September through November. On November 3, a subadult male was found that had been killed by a charge of shot and then scavenged upon by a mink.

The muskrats of Little Wall Lake were never seriously affected by drought in 1947, and rains in late October improved their situation still more. In view of a closed trapping season on muskrats in the fall of 1947 , the best I could do to obtain representative sex and age ratios was to compile data from animals found dead, excluding suspected victims of old age. The Little Wall Lake specimens actually handled were 7 adults ( 4 males, 3 females) and 25 young ( 16 males, 9 females), but, because of the smallness of the sample, more nearly representative ratios would probably be obtained by considering along with these data those from other central Iowa areas. The Little Wall Lake series added to 58 specimens from neighboring Goose Lake and 11 from Keigley's Branch and Squaw Creek drainages, would give totals of 19 adults ( 7 males, 8 females, and 4 of undetermined sex) and 82 young (36 males, 20 females, and 26 of undetermined sex).

From available data, we may judge that about 24 of the original breeding females of Little Wall Lake for 1947 were still alive and present in the fall. Application of the over-all central Iowa sex and age data to 24 adult females at Little Wall Lake would give a figure of about 243, which might be assumed to represent essentially the truly resident fall population. Allowing for about 50 animals coming in - which I think should be ample allowance, considering the scarcity of muskrats in the central bulrushes - the total fall population should be around 300 .

This population wintered with little loss until March, 1948. Only 
two winter dead were found, of which one was an old male suspected of having died from age. None of 10 mink scats deposited, December through February, contained muskrat remains.

\section{THE BREEDING AND POSTBREEDING MONTHS OF 1948 AND 1949, TWO YEARS OF SPORADIC DISEASE LOSSES AND LOWERING WATER LEVELS}

From March well into May, 1948, intraspecific tensions among the Little Wall Lake muskrats were manifested by shore-wandering, fighting, and mortality from predation - particularly along the west shore, which was frequented by a disproportionate number of the total population of some 300 muskrats. That the minks responded is shown by the incidence of muskrat remains in 14 of 21 scats examined for March and early April. Beginning about the middle of March, as more and more dispersing animals and territory seekers worked the shore, a farm dog largely took the place of the minks as a lethal agent, until it lost interest in the muskrats and stopped its deliberate hunting of them soon after the middle of April. Thirteen victims of the dog were examined between March 18 and April 15: two old males, one old female, eight immature or newly mature males, and two immature females. These specimens probably comprised a fair crosssection of the shore-dwelling population of transients, but they may also have included a few true residents.

Muskrat victims of motor traffic were found on U.S. highway 69, at the west side of Little Wall Lake, on March 3 and April 25. An adult female, dead from unknown cause, was found April 5. A local epizootic of the hemorrhagic disease started killing muskrats toward the middle of March; this die-off coincided in time and place (the northwest corner of the marsh) with the dog killings, but the dog victims showed no recognized disease lesions.

The epizootic "smoldered" for the next two months, killing a known two or three muskrats a week between early April and early May in the northwest corner. On May 5, a disease victim (dead about two days) was found along the west central shore, several hundreds of yards to the south of the sites of dying earlier in the spring, and a second victim was found, freshly dead, at the new place on May 10 . Of the 13 verified or highly probable disease victims examined, the sexes and age classes of 11 were recorded: two old males, two old females, and two and five of immature or maturing males and females, respectively - presumably a cross-section of a largely settled population.

After May 10, the epizootic seemed to subside, and no muskrat remains were found in 70 early-summer mink scats. But, for August, a time when certain burrow sets along the west central shore became mysteriously muskrat-vacant, eight of 39 scats contained muskrat remains, as did three of five scats deposited in late October and early November at a well-known old infection focus. Remains were found of only a single animal that may have died of disease between June and September, that one also dying along the west central shore. 
The 1948 breeding population was the equivalent of 89 pairs, or, using the previous winter's sex ratios, a total of about 225 adults, as of early and into mid-May. The territories were massed along the more attractive parts of the west and south shores and especially in places having burrow systems of previous years. There was, nevertheless, sufficient crowding to result in considerable establishment of breeding territories in some of the less habitable stretches of shore along the north and east sides. Substantial emigration took place in late May and early June, but 50 territories were still being maintained by August. By the end of August, four territories had been lost from disease. In view of the lack of evidence of cross-country movement in late summer and fall, even as central Iowa streams dried up, I am sure that little emigration from Little Wall Lake occurred during the months immediately preceding September. By then, the upper parts of numerous burrow systems were exposed but not enough, on the whole, to cause their occupants any real inconvenience or danger. Indeed, the latter made easy adjustments as the water continued to recede slowly until November rains came.

Of five muskrats dying about freeze-up in 1948 and prior to the opening of the trapping season on December 1, two (an adult and a young male) were found dead of shot wounds, two were adult females dying from unknown causes (possibly disease and old age), and the fifth was a large young male having a very severe strife wound across hindquarters and abdomen. Two subadults lay freshly dead, November 29 , on the shore of a private impoundment east of the marsh; these evidently had been killed by a dog, their wounds suggesting powerful bites and "mouthing." The same area of Little Wall Lake that served as a fur refuge in the fall of 1946 was also reserved for the same purpose in 1948, and the known legal catch from the parts open to trapping totaled 93, of which the carcasses of 84 were examined. All together, counting animals dying from disease and predation, we have 97 specimens that we may regard as a nearly random sample for the winter of 1948-49: 9 adult males, 12 adult females, 52 young males, and 24 young females. The latter sex and age ratios applied to the 46 of the 1948 adult females judged to have been still present in the fall at Little Wall Lake would give a fall population of about 370, including about 290 young of the year.

After the trapping, excellent current signs were to be seen about one burrow system in the part of the marsh that had been open to trapping, and nine other places of that part also showed evidences of living muskrats. Nearly half of the shore zone had been depopulated by the trapping, and my estimate of the number of muskrats that escaped the trapping on the trapped area was about 40 . On the refuge tract were 25 major sets of burrows and 31 more or less independent minor ones; if an average of six muskrats apiece be assigned to the major burrows and three to the minor ones, the early winter population of the refuge would amount to nearly 245 . This figure added to the known trapping catch of 93 and the estimated 40 escap- 
ing the trapping off the refuge would give a grand total of about 375 , which is not far from the 370 computed through sex and age ratios and the fall territorial data.

Ten of the adult females examined from fall, 1948, to spring, 1949, were in good enough condition to permit counting and aging of placental scars. One had not conceived in 1948; 2 had conceived two litters each; 5, three litters; and 2, four litters. Four of the 27 litters indicated by the placental scars were assigned to the early part of the breeding season; 19 to a mid-season (May-June-July) grouping; and four were late litters, including one probably born about the first of September. Three of the four females conceiving late litters had also conceived early ones and then apparently passed through about two months without conceiving until the times of their late pregnancies.

The muskrats surviving the trapping at Little Wall Lake wintered very well, 1948-49, both on and off the refuge tract, except for a single known transient frequenting the south shore and the occupants of a single burrow at the southwest corner of the marsh. During the first half of the winter, five of nine mink scats picked up near this burrow (the chamber of which had been opened by a mink) contained muskrat remains, compared with no muskrat representations in eight winter scats found away from this site. Such a high incidence in scat samples for a period of several weeks between mid-December and February was considered most suggestive, though not fully appraisable at the time. The possible presence of dead muskrats in or about this particular burrow was kept in mind, and, when the ice went out, six water-rotted but otherwise nearly intact bodies came to shore nearby. The four best-preserved specimens of these were young animals having charactersitic liver lesions and appearances, despite postmortem changes, of acute enteritis. Deaths of all six were dated back to about December, 1948, on the basis of their sexual states.

The vicinity of the burrow was watched in the spring for evidence of recurrence of the local die-off. However, the upper part of the burrow, along with whatever muskrat remains were in it, became effectually buried by the push of the midwinter ice, and later wave action erased the external evidences of former muskrat activity. In the course of the spring and summer of 1949, muskrats rehabilitated another old burrow system some yards from the infected one, but they did not seem to get into the latter.

Miscellaneous spring mortality recorded in 1949 at Little Wall Lake included a muskrat killed on the highway on May 9, an adult female killed by a .22 caliber bullet in late March, and two dog victims (both newly-mature males) examined March 28 and May 26. On May 24, an old male muskrat, dead about two days, was found outside one of the west central burrows where late spring and early summer disease mortality had occurred in 1948; its disease syndrome was chiefly pneumonic, but it had liver and intestinal lesions as well. 
The settled breeding population at Little Wall Lake in 1949 was the equivalent of 35 pairs as of May 26, 3 pairs lower than at the first census of early May. The sex ratio of 62.0 per cent males obtained for the winter specimens applied to 35 territories would give a calculated total population of about 95 adults.

The water had receded enough from the shoreline ice ridges by June to expose the upper parts of some of the channels leading to the muskrat chambers in the banks. During a dry summer, it receded still more until, by early October, it was down well over two feet below the 1944 overflow level. The muskrats of the one stretch of shore having good bulrush stands within easy reach abandoned the shore burrows to build lodges in the bulrushes. Elsewhere about Little Wall Lake in 1949, the muskrats responded by deepening burrows and channels, plugging caved-in parts of chambers, improvising nests under root tangles of trees, building shoreline lodges or small structures out in shallow water, on floating logs, boats, and other floating objects.

Summer mortality appeared to be quite heavy. The incidence of muskrat remains in mink scats was high -11 in 24 scats examined for that season, compared with one in 29 for September - and some of this surely could have represented mink predation upon occupants of exposed burrows. The remains of the muskrat in the September scat were of a "kit," whereas those in the summer scats ranged from "kits" to adults - mostly adults and subadults. Mink-eaten remains of an adult were also dated to the middle of September. Several burrow systems retaining plenty of water and appearing to be entirely habitable took on unused aspects suggestive of a continuing summer epizootic. The majority of these dead burrow systems were restricted to that part of the marsh (the northwest shore) where dying from disease had occurred during the spring and summer of 1948. The hemorrhagic disease was almost certainly the agency of much of the 1959 summer loss at Little Wall Lake.

There were a good many signs of activity along the west shore in early October, but, by the latter part of that month the patently regular residents were living in small to medium-sized, off-shore lodges, and such few animals as continued to frequent the shore were suspected of being transients. Fifteen of 82 October mink scats contained muskrat remains. One scat deposited about October 26 consisted of remains of a "kit." The October scats with muskrat representations were found scattered about the periphery of the marsh, hence were not indicative of any particularly localized availability of muskrats.

Numerous muskrats were reported as having been wantonly shot by duck hunters in the central bulrushes shortly before freeze-up, but, although I worked this area several times as soon as the ice would hold me, I did not succeed in finding them. There remains the question of whether a group of several said to have been floating in one part of the marsh might have been disease victims instead. An adult 
male turned in by a trapper in early December had dozens of liver lesions that did not look quite typical for the hemorrhagic disease.

The experimental fur refuge area was changed in 1949 to give legal protection from trapping to the muskrats of about the south third of the marsh. Fifty-six December-caught carcasses from Little Wall Lake were examined, along with 21 others from a neighboring drainage ditch. Sex and age ratios for the Little Wall Lake sample were 9 adult males, 8 adult females, 18 young males (including 6 "kits"), and 21 young females (including 8 "kits"). For the Little Wall Lake and ditch samples combined, the ratios were 12 adult males, 10 adult females, 27 young males (including seven "kits"), and 28 young females (including 10 "kits"). Of the 8 adult females from Little Wall Lake, one had not conceived in 1949, one had conceived two litters, and 6 had conceived three litters each; 4 of 20 sets of placental scars represented young born later than late July. The two adult females from the ditch had conceived 45 young in five litters between them, including one litter assigned to August.

The variables introduced by disease, partial drought exposure, and ingress make calculating the fall population a very tricky matter. Splendid visibility under new ice in December, 1949 (after the trapping had practically ceased) permitted counts of 7 heavily used lodges or burrow systems in the refuge area and 2 more outside of it; about 8 muskrats may be provisionally assigned to each. There were also 27 moderately well-used lodges or burrows on the refuge and 20 more outside; perhaps 5 muskrats may be assigned to each of these. Thirteen places having few signs but at least a single muskrat were counted on the refuge and 29 more outside; assignment of a single muskrat to each of these would result in underestimation, but, since the assignment of 5 muskrats to each of the moderately used habitations may result in some overestimation, the two errors may tend to counterbalance.

Allowing for 14 muskrats caught after the census counts, the above bases would give a total of about 205 muskrats alive on the refuge and about 130 on the trapped part after the trapping. The trapping itself was of very moderate intensity, with no known loss from wringing, and the 56 muskrats examined may be regarded as the total catch. The catch, added to the post-trapping estimates, would give a pretrapping total of about 390 , with more than half of these being on the refuge.

The data for early September, 1949, indicate that perhaps three of the adult females had been lost during the summer at Little Wall Lake, plus adult males and large numbers of the season's young. The losses of young, in fact, seemed to have been disproportionately heavy. Fourteen "kits" were listed among the 39 young of the trappers' catches, and, in actuality, the proportions of late-born young were still higher, as five other of the 39 young were plainly small, yet not quite small enough to have been graded as "kits." When 
nearly half of the total sample of young of the year trapped in December turn out to have been late-born, compared with only a fifth of the season's known litters having being born as late as this, something must have happened to many of the early-born young. The high percentage of late litters among the total conceived may in itself be regarded as evidence of compensatory breeding in response to unusual losses of early and mid-season young.

A fall figure of 32 adult females used as a base for calculating the resident population at Little Wall Lake would give a total of about 225 , whether through application of the sex and age ratios of the trapped specimens from that marsh alone, or the ratios from the marsh specimens plus those of the ditch nearby. The pre-trapping total of about 390 minus 225 residents would then make it appear that numbers in excess of 165 may have come into the marsh in October, when so much evidence (shore signs and mink predation) of transients was seen, especially early in the month.

The population of around 335 muskrats calculated to have survived the 1949 trapping wintered securely and comfortably despite the low water level and the presence of only fair food resources about the shore zone. The ice in no case thickened to the extent of completely cutting off the food of any wintering group of muskrats, and there was always water in the channels even of the partly exposed burrow systems. Two bodies of young muskrats datable to early winter were found after the ice went out along the west central shore; these were suspected of having been diseased. No muskrat remains were found in five midwinter mink scats.

\section{THE BREEDING AND POSTBREEDING MONTHS OF 1950-52}

In late February and March, 1950, some mortality of the muskrats of lodges in the central bulrushes became apparent, as two of five locally deposited mink scats contained muskrat remains. Both of these two scats having muskrat representations were from repeatedly "bored" lodges of the south center. They were believed to have reflected increasing intraspecific tensions of late February in the most densely populated part of the marsh, for it was on the nearest shore that the signs of dispersal and land activity first became pronounced after the ice melted around the margins in late March. Fifty-two mink scats of similar dating from elsewhere about Little Wall Lake contained no muskrat remains. Nine muskrats dying in late March and April were found: five traffic and four disease victims. Three of the traffic victims - and later associated with them the body of a mink, presumably killed while scavenging - appeared to have been struck as a group.

The spring dispersal occurred in two big movements, the first following the shore activities on the refuge tract in March and involving possibly as many as 100 animals. This was no doubt hastened by wind action breaking up all the lodges in the south central bulrushes, 
thus evicting their occupants from the part of the marsh in which they may be said to have had property rights. The second big movement culminated in mid-April, and evidences thereof were most pronounced about the rest of the heavily populated refuge tract, particularly that of the southwest corner of Little Wall Lake. Food shortage may well have had something to do with the magnitude of the dispersal here, for animals that I watched feeding seemed to eat about everything that was at all edible, searching the drift for particles of green vegetation, etc. The majority did not have ready access to any choice foods, such as bulrush rootstocks.

Of the 335 muskrats calculated to have survived the fur trapping, fewer than 100 remained as the breeding population, as of the first of May, 1950. At this time, 33 breeding territories were distinguished. There were three main sets of burrows that might be considered as infected with the hemorrhagic disease in the winter and spring of 1949-50 and in which more muskrats may have died concealed underground than were retrieved; and these had had a total early winter population estimated at about 25 . If it be assumed that the occupants of these burrows died out before spring, and if an allowance be made for about 15 dying from miscellaneous causes in late winter and early spring (11 individuals were accounted for), then about 200 of the spring decline of 1950 might be chargeable to dispersal.

As in early May, the late May checkup gave 33 breeding territories, but the sites of three territories had been shifted considerable distances in the meantime. In all three cases involving big territorial shifts, the animals later abandoned their late May sites as well as those earlier maintained. By late June, one breeding territory was established in the central bulrushes, about 500 yards from one of the ephemeral shorezone territories abandoned about this time; and the total number of maintained territories dropped to 29 . Then, by late July, four more shore territories (in the southeast corner) disappeared, but with a corresponding increase of muskrats in the south part of the central bulrushes lying out from the vacated shore. By mid-August, the marsh seemed to have about the equivalent of 29 maintained territories, including four that were productive of few if any young.

Of the four unproductive territories, three were situated in partial isolation along the most sparsely populated stretches of the shore zone - the north end and the east central side. Along a stretch comprising about 2,000 yards, or about half of the shore zone of the marsh, there were, along with these three unproductive territories, only four productive ones. The sole territory of the better-populated shore that proved to be noticeably unproductive was adjacent to a territory of which the occupants were found to be dying of disease in late August and early September.

The latter disease victims were the only ones actually found at Little Wall Lake between late spring and midautumn, 1950, but two of the four territories becoming nonfunctional without compensating 
gain elsewhere in early June were at sites of infection foci of the spring. The loss of one of the other territories in June may have been associated with the washing away of a shore lodge by high waves of a storm; this, though not attended by death of any adults (it probably did drown a litter of young), is thought to have been followed by departure of a female from the marsh.

Water levels of the marsh had been restored by May and June rains to within about a foot of overflowing into the outlet, and the water receded only to a moderate degree during the dry weather of late summer and early fall of 1950 .

In early and mid-September, considerable local readjustment of the Little Wall Lake muskrats was in progress. Newcomers rehabilitated two of the previously abandoned territorial sites, and a group of animals established itself at one place about 150 yards away from any earlier 1950 retreat of muskrats. On September 21, signs of transient animals were recognizable along two other long-vacant stretches of shore.

Mid-November population estimates at Little Wall Lake, made with the aid of good bubble signs under clear ice, totaled about 435 . The sample of 125 carcasses examined consisted of 8 adult males, 9 adult females, and 108 young of the year. These ratios, applied to the 29 adult females judged to have been alive and present in maintained territories (including four territories that were productive of few or no young) by mid-August, would give a total fall figure of about 400 . The latter figure should be very close to the actual pre-trapping population, distributed as about 160 in a fur refuge area in the south part of the marsh and about 240 in the north part open to trapping.

Two adult females in addition to the above 9 yielded reproductive data for Little Wall Lake in the fall of 1950. Two of the total of 11 examined had not conceived in 1950 - which fits in with the field data obtained from the summer's territorial studies - but 7 females had conceived 3 litters each and 2 females had conceived 4 litters each in 1950. A single small female judged to have been born in May, 1950, herself gave birth to a litter of 4 young in August. The nine 1950 breeders among the 11 adult females conceived a mean of 24 young; and, of the 29 litters conceived, the births of 4 were dated to May, 9 to June, 9 to July, and 7 to August and September.

The main event affecting the Little Wall Lake muskrats before the trapping was a northwest windstorm reaching its height on November 9. It washed away the lodges of a centrally located tract of hardstem bulrushes. Individuals that had merely extended their home ranges from bank burrows to deep water lodges returned to the familiar banks when their lodges disintegrated, but many of those living far out in the marsh came ashore as evicted strangers, and the behavior of these latter was repeatedly observed.

Four homeless muskrats (two big ones, one of medium size, and a rather small one) were seen sitting out the storm along the wave- 
beaten southeast shore on November 9, and a mink scat from the night consisted of muskrat remains. One mink scat deposited before the storm and seven deposited some days afterward were without muskrat remains. Two dead muskrats - old and young males - found intact in the rushy drift showed no disease lesions and were thought to have drowned in the violent waters. Four evidently wandering muskrats were reported by a hunter as taking refuge under a boat on the southwest shore, and other animals worked along the east shore. On November 14, three new superficial burrows were examined along the east central shore, of which one burrow had about three muskrats and the others single animals. Between these burrows and the part of the southeast shore where the four evicted ones had been seen on November 9 were at least six land holes that showed sign of temporary occupancy.

Land activities attributed to storm-evicted newcomers could be seen along most of the shore of Little Wall Lake up to the beginning of the trapping on November 25, and, in the refuge part, past the end of December in those places drawing the greater proportion of the homeless ones. One of the young females taken by a trapper was suspected of having been an animal trying to make late adjustments. It had a very severe, recently healed muskrat bite near the base of its tail.

The hemorrhagic disease, though still at Little Wall Lake in the fall of 1950, had almost no significance as a population depressant. Eight or 13.6 per cent of a lot of 59 trapped mostly from the west central shore - the deadliest part of the marsh from the standpoint of epizootiology - had liver lesions, an exceedingly high incidence in animals active enough to be caught in traps. But the post-mortem appearance of many of the lesions suggested good progress in natural healing. A single disease victim was found dead under the ice, and two others were examined from a privately-owned impoundment northeast of the marsh.

Water conditions were favorable on Little Wall Lake during the fall and winter of 1950-51, but the food supply was really good only in such places - mainly the central part - as were dominated by bulrushes. Elsewhere on the marsh, the muskrats subsisted upon rather inferior foods, particularly yellow water lily. During cold weather, this diet was supplemented by some feeding on the flesh of painted turtles and fishes. Nothing resembling a hunger crisis was noted, but, from the feeding behavior of the animals and the condition of specimens found dead through different agencies of mortality, it may be judged that the population on the whole tended to be somewhat undernourished.

The apparent food limitations were considered partly responsible for conspicuous unrest and movements away from the marsh in early April, 1951. Approximately 250 muskrats (nearly the whole population remaining after the fur trapping in early winter) had survived the 
winter; yet by early May, only about 100 muskrats seemed to remain, these living in 41 fairly well recognized territories. Up to this time, little winter or spring mortality had occurred -7 dead from miscellaneous causes were found after the ice went out. However, by early June, the number of functional territories had been reduced to 24; by early July, to 15 , plus 6 places having probably lone animals in residence, thus giving a total of perhaps 40 adults alive on the marsh. One stretch of shore zone having 9 original territories had a probably lone animal in residence by July 5 . Another stretch having 12 original territories had 3 territories and 4 adults judged to be living alone by July 2. Only along 7 short stretches of shore could muskrats be said to be thriving by July. The losses continued, and, by midJuly, the east half of the marsh and most of the west half had almost no muskrats. Two groups of thriving muskrats were left, both groups living in the midst of superior food resources.

For many weeks it was not satisfactorily demonstrated that the 1951 population actually was being reduced to the extent indicated. Some stretches of shore had abundant signs and others, inexplicably, hardly any or none at all. The over-all pattern suggested an epizootic, but the muskrats had not died in important numbers during the preceding fall and winter, despite the very high incidence of sublethal cases of hemorrhagic disease; nor were more than a few found dead during the period of greatest decline in the spring and summer. The problem was met by watching closely the obviously functional territories, to see whether something diagnostic might happen and be recognized before the signs became obliterated through weather, wave action, scavengers, or decay.

The reduction proved indeed to have been due to an epizootic apparently of the hemorrhagic disease, as usual, though of the deadly pneumonic syndrome. The fresher of 14 dead found in the course of special searches between mid-May and September showed extreme congestion of blood not only in the lungs but about the whole thorax. Virtually no other lesions were seen in the victims except for occasional more- or less-healed necrotic foci in some of the livers. Many animals appeared to be dying out of sight in the burrows. In two instances, I smelled odors of decay through the ground over the chambers of muskrat burrows. The 1951 epizootic seemed to be almost confined early in its course to the vicinities of old infection foci, spreading slowly as the season advanced until, by June, it got around the shore zone except for the two places mentioned. By August, it may well have covered all of the muskrat-occupied part. Then the dying slackened by fall. Six animals were found that died in October of which three had been shot by hunters, and the other three were not certain victims of the disease.

Little Wall Lake was minkless during the spring and summer of 1951 until one appeared in August. One of 72 mink scats deposited, August-October, contained muskrat remains. This muskrat-containing scat was found under circumstances suggesting that the victim had 
newly arrived in a place that had been muskrat-vacant for months. A quite substantial (but local) movement occurred in late August and September along the shore away from the northwest part. Animals moved both southward along the west shore, and eastward and then southward along the north shore, to repopulate to a varying extent many of the vacant burrow systems.

From the first of November to the middle of that month, clear ice afforded good opportunities to read bubble signs in the vicinities of most of the used burrow systems of Little Wall Lake. It soon became apparent that a tremendous amount of variation in bubble signs was occurring between visits at the sites of some of the burrow systems. The latter variation was partly due to different intensities of muskrat activities along a given stretch of shore. Sometimes the muskrats would be mainly frequenting one set of burrows and then they would be frequenting one of the neighboring sets for a few days.

The state-owned area of Little Wall Lake was closed to trapping, but Leigh Johnson, the owner of the north end, was encouraged to trap his private holdings during the general open season so as to provide some definite population data that could be used as an index for estimating numbers of muskrats in untrapped parts. His catch of seven muskrats from the extreme northwest corner seemed to reduce by about a third the amount of bubble signs being laid down there; and the amounts of pre-trapping signs of that corner were compared with signs recorded on the same days and under comparable conditions along other stretches of shore. The shore habitat was blocked off for study according to similarities usually to be noted in quantities and distribution of bubble signs, not only on specific days but also for periods of days. From all of the data, one set checked against another, a final estimate of about 160 muskrats was arrived at, representing the population of Little Wall Lake as of early November.

The above population was evidently composed of the few survivors remaining of the spring and summer adults, plus the young reared in five highly productive territories, plus what young may have been reared in two other territories that may have been productive to some extent. No significant ingress of animals was believed to have increased the population of the marsh during the late summer and fall period of adjustment. All adjustments described at Little Wall Lake in detailed notes in 1951 were manifested by diminished signs in formerly occupied places, as animals established new quarters elsewhere. All fall, only one animal was noted that behaved like a footloose wanderer. This one lived by itself in the central bulrushes until forced ashore by a storm, after which it returned to the center. The marsh was outside of any known routes traveled by adjusting muskrats of the neighborhood in 1951.

Wintering losses, 1951-52, were fairly light and all but confined to a stretch of the south shore that had the greatest concentration of muskrats on the marsh. For the above stretch of shore, a population 
of about 25 was estimated from signs after freeze-up, and this would seem to have been about the correct number. As spring approached, as many as 14 could be seen sitting together about a small patch of open water lying out from the best-used burrow system; six others were in sight at the same time, and there were at least three muskrats at other places in this stretch. In this group, remains of six dead were found. All had been fed upon by predators in mid- and late February and March, but the muskrats evidently had been dead since earlier in the winter. One of these had been dug out of a deep snowdrift by a fox. Another had suffered loss of some of its toes and tail through freezing before being eaten upon by minks, foxes, and crows. None of 78 mink scats deposited from late fall to early February contained muskrat remains, but 19 of 47 scats for the middle and latter part of February did, as did one of 50 March scats.

On March 31, a muskrat was found killed by highway traffic south of Little Wall Lake, and considerable breeding-season adjustment was by then in progress. The first evidence of animals dispersing from wintering quarters was seen on March 13. The best figures obtained for the late April to June period gave a total of about 42 breeding territories or, following a central Iowa sex ratio of 53.0 per cent males for the winter of 1951-52, about 90 adults. The greatest breeding concentration on the marsh was in the northwest corner, where four territories were found along a 140-yard stretch of food-rich shore. No further dying from disease was noted during the spring and early summer of 1952.

However, about late June, some dying from the pneumonic syndrome began at one place along the west shore, at one of the sites of mortality of previous years. This epizootic gained headway by midJuly, when dying was occurring in at least three widely separated places, including the old focus mentioned above. No muskrat remains were found in 48 mink scats for June, compared with remains in 5 of 161 July scats. By early and mid-August, animals were dying in several places along the west and south shores; and this continued to be the situation into late August and early September, when some very good specimens of pneumonic victims were examined. Of 24 mink scats recorded for August, 5 contained muskrat remains.

By mid-September, the dying seemed almost over. One animal having massive liver abscesses - these amounting to about two-thirds of the volume of the liver - was found dead on September 17 at one focus at which only pneumonic victims had previously been found in 1952. Dr. Paul C. Bennett, of the Iowa Veterinary Diagnostic Laboratory, obtained from these abscesses a pure culture of the pus-forming Aerobacter aerogenes, well known as a secondary invader. On October 15, another animal having massive multiple abscesses in the liver and other viscera was found at the same place, but it really had died of a terrific case of pneumonitis. A typical pneumonic victim was found on September 25 in the sparsely-populated hardstem bulrushes 
of the center, well away from any known site of previous disease mortality.

The 22 dead (14 from newly-weaned to "kit" sizes, 4 subadults, and 4 adults) that were accounted for as individuals during the summer and early fall epizootic doubtless represented only a fairly small fraction of the total dying. Only 3 dead were found, for example, outside the burrow where the first dying was noted; yet this burrow had taken on a lifeless appearance by September, despite the fact that at least two and probably three litters of young had been born and reared there up to the time of dying. But, as a rule, not many of the burrow systems where animals were known to have died in 1952 showed evidence of annihilative or even severe losses. A burrow system, outside of which 4 dead had been found between late August and mid-September, was heavily used by muskrats through September. Another dead muskrat was found here on November 1 .

Few mink scats were obtained in midfall, only nine (none with muskrat remains) for early October. There were, in fact, very few minks around after midyear, 1952, and one of those few was found dead in late summer.

The over-all muskrat sign in late September, after the dying largely had ceased, indicated a near-saturation population for the marsh in the condition that had been characteristic of it since 1945. Although there may have been some ingress from a neighboring ditch, the population seemed essentially self-contained up to mid-October. (A total of about a dozen muskrats, including the pneumonic victim found dead on September 25, stationed themselves in the center and northcenter somewhat after the manner of strangers.) The second week of September was a time of extensive readjustment at Little Wall Lake, with all adjustments seeming to be on a very local scale. In four instances, the sources of animals rehabilitating old burrows or establishing quarters along previously vacant places were convincingly traced to parts known to have been highly productive of young during the summer. Trapping was legally restricted to the west part of the marsh in the fall of 1952, and only 42 carcasses ( 2 adult females, 17 young males, and 23 young females) were obtained for examination. The smallness of this series, combined with the effects of the pneumonic losses of late summer, introduced many uncertainties into population calculations. From data obtained in late July, it could be judged that only 25 of the original 42 territories were productive of young, and, by late August and early September (before the big population adjustments), only 21 were being maintained by what had the appearance of substantial family groups. Of the 21 territories that remained unproductive or were lost during the summer, 5 were along a sparsely populated stretch of shore (hence probably maintained by unbred females), 3 were clearly depopulated through disease, and the causes of failure were not specifically ascertained for the 13 others. Of the 21 functional territories of late summer, 3 were sites of severe though 
not annihilative disease mortality. If 19 territories be used as a base for calculations, for application of the sex and age ratios of the trapped carcasses, the total late fall population should have been in the vicinity of 425 muskrats, or somewhat above the usual fall saturation levels of late years. This figure would be fairly consistent with the impression gained from the earlier "reading of sign."

The 1952 disease losses at Little Wall Lake therefore seemed to have been well compensated. Certainly to some extent, the mechanism was a near-maximal rate of breeding on the part of such adults as were in position to breed: both of the trapped specimens of adult females had conceived 4 litters, totaling 73 young, in 1952. One of the 23 young females examined in November had conceived a litter of 7 - an exceptionally large litter for a precocious breeder.

About 60 muskrats were accounted for as taken by trappers during the fur season. Continued signs of probably twice that number could be made out after the trapping had terminated on the part open to trapping. In addition, there were considerable concentrations of muskrats in two main tracts of the refuge area. All together, at least 300 muskrats entered the winter at Little Wall Lake, and these wintered very well, despite moderate lowering of water levels as a result of the dry weather of summer and fall.

The marsh was devoid of minks from early winter up to mid-February, 1953, but red foxes systematically sniffed the lodges and pushups and worked the shore zone throughout the winter. About February 10 , a mink appeared, to remain until spring. It was remarkable how soon this mink found and established itself at the two infectious burrow systems of the summer and fall epizootic that still had live muskrats after the trapping season. From one of these, the mink dug out the bodies of at least two muskrats, and all of 10 mink scats deposited between mid-February and March contained muskrat remains. At the second burrow, the mink found at least one muskrat, and 17 of 33 of its scats for late February contained muskrat remains, compared with none in 32 deposited in the first half of March at the same place. Away from these two known foci, only one dead muskrat was recorded in the field notes for this period, and that one decayed without having been utilized by scavenging mammals or birds.

\section{THE BREEDING AND POSTBREEDING MONTHS OF 1953-55}

A big reduction in the Little Wall Lake muskrat population occurred between the break-up of the ice and mid-April, 1953, which may be ascribed to ordinary spring dispersal. As of early May, the settled muskrat population figured out at about 80 adults maintaining 47 territories. By mid-June, only 37 territories remained functional. Most losses of territories were along the west side, and so was nearly all evidence of actual disease mortality. Six disease victims were handled.

In addition to the disease losses taking place before the breeding 
season gained headway in June, there was more loss by late July, especially in about five burrow systems at which mortality from disease had been recorded in preceding years. Annihilative losses were noted at two of these five burrow systems. In one case, a raccoon did much of the scavenging upon the dead in an exposed burrow system, though muskrat remains were recorded in two of 16 mink scats deposited near by. In another case, 25 of 239 mink scats for early and mid-July contained muskrat remains, whereas none of 172 scats deposited later (through October) contained muskrat remains - and all of the 25 muskrat-containing scats were datable to a period of less than two weeks, all traceable to one burrow system that suddenly went dead.

The continued exposure of the shore zone during a late-summer drought forced most of the muskrats to move toward the center, away from the really dangerous old foci of infection. There was very little dying from late summer through the fall of 1953. The deeper water offered the adjusting muskrats plenty of space and passably good habitat, and, generally, the local animals acted as if they belonged and knew what they were doing. A very few, wandering about the shore, were thought to have been strangers from the dry streams of surrounding areas.

As a conservation measure during a year of drastic reduction of central Iowa muskrats, Little Wall Lake, as a public-owned marsh, was closed to trapping in 1953. Because of the resulting lack of data from trapped carcasses, the only calculations of fall populations that could be made were on the basis of lodge counts and signs - a task made easier than usual by the abandonment of bank burrows forced by the drought. The population, as of early December, was calculated at between 350 and 400 , probably nearer the former.

The water level, though conspicuously reduced by the drought, still was not reduced to the point of crisis. An estimated 300 - after some illegal trapping - wintered well despite mediocre food resources. However, the marsh was almost abandoned by muskrats in early April, 1954. The migrants moved out of here, cross-country, in response both to population pressures and to the over-all unattractiveness of the place for muskrats. With the coming of spring, the continued low water level left the bank burrows exposed along the periphery of most of the marsh, and the deeper water was too wind-swept and lacking in emergent vegetation to encourage building or maintaining of lodges. After some milling about the shore zones, the restless and homeless ones took the alternative open to them.

A carefully estimated population of 30 remained on April 19. On June 4, a good census gave only 13 currently maintained territories, representing about as many muskrats as had been originally estimated. By late summer, it was clear that Little Wall Lake had a total of 17 maintained territories. The connection between clumping of territories and successful reproduction in a low-density population was pronounced. None of six territories scattered along the shore of the east 
half produced young, whereas 10 of 11 in the west half (including eight territories arranged in three clumps) produced young.

Two territories were lost because of disease in early summer and two others also may have suffered considerable disease loss in late summer. A certain amount of territorial shifting occurred in the west half as the breeding season progressed, but very little evidence of wandering was noted. The more conspicuous of adjustments involved one family and probably no more than a half dozen individuals working into the most heavily vegetated central parts. All of five evidently lone animals staying alive along the east shore retained their territorial sites throughout the summer.

In late September and early October, many muskrats came into Little Wall Lake from a drainage ditch lying to the north, to settle in those parts having fairly attractive combinations of food and water and few or no muskrats already in residence. The locally reared young were judged to have been the offspring in about thirty-three litters having the following estimated birth periods: five litters in April, seven in May, nine in June, seven in July, four in August, and one in September. All together, the population of locally resident adults and their season's young was carefully estimated at slightly fewer than 200, as of early October. After the removal by trappers of at least 100, the signs to be seen through clear ice indicated a population still between 300 and 400 . This would signify a 1954 fall ingress perhaps in the vicinity of 300 .

After the trapping season, the population wintered with no detected loss, 1954-55. The population was nevertheless top-heavy for the nearly open-water marsh in the spring, and a pronounced egress occurred in early April. At the time of maximum restlessness, fox-eaten remains of two were found on shore.

By mid-May, 1955, the population remaining after the spring dispersal was well established in 31 territories, all in the shore zone and about half of them in a stretch representing less than a fourth of the shore zone. The favored stretch had been deepened near shore by dragline operations two years previously and was thus more protected from exposure during low-water stages. By mid- and late June, there were still 31 maintained territories, mostly located as before but with some outstanding exceptions. Four territories were then located in central stands of emergent vegetation and a corresponding number of earlier ones along relatively unattractive shore zones showed evidences of abandonment.

The 31 territories were maintained by about 50 adults. Most of the territories located in the more isolated positions were unproductive of young. The unproductive were nine of 12 territories scattered about the east and south two-thirds of the marsh. The 16 territories that were productive of young among the other 19 of the Little Wall Lake territories included nine territories of the northwest shore that were massed along a 500-yard stretch having the dragline trench. 
The latter was the place that still had an estimated three-fifths of the muskrats living at Little Wall Lake by the last of September. This was after two months of gradually increasing drought-exposure of the shore zones and a period of substantial population adjustments beginning well before the onset of the drought. A little dying was noted in the vicinity of a notorious old disease focus, but nothing serious developed from it, and few muskrats of the Little Wall Lake population were now living in places especially hazardous from the standpoint of disease. Neither was there much evidence of summer mortality from other causes, nor of summer movements to or away from the marsh. The muskrats present by late September represented essentially the population belonging there, irrespective of the considerable readjustment that occurred on a local scale.

By early October, evidence was noted of activities of probable newcomers, and, by freeze-up, considerable evidence of newcomers was to be seen. Many ill-situated individuals that behaved like strange wanderers remained active about the drought-exposed northwest shore (in the principal line of travel of wanderers from the drainage ditch lying to the north) throughout December.

The 1955 trapping catch of muskrats totaled about 90, and it did not conspicuously reduce the population entering the winter. The most carefully studied sample of marsh had an average of about four and one-third muskrats per medium-sized and large lodge, as calculated from trapping data. This ratio, applied to a total of 112 lodges of like sizes, would give a total late fall population of about 485 .

Of the 85 muskrat carcasses representing the sample handled from Little Wall Lake in late November and early December, 4 were adult males, 11 were adult females, 48 were young males, and 22 were young females. The calculated total of adult females then on the marsh was 63 , of which only about 30 could have been regular summer residents. Although only 19 of the territories maintained during the 1955 breeding season showed evidence of having been productive of young, most of these were obviously quite productive. From the above ratios, combined with data on population samples of the stream dwellers from which late fall immigrants were recruited (see Chapters 10 and 11 for 1955 stream data), it may be calculated that the 19 productive territories reared an average of nearly 15 young in each, or a total of about 280 of the young present in the fall. According to the same calculations, the fall immigrants consisted of about 33 adult females, a very few adult males, and about 120 young. The calculated late fall population may therefore be broken down into about 330 resident muskrats of all ages and about 155 immigrants of all ages.

The 11 adult females in the 1955 trapped sample from Little Wall Lake (which necessarily included immigrants as well as residents) had conceived a total of 35 litters during the breeding season. One of the 11 adult females examined had not conceived young in 1955 . 


\section{VARIABLE FORTUNES OF THE MUSKRAT POPULATIONS FROM JANUARY, 1956, THROUGH APRIL, 1958}

Nearly 400 muskrats survived a brief trapping season in late November and early December, 1955. Thereafter, the detected 1955-56 wintering mortality from all causes was practically confined to a sparse population of animals living or trying to live in one sizable tract of frozen shallows. Here, luckless animals commuted from bank holes out across the ice, or from holes in frozen mud lodges to the vegetation fringing the shore, or just worked around finding little to eat and much trouble. The marsh was minkless during the winter crisis of these muskrats, which seemingly prolonged by several weeks the time that some badly situated muskrats were able to stay alive; but hunger, cold, bleeding from gnawed-off frozen tails, and fighting among themselves finally accomplished much of the eliminating that the absent minks failed to do. Of 11 shallow-zone muskrats that could be fairly well distinguished as individuals on the basis of appearance or activities, 8 were known to have died by the middle of February.

Among the more informative victims of winter-killing was a subadult, which had been living in a bank hole and foraging on the exposed marsh bottom. It came out while the temperature was 23 degrees below zero (F.), worked over the snow in its accustomed way, turned over on its back, and died. Previously, it had gnawed off about half of its frozen tail. Another died in a hole in the side of a lodge, where one of its cannibalistic fellows was discovered feeding upon it. One muskrat continued to gnaw on its frozen tail until it had only a short stub left, and this stub kept bleeding conspicuously for a period of at least 11 days before the animal died. Much fighting took place between the desperate muskrats working on the surface of the ice, and several individuals caught by hand for superficial examination showed fight wounds as well as frost injuries.

The particular muskrats that managed to live the longest in the shallows were chiefly big strong ones that had access to substantial quantities of bulrush rootstocks mixed with rush stems in the material of which the lodges had been built. Although such rootstock-containing lodges were partly hollowed out by muskrats from within, the usual procedure of surface-feeding muskrats was to search for the rootstocks from the outside. This left proportionally more of the Little Wall Lake lodges with rumpled exteriors than at Wall Lake, where the presence of minks may have been making the muskrats more circumspect in their behavior (Chapter 7).

A pronounced exodus of muskrats from Little Wall Lake coincided with a period of local readjustment in late March and early April. Between March 29 and April 9, five traffic victims and one apparent example of a transient drowning during a windstorm were found at or near the marsh. By late April and early May, the remaining muskrat population was fairly well established in definite territories, 
and later checkups confirmed most of these territories, besides adding a few more. As of mid-June, there were 67 recorded territories, of which 5 were judged to have been maintained by lone adults. From the winter and spring sex ratio of 62.2 per cent males in a sample of 91 specimens, the established mid-June population of adults may be calculated at about 170, or approximately half of the animals that had probably gotten through the winter on the marsh.

The population of mature animals, higher than usually remained on the marsh after the spring dispersal, may be largely attributed to an actual improvement of muskrat breeding habitat that resulted from partial drought exposure. Not only were the resident muskrats forced away from long stretches of shore zones - including the most dangerous old disease foci - but they also found the shallower central waters offering attractive sites for lodge building that had not been there at times of generally deeper water levels. By the end of June, however, the exposure of large tracts of marsh bottom was bringing about increasingly critical conditions for the muskrats resident in 20 of the maintained territories.

As at Wall Lake in 1956, something happened at Little Wall Lake that seemed inexplicable in terms of the usual patterns of climatic emergencies, mortality, and population behavior. Away from the drought-exposed territories at Little Wall Lake about 100 acres remained in attractive condition for muskrats throughout late summer and fall; yet only 22 of the total of 67 territories on the entire marsh were showing, or had shown, evidences of productive breeding by mid-July. The muskrats of only 2 of the 20 territories most affected by the drought seemed to make successful adjustments in the direction of deeper water. By early September, many of the formerly occupied parts of the marsh had been abandoned, without detected evidence of where their respective occupants went. As of late summer and early fall, the postbreeding population of muskrats was estimated at about 220 .

One of the mid-June litters was seen to be preyed upon by a large muskrat. The only other mortality actually noted on the marsh during the warm-weather months was of two adults, both found dead on exposed marsh bottom near disease foci of previous years. Nevertheless, it is most doubtful that disease significantly contributed to the muskrat losses between early summer and fall. Nor was it merely a matter of drought, for, in most abandoned territories, abandonment occurred while some water still covered the marsh bottom about the territorial sites.

Times of birth of 23 litters were recorded from Little Wall Lake field data in 1956: sixteen from early April to early May, three for about mid-May, one for early June, two for mid-June, and one for early July. In addition, there was some evidence of late breeding on the east side of the marsh, where food and water conditions remained most favorable for the muskrats. It is of interest that the lone example 
of a three-litter female recorded for Little Wall Lake during the summer of 1956 lived in an isolated dredge pool next to shore. Members of this family group were repeatedly observed, without finding any evidence of unusual irritability, restlessness, or inability to take care of themselves.

A heavy ingress of muskrats became apparent in the late fall of 1956, until a population of about 550 had been built up by the opening of the trapping season on December 1. Trappers took about 225 during a 15-day open season, and their catch rates were holding up well when the season closed. Ratios for 196 trapping season carcasses were 18 adult males, 25 adult females, 85 young males, and 68 young females. The 153 young of the year included 10 "kits," judged to have been born in August.

Two of the 25 adult females of these muskrats of mixed origin had not conceived in 1956, and one of the 23 productive females was in unsuitable condition for the counting and aging of placental scars. Of the other 22 adult females, 3 had conceived two litters each; 9, three litters; 9, four litters; and 1 a probable five litters. None of the 68 young females had bred precociously. The seasonal distribution of birth dates estimated from placental scars of the trapped sample showed 15 litters for April, 18 for May, 21 for June, 16 for July, and 4 for August. The differences between the above distribution and the seasonal distribution of litters observed during the summer's field work of course reflected in part the mixture of true residents and immigrant animals in the trappers' catches.

For the early part of the winter of 1956-57, the approximately 300 muskrats that survived the trapping season suffered little mortality, despite continued surface activities on the part of several groups living in drought-exposed and shallow-water zones. Even when minimal temperatures went as low as 30 degrees below zero in the first half of January, the surface-active muskrats were usually taking care of themselves. But, by the spring, most of the vulnerably situated muskrats were dead, as were the occupants of sizable tracts of marsh having fair to excellent wintering conditions.

The principal detected agency of loss was the hemorrhagic disease. Between freeze-up and spring, dying began at three places, at least, of which two had been sites of rather minor disease mortality during previous years. Then, the epizootic swept through a wellpopulated tract of about 10 acres, besides killing many muskrats on three additional smaller tracts. It subsided in late spring, just as it seemed ready to sweep the whole marsh.

Over some parts of Little Wall Lake that were not positively known to have been sites of disease mortality during the winter of 1956-57, the field evidence was not at all clear as to whether the wintering losses were due to disease, to hunger and cold, to mink and fox predation upon drought-exposed muskrats, or to all of these agencies in combination. One such site of imperfectly diagnosed mor- 
tality in 1956-57 was adjacent to the only proven focus of the hemorrhagic disease at which muskrats had died during the winter of 1955-56.

Five distinguishable minks (three males and two females) were present on Little Wall Lake from mid-December through the next two months, but only three (an enormous male and the two females) remained from late February until break-up. The food habits of these minks reflected well the deteriorating fortunes of the muskrats as the winter progressed.

The first evidence of a local population collapse from disease was found in late January, and, thereafter, mink diets ran heavily to muskrats instead of to the mice and dead waterfowl upon which they had earlier subsisted. For late January and the first half of February, 4 of 14 mink scats contained muskrat remains; for the second half of February, all of 15 mink scats did, as did also 9 of 18 scats for March. Mink-eaten remains representing at least 14 individual muskrats were found, but the actual number scavenged upon was doubtless much higher. After the middle of March, the minks were no longer frequenting the tract of marsh most likely to have had dead muskrats lying about.

Of 21 disease victims found in suitable condition for post-mortem examination, 18 had lesions suggesting low resistance (Errington, 1957).

The 1957 summer rains improved the habitat for muskrats at Little Wall Lake, though most of the parts that had been droughtexposed for the previous year regained little water. As of late May, there were 30 territories maintained by about 65 adults. By the time that the epizootic subsided, or by late June, 26 maintained territories (representing about 60 adults) could be distinguished. Thereafter, losses of undetermined nature, but probably from disease, occurred at one territory - at the site of what had been bona fide disease losses in the spring. Remains of three young muskrats were recorded for the latter site, including one eaten upon by another muskrat and one eaten upon by a mink.

The muskrats surviving the epizootic may be considered to have had a normal breeding season in 1957. As the period of late summer adjustments came on, muskrats moved into places that were up to hundreds of yards distant from the season's breeding territories. It may be doubted, however, that these adjusting individuals represented newcomers from the surrounding countryside, for, in most cases, their spreading away from the local breeding territories could be traced from signs.

The reported trappers' catch at Little Wall Lake during a 15-day open season was 251, of which 190 specimens were posted: 10 adult males, 23 adult females, 92 young males, and 65 young females, including 2 breeding precociously in the calendar year of their birth. 
Three of the 23 adult females had not conceived in 1957; 1 had conceived a single litter; 1 , two litters; 10, three litters; and 8, four litters. Counting the 13 young conceived by the two precocious young, the number conceived by the breeders in the trapped sample totaled 500 .

For purposes of computing the total late fall population, the marsh may be divided into four tracts, of which two were trapped hardly at all and two were trapped quite heavily. For the trapped tracts, consideration of the way that catches declined during the open season permits reasonably satisfactory estimates of the probable numbers of muskrats remaining at the close of the season. For one trapped tract, a catch of 44 represented a probable four-fifths of the population; for the other, a catch of about 207 represented a probable two-thirds of the population; and thus the fall population of the trapped tracts figured out at about 365. The untrapped tracts had lodges and other signs suggesting a population a little more than 50 per cent greater than that of the tract yielding the 44 animals judged to have represented four-fifths of the local group; hence, the populations of the virtually untrapped tracts should have been in the vicinity of 85 . Adding 85 to 365 gives a total of about 450 as the pretrapping population of Little Wall Lake.

Selective early-season trapping pressure upon adults is shown by the ratios of 3.4 young per adult in 80 specimens taken during the first few days of the trapping and 6.3 young per adult in 110 specimens taken during the rest of the 15-day open season. Undoubtedly, there were still adults among the approximately 200 animals untrapped, but the ratio of young per adult must have been high among the survivors of the trapping season. According to the changes shown by the age-ratios in the trapped samples as the trapping progressed, the true age ratio for the whole population of about 450 animals should have been about 10 young per adult. This gives a total of about 45 adults, of which about two-thirds, or about 30 , should have been females - essentially the same number as those maintaining territories at the time of the first good checkup in late May.

In all probability, the 26 maintained territories recorded for late June corresponded to actively breeding females - which would balance out about right, in view of the three non-breeders found in the 23 carcasses of adult females examined. If the breeding performances of the 20 adult females examined be prorated to the total of 26 adult breeders, the total number of young conceived would be about 630 . Prorating the data from precociously breeding young females would give about 30 more young conceived. The total number of young conceived for the marsh in 1957 would therefore be about 660 , of which some 400 or more could have been reared to bring the population up to the 450 level of late fall. Rearing of 400 out of 660 conceived would represent a plausible degree of reproductive efficiency for a comparatively well-situated population, and no im- 
portant ingress of adjusting animals from neighboring streams need be postulated to account for any of the 1957 fall population of muskrats on the marsh.

There was one place - in the food-rich shallows of the northwest corner of Little Wall Lake - that may have been stocked by newcomers from outside, moving in during late fall. This place was in the usual line of travel of such animals as did move into the marsh in some falls from a drainage ditch that runs close by. The number of muskrats living by themselves in the northwest shallows seemed to have been about the equivalent of an ordinary family group, or possibly 10 to 15 ; but these were not animals that were by any means proven to be newcomers. They were situated in a tract of marsh that had been most difficult for a human observer to get into in the spring after the melting of the ice, and the muskrats found there in the fall may have been an earlier overlooked pair and their increase.

The specimen data from Little Wall Lake contributed further to our knowledge of the 1957 breeding fortunes of the local muskrats. The adult female that conceived the one litter had only a single young in the litter, having a birth date assigned to April; this mother was rather small and considered to have been born late in the breeding season of 1956. At the opposite extreme was a female conceiving 38 young in four litters. The breeding adult females averaged well over three litters, and a fair amount of late-season breeding took place. The seasonal span of birth dates of Little Wall Lake young (including the two litters born to precocious young) may be assigned on the basis of placental scars to the following months: 13 litters in April, 19 in May, 18 in June, 12 in July, four in August, and one in September. The occurrence of only 3 (or 1.9 per cent) "kits" in 157 young of the year in the posted sample suggests disproportionately heavy mortality of the litters born toward the end of the breeding season.

The approximately 200 muskrats surviving the 15-day trapping season in December, 1957, suffered undetermined though probably light losses in scattered places during January and February, 1958. Although the evidences of these losses were found almost exclusively in shallow-water zones, and the minimal daily temperatures got down to 19 and 22 degrees below zero in mid-February, the losses did not seem to have been associated with freeze-out crises. Rather, there was a remarkable association between the losses and places at which some mortality had occurred from the hemorrhagic disease, not only during the previous winter but also, in three places, to minor disease foci dating back for many years.

Four minks could be individually distinguished throughout January. During the first half of February, only two seemed to be regularly frequenting the marsh. But, on February 17, at the height of the cold snap, at least six minks were briefly present. The minks showed interest in certain of the muskrat lodges chiefly during Janu- 
ary; and, when considered closely according to their sites of deposition in different parts of the marsh, of 41 mink scats examined from old sites of dying from the hemorrhagic disease, 34 contained muskrat remains, compared with 4 in 14 scats examined from elsewhere on the marsh. Nevertheless, muskrats successfully wintered in all of the shallow-zone tracts that had any muskrats at the close of the trapping season, and no sweeping epizootics got started, either in the winter or the spring. No dead muskrats were found on Little Wall Lake after the ice went out.

A breeding-season checkup in early May, 1958, gave a total of 102 maintained territories, representing, on the basis of a winter age ratio of 53.7 per cent males, about 220 adults. This figure may represent more muskrats than actually had wintered on the marsh, for signs suggesting a few newcomers appeared in April in the northwest corner, near the usual route of travel of muskrats moving into the marsh from the nearest ditch. 


\section{Chapter 9}

\section{The Goose Lake Area, Central Iowa}

GOOSE LAKE is a privately owned marsh of about 100 acres. It is situated less than a mile east of Jewell, Hamilton County, Iowa, and three miles north of the Little Wall Lake area of Chapter 8 (Figure 8.1). I received cooperation there from many people, including Dr. H. H. Knight of Ames (manager of a club that leases hunting rights over most of the marsh), Dr. C. E. Anderson and Mrs. Anderson of Madrid (principal owners), Dr. Cecil Anderson and his daughter, Donna, Clark Voss, and Roy A. Bonner of Jewell (owners of the smaller tracts usually occupied by muskrats), former Conservation Officer Kay Setchell, and the trappers, Verl Black, R. E. Kautzky, Walter Sampson, John R. Reese, and Harry Hudspith.

\section{BACKGROUND}

Between 1932 and 1940, the years when I made only a few incidental observations on the area, water levels were known to have varied considerably. The bottom of the south half was exposed several times because of drought. The whole marsh went dry in 1934, but water returned in 1935. Hendrickson (1936) referred to three feet of water and 30 acres of bulrushes and cattails over 80 acres of marsh as of midsummer, 1935; Scott and Sooter (1937), to the fact that during the period of their observations, August 21 to November 8, 1936, not more than 20 acres were in open water, the rest being grown to bulrushes and cattails. Dr. Knight informed me that, from 1937 to 1940, the water came back slowly but rather steadily, despite the continued drying up of Little Wall Lake, three miles away; the emergent vegetation was not noted to have changed greatly in these years.

No data exist that may be considered wholly reliable with respect to muskrat fluctuations from 1932 to 1940 other than the general 
evidence that the species was sometimes scarce and never excessively abundant. It is unlikely that the 1934 drought left many alive, and little recovery would be expected before the summer and fall of 1935 . By the fall of 1936, the amount of marsh habitable for muskrats was still very restricted.

In the fall of 1941, when I first thoroughly worked the area, a dense stand of vegetation dominated by cattails covered the south half, except in two small tracts of deeper water. The north half consisted of a shallow lake having scanty emergent vegetation but extensive beds of yellow water lily, coontail, and pondweeds. Including muskrats living in dry habitats, the fall population - located chiefly in the cattails of the south half - was estimated at about 700 through comparing their field signs with that of known populations observed elsewhere. About 60 muskrats were said to have been legally trapped. There was an illegal catch of unknown magnitude, for set traps were seen before the trapping season opened. Mortality from mink predation was noticeable about the dry lodges as winter progressed. Probably the majority of the wintering muskrats survived, and a density of around 400 or 500 adults, probably nearer the latter, for spring and summer, 1942, should not be far wrong.

\section{A HEAVY POPULATION IN A STRONG HABITAT, FALL THROUGH SPRING, 1942-43}

A regular program of investigation was begun in the fall of 1942, as soon as it became apparent that the muskrat population of the cattails was remarkably high. The water lay several inches to three or four feet in depth over all of the marsh bottom that was grown up to cattails, which meant that practically the entire stand of emergent vegetation of the south half was splendid muskrat habitat. The north half was more lakelike than before; its shores also harbored many muskrats, some in lodges though most in burrows.

Numerical determinations of the muskrats wintering, 1942-43, could not be made directly, but the indirect evidence is indicative. Mr. Voss saw what appeared to him an equal abundance of muskrats at Goose Lake in the fall of 1928 (remembered as the last season of legal spearing in Iowa), when 1700 were said to have been pelted. Some animals could be expected to have escaped even severe spearing and trapping, so a total fall population of between 1,800 and 2,000 (about 1,900?) for 1928 would seem quite within reason.

A figure similar to the above applied to 1942 would give a fall population close to 35 per acre for the heavily populated cattail growths of the south half and nearly 20 per acre for the marsh as a whole. The 1942-43 trappers' catch of fewer than 600 (catch actually reported: 538) did not drastically reduce the population. Winter mortality from miscellaneous causes (including trap injuries, disease, intraspecific strife, and predation) almost certainly did not exceed 100. Perhaps 1,100 to 1,200 muskrats survived the winter. The $1942-$ 
43 trapping catch was said to have included an unusual proportion of large and presumably old muskrats.

In late March, 1943, many muskrats left wintering quarters to travel along the shore and to sit out on the ice. Minks took advantage of some of these. Ten of 29 contemporaneously deposited mink scats contained muskrat remains, whereas no muskrat remains were found in 47 mink scats of late fall to early March - although the minks had done much fall and winter digging into muskrat habitations. Very likely, the early winter trapping served to remove a large proportion of the individual muskrats that were or would have been vulnerable to mink predation: the ill-situated and those having tendencies to come out on the ice during thaws or otherwise to engage in hazardous activities. Indeed, the trappers followed a practice of setting traps in the vicinity of superficial signs that would work to eliminate exactly those animals, the same ones that would ordinarily make up a large part of the winter mink victims (see Errington, 1943; 1954b). A single winter horned owl pellet consisted of remains of an adult muskrat.

As the spring dispersal and establishment of breeding territories progressed into April, 1943, the tensions once latent in the top-heavy population of late winter were manifested. Fighting occurred especially near shore, where residents and transients were most apt to come in contact. Dead muskrats - principally victims of intraspecific strife and of at least three shore-ranging dogs - were to be seen literally everywhere about the marsh. Reese said that over 25 were killed in one week by auto traffic on the main street of Jewell. Goose Lake, about a half-mile distant at the nearest point, was not the only possible source of these travelers but it was the likeliest. An equal number of dead was reported to be scattered over the Voss farm, which lies between the marsh and the town. In one day, alone, I examined 11 freshly and recently dead along less than a half mile of shoreline; between April 20 and June 22, a total of 31 dead adults along the same shore. The numbers dying on other farms in the vicinity of the marsh must have exceeded 100 if the evidence from the Voss farm is representative. The total participating in the overland movements from Goose Lake in the spring of 1943 must have been several hundred.

\section{A HEAVY POPULATION IN A DECLINING HABITAT, 1943}

The overland movements from and about Goose Lake in the spring of 1943 are not thought to have been excessive in relation to the densities involved and the condition of the south half of the marsh. For all of the wintering pressure of the muskrats, an abundance of food in the form of cattail rootstocks remained available through the main period of dispersal.

But, by summer, it became apparent that nearly all of the cattails were dead or dying, in consequence of a further rise in an already 
high water level following the raising of the sluiceway of a dam. A few scattered cattail plants grew where the deep-water stands had been, including some that were simply sprouting rootstocks floating on the surface. A cattail strip remained alive along a railroad grade, and a series of small living patches remained near a shore having tile flows and seepage water. With the exception of the railroad strip, these remnants ultimately became well eaten away by the muskrats. Failure of such a supremely important food supply was followed by pronounced readjustments. Essentially entire muskrat populations of some marshy tracts visited shore and raided adjacent corn fields.

The breeding population was fairly settled by the last week of April. At least 10 transients (some showing strife wounds noticeable at a distance) were still living vulnerably about the marsh borders. A month later, it could be seen that, as the height of the breeding season left fewer places among the established territories where surplus animals were tolerated, more animals were being forced ashore. Some of the newcomers to the shore zone could be recognized individually at times when observations were made as often as four days a week, and four of the most interesting were shot for examination.

Of 19 more or less strife-torn transients collected about Goose Lake or found dead in good enough condition to examine from late March to the middle of June, 1943, four were females. Of these females, a badly battered one collected on May 19 was pregnant though a transient; another, with only inconspicuous wound scars by June 4 , was neither pregnant nor lactating but had given birth to a litter early in the spring.

From the field evidence, few young were judged to have been born after the middle of June. Four of 168 young of the year (mainly trapped by Reese) examined from Goose Lake or adjacent waters in November and December were "kits," or August-born young. Two of the twenty-seven Goose Lake adult females of which the uteri were examined macroscopically after the 1943 breeding season had conceived four litters each during the spring and summer. The placental scars of one of these suggested a very late litter. Three others of the twenty-seven females had placental scars thought to have represented litters born at dates materially later than the field data would imply, and at least two of thirteen other adult females from adjacent waters had late-looking placental scars. This would make six of forty local females that could be designated as late breeders. The six latest litters comprised nearly 9 per cent of sixty-eight evidently conceived by the forty females, or about three times the percentage of the late-born in the aforementioned 168 young of the year.

The total of only 68 detected sets of placental scars in the uteri of forty adult females known to have passed through the 1943 breeding season may be construed as reflecting population tensions. Five of the adult females had not conceived; 14 had conceived single litters; 12, two litters each; 6, three litters; and 3, four litters. Sixty-two of the 
sets of placental scars were counted with fair satisfaction, but their mean of nearly 8 scars per set hardly suggests an appreciable decrease in size because of the crowding. One uterus indicated an early litter followed after an interval of two or three months by another litter. A recently pregnant female found dead on June 23 showed a similar irregularity in breeding, the placental scars of her previous litter having been assigned with confidence to early spring. Judging from the relative freshness of their placental scars, at least 8 of the 14 onelitter females gave birth to their only young after the middle of May.

Lodges, improvised nests, and bank burrows representing known or very probable breeding territories were repeatedly counted and the results kept separate for given units of marsh. The total arrived at gave the equivalent of 293 muskrat pairs, as of the middle of June. By this time, the population was as nearly settled as it ever became during the breeding season, with the fewest transients and lone animals about the outskirts of established summer territories. If allowance be made for possible undetected adult mortality in such established territories and for overlooked bank territories in tracts having too much water and dead vegetation to permit easy observation, the equivalent of about 300 pairs should not be far from the true total for the marsh. Of 80 November and December carcasses of adults examined from Goose Lake and vicinity in 1943, 42 were of males. Applying the 42:38 ratio, we would get 332 adult males for 300 adult females, or a total June population of about 630 adults.

Despite a great amount of friction between adults about the periphery of the marsh, some remarkable concentrations were tolerated in certain marshy tracts. An early June population of seven and one-half pairs per acre on six acres was arrived at on the basis of adults in sight at practically the same time. Including the above, the adults on the most heavily populated twenty acres of marsh averaged close to the equivalent of six pairs per acre, and these were primarily lodge dwellers, distinct from the equivalent of nineteen pairs that lived primarily in the burrows of two small islands in the midst of the twenty acres. The food situation here was described as very critical in my field notes as early as June 11, except for a surface covering of duckweed and a variable growth of submerged vegetation. Still, the adults were not seen to be unusually antagonistic toward each other, and four were once watched peaceably using together one of the lodges near shore.

On the other hand, the reproductive fortunes of the crowded area were poor. Young were to be seen about lodges, some in company with adults but many quite evidently living harrassed and furtively where they were able to live. Of five young victims killed by adults, all were between five and eight weeks of age. Doubtless other killings of young, including unweaned, took place out of sight, for, to avoid disturbing the muskrats of a privately owned marsh, I opened only two lodges at Goose Lake during the 1943 investigations. The vulner- 
able young also were subject to substantial predation. During sixteen days in late June and early July, eight recognized victims of predators (two of dogs, six of minks) of between four and six weeks of age were found on land surrounding the six-acre tract having the heaviest population. Sixteen of $97 \mathrm{mink}$ scats examined in late June from a den on one of the islands consisted of remains of young muskrats. The mink pressure on the young continued to some extent during July and August, nine of 161 scats containing remains of the young. In contrast, no muskrat remains were found in 31 scats of a big mink deposited from late April to early June, before the season's young muskrats began circulating hazardously.

In early August, a careful effort was made, with the advantage of exceptionally favorable visibility, to obtain age ratios from two characteristic types of muskrat-crowded marshy habitat. In one type, where psychological or physical barriers discouraged dispersal of young, 16 adults and 18 young (7 to perhaps 12 weeks old) were counted. In the other type, from which good avenues of travel permitted easy movement - especially of young - to a shore zone near an increasingly raided corn field, the sample count was 32 adults to 26 young.

About 70 of the deep-marsh territories recorded as of the middle of June (including those of the islands) were those of a rather selfcontained population. Application here of the appropriate sex and age ratios would give a total of about 147 adults and 165 young, or an early August population of about 312. Twenty-six other territories were believed to have been sufficiently unaffected by summer movements that they, too, might be regarded as similarly self-contained. The only age ratio ( 3 adults to 13 young of the year) available for the latter group is from animals trapped for fur in November. Considering the fact that the majority of these 26 territories showed scarcely any evidence of mortality in late summer and fall, the postbreeding figure of about 293 indicated by the 3:13 age ratio, combined with the general sex ratio of adults, should be as close to the truth as the data permit. A postbreeding total of 605 would seem quite within reason for the more or less self-contained territories.

Roughly, the 204 other territories (using the 300-territory basis instead of the 293 counted) may be apportioned among the following three groups: (A) about 110 affected by movements toward a corn field southeast of the marsh, (B) about 40, by movements toward another corn field and a field of soybeans on the west side, and (C) about 54 , by movements toward the outlet leading to a ditch to the west and thus away from Goose Lake.

By early August, only about 7 of 33 former lodge territories in group $\mathrm{C}$ were being maintained - by about 24 muskrats in all. The shore territories seemed to have experienced little change as a result of the shoreward drift of deep-marsh animals, except as young produced in the shore territories may have migrated off to the southwest 
along with the newcomers from the deep marsh. Several people working in the neighborhood of the outlet flow observed small companies of animals leaving the marsh. Fifty-eight carcasses of muskrats trapped in November from the ditch to the west of Goose Lake (where there is reason to believe that the migrants did much settling) consisted of 13 adults and 45 young of the year, which, for lack of anything better, may be considered a sample of the animals leaving Goose Lake. The ratio in November carcasses from the vicinity of the outlet and the south shore was 14 adults to 17 young. No significant changes in age ratios were known to have occurred here between August and the trapping, so, from the ratios at hand, it might be calculated that a total of about 245 left the marsh and about 97 remained in the south shore zone, as of early August. The 97 added to the 24 remaining in deep marsh would give a figure of about 120 still resident in group C.

In the A group, 88 of the original territories were in lodges, and the adults of about 40 territories, together with some young, appeared to be maintaining residence in late summer. A deep-marsh total of about 150 muskrats may be calculated here from sex and age ratios. The equivalent of about 70 adult females and associated males either lived in the bank burrows from spring to fall or there established themselves after the breeding season, upon coming to shore to forage. Application of a November ratio of 19 adults to 28 young would give a figure of about 365 for the shore-dwelling population, or a total population of about 515 for A, as of early August. One clear and calm September evening, between 45 and 50 muskrats were simultaneously in sight along a 100 -yard stretch of shore that was visible in the dusk.

Only 15 of 40 territories assigned to the B group were centered about lodges, and, by August, practically all the occupants of these were coming to shore to feed on corn and soybeans. A nine-acre field of soybeans had nearly 100 well-beaten trails leading into it. The cultivated fields undoubtedly drew many of the young muskrats of other groups in the course of the postbreeding adjustments, which probably explains the high ratio of 30 young to 8 adults in November carcasses trapped mainly along the shore at this place. The early August population of $B$ figures out at about 400 .

Allowing for a calculated 245 (55 adults and 190 young) leaving the marsh via the outlet corner, the total of about 1,640 (about 575 adults plus 1,065 young) obtainable through adding up the figures from the different territorial groupings would be too high. Even if the age ratios arrived at were wholly representative for the groupings and their subdivisions, a recorded mortality of 21 adults for June and July was borne mainly by individuals that either were, or could have been, associated with territories. The data are not such as to permit accurate assignment of these losses to specific groupings. If the 21 be accepted as near the total midsummer loss of resident adults, it could 
be subtracted from 575 to give a new base of about 555 adults. The new base, used with the over-all age ratio of 35.1 per cent of adults originally calculated for the marsh, would allow a grand total of about 1,580, which might still be suspected of being somewhat high. Scaling the 1,580 down a little more, we could get a revised grand total of about 1,550 in rounder numbers as the early August muskrat population of Goose Lake.

Later in August, more population adjustments occurred, but these were not of sorts to influence perceptibly the numerical status of the muskrats in the territorial groupings. Many of the muskrats took increasing advantage of the growths of yellow water lily in the north part, the animals of one stretch of shore abandoning the bean field to do so. Some were watched converging toward the north center from all sides, swimming distances up to 300 yards. The raiding of the corn field southeast of the marsh diminished (although the corn field to the west continued to show heavy use all fall), and the muskrats of the southeast part centered their feeding on natural shore growths and upon the rather sparse stands of hardstem bulrushes appearing during the summer. These bulrushes suffered very severe exploitation, as did the chief remnant stand of cattails. Hundreds of shallow muskrat burrows could be distinguished along the southeast shore.

Not much general change of feeding occurred in September and October, except that, as fall came on, the southeast corn field and the soybeans were again more heavily raided. Just before the trapping season opened on November 10, most of the shore trails remaining in use were those leading into the corn fields.

\section{THE COLLAPSE OF A HIGH DENSITY POPULATION, CHIEFLY THROUGH AN EPIZOOTIC, 1943}

What did bring a change in the late summer and fall status of the muskrats was the onset of a deadly epizootic of the hemorrhagic disease, apparently the first ever to be studied in detail.

Fortunately, for purposes of analysis in a situation already complex because of major variables, the disease losses for the first few months of the epizootic were almost entirely confined to the vicinity of the islands, or to the muskrats of some of the more self-contained territorial groupings. Before the bank dwellers of the islands were known to have become infected, about three animals were judged to have died per day during October and early November, which would suggest a loss rate from disease of about 100 per month; earlier in the fall, the average of muskrats dying per day evidently had been lower. The total disease mortality, from its first observed occurrence in August to freeze-up in November, was estimated at about 200.

Other types of mortality elsewhere on the marsh for the above period were fairly low in terms of muskrats present. Hostile displays especially between big animals - were frequently seen in September 
and October. Two of five dead adults found on shore during October showed typical wounds of intraspecific strife, the others being victims of a mink, of a dog, and of probable old age. On November 12, dozens of muskrats could be seen traveling across the new ice, and these behaved like transients or highly insecure individuals; three of four freshly dead ones examined had severe strife wounds. Increasing frictions of late fall were reflected by the contents of mink scats. Of 127 scats from the first half of October, only 6 contained muskrat remains, compared with 15 in 136 scats for the second half. Then, after trapping on shore had rather well eliminated the land-active muskrats, only one of $41 \mathrm{mink}$ scats of mid-November contained muskrat remains.

In the course of about three weeks, late November to the middle of December, the disease spread to all muskrat-occupied parts of the marsh and brought to pass a most spectacular collapse of the population. The mid-November spurt of surface activity on top of the ice may be suspected of having accelerated this spread. As many as nine dead were found in a day, and these surely represented but a trifling fraction of the numbers dying out of sight, under cover of the ice, and inside lodges and burrows. For years afterward, bones of adult-sized muskrats continued to be exposed by dogs and woodchucks breaking into or digging out datable burrows that could hardly have been used by muskrats at any times except in the latter half of 1943, contemporaneously with the big die-off. For example, on February 15, 1946, and January 6, 1948, totals of 15 skulls of practically certain epizootic victims were counted amid the debris excavated by woodchucks renovating for their own use the upper parts of the 1943 muskrat burrows on an island having a high water (or 1943) circumference of 144 paces or perhaps 130 yards - a number of victims three times as great as the number (five) found on the island's surface and periphery during the epizootic.

Minks, after their nearly muskratless diet of November, soon discovered the new abundance of food in the form of dead or sick muskrats in the lodges and burrows. Altogether, 53 of 113 mink scats from the first half of December contained muskrat remains.

Conceivably 50 muskrats were alive on the marsh as of December 13 when the clearness of the ice permitted easy "reading of sign"; these were nearly all in places well removed from the islands. By spring, the mortality seemed to have been complete, as the first unmistakable sign of a living muskrat was found March 18, by which time an ingress of muskrats, via the outlet, was beginning. Muskrat remains were found in 22 of 43 mink scats for the second half of December; then in 43 of 85 up to the middle of March, but in only two of 36 for the second half of March and early April. While the sudden lowering of the water level by about 15 inches after breaking of a dam across the outlet in mid-December might have meant greater vulnerability of muskrats still present, the evidence suggested that 
the occasional visiting minks were largely scavenging upon the muskrats that had died in the fore part of the winter. Remains or intact bodies of 13 muskrats were discovered during the main winter months, but nearly all of these had the aspects of having died in November and December, when the epizootic had been so conspicuously lethal. There seemed to be a further connection between incidence of muskrat in mink diet and periods of mild weather, when the softening of lodges and burrows allowed the minks easier access to dead muskrats within.

The population was practically wiped out by the end of 1943 , and wholly so by the end of the winter. Of the 1943 postbreeding population of 1,550 muskrats computed on bases given in preceding paragraphs, fewer than 200 were accounted for as taken by trappers. After making as generous allowances as seem within reason for possible errors in computations, for unreported trap catches, and for all agencies of decline other than the epizootic, the latter would seem to have been the agency of mortality of between 1,000 and 1,300 of the muskrats.

\section{AND 1945, THE FIRST TWO YEARS AFTER THE GREAT COLLAPSE}

The new population at Goose Lake quite literally began with the immigrants of late March, 1944. The principal avenue of ingress was the ditch leading to the outlet. Natural restocking progressed slowly, probably in consequence both of limited numbers of animals coming in (the surrounding habitats, except Little Wall Lake, had been severely trapped) and of the dying of newcomers soon after arrival. Nine fresh disease victims were examined in April and May, and eight of these were found on the shore within a few hundred yards of the outlet. On May 20, four freshly dead were seen, compared with but a single live one. The equivalent of two pairs became established (plus a shifting population of two to four judged to have been extra males), and young were produced in both territories by early July. The two breeding territories were in the southeast part of the marsh, centered in burrows about 80 yards apart. Four more animals (including three adults) were known to have died before the end of July, but no victims were found in August and September, and the disease was thought to have run its course. Largely through ingress, a population of perhaps sixty to eighty (probably nearer the larger number) was built up by October. The age ratio of eighteen trapped specimens was five adults to thirteen young of the year. In October, the disease with relative suddenness all but depopulated approximately the north half of the marsh - without, however, killing muskrats in the south half.

Judging from the chronology of the dead found, the new epizootic broke out almost simultaneously about the middle of October west of the islands and a couple of hundred yards to the north; and, in the space of three weeks, twelve were known to have died here in 
places where they could be seen. Another dead was found on the east central shore, but the disease did not seem to get a start at this place. There was a fine set of burrows in a rocky road grade adjacent to a north stretch of the east central shore, and here eight victims were found, with dates of death estimated at between October 25 and November 4 . The first known victim at the road grade died in the channel of the main burrow just where the others would repeatedly swim past it. The several muskrats that were alive in the north half on November 15 were regarded as newcomers attracted by vacant burrows. Two that came to the rocky grade were found freshly dead in a nest on November 21. A third muskrat, believed to have taken up quarters in the rocky grade about November 21, was obtained alive and uninjured on November 25 and was dead of the disease in its laboratory cage by November 27.

Clear ice in late November permitted a good checkup on the Goose Lake muskrats, and a current sign was found at only one place in the whole north half. By early December, the tracks of two or three evidently transient animals were to be seen on the snow-covered marsh, and, past the middle of the month, freshly dead remains (of one of the transients?) were found in the northwest corner. Two minkeaten carcasses, fresh-appearing as of early March, 1945, were found about 200 yards from the one place where a sign had been noted in the north half in late November. It is not definitely known that the latter muskrats were diseased, but they well could have died from this cause at any time from December to March. Their freshness in early March may have meant simply that the mink then gained access to them after weeks or months of frozen preservation. All of six mink scats from the vicinity of these two dead consisted of muskrat remains.

Of 288 other winter mink scats, three contained muskrat remains - all of the three muskrat-containing scats picked up fresh on March 8 from one mink-opened lodge near the south shore. At least two minks were resident for most of the winter, but the above three scats constituted all of the detected evidence of minks feeding upon muskrats in the south half.

In addition to the infected live specimen from the rocky grade of the north half, 18 muskrats were reported trapped from the south half, and a survival of about 15 was calculated from animals seen and signs, as of March 21. This and the recorded mortality would account for about 60 of the animals present in the fall. Unquestionably, others died concealed in some of the north-half burrows, particularly in the rocky grade.

In late April and early May, 1945, two animals were found dead, neither of which was positively identified as a disease victim, but they probably were victims. An adult population the equivalent of six pairs was ascertained, as of June 16, with territories distributed at rather uniform intervals along the shore. No muskrat remains were found in 22 mink scats examined from April to July. 
The status of the Goose Lake muskrats was favorable from late spring to early fall, although the water level became so low that the marsh bottom was barely covered in the thick bulrush fringes then making up the most attractive muskrat habitat. There must have been close to 100 muskrats (including late summer immigrants as well as resident adults and locally reared young) on the marsh by the first of October.

In early October, what had the aspects of a typical epizootic started in three parts in or near the center of Goose Lake. Practically all of the muskrats living adjacent to these three foci of infection, or in the central one-fifth of the marsh, were eliminated by October 19. By this time, twenty-two dead had been counted, eight about a single lodge. In late October, a freshly dead one was picked up in the southwest corner, but this did not prove to be the forerunner of a new die-off.

The epizootic subsided for several weeks between late October and late November. During mid-October, the lodges in the central area were dug apart with a spade and left with the debris in flattened heaps. This procedure was believed to have diluted the sources of infection for the muskrats remaining alive in or at the borders of the infected zone and for those newcomers that later established themselves in places where the previous occupants had died. After the advent of freezing weather, the experimental leveling of the lodges was discontinued. By early December, most of the newly restocked places of the disease-swept center and some adjoining them were again muskrat-vacant. Since no more dead were actually seen here, it cannot be demonstrated that the occupants died of disease. The chances are, however, that they died underground. By the last of November, the fresh body of a disease victim had worked up through the thin ice out from the south central shore, and the lodges near by showed an untenanted appearance, suggesting that an entire population group had died.

Favorable opportunities for "reading sign" under the ice permitted population estimates totaling about 60 muskrats alive, as of the middle of December, before the ice clouded enough to interfere with observations.

The 1945-46 winter survival was low - judged to have been only about 13 individuals, as of the middle of March. The known appearance of the disease in a previously unaffected part of the marsh at the time of the last good under-ice observations would be logical grounds for expecting it to have continued its spread. That the disease was the dominant agency of death is strongly indicated, but wintering conditions were sufficiently adverse to have brought about some mortality from causes other than the disease.

The water level was still low at freeze-up. As the frost line sank into the mud and peat of the muskrat-occupied, food-rich shallows, the animals built new feed houses on the ice over the deeper parts 
and finally lived in burrows having little or no unfrozen water. With the exception of three distinctly ill-situated individuals that engaged in much surface activity, and either bore wounds of intraspecific strife or had extremities frozen through exposure, the muskrats nevertheless appeared to live securely through December. Of 43 mink scats for late November and December, two contained muskrat remains, and these almost certainly were from the body of one of the October disease victims.

Then, in early January, 1946, a three-day rain and thaw put about 5 inches of water over the ice and forced the muskrats living underneath to return to long-unused lodges that were out of repair. For a time they were highly vulnerable to mink predation. Seven muskrat bodies upon which the minks fed were dated to this emergency, including one (with a frozen tail) that had been traveling overland to a corn field before the rain. The crisis was of brief duration, lasting not longer than a day or two, after which the muskrats lived with noticeable security in their renovated quarters until late January. Only one of 32 mink scats for early January before and during the rain contained muskrat remains, but remains were found in 20 of 21 scats deposited immediately after the rain and coincident with the known feeding upon the 7 dead muskrats. After this, the incidence of representation of muskrat remains fell to 1 in 7 mink scats.

Following their apparently secure period in the middle of January, Goose Lake muskrats again attained prominence in mink diets. Forty of 50 scats for late January through the middle of February and 12 of 25 scats for late February and early March contained muskrat remains. Three dead muskrats of late winter were too fragmentary to reveal anything as to possible disease lesions, but 2 of these were found in the habitat adjoining that in which the population group. evidently had died in late November. The third was found in the northwest corner, where residents were due to be wiped out by disease in April and May. The available data suggest a general spread of the disease under cover of the ice. On the other hand, muskrats did survive the winter in scattered places, among which was one of the disease foci of the October epizootic.

\section{THE DRAMATIC VICISSITUDES OF 1946-50}

The equivalent of 7 pairs became established as the 1946 breeding population of Goose Lake. All were in the south half, mostly in what had become the best-vegetated tract of about 20 acres in the southeast quarter. Here, in fairly extensive growths of hardstem bulrush, the territories were concentrated, yet still with their centers 100 yards or farther apart. The muskrats of the south half escaped the disease and lived securely through spring and early summer, although the animals attempting to live in the northwest corner continued dying. Four of 143 mink scats for the middle of March to early May contained muskrat remains. 
In the northwest corner, three disease victims were found in April and early May, and no evidence of any other muskrats was seen there during the breeding season.

Between late May and August, an epizootic of surpassing deadliness apparently killed the entire muskrat population remaining on Goose Lake. A current sign was seen in but a single place during a checkup in the first week of August, and the maker of even that sign afterward disappeared. Later, an ingress of an estimated 80 to 100 muskrats restocked the more attractive parts of the marsh by late September. The newcomers displayed a tendency to take over and rehabilitate the previously used lodges and burrow systems, but nothing that could be called a real epizootic occurred during the fall months except in the vicinity of the islands.

The first probable disease victim found in the fall of 1946 died in late September or early October. In the last week of October and the first week of November, eight were known to have died: two in the southwest corner of the marsh and six either about the islands or on the nearest shore (within 150 yards) to the northwest. All of the 10 muskrat-containing mink scats in 32 examined for October were found together on the above shore northwest of the islands. Four dead were found that were assignable to the middle of November: one near the east central shore and three at one small lodge west of the islands.

At the latter lodge, the first disease victim was found freshly dead on November 11. The second was partly eaten by a mink about November 14. Later, mink-eaten remains of the third occupant of the lodge appeared. Six of 10 mink scats deposited near the above lodge contained muskrat remains, compared with only one of 53 other scats from the rest of the marsh in November.

Careful calculations gave a population figure of about 60 muskrats alive on Goose Lake as of late November, 1946.

Of three dying in December and in the first half of January, 1947, one was found near the islands, one (intact enough to be a clearly recognizable disease victim) was dragged by a mink from a lodge in the south center, and one was found in the southwest corner. Muskrat remains were found in six of 255 mink scats for this period, and five of the six scats with muskrat remains were deposited either on the islands or in the southwest corner - the two places where most of the muskrats had died of disease. Next, in the course of the winter, losses became severe more or less simultaneously in the southwest corner and in the whole south shore zone. During February, the remaining muskrats adjacent to and to the north of the southwest corner were wiped out, as were the hitherto secure muskrats of the southeast corner. The last places with living muskrats in the southeast part were at least close to the place where the mink had dragged the disease victim from a lodge in the south center, and the epizootic also could have been introduced through healthy muskrats visiting the 
disease-swept lodges to the south. Ultimately, some fine burrows along the east central shore took on a dead appearance. Data on the sexual state of well preserved disease victims dug out of thawing lodges in early April confirmed the sequences of the winter epizootic, as these previously had been worked out through the regular field observations.

By March 20, evidences of living muskrats were detected in but two places, both isolated from the main occupied tracts. One of these isolated places had had a lodge with a solitary muskrat since fall. (This muskrat had been a recognizable individual, several times observed under favorable conditions.) The other place, in the northwest part, had a fall population judged at about eight; and, while there may have been winter mortality here, the March signs were sufficiently pronounced to leave an impression that several animals had succeeded in wintering. A survival of perhaps half a dozen, or about 10 per cent of the Goose Lake population beginning the winter, would seem fairly close to the truth.

For the period between the middle of January and late March, when the ice softened and began to break up, 213 of 249 scats from 4 distinguishable minks contained muskrat remains. From late March, through the first half of April, the incidence of muskrat-containing scats dropped to 3 in a total of 95 .

On April 16, 1947, a tentative estimate of 5 breeding territories, or the equivalent of pairs, was made; by April 23, there was evidence of 10; by May 2, another had appeared; by May 14, so had another; and the same figure of 12 territories was verified on May 16. Two additional territories were later established, bringing the total up to 14, representing 30 or more adults. As muskrat habitat, the marsh had decidedly improved since 1943 , the high-water year. The muskrats by now had their choice of good territorial sites in the bulrush and cattail stands of the south half and also in a tract in the northwest quarter.

Three dead adults were seen in the first half of May, and of these, the only one fresh enough for satisfactory examination was a disease victim. The latter lay beside the burrow in the northwest corner where the annihilative disease mortality had occurred in the spring of 1946. No muskrat remains were found in fifty-four scats deposited from the middle of April to the middle of May, 1947. Mortality of an adult (remains were found in a mink scat) and the loss of one territory about the first of June had an evident connection, but only this one scat of seventy-nine deposited in late May and June contained muskrat remains. The only other mortality of Goose Lake muskrats detected from the second half of May to late July was from cannibalism; on June 19, a lodge was opened for examination just in time to surprise a young of about five weeks as it was eating a freshly killed member of a litter of about three days. The cannibal was doubtless a member of a litter born to the same mother about 
May 12. Members of both litters were still found in their natal lodge by July 24 . On the latter date, two of the smaller size and five of the larger were simultaneously in sight.

Twenty-three litters were determined to have been born in the thirteen territories that remained functional, and at least five more litters were recognized, which (because of adjustments ultimately forced by (lrought) could not be assigned to any given territory. Of these twenty-eight litters, two were judged to have been born in the second half of April; six, first half of May; four, second half of May; two, first half of June; three, second half of June; three, first half of July; one, second half of July; six, first half of August; and one, second half of August. Some other young born in early July could have been members of a litter different from any listed above. A total of 29 litters for the thirteen territories would give a mean of 2.23 litters per adult female.

If 29 litters be accepted as the number born on Goose Lake during the breeding season, multiplication by the known mean size of 7.7 recorded for central Iowa litters of the 1947 season would give 223 young produced on the marsh. The peak population was reached about the middle of July, when a total of perhaps 180 (29 adults plus about 150 young) may be calculated. From this time on, the birth of late litters seemed more than offset by increasing mortality.

Many weeks of hot, dry weather followed heavy rains in June, and the Goose Lake muskrats were affected by drought as early as late July. By mid-August, considerable adjustment had taken place. The shallows of the northwest corner dried up first, and the muskrats abandoned two territories there. By late September, less than three inches of water remained over the mud of the north half, or the deeper part of the marsh, generally. One family group of muskrats of the southeast corner had moved nearly a quarter of a mile northwest to a set of lodges that had previously been abandoned by another group of muskrats moving into the north half. All muskrats of the southeast part (except a few stragglers) had either left the marsh (or died) or had moved into the north half. Meanwhile, the animals of the southwest corner had suffered heavy losses from emigration and mortality, with survivors largely establishing themselves in food-rich though dry stands of cattails and bulrushes. By mid-October, all marsh bottom of the south half was exposed, and only an estimated six or eight muskrats remained. At about this time, the last former territory at the northern extreme of Goose Lake was likewise abandoned, and the wet marsh population was about sixty (fifty-two counted in mainly open nests and eight more estimated for the burrows).

Rains in the last week of October restored the water level to about a foot over much of the north half, which had had little except wet mud on its bottom. Contemporaneously with the rains, the remnant of a family group in the southwest part moved about 150 yards to 
the south edge of the water of the north half. In early November, water covered the deeper parts of the south half to a depth of a few inches to a foot, and the maximum depths of the north half were up to about 15 inches.

The field notes refer to a known mortality of 47 Goose Lake muskrats ( 5 of which had been tagged when young), from the onset of the drought through November. These included 20 victims of the hemorrhagic disease. Animals were found dying from the disease about September 7 in the southeast part of the wet north half, into which two family groups had moved from the drying south half. (Eight died in a triangle covering about 150 square feet.) Then, the contagion rapidly spread northward into the marsh where the muskrats were concentrated, but inexplicably subsided just when it seemed ready to sweep through the population. No certain or probable disease victims were found here after September 19. The disease also started up in one of the drought-exposed places near the south shore of Goose Lake, but this did not result in severe losses. Others of the dead found both before and after the time span of the recognized epizootic may have died from this cause, but rapidity of decay prevented accurate diagnosis in at least four possible cases.

Five of the drought-exposed dead were known to have been fed upon (and probably killed) by minks; and 6 of 71 mink scats deposited from late July through September contained muskrat remains. Six of 22 similarly dated horned owl pellets contained remains of 6 young muskrats -5 of about four to six weeks of age and one subadult. Three muskrats were found killed by farm dogs, one probably died from a pathological condition of a jaw similar to the actinomycosis reported by Dozier (1943), one was struck by motor traffic as it emigrated southward from the drying marsh, and a tagged one died of the hemorrhagic disease on the southeast shore of Little Wall Lake, 3 miles to the south.

No muskrat remains were found in 81 mink scats for October and November, which may be said to reflect the passing of the period of greatest drought vulnerability. As of December 1, there were about 60 muskrats left in the wet marsh of the north half, plus possibly four in the shallows of the south half. The latter got along all right until the middle of December, when the shallows froze to the bottom, and the animals started coming out on top of the ice and to forage in the shore growths. There also was occasional land activity on the part of apparently two muskrats living in dry holes west of the wetter north half.

In contrast with the as yet comfortably situated regular residents of the wetter north half, the approximately six land-active muskrats were eliminated by predators in rather short order. Deaths of five were accounted for from about mid-December, 1947, to early January, 1948, including four mink victims and one fox victim. Of seventeen mink scats assigned to the first three weeks of December, none 
contained muskrat remains; then, representations of this prey were found in twenty-three of ninety-four mink scats for late December through the first week of February. The feeding on muskrats by minks during this period was nearly all traced to muskrats that were either transients or individuals frozen out of the south shallows.

Until late January, the population of the wetter north half was visibly secure. It was not known to have suffered any losses whatever since fall, despite intrusions into lodges by probably three minks. The minks fed chiefly on fishes congregated in the muskrat channels beneath the lodges, on remains of dead ducks and coots, and to some extent on mice and rabbits of the surrounding land.

But, early in February, the wet marsh of the north half was freezing to the bottom. Muskrats were traveling in increasing numbers on top of the ice from one lodge to another in search of better quarters. Mortality began with a single mink victim about the first of the month. On February 6, an animal, blind and with flesh of tail frozen and chewed away, died from cold on the ice. Four muskrats (including one marked by toe-clipping) were known to have abandoned the marsh as the crisis became worse, and others doubtless did also.

The night of February 8 (the second of two cold nights during which temperatures fell to about 15 degrees below zero Fahrenheit) virtually completed the transition from tolerable to intolerable living conditions for the remaining muskrats of Goose Lake, although a few of the better lodges retained some degree of habitability for another week or longer. In less than three weeks, Goose Lake was devoid of living muskrats, very spectacularly as a result of their increasing vulnerability and through the agency of minks.

Not all of the February mink killings could be figured out from signs, but a relatively complete record of the exploitation by the minks was obtained from visits to the marsh on 15 of 18 days during the period of greatest mortality and from occasional visits thereafter. It is believed that the fates of very nearly all of the muskrats dying at Goose Lake after February 8 were accounted for -20 in all.

Prior to the latter date, most of the muskrat activity on top of the ice had been in the southwest and southeast corners of the wetter north half where restless animals had explored unoccupied lodges and the burrows and vegetation of the shore. On the night of February 8 , minks were known to have killed a muskrat in a land hole southwest of the north half and another one on or near the shore of the southeast corner. The final places of deposition of the carcasses could not be ascertained because of poor tracking conditions. Little could be learned of the circumstances of death of a third victim except that it occurred. On February 9, a mink killed three muskrats in the southeast corner of the wetter north half - apparently all there were - and left them piled uneaten inside of a lodge.

In late afternoon of February 11, five muskrats left the main lodge in the southwest corner for a smaller unoccupied lodge 45 
yards away, where two of them remained. The other three continued to another unoccupied lodge 80 yards farther on. In the evening or night, a mink made three round-trip visits from shore to the latter lodge, dragging away two muskrats (to cache them in different holes in the upper chambers of abandoned muskrat burrows 55 to 75 yards away) and returning unsuccessful from the third visit. The third muskrat here was alive the next day, but the mink returned in the evening (February 12) to kill it and drag it 265 yards across the snow to another land hole. The mink later visited the first-mentioned lodge having the two muskrats, killed one and dragged it 190 yards to the same land hole in which it had deposited its first kill of the night. It returned for the last muskrat of the original five that had journeyed forth from the main lodge in the southwest corner, injured it but did not kill it. This muskrat returned to the main lodge, staggering in the snow and leaving blood as it rested; an animal corresponding to it died in the lodge, to be eaten by its fellow muskrats.

No sign of mink was seen for the night of February 13 in the southwest corner of the north half of Goose Lake. More muskrats left the main lodge to station themselves in the smaller lodge 45 yards away. During the night of February 14, the mink came back and killed three muskrats in and about the smaller lodge. It left two carcasses cached where killed and dragged the third to another small lodge near by.

During the night of February 15, one of the two dead muskrats cached as above was carried away by a mink, and a mink visited a place in the east central part of the north half where hitherto secure muskrats were coming out on the ice. Here, the mink killed two and left them uneaten (except for a few bites taken out of the neck of one) in a feed house. One of the victims had liver lesions of the hemorrhagic disease. The next night, the mink returned to kill and eat a third muskrat.

By February 16, only one place on the marsh was known to have living muskrats, and one muskrat was killed and largely eaten by a mink during the night. A second was killed and left uneaten on the night of February 20. A third-evidently the very last one-was killed on February 27. On March 1 and 5, checkups were made under favorable field conditions without finding any sign of muskrats remaining alive, in lodges, land holes, or anywhere else about Goose Lake.

Of 40 mink scats deposited from February 6 to February 26, 38 consisted of muskrat remains. After annihilation of the local muskrats, the minks (still about 3 individuals distinguishable on the basis of tracks) fed upon muskrat carcasses cached in various land holes and lodges for perhaps another week and even continued visiting the fragments of some carcasses past the middle of March. Only 2 of 9 mink scats found for this period contained muskrat remains, never- 
theless, and it could be seen that this source of food soon became exhausted. Apart from 3 carcasses cached in the bottom of a lodge that filled with water during a thaw and froze over, nearly all of the muskrats killed by the minks in February were sooner or later eaten by minks, though often some days or weeks after the actual killing.

Altogether, mortality of 74 muskrats was detected at Goose Lake from the beginning to the end (late March) of the 1947-48 drought emergency.

Compared with other winter drought crises observed, the one at Goose Lake in February, 1948, was singularly severe in view of the depth of the water over the muskrat-occupied parts at frceze-up. In the winter of 1945-46, muskrats had, in fact, lived with considerable security in the rush-grown south half of the marsh after freezing of the shallow surface water and much of the mud underneath; but they still had had access to rootstocks and other rich sources of foods imbedded deep in unfrozen mud. In 1947-48, except for the vegetation making up the lodges, the entire food supply of the muskrats of the north half became encased in ice as cold weather continued - the coontail and pondweed growths, the rootstocks of yellow water lily, and the fishes that found their last refuge in the muskrat channels and the muskrats simply could not gnaw it out in satisfactory quantities. For a time, certain individuals seemed to specialize on frozen fishes, and there was feeding by muskrats on remains of some of the muskrats killed by minks; yet, as the water of different parts of the north half froze to the bottom, the muskrats broke out of their lodges virtually in groups, to search diligently about the vicinity for more livable quarters. As a rule, the muskrats were in fair to good flesh and uninjured by cold at the times of their death, but their alimentary tracts tended to be rather empty or filled with harsh material. It was apparent that they suddenly had become hungry and desperate.

Another distinction having a bearing on this winter crisis should be pointed out. Instead of the large, insulating lodges of cattail and bulrush marshes, the lodges of the north half of Goose Lake were small shells of ice-lined coontail and algal masses, heaped around holes or cracks in the ice. Even the largest were eaten-out shells, having disproportionately large basins within, and very limited ramifications of burrows and channels underneath. Inferior for protection during cold snaps, caving in during thaws, requiring frequent repairs whatever the weather, these flimsy structures doubtless did not impose the handicap on their occupants as did the sealing of the food supply by the ice, but they surely were not much of an asset when the crisis came. Indeed, Iowa muskrats may sometimes remain alive for weeks in midwinter in drought-exposed marshes - the necessity for outside foraging and the presence of minks notwithstanding - if only they can withdraw into the better types of lodges.

On the whole, the February situation exemplified a combination 
of adverse factors beyond muskrat limits of toleration. The mink predation followed standard patterns and was appraised as being symptomatic of vulnerability rather than a true cause of population decline of the muskrats. Except possibly for a group of three muskrats living partly in a land burrow and partly in adjacent lodges, few of the animals killed by minks would have stood, under the existing circumstances, much chance of survival even in the absence of the minks.

Although the winter-killing of the entire Goose Lake population in February, 1948, had not been due to disease, muskrats coming in from outside during the spring dispersal started dying soon after their arrival. Only 2 diseased dead were actually found, these dying about April 5 and April 18, but, at the time of death of the second disease victim, mink-eaten remains of 2 other muskrats were found in the vicinity. Muskrat remains were found in 2 of 23 mink scats deposited in late March and the first week of April and in 6 of 59 scats for the middle two weeks of April.

By early May, three evident territories had been established, and, on May 21, a settled breeding population the equivalent of eight pairs, or perhaps twenty adults, was determined. Five of the territories were in the increasingly heavy vegetation of the south half of the marsh. The other three were along the northwest shore of the north half, in a thick and attractive fringe of cattails and bulrushes less than 200 yards long. Of the latter three territories, one - this near the site of most of the known mid-April mortality - seemed to be depopulated in late May or June.

In response to summer drought exposure of the south half, occupants of three territories in the vicinity of the islands converged in August at the north end of the largest island where it adjoined the wetter north half of Goose Lake. Here were four sets of well used burrows close together in what had all the aspects of common ground. The occupants of the two remaining northwest territories also reestablished themselves near deeper water in response to the drought.

In the southeast quarter, the movements of two family groups of muskrats were traced. One of these two groups moved in gradual stages northward from the south center of Goose Lake and finally arrived at the south edge of the deeper water of the north half in early October. The other group also worked northward but nearer the east shore, arriving at and renovating in late August the exact set of burrows where the late summer epizootic of 1947 had started. Here they died in 1948, also - six demonstrably in the first week of September and four more in the next six weeks.

Five more had died by mid-October at or near a lodge about 180 yards west northwest of the lethal burrow system, but thirteen muskrats living at this and a neighboring lodge escaped death temporarily. On October 21, one died at an isolated small lodge hundreds of yards 
from either of the two infection foci. All three of seventeen contemporaneous mink scats that contained muskrat remains were from a set of dry burrows previously known to have been occupied by a muskrat in the south half of the marsh. This appeared to reflect simple drought vulnerability rather than availability of a disease victim to minks.

The new fall epizootic, following some three months of apparent quiescence, operated with notable irregularity in a low population mainly restricted by drought to the north half of Goose Lake. A very satisfactory census on October 21 gave 39 live muskrats, with 17 dead having been accounted for since early September, or a known early fall population of 56 -about 60, allowing for some overlooked mortality. Sex and age ratios of 18 specimens were 2 adult males, 1 adult female (with 22 placental scars of 3 litters assigned to early May, early June, and early July), 12 young males, and 3 young females.

After the October 21 census, 2 more died of disease at widely separated places, including one dying on the east shore about 200 yards north of the burrow system where the 10 had died in September and the first half of October. No more mortality was detected from any cause until 4 died in the second half of November, at a small lodge not far from the site of death of the disease victim found lying on the shore. Of a maximum of 33 muskrats remaining alive by the opening of the trapping season, December 1 , authorized trapping accounted for 14. (A few others probably were taken by unauthorized persons, as signs thereof were noted near the main island.) By January 7 , 1949, after closing of the trapping season, muskrats were still alive in three lodges, a total estimated at between 12 and 15; and there appeared to have been disease loss in a set of burrows that had been dug late in the fall. By the middle of February, the marsh had no recognized sign of living muskrats, but later data suggest that a lone animal may have survived in one of the island burrows. Remains of a muskrat in one of two midwinter fox scats were probably from a victim that had been active on top of the ice.

The contents of the 1948-49 winter mink scats lined up well with known events at Goose Lake. Of fourteen scats examined for December, seven contained muskrat remains from two determined sources: two trapped muskrats partly eaten in the traps and two of the late November disease victims that I removed from the water and threw up on the lake bank, later to be consumed by the minks. Muskrat remains were found in but one of fourteen January scats, this one from the new burrow in which it is believed that the muskrat occupants had died; for February, remains were found in thirteen of sixty-five scats. Forty-eight scats for March and early April revealed no feeding upon muskrats.

Goose Lake had no resident muskrats whatever during most of the spring of 1949. Between April 3 and 7, a sign of either a lone winter survivor or of a newcomer was recorded. This individual later 
disappeared, and the marsh remained barren of detected muskrat signs until May 24, when fresh droppings were again found. At some time later, probably in June, the equivalent of three breeding pairs became established. Two of the new territorial sites were within 200 yards of the dry outlet, about 200 yards apart, and in some of the most attractive habitat of the marsh. The third territory was near the north end of the larger island, about 150 and 175 yards from the other territories. What seemed to be a single animal lived in another place.

The water reached without exceeding the overflow level in early May, and the marsh was in splendid condition for muskrats most of the summer. Then drought restricted the surface water to the north half and to the two deepest parts of the south half. By early September, one of the family groups had moved about 250 yards in gradual stages, finally to construct an elaborate system of burrows and small lodges close to the site of the lethal burrows of the preceding two summers. September was a month of considerable local adjustment on Goose Lake, much of which seemed to be on the part of locally reared subadults, but the signs appearing at the extreme north end suggested the behavior of outsiders. The lone adult mentioned for the south half stayed in its accustomed home range despite drought exposure until killed by a mink about freeze-up.

A highly satisfactory census of 29 muskrats was made by direct enumeration in the north tip and northeast corner in late fall, 1949. Fair estimates of populations in other parts were about 17 for a territory in the south half, where the muskrats appeared to remain as a self-contained unit in a food-rich place having some surface water; the lone muskrat later killed by the mink; about 23 in or near the island burrows; and about 11 remaining along the east central shore after moving as a family group from the drying south half.

Of the total of about 80 arrived at, the first known to die was one that looked as if it might have succumbed either to disease or old age in late October or early November. The year 1949 was the first since the collapse of 1943 in which the marsh did not have at least one epizootic. None of 115 mink scats deposited from September through November contained muskrat remains. Water levels were much as they had been during the two previous winters.

One of seven mink scats from early December contained muskrat remains, but that scat was from the lodge in the south half that had been occupied by the lone adult. Up to the end of December, no general crisis was brought about at Goose Lake by the sinking of the frost line into the mud, though few of the muskrats could have had access to much unfrozen water except in their deepened channels. One of 18 mink scats for the middle to the end of December contained muskrat remains.

By mid-January, 1950, the water in the deepened channels had frozen, and the mud above had buckled from the pressure. The musk- 
rats of the north half had withdrawn to their bank burrows by the first of the year, and their small lodges out from shore and their larger mud-plastered shore lodges both remained unrepaired after intrusions of minks. In contrast, the bigger rush lodges of the foodrich shallows of the south half had mink holes promptly repaired, and push-ups continued to appear on the ice. By early February, the rush lodges of the south half, too, showed no evidence of living muskrats, and any muskrats yet alive at Goose Lake were either in bank burrows or living under the ice away from externally visible habitations. In this period, proof of death of only six distinct victims was found, but 27 of 66 scats examined from probably three resident minks contained muskrat remains. At the time, this winter mortality was attributed to predation by minks upon muskrats vulnerable because of a freeze-out crisis, but, by the following year, it became evident that sites of the 1949-50 wintering mortality included some serious foci of the hemorrhagic disease.

An early March thaw put up to ten inches of water over the old ice and brought the marsh up to within about three inches of its overflow level at the dam. This water flooded many of the mink caches of dead muskrats. Fourteen of twenty-four scats dated from mid-February up to the flooding contained muskrat remains, whereas this item was found in none of seven scats deposited March 6-8 in the vicinity of some of the best caches. But four of six scats that were fresh on March 14 contained muskrat remains.

I opened, on March 6, all lodges and parts of some of the most accessible burrows, without finding any sign of living muskrats, nor was any found a week later, when the melt water froze over the old ice. Visits were made in the latter part of March as the ice receded from the shores, and the marsh continued to be devoid of current muskrat signs. No muskrat remains were found in 21 mink scats deposited in the first half of April.

The first evidence of a newcomer to the marsh following the annihilative winter losses appeared about April 5. What was probably the same animal was seen in the same vicinity - the heavy bulrushes of the east center, quite apart from any of the 1949-50 wintering retreats of muskrats - on April 14. It was a big animal, battered in appearance, and depending for shelter on temporary nests in heavy rushy growths.

\section{THE RECOVERY YEARS, 1950-52}

From spring throughout the rest of 1950, environmental conditions were the best for muskrats at Goose Lake since before the pronounced deterioration of marsh vegetation in 1943. Not only did the south part grow up heavily to bulrushes and cattails but much of the north part was thickly fringed with marshy emergents. Water conditions remained favorable, although practically no overflow into the outlet occurred until fall. 
In late April or early May, a lone, pregnant female moved in and built a small lodge; she raised a single litter born about May 13 . On May 4, a pair of muskrats, distinct from the pregnant female, was watched mating out from the entrance of the same burrow system where the late summer epizootics of 1947 and 1948 had been observed to start. This pair seemed to disappear permanently soon thereafter, almost certainly dying from hemorrhagic disease at one of the deadliest foci of infection on the marsh.

Prior to about the first of October, the only muskrats detected were those of the one-litter family group living there since May. Then, as water overflowed the dam following locally heavy rains in late September and early October, immigrants trooped in via the flowing outlet. Most of this movement and resettling was over by the middle of October, but diminishing evidence of its continuation was seen in the second half of the month. Goose Lake was the sole central Iowa observational area to draw any substantial immigration in the course of drought-forced adjustments on the part of stream-dwelling populations, and that occurred only while water flowing in the outlet offered an inviting avenue of travel.

Estimates made from bubble signs under clear ice, November 11,1950 , gave a figure of around 150 , which would mean an increase in the fall of 1950 of around 140 animals, datable largely to the month of October.

Indirect evidence of hemorrhagic disease was seen in the vicinity of the old focus of infection where the mated pair almost certainly had died in late spring. One of the lodges erected in October within easy cruising distance of the infected burrow system showed disuse by the time that the ice formed, and, on December 9 , a small mink dragged a dead muskrat out of the neighboring lodge. Two of three mink scats deposited in this part of the marsh in early February, 1951, contained muskrat remains. Under such circumstances, this sort of sign is highly indicative of disease mortality.

Elsewhere on Goose Lake, the muskrats wintered well up to midFebruary. No muskrat remains were found in 35 mink scats gathered from November, 1950, through January, 1951, away from the suspected disease focus. Unauthorized activities of a trapper were noted about the muskrat lodges on opening day (November 25) of the trapping season, but I am sure that few if any muskrats were actually trapped there.

Sinking frost lines in midwinter were accompanied by rather general abandonment of feed houses and the smaller lodges. Many of the larger lodges were dug into by minks but these were usually repaired rather promptly. In one instance, one half of a large lodge continued to be used by muskrats, while the other half was left with an unrepaired mink hole. Outside activity was noted on the part of a single muskrat in early February.

Of 191 mink scats examined from mid-February through April, 
1951, 49 contained muskrat remains, and 26 of the muskrat-containing scats were deposited in the vicinity of the old disease focus of the east central shore zone. During this late winter and early spring period, mortality of at least five muskrats was detected, and a fair case could be made for the demise of at least eight more-mostly, but not exclusively, in the vicinity of the same old disease focus. Away from here, one muskrat that persisted in coming out on the ice during thaws was killed by a predator (probably a great horned owl); a rather minor amount of mortality took place in shallow water zones of the northwest corner and north end as the ice thickened; and perhaps two or three animals (judging from remains found in mink scats) died after the ice went out.

Preliminary estimates of Goose Lake breeding territories were made in late April, 1951, and the total arrived at was 45, or, following the central Iowa sex ratio of 58 per cent males for the fall of 1950 , a total of about 107 muskrats. This value checks fairly well with the estimates of the wintering population after allowing for mortality. No evidence of movement in or out of the marsh via the flowing outlet was found either in the spring and early summer or in the fall of 1951, so the breeding population and its increase may be considered self-contained for this particular year. Extensive territorial readjustments were noted by the middle and latter part of May, but these were practically restricted to the vicinities of the territories recorded a month earlier. Irrespective of changes in the exact locations of territories, the totals to be perceived in given tracts of the marsh tended to remain unchanged.

Second and third checks from mid-May to mid-June gave the same territorial totals as in late April, except that three territories were apparently lost early in the summer. One of the territories considered lost without compensating gain elsewhere was at the site of the familiar old disease focus of the east central shore. Enterprising dogs (individuals known as habitual muskrat hunters) seemed responsible for the uncompensated loss of two territories. (Actually, five systems of bank burrows representing muskrat territories were thoroughly dug out by the dogs, but, in three of these territories, the occupants evidently succeeded in avoiding capture and in adjusting to this molestation.) Approximately 100 adult muskrats should have been alive on the marsh by late June, with the prevailing food and water conditions being excellent and the hemorrhagic disease killing muskrats only in a very restricted area.

By fall, 1951, Goose Lake was still in excellent condition for muskrats. Its supporting capacity appeared to be nearly equal to that of 1942, when the marsh had offered the best habitat for muskrats during the entire period of study. But, although the total quantities of superior food were similar in both years, the composition and distribution of the food plants of 1951 differed greatly from that of 1942. In 1942, the main food supply was a dense stand of broad-leaved 
cattails covering roughly the south half, whereas, in 1951, the emergents of the same area were largely bulrushes, with more open spaces. However, in 1951, there were far more bulrushes elsewhere on the marsh, besides thick growths of duck potato dominating the open water shallows, as well as considerable stands of cattails.

No evidence of summer and fall mortality from hemorrhagic disease was found on Goose Lake until early October, when muskrats proved to be dying in two places. One place was the site of most of the dying of the previous winter and spring, the notorious east central focus at which muskrats had died since 1947 (except in 1949 when they had not been present there). The other place, though muskratvacant in 1950, was the only site of suspected dying from the disease that had occurred on the marsh in 1949. Later in the fall, a few diseased dead were found in a third place, not so very far from the last-mentioned. All together, only eight dead muskrats were recorded in the Goose Lake notes for October and November, 1951. Four of 284 trapped carcasses examined in late November and early December had liver lesions, all well-advanced in healing.

Sex and age ratios of the trapped carcasses were 19 adult males, 17 adult females, 135 young males, 113 young females. Aside from 18 young of "kit" sizes (7.3 per cent of the young), most of the young were of decidedly large sizes by early winter. Five of the animals classed as young females of 1951 had conceived single late (early August to early September) litters -5 young each for 4 pregnancies and 4 young for the other. The 17 adult females had conceived 58 litters or a mean of 3.4 litters, with a mean size of 8.0 young per litter. Of the 17 adult females, 1 had conceived a single litter, this one assigned to May; 2, two litters each; 3, three litters each; and 11, four litters each. Eleven of the 17 adult females were judged to have given birth to their last litters in August or later.

About 40 adult females were left on the marsh before the trapping, as of mid-November. The fur trapping on the main part of the marsh was conducted in such a way as to leave about half of the population for breeding stock and to obtain the most representative carcasses for examination. The sex and age ratios for the carcasses, applied to a base of 40 adult females, gives a total fall population of about 670 .

The above calculations ignore the young contributed by the precocious young females in 1951. According to the sample data, the adult females conceived about three and one-half times as many late-born young as did the precocious young females. Even if it be assumed that the young born of precocious young mothers had survival chances equal to the chances of the late-born of experienced adult mothers, only about nine young (fewer than 2 per cent) of the total of 584 young of the year arrived at from the calculations may thus be credited to the precocious females.

At least 300 muskrats survived the trapping, and most of these 
wintered well, including the occupants of the shallower parts and also including most of the occupants of two strips of shallow shore zones that had not been subject to trapping. All detected mortality at least 17 dead were accounted for - after the first of the year took place either at or near definite disease foci. Three regularly resident minks frequented these places. None of 54 mink scats deposited from late fall through January contained muskrat remains, compared with muskrat remains in 7 of 34 for February and in 31 of 88 for March.

Signs of spring dispersal from wintering quarters were noted as early as March 20, 1952, although the ice covering was still unbroken about all except the edges of the marsh. Only the very slightest evidence was found of animals leaving the marsh entirely. As of early May, 120 breeding territories were distinguished, which following the winter sex ratio of 54.2 per cent males, would give a remaining total population of about 260 adults. This would seem consistent with the other population data, allowing for the death of 40 to 50 muskrats at the disease foci between early January and break-up.

The disease foci continued to be sites of mortality. At least 19 territories were depopulatd during May and the first half of June through the agency of the pneumonic syndrome of the hemorrhagic disease, thus cutting down the adult population to about 220 .

Goose Lake had some remarkably high breeding concentrations in the late spring and early summer of 1952, all in places on which little or no effective trapping had been carried on during the preceding fall and winter. The most prominent was one of 15 territories in a rushy shore-zone strip having a total area a little less than one and three-quarters acres.

From late June on to fall, local population adjustments tended to refill the disease-swept places, but little further dying was known to have occurred prior to October. Such repopulation through postbreeding adjustments was generally rather incomplete, however, and most of the formerly disease-swept tracts (there was a single outstanding exception) had decidedly fewer muskrats by fall than the neighboring tracts that had been spared disease mortality.

The marsh remained in good condition for the muskrats up to mid-September. As a fall drought progressed, the occupants of some of the shallower tracts became relatively more exposed. The most pronounced adjustment occurred in the extreme northwest corner, which went dry in late summer. This corner had a mid-May population the equivalent of eight breeding pairs - five of them farther than 100 yards from deeper water - and these territories had been highly productive of young up to August. As of that time, the muskrat occupants of 21 large and medium-sized lodges had been concentrated in a strip of drying shallows about 150 yards in length and from 20 to 30 yards in width. By the last of October, signs of perhaps a dozen remaining muskrats could be made out in the northwest shallows, mainly occupants of the 3 territories situated nearest the 
deeper water of the marsh proper. The others adjusted along the 150 yard strip, and then, after much explorative traveling back and forth over an 80-yard trail to the deeper water, took over the site of a food-rich old disease focus that had been all but muskrat-vacant since spring. By mid-November, only a single muskrat seemed to be left in the 8 former territorial sites of the northwest shallows.

The next-to-the-shallowest area of Goose Lake having considerable numbers of muskrats in residence in 1952 was near the west central side. The occupied lodges never had been completely drought exposed (in the sense of losing all surface water) during the summer and fall. Far greater restlessness was noted on the part of the equivalent of the 19 pairs and their season's young living here than on the part of the muskrats of the northwest corner. Beginning about midOctober, much evidence of fighting and abandonment of former home ranges was noted, with footloose wandering occurring particularly over the farm land to the west. To a lesser extent, similar observations were made about other shallow-water zones of the south half of the marsh. Many strife-battered animals reached the deepwater north half of Goose Lake, there to find temporarily endurable living conditions. One type of adjustment on the deep-water north half is illustrated by the erection of a large lodge near the center outside the ordinary cruising radii of the shore-dwellers - in early October. Twenty muskrats were taken from this isolated lodge during a few days of trapping in mid-November, and the lodge was still being maintained after the trapping!

In comparing the peaceful adjustments of the muskrats of the northwest shallows and the far more troublous ones of the west central and south shallows, certain distinctions as to chronology of the events should be recognized. The actual drought exposure of the muskrats of the northwest shallows was incomparably more severe than were the exposures involving the other shallows, but the residents of the northwest shallows accomplished most of their adjusting before the end of September, weeks before any notable intraspecific tensions became apparent. The residents of the west central and south shallows, though living in superior habitats compared with the earlyabandoned northwest shallows, were trying to adjust at a time of fighting and wandering on the part of increasing proportions of animals leaving familiar home ranges.

The ingress of the muskrats of the dry northwest shallows into the adjacent old disease focus precipitated the first detected mortality from the hemorrhagic disease since the pneumonic syndrome epizootics of late winter and spring had subsided in May and June. On about October 16, 1952, a large subadult died right in the middle of the disease focus. During the next three weeks, an epizootic spread from this place southwestward along the shore zone for 200 yards and northward for at least 55 yards. It was estimated, on the basis of newly dead lodges and other signs, that about three-fourths of the 
population of this 255-yard stretch-including many of the former occupants of the northwest shallows - died during the last ten days of October. All together, remains of thirty-one dead were found in this disease-swept stretch up to mid-December, and many other dead were doubtless overlooked. The degree of depopulation in consequence of the epizootic is indicated by the fact that fewer than a dozen animals were taken from the stretch during the fur trapping and here the trapping was done very intensively. The disease mortality amounted to the equivalent of about eighteen complete family groups.

Elsewhere on the marsh a considerable amount of late fall and early winter dying was localized about old disease foci. From one to eight dead were found at or near seven of these, including some old foci at which no mortality had been observed for years. One that had been notoriously deadly between 1944 and 1946 had few if any muskrats in its vicinity until the fall of 1951. Apart from a single dead muskrat found near by in the spring of 1952, reoccupancy of this site had not been accompanied by renewed dying until November of 1952, but five were known to have died here up to mid-December. Another site of disease mortality in the falls of 1947 and 1948 had muskrats living at least near it in 1951, but it was not until the fall of 1952 that muskrats again were known to have died; from late October to mid-November, 1952, eight dead were found, and one of ten specimens systematically shot here for examination had severe lesions. The deaths of six were recorded from mid-November to late December, 1952, from a lodge at which at least three had died in winter and spring, 1951-52, but at or near which no mortality had been detected during the intervening summer and fall months. Twelve living muskrats showing lesions of varying severity, including some (in four cases) indicative of approaching death, were taken for specimens mostly in the latter vicinity in early December, 1952.

The most notorious of the disease foci - the site of most of the hemorrhagic mortality of recent years-showed evidence of only one death during the fall of 1952. Prior to the fur trapping in midNovember, this place did have fair numbers of muskrats (which had moved in during some local population adjustments of mid- and late summer). After the trapping, few muskrats remained in the infected tract.

The 1952 fur trapping was done in two periods of the open season. In mid-November, 282 muskrats were taken before freeze-up from the open water part of the marsh. In early December, 125 more were taken, but all except about 30 of these were from the partly dry shallows of the south part. The sex and age ratios in possession for a total of 399 fall specimens gave 13 adult males, 19 adult females, 188 young males, and 179 young females. But these ratios should not be applied directly to the approximately 100 territories that remained functional after the known dying had ceased in June, for the evidence 
on local adjustments points to disproportionally more young in both major trapped samples than held true for the marsh population as a whole.

The single tagged young recovered during the 1952 fall trapping well illustrated the behavior that must be considered in applying sex and age ratios to shallow-zone territories during a dry year. The animal had been tagged in May in one of the territories of the northwest corner that almost went dry in late fall, and it was trapped in the open water at least 150 yards to the southeast. On the other hand, a few of this family group (which conspicuously included large, surely fully adult animals) remained in the original territorial lodge until the trapping was over and did not get near any place where traps could feasibly be set. This type of behavior could easily be traced through "reading of sign" between many shallow-zone territories and deeper adjacent waters.

Of the 282 muskrats caught in the open-water part before freezeup, 259 were sexed and aged. They were 5 adult males, 11 adult females, 125 young males, and 118 young females. These represented a fair cross section of the occupants (all ages) of 16 territories, plus a large proportion of the adjusting young of 11 more territories of adjacent shallows. From the above ratios, the population of the marsh that was accessible by boat during the trapping figures out at about 375. The evidence from trapping partly abandoned territories of the shallows after freeze-up indicates that from 1 to 7 or more muskrats were left in each territory, averaging perhaps 4 in each. The figure of 4 per territory applied to the 11 partly abandoned territories of the shallows adjacent to the early-trapped area gives 44, which, added to the 375 , would give a rather circumscribed population group totaling about 420 animals, as of early November, 1952. The figure of 420 also agrees with an estimate made on the basis of the trapping results: by the last day of open-water trapping, the catch rates had fallen off sufficiently to indicate that, with a catch of 282, about twothirds of the population in and about the open water had been taken.

The population of the south part of the marsh, which was not trapped before freeze-up, is harder to calculate satisfactorily. Subtraction of about 30 taken from the open water part after freeze-up from the total of 125 then trapped on Goose Lake would leave about 95 taken from the south shallows and their remaining tracts of fairly deep water. These 95 represent an estimated three-fourths of the adults and young of 6 partly abandoned territories, plus most of the adjusting young from about 11 other territories. In addition, there were about 20 occupied territories at which no effective trapping could be done because of the shelter afforded the animals by immense snowdrifts. Well-maintained though more or less exposed territories had a mean of about 11 animals prior to the trapping, in contrast to the estimated 4 per partly abandoned territory. From the 
population samples obtained during the trapping, a pre-trapping population of about 365 may be calculated for the south and southwest shallows and associated deeper waters.

The total fall population would then figure out at about 785 muskrats, as of early November. Allowing for a mean reduction of 7 muskrats each for the 19 territories of the west central side that had been partly depopulated through egress without known compensating gain elsewhere on the marsh would account for about 130 animals presumably engaging in cross-country movements in October. A total loss of the equivalent of 18 complete family groups from the epizootic of October and early November in the northwest corner - these groups averaging about 16 muskrats each, according to excellent sampling data from disease-free neighboring populations - would give a loss figure of about 290 for this part. For the rest of the marsh, the pre-trapping fall losses from disease, predation, fighting, and wandering probably did not exceed 50 animals. Adding a total fall loss figure of about 470 to the pre-trapping total of 785 would give a grand total of about 1,255 muskrats, as of mid-fall, 1952.

Concerning the 1952 breeding statistics: of 17 adult females carefully examined during the trapping, one had not conceived in 1952; one had conceived a single litter (assigned to June); 2 had conceived two litters each; 6 , four litters each; and 1 had conceived five litters assigned to the calendar year. Four of 179 young females born in 1952 had themselves conceived single, small (averaging 5.5 young), late (August) litters. The 16 breeding adult females of the sample had conceived a total of 52 litters, or a mean of 3.3, with an assigned seasonal distribution of 6 in April, 11 in May, 16 in June, 15 in July, and 4 in August. The mean size of litters conceived per adult female was 8.2. Among the 367 young of the year examined in late fall and early winter, 24 or 6.5 per cent were judged to have been Augustborn, compared with 8 or 14.3 per cent August-born litters in the total of 56 (including those of the precocious young females) for which seasonal data were obtained.

\section{MORE YEARS OF VICISSITUDES, 1953-55}

It was apparent by mid-December, 1952, that the approximately 350 muskrats judged to have been alive after the fur trapping had prospects of severe wintering mortality ahead of them, and so it happened. At this time, most of the muskrats of the disease foci that had escaped traps and disease died with relative suddenness. The dying now occurred more or less simultaneously in widely-separated places and accounted for at least 100 animals. In late December, a period of conspicuous wintering crisis began for muskrats living in shallow-water zones. Between then and March 13, 1953 (the last day that the ice permitted walking), I spent 44 afternoons on the marsh studying the complicated wintering histories of local groups of muskrats and the responsiveness of mammalian flesh eaters thereto. 
The dead and handicapped muskrats were exploited by a population of at least nine distinguishable minks - representing just about the maximum levels that the minks themselves would tolerate. In addition, Goose Lake was regularly worked over by red foxes and, occasionally, by farm dogs and a winter-active striped skunk and a raccoon. Up to late December, the feeding by flesh eaters upon muskrats had been chiefly scavenging, but, soon after, the minks and foxes ceased working the disease foci, to work systematically about the places where the muskrats of the shallows were confronted by a mounting freeze-out crisis.

Whole groups of the muskrats traveled regularly back and forth between exposed lodges and the snowdrifts covering certain of the better feeding grounds, and the more insecure naturally drew some predation. But, even in the shallows, considerable numbers of muskrats were able to survive in the protection afforded by the snowdrifts or a little unfrozen water or mud beneath the ice, and, even here, a large proportion of the muskrats eaten or carried off by the minks and foxes had clearly been dead when found. Some of the victims had self-amputated frozen tails signifying hardship if not death from freezing. The bodies of others had been wrenched by predators from frozen mud or from frozen lodges. Once, a mink obligingly revealed its source of food by eviscerating a freshly dead muskrat dragged from a lodge and leaving the intestines - distinctly hemorrhagic from disease - in the trail. Many fresh-appearing dead muskrats that I found in late winter and early spring were refrigerated victims having times of death traceable, from sexual condition or stage of peltpriming, to the December die-off. Utilization of the local muskrats by the minks paralleled closely the changes in availability of this item as food. No muskrat remains were found in 27 late-summer and early-fall mink scats, and remains were found in only three of 113 scats deposited in early and mid-October, at the beginning of the dying from the hemorrhagic disease. For late October and early November, when the dying was all but restricted to the sweeping epizootic of the northwest shore, 10 of 66 mink scats contained muskrat remains. From mid-November through December, the period of most dying from hemorrhagic disease after freeze-up, 47 of 86 mink scats contained muskrat remains. Many victims of this dying were also found in frozen condition by the minks later in the winter, at the time that the lodges softened in the spring. Extremely high incidences of muskrat remains in mink scats for January (in 51 of 60), and for the first half of February (in 48 of 52), reflected not only continued availability of muskrats dying earlier but also the increasingly severe wintering crises confronting the muskrats trying to live in the less habitable shallows.

Mild temperatures during the second half of February relieved the wintering crises for many of the muskrats surviving up to then, and the incidence of muskrat remains in mink scats dropped to 31 of 43 . 
However, cold snaps that followed thaws imposed deadly hardship upon individual muskrats before they were able to adjust to the flooding of their subsurface retreats. In two instances, muskrats were known to have left their home ranges to station themselves in unfamiliar places elsewhere on the marsh, and to die later when caught by cold weather.

Thirty-five of 53 mink scats from the first half of March contained muskrat remains, at a time when essentially all of the muskrats that had successfully wintered at Goose Lake were living with security from predation, but this was also a time when minks had convenient access to disease victims in many softening lodges that they had not previously penetrated. None of the seven mink scats examined during the second half of March contained muskrat remains, though floating dead from early winter were appearing at old disease foci.

Of 179 dead muskrats listed in the Goose Lake field notes, from mid-October, 1952, through March, 1953, 21 had died under circumstances that could not be satisfactorily appraised. Of the other 158,113 had died demonstrably or almost certainly from the hemorrhagic disease (whether eaten upon by predators or not) at old disease foci and 22 more at what I came to regard as possible old disease foci. One dead muskrat had been dug out of a frozen lodge by a raccoon, but, of hundreds of raccoon scats looked at during the period of disease mortality of the fall and winter of 1952-53 at Goose Lake, only a single scat accompanying the above dead muskrat contained muskrat remains. Nine other dead muskats had been eaten upon or played with by foxes, four of them in the stretch of shore zone first swept by disease in the fall. Two of the dead muskrats examined had been victims of intraspecific strife. Four had been trap cripples. Seventeen could have been functional though handicapped animals killed by predators. The latter included one surprised outside a lodge and killed by a fox and another killed under similar circumstances by a dog. Of the 15 that had seemed the likeliest victims of mink predation, per se, at least five had suffered enough from exposure to lose the ends of their tails from freezing.

About 70 muskrats survived the winter of 1952-53 on Goose Lake. As of late May and early June, 1953, 28 well-maintained territories were recorded, which would mean a total population of about 60 adults, and a similar figure was arrived at for late June. It may be said that, in general, the winter survivors stationing themselves in known disease foci died (five dead were found in these places in April) and that the others lived securely. Two of 59 mid-April to early May mink scats contained muskrat remains, and both muskratcontaining scats came from a notorious disease focus.

By midsummer, practically all muskrats living in or very near old disease foci had died, thus leaving about 50 adults residing in the safer places. Most of the latter adults and their season's young got along splendidly in lush vegetation and adequate water until 
the food-rich shallows of the south part again dried up in late September. Most of the young animals and some of the adults then moved to the main body of water remaining, that of the relatively food-poor north half of the marsh.

The midfall population of 1953 amounted to about 230, including few, if any, immigrants from surrounding dry streams, insofar as the marsh was well outside all the travel routes taken by adjusting and wandering stream-dwellers. About 90 of the 230 still lived in food-rich shallows up to the middle of October. By November, scarcely more than a dozen were left in the shallows, the others having moved, for the most part, into the wetter but food-poor north half. Here, the newcomers had sufficient space in which to keep out of serious trouble with their fellows that got there first, though healed fight wounds on five of 71 specimens trapped on the wet marsh in mid-November did not bespeak wholly peaceful relations. Two of the most chewed up muskrats were noted to have been living very much alone.

Twelve of 18 dry-marsh mink scats datable to the period of probable greatest deadliness (with zero or lower temperatures on the nights of December 15-16) contained muskrat remains. By late December, only a lone, very large muskrat appeared to be alive in the dry and hard-frozen south half, and minks were diligently boring into the two principal groups of dry lodges in which the last of the other dry-marsh muskrats had persisted in trying to live.

Severe local dying from the hemorrhagic disease had begun at two of the deadliest old disease foci shortly after these had been repopulated by muskrats in the course of the September adjustments. Later in the fall, dying had started at two more old foci lying adjacent to the main body of water of the north half. By the first of November, an epizootic had been advancing on three fronts (from three different disease foci) into some 30 acres of wet marsh having a concentration of 200 or more muskrats. Dying also had started at another old disease focus on the opposite side of the marsh from the advancing three-front epizootic.

Seventy-six certain or very probable disease victims were recorded for the above period of fall and early-winter dying, and the evidence suggests mortality from disease of about 40 more. All of the recorded victims except two were found at or not far from notorious old disease foci. As usual, the outstanding disease focus of the Goose Lake studies - that of the east central shore mentioned so frequently in accounts of previous dying - became a site of mortality when reoccupied by muskrats in the fall; 29 dead were found here, of which 24 were datable to late September and October and the other 5 to early November, after which this part of the shore zone remained unpopulated by muskrats. Two other consistently deadly foci were occupied by muskrats at about the same time, but their new occupants were not known to have started dying until several weeks afterward; 
the dying then slowly gained headway until no more muskrats were left alive by mid-December. Eight dead were recorded at one place and 12 at the other, mostly after freeze-up. The two disease victims dying away from known foci were occupants of the same lodge and burrow system; while more may have died here undetected, this local dying was neither very drastic nor part of any sweeping epizootic.

Exceptionally significant data were obtained from a disease focus that had been the site of a locally severe die-off in the late summer and fall of 1947. It had then remained muskrat-vacant for five years, until the fall of 1952, with muskrats living securely on all sides of it. Its muskrats had died out again during the winter of 1952-53 and it had remained muskrat-vacant once more, until the fall readjustments of 1953. Then, from late September to early November, 1953, this place and its immediate vicinity became completely depopulated, most of its 22 recorded victims dying in October. This constituted the second example at Goose Lake of a lethal disease focus retaining a distinctive infectiousness for five years in the absence of muskrat culture media of the hemorrhagic disease.

Experimental trapping was carried on, mostly November 10-14, to remove those muskrats that were in greatest danger from the contagion then spreading. Accordingly, the trapping of 76 animals virtually depopulated the tracts lying between the disease foci and the bestsituated muskrats having a minimal chance of surviving the winter. The latter remnant was estimated at about 30 , as of early December. The other muskrats then alive on the marsh may not have exceeded the lone animal in the dry south shallows and possibly one or two still maintaining an isolated lodge near one of the disease foci.

Of the total of 76 muskrats trapped, 5 were adult males, 5 were adult females, 40 were young males, and 26 were young females. Of 18 late-fall disease victims yielding sex and age data, 4 were adult males, 5 were young males, 5 were young females, and 4 unsexed young. Only 3 of the 80 young in the sample were judged to have been late-born, with times of birth assigned to early August. None of the young females of the sample had conceived young in 1953. All 5 adult females had conceived 3 or 4 litters, the mean being 3.4 litters per female. For 17 litters, the assigned birth months were: 3 litters in April, 5 litters in May, 5 litters in June, and 4 litters in July.

The estimated 30 muskrats alive on wet-marsh Goose Lake after the 1953 experimental trapping consisted of three population groups. One group was in the food-poor central part having up to a foot of water at freeze-up. The second group was strung out along the muddy east edge of the wet marsh and it lived partly in lodges containing large quantities of stored duck potatoes. The third group was at a place having neither the deeper water nor good food resources.

The water froze to the bottom of the marsh in all wintering sites during the second half of January, 1954, despite deepening of the strategic burrow systems by muskrats responding to the crisis. Almost 
suddenly, the accessible food of the former wet-marsh became exhausted, except in the mud lodges of the east edge that had been stocked with duck potatoes. It was only at the latter that any evidence of muskrats being alive was found in late winter.

Responsiveness of the local predators to muskrat flesh followed familiar patterns. The numerous raccoons were unable to exploit either the drought-exposed or the diseased muskrats to any important extent. Latrines made up of thousands of raccoon scats were examined in the field from August through December, 1953, without finding any muskrat remains. Red foxes fed upon at least two muskrats at disease foci. As usual, the minks were the predators specializing on the handicapped and dead muskrats, but they found little muskrat flesh available to them until freeze-up. Even the drought-exposed muskrats of the south shallows were not known to have suffered losses from the minks until the ground froze solidly. No muskrat remains were found in 69 mink scats deposited from October through mid-November in the dry marsh, compared with remains in 14 of 20 scats for the middle to the end of December, in 10 of 33 for January, and in 8 of 9 for February.

Minks probably killed the last muskrat trying to winter in the long-dry but food-rich south part of the marsh, as well as two other muskrats abandoning the frozen wet-marsh lodges to move into wellvegetated shallows of the edge. They also were known to have killed two of the frost-evicted muskrats on the ice.

During the winter of $1953-54$, at least nine muskrats died from the hemorrhagic disease at sites 50 to 150 yards distant from major disease foci. Some of the dying away from known foci may be explainable in terms of victims contracting the disease while visiting sites of earlier mortality, but it is by no means certain that this was invariably the case. Mink scats examined at or near sites of disease mortality contained muskrat remains in $\mathbf{5}$ of 26 for late November, in 25 of 69 for December and January, and in 20 of 35 for February. Most of the feeding of minks upon muskrat flesh in February was in response to dead muskrats becoming easily available inside lodges softening during a prolonged thaw.

Neither minks nor disease seemed to be involved in the serious wintering troubles of some of the muskrats. In mid-January, while the air temperature went as low as 15 degrees below zero Fahrenheit, a group of muskrats sat huddled within a partly open small lodge, too beaten by hunger and cold to repair the lodge. Other muskrats ate away about all that they could reach of the inner walls and tops of their dwelling lodges, even those having great quantities of mud mixed with the vegetation used in building. The two animals killed by minks on the ice had almost nothing but sand and harsh plant debris in their alimentary tracts. Some of the last muskrats observed to be alive were coming out on the wet ice during a thaw, to dig and gnaw on the top of a marsh-edge lodge composed chiefly of mud, 
and these had first so thoroughly eaten out the interior of the accustomed dwelling lodge that the sides broke through in two places. Nevertheless, these muskrats (which were so tame from hunger that they permitted watching of their activities from a distance of a few yards) did rehabilitate a once-abandoned shore lodge having stored duck potatoes, and there apparently was some successful wintering at this lodge.

Although water did not return to Goose Lake in time to save the wintering muskrats from deadly crisis, the rains of May and June, 1954, well filled the marsh and left it in splendid condition - with but a lone muskrat in residence by the middle of June. The origin of the lone animal is uncertain but the evidence suggests a winter survivor. What appeared to be this same individual spent the whole summer in the vicinities of two of the deadliest disease foci on the marsh.

Except for the above, Goose Lake continued to be without muskrats until late September and early October, when about thirty animals moved in from a ditch via the flowing water of the outlet of the marsh. As of early December, the population was estimated from signs at about twenty-three, following known or suspected mortality from disease at or near four old disease foci. Food, cover, and water conditions were excellent, but most of the newcomers were hazardously located with respect to disease. By early April, 1955, signs of successful wintering could be seen in five places (including the vicinity of the deadliest disease focus on the marsh), and about eight muskrats were judged to have wintered. Two of these survivors were later found dead of hemorrhagic disease, and remains of four winter victims were noted. Nearly all dying occurred in or near the notorious old disease foci where most of the newcomers had settled in the fall.

The high population of nine minks regularly frequented Goose Lake and its immediate environs through December and January, 1954-55, and well into February. By February 23, only six minks were remaining, the other three having disappeared about the time that the breeding season of free-living minks started. These minks cruised the marsh sufficiently to take advantage of muskrats dying from disease, though they subsisted principally upon the meadow mice of the marsh fringes. Three of the fifty-two winter mink scats examined contained muskrat remains.

Of eight muskrat territories recorded at Goose Lake from late May through June, 1955, three were attributed to animals having wintered there and five to those having come in via the flowing outlet during the spring dispersal. The newcomers were distributed along the west side of the marsh, in the usual line of travel of muskrats entering from the outlet. One of the territories attributed to winterresident stock was lost because of disease in mid-May. As of late June, four of the seven functional territories were doubtfully productive, and one seemed to be maintained by a lone animal. There was no evidence of anything to be called full-scale breeding, and possibly 
as many as three of the four indubitably productive territories actually produced only single litters of young, born to lone females that had been pregnant when they established their territories.

The water level went down during a late summer and fall drought until only about 30 acres of the deeper marsh had water covering the bottom by late September. The muskrats then alive were localized either in a few newly-built central lodges or along a 150-yard stretch of east central shore zone. Adjustments in dry or drying habitat were - except for the death of the occupant of a loneanimal territory-unaccompanied by detected mortality, and it is thought that most of the young born in the productive territories were reared to independent stages.

A well-based population estimate of about 45 muskrats was obtained in mid-November, up to which time little loss had resulted from the drought conditions. Freeze-up came with no more than a foot of water remaining in the deepest places. Few muskrats were left alive by late December, when all of the food-poor remaining water was frozen to the bottom. By the end of the first week of January, 1956, all muskrats at Goose Lake were dead except possibly at one lodge; and certainly none got through a period of subzero weather beginning shortly after the middle of the month, with a minimum temperature of 23 degrees below zero. While the muskrats were still alive, they hollowed out the interiors of all maintained lodges, ate on the tops from the outside, and some did a considerable amount of foraging in drought-exposed food-rich shallows.

Two locally resident minks took advantage of the frost-evicted and starving muskrats. Muskrat remains were found in only 3 of 11 mink scats examined in mid-November, when the freeze-up crisis was just beginning; but 9 of 18 scats examined in early December and 15 of 19 scats examined for the last of December and the first week in January contained muskrat remains. By the middle of January, the minks were no longer visiting the dead muskrat lodges, but foxes were showing interest in them. Three of five mink scats deposited during the first half of March contained muskrat remains - representing two individuals whose bodies were thought to have become available to the minks with the spring thaw.

By early April, 1956, water was again covering about half of the bottom and, by mid-May, about three-fourths, or all of the deeper parts. Less than a month later, the entire marsh bottom was drought-exposed. It remained without surface water or muskrats throughout the summer and fall. It had a solid head-high growth of vegetation, with smartweeds and seedling cattails and bulrushes dominating the previously exposed mud flats.

By the spring of 1957, Goose Lake again had water over much of its bottom, and the marsh was in habitable condition for muskrats during summer and fall as well - but without muskrats. Then, in mid-October, muskrats reappeared, to build, almost simultaneously, 
several groups of lodges in different parts of the marsh. The origin of the newcomers could not be traced, but it is suspected that they had come in from a large drainage ditch lying less than a mile to the west. From careful fall-to-spring estimates, it was concluded that about 35 muskrats had originally established themselves in the fair-togood habitat that they had found available in late fall. Evidence of unauthorized human disturbance (presumably trapping) was detected in one part of the marsh in early winter, with an estimated reduction of about 10 animals; but, apart from this, the muskrat population wintered very well, despite the intrusions of three individually distinguishable minks into the lodges. No muskrat remains were found in 16 winter mink scats.

By spring, 1958, fresh muskrat signs were still to be seen in expected places, and about in expected proportions at each wintering lodge. A survival figure of about 25 would be consistent with the amount and distribution of current signs, as of the time that the ice melted. By May, however, only four territories were being maintained, including one territory judged to have been recently established by one or more recent newcomers to the marsh. 


\section{Central Iowa Streams and Outlying Waters: Introduction and Story City Block}

Central Iowa muskrat habitats here treated were selected for longterm study on the basis of their representativeness as places frequented by primarily stream-dwelling populations. The regularly observed habitats included the small and medium-sized rivers and creeks, pasture brooks, tile flows, ditch and oxbow pools, and field ponds that together comprised the muskrat habitat - whatever the quality - to be found more or less typically in the equivalent of two townships of farm land in the central part of the state. All lie in the extensive Skunk River drainage and may be chiefly grouped in two blocks. One block lies south, southwest, and west of Story City (Figure 10.1); the other, north and northwest of Ames and southwest, west, and northwest of Gilbert (Figure 10.2). Descriptions of the individual areas may be found in Appendix D.

Studies of muskrat populations of central Iowa streams and outlying waters were all but confined to private property, and I am grateful for the cooperation received from farmers and trappers. In this connection, I should particularly express appreciation for the help given me on so many occasions by Magnus Olson of near Story City and by the late Cleo Turner of near Gilbert. Others to whom I owe special thanks include the following trappers who saved valuable specimen material for me: Clarence Adams, O. Boyd, Ralph Brown, Noble Christianson, Ernest Clouser, F. C. Corneliussen, Harley Doolittle, Merlin Doolittle, Wesley Doolittle, Edwin Egenes, Herbert Egenes, John Egenes, Theodore Hermanson, Torkell Hill, Walter Hill, Leslie Hoffman, Willard Johnson, Simon Kemmerer, J. M. Kerr, Curnie Larson, Arthur Matheason, George Matheason, Guy Mathews, Andrew Mathison, Irvin Mathison, Victor Mathison, Frank 


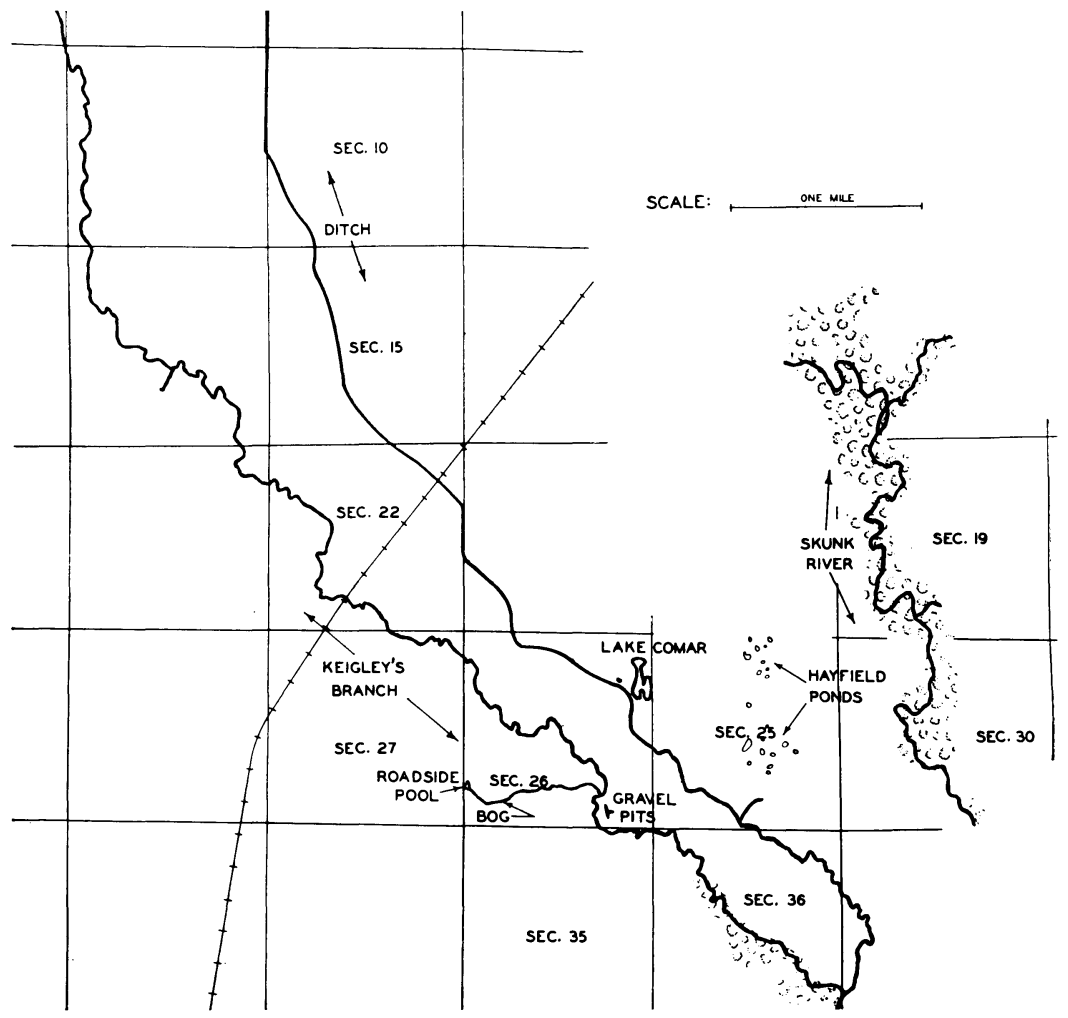

Fig. 10.1. Map of Keigley's Branch drainage and neighboring Skunk River, mostly south of Story City, lowa.

Mattingly, Forrest Millikin, Homer Olson, George Roberts, LaVerne Russell, J. B. Stahlman, Earl Sturtz, Edward Sturtz, James Thorson, Richard Turner, Robert Turner, and Ole Wald. Iowa State Conservation officers Warren Wilson and Eugene Hlavka collected specimen material at times when such was particularly needed.

While marshes may have either high or low water levels at rather unexpected times, with occasional pronounced differences even in the same neighborhood, the status of central Iowa stream habitats for muskrats often reflects more immediate weather conditions.

The weather data summarized in Appendix E pertain to Ames and vicinity. The averages and extremes presented in Table 5 (also in Appendix E) were largely furnished by Robert Elford, State Climatologist, Des Moines, and comprise an 82-year background against which the weather vicissitudes for the study years may well be considered. The detailed Iowa State University and U.S. Weather Bureau data 


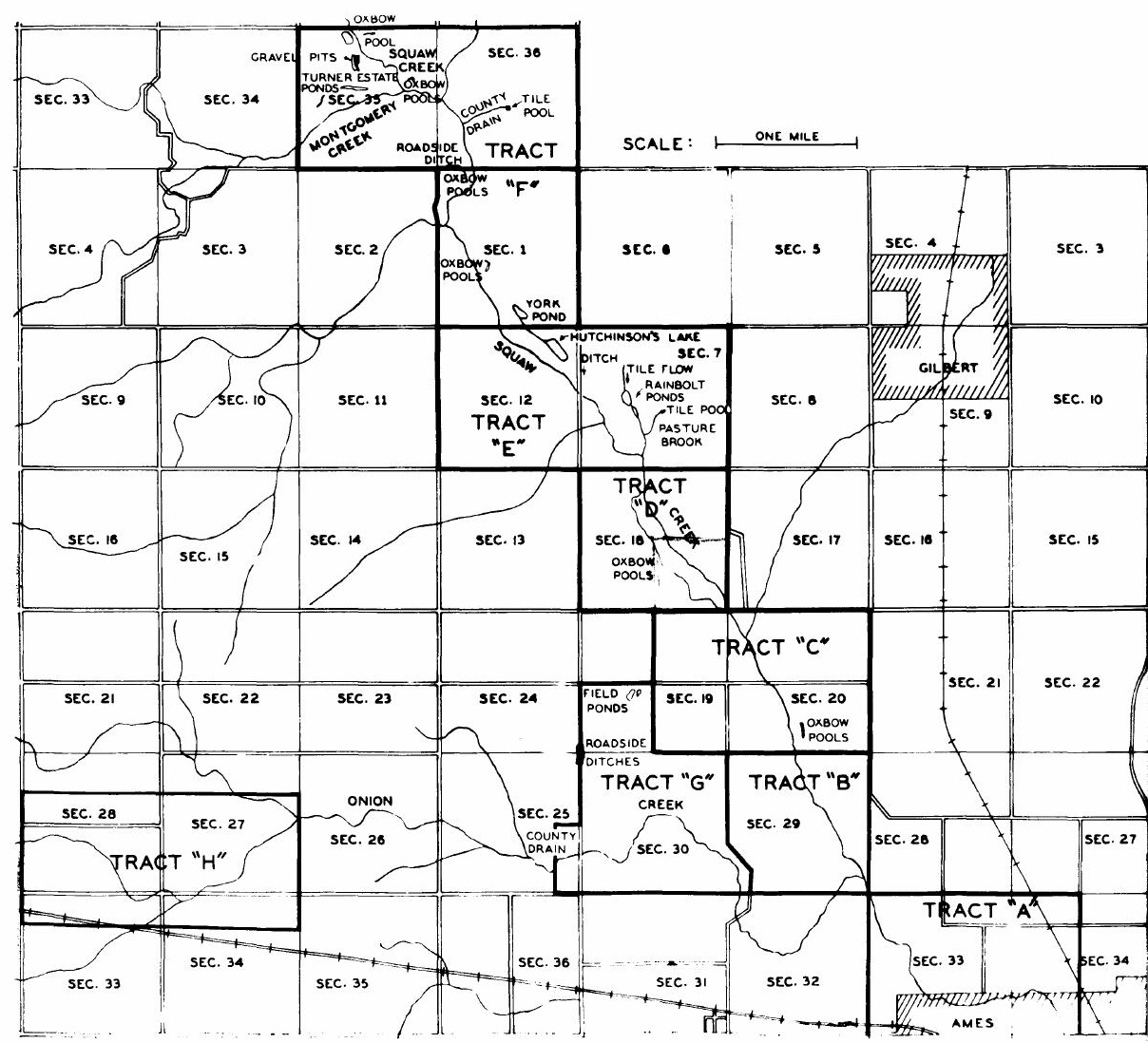

Fig. 10.2. Map of Squaw Creek drainage, including Onion Creek, west and northwe of Ames, lowa.

were obtained through the cooperation of Doctors Gerald L. Barger and Robert H. Shaw.

The area case histories follow.

\section{SKUNK RIVER (STORY CITY BLOCK)}

The mile-and-a-half stretch of Skunk River southeast of Story City was put under observation in 1939, rather late in our study program. It then had 9 muskrat territories or about 20 adults in early summer, including one territory in an oxbow less than 100 yards west of the main stream. By early October, the surface water was reduced to pools, some isolated, some in connected strings. The total fall population was estimated, pool by pool, at about 65 . Low water notwithstanding, the muskrats wintered under the ice in good numbers, especially along and near a dredge cut bordered by a much-raided corn field.

Fifteen territories in 1940 (including one in the same oxbow 
occupied the preceding year) probably meant around 35 adult muskrats during the early breeding season. Dry weather in midsummer and fall lowered the stream level but never stopped the flow, and excellent pools always remained. A sample of 240 carcasses of muskrats trapped during the 1940-41 fur season from upstream and downstream, as well as from within the observational stretch of Skunk River, consisted of 14 adult males, 18 adult females, 109 young males, and 99 young females. Application of these ratios to a base of 15 adult females for the observational stretch would give a grand total of about 200. I would say that more than half of these animals were massed along about 250 yards of stream bordering a corn field.

Placental scars in the uteri of the 18 adult females of the trapped sample averaged 15.3 per female for the breeding season of 1940, mostly reflecting early-season breeding and a little more than 2 litters of young per female. No "kits" were listed in the post-mortem notes on the 208 young of the year, and only one of the breeding females had a set of placental scars suggesting a late - probably late July litter.

Working conditions on the observational stretch were unfavorable early in the summer of 1941, and no wholly satisfactory data on breeding densities were obtained. The figure arrived at was of 11 territories, representing about 23 adults. Water levels for May were rather low, but the heavy rains of June and part of July kept up the flow until fall. Of 82 trapped carcasses examined for the fur season of 194142, 6 were adult males; 5, adult females; 38, young males; 31, young females; and 2, young of undetermined sex. Based on the above figures, the pre-trapping fall population figured out at about 165 .

One of the specimens of adult females had conceived two litters in 1941; 2, three litters each; and 2, four litters each. Only one of the 16 sets of 1941 placental scars was of a fairly late litter, assigned to late July.

The muskrats surviving the trapping appeared to winter well, and, on March 12, 1942, signs were generally heavy in favorable places. There were 9 territories, representing about 20 adults, being maintained by early summer. The sample of trapped carcasses from the Skunk River, itself, was not sufficiently large to afford valid sex and age ratios for the 1942-43 trapping season. If we apply the ratios from 52 carcasses taken in the vicinity of Story City -4 adult males, 4 adult females, 24 young males, and 20 young females - we would get a fall population figuring out at about 115 for the mile-and-a-half stretch of Skunk River.

The 1943 breeding-season check showed 14 territories (including 2 in oxbows), or around 30 adults. Except in the vicinity of the dredge cut having adjacent corn fields, the 1943 territories were almost restricted to heavy stands of scrub willows, yet the evidence was beginning to suggest that more was behind the patchy distribution of the muskrats than inequalities in food resources. In a spring of generally saturated breeding densities over the central Iowa country- 
side, with seven territories crowded into the middle third of the observational stretch, the south third had a single territory. As for the preceding trapping season, the sample of trapped carcasses obtained from Skunk River, 1943-44, was insufficient to afford suitable sex and age ratios; and the ratios from specimens from the entire Story City block had to be used for a basis for calculations. Of 202 carcasses, 12 were of adult males; 19, adult females; 102, young males; 66 , young females; and 3, young of undetermined sex. If we assume negligible spring to fall losses of adult females and apply the Story City ratios to the 14 Skunk River territories, we would get a 1943 fall population of about 140 for the observational stretch.

Eight territories, or about 20 adult muskrats, were recorded for the 1944 breeding season, including 3 territories in the suspicionarousing lower third of the observational stretch. Of 71 carcasses of muskrats trapped along the mile and a half of stream during the 1944-45 fur season, 3 were adult males; 5, adult females; 42, young males; and 21, young females. Assuming no spring to fall loss of adult females, we would, applying the above ratios to eight territories, arrive at a total of about 115 as the fall population. However, there were some unusual variables in the local population equation.

Summer floods had been highly destructive to young muskrats born in the first half of the 1944 breeding season, but the effects of this on muskrat production had been partly offset by prolonged, late breeding. Each of the five adult females had conceived three litters, and, of the 15 litters, seven were assigned to July and August. No exact figures are at hand concerning the incidence of "kits" in the 63 specimens of young animals handled during the trapping season, but the last lot of 12 examined consisted entirely of young judged to have been born in July or later, and probably a good half of the 63 specimens actually belonged in this category.

The hemorrhagic disease was known to have wiped out most of a concentration of muskrats along a long-raided corn field. At this place, the equivalents of 3 pairs and their season's young, probably together with some animals from downstream, or a total of about 60 , had been living along a stretch of less than 200 yards; yet the trapper caught only 7 there and found 1 dead on land, which he saved for examination. The dead one proved to be a typical victim of hemorrhagic disease. Earlier, the same trapper had found a freshly dead one downstream, opened the body cavity, noted the spotted liver, and buried the animal. Two of the last 12 animals caught (examined on November 25) were diseased. Not many muskrats survived on the observational stretch even to enter the winter of 1944-45, and, considering the hemorrhagic infection in the corn field burrow systems, still fewer may be judged to have wintered.

The spring, 1945, breeding census gave six territories or a total of about 15 adults. Considerable upstream and downstream adjustment was noted in late summer and early fall. Observant trappers reported conspicuous mortality upstream; this was attributed to disease, and, 
in one case, several dead muskrats were lodged together in stream debris in early November. Whatever happened, there were unusually few muskrats living along the mile-and-a-half stretch by the opening of the 1945-46 trapping season. The 24 muskrats caught by a trapper surely represented almost the whole population: 2 adult males, 4 adult females, 13 young males, and 5 young females. Of the 4 adult females, one had conceived 12 young in two early litters in 1945; two, 17 young each in three early to midsummer litters; and the fourth, numerous young (the placental scars were uncountable because of decay of the specimen) in probably four litters, including a litter assigned to August. Two of the 18 young in the trapped sample were of "kit" sizes.

The spring, 1946, breeding census gave eight territories, or about 18 adults. The 1946 territories were rather uniformly distributed, which meant more muskrats in the usually more sparsely populated central and south parts and fewer at the north end. By early September, there was evidence of much readjustment. For the muskrats, some dry weather in late summer resulted in only a harmless lowering of water levels. Still, the animals displayed conspicuous restlessness and, for no patent reasons, engaged in a tremendous amount of not only upstream and downstream but also cross-country movement involving both sexes and all mobile ages. Trapped carcasses examined for the 1946-47 fur season totaled 39 (4 adult males, 1 adult female, 11 young males, 18 young females, and five young of undetermined sex), and about 14 other muskrats were known to have been trapped but not obtained for examination. The pre-trapping fall population probably had been about 65 .

A careful breeding census gave only four territories, or about nine adults, for 1947. Three territories were fairly close together in the most attractive part of the north end, and the other was far downstream. Floods in June were probably very destructive of early-born young. In mid-July, I doubted that there were more than 6 or 8 young muskrats along the observational stretch other than at the north end. At the north end, there may have been the equivalent of about three full litters, including one late-born litter. This would add up to perhaps 35 animals in all.

Then came weeks of rainless, hot weather. By late August, considerable readjustment of the Skunk River muskrats was in progress, without any important cross-country movements. By late September, the stream flow had ceased, except for seepage between pools. After more readjustments in the fall, probably about three-fourths of the muskrats were restricted to a series of residual pools. Because of the legal closing of the 1947-48 trapping season on muskrats, no carcasses were obtained for examination. A final, generous estimate would be of about 30 muskrats remaining at freeze-up, or possibly nearer 25 .

The observational stretch had eight territories in late spring, 1948. Five of the eight territories were concentrated in the north third of the stretch; one was near the middle; and the other two were well 
down toward the south end but over a quarter of a mile apart. The old dredge-cut was widened during the summer, and the old river channel was partly filled in with dirt; the muskrats nevertheless adjusted well to these drastic changes, and, by mid-September, signs were heavy in the neighborhood of three original territorial sites. At this time, drought had almost stopped the flow over the stream bed at the north end. Farther south, the flow had stopped, but several favorable pools still had many muskrat signs. Most of these signs were localized about the breeding territories, but certain other places were also occupied - some having by far the most muskrats in many years. I estimated, from comparisons with signs of other years, that there were well over 150 muskrats living along the mile and a half of stream in September. Two months later, possibly about a sixth remained.

Almost-critical if not critical drought - from the muskrats' position-continued past the middle of November in 1948. I do not know of anyone taking muskrats from the observational area during the December trapping. Wintering muskrats came out of some of the frozen-over pools to forage on bank vegetation or to raid convenient corn fields. There was also evidence of winter-wandering up and down the partly dry stream bed.

An early May, 1949, breeding census gave twelve territories, of which six were concentrated in the upper third of the stretch and the other six were rather uniformly distributed throughout the mile below. The flow of water over the stream bed was slight by mid-September, with pools being well-defined. Pool-by-pool population estimates totaled about 135, of which about 85 frequented the upper three-quarters of a mile. The muskrats were much more scattered through the lower three-quarters. Trapping conditions were favorable along Skunk River during a short open season in December, and 95 of the 130 trapped carcasses examined from the vicinity of Story City were from Skunk River, though not all from the observational area. The 95 from Skunk River consisted of 7 adult males, 4 adult females, 44 young males, and 40 young females, but the entire 130-carcass sample from the Story City block was probably the more representative: 10 adult males, 9 adult females, 57 young males, and 54 young females. Allowing for a spring-to-fall loss of the equivalent of 3 pairs suggested by late-summer data, the pre-trapping fall population of the Skunk River area should have been virtually the equivalent of the Story City trapped sample, or about 130 .

Of the 9 adult females in the Story City sample, one had conceived a single early litter in 1949; 3, two litters each; 2, three litters each; and 3 , four litters each. Three of the total of 25 litters were assigned to August, which is in close agreement with the 12 "kits" recorded among the 111 young of the year.

There was evidence of substantial local adjustments upstream and downstream in September, and it is certain that the late fall occupants of the observational stretch were not exclusively animals breeding and reared in the area. Apart from these adjustments, the 
scarcity or lack of animals about some very attractive pools at the south end of the Skunk River stretch suggested effects of the hemorrhagic disease. My failure to find any dead during three visits made during the period of decline may be partly explainable in terms of the large number of raccoons and foxes that hunted and scavenged about the drying stream bed. In December, one of the trappers did bring me a typical hemorrhagic victim from upstream.

Because of greater fluctuations in water levels, the Skunk River area was the most difficult to study in the Story City block in 1950. As of early July, it had 10 recognized breeding territories, of which three were situated close together (along about 250 yards near the middle), and the other 7 were well separated from each other. The lower threequarters of a mile had only two territories, still maintained by midAugust, but with few muskrats. The 1950 breeding season appeared to have been productive in the upper three-quarters of a mile, and the respective family groups stayed at their territorial sites. Weather conditions during the 1950-51 trapping season were sufficiently unfavorable to prevent any effective harvest of muskrats in the observational area, and probably upwards of 100 muskrats wintered there.

But, in 1951, the observational area had, early in the breeding season, a population of only about ten adults. Three territories (including one in a shallow oxbow that was abandoned in the course of late-summer adjustments) were in the upper half mile, but the lower mile was almost muskrat-vacant by late July. Then, very peculiarly, five territories were established in the lower mile, of which four were showing tracks of six-to-eight-weeks young by September 6. There were also signs of some drifting of muskrats into the mile-and-a-half stretch from downstream. Adjustments continued into the fall, with two of the original territorial sites in the upper half mile remaining well-used. Ten fall-trapped specimens from the above two territorial sites were two adult males, two adult females, four young males, and two young females. The two adult females had their young early the last of three litters of one female was assigned to mid-June and the last of four litters of the other was assigned to July - which agreed with the track sign. No really accurate basis exists for determining the late fall population, but my estimate would be a little over thirty for the entire stretch.

Nine territories were present in 1952, including one in an oxbow. Six of the territories were close together in the upper third of the observational stretch, and the equivalents of 4 of these were remaining functional by late fall, when they had a population figuring out at about 60 animals. An estimated 15 more remained in the lower part, which would bring the total population up to about 75 . Nine carcasses of muskrats trapped in the lower part were examined in late fall, 1952, and 3 of these showed lesions of the hemorrhagic disease, thus suggesting clearly the agency of the partial depopulation earlier observed.

Four territories were maintained in the late spring of 1953, of 
which three were localized along about 500 yards of the food-rich upper end of the observational area. The lower half mile was devoid of muskrat signs of any recent age: a circumstance believed due to disease. By late September, about 85 muskrats were estimated to be present on the whole Skunk River area, including about 50 at the sites of the massed territories of the breeding season. Skunk River, having more water than the smaller streams, drew considerable numbers of muskrats during the drought-accelerated adjustments of late summer and fall, but so much of Skunk River was food-poor, and the better places were so full of intolerant residents, that it offered no really good attractions to home-seeking newcomers. Downstream, the half mile that seemed dominated by the hemorrhagic disease had almost no sign of living muskrats even at times of the most general movements.

May and June floods and high water at other times forced postponement of the 1954 breeding census until early July, when 5 territories were recorded, all in the northern third of the observational stretch. These were still the places having the muskrats by late September. The midfall population was estimated at about 60 ; by late fall, at about 85 , after an upstream movement had been in progress for a few weeks.

In the spring of 1955, the area had seven territories, including one with a solitary animal. This was the only muskrat known to be living along the lower half mile, which had been showing evidence of becoming essentially uninhabitable for muskrats because of the hemorrhagic disease. Four of the productive territories were in the channel of the upper third of the area, and nearby were two territories in oxbow pools. The oxbow territories were abandoned in July as their water went down, but the flow continued in the channel of Skunk River until mid-August, and the deeper pools retained sufficient water for muskrats until freeze-up. The attractive food resources were sufficiently localized, however, so that the places still holding muskrats by late September were chiefly those having well-worn trails from pools to corn fields.

Contemporaneously with drought-eviction of muskrats from central Iowa stream habitats, substantial numbers appeared on the observational stretch of Skunk River in the fall of 1955. The population figure arrived at before freeze-up was about 125 , and the greatest concentration was in a place having no better food resources than thickets of scrub willows. With the onset of freezing weather, the status of the massed newcomers became precarious; they did much foraging in miscellaneous dry and woody vegetation on shore and preyed upon drought-handicapped fishes. Six of eleven mink scats for late October and early November contained muskrat remains (all, I think, of separate muskrats), and evidence of a seventh victim was seen. There was 
also evidence of some outside activity, if not wandering, after freezeup. Probably few muskrats survived the winter on the observational stretch except in a beaver dam pond next to a corn field.

The 66 specimens of central Iowa muskrats examined in the fall of 1955 are probably as representative of the Skunk River stretch as of any one area: 9 adult males, 12 adult females, 31 young males, and 14 young females. The adult females had conceived a mean of 3.25 litters. A mean of 3.75 young per adult female in the sample, compared with a mean of 22.8 young conceived, would seem to reflect the severity of the drought as much as any known factor. Only one (2.2 per cent) of the young in the sample was judged to have been born in August or later, whereas six (15.4 per cent) of 39 litters represented by placental scars were assigned to this late in the breeding season.

Only four maintained territories (including one occupied by a lone animal) were present on the mile-and-a-half observational stretch, as of late May, 1956. Movements of unsettled animals were still in progress at that time, and one probable transient was known to have been preyed upon by a red-tailed hawk.

By the first of July, a territory next to an old and dangerous disease focus had been lost, and the remaining three territories were restricted to beaver pools. All three were productive of young and were well maintained throughout the summer. By late September, the muskrat population of the observational area was still all but confined to the three territorial sites; by late October, the signs indicated a remaining muskrat population estimated at no more than about 20.

Unfavorable working conditions on Skunk River prevented an accurate determination of breeding territories in the spring and early summer of 1957, but there certainly were few in the observational area. However, in midsummer and early fall this area proved to be virtually the only one of the regularly observed central Iowa stream areas that had muskrats, and most of these were congregated both upstream and downstream from a newly constructed beaver dam. Here, there were possibly 100 muskrats at one time along less than a mile of stream, with the lower half mile of the long-observed stretch still almost muskrat-vacant. By early October, the muskrats were no longer congregated about the new beaver dam, and, at freeze-up, possibly 20 muskrats remained in the area, to winter without any detected trouble.

\section{KEIGLE'S BRANCH}

The Section 26 stretch of Keigley's Branch shown in Figure 10.1 was the only one on which observations were made in 1934, and the downstream stretches of sections 35 and 36 were not put under regular observation until 1939. Meanwhile, more or less attention was paid to the northeast corner of Section 27 and the middle of Section 22 
between 1935 and 1939 , but no especially significant data were obtained; the muskrats of these stretches merely responded to drought exposure and availability of choice foods in typical ways.

Section 26 had five probable territories or about 12 adult muskrats in the spring of 1934; and, on an inspection trip of October 11, I estimated, pool by pool, a population close to 35 . The 1935 census gave 5 territories or about 12 adults for spring and about 55 muskrats as a midfall estimate. Four territories were accounted for in 1936; by mid-September, the signs of partly grown young could still be seen, despite drought conditions, and a late fall population was estimated at between 15 and 20 . Some outside activity of muskrats was noted during the winter of 1936-37, but the signs to be seen early in March suggested that nearly as many may have survived as entered the winter - and despite the possibility of undetected mortality from mink predation under the ice.

On May 11, 1937, three territories were localized along about a quarter mile of stream in lower Section 26, but signs of unsettled animals were abundant over the rest of the stream in this section. Except for the occupants of a fourth territory established later, the animals of the upstream part ultimately departed. By mid-September, the stream had stopped flowing, and much evidence of adjustment was seen. One territorial site had been completely abandoned by then, and a new muskrat headquarters appeared a half mile upstream, where an inviting pool in food-rich surroundings persisted. The first half of October was a period of much traveling along the stream bed, but this represented activities of obvious residents, busy carrying food and repairing nearly dry burrows. By mid-October, the water levels were improving, and the stream was soon filled up to about its usual midsummer level. My pool-by-pool estimate of the late fall population was about 17.

The muskrats entering the winter of 1937-38 seemed to survive until spring, but, with the softening and break-up of the ice in late February and early March, they may have been unusually vulnerable to predation as they foraged along the banks. A mink scat deposited about the first of March consisted of muskrat remains, what I now interpret as remains of a second mink victim dated back to late February, and a horned owl pellet datable to about the first week of March consisted of the forequarters of a third muskrat. All of this mortality occurred somewhat prior to the recognized spring dispersal.

In the spring of 1938, five territories were established in Section 26 , three near the west boundary of the section and two near the south, thus leaving nearly a half mile of stream unoccupied by muskrats. By fall, after a summer of favorable weather conditions, it could be seen that a substantial muskrat population was present, including a few that had moved into a wet gravel pit in the southeast corner of the section. By November 1, the muskrats had abandoned the gravel pit, and additional reorientation had occurred. One of six mink scats deposited in early November contained muskrat remains. Thirty-five 
carcasses of muskrats taken by trappers during the fur season in November were 2 adult males, 3 adult females, 17 young males, and 13 young females. These ratios applied to five territory-maintaining females of late spring would give a total fall population of about 60 . The population of perhaps 20 surviving the trapping seemed to be mostly comfortable and secure, and only one was noted to be coming out on the ice or snow during the winter of 1938-39.

Section 26 had six territories in 1939. The dry weather of late summer did not bring about any known crisis for the muskrats before September, but, by then, evidences of a pronounced adjustment were to be seen. Except for one place in the east half of the section, nearly all of the muskrats of the observational stretch were massed within a quarter mile of the west edge in the deeper pools there available to them. Within the first two weeks of September, the creek dried up until only residual pools contained surface water, and much movement of muskrats between pools occurred. Flattened bodies of two subadults were seen, September 18, on a paved highway to the west. By early October, the remaining population was all but confined to the vicinity of a single pool. Mink-eaten remains of possibly two muskrats lay on the creek bottom in a trail between two pools.

Beginning on October 7, 1939, flowing water gradually covered the creek bed. This partial relief from the drought promoted extensive readjustments, muskrats appearing in parts of the east half of the section that earlier had been devoid of the species. By about the first of November, the population had stabilized, most of the muskrats then being localized in five places - of which four were sites of 1939 breeding territories. The pool in which the muskrats concentrated at the height of the drought was one of two places showing the most signs at freeze-up. My pool-by-pool estimate was about twenty. One of four mink scats deposited in late October and November contained muskrat remains. In late December, muskrats were gnawing through the ice of two pools to forage outside. One winter-active individual improvised a system of snowdrift tunnels and chambers on top of the bank, and its mummified body, partly eaten by a mink, was found when the drift melted in the spring.

It was also during 1939 that regular observations were begun on another stretch of Keigley's Branch, this stretch being downstream from long-observed Section 26 and running through the northeast corner of Section 35 and most of Section 36. Of two 1939 territorial sites in the newly observed stretch, one was still occupied by late October, and the estimated four or five muskrats seemed passably well situated for wintering.

Section 26 had five territories in 1940, and Section 36 had another. Of 53 carcasses of muskrats trapped during the 1940-41 fur season, 4 were of adult males; 4, adult females; 18, young males; and 27, young females. These ratios applied to the six territories of the breeding season would give a fall total of about 80 muskrats for the two miles of creek. The four adult females in the trapped sample had a 
mean of 14.8 placental scars for 1940, representing about two earlyseason litters each. These early-born young had been quite self-sufficient at the time of floods coming in late July and August. The twomile stretch was in flood again in mid-February, 1941, but this is not thought to have seriously endangered the muskrats surviving the trapping, for signs were plentiful in early March in expected places.

Section 26 had five territories in 1941, and Section 36 had two. All territories were clearly established with reference either to especially attractive food resources or to old sets of burrows. The summer brought great variation in stream flow, droughts and floods alternating. One territory was situated right in the midst of a horned owl territory, but no muskrat remains were found in 71 of the owl pellets deposited mostly during a period of considerable land activity of the resident muskrats. By late August, the stream in Section 26 showed well-distributed, locally heavy signs (in the horned owl territory as well as elsewhere), though only the central stretch in Section 36 continued to be well-used by the muskrats. Little further change was noted until the stream was again in full flood, on October 7 and November 1. Trapping conditions were difficult during the 1941-42 fur season, and only 20 carcasses were examined: an adult male, an adult female (with 19 placental scars for 1941), 9 young males, 7 young females, and 2 young of undetermined sex.

The 1941-42 Keigley's Branch specimens comprised such a poor sample that it should be preferable to combine the data from these with the data from specimens taken from elsewhere in the neighborhood. The combined sample totaled 46 specimens: 2 adult males, 4 adult females, and 40 young of the year. These sex and age ratios applied to a base of 7 breeding territories would give a pre-trapping fall population of about 60 for Section 26 and about 25 for Section 36 . These would seem plausible figures, for it was very apparent by late January, 1942, that unusual numbers of muskrats were wintering in Section 26. Conspicuous signs could be seen under ice shelves, in places where the stream was ice-free, and about upper parts of burrows. No muskrat remains were found in 10 early-winter pellets of a horned owl that roosted near one of the burrows showing the most activity.

Despite exceptionally heavy wintering densities, the Keigley's Branch muskrats seemed disinclined to begin large-scale cross-country movements in the spring of 1942. As late as March 24, the heaviest sign was still to be seen along stretches known to have wintered muskrats. Members of closely observed populations took their own time about leaving familiar quarters, engaged in much preliminary commuting, and behaved as if easily satisfied when establishing living quarters in new places. The spring dispersal took place without the stimulus of floods and was manifested chiefly by increasing local activity.

Section 26 had five breeding territories in 1942, all well situated with respect to food. In Section 36, none of 3 territories had especially 
attractive food resources. Only 18 trapped carcasses were examined from observed stretches of Keigley's Branch during the fur season of 1942-43: 2 adult males, 3 adult females, 8 young males, and 5 young females. In view of the smallness of this sample, it should be preferable to consider the entire series of 52 carcasses examined from the vicinity of Story City: 4 adult males, 4 adult females, 24 young males, and 20 young females, and, of the 44 young, 11 were "kits." One lot of 13 muskrat specimens included 7 "kits," some of which looked as if they had been born in September. Of the 4 adult females, one had conceived 3 litters, including a late litter; and 2 females had conceived 4 litters each, including 3 late litters. The Story City sex and age ratios applied to the 8 territory-holding females gives a late-fall population of about 65 for Section 26 and about 40 for sections 35 and 36 .

Repeated floodings during June and July, 1942, drowned a large proportion of the season's young. Biologically, the losses of so many helpless young were in part offset by prolonged late breeding and high survival rates of the late-born young. Tracks of very late litters could be seen almost anywhere along the two-mile stretch in the fall. Some trappers quit trapping for the stated reason that, even in midDecember, they were catching "nothing but young ones," i.e., the lowvalue "kits." The floods also changed the configuration of the observational stretch by cutting off oxbows, filling in old pools and gouging out new ones, washing away fallen trees and drift debris of former years. At the height of floods, the adult muskrats responded by improvising nests under hanging banks and extending burrows upward under the sod. Undoubtedly some movement took place in and out of the two-mile stretch, though there seemed to have been little movement on the part of territory-holding adults.

Field observations late in the winter of 1942-43 indicated that an abundance of muskrats remained alive along the stream in both sections 26 and 36. In the spring of 1943, the Keigley's Branch channel in Section 26 had eight territories, plus another in an adjacent gravelpit pool; Section 35 had one territory; and Section 36, although relatively unfavorable habitat, had seven territories. These seventeen territories along a two-mile stretch were remarkably evenly spaced, presumably as one result of a near-saturation density of muskrats. Extremely little evidence of late summer and early fall movement was detected.

Of 62 carcasses of muskrats taken during the 1943-44 fur season, 4 were adult males; 7 , adult females; 36 , young males; 12 , young females; and 3, young of undetermined sex. The ratios from the trapped sample applied to the number of territory-holding females (assuming no losses or departure of adult females between spring and fall) gives a pre-trapping population of about 80 for Section 26 and about 70 more for sections 35 and 36.

The 1943 season's breeding showed considerable irregularity. Two of the 7 adult females had conceived early litters only, another had conceived only late litters (assigned to July and August), and another 
had conceived two small litters (averaging five young each) having birth dates assigned to June and July. The over-all record for the breeding season for the 7 adult females: one had conceived a single (early) litter; 3, two litters each; and 3, three litters each. The rather low mean of 7.3 young reared of 18.6 young conceived per breeding female may have reflected crowding as much as anything, with several agencies of mortality operating to reduce the population surplus. Only one of the 51 young of the year examined was a "kit." A single mink scat found on November 21 consisted of muskrat remains. The creek had numerous minks, foxes, dogs, and horned owls hunting it, but strong local populations of predators were not peculiar to this high-density year of muskrats.

Many muskrats escaped the trapping, 1943-44, to winter - so many that external signs suggesting food shortages could often be seen as the winter progressed; and, with the spring dispersal of 1944, the population was sharply reduced. Only six territories were maintained in 1944 in Section 26 and one in Section 36.

The 41 muskrats taken during the 1944-45 fur season from the two-mile observational stretch of stream represented nearly the entire population: 6 adult males, 7 adult females, 15 young males, and 13 young females. Of the adult females, 4 had conceived two early litters each; one, two midseason litters; 2, four litters each, including late July or August young for both females.

As in 1942, floods were very destructive of young muskrats in 1944, though resident adults sat out the high waters and remained in their home ranges without apparent difficulty. The ratio of only four young per adult female in the fall-trapped population for a mean of 17.7 young conceived suggested heavy losses after, as well as during, the period of flooding. The evidence was that the hemorrhagic disease may have been a principal agency of loss, especially about the time when the trapping was coming to a close. One of the very last animals to be taken showed disease lesions, as did two of the last taken from an outlying muskrat habitat connected with Keigley's Branch.

Despite the combination of unknown disease losses and practically annihilative trapping of the previous fall and winter, the twomile stretch of stream had six breeding territories in the spring of 1945. A total of 112 fall-trapped muskrat carcasses was examined from Keigley's Branch for 1945 (9 adult males, 7 adult females, 48 young males, and 47 young females), but most of these muskrats were trapped outside the two-mile observational stretch. The 38 animals (3 adult males, one adult female, and 34 young of the year) trapped from sections 26 and 36 probably represented a good two-thirds of the population present at the time, for only in one place did many muskrats escape the trapping. The fall population of sections 26 and 36 would seem to have been about 65, with perhaps 60 of these in Section 26.

Disease and summer and fall movements surely affected the muskrat populations of sections 26 and 36 in 1945. Something of the magnitude of the movements is indicated by the finding of three 
traffic victims in a seven-week period of August and September within a mile of the stream; and a substantial cross-country movement continued into October. This movement is not to be explained in terms of unsuitable habitat for the muskrats, and it took place several weeks in advance of the time when muskrats were known to have started dying from the hemorrhagic disease. Diseased specimens included one of 35 muskrats caught in Section 26, two of 50 caught downstream from Section 36, and one found dead upstream from Section 26.

In reviewing the population changes of the muskrats of Keigley's Branch in 1945, I would judge that a relatively small proportion of the late summer and fall movements away from sites of breeding territories or original home ranges took place as gradual upstream or downstream adjustments. There seemed to be almost a tendency for resident animals either to stay or to break completely away from the familiar surroundings to wander - though such a statement might be an oversimplification.

The adult females caught by trappers were probably true residents of the places in which they were trapped. The specimen of an adult female from Section 26 had conceived 29 young in 4 litters in 1945, of which the latest litter was assigned to August. Of 2 adult females trapped upstream, one had conceived a single midsummer litter of 5 young, and the other had conceived 18 young in 3 early to midsummer litters. Of 4 adult females from downstream, 2 had conceived 2 early litters each, totaling 16 and 17 young; one, 15 young in 2 midsummer litters; and one, 23 young in 3 early-summer to midsummer litters.

A mid-April, 1946, breeding census gave six territories in Section 26, another territory in Section 35, and two more in Section 36. In sections 35 and 36 , the territories were widely separated. Those of Section 26 were distributed as two rather closely adjacent territories in the south part and as four territories almost crowded into the west part, with nearly a half mile of unoccupied stream between the two groups of territories. By August, there was evidence of only two functional territories and perhaps a half-dozen muskrats elsewhere in Section 26; the Section 35 territory had a few muskrats remaining; and only one territorial site in Section 36 had many muskrats. The total midsummer population of all ages occupying the two-mile stretch was estimated at about sixty, with about thirty-five being in Section 26.

In September, a great influx of animals, apparently coming from downstream, filled the choicer Section 26 stretch about up to capacity. My estimate for an early October muskrat population was about 75 for Section 26 and about 40 for sections 35 and 36 combined. A trapper's catch of 101, examined from Keigley's Branch during the 1946-47 fur season, was not taken exclusively from the observational stretch but was considered about the equivalent of the population resident there, as of early November.

Sex and age ratios for the above sample were 7 adult males, 5 adult females, 47 young males, and 42 young females. There were no young 
of "kit" size among the 89 young of the year. Of the 4 adult females that were in fit condition for examination, one had conceived 2 early litters; one, 2 midsummer litters; one, 3 early to midsummer litters; and one, 4 litters.

Three of the 101 trapped carcasses had gross lesions of the hemorrhagic disease. One of the animals - an adult female - seemed about ready to die when trapped. I would say that an epizootic was about to get started at the time that the trapping reduced the local population.

As of early May, 1947, Keigley's Branch in Section 26 had seven territories, fairly evenly spaced; Section 35 , one territory; and Section 36 , four territories, of which all were evenly spaced throughout the upper half of the section at the same time that the lower half was muskrat-vacant. Rechecks of breeding territories in late July showed that Section 26 had one less territory than in early May and that the six functional territories were divided into groups of three each by a long stretch of unoccupied stream. The three territories lying farthest upstream had retained their May sites, but two in the mid-stretch of Section 26 had disappeared, and the downstream part ultimately had three instead of an originally well-separated two. Downstream, in sections 35 and 36 , only three territories persisted by late July.

June floods, which left windrows of drift a good foot above the banks in the flatter parts of the valley, effectually eliminated the muskrat litters of helpless sizes born over a period of six to seven weeks in the middle of the 1947 breeding season. There is no reason to suspect, however, from careful consideration of the local situations, that the May-to-July territorial changes were related to the floods. The territories that were abandoned were no more hazardous for the floodedout adults than the majority of territories that were tenaciously retained, and the lost territories included one of the most favorably situated with respect to flood refuges.

Track signs during the hot, dry weather of late July, 1947, indicated the active presence only of adults and of the larger sizes of young that had been born in mid-May or earlier. Later, the tracks of weaned July-born young appeared, and these, in the absence of tracks of intermediate sizes, contrasted with the tracks of the very large young. Heat and drought continued into the fall, but the ground had been so saturated early in the summer that a trickling flow persisted for weeks over the stream bed. The flow ceased only for a couple of weeks from the middle of September to the end of the month, though nothing approximating a fair water level was restored until November. But the floods of 1947 gave individual pools in the bed much more filling in than scouring out and left them less attractive and habitable for muskrats during the drought of 1947 than they had been during the actually more acute droughts of 1934, 1936, 1937, and 1939. Nevertheless, it was noted in early September, 1947, and thereafter up to the restoration of normal water levels in late fall, that muskrats were not engaging in the general cross-country movements that had been so 
conspicuous the previous fall. Such movements outside of established territories or home ranges as did occur and could be traced in late summer and fall, 1947, consisted typically of minor adjustments upstream or downstream along the exposed creek bed between pools; they were followed by orderly establishment of new living quarters at variable but almost always rather short distances (i.e., within radii of a few hundred yards) from old quarters.

As of October 9, 1947, muskrat signs along the two-mile observational stretch of Keigley's Branch were fair to excellent in or about all sites of territories that had been functional from midsummer on. About the last of September, numerous muskrats moved into one of the gravel-pit pools near the stream, but these animals clearly had their origin in one of the stream territories. The best late-fall estimates from signs gave something like 60 muskrats in the Section 26 stretch (including the gravel pit) and about 40 more for the corner of Section 35 and the upper half of Section 36 . With legal protection from trapping during the 1947-48 fur season, an obviously substantial population wintered, especially in the gravel pit and in the deeper pools of the stream bed that were near corn fields.

Section 26 had ten territories as of mid-May, 1948, Section 35 had one, and Section 36 had six. By September 9, the stretch of creek was dry except for pools, most of which were in the west half of Section 26. At this time, signs of only a single muskrat - that one a transient could be seen along the bed in the southeast quarter of Section 26 and in sections 35 and 36 . A gravel pit had a good sign although the water was low, and a dog had been digging out the upper parts of the muskrat burrows.

In the west half of Section 26, the muskrats were concentrated in two sets of burrows. A tremendous number of trail signs revealed the adjustments that had taken place between newly abandoned old burrows and the last two sets to be occupied. Rotten remains of a suspected disease victim lay in the pool having the most living muskrats, but no further mortality was detected here. By mid-October, the entire muskrat population of the two-mile observational stretch was concentrated in two sets of burrows near the west edge of Section 26. One of these two burrows was that of the pool having the dead muskrat of early September, but the other set had been recently excavated a short distance upstream by what was judged to have been a group of animals moving into the observational stretch from upstream. This place, with a series of pools and a corn field nearby, would have been inviting to newcomers except for the presence of the established residents. The occupants of these two sets of burrows (which were about 40 yards apart) did stay by themselves as social units, practically no current tracks crossing the mud bottom separating their respective home ranges. Both groups raided the corn field but via separate routes. These muskrats were trapped out illegally before the fur season opened on December 1, but, on the basis of signs, I estimated the pre-trapping concentration at about 40 . 
The spring dispersal of 1949 put the equivalent of five pairs of muskrats in the previously depopulated stretch of Keigley's Branch in Section 26, one pair in Section 35, and another pair in upper Section 36 . No muskrats remained past midsummer except at the sites of three territories near the west side of Section 26. By early September, the signs indicated that the muskrats in residence at the latter places had maintained relatively independent living quarters as late as the middle of August, although, at that time, all three groups had massed along about 100 yards of stream. Next, the remaining animals had all congregated in a puddle beside a big root-tangle of a fallen tree that was adjacent to a corn field; they had plugged and plastered the roottangle with mud to make a lodgelike habitation out of it and they had raided the corn field for weeks after the surface water disappeared from the puddle. My guess was that upwards of 20 muskrats were here at one time, but that no more than 10 remained when a slight flow of water returned to the stream in November. This population remnant had ear corn stored under the root-tangle and wintered satisfactorily.

In 1950, four territories were established and maintained from late April through July, within a 500-yard radius of the root-tangle, and clearly by animals that had wintered there. Downstream from these territories, a mile and a half of stream had no muskrats in early spring, but, as of the last week of April, four territories were established (or in process of establishment) in the lower mile. The upper one of the four lower territories - in Section 35 and the lower edge of Section 26 - showed considerable readjustment over a stretch of about 300 yards between April 20 and June 20; and, after weeks of vacancy in May, June, and July, the original territorial site was taken over by other animals for a new territory.

The really astounding territorial adjustments occurred in Section 36. This stretch had but three territories by late April, then enough muskrats moved upstream into the lower mile of the area to raise the total of established territories to nine, the greatest breeding-season concentration of muskrats observed in that section in the course of the Iowa investigations. "Reading of sign" indicated that essentially no upstream movement of newcomers occurred past the middle of the two-mile observational stretch until late summer. From May into August, the nine breeding territories of Section 36 were centered 80 to 225 yards apart, at mean distances of less than 150 yards. The occupants of each of the more downstream territories seemed content to crowd rather close to their upstream neighbors but without attempting to pass them and continue moving into less crowded habitats. Furthermore, the general food supply of Section 36 was inferior even for a generally food-poor type of habitat; of two corn fields planted within convenient muskrat-reach of the water, only one was raided and that by few muskrats; and the other muskrats fed upon what watersedge vegetation was growing in a partly open, partly wooded cattle pasture. But such fare seemed ample until late summer. 
By early August, eight of the nine territories of Section 36 were still functional, but some changes were occurring. A territory at the extreme lower end had by then been abandoned; its former occupants apparently moved downstream. The occupants of the three territories lying next above were massed into a 100-yard stretch, above which was a muskrat-vacant stretch of almost a quarter of a mile. The next quarter mile above that contained the members of all of the other five territories in Section 36. This behavior could not be attributed to dry weather, for Keigley's Branch still had a good flow, and all pools were almost as deep as they had been in June. At the time of the late-summer adjustments of Section 36, the muskrats of Section 26 were still living at or in the vicinities of the old territorial sites.

Most of the muskrats of Section 26 left the observational stretch in 1950 without any detected preliminary massing. This egress involved occupants of pools where the continuity of water over the stream bed was unbroken as well as where the bed was exposed except for isolated shrinking pools. It was characterized by relative suddenness, datable to late August.

By mid-September, the territorial sites of Section 36 were abandoned, with the exception of two, of which one still harbored a family group of late-born, newly-weaned young. Fresh trails of two transients could be distinguished - of a small "kit" (having an estimated age of about 70 days) heading upstream and of a probable subadult heading downstream. In Section 35, perhaps a dozen animals moved into a previously unoccupied, food-poor pool. In Section 26, the muskrat population consisted of an estimated half dozen in one pool, about two more in another, and about eight in a third.

By late fall, 1950, all of the muskrats had left the two-mile stretch except for a few that wintered precariously in a nearly waterless habitat next to a corn field, at the 1949-50 wintering site under the roottangle in the west part of Section 26. At least two muskrats got through the winter of 1950-51, despite attentions of minks working about the exposed burrow entrances.

Section 26 had nine territories in late June, 1951, while Section 36 had two. Of the nine in Section 26, four were massed along less than a quarter mile of stream, and most of the active young of the whole twomile observational stretch were localized here. Of the other seven territories of the two miles - which were far more widely spaced with reference to each other - only three had active young and obviously not nearly so many per territory as the signs indicated for the four territories massed upstream. These differences were considered a manifestation of the less efficient mating to be expected in the more isolated territories.

By the second week of August, it could be seen that six territories in Section 26 were still functional, as were two in Section 36, though two of the Section 26 territories had relatively light signs. At this time, nothing more than the most localized up-and-down-stream movements 
were taking place. By early November, after weeks of adjustments, signs could be seen of what were judged to be single animals or small groups scattered rather widely along the stream in Section 26. I estimated that no more than 20 muskrats then remained in the channel of the two-mile stretch, plus possibly a half dozen more living in a gravel pit in lower Section 26. The observational stretch was nearly depopulated by the beginning of the trapping season, November 20 , and only a very few muskrats, if any at all, successfully wintered there, $1951-52$.

Section 26 had seven territories in 1952, of which only one was located in the formerly favored sites near the west edge. In addition, a breeding pair became established in a small, wet gravel pit away from the pit that commonly had the muskrats during the preceding years. Section 35 had a territory, and Section 36 had four, all in the upper half mile. Postbreeding adjustments were very extensive, but most of the Keigley's Branch animals appeared to remain within the two-mile stretch or its vicinity. Sex and age ratios for 303 carcasses trapped from the vicinity of Story City during the 1952-53 fur season were 17 adult males, 21 adult females, 143 young males, and 122 young females. Application of these ratios to the 13 original territories of the two-mile stretch would give a fall population of about 190, a figure that is probably close to the truth.

One of the most interesting situations was studied at the small gravel-pit pool. This pool had a surface area of 27 square yards but was watered by an artesian flow and was partly covered and fairly well surrounded by cattails. About mid-July, muskrats moved in from a larger but food-poor pool lying 70 yards distant. On August 4, I watched a very tame family group consisting of two adults and a minimum of eight young of two sizes (about a month and two months old), which were living on grassy and weedy growths and had hardly started cutting the cattails. By August 28, the muskrats had cleared about two-thirds of the cattails. By September 11, it could be seen that some animals judged to have come from the gravel pits were established along neighboring Keigley's Branch to the west; the little cattail pool was almost denuded but still had many muskrats. About a month later, the whole gravel-pit territory was nearly, if not wholly, abandoned.

One of thirty-eight trapped carcasses known to have come from Keigley's Branch had lesions of the hemorrhagic disease, but more evidence of disease was found in two neighboring stream habitats than on Keigley's Branch itself.

Section 26 and Section 36 each had 6 territories in 1953. By midsummer, an estimated residuum of about 35 muskrats was massed along about 125 yards of still-wet bottom lying adjacent to a corn field near the west edge of Section 26. By mid-September, these muskrats were concentrated at the sole habitable pool near the corn field. By late October, perhaps half of the muskrats had abandoned the 
pool. Of those remaining, several muskrats survived the winter of 1953-54.

The above survivors, together with some migrants coming upstream from Skunk River, established seven territories in the two-mile stretch in the spring of 1954: three each in sections 26 and 36 and one in Section 35. The creek was flooded twice in June, with probably deadly consequences to young muskrats of helpless sizes. By mid-July, the two-mile stretch had only two functional territories (both with young), and it had only one territory left by late September. This one place that continued to be occupied was also the only one that had had muskrats by late fall of the previous year. Few if any muskrats were known to have survived the winter of 1954-55 on the Keigley's Branch observational area.

Twelve territories were established in April and early May, 1955: six well separated in Section 26, three in the corner of Section 35, and three in the upper half of Section 36. By the first of August, when the surface flow was stopping in a few places, ten of the territories showed varying degrees of productivity. By mid-August, the two-mile stretch was well on the way toward abandonment, except for a territory having a late litter. By September 2, only a single resident animal seemed to be left. The exact routes of departure could not be traced satisfactorily; one downstream trail was dated to the first week of August and another to September 2.

Signs of rather pronounced movements were to be seen by midApril, 1956. Three productive territories and two lone-animal territories were established along the two-mile observational stretch by early June. Two family groups and a lone animal remained by the end of June. The most productive group (having three litters, with births assignable to late March, late April, and late May) did considerable adjusting along less than a quarter mile of stream, from late June through August. By mid-September, this group had gone. The members of the second family group (having two litters, assignable to early April and early May) left the upper part of the area in late June, took over the abandoned territory of another upstream family group (which had in turn moved about a half mile farther upstream), and spent the latter part of the summer moving back and forth out of and into the observational area. By mid-September, only a single muskrat seemed to remain here.

One of the lone-animal territories provided an exceptional case history. Because of its isolation along a stretch of creek having had no known muskrats passing through over a period of 13 months, the local sign may with some confidence be considered that of a single individual. On September 2, 1955, a medium-sized muskrat had come down the then exposed stream bed and built a retreat under a roottangle. It had stayed until freeze-up, wintered on stored ear corn, and continued to stay on through most of the summer of 1956 . It was by then a full-grown animal having a characteristic living routine. In 
mid-August, 1956, it shifted its main living quarters to another roottangle (which was more conveniently situated in relation to raidable corn and soybeans) about 125 yards downstream, but it was still visiting the old retreat at the last of the month. It then disappeared from the observational area, after having spent a year in a very circumscribed radius of activity.

As of the middle of May, 1957, the two miles had five territories, or about eight adults; as of late summer, an apparently lone animal. Whatever may have been the reason for this decline, it could not have been due to lack of water. The two-mile stretch again had muskrats by October, perhaps about 25, on which no further data were obtained.

\section{DRAINAGE DITCH WEST OF STORY CITY}

The three-mile observational stretch had five territories in the drought year of 1936 - all localized in the northeast corner of Section 22 along a half mile of ditch bordered by corn fields and kept wet by an artesian flow. The ditch muskrats were still concentrated there in late October, at which time a careful estimate of about 60 was made. Fall rains that broke the summer's drought for the muskrats of naturally flowing streams of central Iowa did little to improve the situation for the ditch-dwellers, for the dry ground took up so much of the moisture as to leave nothing to flow from the tile openings in the upper miles of the ditch. Hence, the muskrats here entered the winter of 1936-37 with no more water than they had had all summer, or with barely enough to cover their burrow entrances. They did respond to the scantiness of the water in some effective ways, as by deepening channels in the ditch bottom, digging labyrinths of tunnels in the banks and under the bed of the ditch, and storing great quantities of ear corn in the burrow chambers.

Remains of six dead muskrats were found during the winter, of which three were judged to have been mink victims, though there is a suspicious connection between the main site of mortality and minkfeeding upon muskrats and a disease focus studied in later years. Two minks were known to frequent the ditch, including a big one surprised, February 16, while feeding on a muskrat in a snowdrift tunnel right next to the place where the disease focus was later found. Three of seven mink scats contained muskrat remains. Two of the three muskrats killed or fed upon by minks had been either wanderers or ill-situated individuals, while the third - the one the mink was eating when surprised on February 16 - was at least fat. A fat adult female was found dead, February 12, under a melted snowdrift, and it had what was recorded as a ruptured, suppurated stomach.

Water from the artesian flow and from snow melting during thaws laid down increasingly thick overlayers of ice in January and February, 1937. Muskrats came out in places during mild weather of midwinter and again in late winter. One muskrat broke out of a drift to travel on the surface of the ice and snow for three consecutive days, Febru- 
ary 7 to 9 , but it failed to find a place where it could get back under the ice on February 10, when its passage hole had drifted full of snow. The animal gnawed at the ice in many places in the vicinity and finally moved down the ditch to leave the area.

The ditch in Section 22 was the site of an extremely detailed investigation of muskrat food habits and damage to corn fields in 1937 (Errington, 1938). Section 22 had four territories, and the south part of Section 15, across the road to the north, had another territory. The animals responded to the drought of late summer and fall in their usual ways, by deepening channels, enlarging or repairing bank retreats, and by filling their chambers with ear corn. No muskrat remains were found in 10 mink scats from early fall, despite much foraging on land by the muskrats.

Two territories did not produce young in 1937. Of 39 carcasses of muskrats taken by trappers from the observed stretch of ditch in November, 3 were adult males, 2 were adult females, 20 were young males, and 14 were young females. By the opening of the trapping season, the population had been largely concentrated in two sets of burrows, of which the more extensive set yielded about 20 without being completely trapped out. With the aid of the specimen data, the pre-trapping population was calculated at about 60 , including about 20 in lower Section 15.

The animals surviving the trapping wintered fairly well. Most of them revealed their presence to outside view only by plugging holes left by intruding minks, though one individual came out frequently in mild weather. As the ice melted in late winter and spring, 1938, signs of living muskrats could be seen in expected places.

There were three 1938 territories in the Section 22 stretch, plus another at the south part of Section 15. Crop rotations left decidedly less corn conveniently available to the ditch muskrats in 1938, and the local population reoriented itself with respect to the two corn fields remaining. In late fall, a big dog engaged in extensive digging out of burrows - mostly near the site of the suspected disease focus of 1936. In November, 35 muskrats were known to have been legally trapped from the observational stretch of ditch, of which 25 were examined. They were an adult female, 13 young males, and 11 young females (including 4 of "kit" sizes). A dog (presumably the one that did the digging) robbed traps of 3 other muskrats. The pre-trapping fall population was calculated at about 80 .

Of seven breeding territories listed for 1939, three were at widely separated sites in the upper two miles, one was in lower Section 15, and the other three were in the artesian-watered stretch in Section 22 that usually had concentrations of muskrats. Drought, in combination with less convenient access to corn fields, localized the remaining population by October. Only one of the three upstream territories had muskrats in late fall, and this one possibly had a half dozen. The little surface water remaining was solidly frozen by early winter, but the muskrats revealed their continued presence by plugs. Concentrations 
of muskrats were by no means restricted to the vicinity of corn fields, for good wild food plants (such as sedges and composites with edible roots) grew abundantly along some of the ditch banks. By midDecember, the greater part of the population lived at a single set of burrows - incidentally, not adjacent to a corn field - and the signs here indicated about twenty animals. The total population of the three-mile stretch entering the winter of 1939-40 was estimated at about forty-five. The only outside activity studied in detail during the winter was on the part of a wanderer that explored several places on December 22 and finally went on through, heading downstream. In the spring, the body of a dead muskrat from the winter was found partly eaten by a mink.

The mile of ditch in northeast Section 22 and lower Section 15 had five territories in 1940, and the two miles of ditch upstream had three widely separated ones. The ditch muskrats were not fortunately situated with respect to corn fields in 1940: no corn was planted adjacent to any part of the observational stretch that had old burrow systems, and the two main corn fields near the observational stretch were out of the radii of activity of settled muskrats. One of the 1939 burrow systems in Section 10 was evidently taken over by muskrats in 1940 because of the old ear corn stored within. The usual foods of the ditch muskrats in 1940 were legumes and composites and planted oats. Oat fields were raided much as the muskrats usually raided corn fields, though on a lesser scale. Water levels in the ditch remained fairly constant during the alternating wet and dry periods in 1940. In late summer and early fall, muskrats moved upstream from the more populous lower mile of the stretch to dig new burrows in many places that had not been occupied for years.

Fifty-five trapped carcasses were examined during the 1940-41 fur season. They were 7 adult males, 4 adult females, 30 young males, and 14 young females. Three of the young were of "kit" sizes, classed as August-born. Of the 4 adult females, one had conceived a single litter in 1940; 2, two litters each; and 1, three litters. One of the two-litter females had given birth to a rather late litter. From the above ratios, and assuming neither spring to fall losses of adult females nor substantial movement in or out of the area, the total fall population of the three miles of ditch may be calculated at about 100, of which roughly half remained localized in the lower mile.

Downstream from the three-mile stretch of ditch and in the northeast quarter of Section 26 is the series of artesian-fed artificial ponds known as Lake Comar, owned by F. C. Corneliussen. The ponds themselves were never kept under regular observation as part of the research program, but a two-thirds mile of creek into which the artesian overflow drained was added to the study area in 1940. This two-thirds mile of creek ran through the southwest corner of Section 25 and was a continuation of the Story City drainage ditch, though not dredged 
except at its upper and lower extremes. It was pastured along its length (except for a short, brush-grown stretch parallel to a road), but corn fields always were within easy reach of the water in places.

In 1940, the two-thirds mile of creek had a single territory, this in the roadside brush. There was, however, a movement of muskrats out of the stretch, culminating in early September, at the height of local drought conditions. By late fall, after the water came back, the remaining population was estimated at about 10 - mostly large-sized animals. No muskrat remains were found in 16 mink scats from September, 1940.

Muskrats were scarce along the three-mile stretch of ditch in the spring and early summer of 1941. There were four territories, all in exceptionally favorable situations, as the few muskrats present took their pick of available sites. Two of the territories were depopulated by late summer drought, and another had only a single muskrat after a heavy rain put puddles back in the ditch bottom. Muskrats spreading upstream from the two functional territories in late September and early October rehabilitated an old burrow system lying a mile or more away. Here a trapper took 25 in December, but I did not learn of the catch in time to examine the carcasses.

The total of 49 specimens examined from the ditch during the 1941-42 fur season (including some caught below the three-mile observational stretch) was probably close to the equivalent of the population of the three-mile stretch. They were 3 adult males, 4 adult females, 23 young males, 16 young females, and 3 young of undetermined sex. Three of the 4 adult females provided data from placental scars: one had not conceived during the 1941 breeding season, whereas the other 2 had conceived 13 and 29 young in two and in at least three litters, respectively.

The extent of the population adjustments taking place along the ditch after a return of flowing water is indicated by data from the two-thirds mile of undredged creek below Lake Comar. This stretch of creek had no breeding muskrats in the spring of 1941 and was dry in mid-August. But, with the onset of fall rains, a surprisingly large number of muskrats moved in, to start the winter near the edge of a corn field. At this place, the newcomers dug a fine set of burrows in once-vacant habitat, from which I examined 19 carcasses trapped in early December: 1 adult male, 3 adult females, 2 young males, 8 young females, and 5 young of undetermined sex.

The ditch had four territories in northeast Section 22 and lower Section 15 in 1942, and six were established in the upper two miles, making a total of ten for the entire observational stretch. Four of the upper territories were at sites not previously used for breeding territories, but they actually had their origin in burrows dug in the course of the population adjustments of late summer and early fall of 1941 and then were stocked with 1941 ear corn. 
By mid-September, the south mile had heavy signs in one place, representing probably about 30 muskrats. Three of what had been four well-used territories showed many old but few current signs - fading trails into corn fields - and these three territories in a foodrich and attractive place were contiguous. Although this antedated our real experience with the hemorrhagic disease, the evidence looked to me like that of an epizootic, nearly depopulating about a mile of ditch.

Elsewhere, in the upper two miles, a trapper reported catching between 55 and 60 (which I had no opportunity to examine) in December, 1942, and an allowance may be made for perhaps 10 escaping the traps. This would give a total of about 100 for the pretrapping population of the three-mile stretch.

Downstream from the ditch, the two-thirds mile of creek in Section 25 had three territories in 1942. One was at the old site near the brush-bordered road, and the others were in burrows that had been dug in the late summer and early fall of 1941 and then stocked with ear corn. About twenty-five muskrats entered the winter.

In 1943, the three miles of ditch had 11 territories or about 25 adults, which was not, comparatively considered, quite the breeding population that one might have expected from the overpopulated status of Keigley's Branch and environs. The territorial site of 193642 in lower Section 15, suspected of being at or near the focus of infection of the hemorrhagic disease, had no breeding muskrats living near it in 1943. As during previous springs, settling muskrats showed an evident partiality for vacant burrow systems that already had been stocked with ear corn. Forty-three carcasses examined from the three miles during the 1943-44 fur season were 2 adult males, 4 adult females, 19 young males, and 18 young females. No apparent scarcity of muskrats was noted in the fall in any of the territorial sites of the breeding season, so negligible mortality of adult females between spring and fall (as from disease) may be assumed. These ratios applied to the 11 territories would give a fall population of about 115 . Of the 4 adult females examined, 2 had conceived two midsummer litters each, and 2 had conceived three early-season litters each.

The two-thirds mile of creek in Section 25 had three territories in 1943. By mid-September, the heavy signs were localized at the edge of a corn field, but there were some muskrats elsewhere along the stretch. Thirty-three carcasses trapped from or near the two-thirds mile are considered practically the equivalent of the fall population of muskrats resident there: an adult male, 3 adult females, 17 young males, and 12 young females. One of the adult females had not conceived young in 1943, and the other 2 had each conceived 26 young in three midseason litters.

The three miles of ditch had 8 territories in 1944, and there were 3 along the two-thirds mile downstream. The ditch did not flood during the wet summer, and, though the small creek flooded, it still reared early-born young. Forty-one trapped specimens from or near 
the two-thirds mile of creek were about the equivalent of the total population living there by late fall: 2 adult males, an adult female (with 29 placental scars of four ages, the latest of about August), 25 young males, and 13 young females. No trapped carcasses were obtained from the 3 miles of ditch during the fur season of 1944-45, but the over-all sex and age ratios for 192 carcasses from the vicinity of Story City were 14 adult males, 15 adult females, 105 young males, 57 young females, and one unsexed young of the year. Application of these ratios to the 8 ditch territories without correction for possible losses of adult females between spring and fall would give a total of about 100 muskrats as the late fall population for the 3 miles of ditch.

The ditch had nine territories, and the two-thirds mile of creek had one in 1945. Fourteen of an estimated twenty muskrats in the two-thirds mile were caught in November: an adult male, an adult female (with fourteen placental scars of two early-season ages), six young males, and six young females. The ditch had been the site of both extensive late summer and fall movements and severe illegal trapping before season. Samples totaling three adult males, two adult females, twenty-one young males, and twelve young females from or near the observational stretch of ditch were probably representative for the ditch populations, but these ratios can not be applied without correction to the original number of territories. There is reason to consider that the reduction through late summer and fall egress may have been about 40 per cent, which would have left a population of about a hundred remaining along the ditch by the beginning of the human exploitation.

Of the 2 adult females legally trapped from the ditch, one had conceived 16 young in two early litters and the other 14 in three early to midsummer litters. Of 158 young of the year examined from the Story City block, 15 were classed as "kits," or August-born, and all but 2 of these "kits" came from the ditch.

The ditch had 10 territories, and the two-thirds mile of creek had one in 1946. By late August, 8 ditch territories and the creek territory were still functional. The site of the creek territory yielded an adult female, 7 young males, and 4 young females during the 1946-47 trapping, but, insofar as the female had conceived only a single litter of 6 young in 1946, many of the trapped young had to be animals born and reared elsewhere. Of 84 trapped from the ditch, 5 were adult males, 6 were adult females, 39 were young males, and 34 were young females. These ratios should be fairly applicable to the eight functional territories recorded for late August, which would give a pre-trapping ditch population of about 115. Although six of the sixteen litters conceived by the 6 adult females from the ditch were July or August litters, only one of the 73 young of the year was of "kit" size.

Central Iowa trapping conditions for muskrats in November, 1946, were ordinarily favorable, but trappers were disappointed in their catches from the Story City block - though probably less disappointed 
with their catches from the ditch. Even so, the muskrats of the ditch certainly shared to some extent in the mortality and unrest manifested by the muskrats of other central Iowa stream areas. A trapper brought in for me a victim of hemorrhagic disease that he found on the ditch bank, and the ditch was right in the midst of a general area in which hundreds of muskrats engaged in upstream and downstream adjustments and footloose cross-country movements in late summer and fall. Undoubtedly, many muskrats just moved out of given habitats, to be eliminated by enemies, exposure, accident, and strife.

The three miles of ditch had nine territories in early May, 1947, and there was another in the two-thirds mile of small creek. The creek territory was abandoned in June or early July, but the ditch which neither flooded during the June rains nor dried up during the following drought - had a carefully estimated population of about 120 by November. No legal trapping of muskrats was permitted during the 1947-48 fur season in central Iowa. I doubt if more than about 100 entered the winter along the ditch, however, for one territorial site - situated next to a bridge - was completely depopulated, evidently through illegal trapping.

The ditch had 11 territories in 1948, and the two-thirds mile of creek had 3. The creek retained its flow throughout the drought, but only one territorial site had a wintering group, which was estimated at between 20 and 25. In view of the unfavorable status of muskrats, generally, in the Story City area, the trapper controlling the twothirds mile of creek gave this group complete protection as breeding stock.

The three miles of ditch became drought-exposed except for the half mile watered by an artesian flow. About 90 animals had concentrated along the wet half mile by late fall, with about 30 still remaining along the dried-out stretch. Fourteen trapped carcasses, mostly from the dried-out part of the ditch, consisted of an adult male, 3 adult females, 8 young males, and 2 young females. Of the adult females, one had conceived two early litters in 1948 and the other 2 had each conceived three early to midsummer litters. No specimens were obtained from the half mile of ditch having the heavy concentration, for this stretch again had been virtually depopulated through illegal trapping before season.

During the drought of 1948, there was much moving away from established quarters in the Story City block but remarkably little evidence of cross-country movement. Upstream and downstream adjustments occurred on an increasing scale from late summer until the acute stages of drought were relieved by a rain on November 19 , but these adjustments had an orderliness not witnessed in the course of the extensive and obscurely motivated footloose movements of 1946. In 1948, a large proportion of the total movements seemed to result from bands of muskrats (presumably of family or otherwise 
closely associated groups) moving deliberately and remaining together as social units while exploring for new living quarters after their old quarters became untenable. There seemed to be a greater tendency, also, in 1948, for animals to headquarter in their familiar burrows until these burrows lost all of their surface water.

In 1949, the two-thirds mile of creek furnished a splendid illustration of the role of locally wintering animals in restocking for a new breeding season. The stretch had four territories, including one at the 1948-49 wintering site previously mentioned and the other territories were distributed with some uniformity along the rest of the two-thirds mile. The ditch had nine territories; though no muskrats were known to have wintered, 1948-1949, along the three miles, it cannot be said with certainty that none had; hence, the 1949 breeding population may have consisted of both newcomers and old residents.

Except for the half mile kept wet by the artesian flow, the ditch was practically dry by August, 1949, and stayed dry all fall. As of mid-September, the carefully estimated population was about 50. By early winter, 1949-50, the observational stretch of ditch had no living muskrats left. The loss of perhaps 20 muskrats occupying the burrow sets near a road may be charged, as in some other years, to illegal trapping before season. Other than that, the reduction was due mainly to a combination of drought exposure and disease, and the crisis resulting therefrom was studied in particular detail throughout the fall of 1949.

No muskrat remains were found in 19 mink scats deposited in the first three weeks of September along the wetter half mile, nor in 56 scats of earlier deposition. One of 13 scats deposited in late September did contain muskrat remains. The victim was a young of about six weeks of age from a dried out burrow system at or near which 5 other occupants died in the space of days.

The latter burrow system had had something over a half dozen residents in mid-September. On September 23, remains of six dead were found outside or just visible within the burrow entrances: (1) an adult male was clearly a victim of hemorrhagic disease, though it had been carried about eighty yards down the ditch and urinated upon by a red fox, (2) a subadult female without recognized disease lesions, killed outside the burrow and left there by the fox, (3) an intact six-weeks young that had crawled into a hole to die of disease, (4) the previously mentioned six-weeks young that had been eaten upon by the mink, (5) a third young of about six weeks, dying several days earlier than the others, to decay in otherwise intact form (with no broken or disarranged bones) outside the burrow, and (6) a subadult male dead about two days from hemorrhagic disease.

At least two and probably up to a half dozen of the ditch muskrats hung on to a dry burrow system most tenaciously. They had beaten trails to a corn field and left ear corn all about what was the 
last freshly plugged burrow entrance to be seen on September 21. Remains of a freshly eviscerated small muskrat - probably a subadult lay on the mud. A fox or a raccoon had dug out one of the main chambers probably in late August, and the soft mud on the bottom revealed the continued interest of these two species. By October 5, the last muskrats here had either died or abandoned the burrow system.

At the upstream end of the half mile made wet by the artesian flow, the concentrated muskrats got along well until early November, though by mid-October water remained only in the channels of the burrow entrances. On November 10, a freshly dead victim was found lying on the bank, out of reach of a drove of hogs that was systematically rooting out the most accessible parts of the burrow system. On November 22, a good covering of ice showed no bubbles of living muskrats beneath, and the evidence indicated that the entire group had died of hemorrhagic disease, chiefly deep in the burrow system or in the mud where the hogs picked them up. (This place was in the vicinity of the suspicious mink and dog activities of 1936-38.)

It may be mentioned that wet mud surfaces upstream from the muskrat concentration of 1949 showed that at least one animal had come from the drought-exposed part of the ditch to join the group in late fall. The ditch bottom extending downstream had wet mud along the edges that was highly suitable for the taking of tracks, and the part flowed over by the artesian water had a diatomaceous film on which muskrat tracks were conspicuous for a distance of 30 yards downstream from the last part of the burrow system showing signs of living animals during the dying. Downstream from there, not a track of a muskrat was seen after early fall on either mud margin or diatomaceous film for a distance of about 600 yards.

The occupied burrows near the extreme downstream end of the three miles of ditch - the site of so much illegal trapping near the highway - may have recruited a few muskrats from downstream in October, for the increased signs to be seen there in late fall could well have reflected more animals than had been present in September. Less than a half mile downstream (off the regularly observed stretch) was another concentration, a "fur pocket" from which a trapper took 26 without trapping it closely. The sex and age ratios of the sample were 2 adult males, 3 adult females, 10 young males, and 11 young females, including one of "kit" size. Of the 3 adult females, one had conceived an early small litter (5) in 1949, and the others had conceived three litters each of early to midsummer ages.

Starting about a half mile farther downstream from the above "fur pocket," the two-thirds mile of creek had an estimated population of about eight muskrats left in the four territorial sites by late September. The flow was then good, but earlier the stream had been dry or practically so. No trapping was done here during the 1949-50 fur season, but nine muskrats taken nearby were an adult male, two adult females, three young males, and three young females. The two 
adult females had each conceived four litters during the 1949 breeding season, and the time of birth of one of these litters was assigned to August. The "kit" in the catch from the upstream "fur pocket" was probably the offspring of one of the four-litter females. The two four-litter females had conceived a total of 74 young in their eight litters, which would imply that these particular females must have had superior living conditions.

The 1949 drought crisis in the Story City block was characterized by a minimum of cross-country movement. I saw no traffic victims at the height of the drought. Neither had any of the resident trappers and farmers with whom I talked. Some stream-bed exploration occurred in places, but other places favorable for taking track signs did not have a track laid down for weeks, even when conditions were critical for local animals.

By late April, 1950, five territories were established along the three miles of regularly observed ditch, and soon thereafter another territory was established. These newcomers to a depopulated stretch almost certainly came from the moderately trapped "fur pocket" lying between the observational stretch of ditch and the two-thirds mile of creek below. Few if any muskrats moved through the two-thirds mile during the spring dispersal.

Minor adjustments occurred along the reoccupied three miles of ditch during the summer of 1950. The territory nearest what had been one of the disease foci of the previous year seemed to have only a single muskrat in it by early August. Later, after rehabilitating the burrows of the old focus, this animal also disappeared. Five territories - all situated along a wet ditch adjacent to raidable fields of corn and soybeans - were patently successful in rearing and holding young.

Another group of muskrats settled in the lower part of the threemile stretch, the animals moving in from a food-poor territorial site immediately downstream. The obvious new attraction was a corn field. The first of the newcomers to be noted was a "kit," which left its tracks at the lower edge of the three-mile stretch about the first of July. In the course of July, the muskrats from downstream took over the whole lower end.

The surface water disappeared from about half of the length of the three-mile stretch of ditch during the fall of 1950 . By midNovember, the ditch-dwellers had withdrawn from two of the five productive territories of the summer and from the place at the lower end that had been occupied by the immigrant group in July. Following these withdrawals, the ditch population congregated about the three other territorial sites, there to maintain themselves with very little apparent change in total numbers until the 1950-51 fur trapping.

The two driest of the three occupied territorial sites along the ditch showed considerable surface activity of the muskrats when the 
trapping season opened on November 25, and a trapper caught 20 here in land sets. The pre-trapping population for the three miles figured at about 80 , of which probably between 50 and 55 survived the trapping - all in the most habitable of the old territorial sites. No wintering mortality, 1950-51, was detected, and the best-situated local population was estimated at about 40. Signs as early as the last days of February indicated that some muskrats were beginning to disperse from this latter group. The farthest movements occurring at this time (during a thaw) could be traced about a quarter of a mile both upstream and downstream. This was the only place along the regularly observed central Iowa streams where evidence of dispersal was seen so early, and it may be judged that certain individuals of a crowded population were desirous of getting away.

The two-thirds mile of creek had a single territory established in the lower part by a muskrat or two appearing late in the spring dispersal of 1950. A young animal judged to have been April-born appeared briefly at the lower end of the two-thirds mile early in July. In early August, a lone animal (probably a subadult) moved into the upper end of the stretch, there to stay through September and part of October. The maintained territory never did have signs of many animals and may have had only one animal in residence during the breeding season. It suddenly became vacant in late September, despite the proximity of a muskrat-raided corn field and a continued flow over the creek bed throughout the driest weather.

The animals surviving the winter of 1950-51 filled the three miles of ditch about up to capacity for the breeding season of 1951 . As of late May, the stretch had 12 territories or about 28 adults. No evidence was seen of animals moving into the three-mile stretch from downstream. A single animal was known to have died from undetermined cause in late April or early May.

Ten territories were plainly functional by late July, but, by midNovember, the muskrats of the three miles were almost restricted to three places, all in the vicinities of corn fields. The lower 30 yards had the heaviest concentration in its recorded history, or probably between 60 and 80 , of which perhaps 40 were illegally trapped before the opening of the 1951-52 fur season. On the basis of sex and age ratios of 111 legally trapped muskrats (4 adult males, 12 adult females, 48 young males, and 47 young females), the late fall population figured at about 165 .

The occurrence of 12 adult females in the trapped carcasses agrees well with the known distribution of territories, including 2 nonproductive ones. (Two of the adult females had not conceived young in 1951.) There was only one "kit"-sized or August-born young among the 95 specimens of young of the year, although 5 of the 10 adult females that bred in 1951 had placental scars assigned to August. Of the 10 breeding females, 4 had conceived three litters each during the 1951 season, and 6 had conceived four litters each. If the 111 spec- 
imens be regarded as a representative sample for the stretch, a total of 95 young reared of 313 conceived would still reflect poorer reproductive efficiency than is thought to have been the case. It does then look as if a substantial number of young, plus most of the adult males, could have moved downstream out of the area - this despite the adherence of the adult females to their home ranges and the unusually high population of muskrats maintained until the trapping. Two of the young in the trapped sample had lesions of hemorrhagic disease.

The two-thirds mile of creek had, during the breeding season of $195 \mathrm{l}$, an interesting population of four territory-holding lone individuals, all establishing themselves since spring and all being unproductive of young. However, the creek drew a heavy ingress of muskrats in the fall. By late fall, the lower part of the two-thirds mile, which was well-lined by corn fields, was literally filled with muskrats. Of 69 trapped during the 1951-52 fur season from or near the twothirds mile and downstream, three were adult males, three were adult females, 38 were young males, and 25 were young females. The three adult females in the sample had finished their breeding by late July or earlier, though two of the 38 young of the year were of "kit" sizes, judged to have been born in August. One of the adult females had conceived two litters, and the other two females had conceived three litters each.

The 1951 data for the Story City area as a whole may here be summarized to put the ditch and two-thirds mile of creek in perspective. Twenty-six territories were recorded from the regularly observed areas in late spring and early summer. The over-all sex and age ratios shown by a total of 193 fall-trapped carcasses were 9 adult males, 17 adult females, 90 young males, and 77 young females. If insignificant mortality of adult females (which is consistent with the known facts) be assumed and if these ratios be applied to the 26 territories, the fall population should have been about 300 . When we consider that only the drainage ditch had even a fairly self-contained population in 1951, and that the Keigley's Branch and Skunk River stretches were sites of such pronounced changes, the transitory importance of the little creek extending downstream from the ditch becomes all the more marked. A place that usually harbored few if any muskrats and lacked a breeding population in 1951 thus seemed to serve in this one fall as a principal catchall for adjusting muskrats living in its vicinity. The Camp Comar fish ponds also drew in the largest number of adjusting muskrats within the memory of their owner, F. C. Corneliussen.

In 1952, the ditch had ten territories, and the two-thirds mile of creek had three. The ditch had the more nearly self-contained population, much as during the previous year. Sex and age ratios of 17 adult males, 21 adult females, 143 young males, and 122 young females obtained chiefly from the Story City block may be applied to 
the ten ditch territories, which would give a fall population of about 145 for the three miles. The two-thirds mile of small creek should have had something less than 50 , a substantial population though not representing as much massing as during the previous fall. The impoundments of Lake Comar, lying to the north of the creek though connected with it by flowing water, appeared to be the main site of local massing, with up to 100 muskrats present by late fall.

Of the 21 adult females examined from the Story City block during the 1952-53 fur season, one had not conceived in 1952; 2 had conceived a single (June and July) litter each; 4, two litters each; 9, three litters each; and 5, four litters each. The sample of 122 young females of the year included 3 precocious breeders, each having had an August-born litter. Of the 57 litters conceived by full adults, the times of birth of 4 were assigned to April, 12 to May, 15 to June, 17 to July, and 9 to August. Of the sample of 265 young of the year, 25 or 9.4 per cent were classed as "kits," or August-born, compared with 20.0 per cent of the total number of litters born to the females of the sample at a comparable time of year.

The status of the hemorrhagic disease in the Story City block was hard to appraise, but there were 6 diseased among 181 trapped muskrats examined largely from the drainage ditch. Of 10 diseased animals from the entire Story City block that had been sufficiently active to have been caught in traps, 5 were "kits," and 3 of the 5 large diseased animals had lesions of patent severity. The ditch had two disease foci at which victims were found -2 dead at one place and 6 dead at the other.

The ditch had 9 territories in early summer of 1953, and the twothirds mile of creek had three. By late September, careful estimates gave a total of about 100 muskrats present along the ditch. However, most of the ditch bottom was dry, and all but about a dozen of the animals were concentrated in the few still-wet places situated in the vicinity of conveniently raidable corn fields. One of the drought-exposed ditch territories was the site of dying from disease in late September, and, by late October, it was doubtful if more than 30 to 40 muskrats remained, these being almost confined to the halfmile watered by the artesian flow. Six dead of hemorrhagic disease were found at one shrinking pool in October and early November, but about as many more were known to have survived until the fur trapping started. Along the two-thirds mile of creek, about 15 were localized near a corn field from September to November.

Only about 20 muskrats appeared to have survived the winter of 1953-54 in the Story City block, and these survivors were mostly residents of the ditch. Peculiarly, the above site of mortality from hemorrhagic disease of at least six muskrats was also the place where most of the muskrats successfully wintered. The burrows here had been well stocked with ear corn.

The three miles of ditch had only two territories, as of early May, 
1954, and the two-thirds mile of creek had one territory. By midsummer, the ditch had one functional territory, and the two-thirds mile of creek had no muskrats at all. These areas were virtually devoid of muskrats during the winter of 1954-55.

As of late May and June, 1955, the ditch had seven functional territories, established by newcomers from downstream, and an eighth territory seemed to have been lost through disease. Downstream, the two-thirds mile of creek had a probable lone-animal territory, which was abandoned by early July. Evidences of upstream and downstream adjustments were noted along the ditch as early as mid-July, and, by late August, the muskrats were showing highly variable local behavior.

A group occupying one of the more productive territories had a corn field conveniently close by. This group maintained dry burrow systems from late August through September, packing trails from burrows to the corn field, and plugging burrow entrances with miscellaneous dry vegetation. In late August, another group rather suddenly appeared some 500 yards from the nearest 1955 territory, at a not-quite-dry territorial site of previous years. It rehabilitated the old burrow system, stayed about a week, and then disappeared. Nearly a half mile from the nearest breeding territory a fair-sized pool, which had had no early-summer muskrat signs, suddenly did have muskrats in late July. The newcomers soon left, however, and the pool remained muskrat-vacant and about 600 yards from muskrat-occupied retreats until about the first of September. By September 13, the pool had heavy signs of muskrats - recently dug burrows, a heavy trail to a corn field 40 yards away, corn in trails and floating in the water - and these corn-feeding animals, too, behaved as if intending to stay. This group was about a mile and three-quarters from the nearest place then occupied by muskrats. A 150-yard stretch that had the most muskrats during the breeding season (equivalents of two pairs and young) was sufficiently food-poor to be abandoned in late summer, though it was watered by the artesian flow; but a similarly wet stretch 200 yards upstream had raidable corn fields on both sides, and here the majority of the muskrats still alive along the three miles of ditch were concentrated by September. The signs here indicated a well-situated population estimated at 25 to 30 , which would mean a total of perhaps between 40 and 50 still being present along the three miles.

Most of the muskrats abandoned the ditch before freeze-up. There was some fall mortality (possibly due to disease) at one dried-out burrow system. In the latter case, remains of a dead muskrat were dug out of the burrow by a large striped skunk. A few muskrats wintered, 1955-56, at a corn-stocked burrow at the head pool of the three-mile observational stretch; an unknown but probably small number, near the lower end.

There were, as of early May, 1956, four maintained territories 
along the three miles, and a single, very temporary, territory in the downstream stretch of two-thirds of a mile. Of these, only two of the ditch territories (including a lone-animal territory) were at or near the burrows where animals had survived the previous winter. The origins of the other animals that established territories were not traced.

By late June, the three miles of ditch were, except for puddles, drought-exposed. Three of the four territories were in process of abandonment, but some muskrats were then beginning to move in from downstream. Only two of the territories appeared to be productive of any young at all. The young of one of the territories just seemed to disappear, but an old animal established itself, alone, at a pool next to a corn field about 500 yards distant. The old one remained through September.

One territory was truly maintained throughout the breeding and postbreeding months. It was at the head pool of the ditch, where some muskrats had wintered on stored ear corn. Evidence was found of four litters having been born here in 1956 - in April, May, June, and July. The surface water became foul but did not quite disappear at the height of the drought, and the family foraged both in ditch vegetation and in an adjacent corn field.

\section{OUTLYING WATERS OF STORY CITY BLOCK Indian Creek Area}

The mile-and-a-half observational stretch of brook near the headwaters of Indian Creek had fewer muskrats in 1938 than had a pool formed by water from a broken tile in a corn field about 100 yards to the side of the brook. The trapping catch from the brook itself for the 1938-39 fur season was four or five muskrats, compared with a catch of about 20 from the corn field pool. The landholder dug out the burrows of the pool in connection with repairing the tile in the spring of 1939, and I examined them carefully. The pool itself was about four feet deep and eight feet across, and, in the banks, the muskrats had an extensive set of burrows stocked with ear corn. At least two bushels of corn had been stored in the visible chambers.

The 1939 breeding census for the Indian Creek brook gave four territories. By mid-June, much of the brook was dry, and adjustments by resident muskrats were in progress. By early July, even after some rains, muskrats were living in plugged culverts and nearly exposed burrow systems. A five-weeks young was found dead with no recognized evidence of pathology. By early September, the whole watercourse had long been dry except for a spring-fed pool. Muskrats were living in the weeds about the latter pool and also in a road culvert kept slightly moist by seepage water. Another young, likewise of five weeks, was found freshly dead in early September; it was thought to have died of heat or thirst. By early October, muskrats were still alive (though leaving many fewer signs) in the same two 
places of the observational stretch that had been occupied a month before. The road culvert was almost filled with mixed vegetation and ear corn and kept tightly plugged with mud wet from traces of seepage water that continued to appear. By November, the culvert looked dry, with about a bushel of ear corn stored in it and plugged with corn, mud, and debris. I think that the local muskrats suffered a total loss during the winter.

The mile and a half of brook had the equivalent of a single pair in late June, 1940 - at least two adult-sized muskrats lived in the same road culvert that had been used in 1939. This was one of the few places retaining surface water in the area. By early July, the culvert was dry, and only a single muskrat seemed to be left. By early September, the brook flow had been resumed, but only the one muskrat was still around. No evidence of successful breeding was seen.

By the spring of 1941, the culvert showed long disuse, but two territories were established, by early May, along the brook itself. One pair was evicted and its territory ruined by road grading during the summer. By August 19, the brook was dry except in a few places; one territory was still well-used, and what appeared to be a single individual was again living in the road culvert. Five fall-trapped muskrats from the area were all young of the year, and my estimate of the pre-trapping population was eight to ten animals.

In 1942, the brook had two territories. One muskrat pair lived and produced young in or near the road culvert, despite the grading of the road and the installation of a new culvert during the summer - the muskrats adjusted to the disturbance and readily accepted the new culvert in place of the old. Trappers took 24 muskrats from the mile-and-a-half observational stretch by New Year's, 1943, of which eight were from the culvert.

No further studies were conducted on the area.

\section{Headwaters, Keigley's Branch}

In late September, 1940, a survey of the headwaters of Keigley's Branch was undertaken, about fifteen miles of dwindling creek being inspected upstream from the regularly observed stretch in Section 26, northwest into Hamilton County. Above the Section 22 stretch, on which observations had been made during earlier years of the central Iowa studies, there were practically no muskrats nor attractive environment for them until one came to a series of gravel-pit pools lying about four miles southeast of Stanhope. The gravel-pit pools drained at high water stages by means of a tile leading to Keigley's Branch, which at that place was only a brook. Some of the pools were deep and with considerable vegetation, including cattails. Muskrat signs of varying ages could be seen about the pools having the most food, and I think that the equivalent of about a pair and their season's young were in residence. Signs in the spring of 1941 indicated that 
the animals may have wintered there in nearly the numbers present in the fall of 1940.

The Stanhope gravel pits were visited occasionally during later years, and some general observations were made that may here be summarized. During 1941, 1942, and 1945, the pools collectively had single breeding territories and by each fall possibly eight to ten muskrats. The pools never were very productive for the muskrats, which is partly explainable in terms of food limitations. Neither did the pools prove to be gathering places for muskrats engaging in the pronounced upstream and downstream adjustments of the late summers and early falls of 1955 and 1956, when all muskrats then present in both years were behaving like established residents at two territorial sites. In 1957, there was an apparent family group at the pools in early summer, then these animals disappeared, to leave the pools virtually without muskrats for months. Several muskrats established themselves at one of the pools about the middle of October, and at least one very large animal successfully wintered.

One concentration area of muskrats near the headwaters of Keigley's Branch was studied in 1956 and 1957. It was situated five miles west of Randall and six miles upstream from the regularly observed two-mile stretch near Story City.

In the summer and fall of 1956, a half mile of stream was bordered by corn fields and ungrazed herbaceous and grassy vegetation and had some wet spots that had not dried up completely during the driest weeks of the drought. Although it was an exceptionally attractive stream habitat for muskrats, it looked no more favorable to my eyes than some places that had neither attracted nor held muskrats at the peak of their postbreeding adjustments along the central Iowa streams. An estimated 60 to 80 muskrats had congregated in the halfmile stretch by late fall. Of 76 carcasses (mainly trapped muskrats, but including 3 victims of hemorrhagic disease) examined from or from near the area, 7 were adult males, 6 were adult females, 33 were young males, and 30 were young females. Five of the 6 adult females yielded breeding data: 2 had not conceived in 1956, 2 had conceived three litters each, and 1 had conceived four litters. Of the 10 litters represented by placental scars, none had a birth date assignable to August or later, yet 2 of the 63 young of the year were still of "kit" sizes by December.

The above stretch was kept under regular observation during 1957, when it had three territories. In early April, three dead muskrats were found in what appeared to be a focus of the hemorrhagic disease, and this also was the site of a territory that later "went dead." More evidence of mortality was found here during the summer, and the main burrow system of the disease focus remained virtually unoccupied until fall. The other two territories were well maintained and productive.

Crop rotation left the half mile in less attractive condition for 
muskrats in 1957 than had been the case in 1956, for the muskrat occupants of 1957 had no convenient access to corn fields - though the dense stands of natural vegetation bordering the creek were of obvious utility to them. The next half mile of creek lying downstream was in more attractive condition, however, and better utilized by muskrats in 1957 than it had been in 1956, so the concentration area of 1957 accordingly consisted of about a mile of stream instead of the half mile of 1956. As of early fall, 1957, the muskrat population of the mile stretch was estimated at between 80 and 100 . Despite the existence of one known and another strongly suspected disease focus, no epizootic accompanied the fall and early winter massing of the muskrats.

The early-December trappers' catch from mainly the mile stretch consisted of 7 adult males, 4 adult females, 45 young males, and 33 young females. Two of the adult females in the sample had not conceived in 1957, but the other 2 had conceived four litters each and a total of 66 young for the season. The fact that more young (78) were trapped than had been conceived by the population sample substantiates the field evidence indicating that adults had more of a tendency than young animals to stay in their original home ranges at times of extensive population adjustments. Animals drifting into the upper stretches of the water course contained higher percentages of young than did the parts of populations that tended to remain more at home in or near their scattered territories of the breeding months.

From the mile stretch, itself, muskrats had been noted to work both upstream and downstream during the late summer and fall of 1957. The first sign of a large number of muskrats moving as a group had been noted on August 5, and such movements had still been occurring as late as late October. Patently, the muskrat populations entering the winter on the concentration area had been of very mixed origin.

\section{Hay Field Ponds South of Story City}

The wetness of 1942 made habitable for muskrats a scattering of hay field and other ponds lying between Skunk River and the twothirds mile of creek downstream from the Story City ditch, but they did not seem to draw any muskrats during that year.

The equivalent of four pairs of muskrats established territories in these ponds in the spring of 1943. By late fall, but before the trapping began, some 15 small ponds had one or more muskrat lodges in each one. Considerable local adjustment was by then apparent. One family group moved from a drying pond in a corn field (the site of the summer's breeding territory) to a larger and wetter hay field pond 80 yards distant. About 20 animals were accounted for at the ponds, collectively, as of late fall and early winter, of which 14 were trapped and about a half dozen were estimated to have survived the trapping. Thirteen carcasses examined were of 2 adult males, 1 adult female 
(having 30 placental scars of 3 early to midsummer litters), 5 young males, and 5 young females. One carcass had lesions of the hemorrhagic disease. The 10 young of the year among the trapped specimens were exceptionally large, doubtless as a result of early birth combined with access to corn, cattails, and other excellent food. As of late January, 1944, the deepest ponds had about a foot and a half of water under the ice prior to a two-inch rain. One animal was noted to forage outside during the winter, and that was an occupant of one of the shallower ponds. In March, when conditions for reading signs were very good, at least two muskrats were living in each of two lodges on separate ponds, and two lone muskrats lived at other ponds.

The hay field ponds had a single breeding territory in 1944, but, presumably because of the lowered water levels of summer and fall, no muskrats were known to have remained until the 1944-45 fur season. With the disappearance of the original breeding adults of 1944 , together with any offspring produced in that season, these ponds almost ceased to be occupied by muskrats for the period of our records. They were in good condition from the June rains of 1947 but without muskrats. A few drifters came in during the summer or fall of 1950, and three young (one male and two rather small females) were trapped in late November. There was a productive territory in 1952 , but this was abandoned in late summer.

\section{Gully Near Keigley's Branch}

During the years of study of Kiegley's Branch in Section 26, this gully had muskrat residents for the first time in 1943. It then had two places habitable for muskrats: a pool just below a culvert under U.S. highway 69 and a boggy area of about a half acre lying next to a corn field. The bog did have two territories, and the population was considered to have been quite self-contained up to the beginning of the trapping season of 1943-44. At my request, the trapping was done as annihilatively as possible, to give the fullest data on the population group. Two adult males, 2 adult females, 20 young males, and 13 young females were caught. The 33 young may be regarded as essentially "home grown." One of the adult females had 33 placental scars of four ages, and the birth date of the latest litter was assigned to early July; the other adult female had 29 placental scars of three ages, of which the latest litter was assigned to July. Thus, of 62 young conceived, it appeared that around 33 actually had been reared by the two isolated pairs. Not only did the bog have an excellent food supply in its natural cattail growths and the corn of the adjacent field, but the digging of the muskrats in deepening and enlarging their burrows also resulted in partial damming of the water trickling into the gully.

The fall population of 1944 turned out to be similar to that of 1943 , but the spring and summer events of 1944 were by far the 
more complex. Only one pair occupied the boggy part in spring and early summer of 1944, but there was a lone male at the pool. This latter had been captured uninjured while wandering in the Skunk River bottomlands, toe-clipped, and released on April 20 in a set of old burrows at the pool, and the burrows had been experimentally stocked with ear corn to induce this stranger to stay. Its distinctive tracks had been made out until late June at the site of release, within 100 yards of the naturally established pair of animals. Of 40 muskrats trapped annihilatively (as in 1943) from the bog during the fur season of 1944-45, 3 were adult males (not including the toe-clipped one), 2 were adult females, 24 were young males, 10 were young females, and 1 was a young of undetermined sex.

Where, presumably about midsummer, had the second adult female and the second and third adult males come from? The origin of the second adult female seemed traceable with fair satisfaction from one of two closely adjacent territories near the mouth of the gully. The evidence was that it had moved up the gully in midsummer. One of the adult females had conceived 21 young in three litters and the other, 33 young in four litters during the breeding season of 1944.

The last animal (a very fat young female) trapped in the boggy drain in early January, 1945, had lesions of the hemorrhagic disease suggesting that it was just becoming sick. One of a lot of 10 taken shortly before also had lesions.

The bog was drained naturally by a ditchlike erosion channel cutting through it in the early summer of 1945. The roadside pool, however, had some muskrats in subsequent years.

In May, 1947, a pair reoccupied the pool, but these adults and their offspring were evicted by the late summer drought, and this loss was uncompensated by any known establishment of a group of newcomers elsewhere along the two-mile observational stretch of Keigley's Branch.

In 1948, the pool was silted in, and the erosion channel through the bog cut down to about three feet below the surface. The pool regained its attraction for muskrats during the next few years, though apparently no more muskrats lived in it until the spring of 1955, when it became the site of a probable lone-animal territory.

The above territory continued to be maintained by what seemed to have been the same animal through September, 1955. By midOctober, more than one size of tracks could be made out in the marginal mud. By freeze-up the main burrow entrance had only a small puddle of surface water, and I was not sure that any muskrats remained in residence. Thus it looked all winter until February 20, 1956, when it could be seen that muskrats within the burrow were using ear corn for plugging material. At least two muskrats successfully wintered.

The pool was the site of a maintained territory in the spring of 1956, although one of the occupants had been killed by highway traffic 
in early April. Flooding by a freshet in late May terminated the territory, for no further sign of occupancy was seen after the water receded. In 1957, a lone animal maintained a territory at the pool in early summer, then abandoned it. No further muskrat sign was observed here for the duration of the study.

\section{Drainage Ditch Lying South of Wall Lake}

The observed mile and a half of ditch had the equivalent of eight breeding pairs of muskrats in 1940. The ditch became dry except for puddles, but, insofar as most of the muskrats continued to have access to some water and to an abundance of corn, I doubt that the residents suffered any important pre-trapping mortality. By October 19, the signs suggested considerable local massing in the best places, after abandonment of the burrow systems in the food-poor or the long-dry places. Between this date and the opening of the legal trapping season, November 10, illegal trapping so drastically reduced the ditch population that I obtained only 19 carcasses for examination: 4 adult males, 1 adult female, 8 young males, and 6 young females. If this ratio be applied to the breeding density of the summer and if it be assumed that little movement in or out of the observational stretch occurred during the summer and fall (though there was considerable adjustment from pool to pool), the late fall population would figure at about 130. This should not be out of line with the heavy local signs and the actual data from comparable situations analyzed elsewhere.

In the spring of 1941, the equivalent of nine breeding pairs occupied the observational stretch of drainage ditch. Later, the ditch was cleaned out and widened by dredging that cut through the burrow systems and heaped towering spoilbanks. Four of the nine territories were ruined, but five continued to show heavy use after the mud settled. The territories maintained despite the upheaval were all located in stretches of the ditch having burrows of long standing in hard clay soil and extending deep into the banks. The ditch also went largely dry, but it may be doubted that a lethal crisis resulted, as there was by late August about as much sign as might have been expected in the territories that were still functional. The pre-trapping sign suggested a population of perhaps 80 , situated mainly along three-quarters of a mile of ditch where the muskrat habitat nearest corn fields best withstood the dredging.

Work on the mile-and-a-half stretch of ditch was discontinued after a breeding census in June, 1942. Only three breeding territories were then distinguished, and few other muskrats were using other places there. The ditch itself was then functioning with maximum efficiency for drainage purposes, with a steady shallow flow over the bottom and with pool-like waters in but three places, of which two were territorial sites.

Roadside ditch pools near the above drainage ditch also yielded data for 1940 and 1941. A breeding pair that established itself in one 
of the shallower pools in May, 1940, raised many young, despite adjustments forced by drought and the presence of a big mink. None of 23 early-summer mink scats contained muskrat remains, nor did the prey debris littered in and about numerous mink holes in the road grade. In late June, most of the family group of muskrats took over some old burrows in a deeper pool about 200 yards from the original territorial site, but the latter continued to be frequented by some muskrats up to late August. By mid-December, good muskrat signs could be seen under the ice over the deeper roadside pool, but muskrats did not winter successfully at or near this place.

No territorial foci were recognized in the roadside ditches as late as May 19, 1941, though later field notes indicate that a pregnant female may have been in the process of settling at that time. Just when a male appeared at the roadside ditch is not clear, but there was a male around to father a second litter. By late August, before rains relieved the drought, all the roadside muskrats were living in the deeper pool, which, by then, was dry, too. No evidence was seen of summer mortality, and, by early November, good signs were visible at the above pool. After the trapping season opened on December 1, I was able to obtain data on seven trapped carcasses: an adult female (with nine placental scars representing two litters assigned to June and July) and 6 young of the year. As of December 6, when the trappers took up their traps, I estimated from fresh signs that at least three more muskrats remained alive.

The last entry in my notes concerning the muskrats in the roadside pool is of June 24, 1942, when signs of a territory and recently weaned young could be distinguished. Soon thereafter, the drainage of the roadside ditch was artifically improved and its attractiveness and habitability for muskrats lost. 


\section{Chapter 11}

\section{Central Iowa Stream Areas and Outlying Waters; Ames-Gilbert Block}

THERE ARE SEVERAL IMPORTANT WATERSHEDS in the area surrounding Ames and Gilbert; each demands careful and individual study.

\section{SKUNK RIVER (AMES-GILBERT BLOCK)}

No regular studies were made of the muskrats of a one-mile observational stretch of Skunk River lying east and southeast of Ames until 1934, but some data had been obtained incidental to horned owl studies on neighboring stretches in the spring of 1933. Substantial local predation by the owls then reflected vulnerability of muskrat occupants of two series of oxbow pools (Errington, Hamerstrom, and Hamerstrom, 1940, pp. 841-42). Of 88 owl pellets from late winter and early spring, one contained muskrat remains, but there were remains in 9 of 70 pellets dated from late spring to midsummer. The victims, with one exception, were young animals that evidently had been taken from a particular territorial site at a drying pool. These pools were marginal habitats at best and, as the water receded from the muddy banks, living routines of the muskrats became increasingly hazardous.

The 1934 data indicate nine breeding territories or about 20 adult muskrats along the one-mile stretch. Sufficient water remained over parts of the stream bed to protect the muskrat population from critical drought exposure. A carefully estimated total of about 60 entered the winter of 1934-35, under the legal protection of a closed trapping season. The animals were locally concentrated in their wintering quarters, and one such wintering group suffered some mortality. Of 80 scats of a single mink (a medium-sized one, probably a female), 74 consisted of muskrat remains. All of this material, which represented about three individual muskrats, was taken from a snowdrift latrine 
used by the mink from about the middle of January to the middle of February, 1935. This mortality could have reflected either or both population tensions or dislocations caused by two winter floods. A third possibility is of an undetected focus of the hemorrhagic disease at the site of the greatest concentration of the muskrats.

In 1935, the figure arrived at for the stretch was eight territories, representing about 18 adults. By fall, muskrat signs were not only abundant along the main channel, but some muskrats also lived in wet oxbows to the side. The fur trapping was highly competitive and "dirty," with much thieving, and neither reliable information nor specimen material could be obtained from most of the trappers. The best pre-trapping estimate that I could make for 1935 was about 70 .

In 1936, the stretch had six territories or about 15 adults, and the pre-trapping fall signs indicated a population of about 60 . Again the muskrats were given legal protection from trapping, but this was only partly effective, as the use of water sets for other fur bearers was permitted. One trapper told of seeing about a dozen dead muskrats discarded beside a strategically located trap, and, while I did not see anything like this, I did see dead trapped muskrats.

Unusually satisfactory winter observations were made in midDecember, 1936, at which time under-ice signs were very heavy about certain burrow systems, and the animals appeared to be getting along well. Conditions for observations became more difficult as the winter progressed, but evidence that muskrats were wintering in fair numbers could still be made out in places, until the ice broke up in mid-February.

Nine breeding territories, or about 20 adults, were recorded for the spring and early summer of 1937 . By late September, the dry weather had almost stopped the river's flow, but, because of the reduced evaporation in the cool weather of autumn, the slight flow increased and was well maintained through the winter. Prior to the trapping season of 1937-38, very abundant signs could be seen, and my estimate of the fall population was about 100 .

Three territories were established in 1938, and there could hardly have been more than about 30 muskrats present by fall. Trappers took few if any muskrats from the stretch during the 1938-39 fur season.

In 1939, five breeding territories were established. The dry Indian summer reduced but did not quite stop the flow over the main stream bed. More important than drought in the upper 200 yards of the mile seemed to be pollution by calcium and magnesium carbonates from the city of Ames water softening plant. Very few muskrats remained in the polluted zone, though downstream the animals did not appear to be affected. My fall estimate for the observational stretch was about 70. Most of the muskrats wintered well under the protection of a closed trapping season.

Six breeding territories were recorded for the early summer of 1940, the last year of intensive studies. Water fluctuations were well 
within the toleration limits of the muskrats, and many signs of freeliving young could be seen by late June. The fall population was estimated at about 80 .

A three-mile observational stretch of Skunk River south of Cambridge was put under observation in 1939. Breeding censuses gave an equivalent of 23 pairs, or probably more than 50 adults. Even when the weather was driest in 1939, the flow never completely stopped, and the deeper pools were always in excellent condition for muskrats and usually within easy raiding distance of corn fields. In September and early October, very heavy signs were localized about favored retreats. The population was then estimated at about 240 .

Two separate 1939 breeding territories could be distinguished in a pool lying east of the river. By October 3, about half of the area of the pool had water over it, and lying at the edge of the water was a freshly dead subadult female. From field notes, I would now diagnose this as a victim of the hemorrhagic disease. By November 7 , the pool had been dry for some time, though many muskrats still remained; the exposed burrows were plugged with corn, grass, mud, and debris. I doubt that any muskrats survived the winter here, whether because of drought exposure or disease or both.

The three-mile stretch had, by midsummer of 1940, the equivalent of 31 more or less successful breeding pairs. There was evidence of an early-season loss of perhaps five territories, which suggests an initial settled population that may have been about 80 adults. Environmental conditions were favorable-moderately fluctuating water levels and a superb food supply - and by early July the mud margins nearly everywhere along the stretch were tracked up by newly independent young. A family of great horned owls frequented the stream banks, but, of 14 pellets examined that had been deposited from mid-June into July, none contained muskrat remains.

The 59 carcasses examined from the three-mile stretch during the 1940-41 fur season were 4 adult males, 4 adult females, 28 young males, and 23 young females. The population equivalent of 31 pairs recorded as successfully breeding should have been about the number of adults present by fall. The sex and age ratios of the specimens applied to 31 females should give a pre-trapping population of about 450 , or an average of 150 per mile.

The year 1940 was notable for a populous colony of brown or barn rats (Rattus norvegicus) centered about a crib of ear corn that had been stored near the river bank since 1938. The burrows of the rats riddled 225 yards of the bank nearest the corncrib, and the ratdominated part of the stream was avoided by the muskrats. However, dominance by the rats may not have had much actual depressive influence on the muskrats, which simply withdrew across the stream to live in the opposite bank. In late summer and fall the concentration of barn rats dispersed away from the river bank. By early October, scarcely any rats remained there, and the muskrats were again using the formerly rat-infested bank of the river. 
The 1940-41 trapping toll of muskrats was very moderate along the three-mile stretch, and the trapping ceased before the first of December, leaving about half of the fall population still alive. Trappers reported seeing many muskrats dead from unknown causes during the trapping. I was unable to obtain any specimens of these dead ones for examination. Now I am almost certain that they must have been victims of the hemorrhagic disease and, furthermore, suspect that the disease had had something to do with the loss of territories observed during the summer.

When spring came in 1941, astonishingly little evidence of living muskrats was found along the three miles, and the animals remained decidedly scarce - that is, compared with their 1939 and 1940 abunclances - throughout the rest of 1941. I doubt that the breeding population was more than about 30 adults. Fall signs indicated fewer than 100 muskrats. Fifteen trapped specimens examined in December were an adult male, 2 adult females (which had conceived two early litters each), 4 young males, and 8 young females.

After 1941, observations on the muskrats of the Cambridge stretch of Skunk River were made only as they related to special problems.

In 1947, the three miles had only five territories (four of them with young by July) along the entire stretch. In this case, it was believed that some adult as well as young muskrats had been drowned or swept away by extremely high early-summer flood waters, which in places had covered the bottoms up to a mile or more from the channel. But, in addition, there are excellent grounds for suspecting that the fewness of muskrats was due in part to disease.

The three-mile stretch continued to have a flow at the height of the 1949 drought, and I was able to make especially good observations on the process of depopulation through an epizootic of the hemorrhagic disease. Pool-by-pool estimates in mid-October gave a total of about 180. Probably fewer than a dozen of these muskrats lived along the upper half mile of the three-mile stretch, although some favorable-looking pools adjacent to corn fields and some little-used or quite unused burrow systems could be seen there. The main population (an estimated 125) was concentrated along a strip of somewhat less than 1,000 yards extending a short distance into the middle mile; this population filled its habitat to near apparent capacity. Then, for almost the full two miles to the south end of the observational stretch, the total estimate amounted to only about 45 , patently a remnant of what had been a much higher population earlier in the fall. Inspection downstream for a half mile south of the boundary of the observational stretch revealed similar evidences of depopulation.

The south two miles of the three-mile stretch were reworked when it became clear that something special was wrong. Of two diseased dead that $I$ found, one was in rigor mortis at the edge of a pool and another (a slightly smelly one) had been caught on a branch overhanging a swift, deep riffle, there to hang out of convenient reach of the numerous scavenging raccoons. Decay-tainted air about an open 
bank burrow presumably meant another dead one inside. Upstream from this site, a raccoon had just dug out part of a burrow. Still farther upstream about 600 yards, some fresh muskrat signs were visible, but most of the signs were only of recent origin - there were numerous unused holes and burrow systems, including two that had been dug into by raccoons. Downstream from the dead muskrats were several vacant or almost-vacant stretches of 300 yards or more in length, with lone or small groups of living muskrats between them. In three places in particular, most of the signs looked a month or more old, which afforded a minimum basis for judging the time of onset of the lethal epizootic - early to mid-September. Only one trail of an animal behaving like a transient was seen on the mud and sand of the stream bed in three days of field study.

\section{SQUAW CREEK}

Preliminary work along Squaw Creek in 1934 and 1935 was restricted to a seven-mile stretch, tracts $\mathrm{A}-\mathrm{E}$ (Figure 10.2). As actual records of territorial sites were not obtained prior to 1936 for Tract $\mathrm{F}$, the whole nine-mile stretch may be treated as a unit in the earlier years of the study only if prorata interpolations are made for 1934 and 1935 to supply equivalents for the missing data.

The figure thus calculated for 1934 was 30 territories for the nine miles, or a total of about 65 adults. The summer's drought was relieved before most of the muskrat-occupied pools went dry and, so far as I know, the Squaw Creek muskrats suffered little mortality because of the drought. They seemed generally to remain within their familiar home ranges, not engaging in much cross-country movement. Such adjustments as they made in response to partial drought exposure were made in gradual stages up and down the stream bed. The most extensive adjustments occurred in early fall, as animals spread away from crowded pools after the return of flowing water.

Estimates of the 1934 fall population for the nine miles totaled about 250. These muskrats had legal protection during the 1934-35 fur season, but a terrific winter emergency surely killed large numbers. While the creek was in a very high flood stage in late January, 1935, the temperature dropped to 19 below zero Fahrenheit officially (an unofficial reading gave nearly 30 degrees below zero), to leave few places habitable for muskrats. Two individuals living under heaped ice on shore and foraging on land were known to have survived the crisis, but nearly all of a population calculated at between 34 and 45 along a two-mile sample stretch evidently died. Fully two-thirds of the muskrats living along the nine-mile stretch must have been exposed to the flood waters and cold to a similar extent as those of the above sample stretch.

The prorated figure for 1935 was 29 territories or a total of about 65 adults for the nine miles. My best estimate of the population entering the fall was about 240 , or somewhat fewer muskrats than in 1934, the much better environmental conditions of 1935 notwithstanding. 
Shortage of signs in some of the more attractive places for muskrats aroused suspicions of local disease losses, but evidence of considerable movement up brooks and small creeks was also noted in late summer and early fall.

In 1936, the nine-mile stretch had fifteen territories or about 35 adults, and late-fall estimates totaled about 120 animals. The surface water disappeared in all except the most nearly permanent pools. A rain of over four inches in early September broke the drought, but did not do much more on Squaw Creek than to fill the stream-bed pools and start a slight flow. More rains came in mid-September and later in that month. Unquestionably the Squaw Creek losses had been severe during the summer, and they did not cease with termination of the drought. I saw one partly hairless animal for the first time on September 4 (at an estimated age of between 40 and 50 days), and am sure that it was afflicted by a fungus like the Trichophyton mentagrophytes with which I had much experience at Round Lake (Chapter 5 and Errington, 1942b); the presence of such a lethal and contagious skin disease of young muskrats could hardly have meant other than mortality. On September 13, a dead suckling female was found with lesions that were almost certainly those of the then-unrecognized hemorrhagic disease.

A closed trapping season on muskrats seemed to give the species fairly effective protection on Squaw Creek, despite legal water-trapping of minks and raccoons. Only one muskrat was noted habitually to engage in outside activities during the winter of 1936-37, and it appeared to have died in early February.

Twenty-two territories, representing about 50 adults, were recorded in 1937 for the nine miles. The fall drought crisis was accompanied by much population adjustment. By then, the muskrats were sufficiently reduced so that they or their signs did not occur abundantly just anywhere, but along Squaw Creek they were abandoning untenable retreats, trying to establish new quarters under difficult conditions, being caught in exposed places by cold weather, and engaging in a certain amount of desperate wandering. Their increasing vulnerability was reflected by their remains in 5 of 95 mink scats. Each representation was of a different victim (one adult and four young), taken as drought exposure became locally acute. The predation followed a definite pattern, and an observer could virtually predict when the minks would start killing muskrats at a given pool - as the last surface water in the burrow entrances dried up. Because of the severity of the drought, probably no more than 20 muskrats were alive on tracts $\mathrm{A}-\mathrm{E}$ by the opening of the trapping season on November 10; Tract F, with considerably more water, had about 30.

Fur trapping completed the annihilation of muskrats along a fivemile stretch in tracts $\mathrm{B}-\mathrm{E}$; and the total catch here, according to the trapper, was 10 . Seven of the 10 (including 2 living in holes in dry ground) were caught from the vicinity of one pool. A lone muskrat 
was known to have lived from midfall to late November in dry lodges erected in a corn field, to disappear after the weather turned cold. Farther downstream in Tract $\mathrm{A}$, another lone muskrat came out at intervals all winter to forage on bank vegetation; and one of two animals behaving in a similar way still farther downstream was illegally shot by a hunter in mid-January, 1938.

My estimate was that between five and eight muskrats wintered in 1937-38 on the whole stretch of Squaw Creek represented by tracts A-E, and these were all in Tract A. Upstream in Tract F, neither drought nor trapping on drought-exposed and drought-concentrated remnants had such serious effects, and I think it probable that nearly all of that tract's muskrats entering the winter survived until spring.

The 1938 spring population was about 30 adults, maintaining 13 territories. Animals resettling the depopulated five-mile stretch in tracts B-E invariably established themselves in what had been the lastoccupied pools of the preceding summer and fall, despite generally favorable water conditions in the whole area. Considerable evidence was seen of late summer and fall movements within the ordinary cruising radii of the resident muskrats, or up to 200 to 300 yards away from the territorial burrows. Up to the middle of September, several long stretches remained unoccupied by muskrats, but by late October enough muskrats gradually came into the vacancies so that there were no great differences in local populations anywhere along the observed nine miles of stream. The muskrats seemed comfortably situated throughout this time, and no remains of the species were found in 126 mink scats. Some animals (mostly if not all subadults) appeared in outlying waters.

Fur trapping during the 1938-39 season nearly annihilated the muskrats along most of the nine-mile stretch. Forty-seven carcasses or skins representing most of the population of tracts B-D were examined: 4 adult males, 6 adult females, 14 young males, 15 young females, and 8 young of undetermined sex. Muskrats were believed to have survived the trapping at only five places in tracts B-D, probably one or two in each place, from which a pre-trapping figure of about 55 may be estimated for $\mathrm{B}-\mathrm{D}$, not counting occupants of outlying waters. This figure, applying to five miles of stream and seven or slightly more than half of the territorial sites, might be assumed to comprise slightly more than half of the fall population of the ninemile stretch. If the population data obtained from tracts $\mathrm{B}-\mathrm{D}$ were prorated to tracts $\mathrm{A}, \mathrm{E}$, and $\mathrm{F}$, the total would be about 100 for the nine miles. However, in view of a late September drift into tracts $\mathrm{A}$ and $F$, which had few breeding muskrats in spring and summer, the actual fall population was probably higher than the prorated figure or possibly about 130 .

The nine-mile stretch had 21 territories, or about 50 adults, in 1939. No extensive crisis appeared to develop along either the channel or the outlying waters during the spring and summer months. None of dozens of horned owl pellets examined in bulk in late April, and 
none of 140 mink scats for June and July contained muskrat remains. In August and September, typical adjustments occurred up and down the increasingly exposed stream bed. Beginning about the last of September, conspicuous mortality of muskrats was observed on the highways. Four of 22 early-winter mink scats contained muskrat remains (of two individuals, an adult and a "kit"), compared with no representations of this prey in 22 scats deposited in the Squaw Creek area from September to November.

The muskrats of Tract $F$ were less affected by drought than the muskrats of the downstream tracts. Early-winter estimates for the nine miles totaled about 50, of which about 20 were resident in Tract F. From consideration of the field notes, I would say that the Squaw Creek animals entering the winter of 1939-40 got along henceforth with little mortality, but also without much comfort, under the wintering conditions prevailing. For the duration of a snowless early period, or up to about the middle of January, many occupants of the frozen-over stream pools had no access to vegetation under the ice except for such roots as they could still reach. Their main diet was of animal matter, bullheads and other fishes, as well as frogs, that they preyed upon much as did the minks. They also fed upon the dry grass and other vegetation that they had stored or used as linings in their burrow chambers. In warmer weather, they would come out to forage amid the dry weed stalks and scattered green plants on the banks.

In 1940, the nine miles of stream had 22 territories, plus another in a shallow oxbow close by. Territorial adjustments continued into late May and early June. It is probably significant that the best evidence of late territorial adjustment was seen in the most densely populated stretch of the creek - in a two-thirds of a mile having 4 territories. On May 17, two muskrats considered to be a mated pair were actually watched (or trailed) while they worked upstream some 700 yards; as I watched, one of the animals started carrying vegetation to a retreat under a bank, and this place shortly afterward had the appearance of an established territory.

The productivity of the Squaw Creek muskrats was poor in 1940. I am not at all sure that environmental extremes provide a full explanation, but there were extremes. The creek was dry except for scattered pools by the last week of July, and this seemed effectually to inhibit reproduction. Field signs indicated that nearly all of the young successfully reared had been born in April, May, and early June. Of 20 trapped carcasses taken from the main channel during the 1940-41 fur season, 6 were adult males, 4 were adult females, and there were 5 each of young males and young females. Two of the adult females had conceived two early litters each in 1940, and 2 had conceived three litters each. One of the three-litter females had conceived two early litters, and a late one assigned to late August or early September doubtless had been conceived soon after the breaking of the drought in late July.

I question whether mortality resulting from the drought was im- 
portant, but the violence of floods in August imposed upon the muskrats a variety of troubles. Responses of the muskrats to flood emergencies were then carefully studied both during and after the periods of high water. Appearance of animals in odd places following subsidence of the water may indicate that these were not swept away bodily so much as that they were forced outside of their radii of familiarity and simply got started wandering, often in the direction of some of the outlying waters referred to later in this chapter. For example, a corn field lying between Squaw Creek and the outlying Rainbolt Ponds had footloose muskrats ranging throughout it, and several (at least six) of the flood-evicted wanderers moved into one of the ponds to live for the rest of the summer and fall until the 1940-41 trapping. At least two more moved into the little Hutchinson's Lake, and above it York Pond drew a few animals, but these latter left before freezeup. The pool at the head of the county line ditch in Tract $E$ had at least one muskrat.

In taking care of themselves during the peaks of the August floods, adult and subadult muskrats seemed able to swim wherever they needed to go, to improvise nests, and to sit around with some safety on logs, stumps, and drift. On the other hand, the young less than two and a half months of age were probably under such a handicap that many of them drowned. Two family groups of young were watched during flood crises from distances of a few feet. These were members of a litter of about eight weeks on August 13, and of a litter of about seven weeks on August 17. Both litters had about run out of alternatives, as the water was closing over the tops of the banks and the upper openings of their burrows in which they were lying with heads out.

Among the imperfectly appraisable consequences of the August floods were the changing of stream channels of Squaw Creek, the cutting through of meanders and silting in of oxbows and eddies and, possibly as significant for the muskrats as any one thing, the general scouring of herbaceous vegetation away from the banks or from near the banks. When the waters went down, the stream channel and its immediate vicinity were singularly short of muskrat food. This may have induced footloose movements or local readjustments as much as eviction by rising waters.

Even so, practically all of the places occupied by muskrats prior to the floods continued to be occupied afterward. Young animals lived along with adults, though an unusually high proportion of adults in the remaining population was evident from track signs before it was verified by a 50-50 ratio in the trapped carcasses. There is no reason to think that the adult muskrats of Squaw Creek suffered more than trivial losses between spring and fall, and the ratios for the trapped carcasses applied to a breeding density the equivalent of 23 pairs (including the occupants of the shallow oxbow lying near the creek) would give a total of about 115 as the pre-trapping population for the nine-mile stretch. 
The latter figure is probably close to the truth, but many of the Squaw Creek young established themselves elsewhere in the outlying waters. It is also extremely likely that considerable numbers of the Squaw Creek young found satisfactory refuge downstream along Skunk River southeast of Ames, where water fluctuations were comparatively moderate.

No muskrat remains were found in 121 mink scats deposited along Squaw Creek from May through July, 1940, though mink signs (of at least one locally reared litter) were very heavy about the drying pools. Remains of a subadult muskrat dating back to the time of one of the floods were found in 2 of 26 mink scats deposited from late August to October. Other predation upon muskrats was suspected, particularly while the marooning of a variety of terrestrial animals - grasshoppers, mice, rabbits, and even a big house cat - on stumps, fence posts, and like refuges attracted avian predators to the bottomlands. On August 17, a Swainson's hawk (Buteo swainsoni) circled about 35 yards overhead while I wrote in my notes of a muskrat sitting in a patch of flooded weeds.

Despite frequently observed outside activity along the waterscoured banks of Squaw Creek during the winter of 1940-41, a good proportion of the survivors of the trapping season also survived the winter. Plenty of evidence of dispersing muskrats was seen in late March, but the dispersal signs really became heavy about the second week of April, 1941. Muskrats were indeed so conspicuously in circulation in mid-April that I made a special effort to determine whether they were being preyed upon by the resident horned owls. No muskrat remains were found in 99 owl pellets for April and May, nor in 213 dated back from March into the winter.

The 28 territories of 1941 were close together in places and far apart in others. As contrasts, Tract $\mathrm{D}$ had a lone territory and Tract $\mathrm{B}$ had five territories concentrated in its lower half. According to the 1940-41 sex ratios, there should have been about 70 adults for the 28 breeding territories along the main channel of the nine-mile stretch of Squaw Creek.

The 1941 productivity of the above stretch is hard to appraise. Floods occurred three times during June and July and, as of early August, water levels were still moderately high. Muskrat signs, where mud margins were present to take them, were spotty, concentrated in places, lacking in others and generally less than expected. Considerable fluctuation in water levels also occurred in August and September. My suspicion was that substantial, though then undetected, disease losses might have depopulated certain territories or groups of territories, as had happened along the Skunk River stretch south of Cambridge. Checkups in August and September indicated that the principal losses had taken place in Tract F, where there were muskrat-vacant stretches corresponding to four territories.

Seventeen trapped carcasses were obtained in December, 1941, from Squaw Creek: 4 adult males, 3 adult females, 5 young males, and 5 
young females. Though small, this series should be fairly representative of a population sample from the main stream, if allowance be made for some late-summer and early-fall movement into such places as the county line ditch. Allowing for the loss of four of the 28 mainstream territories between the breeding census and the trapping season, there should have been about 24 adult females left to use as a base for calculations. Application of the sex and age ratios of the trapped carcasses to this base would give a total of about 135 muskrats for the nine miles in late fall.

The 1941 placental scars of the three adult females examined from Squaw Creek were all of early or mid-season litters: two litters for each of two females and three litters for the third. The fall ratio of 10 young per three adult females may not be thought to reflect actual breeding success; but, even if it be assumed that as many of the young reared by these females established themselves safely in side streams and similar places as remained in their natal ranges, the net reproductive success would not be much more than a third of the number of young conceived.

Difficult trapping conditions, 1941-42, left an unusually large proportion of the Squaw Creek muskrats to winter. Field notes refer to outside activities by a few individuals, including some possibly showing early pre-dispersal restlessness. By mid-March, 1942, muskrats were appearing literally everywhere along Squaw Creek and its tributaries. A week later, however, the heaviest signs were being laid down along stretches of stream known to have wintered substantial populations of muskrats. Among these particular animals, dispersal, so far, seemed to be manifested more by increasing local activity than by footloose movements. Neither 18 horned owl pellets nor 19 mink scats, deposited contemporaneously in areas where muskrats were active, contained muskrat remains. A raccoon grappled and killed a very large old male muskrat on the creek bank in late May.

Heavy rainfall in 1942 considerably expanded the habitats available to muskrats in outlying waters of tracts D-F. At the same time, the stream channel became less attractive, partly through obliteration of old burrow systems by repeated floods. The June and July floods themselves were destructive to young muskrats of helpless sizes. Another flood in mid-September probably came too late to have lethal significance for the species.

Fifty-six carcasses of stream-dwelling muskrats were examined for the fur season of 1942-43: 6 adult males, 5 adult females, 25 young males, 19 young females, and 1 young of undetermined sex. The uteri of 4 of the adult females were in suitable condition for examination; and, of these, one had not conceived in 1942, one had conceived 23 young in three litters (including two litters of late summer), one had conceived 27 young in three litters (including one litter early in the breeding season and the other two rather late), and one had conceived 35 young in four litters (including two litters in late summer). Six of 
the 45 young of the year in the trapped sample were classed as August, if not early September, "kits."

Other than the old male killed by the raccoon in May, no losses of adults were noted for the stream-dwelling muskrats of tracts A-F for the summer of 1942, and it is felt that any losses of adults that did occur were negligible. Application of the ratios of the trapped carcasses to 24 adlult females would give a total of about 265 for the pretrapping fall population of the nine-mile stretch of creek, exclusive of the animals of outlying waters.

Considerable activity on land was noted about the Squaw Creek drainage during the winter of 1942-43. Although not all of this activity was restricted to the vicinity of the channel, it will be taken up here for the sake of convenience. One animal fed on potato peels near a house instead of engaging in the usual foraging in corn fields. Two commuters across a barren pasture separating two brooks were an old female (with 28 placental scars in three litters assigned to spring and early summer, 1942) and a young animal of undetermined sex. Some, with or without apparent reason, came out in places where living conditions were judged to vary from excellent to poor. A lone individual lived in a tile flow and raided a corn field daily from December 8, 1942, to February 1, 1943, when it was collected for a specimen. It was a young male, in fair flesh, though a trap cripple with a frozen tail.

Both minks and muskrats were as abundant in central Iowa at the end of the 1942-43 trapping season as they ever were during our intensive investigations. In the Squaw Creek valley, mink predation upon wintering muskrats was light and centered almost entirely upon individuals living at a disadvantage. Two of $21 \mathrm{mink}$ scats for December, January, and early February contained muskrat remains, and those two were among six scats deposited during a flood. Of two mink victims found, one had been killed at the time of the flood.

About February 20, 1943, following springlike weather, muskrats began moving overland - clearly earlier than might have been anticipated from data obtained in other years. At least some mating took place during this period, which was also remarkably early for the north central region. Cold weather in March terminated most land activity but, with each successive thaw, muskrats came out again. Dispersing muskrats finding themselves in strange environments when the weather turned cold behaved like ordinary winter wanderers and lived where they could, in culverts and open tiles, in cavities under tree roots, in snowdrifts and lodged debris along streams, and in miscellaneous land holes. Of 13 specimens of March transients examined, 10 were sexually mature males, 2 were unbred females, and 1 female was of undetermined sexual status. Only two of the 13 specimens had strife wounds and those two were males examined late in the month by which time signs were visible in practically all places in Squaw Creek valley where muskrats would be likely to visit. Three spring 
mink victims were found along the nine-mile stretch, and there were muskrat remains in 14 of 40 mink scats deposited from late February to the middle of March, 1943, as well as in 5 of 11 scats deposited in the second half of March.

By early and mid-April, little activity of transient muskrats was seen, though most habitats were well filled with muskrats that seemed to have established themselves in regular residence. The single April specimen of a transient was an unbred, strife-torn, old female. This lack of activity on land, together with absence of muskrat remains in 10 April mink scats, may suggest that the local transients had been, in effect, eliminated. The settled muskrats acted as if they were unusually content, individually, their existing high densities in relation to specific habitats, notwithstanding.

The main channel of the nine-mile stretch had 34 territories in 1943 or, following the 1942 fall sex ratios, about 80 adults. Territories were distributed with some irregularity, Tract $\mathrm{F}$ having, for example, a muskrat-vacant stretch of about three-fourths of a mile, yet with eight territories in another stretch of a mile. Insofar as the fortunes of the channel muskrats for 1943 in particular were closely interlinked with those of muskrats in the outlying territories of tracts $\mathrm{A}-\mathrm{F}$, some preliminary mention may be made at this point of the outlying territories. The 17 territories recorded for the outlying waters brought the total of territories for tracts A-F up to 51 .

Population adjustments occurred on a substantial scale throughout the Squaw Creek drainage during late summer and fall. Muskrats appeared to establish quarters in many places that had had no breeding territories during spring and early summer. No traffic victims were noted in this locality, and the evidence suggests that the adjusting movements had taken place in easy stages along streams or other inviting routes.

Sex and age ratios for 90 muskrats trapped during the 1943-44 fur season from the nine miles of Squaw Creek were 9 adult males, 8 adult females, 38 young males, and 35 young females. Seventy-six trapped from outlying waters were 5 adult males, 7 adult females, 38 young males, and 26 young females. The 14 adult females having countable placental scars in the combined sample had conceived a mean of 3.2 litters.

Application of the ratios from the trapped carcasses to the spring density of 34 channel territories without correction for possible losses of adult females during or after the breeding season would give a pretrapping fall population of about 380. For the 16 territories of the outlying waters that remained functional, there would be a pretrapping population of about 175, or a total of about 555 for tracts A-F. One of the outlying females was known to have been killed by a dog during the breeding season, and her suckling litter surely died after her. One of the adult females from the channel and two of the young from outlying waters were diseased, and it may be assumed that there had been some other (though probably not much) reduction in 
late fall through this agency. Possibly the truth might be more nearly approached by reducing the fall figure for the nine miles of channel to about 370 , and the figure for the outlying waters to about 160 , or the total for the observed parts to about 530 .

Late-born young had an obviously poor survival in 1943 in both channel and outlying habitats. All of the adult females trapped from the channel and 3 of the 7 from the outlying waters had conceived litters datable to July or later, whereas only three of 137 young of the year were late-born. Such losses of the late-born were rather expected. Not only were breeding populations sufficiently high to make densitydepression of late-season rates of gain probable, but a flood of sufficient magnitude to drown many helpless young also occurred in late July and early August.

Trapping pressures were quite severe on tracts $\mathrm{A}-\mathrm{F}$ during the 1943-44 fur season. The muskrats escaping seemed to be, with one exception, comfortably situated. The exception was a big animal engaging in outside activities throughout the winter. None of 60 early to midwinter mink scats contained muskrat remains.

The amount of movement observed at different periods of the spring dispersal of 1944 varied with the tract in the Squaw Creek drainage. One brook joining Squaw Creek in Tract C had heavy general signs along a previously unoccupied stretch in late March, and many muskrats were appearing in other out-of-the-way places and being killed by motor traffic on the highways; yet, along some stretches of the main channel and tributary streams, little movement occurred. During the first three weeks of April the dispersal spent its momentum until, by the end of that time, the muskrats were occupying as much of the Squaw Creek drainage as they were going to occupy in 1944. The main channel had 33 territories or about 75 adults, and the outlying waters had 12 territories, so tracts A-F had a total of 45 territories and about 100 adults.

Squaw Creek flooded sufficiently in May and June to drown most of the young muskrats born before the middle of June. Adults were seemingly little affected by the floods, and signs showed that they usually remained in their established territories or returned to them as soon as subsidence of the water permitted. They gave birth to many late litters that compensated at least in part for the loss of their earlier ones.

Movements of muskrats became increasingly apparent in tracts A-F as the summer of 1944 progressed. As early as July 18, an animal was known to have traveled along a small side creek in Tract C. Another small creek, this one in Tract $\mathbf{F}$, had a heavy drift of muskrats in early August; but this creek had no established territories during the summer, and all newcomers went on through. A considerable cross-country movement occurred between mid-September and early October, accompanied by mortality from motor traffic. Some of this may be ascribed to the drying of outlying waters, but much remains inexplicable on ordinary grounds. 
Eighty muskrats trapped during the 1944-45 fur season from these tracts consisted of 8 adult males, 7 adult females, 33 young males, 31 young females, and 1 young of undetermined sex. For calculating the 1944 fall densities, these ratios were not applicable to the spring census figures without some correction for adult losses in spring and summer. On May 10, a small dog was watched doing an efficient job of eating an adult male muskrat that it presumably had killed on land south of Tract A. Both members of a pair living along a brook in Tract $\mathrm{E}$ died from hemorrhagic disease in late June. That the hemorrhagic disease probably killed considerable numbers of muskrats elsewhere in the Squaw Creek drainage is indicated by midfall notes relating to 3 dead within a quarter-mile radius in Tract $F$, and by what had the aspects of a fall and winter epizootic at some field ponds just outside of Tract C. Abandonment of territories in late summer and fall must also be considered, but I do not think that this greatly reduced the local population of adult females.

The best I can do is figure a loss of six territories for the nine miles of channel, which would leave 27 adult females still in residence to which to apply the carcass ratios. This would give a total fall population of about 310 for the channel habitats. Few of the 12 orginal territories of the outlying waters were being well maintained by the resident muskrats by fall, so reliance must be placed upon a group-bygroup estimate totaling about 120 muskrats. This would bring the population for tracts A-F up to about 430 , as of late October or early November.

Up to half, or maybe even two-thirds, of the channel muskrats were believed to have survived the 1944-45 fur trapping. Some betrayed restlessness through their outside activities during the winter. One animal was noted foraging in a field of winter wheat from late December through most of January. Another foraged far out in a field of shocked corn from late December until the creek flooded on February 15. Both returned to regularly-used retreats under the ice after each trip.

Some others, known to have come out only once during the winter and then without visible incentive, are now suspected of having been sick. The role of the hemorrhagic disease in the wintering fortunes of the muskrats of the Squaw Creek drainage is not as demonstrable as might be wished, yet the fragmentary data suggest that the disease may have been quite generally distributed.

In the spring of 1945, tracts A-F had 23 channel territories and 8 outlying territories. Following the 1944-45 sex ratios for the animals taken by trappers, a total of 31 maintained territories would mean a total of about 65 adults. Trappers generally were disappointed in their muskrat catches for the 1945-46 fur season, which reflected a very spotty distribution of the population present by early November.

Of 69 trapped carcasses, 6 were adult males, 5 were adult females, and there were 29 each of young males and young females. Three of the 5 adult females had conceived three litters each in 1945, and the 
other 2 had conceived four litters each; but only 2 of the 5 adult females had conceived litters judged to have been born as late as late July, and no "kits" or young assigned to August or later were found in the sample of 58 young of the year handled. Of the 69-carcass sample, one lot of 14 came from the site of an outlying territory, and the single pair and associated young in this lot gave essentially the same age ratio as that of the entire sample from tracts A-F. The above ratios contributed valuable information, but they must be applied with much discrimination if they are to be used in calculating the fall population after a summer and fall of such ecological complexity as that of 1945 .

Except for a very local cloudburst on August 4, which flooded Squaw Creek but not other observed streams in central Iowa, and a near-flood on August 14, the late-summer and early-fall period was dry. Light to moderate drought conditions were relieved by rains on September 27, after which the stream flows of the area never quite ceased before rains came in November. The shallower field ponds and oxbows went dry, generally to be abandoned, at least in part, by whatever muskrats were living in them.

I cloubt that much actual mortality of muskrats in tracts A-F should be charged to drought. The drought was accompanied by some notable reorientation up and down the stream channel, but the greatest decline was observed at times when the animals had no visible incentives for leaving their regular home ranges. The main crosscountry drift began about the first week of August; and, through October, it was manifested by highway victims in out-of-the-way places. Muskrats also appeared in August in outlying waters while the streams were in good condition.

Observations along Squaw Creek suggest that hemorrhagic disease may have cut down the 1945 population to a substantial extent, beginning about the middle of October. A single probable victim (subadult female) was found in late October on Tract A, and the signs of living animals were recorded as good in only two places along the entire tract - indicative of about 15 to 20 muskrats occupying the sites of five breeding territories. Another diseased subadult female was caught by a trapper in November from Tract $\mathrm{E}$ or F. A large adult in mummified condition, found in June, 1945, in that part of Tract F where muskrats had died of disease in the fall of 1944, presumably had been a late-spring victim of the contagion. A decline similar to that mentioned for Tract A also occurred in tracts B-D, from which I judged that only some five or six of the original breeding territories of tracts A-D retained their family groups until the trapping. The over-all sex and age ratios from the trapped carcasses applied to five or six territories in tracts A-D should give these tracts a pre-trapping population of around 70 to 85 , probably nearer the former figure. For the main channel of Tract $\mathrm{E}$ and sections 1 and 36 of Tract F, the known trappers' catches of 21 are believed to reflect a pre-trapping population of about 45 , or the equivalent of three family groups re- 
maining. Tract $\mathrm{E}$ included the best-populated part of the nine-mile stretch of Squaw Creek. For Section 35 of Tract F (the site of an observed focus of infection of hemorrhagic disease), the decline is believed to have been still greater for the three main channel and the four outlying territories involved. There could hardly have been more than 25 muskrats resident in all of Section 35 by November. Trappers' catches of 15 in Section 35 were largely from the channel, for the outlying ponds were more or less dried up. Pre-trapping calculations and estimates for the nine miles of Squaw Creek channel totaled about 140, to which may be added a figure of about 20 for outlying waters, thus adding up to a fall population of about 160 for tracts A-F in 1945 .

Only one Squaw Creek muskrat was noted to be engaging in outside activities during the winter of 1945-46 - that was on December 21 and in the vicinity of the focus of infection of the hemorrhagic disease in Section 35 of Tract F. Near this same place, a muskrat was eaten by a horned owl in early January, which victim may be suspected of having been a land-active, diseased one or one forced out by a flood in early January. Other floods in early February and early March resulted in no known crises among the local muskrats. The best-populated stretch of stream in Tract $\mathrm{E}$ had good signs of resident animals in five places on the first of March before any known dispersal from wintering quarters occurred.

The 1946 breeding population of tracts A-F consisted of the occupants of 26 channel territories and 12 outlying territories. Following the 1945-46 sex ratios, this would amount to about 75 adults in the total of 38 territories. The fortunes of the muskrats were followed with particular thoroughness during the breeding months by Sprugel (1951) and myself.

By early August, only one of the 26 channel territories showed disuse without evidence of re-establishment nearby. This one territory was close to the place where a probable disease victim had been found during the previous fall, and its occupants may be presumed to have died. One of the outlying territories was also suspected of having lost muskrats from disease. Two other outlying territories were gradually abandoned as their occupants extended their home ranges to the adjacent creek channel. Much reorientation took place during the second and third weeks of September, though plenty of water remained over the creek bed. By late September, muskrats were massing so much in some stretches and deserting others that no semblance of population stability remained in these places. Some of the most attractive habitats had no muskrats, whereas, for inapparent reasons, muskrats congregated in some places having nothing special to offer them. The rather food-poor habitat of Section 35 in Tract $\mathrm{F}$ had the heaviest signs that I ever saw there in late September and early October. But the greater proportion of the massed Section 35 population had departed by the opening of the trapping season on November 10 .

In attempting to judge what was different about the late-season behavior of the muskrats for this year, it should be remembered that the 
over-all population densities for tracts $\mathrm{A}-\mathrm{F}$ were not top-heavy in terms of densities tolerated in some other years. Neither were the restless animals confronted by environmental or weather crises of the sorts that might be expected to start them moving on such a scale and in so footloose a manner. A big cross-country movement was about over by mid-October, though a few animals were still in circulation after freeze-up.

Forty trapped carcasses were examined in November, 1946: 3 adult males, 4 adult females, 17 young males, and 16 young females. Of the adult females, one had conceived two litters fairly early in the breeding season; 2 had conceived three litters each, early to mid-season; and the fourth had conceived four litters, two early and two late, including one assigned to August. Field observations on the early fall movements suggested that entire local groups as well as all manner of individuals were participating, so the sex and age composition of the departing animals and those remaining behind may have been similar. The ratios from the trappers' catch were therefore probably representative of the fall population, and the chief problem in calculating numerical values for the fall population would seem to be one of obtaining a base to which to apply the ratios.

From close study of the data from the different tracts, I could be reasonably sure of the net loss of the equivalent of only five family groups along the main channel (three of them in Tract D) and of four other family groups of outlying waters (two in each of tracts D-E). The ratios from the trapped carcasses applied to 21 of the original 26 pairs of adults judged to have been present by fall along the main channel of the nine-mile stretch would give a 1946 fall figure of about 210. For the outlying waters, six of the original breeding territories were still maintained by late fall and, of these six, four territories retained essentially full family groups. The fall population for the latter four territories figured out at about 40. To these should be added the muskrats living in two partly depopulated territories, which had something like a total of 15 , as of the beginning of the fur trapping. The late fall population of the outlying waters should then have been about 55 , which would bring the total for tracts A-F up to about 265.

In 1947, the nine miles of channel had twenty-three territories and the outlying waters had four. The total adult population of muskrats for tracts A-F figured out at about 2 per territory for twenty-six territories, and a lone female for the other territory. The area's muskrats betrayed a remarkable intraspecific intolerance and restlessness during the period of spring dispersal and settling of 1947. In tracts E-F, alone, three of the channel territories were known to have been moved distances of 100 to 400 yards between initial settling and midsummer. In tracts $\mathrm{B}-\mathrm{C}$, the territories, while not crowded in the usual sense, were still rather uniformly distributed at close to quarter-mile intervals; and changes in territorial headquarters would have put their occupants nearer to their neighbors than they evidently wished to 
live. In contrast, the animals changing territories in tracts E-F were able to do so and still remain at least a quarter mile from the territorial headquarters of their nearest neighbors.

The June floods came too late to endanger seriously the earliestborn young, but they surely killed many young of helpless sizes along Squaw Creek. In some cases, the adults saved their young by placing them in improvised nests above the water, as on a protruding stump or at the edge of a steep bank. In July and August, the tracks of recognizably young animals ran to two extremes - either large or small - with few of intermediate sizes. The loss of a pregnant female was recorded in early July, but it was too decayed to show cause of death.

As dry weather continued through the late summer and fall of 1947, the creek flow ceased by mid-September. Some heavy rains fell (2.21 inches on September 11-12), but the dry bottom quickly absorbed the little water that flowed, until a fair flow was restored by several inches of rain in late October (2.03 inches on October 23-24, 1.18 inches on October 26-27, and 1.88 inches on October 31).

The muskrats were very unevenly distributed along the channel by early November. The heaviest signs were in Tract F, but most of the muskrats here disappeared by late November. Downstream were many stretches that were almost muskrat-vacant by late October, including nearly a mile in Tract $\mathrm{E}$, both upstream and downstream from the site where the dead pregnant female had been found in July. Tract $B$, which originally had what came nearest to being a concentration of breeding animals, had an early October population of about 35 , mostly living at four territorial sites.

Extensive adjustments - which were all but characterized by preliminary commuting of animals making changes in a careful manner were of the nature of upstream and downstream movements, largely confined to the beds of watercourses, and almost no evidence of crosscountry wandering was detected. A "kit" of about 80 days, captured in the city of Ames on September 24, was the sole wanderer personally seen alive or dead about central Iowa stream habitats during the entire fall. Some rather pronounced short-range movements from the stream channel to outlying waters occurred, however, in late fall. The outlying waters of tracts E-F, which were drying rapidly by late August and early September, had only an estimated 4 muskrats (in one roadside pool) by late September. By early winter, 1947-48, they had about 40 , or all of the muskrats then remaining in the outlying waters of the Squaw Creek observational area. The channel population was estimated, pool-by-pool, at about 135, which would add up to a total of about 175 for tracts A-F.

Illegal trapping (the trapping season was closed) could have accounted for some of the reduction of muskrats occurring in late fall, and the hemorrhagic disease was surely operative to some extent, especially in Tract E. Considerable winter activity, 1947-48, was noted in tracts E-F, sooner or later to be followed by mortality. The best- 
situated muskrats were the occupants of an outlying brook adjacent to a corn field. Even so, a young female caught at the brook in someone's mink trap in early winter was in lean condition. The water was so low over the channel of Squaw Creek that only one place (in Tract F) had an obviously substantial population of wintering muskrats. A subadult male, in fair flesh, was found on the ice, partly eaten by a predator or scavenger.

The spring dispersal of 1948 was manifested, in late March, by large numbers of highway victims and by the appearance of newcomers in long-unoccupied outlying waters; these movements occurred on a pronounced scale until early May. The nine miles of channel had 35 territories, of which 13 were massed in Tract F. This massing of territories seemed to reflect the local wintering concentration, whereas I suspect that tracts $\mathrm{A}-\mathrm{B}$, with six territories each, were so well populated partly because they were convenient for settling by animals working upstream. Much more unevenness in distribution of the breeding territories could be seen in 1948 than in 1947. Ten of the 1948 territories were grouped in five sets of twos closer together than 200 yards, and there were six places where distances of about a half mile separated neighboring territories. Outlying waters had five territories.

By October, 1948, when the water of the Squaw Creek channel was confined to pools and puddles, there were considerable signs of local adjustments, but very few muskrats were being killed on central Iowa highways, or, for that matter, even moving on the exposed creek bottom between widely separated water holes. Midfall estimates totaled about 150 for the channel and a half dozen more for an outlying brook. As the fall progressed, tendencies toward further local adjustment without known mortality or departure from the observed stretch of creek were noted.

None of 13 October mink scats from Tract $\mathbf{F}$ contained muskrat remains.

Apart from suspected illegal trapping, the muskrats of the observational area were subject to but limited effective trapping during the 1948-49 fur season. The two trapped carcasses examined were of a young male and an adult female having 22 placental scars representing three litters conceived early in the 1948 breeding season.

In 1949, the channel had 42 territories, and the outlying waters had only one. These territories were very irregularly distributed with reference to each other. Despite the semblance of uniformity implied by tracts $A$ and $B$ each having seven territories and Tract $\mathbf{C}$ having six, four of the territories in Tract $A$ were distributed along less than a quarter-mile stretch, and tracts $B$ and $C$ had three stretches of less than 300 yards along each of which were groups of three territories. There were, in tracts A-E, five stretches of about a half mile having no territories. Tract F, which had had the heaviest wintering population, had 13 territories in the spring.

The Squaw Creek breeding population, together with its season's young, underwent a great decline during the summer and fall of 1949. 
Little cross-country movement was detected in central Iowa, even when the drought was most intense, but movements up and down the stream beds occurred as pools dried up. Yet there were long periods in the fall when not even evidence of local adjustments was seen between the remaining pools occupied by muskrats. The nine miles of channel had a carefully estimated population of about 190, and the outlying waters about 10 more, as of mid-September. As of late September, the signs in most places differed little from those seen early in the month, except that in Tract D, they were proportionally heavier downstream and, in Tract F, considerably reduced. More decline occurred later, though water conditions improved as the weather became cool in the fall. The possible role of disease is suggested not only by the finding of many dead in neighboring areas but also by the fact that some of the best-looking stretches of Squaw Creek became muskrat-vacant in the same way as had those of the Story City block and the three-mile stretch of Skunk River south of Cambridge. Some of the late-fall reduction could have been due to illegal trapping before the muskrat trapping season opened, for skillful poachers were known to have been in the area.

I did not know of any trappers taking muskrats from tracts A-F in 1949 and, consequently, had no carcasses for examination. In late December, after the close of the trapping season, the best sign of surviving muskrats could still be seen in Tract $\mathrm{F}$, where nearly half of the fall population had been concentrated. By late May, 1950, twenty-nine functional territories had been established in tracts A-F all of them along the channel. These were most irregularly distributed, with concentrations and muskrat-vacant places reflecting chiefly the presence or absence of groups that had wintered locally. By late July, twenty-one territories were clearly productive of young, and seven more appeared to be maintained by lone adults. Six of the original territorial sites were abandoned, but this had probably been in connection with local adjustments, for five territories were ultimately established in places that had not been occupied by resident muskrats in May. Four of these five new sites were wedged into well-populated stretches, rather than established in the muskrat-vacant stretches, thus accentuating the inequalities of distribution noted earlier.

Squaw Creek was subject to moderate flooding three times in May and June, 1950, then its flow diminished during the dry weather following. The flow never quite ceased up to late September, for water from a gravel pit was pumped into the channel of Squaw Creek at the upper end of the area until past the middle of that month. With cessation of the pumping, the creek bottom became exposed except for the deeper pools and in places where springs kept up the flow for varying distances downstream.

Adjusting movements of the muskrats were studied through repeated visits to stretches known to be devoid of resident animals. No sign of any current transients was seen at the lower end of the area 
in mid-August. By the first week of September, local adjustments were becoming apparent, usually involving shifts of individuals or family groups within a radius of a few hundred yards of the season's territorial sites. By the end of the week, fresh muskrat trails (heading either upstream or downstream) could be made out in some of the long-vacant stretches, while other stretches still showed no muskrat sign of any age. The upstream or downstream movements occurred in easy stages, even when individuals were certainly outside their familiar home ranges of the summer. Extreme cases were manifested by groups congregating in or about favorite pools (notably those adjacent to corn fields or other sources of choice food in tracts D and F), or by lone individuals of different age classes moving into a previously unoccupied pool, to stay there a day or two and then move on.

The source of the moving animals could be exceptionally well traced in one instance. While the county line ditch in Tract E still had a flow, a territorial site had been shifted from the creek channel to about 50 yards up the mouth of the ditch. By mid-August, the ditch was dry except for a food-rich pool about 600 yards away from the creek. The territorial site near the mouth of the ditch was then all but abandoned. Most of the occupants of the lower ditch moved back to the original territorial site of the creek channel, but some animals, after a period of explorative commuting (revealed very well by tracks of different ages laid down in the diatomaceous film covering the ditch bottom), moved up the ditch to establish themselves in the food-rich pool. The latter pool still had muskrats at the end of October, but, as early as the first of September, those returning to the creek channel were traveling upstream, leaving their signs everywhere throughout a half-mile stretch that previously had shown no sign of muskrats since the spring dispersal. Nor did these long remain in the stretches lying immediately upstream from the abandoned (but highly productive) breeding territory of the summer. Their signs then merged with the signs of resident animals in Tract F, farther upstream.

Repopulation sequences of another once-vacant stretch in Tract E are informative. One stretch of about a mile and a quarter had two territories in May, but these were not productive of young. By early July, only a single muskrat - that one easily recognizable by its huge size - remained there. The single big muskrat stayed in its regular home range at least up to early September. In early July, a probable subadult worked upstream to establish itself at the mouth of a tile drain about midway along the mile-and-a-quarter stretch. It traveled through a nearly dry tile to explore one of the drying Rainbolt Ponds some 200 yards distant, returned to the mouth of the tile, and on September 5, an animal leaving the same size tracks was still living there. Toward the middle of July, another probable subadult was known to be working upstream in this stretch, and, some time in late August, an evident family group (including several young born about 
the middle of June) moved in to establish headquarters in a deep pool a full mile from any possible place where the young could have been born or raised up to that stage.

I think that the latter group comprised some of the occupants of three closely spaced midsummer territories in Tract $\mathrm{D}$ and that the other occupants remained to congregate temporarily about a big residual pool. No evidence was found before mid-September of any downstream movement from the sites of the three closely spaced territories.

Pronounced adjustments on the part of the muskrats of long stretches of Squaw Creek were taking place in the last days of September. Some of this could have been in response to the exposure of more and more creek bottom after the pumping ceased in the middle of the month, but most of the adjusting movements dated back to before the exposure of the bottom. Little random, cross-country movement seemed to have taken place (some did, as a subadult killed by motor traffic was found on a road well away from the stream), but there was a rather general abandonment of food-poor, shallow water retreats, partially offset by increased concentration in some of the more attractive places. Much of the late September movement was out of the area in the form of a trickling, downstream drift - without compensatory ingress from the long-dry creek above the gravel pit pump. By freeze-up, the nine-mile observation stretch had lost nearly all of its muskrats, mainly through emigration in a downstream direction. Track signs of only a single animal entering the area from above were seen on the exposed sandy bottom during September and most of October. There was no evidence of muskrats from Squaw Creek congregating along Skunk River, nor were there detected crosscountry movements, except for a brief period in late October and early November that came long after the main adjustment was over.

As of early June, 1951, twenty territories were established, including six apparently maintained by lone animals. Of the fourteen territories then clearly productive of young, only one was at all isolated from other territories. The other thirteen productive territories were distributed as three groups of three each and as two groups of two each. Three of the productive territories were judged to be those of lone females that had been pregnant when they established their territories, though flood waters of early June may have separated some mated pairs. Animals behaving as if they had been flood-evicted were detected in at least four places along the nine miles of stream.

Five territories showed signs of having been highly productive, and six others showed fair to good signs up to late August, when a population estimate of about 240 was made for the nine-mile stretch. Thereafter, adjusting movements became pronounced, and the population remaining (including transients) by early November was estimated from local signs at a little less than 100. Further reduction took place through egress as winter approached, until there were left by freeze-up only about 70 , of which nearly all were believed to have survived the winter. 
No trapped carcasses were examined from Squaw Creek during the fur season of 1951-52, but the field data are sufficiently complete to permit estimates of the numbers of young born to the females of the twenty established territories. Five of the territories were probably of four-litter females; three showed signs attributed to single early-born litters; seven may have been maintained by females that passed unbred through 1951; and the other five territories probably had two or three litters each. A defensible estimate would be about thirty-five litters that had been conceived by the females of the sample. If the counts of placental scars obtained from the neighboring Story City block be applied to the Ames-Gilbert block, thirty-five litters would mean a total of about 305 young. This should not be at all inconsistent with the late August estimate of 240 animals of all ages for the nine-mile stretch.

Some of the adjusting movements were studied in detail, and these were thought to typify what happened in 1951 along the ninemile stretch of channel and outlying waters. The adjustments of late July and early August were very local, manifested chiefly by family groups moving upstream or downstream to congregate in favored places. The first real traveling through was noted about the first week of August and involved only a few animals. The trail of a very large muskrat was distinguished and followed upstream out of the area. This animal was known to have traveled along more than two miles of stream between August 8 and August 11. A month later, distinguishable trails of mainly upstream transients were seen almost everywhere in the diatomaceous film covering the creek bottom in previously unoccupied tracts. Movements of entire groups of muskrats were also noted.

A paucity of food-rich habitats along the nine-mile stretch of Squaw Creek might be a partial explanation for the late summer and fall adjustments and the near-abandonment of extensive parts of the channel. Still, some corn fields were not raided by the muskrats that were living close by and presumably aware of the presence of the corn. Muskrats did not always stay in deep water pools even after they had been taking full advantage of the corn planted in the vicinity. Yet, a small stream running through corn fields just east of the Squaw Creek area was one of those obviously drawing large numbers of adjusting muskrats from Squaw Creek, much as did the small stream lying adjacent to Keigley's Branch in the Story City block. The muskrats of both Squaw Creek and the Story City block behaved as if free to move up and down the water courses as they wished, without getting into trouble with their fellows. They were able to seek and find more or less attractive living quarters somewhere, though away from the main stream channels.

The spring dispersal of 1952 was of considerably greater magnitude in central Iowa than in 1951, and it put muskrats in places that had been muskrat-vacant for years. The channel of Squaw Creek in tracts $\mathrm{A}-\mathrm{F}$ had forty-seven territories, or about 95 adults. Outlying 
waters had eleven territories. In the upper part of Tract F, ten territories were closely spaced along about a mile of channel, then there was a muskrat-vacant stretch of over a half mile in the middle of the tract. Below this, two territories lay close together, followed by another vacant stretch of about a half mile, and finally by three territories in lower Tract F. Tract D had seven channel territories, all massed in less than a half mile. Most of the eight territories of Tract A were in the lower mile, and seven of these were along a stretch of a little over a half mile.

The summer and early fall of 1952 was dry and especially so during practically rainless September, October, and the first half of November. Nevertheless, the weather remained generally favorable for stream-dwelling muskrats of central Iowa, including Squaw Creek. Some outlying ponds and the smaller streams of tracts A-F clried up, but the flow of water never ceased over the bed of the observational stretch of Squaw Creek itself.

Local adjustments on the part of resident muskrats were noted quite early in the summer, long before the really dry weather. The equivalent of two pairs of muskrats moved from the crowded upper part of Tract $\mathrm{F}$ into recently dug gravel-pit pools lying adjacent to the creek channel, and these animals were extremely productive of young in their new locations. Territorial adjustments over distances up to several hundred yards were noted in several places along the nine-mile stretch. The more pronounced adjustments occurred after the breeding was over and were of sorts to be expected of local animals stationing themselves in places having the better combinations of food and water. Adjustments seemed unaccompanied by either mortality or cross-country wandering, though occasional animals moved long distances upstream or downstream, especially in September.

By early October, the muskrats of tracts $\mathrm{A}-\mathrm{F}$ were concentrated in parts of Tract $\mathrm{F}$ and, far downstream, in parts of tracts $\mathrm{A}$ and $\mathrm{B}$. In Tract F, the concentration places were - in addition to the new gravel pits - two pools in the main channel of Squaw Creek in which the water was backed up by obstructions. One of these obstructions was a large beaver dam and the other was an earthen fill made in straightening the channel in connection with an engineering project. Pool-by-pool estimates for tracts A-F gave a total of about 295 muskrats as of late fall, 1952.

As of late May, 1953, the nine miles of channel had forty-one maintained territories; the outlying waters, seven. The spring population of adult muskrats for tracts $\mathrm{A}-\mathrm{F}$ was about 100 . Of the channel territories, fifteen had young active enough to be tracking the mud margins at the time of the late May census. These active litters must have been born in early April.

Living conditions, while excellent early in the summer, deteriorated because of drought. At first, population adjustments were orderly. As of mid-September, the nine miles of channel had a carefully estimated population of about 200 muskrats remaining, and the 
outlying territories had long been abandoned. After another two weeks, the population was down to about 135. Then, beginning in late October and culminating in early mid-November, a period of frantic cross-country movement was noted, and many muskrats were killed by highway traffic. Practically no evidence was found of these desperate wanderers reaching any place where they would have stood any chance of living in peace or safety. By the opening of the trapping season on November 10, there were hardly any muskrats left in tracts $\mathrm{A}-\mathrm{F}$, except for a few still living in dry holes near corn fields or in the deepest of the residual stream-bed pools. Rains that partly relieved the general drought crisis on November 19 did not appreciably improve the wintering status of Squaw Creek's remnant population of muskrats, and the drought conditions carried on through the winter of 1953-54 with little abatement. The nine-mile stretch may be considered to have been essentially depopulated of muskrats by the spring of 1954.

After water again started flowing over the bottom in March and April, 1954, a big upstream migration of muskrats from Skunk River took place. Thirty breeding territories were counted in mid-May, all along the channel. Repeated floodings and near-floodings in June did not prove to be especially destructive of helpless young muskrats. By mid-July, 31 territories could be distinguished, including five occupied by what were judged to have been lone adults. At the latter time, twenty-three territories had one or more sizes of young working the mud margins.

In late July and early August, while water levels were still favorable, muskrats poured downstream until but a single stretch of less than a quarter of a mile retained any substantial population. This place, which had been the most consistently favored by muskrats during some previous years, still held the equivalent of about three family groups after the big downstream movement, and its occupants withstood extraordinarily high flood waters in late August. It was still holding many muskrats by late September, when most of the rest of the nine-mile stretch was all but vacant. Then, reaching its maximum in late September and early October, a strong movement upstream occurred, but the majority of the participating muskrats went on through the study area - for at least 15 miles upstream from Skunk River - far up into headwater tributaries having steady flows and conveniently accessible corn fields.

The November, 1954, public fur trapping yielded samples totaling 121 muskrat carcasses believed to have been representative of central Iowa stream populations, including those living in tracts A-F. Sex and age ratios were 10 adult males, 14 adult females, 52 young males, and 45 young females. Of the adult females, one had not conceived in 1954, 5 had conceived two litters each, 5 more had conceived three litters each, and 3 had conceived four litters each. Birth dates of three litters were assigned to April, six to May, eleven to June, nine to July, six to August, one to September, and one to October. Only 
3 of the 97 young of the year in the trapped samples had been born in August or later, compared with eight late-born litters out of the 37 conceived by the adult females.

Beginning about the middle of March, 1955, and continuing through much of April, the spring dispersal of muskrats from Skunk River re-established a breeding population in tracts A-F. As of early June, thirty-five territories (including four probably of lone animals) were being maintained along the nine miles of channel, together with nine territories (including one occupied by a probable lone animal) in outlying waters. Three of the four lone-animal territories of the channel were situated along a stretch of stream ordinarily having several functional territories, but this stretch was also one in which evidences of a focus of infection of the hemorrhagic disease had begun to show up by 1954 .

Of nine outlying territories, five proved to be more or less productive of young during the 1955 breeding season. The four that were nonproductive were vacated by their occupants between the middle of July and early August. This was also the time of abandonment of two of the productive outlying territories and of a large number of territories along the channel of Squaw Creek. By early August, possibly three-fourths of the muskrats of tracts A-F were concentrated along less than two miles of stream, chiefly in Tract E. The Tract E concentration area did not differ appreciably from the stretches of stream that had been abandoned earlier, and the muskrats gradually abandoned this one, in turn, throughout August and September.

Only five places in tracts A-F collected substantial numbers of muskrats as more or less permanent residents during the late-summer and early-fall adjustment. One place was a series of gravel-pit pools with deep water but only fair food resources, mostly in the form of submerged vegetation. Another was a fairly deep pool next to a well-raided corn field. It had been practically vacated by two family groups of muskrats in August, but it clearly acquired a new population from untraced sources about the first of September, and these animals behaved as if they intended to stay, busying themselves in the corn field in a most conspicuous manner. The third place was a pool about eighty yards from another well-raided corn field. The fourth was a pool from which a local concentration of muskrats raided a hilltop corn field some fifty yards away. The fifth was a series of pools into which a large number of muskrats had gathered by September, after which they established a 200-yard raiding route to the nearest corn field. Only a few remained here to winter, these rather precariously, to the accompaniment of considerable outside activity.

Up to October, the Squaw Creek examples of late summer and fall movements traced along the channel showed notably more upstream than downstream drifting, but no evidence was found of muskrats congregating in large numbers in the headwaters. 
Along Squaw Creek, there was some cross-country movement during the winter. I learned of two cases of muskrats attempting to live in farmyards. A few others were able to winter in rather foodpoor and almost waterless places, where they did considerable tracking in the snow during mild periods. Still others - and possibly up to a dozen all together on tracts $\mathrm{A}-\mathrm{F}$ - packed their drought-exposed burrow systems with ear corn and stayed insicle from freeze-up until spring, without leaving external signs of their presence in the meantime. One small woodland group, illustrating what some muskrats must have done before the white man planted corn fields, wintered on stored acorns, also without engaging in outside activities between freeze-up and spring.

As of late April and early May, 1956, the nine miles of channel had seventeen territories, and there were two more territories in associated oxbows and one more at an outlying pool. Except in the downstream part of the nine-mile stretch, the animals establishing territories appeared to be mostly the few that had succeeded in wintering in the vicinity. This was also true of the two oxbow territories and that of the outlying pool. In contrast, at least eight of the nine territories lying farthest downstream were judged to have been established mainly by animals moving upstream from Skunk River.

By late June, sixteen of the channel territories were still maintained, but seven of those were clearly occupied by lone animals. One of the two oxbow territories was drought-exposed and abandoned, but the other one in the oxbow and the one in the outlying pool were maintained and productive of young.

The reproductive fortunes of 6 of the territory-holding females could be traced with fair satisfaction. Three evidently had been pregnant when they established their territories, and they gave birth to a single early litter each. One was a probable two-litter female, giving birth to litters in late April and late May. Two others (including the one occupying the oxbow near the creek) gave birth to three litters each, dating in both cases to late March, late April, and late May. The probability is that the 4 other adult females in productive territories gave birth to single early litters.

As of late July, the population remaining in the nine-mile observational stretch of Squaw Creek was estimated at about 40. About half of them were animals of the large family group of the productive oxbow territory, these having moved to the creek channel in midJuly. This former oxbow group moved downstream to establish itself at a pool about three-quarters of a mile from the original territorial site; by mid-August its members were almost all of the muskrats remaining along the nine miles of channel. There were only 4 lone muskrats elsewhere along the stretch, and one of these was a transient. All of 4 transients recorded in August and September were moving upstream. By late August, members of the former oxbow group were in process of an upstream adjustment along about a half 
mile of channel and, by mid-September, the main group was newly established at another place in the neighborhood. One large individual, which was patently a member of the group, regularly worked upstream and downstream along about 600 yards of stream channel.

Possibly fewer than a dozen muskrats wintered as a localized group along a half-mile stretch in the middle of Tract $F$, and there were a few more in scattered pools elsewhere in the Squaw Creek observational area.

By the middle of March, 1957, a rather general upstream movement from Skunk River was in progress. As of mid-May, water conditions were again favorable, and the nine-mile stretch of Squaw Creek had ten maintained territories representing about 20 adult muskrats. The outlying waters had none.

The whole observational area had one family group (in Tract E) and a thin scattering of individuals by late summer - about 15 all together - with water conditions still remaining favorable. More muskrats came in to bring the total population for the nine-mile stretch up to about 30. Much other movement was noted. In one case, 12 muskrats left the area in late October, heading upstream apparently as a group.

Most of the animals entering the winter were in the new gravelpit pools at the upper edge of Tract $F$ and at the site of one productive (Tract E) territory of the 1957 breeding season. They should have wintered satisfactorily, though I obtained no further data on the Squaw Creek muskrats during the winter of 1957-58 and the following spring.

\section{OUTLYING WATERS OF AMES-GILBERT BLOCK Onion Creek}

It was not until 1940 that the observed stretches of Onion Creek, in tracts $\mathrm{G}-\mathrm{H}$, became habitable for muskrats. No actual data were recorded until 1935, but the drought of 1934 should justify the assumption that these tracts had not been occupied by muskrats for most of that year. For 1935, there were grounds for considering that a territory had been established in the spring and that about 8 precariously situated, scattered muskrats were present in mid-October, all animals that had been present from a few days to a few weeks. In 1936, no muskrats were found to be present along any stretches of Onion Creek visited in mid-October, though one place had been temporarily occupied weeks before - probably in early September after the first heavy rain. No breeding of muskrats was known to have taken place in 1937, nor were even temporary residents known to have been present in 1938 and 1939 .

In 1940, the Section 30 stretch of Tract G, near Ontario, had no breeding territories, but there were two territories situated to the west, just across the Boone-Story County line. By fall, a population of about 25 was concentrated at the territorial sites, with a lone animal living along Onion Creek in Section 30, itself. A single breeding 
territory was noted in the two-mile stretch of Tract $\mathrm{H}$, east of Jordan, and the signs of late September suggested about a dozen muskrats remaining there.

The observational stretch in Tract G had two territories in 1941, and there was another territory across the county line to the west. Drought exposure during the summer was followed by abandonment of the territories by most of the young reared there, but the adults of two territories held tenaciously to their property rights. The population judged to have entered the winter of 1941-42 was about 10 . These muskrats were obviously hungry much of the time and foraged on the banks under cover of overhanging ice-shelves and out in the open for grain in livestock manure. A mink victim, killed in late February, was found. Tract $\mathrm{H}$ had signs of animals passing through in May, but none of these settled here to breed in 1941, nor was local evidence seen of late-summer movements.

Tract $G$ had three territories in 1942, and there were two more across the county line to the west. The parts of Onion Creek having old burrow systems were highly attractive to spring settlers. In Tract $H$ there was, despite a lack of muskrats wintering locally, a heavy movement (involving an estimated 20 to 30 animals) during the 1942 spring dispersal. Two territories were established. No evidence was found of predation by minks upon muskrats even at the height of the dispersal, though minks were of general distribution along the stream. None of 152 mink scats examined from late March to early May contained muskrat remains.

The wet summer of 1942 was advantageous to the Onion Creek population of muskrats. Abundant signs were to be seen in the vicinity of all of the breeding territories in early September. About this time and later, many muskrats were also moving into previously vacant stretches of the small stream to dig new sets of burrows. As of early September, Tract $G$ had an estimated population of about 65 and Tract $\mathbf{H}$ had about 25. Two months later, Tract $\mathrm{H}$ had about the same number of muskrats and these were quite well situated for wintering. Relatively food-poor Tract $G$ was the site of considerable adjusting as fall came on - mostly as downstream movements. Few muskrats other than those having ready access to corn stayed to enter the winter. The estimated 40 animals remaining in Tract $G$ after freeze-up engaged in considerable outside activity. One of the latter was known to have been killed by a mink in mid-January, 1943.

The two observational stretches of Onion Creek were well populated with muskrats in 1943. Tract $\mathrm{G}$ had five territories, and Tract $\mathrm{H}$ had six. Only one of the territories of each tract was situated at a place not known to have wintered muskrats in 1942-43, and the field evidence suggested that the 1943 breeders were mainly of local origin. Onion Creek muskrats were confronted by no observed crises before two flood periods in the first half of August, and these floods came after the majority of the young were sufficiently large to take care of themselves. Signs were still very heavy in both tracts by late fall, 
especially in the vicinities of raidable corn fields. Undoubtedly, movements of subadults along the creek occurred in late summer and early fall, but there was evidence from trapped carcasses that the adults generally remained in or near their former breeding territories.

Specimen material gathered from the various muskrat-occupied outlying waters of Tract $G$ showed a ratio of 6.5 young per adult female, which applied to the Onion Creek stretch would give a pretrapping fall population of about 40. A diseased muskrat, imbedded in the ice, was found in Tract G. Trapped specimen material was lacking from Tract $H$, but I estimated that the pre-trapping fall population was in excess of 100 . Under wet-year conditions, Tract $\mathrm{H}$ looked virtually as habitable for muskrats as did the Story City ditches. Light to moderate trapping on the part of unknown persons left plenty of muskrats to winter, and these got along with slight known loss. One winter-active individual was killed by a mink, and one (dated to mid-February) of seventeen winter mink scats contained muskrat remains.

Tract $\mathrm{H}$ had ten territories in 1944, which well filled up the observational stretch. By late October, there were good signs nearly everywhere along the two-mile stretch, without evidence of any particular concentrations. The late fall population, as reflected by signs, seemed to be about as it had been in 1943, or probably in excess of 100. I am not sure that subsequent late fall adjustments appreciably reduced the population, but would expect that they did. Apparent disinclinations of the muskrats to concentrate as winter approached suggested tension at the least, especially along a stretch where environmental differences - as exemplified by presence or absence of ear corn in the vicinity of certain sets of burrows - should have invited concentrations in some places and withdrawals from others. During the winter, the muskrats lived mainly in about half of the observational stretch, clearly in the most food-rich part.

Onion Creek in Tract $G$ had only two territories, or about five adults, in 1944. The late fall population was estimated at between 15 and 20 (probably nearer the former), mostly localized in one place. The deterioration of the fortunes of the muskrats of Tract $G$ continued in 1945. Two territories were established, but signs of young were found at only one territory, and my belief is that the two territories between them produced a single litter. By late fall, the stretch had possibly two animals remaining.

Tract $\mathrm{H}$ had eight territories in 1945. Although this still comprised a remarkably high breeding density for the observational stretch, most territories - even in a mile stretch having six-were rather well spread apart, that is, with headquarter burrows separated by distances of 200 yards or more. The greatest concentration of breeding territories - four in the east half of Section 28 -occurred along what was both the most food-rich stretch of stream and the one having had the highest 1944-45 wintering density.

By mid-August, 1945, the muskrat signs were heavy and general 
throughout the two miles in Tract H. By late September, when the creek was dry except for puddles, some puddles were occupied by fair numbers of muskrats, but the population of the observational stretch had been much reduced. Four of the eight territories were completely muskrat-vacant, and one of the others had lost most of its muskrats. In late September and early October, after rains had restored some of the flow, the muskrats were almost confined to a half mile of the creek.

When the trapping season opened on November 10, Earl Sturtz, the farmer having the most heavily populated stretch of creek, found 7 rotting dead lying close together -5 in the water and 2 on land. Two that were less decayed than the others were examined, and they proved to have still-recognizable hemorrhagic lesions. Sex and age ratios from the two disease victims and 19 trapped animals were 3 adult males, 2 adult females, 10 young males (including 2 August or September "kits"), 5 young females, and 1 young of undetermined sex. Of the 2 adult females, one had conceived 12 young in two litters assigned to June and July and the other had conceived 22 young in three litters assigned to May, June, and July. Perhaps the 21 specimens may be regarded as the equivalent of the population living in two of the four retained territories, which would give a late fall population of about 40 for the tract. Known losses of 7 dead of disease plus 19 trapped would leave about 15 to enter the winter after the trapping.

In 1946, Tract $H$ had six territories. Three of the territories were at sites that had been used in 1945, and four of the six were fairly uniformly spaced about 300 yards apart. The parts of the stream most favored by the muskrats during former years had no known breeding muskrats in 1946, though they still comprised the most attractive habitat. The latter, however, included a main burrow system in which mortality from hemorrhagic disease had been prominent in 1945. It is possible that animals settling there in 1946 died without being replaced, as the signs had been good in early April. By September, the creek had only puddles remaining, but five of the six original territories were still well used by muskrats. By freeze-up, with wintering conditions favorable, only three of the original territories had muskrats - about 30, most of which appeared to winter successfully. When the ice opened up in mid-March, 1947, good wintering signs could be seen in the three places where there had been any reason to expect them. Onion Creek in Tract $G$ had a single territory in 1946. It produced young and had good signs into September, but I doubt that any muskrats entered the winter there.

Tract $H$ had seven territories in 1947. The breeding population was very successful in rearing early-born young, but June floods put a maximum of about eight feet of water over the small stream and surely drowned many of the helpless young of that time. At least three of the territories had young born during the first half of July. By September, the creek was dry except for puddles. Only one ter- 
ritory had any sign of muskrats - and not much there. The whole tract became drought-exposed and muskrat-vacant soon after. Tract $\mathrm{G}$ had two territories in the spring and no muskrats left by early fall.

Onion Creek had some sign of muskrats almost everywhere in early April, 1948, but generally these animals did not settle in my observational areas. Tract $\mathrm{H}$ had one territory. By late fall, the creek in both tracts $\mathrm{G}$ and $\mathrm{H}$ was dry and muskrat-vacant. A single pellet of a horned owl, datable to early fall, 1948, was found in Tract G, and it consisted of remains of a "kit"-sized muskrat.

Tracts $\mathrm{G}$ and $\mathrm{H}$ of Onion Creek each had a breeding territory in 1949 , both abandoned quite early in the summer.

Tract $\mathrm{H}$ had one territory in 1950 . The original territorial site had been befouled with farm sewage in early summer; thereafter the territorial headquarters appeared about 250 yards upstream, in an inviting pool next to a corn field. The stream flow stopped in early August. By mid-August and early September, the most attractive puddle was at the territorial site. Although local animals were still present by freeze-up, the tracks of a young animal (probably leaving the area) were followed downstream for about a half mile on July 10, and apparently a single subadult drew off by itself to travel down the stream bed early in September. No sign of other movements far away from the territory could be made out during repeated visits from August, 1950, through February, 1951.

The data suggest that a pregnant female had come in during the 1950 spring dispersal, given birth to and raised a large litter, and that she still lived with nearly all of her young up to at least early winter in the best habitat for muskrats to be found for miles. The animals seemed disposed to stay there, next to the corn field, though they had little water left in the pool of their burrows at freeze-up, and this soon froze to the bottom. All known foraging in the corn field and dragging of ear corn to the pool was done by a very large muskrat, presumably the mother. A medium-sized mink became interested in the wintering burrow of the muskrats and had packed trails leading into it from about the first week of January, 1951, through most of February. Some outside activity on the part of a muskrat was noted in late January. This animal (a big one) made itself a retreat in a snowdrift (which was also assiduously tunneled by the mink) and stocked this with ear corn. When the first spring thaws came in late February and early March, the big muskrat was still alive. By early April, it was gone.

The two tracts of Onion Creek kept under observation had only a lone and restless muskrat in mid-June, 1951, that one in Tract G. Repeated visits yielded no evidence of other muskrat movements along this stream, even at the height of the spring dispersal. Nor were adjusting animals known to have followed this travel route in late summer and fall, though they did move into some small-stream habitats that looked no more inviting. Early summer floods resulted in pronounced changes in the stream bed. 
Tract $\mathrm{H}$ had eight territories in 1952, but pronounced adjustments were occurring as early as early July. The stream was all but dry and muskrat-vacant as early as September. By late October, the only muskrats left were in the vicinity of a schoolhouse sewage flow next to a corn field, and it could be seen that some were then abandoning that site, though it was well situated with respect to food. The tract had a lone animal territory at the sewage flow in the early summer of 1953, but not thereafter for the rest of the year.

Tract G had no more known muskrats for the period, 1953-57.

By early June, 1954, four territories had been established in Tract $\mathrm{H}$ but, by mid-July, only two widely separated muskrats were still in residence. Much movement by transients was in progress in early June. No muskrats were known to be left by fall.

Tract $\mathrm{H}$ had five territories as of early June, 1955, of which three were productive of young. One territory was lost in early summer because of the hemorrhagic disease. Three of the others (including two that had been highly productive of young in early summer) were abandoned in late July, despite a fair amount of water in the creek and the presence of raided corn fields near by. In raiding corn fields, these muskrats were merely eating the succulent parts of the corn plants, without displaying any awareness of the special food values offered by the ears). The adjusting movements of the muskrats were largely untraceable, but two upstream trails were followed for about 700 yards on August 13, and a single downstream trail was found on August 23 in a long stretch having no other muskrat signs. The fifth territory, which was next to a corn field systematically raided for ears, was maintained until the opening of the trapping season on November 20, despite death of the adult female from hemorrhagic disease and drought exposure of the maintained burrows.

The muskrats at this place did much digging, plugging, plastering, and storing. Their industry and persistence contrasted decidedly with the behavior of the two other groups of adults and young that left long before they had reason to feel forced by drought. The adult female, which died on August 22, had 29 placental scars in four sets, with birth dates assigned to early in the months of April, May, June, and July. Twelve muskrats entered the winter here, for that was the number caught by Ted Toms, a farmer who was forced to trap them out because they plugged a drain from his house.

In the west part of Tract $\mathrm{H}$, the creek remained a little wet at the opening of the school sewage drain. By midsummer, 1955, this place was visited by one of the apparent occupants of a practically abandoned territory lying about a quarter of a mile downstream. By fall, what seemed to be the same muskrat was winterizing the sewage drain and stocking it with ear corn. Here the animal successfully wintered, and, after some commuting back and forth between the drain and the old territorial site in the spring of 1956, it returned to live at the drain. Despite the lack of surface water and the foulness of the sewage drain, the animal maintained a territory by itself until 
July. It then disappeared, leaving all observational stretches of Onion Creek muskrat-vacant for the rest of 1956 and through 1957.

\section{Rainbolt Ponds}

The first evidence of these ponds being occupied by muskrats during the years of the central Iowa studies was found in the fall of 1938. A known minimum of five individuals then moved into the upper pond, which was the leeper of the two ponds. One of these animals came out on the ice, obviously sick, on January 8, 1939, remaining there until its death on the morning of January 10. It proved to be a lean subadult male, which recently had wrung off a forefoot in a trap. Dr. E. R. Becker examined it for parasites and found a massive intestinal infection of the fluke, Fibricola, and an associated catarrhal exudate.

An intensive study of responsiveness of muskrats to sinking frost lines in shallow water was carried on, beginning in mid-December, 1938, at which time the ice was about five inches thick. In early February, the mud at the sides of the submerged muskrat channels was frozen to a depth of nearly eighteen inches. By deepening their burrows and passageways to a depth of about two and a half feet, and subsisting largely upon stored ear corn, the muskrats avoided serious crises until the ponds were completely flooded and frozen over in mid-February. The flooding covered every conceivable place where muskrats could be living in lodge or burrow chambers about the upper pond, and the ice-seal was still unbroken on February 22. Either the muskrats had been permanently evicted by the flood to wander about the winter countryside or they had drowned underground. No further evidence of the species was detected at the Rainbolt Ponds until March 15, 1939, when the spring dispersal brought in a big animal from the outside.

The upper pond had one territory in 1939. What were judged to have been an adult female and a few survivors from an early litter remained most of the summer, to disappear by early fall, as the pond became drought-exposed.

Following absence of muskrats in 1940, both upper and lower ponds had their separate territories in 1941. Muskrats remained present by fall in good numbers not only in the ponds but also along a tile flow leading to the upper pond: an estimated 40 animals, of which I examined 7 trapped carcasses. These were an adult male, an adult female having 37 placental scars in four sets (including one set for a litter assigned to August), 3 young males, a young female, and a young of undetermined sex. My estimate was that about 15 successfully wintered, 1941-42.

In 1942, two territories were established in the upper pond, one in the lower pond, and one along the tile flow leading to the upper pond from the north. The situation was so interesting that these ponds were made the site of a particularly intensive study during the summer and fall months. Not only was the biology of muskrats 
living under crowded conditions investigated but also some of the economic aspects of their heavy raiding of adjoining corn fields. Throughout this work I received agreeable cooperation from the owner, Simon Kemmerer, and his family.

The four breeding pairs (or equivalent) living at the Rainbolt Ponds and the associated tile flow comprised the highest local density occuring anywhere within the parts of the Squaw Creek drainage that were kept under observation in 1942. Early in the summer, these pairs and their offspring subsisted mainly upon the grasses, sedges, and young weeds of cultivation of the meadow-like shores. Beginning about the middle of July, the muskrats increasingly raided the corn fields, which had been planted in the lowlands on all sides of the ponds. On the whole, the heaviest raiding occurred after the ears had reached the milk stage, and it continued nearly up to the middle of November. Counts of muskrat-cut corn plants made from July 17 to November 11 totaled 5,243, of which 858 were water-stunted or otherwise defective plants that never would have produced corn, anyway. This leaves 4,385 potentially productive corn plants destroyed by the muskrats. Following the criteria given on page 420 of Errington (1938), 4,385 plants should have been close to the equivalent of about 3,720 ears, and 3,720 ears should have been close to about 24.4 bushels. Allowing further for unmeasured quantities of ears picked up from the ground by the muskrats that foraged without cutting stalks, a total of perhaps 30 bushels of corn destroyed, consumed, or stored by the local muskrats might be arrived at. This, I feel was the most accurate study of exploitation by muskrats of a choice source of food that I have made, and it also represents the severest direct crop damage by muskrats that I have seen.

The field data are sufficiently complete to establish the approximate dates of birth of 15 litters for the 4 adult females, and there is evidence that all 4 probably gave birth to 4 litters each. If calculations be restricted to the proven 15 litters, application of the mean of 8.33 young per litter shown by the placental scars of 5 trapped specimens of adult females from the Squaw Creek drainage would give a total of 125 young conceived or born at or near the Rainbolt Ponds, between spring and late summer, 1942. Not anywhere near this number of young muskrats lived at the ponds at any one time, however, for juvenile mortality involving members of many litters was quite pronounced during the month of August - involving not only young born in July and June but also some of the early-born young.

On August 18, I estimated the number of muskrats of adult and subadult sizes living about three of the Rainbolt territories at about 35. If allowance of about a dozen large muskrats more be made for the fourth territory (for which I did not attempt an estimate at the time), close to 50 adult or nearly grown muskrats should have been present, as of mid-August. This would suggest the actual rearing of something like 40 young from five or six early litters. In addition, 
there were the young from ten mid-season to late litters, including one born about the last of July and another in August, but these late ones did not get along well. There may have been, still as of mid-August, about 20 recently weaned or suckling sizes of young, or a maximum population of perhaps 70 for the Rainbolt Ponds. By late fall, prior to the fur trapping, the remaining population was probably around 60 .

Detected losses of muskrats at the Rainbolt Ponds occurred through the agencies of predation and intraspecific attack, accentuated by crowding and by low water stages in late summer. Field notes describe a young of about ten days found August 10, at the mouth of a burrow; it was freshly dead, with head, forequarters, hind legs, and tail eaten away by an adult-sized muskrat.

Of 87 raccoon scats deposited about the ponds during August and September, a single one dated to August 16 contained remains of a young muskrat of about six weeks. A raccoon was known to have dug out parts of a well-used burrow system about that time and also on August 18. As the burrow was the same one outside of which the muskrat-eaten young of ten days had been found, the raccoon may have been attracted by more dead young within, such as other victims of intraspecific strife or cannibalism; but then, too, I know that the digger may have caught the particular six-weeks muskrat that it ate, either as the victim swam past or was cornered in one of the numerous blind alleys of the burrow that the weaned sizes of young regularly frequented.

Aside from an adult female killed in October in a corn field by a medium-sized predator (raccoon or canid?), the rest of the detected predation suffered by the Rainbolt muskrats was from minks. No muskrat remains were found in 96 mink scats deposited in May, June, and July, nor in 15 for September and October, but 11 of 58 August scats did contain muskrat remains. The muskrats eaten by the minks represented members of at least five litters of young of three weeks up to subadults, largely of the sizes that were less proficient in taking care of themselves.

Eleven muskrats legally trapped from the ponds during the 194243 fur season were 2 adult males, 6 young males, and 3 young females. Illegal trapping probably had greatly reduced the muskrat population of the ponds long before the opening of the fur season.

In 1943, the upper pond had one territory and the lower pond had two. The lower pond was in process of drying and abandonment by mid-September, but there was no important drift of muskrats from it into the much more attractive upper pond. Seven trapped specimens from the upper pond were examined during the 1943-44 fur season: an adult male, an adult female having 15 placental scars representing two early-season litters, 4 young males, and a young female.

Both ponds had lone territories in 1944. By late fall, the upper 
pond had an estimated 20 muskrats; the lower pond, none. By the opening of the trapping season on November 10, few muskrats were left. Three trapped carcasses were of an adult male and 2 young females. An adult female, trapped from a neighboring brook but believed to have passed the 1944 breeding season at one of the Rainbolt Ponds, had 28 placental scars of four ages, the latest datable to about July.

The upper pond had a territory in 1945, but it dried up. No muskrats entered the winter. In 1946, the upper pond had a territory, and good muskrat signs continued to be present until at least late fall, despite low water levels and foulness of the remaining water. In 1947, neither pond had a territory, but about a dozen muskrats moved into the upper pond in late summer, though its water level had been much reduced. These animals did not remain to winter.

A territory was established at the lower pond in 1948, but why the animals settled here was not wholly apparent. The upper pond was in far more attractive condition for muskrats. Neither pond had any muskrats remaining by late fall, nor any in residence again until 1952.

The 1952 signs indicated that a pregnant female came into the north pond in late June, gave birth to and raised most of her litter, and then departed with them in early fall. After two muskratless years, 1953-54, what appeared to have been a lone animal maintained a territory during the first half of the summer of 1955. No sign of muskrats even visiting the ponds was found in 1956 and 1957.

\section{Nobel Christianson Ponds}

The wet season of 1942 seemed to make these ponds really habitable for muskrats for the first time in our central Iowa studies. They had one recorded territory, which was evidently very productive, for by late fall there were four large lodges and many smaller ones. A population estimate of about 20 would seem to fit in fairly well with the destruction by the muskrats of a tenth of an acre of corn planted next to the ponds.

The ponds were in fair to good condition for muskrats in the spring of 1943, though tiling operations began in early May. None of twelve mink scats deposited in early April contained muskrat remains. Three breeding territories were established, and 3 trapped adult females corresponding to these were examined during the fur trapping in November. One specimen had twenty-eight placental scars in three late spring and early summer sets; another, twenty-one scars in three sets, of which the latest was assigned to late July; and a third, forty scars in four sets, representing litters judged to have been born from mid-April to mid-July. In addition to the 3 adult females, the trapped sample included an adult male, 9 young males, and 7 young females. The young females included an animal born 
about late July. These 20 specimens comprised possibly two-thirds of the animals remaining by the beginning of the trapping on November 10 .

The tiling begun in May was not completed in 1943 to the extent that it perceptibly affected the water levels of the ponds, and the deeper parts remained habitable for muskrats during the several intermittent dry periods of late summer and fall. Of the 89 young in 10 litters that presumably had been conceived or born at these ponds in 1943, one litter was probably lost because of human (my own) disturbance. Even so, a reduction of the local young by November 10 to not much more than a third of the total conceived or born reflects a sharp decline. The mechanism behind the decline was not specifically determined. Undoubtedly, there was some emigration in response to repeated exposure of the shallower parts, and there may have been undetected mortality from mink predation, intraspecific attacks, or disease.

Between late December, 1943, and late January, 1944, the marsh bottom became drought-exposed, and 2 January mink scats contained muskrat remains. For several weeks, I had not thought that any muskrats could be still alive, there having been no recognized external sign, whatever. Then a rain (2.06 inches) on January 27 refilled the ponds, and on February 1, a most revealing film of ice had covered the water. Under the ice, I saw 4 different muskrats swimming, and bubble signs indicated the presence of still more. Quite evidently, the whole population surviving the trapping and the attentions of the mink had done so by staying practically sealed in nearly dry retreats - notably in a single burrow system that had been well-stocked with ear corn from the late-fall raiding of an adjacent field. By midFebruary, the wintering muskrats were congregated in one big lodge, though later in the month they rehabilitated some of the previously unused lodges. It may be judged that at least a half dozen muskrats successfully wintered.

The Christianson ponds had the equivalent of two breeding pairs or about five adults in 1944. Though practically full of water in late March and refilled by the rains of May and June, these ponds had no surface water left by July 25 (just before another heavy rain began), and the muskrat sign was that of animals living under drought conditions. A single mink scat from late July contained muskrat remains. By late August, after partial drought relief early in the month (nearly 2 inches of rain fell on August 4), the ponds were again dry, and the muskrats were living in heavy weed growths and ground holes. Rains totaling 3.46 inches, August 25-27, did not appreciably change the local situation. The better places still had abundant muskrat signs as late as early October, but thereafter the exposed population suffered severe mortality.

(It should be mentioned that the tiling operations begun in May, 1943, had been deferred until late October, 1944, so that the water fluctuations of the ponds were still reflecting more or less natural 
happenings in marginal habitat over most of these two years.)

On October 17, 1944, a freshly dead subadult victim of the hemorrhagic disease was found outside of a burrow entrance, and 27 of 29 mink scats deposited between that date and October 27 contained muskrat remains. At the latter time, I excavated the 2 main lodges and found inside of one the mink-eaten remains of a freshly dead subadult. With the tiling becoming effective in late October, the Christianson Ponds ceased to represent even marginal habitat, and no muskrats succeeded in wintering there either in 1944-45 or later, for the duration of the investigation.

What had the appearance of a breeding territory was established in 1945 in a roadside ditch adjacent to the newly-drained ponds, but this site dried out and was abandoned in mid-July.

\section{J. H. Turner Pasture Pond}

The 1942 spring dispersal put the equivalent of two pairs of muskrats into the pond. As of mid-November, the population was estimated at about 35. Five trapped carcasses from the 1942-43 fur season were an adult male, an adult female (with 13 placental scars representing two early litters), 2 young males, and 1 young female.

In 1943, there were seven territories established on something over two acres of habitable environment. In early November, the pond had sixteen large, eleven medium-sized, and nine small lodges, with numerous bank burrows stocked with duck potatoes. Eightyfour muskrats were trapped from two acres of pond, of which 72 were examined: 6 adult males, 5 adult females, 22 young males (including 3 "kits" judged to have been August-born young), and 39 young females (including 7 more "kits"). The sample of 5 adult females did not include the mother of the "kits," for only one of those examined had given birth to a litter dated as late as late June. The "kits" were thought to have represented the members of a single large late litter, as these were trapped from about the same part of the pond. Of the sample of 5 adult females, one had conceived a single litter of 5 (that one born about May); one, two litters; and 3, three litters each. These twelve litters totaled 75 young.

It would be a good guess that the female giving birth to the August young had conceived four litters and that her litters had been big - perhaps totaling 40 or more for the 1943 season. It is also likely that the female of the seventh territory had given birth to two or three litters - probably three, as had most of the adult females examined, or to about 20 young during the season. This would add up to a total of nineteen litters or about 165 young born at or very near the pond. My estimate of the population remaining after the fur trapping was about 30 animals. This figure, added to the trapping catch of 84, would give a fall population of about 115 .

The water was about a foot and a half in depth in the deeper parts and barely covered the mud of the shallows. There was such an abundance of duck potatoes available to the muskrats - either 
in unfrozen mud under the ice or stored in chambers - that the muskrats probably had no food crisis all winter. Nevertheless, the sinking of the frost line may have resulted in some vulnerability to mink predation. On December 30, 1943, only one lodge was seen to have had an unrepaired mink hole. By January 21, 1944, eight of the larger lodges and one of the bank burrows were "bored." Of four mink scats deposited in December and early January, none contained muskrat remains, but one did of six scats dated to late January.

As in 1943, there were seven maintained territories in the spring of 1944. Water and vegetation remained in attractive condition for muskrats throughout the summer. Insufficient trapping was done to provide the specimen data needed to calculate the 1944 fall population, but very similar signs about the pond in 1943 and 1944 might suggest similar populations for both years, or about 115 for the fall of 1944, as in 1943. By late November, a tremendous number of signs could be seen, and a density of about 50 muskrats per acre may be judged to have been present in January, 1945, after a small amount of trapping.

This density really made an impact on the habitat. A small low island was burrowed about as completely as a piece of land could be. In the surrounding pasture, hogs learned to root for duck potatoes stored in the upper parts of the muskrat burrows. Some ramifying sets of burrows had bushels of duck potatoes packed in them. Despite its top-heaviness, the muskrat population seemed to winter fairly well, though a putrid adult female that washed ashore in late March may have been a victim of undiagnosed disease.

The pond had six territories in 1945. By mid-September, it had water covering about half of its bottom, but the borders were badly trampled by livestock. The small low island was the only place then showing continued use by muskrats, and it too was trampled, though not as much as the outer borders of the pond. Pigs also opened up the island burrows to eat the duck potatoes stored by the muskrats. By early November, the only surface water was in a central puddle and in the channels of the muskrat lodges. All of the pond's muskrats, as of this time, were concentrated in four muddy lodges and in a series of burrows at one side of the low island.

Partly as accommodation to me, the pond was trapped drastically during the 1945-46 fur season, and 28 muskrats (nearly the total remnant population) were caught. Twenty-two carcasses were examined: an adult male, 3 adult females, 12 young males (including 2 born in late July or August), and 6 young females. One of the adult females had conceived 12 young in two fairly early litters, and the other two adult females had conceived three litters each, mostly early in the breeding season and totaling 24 and 25 young, respectively.

There was no 1946 breeding population of muskrats at the pond, but muskrats came in to establish themselves during the extensive overland movements of August and September. By early winter, an estimated 8 muskrats lived in 2 large lodges. These were left un- 
molested during the 1946-47 fur season, and most of the animals were judged to have wintered.

The pond had two territories in 1947. Early in the summer, it was in good condition for muskrats, despite the livestock damage of the previous year, but by mid-August the bottom was exposed and hogs were working it over for duck potatoes. No muskrats were left by late fall.

From 1948 through 1957, the pond was in more or less attractive condition for muskrats in the springs and early summers of most years, yet no further evidence of muskrats occupying or even visiting it was found.

\section{Montgomery Creek and Allen Turner Estate Oxbows}

Neither the observed stretch of Montgomery Creek in Section 35 of Tract $F$ nor the oxbow pools of the pasture lying to the north of the creek had any known muskrats in them from 1934 through 1940.

In 1941, the most attractive of the oxbow pools had a territory, and it had many muskrats remaining by the opening of the 194142 fur season. Seven trapped specimens were an adult male, an adult female (with 17 placental scars representing two midsummer sets), 2 young males, and 3 young females. By mid-December, when the trapping was about over, many fresh bubble and feeding signs were still to be seen under the ice, and I estimated that as many wintered as had been trapped. These ponds were away from any regularly used travel route of muskrats, so I doubt that any muskrats had moved into them in late summer and fall. The pre-trapping population may therefore have consisted of the original pair of adults and about a dozen of the 17 young conceived.

The territorial site of 1941 at the main pool was also used in 1942. The whole series of oxbows had high water during the general flood periods, though not enough to have been really damaging to the muskrats. Some of the muskrats living at the oxbows also frequented Montgomery Creek to the south, which also had a lone animal territory. The latter animal is thought to have been an unmated adult female, as one of these was found in 11 carcasses of muskrats trapped at the pond during the 1942-43 fur season. The other specimens in the trapped sample were an adult male, five young males, and four young females. Several more muskrats survived the trapping, and my estimate of the pre-trapping population was about 17 , including the unbred adult female that presumably had maintained the Montgomery Creek territory.

The main pond had another territory in 1943, at the same site as those for the preceding two years. This was not only a productive territory but it was one that probably drew in some muskrats during the late summer and fall adjustments. The observational stretch of Montgomery Creek itself had no maintained territory in 1943, though by fall it had a heavy population. Twenty-six trapped carcasses from the pond and Montgomery Creek were an adult female (with 25 
placental scars in three sets, the latest dated to late July), 14 young males, and 11 young females.

In 1944, the pond had its territory at what had come to be the usual site. Montgomery Creek also had a territory about a quarter mile away. Thirty-five trapped carcasses were examined during the 194445 fur season from Section 35 in Tract F, mostly, but not exclusively, from the Turner Estate oxbow and adjacent Montgomery Creek. These were 2 adult males, 4 adult females, 12 young males, 14 young females, and 3 young of undetermined sex. One of the above adult females had conceived a single litter of 8 , born about May; another had conceived 19 young in three litters born during the first half of the breeding season; and 2 four-litter females had conceived 32 and 33 young, respectively, with the fourth litters of each having been born about August.

The pond and adjacent Montgomery Creek each had a territory at the old sites in 1945. These territories became drought-exposed and abandoned during the summer.

Two of the ponds had territories in 1946, both at sites not previously occupied, but by midfall the pond muskrats had moved into adjacent Montgomery Creek. From late fall, 1946, to the fall of 1947, the Turner Estate ponds were without resident muskrats. About midfall, 1947, an estimated 10 muskrats moved into the main pond; by late fall the main pond was nearly dry, and the muskrats had moved on again.

In 1948, the wet outlet of the main pond had a territory, which was closely observed while in process of establishment during the second week of May. No muskrats were left here by late fall.

Neither the ponds nor the adjacent stretch of Montgomery Creek had muskrats from 1949 through 1951, but in 1952 a probable loneanimal territory was established along the creek just south of the main pond. Another lone-animal territory was established at one of the smaller pasture ponds. These territories were dry and muskratvacant by fall.

In 1953, the observational stretch of Montgomery Creek had three territories, and one of the pasture ponds had another. These, too, were drought-exposed and abandoned by late fall. In 1955, the creek had a probable lone-animal territory, which was abandoned in midsummer. No muskrat remains were found in 24 mink scats dated to about the time of disappearance of the muskrat. Neither ponds nor the stretch of creek had resident muskrats in 1956 and 1957.

\section{York Pond and Hutchinson's Lake}

Neither of these ponds, which are connected by a ditched channel, had observed evidence of muskrats in 1934 and 1935. In 1936, the larger, Hutchinson's Lake, had a territory, the occupants of which departed during the early weeks of the drought.

After a muskratless 1937, Hutchinson's Lake again had a territory 
in 1938, this at the site of the 1936 territory. My interpretation of the 1938 signs is that a pregnant female (perhaps one of those earlier assigned to a breeding territory along the Squaw Creek channel) came in about midsummer, gave birth to and raised most of the young of a single litter. The bubble and feeding signs under the ice during the winter of 1938-39 indicated the presence of about a half dozen animals. The place flooded so badly in cold weather -11 degrees below zero Fahrenheit - in mid-February that I do not see how any of its muskrats could have stayed there and remained alive.

York Pond, but not Hutchinson's Lake, had a territory in 1939, but this pond went completely dry during the last of May. The muskrats did much digging and deepening of their main burrow system before abandoning it about May 27, following which it was taken over as a rearing den for a family of minks. No muskrat remains were found in 140 mink scats examined from the den latrines. Neither York Pond nor Hutchinson's Lake had muskrats for the rest of 1939, nor in 1940.

In 1941 York Pond again had a territory, this one on the opposite side of the pond from the site of 1939. It nearly dried up in midAugust between floodings, and it appears that only four or five young were raised there. This group also shifted its living quarters to the deeper part of the ditch connecting the pond with Hutchinson's Lake. Some animals wintered here, 1941-42.

In 1942, York Pond had a territory at the same site as in 1941. The late-fall signs of 1942 were those of a thriving family group. By mid-October, two main sets of burrows were in regular use and stocked with ear corn. By the opening of the trapping season on December 1, the population had been much reduced, probably by illegal trapping in early November, and the legitimate trapper caught only 3. I would estimate the pre-trapping population at about 20.

Both Hutchinson's Lake and York Pond had territories in 1943. York Pond was dry and abandoned by muskrats in late fall, but it may be suspected that the occupants had moved down the ditch to Hutchinson's Lake, where water conditions were much better. The severe trapping pressure of the 1943-44 fur season seemed annihilative for the muskrats of Hutchinson's Lake, though I was unable to examine specimens known to have been taken from this particular place.

In 1944, York Pond had two territories (including one at the usual site), and the ditch leading to Hutchinson's Lake had one territory. These territories were at least moderately productive, but all three showed a substantial diminution of sign by late fall, and probably no more than a dozen muskrats remained by the opening of the fur season, November 10.

Neither pond had resident muskrats in 1945. In 1946, Hutchinson's Lake had a territory, and so did York Pond, that of the latter being at the principal site used since 1941. Both ponds were aban- 
doned in late summer and fall of 1946. Neither pond had a territory in 1947, but about 5 muskrats came into Hutchinson's Lake and built a lodge there in October.

After three muskratless years, 1948-50, two territories were established at Hutchinson's Lake in 1951 - including one probably by a pregnant female coming in alone. The territorial site of the latter had been abandoned about the first of August, and the family group had established itself about 200 yards away in the ditch leading to York Pond. Then, by mid-September, these animals had moved back about 90 yards toward Hutchinson's Lake and had dug a new burrow system next to a raided corn field. By the end of September, the muskrats appeared to have abandoned the new burrow system after stocking it with ear corn. Pigs and raccoons dug around the exposed burrow entrances but did not get far inside. The second 1951 territory was highly productive, but was abandoned by the entire group about mid-August. Trail signs across 150 yards of pasture identified this territory as the source of the large group of muskrats appearing at the main pool of the county line ditch north of Squaw Creek, which is referred to later in this chapter.

The ditch connecting York Pond and Hutchinson's Lake had a territory in 1952, but the animals were evicted by drought in late summer. In 1953, both the above ditch and York Pond had territories. The one at York Pond seemed to be maintained by a lone animal, which abandoned it to move down the ditch in late June or early July, while a family group of muskrats at the original ditch territory remained until fall. By early October, only what seemed to be a single muskrat remained at the ditch. The only muskrat signs observed in 1954 were of a lone animal at the ditch in midNovember. In 1955, a few muskrats lived along the ditch for a time in late July and early August, then disappeared. No sign of muskrats was seen throughout 1956 and 1957.

\section{Old Oxbow Series West of Squaw Creek}

This series of oxbows, lined up in about three-quarters of a mile of an old channel of Squaw Creek in Tract D, had no known muskrats from 1934 through 1939. In 1940, a few muskrats frequented these oxbows at the time of the August floods, and at least one of them was then killed by a mink.

In 1941, an oxbow pool had a territory, and in October, a large family group almost disappeared without detected reason and without corresponding establishment along the practically unoccupied three-quarter-mile stretch of Squaw Creek lying to the east.

In 1942, the oxbow series had two territories, and a third territory (one of those listed as a Squaw Creek channel territory earlier in this chapter) was situated at a junction of the oxbow series with the creek. The occupants of the latter worked along both the creek and the adjacent oxbow series. In early June, it was seen that the water levels of the oxbows were high but without any overflow into the creek. By the 
first of July, despite some floodings, one of the territories had active young of about five weeks. On September 23, after a severe flood beginning September 14, the pools showed good signs, and several burrows and flood nests were in use. Signs under the new ice of late October indicated that muskrats were living in only three places along the oxbow series, possibly about 15 in all, including an animal living alone. By mid-November, the water was down to about a foot and a half below the summer level, thus leaving the oxbows nearly dry. My estimates were of a lone animal at one place, two or three at another, and several at the place having the most signs - about ten, all together. Beyond doubt, many of the muskrats moved over to Squaw Creek in late summer and early fall. A half-mile stretch of creek having hardly a muskrat in it then lay invitingly within a few hundred yards of one of the well-used oxbow pools; and muskrat paths between pool and creek could be distinguished at this time.

The oxbow series had no territories in 1943, but it had rather general signs of newcomers in late August and more or less heavy signs in three places by September 8. I think that these oxbows were virtually depopulated by severe trapping during the 1943-44 season.

The oxbow series had a territory in 1944, centering about a burrow that had been dug and temporarily occupied in previous years. Few muskrats were left by late fall. The series was muskrat-vacant in 1945, but in 1946, three territories were established there, to be abandoned later in the summer. In 1947, no territories were established in spring or early summer, but possibly a half-dozen muskrats came in during late August or early September, despite the shrinkage of the waters because of the drought; none was left by late fall. In 1948, the series had another territory, near a territorial site of previous years, but again, the muskrats were gone by late fall.

The series had no more known muskrats until a territory was established in the spring of 1952. The latter was abandoned, after occupancy by a considerable group of muskrats, in late June or early July. Then, a probable lone muskrat frequented one of the pools for a time during the summer of 1954. There was none thereafter through 1957.

It should be mentioned that the oxbow series lost habitability for muskrats during the early fifties. All but one major pool filled with silt, until it became difficult even to find the original locations of some of them. Even during wet seasons, the pools would be little more than puddles.

\section{Pasture Brook Near Rainbolt Ponds}

This brook (including its deep head pool next to a large tile) was muskrat-vacant from 1934 through 1941. In late summer, 1942, some animals established quarters and probably wintered at least fairly well.

In 1943, two territories were established along about a quarter mile of the brook; one of these was not much more than 100 yards from 
one of the territories of the Squaw Creek channel. The latter brook territory had only one or two muskrats left by mid-September, while the upstream territory then had splendid signs. An adult male, an adult female (with 18 placental scars representing three early to midsummer litters), 2 young males, and a young female were examined during the 1943-44 fur season, together with 2 young males and 3 young females from a stretch of neighboring brook lying outside the observational area to the east.

In 1944, the brook had a territory, but both adults were found freshly dead of hemorrhagic disease during the summer. The brook nevertheless remained well populated with young animals and, by fall, some more muskrats almost certainly had moved over from the Rainbolt Ponds. Carcasses of muskrats taken by trappers during the 1944-45 fur season were 4 adult males, one adult female, one young male, and one young female. About as many more muskrats were left to winter.

In 1945, the brook had a territory in spring and early summer, later to be depopulated. In 1946, it had another territory, which had few muskrats left by late August, and the hemorrhagic disease was suspected as a reducing agency in this case.

In 1947, the brook again had a territory and splendid signs throughout the summer and fall. My estimate was of about 20 muskrats entering the winter. These were the best-situated muskrats in tracts $\mathrm{A}-\mathrm{F}$, but even so, a specimen of a young female examined in early winter was in lean condition.

In 1948, the brook again had a territory, and a population of about a half dozen remained by fall. It had another territory in 1949 and one in 1952, both of which were muskrat-vacant before the summer was over. In 1955, it had a lone animal territory which was maintained until early in August; thereafter, no more muskrats through 1957.

\section{New Gravel-pit Pools on Turner Estate}

These pools, so new as to be barren of muskrat foods though with attractive depths of water, had two subadults moving in during late fall, 1947. Both were captured by hand and marked by toe-clipping as they foraged in a stock-pastured corn field. When last handled alive after the middle of February, 1948, they were both in extremely poor condition, continuing to risk their lives in all kinds of winter weather for the trifling plunder-including pieces of muddy corn stalks and roots - they were able to find in the field. The one toe-clipped specimen actually retrieved after death for posting had typical liver lesions of the hemorrhagic disease. In view of the isolation of these 2 gravel-pit muskrats and the absence of old muskrat retreats at the ponds, the occurrence of a case of the hemorrhagic disease - evidently just getting a start - is hard to explain. The animals certainly withstood much hunger, and one of them seemed blind from freezing its eyes. 
By 1952, there was sufficient natural vegetation in the water of the new gravel-pit pools to make them more or less habitable for muskrats. Two territories were established in midsummer by muskrats moving in from overcrowded Squaw Creek, and by late summer and fall these were full of young muskrats of various ages. My estimate of the population present in mid-October was between 30 and 40 , mostly centered about the original territories. These animals were practically trapped out during the 1952-53 fur season.

In 1953, the gravel-pit pools had a territory, but by September signs of only a single large animal could be seen. By early winter, the latter animal was gone, and the pools remained without known muskrats throughout 1954. In late summer, 1955, a substantial number of muskrats came into the pools and stayed for a few weeks; they were gone by midfall. No signs of muskrats were seen about the pools in 1956 .

A big muskrat stayed around throughout the summer of 1957, then an estimated 10 to 15 established themselves during the fall, apparently to winter well.

\section{Brooks Northwest of Gilbert}

The two brooks here referred to are in the west half of Section 36 of Tract F. One is a county drain, first appearing on the surface as a pool in front of a tile, which will suffice to distinguish it from the natural brook in the following text.

To the best of my information, neither brook had muskrats in residence from 1934 through 1940, though I may have overlooked some signs of muskrats in the earlier years of the central Iowa investigations. The natural brook had a territory in 1941, and 8 muskrats were here taken by a trapper during the 1941-42 fur season.

In 1942, both the natural brook and the pool at the head of the county drain flow had territories. The natural brook had localized signs of probably a single litter by mid-October, but what seemed to be only a single adult remained to winter. I think that the others abandoned their old territory when it dried out in late fall, to congregate downstream at the junction of the brook with Squaw Creek, where there were some muskrats that might be accounted for on this basis. The remaining large animal foraged actively during the winter.

In August, 1942, at the site of the county drain territory, a big dog devoted much time to digging out muskrat burrows, and the muskrats responded by digging new burrows. The muskrats of active sizes seemed to take care of themselves without difficulty, for, concealed by submerged plant growths, they could move unobtrusively through the shallow water from one burrow entrance to another. In late summer, the territory was re-established in a pool between two and three hundred yards downstream from the usual sites of activity of the dog. No trapped carcasses were examined from the county drain during the 1942-43 fur season, but Wallace Hadaway told me that he caught 6 from the vicinity of the pool. From his description, 
I judged that 2 of his muskrats had been born in August or September. I think it likely that the dog killed most of the members of 2 late-born litters, and that a total of about 10 may have represented the pre-trapping fall population of the upper part of the county drain. Wintering signs of a very few muskrats could be seen about one burrow. No muskrat remains were found in five winter mink scats.

The natural brook had three territories in 1943. Two of these territories were dry and abandoned by September, as was the third by late fall, except for a few muskrats remaining in residence at one place. One of the latter apparently was killed by a mink, as one of ten mink scats dated to November contained muskrat remains. On the other hand, a collection of 216 mink scats gathered locally from May through October contained no muskrat remains. These scats were mostly from a family group of minks having a den in one of the previous year's muskrat burrows along the county drain. The drain itself had a probable lone-animal territory in 1943 .

After two years of no resident muskrats, the natural brook had a territory in 1946, which was maintained in excellent condition next to a corn field until at least midfall; it had no muskrats in residence in 1947. The county drain, which had been muskratless in 1944, 1945, and 1946, had 2 known muskrats in late fall and early winter, 194748.

In the summer of 1948, the pool of the county drain was dredged, and the brook into which it drained was deepened and straightened into a ditch. This meant considerable modification as muskrat habitat, without making it wholly unattractive for the species. Neither this place nor the natural brook had more than an occasional transient from 1948 through 1951.

In 1952, both had territories of which that of the natural brook was highly productive of young but almost abandoned by October. The territory of the county drain seemed to be maintained by a lone animal throughout the summer and well into the fall, if not through the winter of 1952-53. In 1953, the natural brook had a lone-animal territory, and the county drain had no known muskrats. Both were without known muskrats in 1954.

In 1955, the natural brook had two territories, and the county drain had a probable lone-animal territory. The natural brook territories were highly productive early in the summer, but most of the animals left about the first of August. By late August, the observational stretch of brook was all but abandoned, with the remaining few muskrats localized in one fairly deep pool and raiding an adjacent corn field. By early September, the signs indicated that muskrats were coming into the pool from outside; and heavy signs were characteristic of this place through most of October. As the water level went down until the burrow entrances became exposed in late October, the muskrats largely disappeared - though some few animals continued repairing the burrows, raiding the corn field, and depredating upon 
the bullheads, carp, and other stream fishes stranded in the shallow water. By the first of November, a big mink was using the thenexposed burrows. I could make out no positive sign of living muskrats until late in the winter of 1955-56, when it became apparent that some muskrats did remain alive in the corn-stocked burrow chambers.

The dry pool of the natural brook regained enough water in the spring to serve as a productive territorial site in 1956. The resident pair had three litters, these born about mid-April, mid-May, and mid-June. By mid-July, the pool was drought-exposed once more and, a week later, the residents were engaging in limited upstream and downstream adjustments. There was some mortality involving at least the youngest litter at this time. By the end of the first week of August, the territory was abandoned, except for a probable lone animal living at a muddy hole a short distance downstream from the dry pool. Despite great effort, I did not succeed in tracing the route of movement of the muskrats when they abandoned the territory, seemingly as a family group.

Neither the county drain nor the natural brook had any muskrat signs throughout 1957.

\section{Ditch and Brook Habitats North of Onion Creek}

These marginal habitats along the west edge of Tract $G$ consisted of a quarter mile of pasture brook leading from a country drain and a series of roadside ditch pools along the Boone-Story County line.

After the beginning of the central Iowa studies, muskrats were first known to be trying to live along the pasture brook in 1941, when about five animals took up residence in the fall. These foraged in the pasture and stream-edge growths next to the brook by working under the protection of snowdrifts when winter came. They were not confronted by the most desperate of emergencies, but they were vulnerable to mink predation. Three of thirteen winter and early spring mink scats from this place contained muskrat remains. The muskrats that succeeded in wintering left during the spring dispersal of 1942.

A single large muskrat moved in again about mid-July, 1942. It raided a corn field throughout August and September, cutting a recorded total of 115 stalks up to September 22, after which it supplied itself almost entirely from ear corn lying on the ground. A big animal that was probably the same one was caught by a trapper in late December.

During the spring dispersal of 1942, a minor route of travel away from Onion Creek proved to be the roadway on the Boone-Story County line, which led directly to the roadside ditch pools lying three-quarters of a mile north of the creek. What was evidently a lone muskrat appeared here to settle during about the last week of June, after the place had previously been visited by spring-dispersing muskrats up to but not noticeably later than April 21. This animal fed in a corn field from the time that it arrived, and 208 cut stalks 
were counted up to late August; it then subsisted largely upon natural vegetation supplemented by ear corn picked up from the ground.

Water levels of the above ditch pools were much dependent upon current rainfall and only a wet season could keep this partly isolated niche habitable for muskrats - which is an adequate explanation for the absence of muskrats here during the early years of the study. On August 12, 1942 -during an exceptionally wet year - the level was 18 inches below its highest level earlier in the same summer. By August 14, the water went down three inches more, and an inch and a quarter more in the following twenty-four hours. From August 19 to 25 , among other times during summer and fall, the water in the ditch was rapidly reduced to small puddles, until a heavy (2.37 inches) rain on August 26 refilled the ditches, and the drying sequences started all over again.

After evidences of a moderate amount of cross-country movement began to be seen about August 15, a subadult male (collected for examination December 12) joined the adult living in the ditch. The adult itself succeeded in wintering, despite the fact that it improvised living quarters in a snowdrift that was repeatedly visited by a big mink. (Four mink scats contained no muskrat remains.) The snowdrift nests and tunnels were used after the water in the ditch had frozen. The adult continued feeding upon corn, whether from stored supplies or carried from the fields during the milder weather.

The pasture brook had, in 1943, what seemed to have been a single old muskrat from mid-March at least to July 10 . The roadside ditch had a breeding territory; one member of the pair was almost certainly the muskrat that had wintered there, while the other came probably about mid-March. At another part of the same ditch but farther north, a chewed-up, sexually active but unbred female was collected for a specimen on April 19, after it had dug a shallow burrow.

Three litters were born to the ditch pair in 1943: in early April, early May, and early June. The water had almost disappeared by July 13 , but was replenished by rains that night $(0.67$ inch) and on July 16 (1.62 inches). By mid-August and later that month, many more signs were centered about two parts of the ditch. By September $9-10$, as the water again went down, signs of many muskrats became increasingly evident. On September 30 and October 30, rains (1.10 inches and 0.41 inch, respectively) relieved drought conditions at the ditches, but partial abandonment of the ditch habitats already had taken place by late October. Nearly all of the muskrats except the old ones had left by the opening date of the trapping season, November 10. Three trapped specimens were an adult male, an adult female (with 28 placental scars representing three early-season litters), and a young female. What appeared to have been the last resident was killed by a mink about December 28, at which time little or no unfrozen water remained in the ditch. 
The pasture brook had no known muskrats in residence after 1943 to the end of our period of study in 1957.

In 1944, the ditch showed the first sign of a newcomer about March 25. On April 7, two muskrats were seen here, and, by midJuly, signs of both young and old were conspicuous. On July 23, when the ditches were nearly dry, abundant track signs could be seen about all exposed retreats. A month later, the signs looked very similar, and excellent signs were still in evidence on September 10 after a rain. By September 18, the water was getting low again, and by October 23, the ditches were all but dry; still, signs continued to be heavy, especially as the muskrats began raiding an adjacent field of soybeans. This group of muskrats was believed to have consisted essentially of the adult female of the original territory and her reared young from one litter.

The raiding of the field of soybeans continued at intervals through the winter of 1944-45. Two of the animals established quarters in the bean field, living in nests under the snow or even in holes dug in the ground. One of the two muskrats of the bean field died from unknown cause - possibly exposure - about December 20. (December, 1944, was a cold month, with a mean temperature nearly six degrees below normal and extremes as low as seventeen degrees below zero.) The other muskrat in the bean field lived in a ground hole and fed on conveniently available beans until about the middle of January, 1945. Ex post facto "reading of sign" during a thaw in mid-February suggested that this animal had moved over to the far side of the bean field before January 23, there to improvise a nest in a big snowdrift well over 200 yards from the ditch; its later fortunes were not traced. The occupied ditch continued to show pushups, snow trails on mild days, and other signs, and, on March 14, four muskrats were simultaneously in sight.

The roadside ditch had, in 1945, a breeding territory that was to some extent productive despite many exposures through drying. Several muskrats lived there through September and into October. Then, new dredging improved the drainage of the ditch, and it lost whatever habitability it ever did have for muskrats for the period of study through 1957.

\section{County Line Ditch North of Squaw Creek}

This ditch really came into existence as muskrat habitat with some dredging operations in 1938. The pool at the head of the ditch drew about four muskrats during the fall adjustments, and one of these muskrats escaped the 1938-39 fur trapping to winter. In late summer and fall of 1941, a few muskrats moved into the ditch and pool; and a similar ingress occurred in late summer, 1942.

The ditch had a functional territory in 1944, but many of the muskrats abandoned it by late fall. There was another good territory at the same site in 1945 and still another in 1946. During all three of these years, the territories were highly productive and were situated 
close to raided corn fields, yet they became practically vacated by early fall.

In 1947, following a muskratless spring and summer, perhaps four muskrats appeared in early fall at the pool, the attractiveness of which had been improving because of an increasing stand of cattails in its vicinity. The muskrats of the pool came out occasionally on the surface during the winter of 1947-48, and two man-killed animals were found, a subadult male and a subadult female.

In 1951, the ditch pool and environs probably reached its maximum attractiveness during the period of study when extensive stands of cattails grew in a series of erosion-cut ditch pools above as well as below the big pool at the head of the dredged part. The ditch had no resident muskrats until late August, when a large group moved in across the pasture from Hutchinson's Lake, lying to the west. Then, after about three weeks of digging, burrowing, plastering of mud, and cutting and carrying of vegetation, this group suddenly departed, leaving the pools entirely muskrat-vacant for the time being. Then, once more, in late September, the ditch began drawing in muskrats, which worked from Squaw Creek up the length of the ditch to the pools. This up-ditch movement was rather gradual but it culminated in another large assemblage of muskrats about the pools, for the period of about two weeks. By late October, the ditch and pools had no muskrats remaining.

In 1952, the ditch had another territory situated next to a raided corn field, and at least two litters were born in early April and early May. There were about 20 muskrats here by late August, plus a probable lone individual at the main pool. They all seemed to have gone by mid-September, but there was at least a lone individual to track up the snow about the pool in early January, 1953.

What seemed to have been a lone individual moved up the ditch about the first of June, 1953, to establish headquarters in the cattail growths downstream from the main pool. The signs indicated that this animal stayed around all summer, to be joined by several more muskrats in early fall. During September, the animals wore a heavy trail to the edge of a corn field about 200 yards downstream, but, by early October, they were feeding mainly on natural vegetation in the vicinity of the pool. All were gone by freeze-up.

No muskrats were known to have been in residence - or even to have visited the ditch and pool - in 1954.

The ditch had a splendid territory in 1955. In mid-July, signs of large young animals from the territory could be seen extending to the main pool, which lay over 100 yards upstream. At the end of the first week of August, there were muskrat signs along the entire ditch, including worn trails over the exposed bottom between residual pools in the lower third of the ditch. The signs indicated that a great troop of muskrats had moved up the ditch from Squaw Creek about the first of August. These animals represented most of a population that had 
been massing for a week or more along about a mile of creek beginning immediately downstream.

The newcomers did no raiding in the corn field at first, feeding mainly on greater ragweed growths along the lower part of the ditch and upon cattails in the vicinity of the main pool. The differences in age of signs about the pool suggested that the occupants of the original territory had moved out a week or so before the heavy ingress from Squaw Creek occurred. By late August, the pool had no current signs, though there was still evidence of a tremendous amount of activity at the lower part of the ditch and adjacent Squaw Creek. By mid-September, muskrats were back up-ditch, not at the pool but living in a dry set of burrows eighty yards below the pool, at the edge of a raided corn field; downstream, heavy trail signs extended up the mouth of the ditch from Squaw Creek. By early October, and continuing until freeze-up, heavy trail signs were laid down between some pools in the stream bed of Squaw Creek and a corner of the raided corn field. The raiding route between stream-bed pools and corn field was about 200 yards long, but the weed-grown condition of the ditch offered the muskrats good concealment over about two-thirds of the distance.

There were muskrats left by freeze-up both at the main pool of the ditch and at the burrows in the creek pools that the newcomers had stocked with ear corn from the field adjacent to the ditch. A lone animal wintered at the ditch pool. It left early in March, 1956, but another one appeared in mid-July, to stay the rest of the summer. No sign of occupancy was found thereafter through 1957.

\section{Roadside Ditches Northwest of Gilbert}

The main ditch habitat here referred to had some fairly deep pools near its junction with Squaw Creek in northwest Section 1 of Tract $\mathrm{F}$, and one of these pools had a territory as early in the study period as 1936. Later in that summer, in response to drought conditions, the occupants of the pool moved to the creek, there apparently to take up living quarters in what was still within their familiar home ranges.

This place thereafter was muskrat-vacant until 1942, when a territory was established in the ditch near the southwest corner of Section 36. The territory probably lost a litter through flooding in early June, and by midsummer all of the muskrats of the ditch seemed to have left. By fall, the ditch was nearly dry, but water remained in the deeper parts, and some animals reappeared to try wintering there. Six carcasses of animals trapped during the 1942-43 fur season were all of young of the year, including a "kit" born about August.

A territory was established in 1943 at the site of the 1942 territory, but the female was killed by a dog about May 11. The victim had ten very recent placental scars and six small embryos due for birth in early June. Earlier in 1943, on March 14, presumably the same dog had killed a young unbred female, the body of which was cleaned up 
by a mink within the following two weeks. The ditch habitat was muskrat-vacant for most of May, June, July, and August, but then some muskrats came in to establion living quarters at the site of the lost territory. They withdrew again to Squaw Creek in late September, as the ditches were going dry.

The next muskrat occupants were some that took over a pond between ditch and Squaw Creek in August, 1945, but they left before freeze-up. However, the pond was the site of a maintained territory during at least the early part of the 1946 breeding season. In 1947, a territory first established at a ditch pool was later transferred to nearby Squaw Creek.

Dredging operations in 1952 terminated the ditch and the pools as muskrat habitat.

The other roadside ditches of Tract $\mathrm{F}$ that were occupied by muskrats from time to time were along the north central and northwest boundaries of Section 35 .

One near the northwest corner was occupied in 1943, probably by a lone female that had been pregnant when she arrived; by September, the territory was dry and abandoned. In 1944, the site of the 1943 territory was again occupied, to be again abandoned in late summer and fall. This ditch was situated next to a sedge-grown swale offering a good food supply, but it hardly had more than a puddle of water even during wet seasons. Its main advantage was a burrow system under a cement culvert that afforded good protection from digging dogs.

The ditch at the north central boundary of Section 35 was also connected with a shallow natural oxbow, and the latter had territories in 1943 and 1945 which were abandoned in late summer and early fall. In 1947, a lone, unbred female maintained a territory here from early April to early May, when she was caught in a set trap that someone had failed to take up at the close of the 1946-47 fur season. An estimated four animals moved in to occupy the drying oxbow about late August or early September, 1947, to move on by late September. The next time that this ditch was known to have been occupied was in early August, 1952, when a lone animal stayed briefly at a wet pool beside a culvert, about 100 yards from the previously used territorial sites.

\section{Miscellaneous Outlying Waters of Squaw Creek Drainage}

An oxbow east of Squaw Creek in Tract C had a territory in 1936, the occupants of which moved to the creek during the early weeks of the summer drought. It was the site of a productive territory in 1943, though abandoned by early fall. The same territorial site was occupied in 1944 and 1945, also to be abandoned by early fall of those years.

Farther north, in lower Tract $F$, a woodland oxbow pool had a territory in 1943, for the only time in its recorded history. It still had several muskrats in late fall, but none remained by freeze-up.

There was, in 1940, a territory in an oxbow pool east of the junc- 
tion of Squaw and Montgomery Creeks. In 1943, this oxbow had another territory, and by the beginning of the 1943-44 fur season, it was full of muskrats, but I failed to obtain any specimens for examination. While no breeding territory was present in 1944, many muskrats came in during the fall, and at least a few wintered, 194445. The oxbow again had a breeding territory in 1945 and another in 1947, both to be abandoned before fall. Thereafter, the oxbow was not known to have had any muskrats, even though in some years it was in attractive condition for them.

Also in Tract F, and about a half mile from the Turner Estate ponds, some old gravel-pit pools had at least two muskrats- a large and a small one - by late August, 1943, and some muskrats entered the winter. In 1948, these pools had a maintained and productive territory for the early part of the summer.

Near the middle of Section 30 in Tract G, one very temporary pool entered our records as muskrat habitat only for the fall and fur season of 1943-44. Eight trapped specimens from here were six young males, and two young females, surely representing newcomers.

South of and draining into Montgomery Creek in Section 35 of Tract $\mathrm{F}$, a boggy ravine drew in several muskrats in the late summer and fall of 1944, and signs of surface activity were seen here in early winter. This was the only time during the period of study that this place was known to have had muskrats.

Three places lying within three miles of tracts A-F were observed during the winter of 1947-48 to learn more about the fortunes of precariously situated muskrats of brooklike habitats. One of these brooks adjoined the highway, U.S. 69, at which place six traffic-killed muskrats were found between January 14 and March 28. The victim of January 14 (the only one intact enough for post-mortem examination) was a thin young male.

Another site of outdoor activity was next to a farmyard, where a lone muskrat came out from beneath a shelf of ice to feed on corn in cow dung from early January until the last of February, 1948, when central Iowa habitats of this sort became flooded with melt water.

The third place in this category was a brook running through the College Arboretum southwest of Ames. Outside activities were noted early in the winter, but the signs did not become pronounced until early February, 1948. On February 7, three individuals were foraging on the land bordering a half mile of brook, and a dead one (cause of death undetermined) was found frozen in the ice. The most comfortably situated of the three land-active animals lived in a tile opening that had been partly plugged with ears of sweet corn. Another made repeated journeys into a rather bare corn field, and the third ranged as far as 300 yards up and down the brook, feeding mainly on fringing sedge growths and coarse grassy or weedy vegetation.

\section{Des Moines River West of Ledges State Park}

This river is larger than any stream kept under regular observation in central Iowa, and a sample mile was worked on July 29,1947 , 
in an effort to obtain more information on the possible effects of the June floods on muskrat populations. On this sample, where the flooding had been exceptionally severe, at least three territories having young over two months of age were distinguished. An estimated population of between 40 and 50 adults and fairly large young was not a very large one, but neither did the population look like one completely overwhelmed by the floods.

The sample stretch was revisited in mid-October, 1948, at which time muskrat signs were remarkably scarce. I figured that not more than three or four lived along the west three-quarters of the sample mile, with maybe as many more along the other quarter mile. To the east, just off the sample, was a burrow system having signs of an estimated half dozen more muskrats. The reason for this sparseness was not evident, for living conditions on the whole did not look grossly unfavorable for muskrats. Beavers were abundant in places; their conspicuous trails and burrows did not seem to be used by the few muskrats present.

Another revisit was made in mid-October, 1949, covering the same mile visited during the previous two years, plus another mile added to insure more representative data. The signs were restricted and usually light. Relatively few places had attractive and livable habitats for muskrats, as the flow was mostly confined to gravelly stretches of the central stream bed, thus missing the sites of old burrow systems. The remaining places that would have been suitable for muskrats banks with willow thickets or corn fields near the water - were dominated instead by beavers. Muskrats did co-occupy some of the best habitat with the beavers, but there seemed to be, if anything, more beavers than muskrats, even where the muskrat signs were heaviest. My estimate of the muskrat population was eight or ten centering in one deep pool and perhaps another half dozen scattered along the rest of the two-mile stretch. 


\section{Part 3}

Biogeography of the Living Forms of Muskrats 



\section{The Muskrat of Eastern United States and Southeastern Canada, Ondatra zibethicus zibethicus}

Central Iowa may be used as a focal point in treating the common or eastern muskrat, the subspecies zibethicus, in relation to its geographic range in North America. This is near the southern edge of recent (Wisconsin) glaciation in Iowa and the southern edge of what was once the great lake and marsh country of the midwestern prairies. Farther south in the state, the terrain looks increasingly like that of Missouri, with its gullies and wooded hills. From Hollister's (1911) published record of cinnamominus, or the great plains muskrat, from Marion County, Iowa (which lies about 55 miles SSE of Ames), it may also be seen that central Iowa may once have been about the western boundary of the range of zibethicus, though the present range of the latter subspecies is known to extend from central Iowa hundreds of miles northwestward into South Dakota, if not westward into Nebraska.

\section{THE GLACIAL LAKE AND MARSH REGION OF NORTHWESTERN IOWA, SOUTHWESTERN MINNESOTA, AND EAST CENTRAL SOUTH DAKOTA}

The Ruthven and Estherville observational areas (chapters 5 and 6) rather typify the glaciated wetlands of the north central region of the United States except for the changes that accompany the gradation of the northern prairies into the northern great plains. The marshes of northwestern Iowa are but remnants of those existing before settlement by the white man. Throughout the $6,000,000$ acres of tall grass prairie comprising the original marsh-interspersed agricultural lands that were chiefly located in that part of the state, practically each 40 acre tract had at least one pothole (Bennett, 1938). The first settlers had sufficient upland prairie to farm so that they did not attempt 
drainage. Then, by the late thirties, Iowa had left only about 50,000 acres of more or less marshy wetlands, mostly in state ownership. Artificial drainage on a similar scale has occurred in parts of southeastern Minnesota and eastern South Dakota. As a rule, however, more extensive marshy areas remain within the next several hundreds of miles northward and northwestward from the Ruthven and Estherville areas.

In the Ruthven area are other bodies of water besides those kept under intensive observation. Trumbull Lake and Lost Island Lake, of 1,190 and 1,260 acres, respectively, are open water, wind-swept lakes having little emergent vegetation, hence frequented by few muskrats except in sheltered places. In the falls of 1936 and 1939, the shores of these lakes were heavily used by miserable transients, fighting among themselves, feeding upon bivalves and fishes, and otherwise betraying their insecurity.

Contrasting changes over the years are illustrated by Barringer's Slough (about 1,000 acres) and Dan Green's Slough (340 acres). The latter was from 1932 through 1935 in splendid condition for muskrats, having the equivalent of about 315 breeding pairs in May, 1935. In the years following, the vegetation deteriorated, presumably as a result of high water levels maintained by a dam and the activities of a large population of carp. By the spring of 1936, Green's Slough had a lodge-dwelling population of about 132 pairs plus bank dwellers. For the next decade and a half, hardly any muskrats lived on or about the main body of water. On the other hand, Barringer's Slough was habitable for muskrats only in limited places during the thirties, when its status varied from that of a dry marsh to an open water lake. In the forties, a combination of natural and artificial changes made it the best muskrat marsh in the Ruthven area, although it did not then maintain its muskrat populations at any noticeably uniform level.

The Spirit Lake-Okoboji area near the Minnesota state line consisted mainly of the summer resort type of waters, with occasional fair to excellent muskrat habitats in bays or adjacent marshes (Sigler, 1948).

The Big Sioux River drainage, which has its source in northeastern South Dakota, north of Watertown, and extends southward to its junction with the Missouri River at Sioux City, Iowa, is now well within the known range of zibethicus. How long this has been the case is undetermined. This drainage system included part of my Brookings County (South Dakota) hunting, fishing, and trapping grounds, 1915-28 (see Appendix F). South Dakota naturalists whom I then knew believed that cinnamominus was the resident subspecies. In the later years of my trapping, after I had had some college training in zoology, I observed many individual muskrats that, on the basis of size and coloration, might have been more convincingly assigned to zibethicus than to cinnamominus; but some also looked like cinnamominus. My present guess is that the population consisted substantially of intergrades. 
The terrific droughts of the early and mid-thirties all but wiped out the resident muskrats over county-wide areas, and repopulation presumably took place chiefly through movements from zibethicusdominated areas downstream, perhaps from as far as northwestern Iowa. A single highway victim picked up north of Arlington, South Dakota, August 27, 1939, was identified as zibethicus by Dr. H. H. T. Jackson of the U.S. Fish and Wildlife Service.

\section{THE CENTRAL PRAIRIES OF SOUTHERN IOWA AND NORTHERN MISSOURI AND THE "HILL COUNTRY" TO THE SOUTH AND EAST}

As the northern prairies extend down toward south central Iowa, the resident muskrats become more and more stream-dwelling. Still farther south, muskrats live in oxbow marshes or artificial lakes much as they do in the more northern glacial marshes and lakes, though subjected to shorter and more benign winters. Trends noted in southern Iowa, northern Missouri, and southeastern Nebraska were toward greater dependence of the muskrats upon corn or soybeans, increased raiding of gardens and orchards, year after year maintenance of elaborate burrow systems in hard clay subsoil. Southern Iowa muskrats living in rivers or ditches from which most vegetation has been washed away from the banks may almost have to get up into cultivated fields to feed and, once finding themselves in the midst of an edible farm planting, they certainly can take advantage of it. I never saw elsewhere the intensity of foraging on windfall apples that I did in southern Iowa in October and November, 1933, but neither did I ever see elsewhere so many and such big orchards in close proximity to small streams well populated with muskrats.

At peak levels, the southern Iowa muskrat densities for comparable small stream (other than ditch) habitats appeared to be about the same as in central Iowa. A farmer-trapper in Davis County caught about 80 muskrats per mile in the fur season of 1933-34 from a small corn-bordered stream. Southern Iowa ditches are inferior to central and northern Iowa ditches for muskrats roughly to the extent that they are fed by surface flows rather than by tiles. Many southern Iowa ditches are merely straightened natural streams.

Skunk River, which has shown close to optimum attractiveness and habitability for muskrats south of Cambridge in central Iowa (Chapter 11), becomes less favorable for muskrats as it grows larger, flowing southeastward to enter the Mississippi River near Burlington. At its wider places, muskrats have much the same problems of living as they have along the Mississippi River bordering the eastern side of the state. Their best habitats along lower Skunk River are oxbows or the mouths of small tributary streams. This also typifies the situation along the central to lower reaches of the Des Moines River, Iowa River, and Cedar River of southeastern Iowa.

In southwestern Iowa, the larger rivers are smaller than in the southeastern part, except for the Missouri River itself. The Missouri River offers, I would say, less habitat to the muskrats than does the 
Mississippi River bounding the opposite side of the state. Among the more important of the Missouri River oxbow marshes of southwestern Iowa are Lake Manawa, south of Council Bluffs, and Forney's Lake, north of Thurman.

When I saw it in mid-October, 1947, Forney's Lake was heavily grown to yellow water lilies as well as emergent vegetation in places, but muskrats were scarce, reputedly because of a recent die-off. Lake Manawa, looked over in mid-October, 1948, had a zone of about 50 yards of exposed mud-margin. Nearly all of the muskrats were restricted to one shore, which had heavy marginal growths of narrowleaved cattails and burrow systems and corresponding lodges at about 50-yard intervals. A 2-acre tract of dead cattails (probably killed by previous high water) had, at the time of this visit, 29 muskrat lodges of varying sizes and freshness, and the shore growths of cattails were crossed by muskrat trails and riddled with diggings.

The stream-dwelling muskrats of southwestern Iowa seemed more susceptible to drought than those of the southeastern part, the southwestern streams being rather characterized by deep channels and steep banks, both in natural and straightened watercourses. Within the banks of the larger streams - comparable in size to Squaw Creek and Skunk River near Ames - there were few real pools in sight during the dry fall of 1947. Oxbows, however, had good muskrat signs, though they were mostly going dry.

According to Bennitt and Nagel (1937), northern Missouri had more muskrats than the southern part at the time of a survey made, 1934-35. Muskrats by then had been decreasing for years, partly in consequence of the drainage of 1,800 to 2,000 square miles of marshy land that had taken place since early in the century. This left most of the suitable muskrat habitat restricted to the bayous, chutes, drainage ditches, and a remnant of swampy land - less than 10 per cent of the muskrat habitat originally present. But, in recent years, many artificial lakes and great numbers of farm ponds have been created both in southern Iowa and in Missouri, and these furnish considerable muskrat habitat. The muskrats of the ponds having good stands of cattails and other marshy emergents live as they do in oxbow or glacial marshes. Missouri's largest lake, the artificial Lake of the Ozarks, covers over 60,000 acres and has some muskrat habitat and muskrats in places. The Ozark region also has thousands of springs, including many big ones, and these and associated brooks and larger streams have places where muskrats live, usually at low densities.

The subspecies zibethicus, though limited in Kansas to the southeast corner (Hibbard, 1933; Black, 1938; Cockrum, 1952), intergrades with cinnamominus over most of the eastern part of the state or that known as the Central Lowlands. Black referred to the Flint Hills, dividing the Central Lowlands from the Great Plains to the west, as being the greatest barrier or break in the distribution of all forms of vertebrate life in Kansas. 
I have been unable to find definite proof of zibethicus in Oklahoma, but it, or at least its intergrades with cinnamominus, should occur in the northeastern part of that state, as in southeastern Kansas. Blair (1939) wrote that the muskrats in the Ozark region would probably be referable to zibethicus. Relating to the Oklahoma part of the Ozark biotic district, Blair and Hubbell (1938) wrote of clear, cold, largely spring-fed streams in a dissected plateau, of much underground drainage and an abundance of sinks and caves. Dellinger and Black (1940) felt that zibethicus was increasing in the Arkansas Ozarks. A recent paper by Sealander (1956) shows that zibethicus is nearly statewide in distribution in Arkansas, except in the extreme southeastern part of the state. Expansion of the rice-raising industry and irrigation has created much new favorable habitat.

Southward through Arkansas into Louisiana, the wetlands become more and more those characteristic of the Gulf States, with cypress swamps and bayous and, of course, the widening Mississippi River. I cannot trace the thinning of the range of zibethicus through Louisiana on the basis of available information, but Lowery (1943) reported that muskrats were not uncommon in the fresh-water lakes around Baton Rouge. At that time, the Louisiana State University Museum had 24 specimens, and the specimens showed intergrading between zibethicus and rivalicius. O'Neil (1949) referred to an approximately 200-mile gap between the ranges of zibethicus and rivalicius.

Eastward and southeastward from southern Missouri, the range of zibethicus may be chiefly classed as river bottomlands or as the dissected Ozark-Appalachian "hill country." Some of the rivers are large, and great floods of the Ohio and Mississippi rivers, in particular, have their own ecological impacts on muskrats and muskrat environment. Frison (1938) referred to southern Illinois as the part of the state having the lowest production of muskrat pelts, explainable by unstable water levels and absence of marshes.

In 1930, I saw some of the muskrat habitat of central Kentucky at about the same time that Bailey (1933) worked there. He then noted a scarcity of individuals but a general distribution along streams and in ponds and marshes. Mostly, the muskrats lived in banks and fed upon shore vegetation. In a county described as typical of the eastern mountainous section of Kentucky, Welter and Sollberger (1939) took several specimens from a creek where the banks were worn smooth by the animals. The muskrats were very common at a pond, from which they made daily visits to corn fields over well-traveled paths. The hills were steep and eroded, and the narrow valleys were subject to flooding.

Tennessee is still well within the geographic range of the muskrat in southeastern United States but may hardly be considered as offering much good habitat. According to Kellogg (1939), zibethicus formerly occurred in most of the streams and ponds. Muskrats were reported as getting scarce in Fayette and Shelby counties after the drainage of 
the cypress swamps. A few muskrats were trapped each year in the marshes around Reelfoot Lake, which was formed by earthquake, 1811-12, in the Mississippi Valley of northwestern Tennessee and southwestern Kentucky. Kellogg found them fairly common during October, 1937, along the Cumberland River and tributaries west of Indian Mound.

Dr. Vincent Schultz, formerly of the Tennessee Game and Fish Commission, has given me a great deal of information concerning the recent status of muskrats in the state. From a letter and enclosures of September 26, 1951:

It appears from these figures... that the best muskrat habitat is in the East Tennessee Valley portions of the Plateau Slope of West Tennessee and the Mississippi Bottoms. . . Throughout my travels in all Tennessee counties I have never seen a good cattail marsh like one finds in the Midwest. In fact, I have never seen a muskrat house but have been told that they occur in the sawgrass of Reelfoot Lake. . . The soils of the Plateau Slope of West Tennessee.... are very sandy and erode easily. ... I have been informed that ... [ muskrats] occur only where stumps, sod or other materials hold the soil in place.

Komarek and Komarek (1938), in working with the mammals of the Great Smoky Mountains of the Tennessee-North Carolina boundary, found muskrats foraging in a cane patch as well as feeding on riverbank willow shoots. The Highlands Plateau, lying southeast across the western tip of North Carolina from the Great Smoky Mountains and having similar climate and biota, has a few muskrats. Odum (1949) mentioned their occurrence on small artificial lakes in the region.

Wiebe (1946), in exploring possibilities for improving conditions for migratory waterfowl on the great artificial impoundments of the Tennessee River in northeastern Tennessee, discussed the extreme water fluctuations due to human manipulation, and one may readily keep muskrats in mind as well as waterfowl. Annual drawdown in storage reservoirs for flood control may exceed 100 feet but in mainstream reservoirs is generally less than 10 feet. With reference to pools of relatively constant level for improving waterfowl habitat on the TVA, Wiebe also wrote that these had the additional advantage of providing a stable habitat for muskrats.

\section{THE SOUTHEASTERN EDGE OF THE MUSKRAT'S GEOGRAPHIC RANGE IN THE UNITED STATES}

Freeman's (1945) distributional map of zibethicus in Mississippi shows that the modern range of the subspecies includes about the northeastern two-fifths of that state. He expressed a view that the animals probably first entered the state in relatively recent years via the Tennessee River and slowly spread southward. They have been artificially stocked in at least four of the southern counties. Yeager (1941), giving an historical account of the fur animals of the Delta 
region of northwestern Mississippi, an area of 8,000 square miles of bottomland between the Mississippi and Yazoo rivers, never knew muskrats to have been present there. James R. Henry (letter to Dr. H. M. Harris, March 14, 1949) did find a few muskrats of this subspecies at the northeastern tip of the Delta "in small lakes and ditches in the Moon Lake region of Coahoma County and in the Coldwater River south of the Arkabutla Dam in Tunica County." The Moon Lake muskrats built lodges and at one time were fairly numerous, though reduced in numbers in 1946-47.

The report by Freeman is most informative concerning zibethicus in Mississippi. Drainage systems having the most muskrats are the Tallahatchie, Big Black, Tombigbee, and Surcanotchee rivers and their tributaries. When beavers live along a stream, more muskrats are found around the beaver ponds than on other parts of the same stream. He recognized no barriers or limiting factors to prevent muskrats from inhabiting the wetlands of the entire state of Mississippi. Big Black River, which has muskrats in its upper part, flows through several counties that do not have them. The Chickasawhay River has a good population on some of its tributaries north of Waynesboro, then flows more than 100 miles through a muskrat-vacant country before reaching the Jackson County marshlands. Pearl River has muskrats above Jackson, but it is 175 miles between these and the rivalicius muskrats in the coastal marshes to the south. Practically the same food plants are to be found along the southern Mississippi streams as along the stretches frequented by muskrats farther north.

Yeager (1937), writing of 1920-26 fur yields from a farm in Webster County in the middle of the zibethicus-occupied part of Mississippi, mentioned muskrats as occurring in small numbers in an area where corn and oat fields extended to the creek banks.

Eastward from Mississippi, the range of zibethicus includes nearly all counties in Alabama, but Arant (1939) and, later, Barkalow (1949) reported the subspecies as being scarce in the southern counties. The latter author doubted its presence in some counties, even in 1942 after continued general increase. According to Beshears and Haugen (1953), Alabama has approximately 10,000 farm ponds impounding an estimated total of 35,000 acres of fresh water, and the muskrats have become established in many of these ponds. Arant wrote that this form had extended its range in southern Alabama after Howell (1921) had not found it there.

Howell found it difficult to understand why zibethicus did not range all of the way down to the coast, for environmental conditions seemed as well suited to it in southern as in northern Alabama counties. He cited a trapper of long experience, C. W. Howe, as stating that muskrats first appeared near Linwood, Pike County, in 1906, and became quite plentiful on the upper Conecuh River between Troy and Union Springs, where none could be found in 1898. Howe found unmistakable signs of muskrats in 1912 along Little River, which is about 50 miles NNE of Mobile. In the spring of 1916, he saw 
a single stray individual still farther south, at Twelve Mile Island in Mobile River.

Hamilton (1943) shows the mapped range of zibethicus as covering only about the northwestern two-fifths of Georgia and South Carolina and the western half of North Carolina. As muskrat habitat, the Piedmont region and the southern Appalachians may be compared with that of eastern Tennessee - of generally marginal character but still having places where limited numbers of muskrats might live. In Georgia, the muskrat is an important fur resource in the Piedmont only (Jenkins, 1953).

The nearly muskrat-vacant parts of Georgia and the Carolinas do have some muskrats outside of what may be regarded as their established range. William P. Baldwin, Jr., of the U.S. Fish and Wildlife Service, informed me (letter of January 28, 1949), for example, of finding zibethicus

in South Carolina at the Jack's Creek impoundment of the Santee National Wildlife Refuge, Clarendon Co., located on a portion of the newly constructed Santee-Cooper reservoirs. ... E. B. Chamberlain, Curator of Vertebrate Zoology of the Charleston Museum (S. C.) . . . stated that the eastern-most S. C. record of muskrat that he had was one taken a few miles west of my location, on the Santee River prior to flooding of the reservoirs. This general area is approximately 90 miles inland from the Atlantic Ocean, and well above the limit of tidal action; it is possible that the new reservoirs may facilitate the rat's spread to within 30 miles of the coast. In this area the rats exhibit the usual scarcity associated with marginal populations.

The absence of true muskrats from southern Georgia and all of Florida has long mystified naturalists. In the spring of 1929, I saw representative parts of this region in the course of field trips with that observant outdoorsman, H. L. Stoddard. As we waded swamps and streams, we made comparisons with northern muskrat habitats and tried to think of explanations for the range of the species thinning out and ceasing in the Southeast. In 1948 and 1954, we talked about this again, still without arriving at any convincing explanations.

I recalled the Wakulla River and bordering cypress swamp in northern Florida and felt that, if these had been located a few hundred miles to the northwest, they surely would have had muskrats. In southern Georgia, I saw a great amount of terrain that never would be classed as good muskrat country, but I could not see why it should not have some muskrats along its streams. The ecological counterparts of the region in Virginia would not have large numbers of muskrats but probably would have some, much as in marginal stream habitats of Tennessee. The upper reaches of the rivers flowing into the Gulf of Mexico through southern Georgia and northern Florida have their muskrats, but the animals dwindle and disappear about half way to the Coast.

Many authors refer to the little so-called round-tailed muskrat (Neofiber) as taking the place of Ondatra zibethicus in Florida wet- 
lands. I do not feel that this is strictly true, and any implications of competition between Neofiber and Ondatra are fallacious. Neofiber's range is almost confined to most of Florida and to the Okefinokee Swamp area of southeastern Georgia. Jenkins told me in conversation in 1956 that the distance separating the ranges of Ondatra and Neofiber was about 100 miles. (For a description of the habits and ecology of Neofiber, the reader may be referred to Harper [1927] and Schwartz [ 1953$]$ ).

Baldwin, in his aforementioned letter of January 28, 1949, emphasized coastal and downstream tidal fluctuations, lack of wide expanses of sustaining habitat during catastrophic periods, and scarcity of certain vegetative communities as factors limiting the distribution of muskrats in the Southeast (see Appendix G).

True muskrats, Ondatra zibethicus, once did live in what is now Florida, during the Pleistocene (Sherman, 1952).

\section{THE UPPER MISSISSIPPI VALLEY AND EAST CENTRAL PRAIRIES}

The Central Prairies extending eastward from central Iowa to the Mississippi are more or less dissected. They have chiefly stream-dwelling populations of muskrats except in artificial impoundments and in the oxbow marshes of the larger stream valleys. East of the Mississippi in the northern and central parts of Illinois, Indiana, and Ohio, evidences of recent glaciation are more apparent, but the main muskrat habitats are still of stream types or stream-derived.

The upper Mississippi River furnishes good examples of certain types of habitat. From 1932 to 1935, I made a number of field trips in the vicinity of Lansing, northeastern Iowa, and spent a considerable part of the summer of 1940 working on that river or its bottomlands. Throughout my Lansing investigations, I had the advantage of the advice and sometimes the company in the field of an excellent riverman, W. E. Albert, Jr., then of the State Conservation Commission. On several occasions, I inspected parts of the Upper Mississippi Wildlife Refuge with Ray Steele, the manager.

In the early thirties, before the profound changes resulting from engineering manipulation of the upper Mississippi, the best local muskrat marshes were then, as now, bottomland oxbows, though the species lived in varying numbers along many of the smaller ramifying stream channels and up the mouths of side creeks draining from the higher land. Densities of muskrats were sometimes very high on the better oxbows during years of abundance.

A memorandum from Aldo Leopold dated December 9, 1941, refers to a catch of forty muskrats from a three-acre pond in Henderson County, Illinois, across the river from Burlington, Iowa. "There were 7 houses in this pond, but a large number of additional rats inhabited bank burrows. The pond is bordered on one side by the railroad bank, hence opportunities for bank burrows are especially good."

The site of the old Iowa State Game Farm on an island above 
Lansing was also a splendid place for muskrats when I first saw it in 1932, and trappers took several hundred muskrats that fall from, or from the vicinity of, 68 acres of state-owned bottoms. This was one of the areas that flooded and lost its productivity for muskrats after installation of lock dams and the nine-foot channel.

In the summer of 1940, the river habitat differed greatly according to localities. For some miles below the dams, conditions for muskrats were in many ways similar to what they had been before the ninefoot channel. Virgin timber had not been cut, and on the whole, about two-fifths of the original bottomland stand remained. Areas extending about a mile below the dams were subject to rapid fluctuations of one and a half to two feet due to "pile-up" as water was let out of the dams. Numerous small, shallow areas were covered with muskrat lodges and grown to sedges, reeds, and some cattails, but with bottoms of sandy rather than mucky consistency. Depths of the marshy impoundments varied from a few inches to about seven feet, depending upon the configuration of the channels and islands before flooding. Some of the partly submerged stump areas (from which the trees had been cut in the course of the engineering program) were literally dotted with lodges in bulrush, sedge, and smartweed areas. I saw one tract of about three square miles in early May in which the winter's lodges and feed houses must have averaged twenty or more per acre. The stumps were important in providing anchorage for lodges, and I could see many shallow burrows extending up under stumps that did not have lodges.

Less spectacular muskrat retreats were seen in small sloughs and marshes on islands. These and oxbow marshes along the shore were often well grown to burreeds and cattails much as were comparable glacial marshes of the northern prairies. They furnished far better habitats than the shaded ponds and bayous of virgin timber. Muskrats lived either in lodges or in shallow burrows. Streamlike channels through wooded parts usually had few muskrats, and the wide, lakelike tracts above the dams had muskrats only in the banks. As muskrat habitat, the drastically altered upper Mississippi River bounding eastern Iowa showed about all gradations from the very poor to the very good, with most of it being very poor and the superior places being sharply localized.

(Appendix $\mathrm{H}$ relates to special local studies of upper Mississippi muskrats.)

The streams of northeastern Iowa may be considered fairly typical of those of the nonglaciated or driftless area of southwestern $\mathrm{W}$ isconsin and southeastern Minnesota. In July, 1940, these had about the populations of muskrats that one would expect to find in rocky brooks and small creeks having occasional pools and little muskrat food besides watercress (Nasturtium officinale) and the bank vegetation of pastured or wooded streams. The best habitats were situated in downstream stretches, which graded off into Mississippi bottomland bayous. Some of the upper stretches would have no midsummer signs of musk- 
rats in one- or two-mile samples, often not even in attractive-looking places. One stream having a width of about 25 feet and a prairie-like appearance had family groups of muskrats at 200- to 300 -yard intervals. Some cattail-bordered artificial ponds near a state fish hatchery had muskrats. In a three-quarter-mile stretch of what was known as one of the best trout streams in Iowa, only one place - a big pool under a rocky ledge - had any muskrat signs.

On the Wisconsin side of the Mississippi, the bottomlands of the Wisconsin River offer big-river type of habitat - good and poor - for many miles, with tributaries similar to those described for northeastern Iowa. Upstream in the Mississippi drainage, many of the best muskrat habitats are river marshes - not only oxbows but border zones and bends of wide streams grown to cattails and like emergents and sometimes covered with muskrat lodges. The Minnesota River, flowing generally eastward through southern Minnesota to join the Mississippi at St. Paul, has some of the best examples of these river marshes, which in some years are practically saturated with muskrats.

In the fall of 1932, I saw near Shakopee, Minnesota, one of the highest densities of lodges of my experience and learned the next year from Dr. R. G. Green of the University of Minnesota that this area had suffered great losses from epizootics of undetermined etiology. McCann and Highby (1942) wrote of the Minnesota River bottoms as being literally dotted with occupied muskrat lodges in the fall of 1941. In late summer, 1948, I made observations on these river marshes and found them to be in attractive condition for muskrats, though decidedly underpopulated. Concerning unfavorable situations, Highby (1941) wrote of tremendous losses of Minnesota muskrats through freezing during the winter of 1939-40, following the long, dry Indian summer that was observed to have had such drastic consequences for the Iowa muskrats.

Eastward into the central Wisconsin sand plains, muskrats may or may not occur in abundance. Hamerstrom and Blake (1939b) introduced one of their papers with the following description of a drained area near Necedah:

Central Wisconsin is a typical example of footless drainage in the Lake States. Once with more marsh than dry land, the country was ditched about twenty-five years ago in an ill-starred agricultural venture. The marshes were drained and duly planted to crops but the expected profits - except to the land speculators - failed to materialize. Farms were abandoned one by one, fires ate out most of the peat, and the job was called a failure.

From the standpoint of the water-loving furbearers it was more than a failure; it was a disaster. With the marshes and swamps gone, the streams straightened ... they had only ditches to turn to. ... [ On 10,000 acres, 200 miles of ditches comprised ] almost the only remaining habitat for muskrat, beaver, otter, and mink. ... A review of the seasonal cycle clearly shows the weakness of the drainage ditch environment: spring dispersal of a small breeding nucleus over a greatly expanded range; in summer the range drying up, population on the move but making a strong recovery none the less; by late autumn muskrats many and well distributed; winter decimation. . . . Ditch heads and short laterals were the preferred breeding grounds in spring. As 
the season advanced the water in these places dwindled to small pot-holes. ... A few fairly stable breeding areas were provided by such favorable spots as beaver ponds, deep holes in bends or behind drift jams, and some of the deeper main ditches. . . The most probable cause of the winter decrease lies in an unbalance between food and water supplies. In the ditches cited as an example, the two main foods - bur-reed and pondweed - die back in winter and do not have fleshy roots. Root foods were almost wholly lacking in the water and along the banks. Ice reached the bottom during the winter. ... Such a condition, while it does not kill every wintering muskrat, unquestionably reduces carrying capacity to a fraction of its potential.

The extensive activities of beavers in damming all types of central Wisconsin ditches and thus indirectly creating muskrat habitat had been described by the same authors in an earlier paper (Hamerstrom and Blake, 1939a).

From July, 1929, through June, 1932, I carried on field studies on many areas in south central Wisconsin (Errington, 1945). While my work was not centered upon muskrats, I covered my study areas with sufficient of an ex-trapper's viewpoint so that I generally knew fairly well the status of muskrats in representative stream areas and glacial lakes. Some of the big lakes - Mendota, Monona, Kagonsa, Koshkonong, for example - had bays or outlying waters grown to cattails and bulrushes and comprising very good muskrat habitat. In general, the muskrats were present or absent about as one might expect from the quality and extent of the habitat available to them.

In the neighborhoods of Beaver Dam, Fond du Lac, and Oshkosh are many muskrat marshes, including some operated commercially as fur-producing units. The site of one of the pioneering ventures in marsh management - the well-known aquatic nursery of Clyde B. Terrell - is at Oshkosh, and "rat-ranching" on privately owned or leased wetlands is a substantial industry.

One area with which I became particularly familiar during my 1929-32 Wisconsin residence was the marshy zone of the southwest corner of 200-acre Lake Wingra, in the University of Wisconsin Arboretum. This corner had a stand of cattails, and between it and a big spring to the southwest lay a boggy tract grown to willow, alder, and birch. The fairly abundant muskrats lived in a variety of habitats, from those of continuously flowing brooks and spring pools to those of the true marsh. In winter, steaming wet spots could be seen in some places away from the principal spring. The less favorably situated muskrats came out in the snow to forage or to wander along the lake shore or be killed by dogs or traffic on the paved streets nearest the marsh and bog. When I again saw this place in late April, 1949, the marshy southwest corner looked about as it had two decades before, but the bog had a much thicker and taller growth of willows and alders and had become more of a northern-type swamp.

The celebrated Horicon Marsh east of Beaver Dam in southeastern Wisconsin was once drained along with so many other fine waterfowl and fur-animal habitats. Later restored by public agencies, it serves as state and federal wildlife refuge and also as a fur-producing area. 
Since the fall of 1946, the Wisconsin Conservation Department has been investigating problems of muskrat management on 10,000 acres of state-owned marsh. These studies have been centered to a considerable extent on measuring mortality and productivity of muskrats on given areas of marsh and the responses of the species to experimental manipulations, particularly to the level-ditching measures that are in common use on private "rat ranches" (Anderson, 1948; Mathiak, 1953, 1956). In April, 1949, Mathiak showed me representative parts of Horicon Marsh, on both state and federal holdings. Practically all types of marsh characteristic of the region were to be seen on around 30,000 acres that were then wet. In the southern part were big expanses of open water interspersed by growths of emergent, shallowwater vegetation. In the northern part, a new road grade had a nearly dry stand of cattails and reeds on one side and a flooded tract of dead willows and floating cattail clumps on the other. The road grade, itself, was packed with tracks of evidently transient muskrats.

Conservation department reports from Horicon Marsh by Mathiak and W. C. Truax reflect many phenomena of sorts that may be noted about major marsh areas. The listed acreage of muskrat habitat increased from 3,150 acres in 1946 to 4,200 acres in 1947 as a result of higher sustained water levels. For the fur season, 1946-47, 8,209 muskrats $(0.92$ per lodge or one per 2.6 acres of habitat) were harvested, compared with a catch of 9,535 (0.62 per lodge or one per 2.3 acres of habitat), 1947-48. For 1946-47, it was estimated that two-thirds of the resident population had been harvested, compared with only onethird in the 1947-48 season, which would indicate populations of around 12,300 and 28,500 muskrats, respectively. The trapping yield for the 1948-49 season was 24,654, despite a considerable period of low water. Ecological contrasts between 1948 and 1949 were very sharp, as large tracts of flooded marsh in the south end lost their emergent vegetation in 1949. On the other hand, the deterioration of muskrat habitat in the south end in 1949 was offset by bringing formerly dry areas into production. The 1949 catch was 28,678.

Horicon Marsh has been the site of losses of muskrats from both tularemia and hemorrhagic disease, according to Dr. A. M. McDermid, then Veterinary Pathologist for the Conservation Department (letter and memorandum, August 29, 1946). An epizootic of the two diseases occurred there at least in March and April, 1946. Losses from the hemorrhagic disease were observed at times during later investigations but not on any very serious scale. I saw evidence of local dying during a week spent with Mathiak in April, 1954. Some private "rat ranches" lying to the north of Horicon Marsh were known to have suffered heavy losses of muskrats from hemorrhagic disease in the fall of 1947 (Clyde B. Terrell, letters of December 2 and 9, 1947). Mathiak and other Wisconsin fur-animal investigators with whom I talked in April and December, 1949, and during the 1954 visit, told me that losses on some private marshes had continued to be serious.

In Illinois, the highest catch of muskrats per trapper is in marsh 
areas of Lake and McHenry counties (Frison, 1938). These counties are in the northeastern tip of the state, where the lake chains are a continuation of those of southeastern Wisconsin.

Most of northern and central Illinois offers muskrats the sort of living conditions that are also characteristic of Iowa streams. Yeager (1942; 1943) did much work on drainage ditches of black prairie farm lands of east central Illinois, where he considered ditches basic habitat for the muskrats. The Illinois prairie has a total of about 6,500 ditch miles, or one mile of ditch per 2.5 square miles of land, not including creeks, rivers, etc. The ditches vary from 6 to 60 feet in width (average 12 feet) and from 3 to 12 feet in depth (average 6 feet). Fewer than 10 per cent have running water at all seasons except during years of evenly distributed rainfall. Many dry up completely during very dry seasons. Yeager gave examples of maximum catches averaging up to 73 muskrats per mile of ditch, 1940-43.

Brown and Yeager's (1943) illustrated bulletin on fur resources describes characteristics of each of the several physiographic regions of the state as well as the muskrat habitats found therein. These authors wrote that, for the two trapping seasons of 1938-39 and 1939-40, the greatest production of marsh muskrats came from the glacial lakes region of northeastern Illinois, where the yield averaged about 50 per square mile. Although stream habitats were generally less favorable than marsh habitats, total catches of stream muskrats in Illinois exceeded those of marsh muskrats insofar as a much larger range was occupied by the stream-dwellers. The comparatively low catches of two to five muskrats per square mile over southern and much of western Illinois were explained in terms of the intermittent character and lack of aquatic vegetation of the streams, as well as by heavy trapping. Water polluted by oil sludge or residues from coal mines damaged in varying degrees the muskrat habitats along the Rock, Galena, and Upper Illinois rivers and in the oil centers throughout southern Illinois.

Bellrose and Brown (1941) compared the status of muskrat habitats of lakes in the Illinois River Valley. They brought out that the vegetation upon which muskrats depended for food and shelter was limited chiefly by seasonal changes in water levels. Lakes with stable water levels (impounded waters, particularly) had less abundant vegetation of emergent types than did lakes with semi-stable water levels. Semistable bodies of water therefore contained the more muskrat houses. Cattail communities, although making up only 0.2 per cent of the aquatic and marsh plants in the lakes mapped by these authors, supported more muskrat houses per unit area than did the other plant communities. River bulrush was of great value to the muskrats and one of the most abundant of marsh plants.

Bellrose and Low (1943) wrote of the effects of floods and droughts on the survival of muskrats in the above types of bottomland waters. Characteristically, the lakes that lie on either side of the Illinois River are shallow and flat-basined. With normal river stages, they 
have little or no current. These lakes vary in size from a few to 6,500 acres. Three of them - Douglas, Rice, and Chautauqua - have been among the most productive of muskrats in the Illinois River Valley. Rice Lake, in 1940, had 413 acres of river bulrushes and 317 acres of American lotus. Lake Chautauqua had a periphery of 140 acres of marsh smartweed (Polygonum muhlenbergii), several hundred acres of black willow (Salix nigra), and about 45 acres of duck potato. Douglas Lake was principally a river bulrush marsh of some 1,300 acres.

Ecological changes following the permanent artificial flooding of a tract of wooded bottomland at the confluence of the Mississippi and Illinois rivers have been summarized by Yeager (1949). After eight years of flooding of timbered areas, the trees were dead. Buttonbush was more tolerant, about 40 per cent surviving except when deeply submerged. Cattails, duck potatoes, and sedges were the most common marsh plants invading the flooded bottoms, with smartweed, wild millet, and rice cutgrass growing on wet soil. Heavy growths of coontail and leafy pondweed, often covered in fall by masses of duckweeds, appeared in clear-water sloughs and lakes during the first four years of flooding. In 1943, 1944, and 1945, severe floods destroyed the submerged and emergent aquatic vegetation, but by the fall of 1946, several species were recovering.

The Kankakee marshes of east central Illinois and northwestern Indiana before the era of agricultural drainage were among the great habitats of aquatic wildlife, including muskrats, of the continent. According to Ling (1935), two trappers caught 7,634 muskrats from a tract of 1,000 to 1,200 acres, between November 1 and December 20, 1912, when the marsh froze over. They speared 1,300 more in a few days after freeze-up. Ling considered this a good muskrat marsh but not exceptional. A companion article by Bridges (1935) stated that, when La Salle discovered the Kankakee in 1679 at its source near South Bend, Indiana, it was perfectly described by its Indian name, "slow river flowing through a wide marsh." The marsh extended back from one to 14 miles from the banks of the Kankakee River in two great tracts: One was the "lower" or Grand Marsh of about 400,000 acres, and this remained flooded throughout the year. The "upper marsh" of about 600,000 acres was usually but not permanently flooded. In the summer of 1935, Bridges, visiting the area long after the old Kankakee marshes had been "drained and ploughed out of existence," referred to some fair-sized areas having been restored to a marshy condition.

\section{EAST CENTRAL AND NORTHEASTERN UNITED STATES AND SOUTHERN ONTARIO, UP TO NEW ENGLAND}

Eastward from Illinois, the prairie types of terrain soon change to those of the hardwoods, which originally covered most of southern Michigan, northern and central Indiana and Ohio and extended eastward into Pennsylvania and New York.

The Upper Peninsula of Michigan, which ecologically may be re- 
garded as a continuation of northeastern $\mathrm{W}$ isconsin, had at least one site of a pronounced response of muskrats to a diking and flooding program. According to a Fish and Wildlife Service news release, "Muskrats 'steal the show' at Seney Waterfowl Refuge," more than 10,000 pelts were taken in the fall of 1940 and spring of 1941 from parts of a 93,000-acre tract that previously had been regarded as inferior muskrat habitat. In the Huron Mountain region, studied intensively by Manville (1948), the muskrat is common in lakes and streams. There were 10 chief inland lakes from 10 to 775 acres in size in a block of 41,050 acres. The Huron Mountains themselves are described as an isolated range of granitic knobs and ridges.

Leedy (1948) described the ecological changes resulting from settlement of Ohio by the white man. Originally, that state was 95 per cent forested, with marshes occurring chiefly in the northern part. In addition to the cutting of the forests, the drainage of wetlands greatly altered the habitat for wildlife, including muskrats. Wood County alone has more than 2,000 miles of open drainage ditches, and the muskrats feed on corn, soybeans, alfalfa, and other crops grown in adjacent fields.

The muskrat marshes about Sandusky Bay, southwestern Lake Erie, are among Ohio's best known. Anderson (1947) reported a catch of 10,191 muskrats for the 1945-46 fur trapping on the holdings of the Winous Point Duck Club. Of a 4,400-acre area, 2,800 acres were marshy, having narrow-leaved cattails, river bulrushes, reeds, sedges, millet, and blue-joint grass. During the previous five years, cattail declines varying from 65 to 83 per cent on the different units had occurred. Tracts 20 acres in size that formerly had been covered by cattails became barren of muskrat food plants in this period.

Northeastward across Lake Erie from Sandusky Bay lies the Point Pelee National Park of Canada and the site of a biological investigation by Dr. C. H. D. Clarke in the spring of 1942. In his mimeographed report dated January 20, 1943, he wrote that "agricultural development has been so great in the Lake Erie region that Pelee Point is the only wild area left in Essex County [Ontario ], and by far the best sample of the Southern Hardwood forest formation left in Canada." Following a résumé of the known history of muskrat populations beginning with the winter of 1919-20, he summarized his findings:

The Point Pelee Marsh, including ponds, has an area of some 3,000 acres. Its water level fluctuates with Lake Erie. ... [ Open ] ponds and wet meadows, extremes unfavorable to muskrats, reduce the actual first class muskrat range to about 1,000 acres. On this range it is doubtful if the population has ever greatly exceeded 5,000. . . Really high populations occur only when the water level is high. . . Decreases in the muskrat population come about through lowering of water levels often combined with restrictions of their winter foraging ability by freezing of underwater passages.

Also in southern Ontario is a privately-owned artificial marsh for which trapping and other records have been kept for many years 
(Hewitt, 1942). The 1,250-acre marsh was dominated by cattails and bulrushes, and food (corn, potatoes, carrots, and marigolds) was also supplied artificially through the ice. The records show catches of 575 on 1,000 acres in 1930, 1,464 in 1931, 1900 in 1932, 2,125 in 1933, 2,222 in $1934,2,416$ in $1935,3,121$ in $1936,5,227$ in $1937,6,351$ in 1938, 7,815 in $1939,5,250$ in $1940,7,300$ in 1941 , and 8,191 in 1942. Only for five winters are lodge counts available: 1,974 lodges for 1934, 2,383 for $1935,2,770$ for $1936,4,041$ for 1937, and 4,452 for 1938. The five lodge counts, if plotted on coordinate paper, line up much like the mid-slope of the Verhulst-Pearl-Reed logistic curve, with the probable upper asymptote beginning to appear just before the near-peak catch of 1939.

Northeastern Ohio and northwestern Pennsylvania afford some decided contrasts in muskrat habitats. The marshes and swamps themselves vary greatly. Some are tree-fringed with open-water centers and boggy margins; some, heavily grown to water lilies and swamp shrubs grading off into deciduous swamp forest of elm, ash, and maple; some show stages from pond lilies through bog heath to coniferous forests of black spruce and tamarack (Aldrich, 1943). The Pymatuning Lake reservoir of the northwestern corner of Pennsylvania has many muskrats at times, though conditions are not always favorable because of fluctuations of water levels. Douglas E. Wade (letter, July 30, 1940) referred to much movement of the species along the shore of this reservoir, as well as along small natural streams, during the drought summer of 1939.

During a ride through Pennsylvania in the spring of 1949, I was able to make some observations of muskrat habitats, and these were supplemented by information given me by biologists familiar with the region. There were some muskrats along almost all watercourses, but the general densities were sparse. Nothing resembling good muskrat habitat was seen along the larger rivers that were subject to repeated floodings, involving rises in water up to 15 or 20 feet. The creeklike tributaries in fertile farming country had accessible growths of scrub willow and cattails and often the corn of adjacent fields. They looked comparable to Keigley's Branch in central Iowa (Chapter 10). As the country grew more mountainous, the smaller streams had few muskrats. This could also be said of the larger streams, like the Yough River in southwestern Pennsylvania. Along the latter stream, however, there were some locally fair to good habitats. One was at the mouth of a tributary having stream-edge willows, and similar vegetation, and a little flood plain looked as if it might have had fair habitat had the water not been so foul with sewage and mine wastes.

The higher stretches of streams were rocky and nearly devoid of muskrat foods, and it could easily be seen why there should be a wide belt of nearly muskrat-vacant terrain along the crest of the Allegheny Mountains. While such a barrier would not be entirely impassable to muskrats at all seasons, it should be sufficient to discourage crosscountry movements from one side of the divide to the other. 
Lying between Pennsylvania and Kentucky, West Virginia has few marshes, but stream habitats in which muskrats live may be found in many places, as where corn or other agricultural or garden crops are planted near the water or where there are beaver-flooded areas. Swank (1949) described the role of beavers in increasing the habitat available for muskrats in the West Virginia mountains. There did appear to be some conflict between beavers and muskrats when the muskrats tended to burrow through dams during periods of low water, and ponds in which beavers were not active were often drained as a result of muskrat burrowing. However, it was evident that many muskrats lived with the beavers in the beaver lodges, though most muskrats lived in burrows in the banks. The muskrat lodges that were built in beaver ponds were the typical structures that muskrats build in marshy areas. One beaver pond had five muskrat lodges from which twenty-one muskrats were trapped in one season, but this was an exceptional pond. It was five years old, about three acres in area, and had extensive growths of emergent plants.

Handley and Patton (1947) list zibethicus as abundant in "streams, marshes, swamps, and ponds" in all counties of Virginia west of the Blue Ridge Mountains. The range of macrodon lies east of the Blue Ridge Mountains in that state.

The New Jersey coastal marshes comprise some of the best habitat of zibethicus in northeastern United States. The ranges of zibethicus and macrodon come close together here. Dozier (1947a) showed the range of macrodon as including nearly all of Delaware Bay, while Hamilton (1943) reported that specimens he examined from Cape May were typical zibethicus.

Cottam and Bourne (1938) gave the total area of tidal marshes extending along the coastal region from New Hampshire to Maryland as approximately 625,000 acres. Most of these marshlands have been ditched for purposes of mosquito control, with highly variable effects on their muskrat occupants (which shall be taken up later in the treatment of macrodon). Well inside of the geographic range of zibethicus in New Jersey, splendid fresh or brackish marshes for waterfowl and muskrats have been created by diking salt marshes.

A substantial amount of research has been done on the muskrat in the great marshes of western New York. Johnson (1925) wrote that no other single area of like size in the state compared with the Montezuma and Cicero marshes in muskrat production. Both Dozier (1945) and Heit (1949) regarded the fertility of the underlying black muck as probably an important reason for the superior physical condition of many of the muskrats that they handled in the Montezuma area, especially insofar as such fertility was reflected in growths of cattails and other characteristic marsh vegetation. Johnson's page 225 and Map 5 at the back of his bulletin show that the smallest muskrats and those with the thinnest pelts were found in the northern part of the state, including the Adirondack region, while medium-sized to small 
muskrats were found in the southeastern part, including the Catskill region. He made no separation of mountain-dwelling muskrats and those of the lower valleys and wetlands of the same parts of the state, but one may easily see, in view of the inferior nature of much of their habitat, why the muskrats should tend to be undersized.

\section{NEW ENGLAND AND SOUTHEASTERN CANADA}

Dice's (1938) map of the biotic provinces of eastern North America shows that the region here to be discussed lies very largely in the Canadian biotic province. From northeastern Minnesota, northern and central Wisconsin and Michigan, and southern Ontario (except along Lake Erie), it extends eastward and northeastward to cover much of New England and southern Quebec and all of New Brunswick and Nova Scotia. Dice pointed out that New Brunswick does not differ greatly from northern Michigan in vegetation or in mammalian fauna and that the muskrat is one of the mammals ranging over most or all of the Canadian biotic province. Differing from prairie wetlands and east central forests, poorly drained situations in the Canadian biotic province have white cedar (Thuja occidentalis), balsam fir (Abies balsamea), tamarack, several species of spruce, with occasional hardwoods. If we visualize New England as something of a continuation of the rougher terrain of New York, we should also be able to appraise fairly well its general habitability for muskrats.

New England does have some good muskrat areas. The lower stretches of many rivers have marshy edges, either occurring naturally or as a result of human manipulation. Of the New England tidal marshes, the majority would appear ecologically similar to those of Long Island, New York, which have been published upon by personnel of the New York State Museum in discussions of mosquito control (Glasgow, 1938). The salt marshes have been largely ditched in a way not intended to drain in the usual sense but to hasten the outflow of tidal waters, and this engineering manipulation often did not fundamentally change the salt-marsh vegetation (Taylor, 1938).

Lake Champlain, on the northwestern border of Vermont, has extensive marshes associated with it, the muskrats of which have been studied by Seamans (1941). Lake Memphremagog, extending into Quebec from north central Vermont is classed with Lake Champlain with respect to habitat types and size of muskrat catches, and the rest of Vermont has its small ponds and streams.

Gashwiler (1948) described much of the muskrat habitat in Maine as consisting of small lakes or ponds, sluggish streams, beaver ponds, flooded bogs, or sedge meadows. Takos $(1943,1944,1947)$ carried on his intensive studies of muskrats in central Maine on about 120 acres of cattail marshes and three and a half miles of sluggish stream.

Muskrats were totally absent from Kent Island (about 115 acres), in the Bay of Fundy, New Brunswick, when the Bowdoin Scientific Station was established there in 1935. They first appeared, according 
to Gross (1947) in 1941, and then built up to astonishing numbers as many as 1,400 have been taken during the April trapping - despite the evident inferiority of the habitat in which the majority of the animals lived. (See Appendix I for a résumé of the Kent Island situation.)

Mainland populations of zibethicus in New Brunswick are similar to those of Maine, occurring as expected in suitable habitats (Morris, 1948). In Nova Scotia, not only is the subspecies usually common in freshwater marshes but it is also found along tidal creeks and nearly all inland watercourses having muddy banks and aquatic vegetation (Smith, 1940). Rand (1944) cited manuscript or mimeographed writings of R. M. Anderson and C. H. D. Clarke to the effect that muskrats were abundant in the area of the Cape Breton Highlands National Park, which is at the northernmost tip of Nova Scotia.

Sheldon's (1936) account of the mammals of Lake Kedgemakooge and vicinity in western Nova Scotia give the reader an idea of the type of terrain to be expected as we follow the range of zibethicus northward into eastern Canada. This lake (which appears as Fairy Lake on most maps, has a rugged shoreline broken by peninsulas and by rivers and brooks, which connect it with other lakes. Muskrats were common in lakes and in rivers having muddy bottoms and were observed using channels and runways made by beavers in the bogs.

The Gaspé peninsula lying north of New Brunswick and south of the St. Lawrence River is about as far northeast as the natural range of zibethicus extends. Jean Duguay, of the Quebec Department of Fish and Game, outlined for me the approximate ranges of zibethicus and of aquilonius in that province (letter and enclosure of April 1, 1949). In southwestern Quebec, the forty-eighth degree of latitude is close to the southern limit of aquilonius, but a wide zone of intergrading between the two subspecies may be expected southeast of James Bay. Anderson (1934) wrote that zibethicus is found around both sides of southern James Bay and that it ranges southeast to the St. Lawrence River.

\section{SOUTH CENTRAL CANADA AND NORTHERN MINNESOTA}

Although the southwestern side of Hudson Bay is within the range of albus, zibethicus appears to be the dominant subspecies occupying a tremendous expanse of the Pre-Cambrian Shield wilderness of northern Ontario. This block of range of zibethicus includes much country that is the "real North," where subarctic living conditions impose handicaps to survival as severe as in any area occupied by the several subspecies that we think of as "northern." From the District of Patricia - where the land is probably as wild as anywhere on earth - to the north shore of Lake Superior and into northeastern Minnesota and southeastern Manitoba, there is an almost continuous succession of more or less wooded rocky hills, rapids-filled rivers, and lake after lake. But like New England, northeastern New York, and the 
southeastern tip of Canada, the habitats suitable for muskrats are much restricted to quiet waters having marshy emergent vegetation.

I looked over a considerable area of northern Ontario in the summer of 1921, chiefly in the rugged Pre-Cambrian Shield between northwestern Lake Superior and Lake Nipigon and the immense coastal plain bogs and swamps of the Paleozoic Basin southwest of James Bay. Stretches of white water, with cascades and falls, were of frequent occurrence, and large rivers roaring through gorges invited neither residence nor passage of muskrats. Perpendicular rock faces (some rising from deep water to a hundred feet or more in height) of lake shores and islands could hardly furnish less attractive places for muskrats, especially where wave-beaten. An occasional bay with emergent vegetation or a widening of a river bordered by marsh plants sometimes did, sometimes did not, show muskrat signs. Small lakes with less precipitous shores had variable amounts of marshy or swampy edges, and some muskrats lived here as well as in numerous connecting channels or marshy spots in small muskegs. Robert H. Smith of the United States Fish and Wildlife Service informed me in 1948 that the Indians make locally good catches of muskrats about fifty or sixty miles west of James Bay, where there are some excellent wild rice marshes.

Muskrats are usually mentioned by mammal students working in the Pre-Cambrian Shield north of the Great Lakes, and when the subspecies is designated it is zibethicus. Clark (1938) referred to the subspecies as common in 1935 on Pancake River and small lakes and rivers in the vicinity of Pancake Bay, Algoma District, Ontario. A specimen I saw killed on a highway about seventy-five miles southeast of the Whiteshell Provincial Park, in the southeastern corner of Manitoba, in 1948, was almost certainly assignable to zibethicus. Snyder (1942) in his 1931 study of mammals in the Sault Ste. Marie region found that trappers there depended largely on muskrats in their fur harvests and that St. Joseph Island had some of the best muskrat marshes.

In 1950, I spent much of the second half of August in the Superior National Forest lying south of the Quetico Provincial Park, especially in areas recommended for study by Sigurd F. Olson and Milton $\mathrm{H}$. Stenlund as being typical of the region. Lake 1 of the Kawishiwi River, an island-filled wilderness body of extremely irregular outline lying about twenty miles east of Ely, was intensively surveyed over a period of several days, and the locations of living muskrats were mapped. Only one tract of fair muskrat habitat was found in the area of about five square miles with which I became familiar, and that was in a threequarter-mile stretch of sluggish stream in the midst of a swamp.

The above stream showed signs of perhaps a small family group per quarter mile, or of an estimated twenty muskrats along its length to the place where it dwindled in the swamp. The best food resources consisted of narrow-leaf cattail mixed with swamp shrubs, and this was the sole passably adequate wintering tract seen in the Lake 1 
survey - and it was not so very good. What appeared to be a single muskrat lived at one of the rocky timbered islands adjacent to the mouth of the stream, and another lived a few hundred yards farther away; these left signs indicative of newcomers, probably subadults. About a mile out from the mouth of the stream was a third animal, probably also a newcomer and a subadult, then frequenting a beaver burrow in a shallow sedge-grown place between two islands. One other possible wintering site was found - a very poor one in a rocky shore, recognized by great quantities of clam shells surely dating back for many months, to spring if not to the preceding winter. This was about three-quarters of a mile from the mouth of the same small stream, and it had the appearance of a 1950 breeding territory occupied in late August by several muskrats, presumably members of a small family group. The total population of the five square mile sample area of Lake 1 should have been about thirty muskrats, as of late summer, 1950 .

A two-mile stretch of the South Kawishiwi River (essentially a narrow lake) was worked without finding any sign of muskrats, whatever, though there were some attractive cattail growths in parts of the shore zones. One of the streams near Ely that Stenlund showed me looked like rather good habitat, with fringing growths of burreed, duck potato, and sedge, but the tract inspected had no current muskrat signs. Stenlund also showed me the best muskrat habitat of which he knew in the vicinity of Ely - a sluggish cattail-bordered stream at the east end of Shagawa Lake - and while this had some muskrat signs, it still was not much in comparison with what might ordinarily be expected.

The Superior region was rated by Dr. Paul R. Highby of the Minnesota Department of Conservation as the most unproductive of muskrats in the state (memorandum, May 11, 1948, Highby to Taylor W. Huston). Catches for 1946 averaged about one muskrat per square mile for Cook and Lake counties, about two per square mile for St. Louis County, and about four per square mile for Carleton County, which is the most southerly of these four counties; and the total catch for the four counties for that year was estimated at 18,750 . Highby's observation (expressed in the above memorandum) of muskrat populations being sparse even in the "slow moving marshy streams between the lakes," where most of the catches are made, and my own failure to find evidence of many muskrats in the best places investigated during my 1950 survey, apparently relate more to the situation in late years. Olson, an ecologist of long experience and one inimately familiar with the region, recalled times when muskrats had been quite abundant locally.

From trappers' reports, I would judge that the hemorrhagic disease may have been in part responsible for this late scarcity of muskrats. One man told me of a fine marsh having many lodges but yielding few 
muskrats during the 1949-50 fur season. After the melting of the ice, he saw many dead muskrats.

The north shore of Lake Superior is inhospitable for muskrats with wave-washed bare rock one of the chief features to be seen. The mouths of streams entering the lake may be gorgelike or flat, depending on their location, and with exceptions, have little quiet water or marsh-type emergent vegetation. One fair-looking muskrat habitat was noted inland from Split Rock, where bog and marshy growths bordered a stream. A beaver lodge was in sight from the road, and there could well have been muskrats in the area. From Duluth southwestward, the marshes, lakes, and streams took on increasingly the aspects of those of the hardwood-forested part of the state.

In late August, 1948, representative areas of the Pre-Cambrian country in southeastern Manitoba and adjacent Ontario, especially the Whiteshell Park, were looked over in company with Arnold Davey of the Game and Fisheries Branch of the Manitoba Government. Five years later, I spent a week in other parts of the Whiteshell.

Lake shores in the Whiteshell were principally of sloping granite outcrops offering little to attract muskrats and this, too, may be said of the islands out in the lakes. But, occasional dense growths of wild rice, and to a lesser extent of cattails and bulrushes, covered whole bays or small lakes, and there were in many places lake-shore fringes of emergent vegetation. Even some wind-swept margins had heavy growths of vegetation. Wild rice generally extended farthest into the deep water and protected bulrushes and cattails from the heaviest wave action. Masses of "goose grass" (Equisetum fluviatile), sweet flag, water lilies, and submerged plants grew in suitable situations - around the entire periphery of some of the lakes - where they would remain accessible to bank-dwelling muskrats having little other food.

One of the superior muskrat retreats examined - the outlet at the north end of Jessica Lake - was bordered by a willow swamp. The outlet, itself, was swift flowing in the center but with slow water along the sides, which had much reed, water lily, cattail, bulrush, sweet flag, and such vegetation, grading off into the typical swamp. The muskrat lodges were mostly newly built, of small size, and located near shore, though one was a summer lodge built into the base of a willow in the swamp. Deep-freezing seldom occurred in this sort of place, both for reasons of accumulations of snow and the nature of the muck underneath. A half mile east of the outlet lay something of a delta of a small stream entering the lake, and this was partly grown to a bed of wild rice, of remarkable thickness. Heavy stands of reed also dominated parts of this delta, and the swamp bordering the stream was at least a quarter mile wide.

Whiteshell Lake, which was decidedly more food-poor than Jessica Lake, had sparse bulrush growths and a few muskrat signs along most of its shore, with vegetation being fairly thick in a few places. 
The best retreat seen for muskrats was about an island having some bank burrows and growths of cattail, bulrush, sweet flag, and reed between the island and the mainland. Fringing vegetation of the lake shore included locally heavy stands of reed but was chiefly of bulrush. Barren stretches of shore usually had no muskrat signs.

The muskrat catches in the Whiteshell area were usually rather substantial and the fur of excellent quality - the so-called "rice rats," famous in the fur trade. Actually, there was not much habitat to be rated as first class, but much was fair to good.

The Lake of the Woods country of the southwest corner of northern Ontario was intermediate in appearance between that seen in the Whiteshell Park and what I remember of that south of James Bay. Among other things, the streams looked at, except for the occasional rapid, had quieter waters than in the James Bay region, with more marsh vegetation growing about their margins. The extremely indented east shore of Lake of the Woods in view from the highway had innumerable bays and corners more or less grown to cattail, sweet flag, wild rice, sedge, reed, and bulrush. Despite long stretches of inhospitable, wave-beaten rocks and beaches, there was living room for many muskrats in the aggregate. Sluggish, interlake streams had both emergent and submerged vegetation growing in likely places. North of Sioux Narrows were splendid marshlike expanses between lakes, which surely must typify others in the many ramifications of the waters of Lake of the Woods. Beaver-flooded creeks afforded additional muskrat habitat. Water levels at most places where emergent marsh vegetation dominated looked at least passable for wintering muskrats as of late August, 1948, and certainly many places should have provided first-class wintering grounds.

Enroute from Sioux Narrows to Rainy River, Ontario, small bodies of water were seen, some of them suited to muskrats. The terrain became flatter southward and westward to the International Boundary, and streams were brown colored and boggy, having considerable bordering vegetation of willows and occasional cattail clumps. The western and southwestern sides of Lake of the Woods were not personally visited, but Dr. Kenneth D. Carlander, who once carried on fisheries research on that lake, described the west side for me as being bordered by great amounts of floating bog and the south side as a shallow wave-beaten beach without emergent vegetation.

Across the Minnesota line southward from Rainy River, Ontario, I looked over during the same trip representative tracts of swamp, bog, and stretches of roadside ditches. The latter were quite well occupied by muskrats. As wintering habitat, the ditches here did not look especially favorable: the water was seldom over one and one-half feet deep, and the best vegetation was no more than scattered growths of sweet flag, cattail, and pond plants. In several ditches on the "Big Bog" between Waskish and the ranger station of Pine Island, the flow varied from trickles to a couple of feet in depth. Muskrat signs could be seen especially about the pools behind beaver dams. 
Away from the grid-pattern of ditches (dredged decades ago throughout the immense, mainly tamarack, swamp lying north and east of the Red Lakes) were occasional places having the appearance of good muskrat marshes. Some were big gravel pits, with deep open water grading off into cattail-grown shallows, and these had expected populations of muskrats. One small gravel pit having some cattails over the water had a freshly dug small burrow, evidently of a single muskrat. Other gravel pits had good cattail growths but no water. A forestry road and ditch embankment had served as a barrier to a past fire, and on the north side was a typical tamarack, spruce, and white cedar swamp, while the fire-swept south side was dominated by cattails growing under the dead poles.

A tiny flow of water coming out of an isolated cattail stand of about a quarter-acre in the midst of a swamp had muskrat and mink signs about it. The cattails were in shallow water but in the sort of place where some muskrats might winter if they had the protection of plenty of snow. Kermit Peterson, the Refuge Patrolman of the Minnesota Department of Conservation, had indeed known them to winter in such places, living in snow nests under the cattails.

As a background for my late summer observations of 1948 about northeastern Upper Red Lake and the Tamarack River, I had hunted and trapped there throughout the fall and winter of 1920-21. In addition, on-the-ground discussions with Peterson, who accompanied me during the 1948 visit to this area, were most helpful, as was information received in correspondence from Taylor W. Huston, then Supervisor of Game of the Minnesota Department of Conservation.

The eastern half of Upper Red Lake had along the north shore a much thicker growth of reeds and rushes (up to a couple of hundred yards in width) in 1948 than in 1920. These emergents were attractive to muskrats - and some muskrats were there-during the warmer months, but the bottom was of hard sand and the water so very shallow that I do not see how the animals would stand any real chance of surviving a winter in this shore zone proper, even with great snowdrifts over the reed clumps. I recall that, by the end of the winter of 1920-21, the bare lake ice had thickened to a depth of between four and five feet.

A long stretch of lake shore, itself lacking in any kind of emergent marsh vegetation, did have a used muskrat retreat at the mouth of a brook. Although the channel leading through the ice ridge to the lake was only about two feet wide and had a flow only about five inches deep, a pool had formed between ice ridge and where the stream came out of the woods. This pool was 15 to 25 feet wide, about 60 feet long, and up to five or six feet in depth, with margins grown to cattails. It was the sort of niche where perhaps two or three muskrats might winter comfortably and where more might conceivably get by. It had fair muskrat signs, as did also the flowing brook upstream.

Muskrats were also noted at two other short natural streams and 
a ditch along the northeastern shore of Upper Red Lake. The ditch, near the lake, was wider and deeper than most of those in the Big Bog and had considerable marsh vegetation growing at its sides. The smaller of the two natural streams was brooklike, mostly shallow with occasional pools and considerable marsh vegetation. It was not good muskrat habitat but it doubtless could winter a few. The larger stream had a sluggish water channel about three feet wide, with masses of submerged and some emergent marsh vegetation; and a combination of peaty soil and deep snow (about five feet had accumulated on the level during the winter of 1920-21) should protect some of the food accessible to muskrats from freezing. All three of the above places had fair muskrat signs in late summer, 1948, the most being seen about the larger of the natural streams, very possibly of more muskrats than really could be accommodated. Twelve of 16 mink scats examined from Big Bog muskrat habitats contained muskrat remains, which is indicative of a high degree of vulnerability for the time of year. Several land-active, presumably transient muskrats also were seen in different places.

Varying stands of cattails - sometimes quite extensive - dominated the flora between the south edge of the Big Bog and the hardwoodsgrown sand ridge and the lake shore lying north of the lake. These, however, tended to be so dry or nearly dry that they could have been of little ordinary use for muskrats. In late summer, 1948, they had few if any muskrats living in them, though, with a rise in water level of the lake, they could have afforded superb muskrat habitat.

By far the outstanding place for muskrats within a large area was the Tamarack River, and this seemed even more true in 1948 than in 1920, when it had been the best seen in weeks of fur-cruising in Beltrami and Koochiching counties. For one thing, profound ecological changes favoring muskrats had taken place in the mid-stretches of the river during the 28-year interval. Furthermore, the 1948 population status of muskrats in north central Minnesota was judged to have been decidedly higher in relation to habitats than it had been for years; and on the Tamarack River, the muskrat population probably approached the accommodation capacity of that stream and environs for the species. I would say that the 1920 fall population of the river had averaged from 60 to 80 per linear mile for about the 10 miles nearest the mouth. The 1948 densities appeared to have been as high, with a promise of being able to rise (though not necessarily to be maintained) still higher during a good muskrat year. Farther upstream, the river became narrow, shallow, and rocky, losing itself as brooklets threading bog and swamp.

In analysis, the superior muskrat environment of the Tamarack River differed little from that of numerous inter-lake streams of the Pre-Cambrian Shield east of Lake of the Woods and northwest into Manitoba. At its mouth, the river was nearly 100 yards wide, sluggish and deep, having wide margins grown to sedge, cattail, reed, sweet flag, wild rice, yellow water lily, and submerged plants. Upstream a 
few hundred yards, it had narrowed to about 50 yards, was still sluggish and deep, and with the same vegetational types. About two miles upstream from the mouth, the river had started to widen again, meanwhile becoming shallow enough so that the bottom could be touched with a canoe paddle, and the margins had locally dense stands of cattail, reed, and redtop grass. All this was in 1948 as it had been in 1920; but in the course of the next few miles, what had been in 1920 a marshy stream with a fringe of hardwoods in the midst of a belt of tamarack and spruce swamp had in 1948 the appearance of stream intersecting a marshy reed and redtop savannah up to threequarters of a mile or more in width. Only remnants (mostly dead stubs) of the stream-side hardwoods were to be seen in 1948.

Farther upstream, the river had in 1948 much greater marshy growths - typically thick fringes of reed, cattail, sweet flag, and sedge, and back toward the redtop, wild rice. I did not visit the upper reaches in 1948 but remember clearly, from 1920, many shallow water burrows in frozen mud having the signs of poorly situated muskrats and muskrat tracks in the snow about air holes over rocky brooks.

So far as the observed 1920-21 wintering conditions for muskrats in the Big Bog area were concerned, the pools between three and four feet deep in the ditches and creeks did not freeze to the bottom under the thick covering of snow. The Tamarack River, three miles upstream from its mouth, had little or no ice under snowdrifts several feet in height that were piled about certain curves where the slow current ran close to the bank, and at almost any place over the main channel the snow-covered ice was less than three feet in thickness. As late as February, after months during which air temperatures had dropped to between 20 and possibly 50 degrees below zero Fahrenheit virtually every night, snowdrift tunnels used by muskrats (and minks) could be traced to open water. Ice-glazed chambers and sitting and feeding places could be found either on the river bank or the ice shelf next to the open current under drifts. The snow tunnels and chambers were similar to those typically existing along less ice-bound streams of northern Iowa and eastern South Dakota. Food debris was also similar, consisting mostly of fish remains. Two muskrats were discovered in the Tamarack River drifts after having been partly eaten by minks in late winter, and these, when skinned for examination, were sufficiently lean to give me the impression that the muskrat population was not getting along very well.

The Red Lakes drain westward into the Red Lake River, which joins the north-flowing Red River near Grand Forks, North Dakota. As I remember the Red Lake River from having traveled it by canoe three times in late summer and early fall, 1920, the best muskrat habitat was in the Indian reservation, west of the outlet of Lower Red Lake, where the channel was bordered by wide growths of reed, cattail, and wild rice. Muskrat signs did not then seem to be as plentiful as expected, but the Indians had been trapping them for food at least as early as September. 
Thief River, a tributary of the Red Lake River and one of the low-gradient streams in the former bed of glacial Lake Aggassiz, was visited in late summer, 1920, two years after completion of the artificial draining of Thief Lake. Thief River was in effect but an elongated, woods-bordered slough, filled near its mouth with backwaters from Red Lake River and finally ending in diminishing puddles in its then exposed stream bed. It was of interest to me chiefly because of the astounding concentrations of small fishes, which could be expected to furnish a source of food available to muskrats under the ice in an otherwise food-poor, mud-margined habitat.

The large, peaty marshes, Thief Lake and Mud Lake, were among the famous waterfowl- and muskrat-producing areas of early settlement days in northwestern Minnesota. They lie near the edge of a zone where prairie and hardwood forest grade off into mixed forest and conifers to the east. Following their drainage for agricultural purposes in the second decade of the present century, the "reclaimed farmlands" of their bottoms were abandoned by bankrupt homeseekers. In midsummer, 1934, after a long drought, I saw Mud Lake as a desolation of burnt or smouldering peat grown up to little except farm weeds. By 1937, when flood waters came again, public agencies had acquired both lakes and surrounding lands and had dammed the outlets, so that by 1941 the lakes together had around 50,000 acres in water and marshes with substantially restored productivity for marsh-dwelling animal life.

Southward from the Red Lakes (which with over 280,000 acres constitute the largest body of water exclusively within the boundaries of Minnesota) extends a complicated system of woodland lakes and marshes and interconnecting waters. Lake Winnibigoshish, Leech Lake, Mille Lacs Lake, and other of the larger lakes are as inhospitable for muskrats along their open water stretches as large lakes usually are, and even many of the smaller have an essentially "northern" appearance, on the whole short of muskrat food plants except for bulrush fringes and such vegetation. But, interspersed with these are also some fine marshes. Southward from Mille Lacs Lake, the wetlands take on more and more of the aspect of those of the glaciated prairies of southwestern Minnesota, northwestern Iowa, and the eastern Dakotas; and like the prairie marshes in late summer and fall of 1948, they appeared to be much underpopulated by muskrats, despite their frequently excellent condition for the species.

The exact boundaries between the range of zibethicus and neighboring subspecies in the Red River drainage basin south of Winnipeg are not clear. The animals living in the Netley Marshes south of Lake Winnipeg had the appearance of albus, and I would expect this to be the subspecies of the lower Assiniboine River, which joins the Red River at Winnipeg. Soper (1946) defined the range of cinnamominus in Canada as from the Red River west to southern Alberta. Bailey (1926) considered cinnamominus as the muskrat occupying all of 
North Dakota. Although such might have been true early in the century, I doubt that it has been in recent years. If there are not typical members of zibethicus living in eastern North Dakota, I would be much surprised if the populations of at least the main Red River valley did not include large numbers of intergrades.

Near the sources of the Red River and the Minnesota River in northeastern South Dakota and adjacent Minnesota are the shallow elongated Lake Traverse and Lake Big Stone, of about 20,000 and 22,400 acres, respectively. These lakes go through all stages from being dry to flooded, and at intermediate stages afford much good muskrat and waterfowl habitat. The Red River, itself, south of Winnipeg, is a medium-small to medium-large stream, ordinarily having a sluggish flow and muddy, tree-fringed banks. It is, however, subject to terrific floods, which may cover a great deal of the valley, sometimes for many weeks. Some of the worst floods are the result of ice jams, as springmelt waters from the south pour northward into places where more winter-like conditions prevail.

The Ottertail River, one of the headwaters of the Red River rising in west central Minnesota, has about its source a large number of lakes and marshes lying generally east of Fergus Falls. These waters are mostly in hardwood country but grade off to the west into those of prairie types and differ little from those about Detroit Lakes to the north, which are near the headwaters of the Mississippi.

\section{OUTLINE OF THE GEOGRAPHIC RANGE OF THE COMMON OR EASTERN MUSKRAT IN NORTH AMERICA}

Because of the very extensive area held by zibethicus in North America, it might be of some value here to review the subspecific range as well as present information permits. The fact that some of the boundaries may be occupied by intergrades rather than by representative members of the subspecies - especially in the Canadian north and along the dividing lines between eastern and western United States. should not introduce undue error. It also should be understood that the outlines of the range of zibethicus have been known to change in the past and that they may change again in the future. These changes are not necessarily of minor significance but may involve distances of hundreds of miles, as is illustrated by the apparently recent advance of zibethicus westward and northwestward into eastern South Dakota and the southward extension apparent in Mississippi and Alabama.

Starting with the northernmost extreme of its range about James Bay, the subspecies extends southwestward probably through southeastern Manitoba and southward along the eastern boundary of North Dakota. I think that it is the muskrat of eastern South Dakota east of the James River Valley. Along the Nebraska-Iowa boundary, its range may possibly overlap with that of cinnamominus, which also may be true along the northern part of the Kansas-Missouri boundary. The southeastern corner of Kansas has zibethicus, however, and so 
probably has the northeastern corner of Oklahoma. From southwestern Arkansas, the southwestern extreme of the range of zibethicus probably angles off southeastward toward Baton Rouge, Louisiana.

In the southeastern Gulf States, the range of zibethicus extends south almost to the Gulf of Mexico in Mississippi and Alabama, then runs northeastward from southeastern Alabama through about the middle of Georgia and the Carolinas. In Virginia, zibethicus is the muskrat west of the Blue Ridge Mountains. Most of Maryland is in the range of macrodon, as is Delaware and southwestern New Jersey; but from Cape May, New Jersey, northward and northeastward to the Gulf of St. Lawrence, zibethicus finds its boundaries delimited chiefly by the salt water of the Atlantic Ocean. Then, from the St. Lawrence River in the general vicinity of the forty-eighth parallel, the range of zibethicus extends indistinctly and unevenly northwestward to James Bay. 


\section{Chapter 13}

\section{The Muskrats of North America Other Than}

\section{Ondatra zibethicus zibethicus}

The fifteen ReCOGnized Forms of muskrats having North American ranges outside of the range of $O . z$. zibethicus show many differences as to population status, habitats, and geographical distribution. Of these other muskrats, O.z. cinnamominus - the subspecies with which, next to zibethicus, I have had the most experience - can be notable for its low densities over tremendous areas of the arid and semiarid Great Plains; it may hardly be represented at all for stretches of hundreds of miles, yet seldom does it fail nominally to hold essentially its regular range, and it often reaches typical muskrat abundance in suitable marsh or stream habitats.

Westward from the range of cinnamominus extend the ranges of the evidently closely related mergens, occipitalis, and osoyoosensis. The one of these having the smallest range, occipitalis, shows some behavior differences, whereas the widely distributed osoyoosensis is probably as versatile with respect to habitats and climate as any muskrat subspecies, including zibethicus.

It is true that zibethicus in northern Ontario and osoyoosensis at high altitudes in western United States illustrate muskrat adaptability to long cold winters and marginal habitats as well as do any of what may be called the true northern muskrats-obscurus, aquilonius, albus, zalophus, and spatulatus. Nevertheless, much may still be learned from this latter group about what constitutes habitability of northern muskrat range and what muskrats can there endure in the way of edge-of-range phenomena.

The subspecies macrodon, rivalicius, ripensis, bernardi, goldmani, and pallidus are all natives of warm climates and all have restricted geographic ranges. Parts of some of the ranges, however - such as 
those of rivalicius and macrodon - may have at times among the highest densities of muskrats to be found in the world. It is conceivable that in certain years rivalicius in its comparatively small range along the Gulf Coast may outnumber zibethicus, although the latter occupies a range in North America equal in size to about half of the United States. Boundaries of ranges are very definite in some cases or marked by wide zones of intergradation in others. There may or may not be manifestations of special habitat niches or of barriers. Often it is not apparent just what determines the edge of a subspecific range, especially where two ranges overlap.

\section{THE GREAT PLAINS MUSKRAT, cinnamominus}

I think of Medicine Lake, in the northeastern corner of Montana, as rather exemplifying some of the muskrat habitats seen in the northern high plains during a personal inspection of waterfowl and muskrat marshes in 1934. The status of this lake varies with the years from that of a great marsh to an open water lake, with marshy tracts confined to shallow bays and outlying waters. Across the International Boundary into southern Saskatchewan lie many similar bodies, of all sizes and all degrees of suitability for muskrats, from cracked-mud bottoms encrusted with salts to the best of bulrush and cattail marshes and, on to the other extreme, foodless open water lakes. The marshes continue northward but soon take on an aspen-fringed appearance. In the wheat-growing areas are thousands of these potholes, most of them less than four acres in area, and usually with an open water center and a thick rim of emergent vegetation.

From the standpoint of the muskrats, the chief drawback of the potholes is the likelihood of their drying up in late summer. If the exposure from drying be neither excessive nor prolonged, the muskrat occupants may take care of themselves fairly well, but in the event of a real drought, they suffer great mortality. By late summer of the drought of 1934, almost the only remaining good habitats that I saw in southern Saskatchewan and southwestern Manitoba were the Qu'Apelle River marshes. The latter showed much lushness in the midst of the dry countryside. Information on winter conditions was given me by Jack Leader, a resident old-timer, and it was clear that a place like this may be strategic in the survival of muskrats for repopulating surrounding areas after cataclysmic weather emergencies.

Soper (1946), in his paper on the mammals of the northern Great Plains, wrote that the subspecies cinnamominus ranges

well north of the International Boundary from about Red River, in the east, west to southern Alberta. In addition to the Great Plains proper, it also occurs on Turtle and Wood Mountains and Cypress Hills; also, it is thought to be this form that occupies Moose Mountain. The animals are well distributed over the territory at large, often occurring commonly in streams, lakes and sloughs even on the high, arid plains of the Missouri watershed. 
Specimens taken early in the century from Touchwood Hills, perhaps about fifty miles northwest of Regina, Saskatchewan, were considered by Hall (1938) to be nearer albus than to any of the three adjacent subspecies, spatulatus, osoyoosensis, or cinnamominus.

I suspect that there is a wide zone of intergrading between cinnamominus and albus, the Hudson Bay muskrat, in southern Manitoba and Saskatchewan. When I worked in Manitoba in 1948, I was informed by personnel of the Game and Fisheries Branch that the Whitewater Lake area in the southwestern part of the province was the source of most of the recognizable cinnamominus taken by the fur trade. The Assiniboine River is the sort of place in which cinnamominus could be expected to occur, but the animals I saw, alive or dead, in the delta marshes south of Lake Manitoba, not far to the north, looked like albus, as did those of the Netley marshes south of Lake Winnipeg.

A wide variety of fair to excellent habitats may be seen over different parts of North Dakota, except for the badlands and other dissected semiarid terrain lying mainly south and west of the Missouri River. In the north central part lie the Lower Souris marshes, once inadvisedly drained for agricultural use, later restored through a series of dams to some approximation of their originally splendid condition for wildlife (Henry, 1939). Their 1948 appearance, when I inspected them in company with C. J. Henry, M. C. Hammond, and Edward Wellein of the U.S. Fish and Wildlife Service, varied from open, windswept bodies of water to solid blocks of cattails, from natural-type marshlands to those intersected by ditches, embankments, and artificial islands. To quote from Henry's paper:

From the pioneers we learn that the Souris (or Mouse) River Valley once was one of the most productive wildlife nurseries in the country. Waterfowl, especially, were very abundant, and from a distance their flights often resembled huge clouds of smoke. ... Sometimes in summer evenings the marsh noises made normal conversation almost impossible among farmers living at the edge of the valley.

Lac aux Mortes, about 80 miles east and southward, was the site of an interesting study of muskrats by Dr. James W. Johnston, Jr., formerly of the North Dakota State University. He observed (unpublished memorandum, 1947) an apparent correlation between large size of resident muskrats and exceptionally thriving stands of cattails, bulrushes, reeds, and like marshy emergents.

From eastern North Dakota, some good muskrat range extends down into South Dakota via the James River Valley. There are also irregularly distributed muskrat marshes in the general area northwest, west, and southwest of Aberdeen, to within 10 to 25 miles of the Missouri River, but these become fewer in central South Dakota, where the terrain away from streams takes on a flat and monotonous aspect. 
The Sand Lake National Wildlife Refuge, of about 11,000 acres of open water and marsh, was the site of muskrat studies carried on, 1943-45, by Aldous (1946, 1947). When I last saw this place, in company with Watson E. Beed in 1938, it had a relatively small proportion in marsh, and as I remember it from my early years as a South Dakota resident, it was typical "Jim River" bottomland. The river itself, running south and southeast past Huron and Mitchell, to enter the Missouri River east of Yankton, had stretches of fair to good sluggish-stream habitat for muskrats, but the artificial impoundments at Sand Lake really were responsible for the high local muskrat densities there. Beed, in a letter of July 9, 1942, explained that

The drought [ of the thirties] had eliminated almost all muskrats. With the return of water they increased until in the spring of 1941 there were 200 lodges confined almost entirely to the James River channel. Muskrats taken during the 1941 season were under size, parasitized and their pelts were of very poor quality. In April, water came down the James River and flooded 8000 acres of marsh to an average depth of three feet. This marsh area was maintained during the entire summer and winter by inflow from the north. A lodge count early in January, 1942, showed 4000 scattered over the entire marsh. Due to poor trapping conditions only 3000 muskrats were taken during the 1942 open season. These rats were taken March 1 to 20 and were of excellent quality, nearly all grading as "sealers."

According to Dr. Wilfred D. Crabb, River Basin Studies, U.S. Fish and Wildlife Service, muskrats barely exist along the main stream of the Missouri River between the mouths of the Cheyenne and Cannonball rivers in north central South Dakota and south central North Dakota (conversation, July 22, 1948). The recorded Indian catch for this approximately 150-mile stretch had averaged less than a muskrat per mile, and the muskrats living there were localized in oxbows, small marshes, and the mouths of creeks. The stream here is heavily siltladen and subject to great fluctuations, cutting away old mud bars and building up new ones; its banks vary from steep cut faces to those of low willow and cottonwood-grown flood plains and islands.

Crabb and his associates reported no muskrats from the Belle Fourche irrigation impoundment of northwestern South Dakota and very few along 113 miles of irrigation streams in the vicinity, but scarcity of muskrats in many irrigation developments is often due to repressive measures taken against them. Muskrats were scarce about the Fort Peck Reservoir in northeastern Montana, which at least would not seem due to remoteness from muskrat-occupied habitat. Crabb referred to the muskrats as being numerous along the Milk and Musselshell rivers, the former joining the Missouri River below the Fort Peck Dam and the latter entering the reservoir near its upper end.

The description by Jellison, Kohls, Butler, and Weaver (1942) of 
an 80-mile stretch of the Musselshell River applies to other streams of similar type in central and south central Montana:

Each year during the fall and early winter months part of this river is frequently not a flowing stream, but is represented by a series of ponds of semistagnant water. These ponds are separated by low, dry gravel bars. . . . When revisited in February [1940] a good stream was flowing and much of the river was covered with ice.

Large cottonwood trees, willow thickets, and a variety of shrubs grow along the banks, the cottonwoods and willows being the principal winter food of the local beavers, which were fairly numerous. No beaver houses were seen as the animals in this area live largely in bank burrows. There were numerous caches of cut willows and cottonwood limbs as well as beaver dams. Muskrats ... were abundant in the smaller streams and in marshes tributary or adjacent to the river, but were not common in the river itself.

These authors' photographs of the main channel of the Musselshell River, taken in late November, reveal little of wintering habitat that would attract muskrats. While the muskrats would not be averse to helping themselves to the tender willow twigs of the beaver caches, it is easy to see how they might be forced into dangerous outside activities in cold weather and why they would not congregate in the main channels as long as they had better quarters available.

Personal experience, beginning in 1924, along the Cheyenne River and some of its Haakon County tributaries in west central South Dakota, provides a background for appraising year-round habitability of steppe streams for muskrats. The Cheyenne River itself alternately swept by flash floods and drying to silt-choked channels and residual pools and riffles - had practically no muskrats at times when those animals were passably abundant in such attractive local niches as did exist. The main stream served as an avenue of travel for muskrats, however, both during the spring dispersal and to some extent during late summer and early fall population adjustments.

The situation at Plum Creek, a tributary of the Cheyenne River, in 1924-25, illustrates the vicissitudes to which "West River" muskrats are subject during relatively favorable years. Late fall, 1924, had been a time of population adjustments between shrunken pools. The muskrat-occupied pools averaged about two and a half feet in depth at the center and had a water surface possibly averaging about 1,500 square feet. Such pools were short of readily available food, and the animals fed rather indiscriminately on vegetation of the surrounding land until freeze-up. Trapping yielded about one muskrat per pool, although six were caught in one elongated pool of about 100 yards in length. My December catch of 149 pelts showed major strife wounds in all stages of healing. A few animals were coming out in subzero weather to feed on the wolfberry (Symphoricarpos) stems that they could find in the snow, but, by New Year's, outside activity had ceased.

Notes taken while I was trapping afforded an index to the mortal- 
ity suffered by muskrats wintering in these pools. A reconnaissance of two creeks before the opening of the trapping season indicated that the fall muskrat population was about the same on each. Only one creek was trapped and, from this, all known trappers took slightly over 160 muskrats from about six miles of stream bed, or probably close to 95 per cent of the total population. Despite the severity of this trapping along one creek, the earliest spring signs appeared to be no heavier along the creek that was not trapped, which suggests near-annihilative losses of the untrapped population.

Mrs. Grace Fairchild, who, from 1902 to the mid-fifties, lived on a ranch through which Plum Creek runs, first noticed muskrats on the creek about 1909. She recalled that many were traveling cross-country during the drought summer of 1911 as the water disappeared from Plum Creek. Only a little water then remained in the vicinity of the Fairchild ranch except in a few puddles of a neighboring creek and behind a large earthen dam. Normal water levels came back in 1912, but muskrats did not again become numerous until 1924, the year of my trapping and the year of greatest muskrat abundance in the memory of the local people. Later, I observed that the muskrat populations for 1925,1928 , and 1930 were fairly well distributed, though much less dense than in 1924. The drought of 1931 did not completely dry up the creek pools; but, by 1932, the pools had further diminished; and, by 1933, muskrats were barely represented. A vestigial population was present in the spring of 1934, but drought depopulated the creek of muskrats before June and July rains refilled some of the pools. By late summer, 1934, what seemed to have been a single muskrat occupied a dam pond three miles away, and muskrats were said to have been living in one other dam pond - a distant one, which was not personally visited. No sign of muskrats was detected along the Plum Creek water course in 1935, despite temporarily favorable environmental conditions. The last year of extreme drought was 1936, and this all but annihilated the muskrats of the whole "West River Country" of South Dakota. A very few muskrats had reappeared locally by the fall of 1938, but stream and dam pools remained essentially unoccupied for several years.

By 1946, muskrats were present in widely scattered places, usually in the choicest habitats available. I did not inspect Plum Creek in 1948, but similar streams in the western Dakotas then showed evidences of slowly recovering populations - at perhaps a tenth of the 1924 level. A late summer drought in 1949 seemed once again to eliminate the creek-dwelling muskrats, though some still persisted in neighborhood dam ponds. There were a few muskrats around in 1954, the last year that I saw Plum Creek.

The creeks of badlands and sagebrush semidesert vary tremendously in their attractiveness and habitability for muskrats. Most of them have neither permanence of water nor food to provide more than submarginal habitat. North Dakota's big program of building 
earthen dams across formerly dry gullies has resulted in many small impoundments that became well-grown to emergent marsh vegetation and occupied by muskrats. I saw similarly splendid marshlike artificial impoundments, with muskrats in them, in northeastern Wyoming in 1948. Scattered about in northeastern Wyoming, southeastern Montana, and the western Dakotas were natural watercourses with marshlike pools - some rather isolated about the headwaters of creeks and seldom connected by running water - others representing merely deeper or more sluggish stretches of intermittent streams. Of these pools, those most likely to harbor muskrats had water between eighteen inches and four feet in depth and were bordered by dense growths of cattails, bulrushes, arrow heads, and other food-rich plants.

The Yellowstone River of eastern Montana has, like the Musselshell, limited muskrat habitat in its main channel, but numbers of the animals live (or could live) in oxbows, about eddies fringed by willows or emergent marshy vegetation, and about the miscellaneous pools, seepages, and irrigation flowages in the valley. Some of the best muskrat habitat and signs seen along the Yellowstone River in 1948 were downstream from Billings, where the clear-greenish, swifter waters of the upper tributaries began to take on more and more of a silted, sluggish appearance.

It is anything but clear just where a dividing line between the ranges of cinnamominus and osoyoosensis might be drawn east of the Rockies. The upper reaches of the Yellowstone River surely have osoyoosensis, and I think that that is the muskrat of Rock Creek and mountain stream tributaries at and west of Red Lodge, south central Montana. Yet, I examined a dead animal found beside a small impoundment up on the tableland about five miles northeast of Red Lodge and another dead one beside another impoundment and desertlike creek a few miles farther east, and both of these looked just like the ones I once handled in western South Dakota. The zone of intergradation is probably wide in many places, and the best I can do at present is to suggest that cinnamominus-like muskrats may be expected in the lower-altitude streams and marshes eastward from Great Falls and Billings, Montana, eastward from the Big Horn Mountains, and through most of the southeastern quarter of Wyoming. The gorges of Clark Fork east of Yellowstone Park would seem a most effective barrier between cinnamominus downstream and osoyoosensis upstream. To my eyes, they looked impassable for muskrats, and their surrounding mountainous country would hardly permit muskrats to travel overland.

The subspecies of that isolated mountain range, the Black Hills of western South Dakota and northeastern Wyoming, is probably cinnamominus. All animals I have seen within 200 miles east of the Black Hills looked like typical examples.

Central Wyoming has streams that are typical of badlands and sagebrush desert, along with some impoundments having rushes and other 
emergent vegetation. East of the Big Horn Mountains are localized irrigation flows and seepages, many of which are entirely habitable for muskrats, and still farther eastward are sluggish streams that have muskrats in the more attractive places. From Newcastle, Wyoming, to Custer, South Dakota, there are a few meadow streams having some muskrat habitat. Near Custer itself are some artificial lakes with considerable growths of submerged vegetation and marshy shores. These had muskrats in 1949, as did also sluggish stretches of small mountain or foothill streams. The little foothill streams along the east side of the Black Hills were extensively willow-grown and occupied by fair numbers of muskrats, but seemingly fewer in 1949 than in the years 1923-28, when I knew this country better.

For that matter, the muskrat populations of the northern Great Plains were patently below the supporting capacities of their existing habitats throughout nearly all of the areas visited in 1948 and 1949. This is reflected by recent data on fur harvests. In North Dakota, for example, the reported muskrat catches were 178,518 for the season of 1943-44; 215,797 for 1944-45; 324,809 for 1945-46; 161,811 for 1946-47; 50,067 for 1947-48; no open season in 1948-49; and 112,440 for 1949-50 (Hargrave, 1950b).

In eastern Montana, a pronounced decline of muskrats was apparent by 1946, this appearing to be less notable about artificial impoundments than along the poorer habitats afforded by natural streams. The evidence, at least through 1949, suggests a continuing subnormal population and the operation of the hemorrhagic disease or tularemia, or both diseases, as well as climatic emergencies. Robert F. Cooney, of the Montana Fish and Game Commission, made inquiries for me concerning the situation. Although Deputy Game Warden E. M. Krost knew of no muskrats dying of disease in the extreme northeast corner of the state (letter to Cooney, September 11, 1946), H. C. Friede, stationed in the counties to the west including those through which much of the Milk River drains, found considerable evidence of disease loss. A dead muskrat examined by Friede had a spotted liver and enlarged "glands in the neck and under the legs" (letter to Cooney of September 4, 1946).

Many of the streams of the western, northwestern, and northern fringes of the Sand Hill country of southwestern South Daokta and northwestern Nebraska have steep shale banks, very muddy water, and almost no attractive habitats for muskrats. Westward extends the sagebrush desert of eastern Wyoming. To the north of the Sand Hills lie the South Dakota Badlands. The larger streams of southwestern South Dakota - such as the Cheyenne and White rivers - are, essentially like any large streams of the northern Great Plains, of very limited habitability for muskrats. This may also be said of the Niobrara River and its larger tributaries running through much of the Sand Hills in Nebraska and of the Platte River to the south of the main Sand Hill formations. But what may be called the real Sand Hill creeks - as these occur south and southeast of Hot Springs - often have cattail 
or other marshy growths in sluggish places. There are also roadside ditches well grown to marsh vegetation. Marshes and sloughs of the South Dakota Sand Hills are abundantly scattered in the general vicinity of Martin, which has some of the best muskrat habitat in the state.

The approximately 25,000 square miles of Sand Hills in Nebraska do not have lakes and marshes distributed with any great uniformity throughout. Two major wet areas of value to the muskrats exist where stream drainage is poor. One of these lies south of Valentine and southwest of Ainsworth and the other mostly east of Alliance. They are about 75 miles apart. These wet areas are literally dotted in places with larger or smaller bodies of water surrounded by hilly and level expanses of sand stabilized, such as it is, by grassland flora.

(Appendix J relates especially to Dr. J. Henry Sather's muskrat study in the Nebraska Sand Hills.)

Wakeeney, in northwestern Kansas, is a type locality for cinnamominus, and Black (1938) considered this subspecies to be of state-wide distribution except in the southeast corner, which is occupied by zibethicus. Cockrum (1952) referred to the muskrat as being much more common in the eastern, more humid, half of the state. It builds lodges in suitable marshy habitats. Of cinnamominus in Colorado, Cary (1911) wrote:

On the plains scores of muskrat houses may often be seen on a single marsh or lake. This is especially noticeable at Barr and other points in the lake region northeast of Denver. Although muskrats are present in most of the streams on the plains, their numbers are small compared with those inhabiting lakes and marshes. They are very troublesome in irrigated regions as they are continually burrowing in the banks of ditches and reservoirs, often causing serious leaks.

Cary mentioned a specimen of cinnamominus: "a female which contained eight small fetuses, taken . . . in a small snow-fed lake at 9,500 feet, near Ward, Boulder County, June 8, 1893." This locality is in north central Colorado and represents what would seem to be extreme edge-of-range habitat for the so-called mountain subspecies, osoyoosensis itself. The occurrence there of cinnamominus demonstrates that the Great Plains subspecies has a wide range of habitat tolerance, also.

Blair (1939) wrote that cinnamominus was distributed over most of Oklahoma from the Cherokee Prairie biotic district westward, undoubtedly including the Oklahoma Panhandle. Of the southeast corner of the state (which is about 200 miles north of the known range of rivalicius in either Louisiana or Texas), Dr. F. M. Baumgartner wrote (letter, September 21, 1950):

Of particular interest is the fact that [citing Duck and Fletcher, 1945] no muskrat pelts were sold in southeastern Oklahoma in the biotic districts known as the Oak-Pine Forest Type, Loblolly Pine Forest Type and the Cypress Bottoms Type. Lawrence B. Semple, Superintendent of Game, has 
informed me that there are apparently no muskrats at all in this area roughly one hundred miles in diameter.

Glass (1952) described the changes in muskrat habitats that followed the years of virgin forests and grasslands. The soil then retained water from the brief and violent spring and summer rains and released it slowly through springs and seeps. At the time of the great land rushes, there were not only springs but even marshy and swampy spots. The plowing and planting of the homesteaders resulted in rapid surface run-off, decreased water storage, drying of springs, and stream flow becoming intermittent. Then, the tragic "dust bowl" conditions stimulated a big program of water conservation.

The work carried on by Glass is of interest not only as relating to cinnamominus living in a part of its range having water only in places but also to a region that the subspecies might find - for reasons as yet unappraisable - less and less habitable toward the south. Edgeof-range effects are suggested, for one thing, by the low densities existing in what Glass has described as superior habitats for his study area. Appendix $\mathrm{K}$ quotes certain parts of his paper in detail.

\section{THE WESTERN MUSKRATS, mergens and occipitalis}

Grinnell, Dixon, and Linsdale (1937, p. 730) showed that the natural distribution of mergens in northern California was confined to an area near the northeast edge and lying mostly less than 50 miles inside of the state line. This is in the Great Basin part of California, eastward from the Sierra Nevada Divide, and the altitudes of occurrence given were from 4,000 to 6,200 feet.

Storer (1937) wrote about the puzzling gaps in the distribution of the muskrat in northern California. If mergens could have reached the Pit River drainage from its native range at Eagle Lake (a distance of no more than 15 miles), it would have been in a position to have reached the Sacramento-San Joaquin basin, thus to colonize most of California. Through escapes from a fur farm in the Fall River Valley (connected by creeks and canals with the Pit River drainage), a muskrat stock of mixed origin finally did become established in a tremendous new but previously muskrat-vacant range.

Twining and Hensley (1943) reviewed the status of muskrats in California. They visited nearly every area in the state that was populated by muskrats. From their introductory paragraphs:

It appears obvious that in prehistoric times they inhabited the shores of the great Lake Lahontan which once washed the eastern base of the Sierra Nevada and with the disappearance of that Lake the muskrats were left to continue their existence in any rivers or sinks that offered suitable habitat.

With respect to the more recent status of muskrats in the newly colonized range of northern California, Dr. A. Starker Leopold of the University of California wrote of "the rapid spread and increase of the muskrat in the Central Valley" in a letter dated March 30, 1948. 
Then, Ben Glading, of the California Division of Game and Fish, wrote (letter, November 27, 1950) that:

Muskrats have spread to practically all of the suitable habitat in the Sacramento Valley but as yet have not spread to all parts of the San Joaquin; however, they are on the increase there, and it is expected that in a few years the entire central valley area will be well populated.

(However, this population does not consist of mergens but of what Twining and Hensley called a great "hodge-podge of types" occupying range that one might almost regard as "rightful" mergens range.)

Hall's (1946, p. 565) map of the distribution of muskrats in Nevada depicts the native range of mergens as divided into two parts. One of these is in west central Nevada (as well as adjacent California), in the Reno-Carson City-Fallon triangle and surrounding wetlands. Hall's map shows mergens range along the Humboldt River and connecting the main western part with a big block in north central Nevada, south of the Snake River drainage. Concerning the muskrats of southern Idaho and presumably northern Nevada, Davis (1935, pp. 329-30) wrote:

Specimens from the Snake River Valley are intergrades between osoyoosensis, the race occurring typically in the northern portion of the state [Idaho], and mergens, a race occupying the Great Basin. . . . Other specimens which I have examined from southern Idaho are light in color like mergens. . . . The subspecific name osoyoosensis, rather than mergens, is here applied arbitrarily to the specimens from the Snake River area, merely for the sake of conrenience.

Ruby Lake, at the altitude of 6,000 feet in the Ruby Mountains of northeast Nevada, is near the eastern edge of the range of mergens. Borell and Ellis (1934) described the area comprising muskrat habitat:

The region in general is arid and the winter climate is severe. Snow and freezing temperatures prevail from October to March and heavy frost may occur, even at the lowest altitudes, during any month of the year. . . . Snow remains on the north-facing slopes of the higher peaks until late in the summer, and some may persist throughout the year. This snow supplies water for the creeks that flow out of the larger canyons. Some of the streams flow throughout the year; others dry up during the summer. The water from these streams is used mainly to irrigate ranches about the base of the mountains. The water that does not evaporate or soak into the ground escapes into Franklin and Ruby lakes on the east slope and into the Humboldt River on the west slope. In addition to the creeks there are a large number of springs, which arise at the base of the mountains. . . Several of these are found along the west shore of Ruby Lake. Among the higher peaks of the range are a few small lakes. . . . Ruby Lake is . . about sixteen miles long and from one to four miles wide. The water in the lake is practically fresh, although there is no visible outlet. It is fed by numerous springs, most of which are on the west side. Most of the lake freezes over during the winter, but the springs, as well as the streams which originate from them, remain open and keep parts of the lake from freezing. 
These authors wrote concerning mergens:

Ruby Lake presents conditions ideal for habitation by muskrats. Since the lake is in reality a large tule [Scirpus acutus] marsh, interspersed by numerous areas of open water, the conditions existing in the middle of the lake are as favorable to muskrats as were those along the shore. Muskrats were quite numerous over the entire marsh but were being rapidly reduced by intensive trapping. During the first part of August, 1928, two or three pairs of muskrats were inhabiting Favre Lake at an altitude of 9600 feet, which is the lowest one of Three Lakes. At Favre Lake the muskrats lived entirely in holes in the bank; there were no houses on the lake. Muskrat trails ran back from the edge of the lake through the tall grass into the willow thickets, where gnawed limbs and cut twigs of willow saplings were found. There was little growing vegetation in the lake.

At Ruby Lake, muskrats lived in holes in the banks and also in houses which were located among the tules in shallow water, rather than out in the open water. ...

Muskrats often were seen abroad in the late afternoon, especially during the winter. On December 21, 1927, at four P.M., eight muskrats were swimming about in an open lagoon. One of these entered a hole in a bank, from which it emerged again in great haste, closely pursued by another rat. On several occasions muskrats were seen walking about on top of the ice. At one place a muskrat trail led three hundred yards through soft snow from one lagoon to another.

Hall (1946, p. 565) quoted a letter of December 27, 1940, from G. H. Hansen to L. T. Turner, Jr.: "Mr. Dill indicates . . . that the rats in Ruby Lake are carrying tularemia."

The Washington distribution of occipitalis is given by Dalquest (1948, p. 363) as, "The southwestern corner of the state, extending north to Aberdeen (V. B. S.) and east to Cathlamet (V. B. S.)." (The V. B. S. initials are those of Dr. Victor B. Scheffer, of the U.S. Fish and Wildlife Service, who indicated in a letter of September 22, 1949, that the eastern boundary must extend a considerable distance east of Cathlamet, which is on the Columbia River only about 30 miles from the Pacific Ocean.)

From Scheffer's letter:

The northern boundary of its range is the Chehalis River, Washington. . . . [ Concerning the ] eastern boundary of its range in Washington ... I can see no natural barriers in its way until one reaches the Cascade Range. . . .

With regard to the habitats of the two races [occipitalis and osoyoosensis ] in western Washington, I think that they are similar. I have tramped over a good deal of the Puget Sound Trough. Certainly the osoyoosensis range in western Washington is more like occipitalis range than it is like the osoyoosensis range in eastern Washington.

Stanley G. Jewett wrote (letter, September 17, 1949) that "occipitalis of the west coast is . . common along the Columbia River from the Cascades to the coast, throughout the Willamette Valley, and along the immediate coast to salt water from Astoria through Tillamook, Lincoln, Lane ... and Coos" counties. 
The Oregon coast muskrat, occipitalis, would then appear to have a range approximately 250 miles long and 90 miles wide. Within this range, Wesley $M$. Batterson, of the Oregon State Game Commission, has done a great deal of field work and summarized his observations in a letter dated November 26, 1949:

Types of country occupied are marsh areas, sloughs, small creeks and streams, drainage ditches in fields, tideland marshes and . . . the edges of the bays within a short distance of the ocean. Muskrats are seldom found in the mountain streams, but are found in some of the higher mountain lakes which afford sufficient plants for a food supply. Most of the sloughs near the ocean have a small colony of muskrats, from ten to thirty.

In another letter (December 5, 1949), Batterson elaborated on the habits of occipitalis:

Even though the muskrats have an abundance of cattails, tules and other suitable vegetation they . . . build no lodges. At times they do pile up a floating raft of tules or cattails which they use to climb out of the water and feed on, but these are not lodges . . . and they build these only occasionally in large lakes. .. . Washing away of floating materials I am sure has no connection as we have many lakes with an abundance of cattails and tules where the lodge could be well anchored or built in protected places.

A great muskrat-vacant area originally lay south and southeast of the range of occipitalis, with many splendid and extensive marshy habitats awaiting colonization. One of these was Tule Lake, in northern California; another, just east of the Cascades in southern Oregon, not very far from the California state line, was Upper Klamath Lake. According to Twining and Hensley (1943), Tule Lake was stocked in 1930 with twenty-two pairs of muskrats purchased from Michigan, and the pelts of the Tule Lake muskrats are exceptionally choice. Jewett (letter, September 17, 1949) wrote that during the twenties

a company of fur farmers started a muskrat farm at Aspen Lake along the west side of Upper Klamath Lake. . . . Before they were well started a spring flood washed out their inclosures and the rats escaped into the main body of Upper Klamath Lake. In a few years they increased greatly over the entire Klamath Basin, to and including Tule Lake and Lower Klamath in California.

Once the muskrats took over these favorable but previously isolated habitats of south central Oregon, they naturally spread into many places. Heustis (1938) reported muskrats in Crater Lake National Park in 1937: "In all [ three] cases these animals were found a considerable distance from a body of water of any appreciable size. . . . It is suggested ... that the specimens seen in the park are immigrants from the Upper Klamath Lake,' which lies about twenty-five miles south of the park. 


\section{THE ROCKY MOUNTAIN MUSKRAT, osoyoosensis}

Bailey (1931, pp. 207-8) wrote of osoyoosensis: "The Rocky Mountain muskrat, a large dark form, occupies the San Juan and Rio Grande valleys of northern New Mexico. .. . There are specimens from Farmington, Costilla River, Rinconada, and Albuquerque, which agree perfectly with others from the mountain region of Colorado and northwestward to southern British Columbia." In northeastern New Mexico, Hill (1942) found no signs of muskrats above 7,800 feet, though Bailey (his page 217) had referred to a muskrat sitting on the edge of a beaver lodge of a pond in the upper part of the Costilla River in the Culebra Mountains at an altitude of 9,400 feet. Cary (1911) reported osoyoosensis in most of the streams of central and western Colorado below 9,000 feet, but found them common only in the marshes and lakes of the intermountain parks.

Despite the local abundances of muskrats to be found in southwestern Colorado, much of eastern Utah does not afford livable habitat for any of the subspecies. This is the desert country traversed by the canyon-bound Colorado and Green rivers. Durrant (1952, pp. 358-59) wrote that almost "nothing is known with reference to animals from the eastern part of Utah - Colorado River drainage nor of animals from the central part of the state."

In the summer of 1949 , I spent considerable time studying the muskrat populations of mountain and desert regions in southwestern Wyoming, northern Utah, southern Idaho, and southern Oregon. This work was largely centered about Great Salt Lake, with the invaluable help and company of Dr. Jessop B. Low of the U.S. Fish and Wildlife Service. The marshes bordering the east side of Great Salt Lake - especially the Bear River and Ogden Bay (Weber River) marshes - are among the most life-rich places on earth. These are given more extensive treatment in Appendix $\mathrm{L}$.

Southeast of Great Salt Lake lies fresh water Utah Lake. When inspected on July 15, 1949, it was said to have been at maximum level. Dead stands of hardstem bulrush could be seen out for about a quarter mile from the northwest side. These hardstem stands, Low told me, were once full of muskrats, but the live bulrushes were reduced to a margin seldom more than 30 yards in width, and the muskrats were reduced with them. Wave action was relatively light because of the usual calmness of the air.

During dry periods, this lake goes down, both as a result of natural lowering of the water levels and pumping for irrigation. Generally, the lake becomes more productive of muskrats in the course of droughts, as the water recedes slowly enough so that emergent vegetation can grow in the successively new shallows. The bulrushes may cover the shallows for as far as a half mile into the lake. Although a sample of about a half mile of shore was looked over without seeing current muskrat signs, a sluggish canal bordering the 
lake and leading to a pumping station did have a fair population of muskrats.

Utah Lake is connected with Great Salt Lake by the Jordan River, which runs through an area of mud flats, open water, and marshes north of Salt Lake City. Most of this area looked rather poor for muskrats, with the stands of bulrush and cattail chiefly occurring next to stream channels. The best marsh I saw in this part of Utah was about a 10-mile stretch of emergent vegetation on the silted bed of the Jordan River.

Three main foci of muskrat abundance then occur along the eastern shore of Great Salt Lake: about the deltas of the Bear, Weber, and Jordan rivers. These deltas and impounded waters have few minks and still fewer coyotes, but a certain amount of predation upon muskrats very probably takes place during periods of vulnerability through the agency of the abundant California gulls (Larus californicus). California gulls are aggressive, and as they are known for their depredations upon young or sick water birds (they may disembowel large ducks sickening from botulism), I should expect them to attack handicapped muskrats if they had inviting opportunities.

West of Brigham, waters of irrigation origin as well as from springs produce some fairly extensive marshes, such as those of the Public Shooting Grounds along Salt Creek, to the north of Bear River. When I visited the Public Shooting Grounds, many of the artificial lakes and sloughs were merely shrinking bodies of open water or dry alkaline bottoms. The deeper waters had much Chara and some Potamageton and Ruppia but almost no emergent vegetation. Few muskrats lived in them except in places where the banks were steep and near the water, as in the vicinity of dikes. The ditches flowing out of these impoundments, however, had green vegetation, both submerged and emergent, and fair populations of muskrats.

Low told me that warm (in the sense of not freezing in winter) springs occur for about 40 miles along the edge of the mountainous promontory extending into Great Salt Lake from the north, and these may be full of muskrats. Two examples of springs were inspected on July 13, 1949. One spring came out at the base of a typical dry hillside, and the water flowed off cross-country for about three-quarters of a mile; its margin was grown to heavy stands of Scirpus olneyi, which spread out in places but usually maintained the form of a narrow belt. The second spring was larger, watering a belt of $S$. olneyi perhaps 100 yards wide and up to two miles in length. Muskrat signs were to be seen about both examples, and Low said that one of the heaviest concentrations of muskrats he had ever observed was along one of these spring-watered strips of $S$. olneyi.

Between the spring-strips and Great Salt Lake may be little muskrat habitat, and the springs may be likened to a series of oases. They are not so far apart that muskrats may not be expected to cross intervening desert from one to the other on occasion, especially at times 
when great numbers of animals may literally overflow from the Bear River marshes. Sulphur Creek, emptying into Bear River near the delta, is a major avenue of travel for muskrats in spring. Individual trappers are said to take hundreds here during some dispersals upstream from the Refuge.

Stray muskrats do reach and establish themselves in remarkable places in this desert region. Despite the inhospitableness of the briny waters of Great Salt Lake for vertebrate life, Dr. S. D. Durrant told me of collecting a muskrat swimming in a spring on Antelope Island, in the southeastern part of the lake. At the place where the muskrat had probably crossed from the mainland four or five miles away, the lake bottom was mostly exposed but with stretches of concentrated salt water seven or eight inches deep. Durrant also showed me in the Museum of the University of Utah a skin of a muskrat collected in 1941 from tiny Egg Island, off the northern tip of Antelope Island, by C. N. Greenhalgh, who was at that time banding gulls. If this muskrat had come from the mainland to the east, it would have crossed a minimum of about eight miles of salt water; if from the south, it would have crossed over to Antelope Island, then traveled up to about 15 miles of the length of that island before crossing to Egg Island.

Antelope Island does have springs of fresh and brackish water and dense growths of Scirpus paludosus, and it lies close enough to the mouths of rivers so that muskrats or even terrestrial mammals might occasionally be transported from the mainland on logs or other flood debris. Readers interested in exploring further the possibilities of mammals reaching and becoming established on islands in Great Salt Lake may well consult Marshall (1940).

The Locomotive Springs are several big springs lying close together and separated collectively by about 15 miles from the nearest water except Great Salt Lake. They come out of the ground in a flat desert, and their flow crosses a few miles more of desert to enter the extreme northern tip of the lake. Marshy growths, notably $S$. olneyi, were seen in mid-July, 1949, extending to the south toward the lake for about two miles.

Dikes built during the years of CCC camps profoundly modified the marsh habitats locally. Above the dikes, which run long distances through the marshes and around the heads of the springs, the emergent vegetation had largely disappeared by 1949 , whereas, below them, splendid-looking growths had insufficient water for muskrats. Fair to excellent growths of emergents existed about some of the spring flows above the diked impoundments, but the acreages of marshy emergents above were not nearly so great as those below the dikes.

Much open water occurs in winter (the steam can be seen for miles), in the spring flows, and even in the lower marshes, freezing varies greatly. Generally, there is water under the ice at all times, fresh from the springs. The muskrats of the open-water impoundments are all 
but confined to the dikes; in the marshes below, muskrats may be either abundant or scarce. The main environmental difficulty here would seem to lie in shortage of water at critical periods. Old-timers maintain that they caught thousands of muskrats annually from Locomotive Springs before the diking, compared with hundreds since then. Whether or not this is an exaggeration, it is very probable that the marshes were damaged rather than improved for muskrats by the diking.

The Locomotive Springs are surrounded by typical northern Utah desert, and when a big environmental crisis is underway and large numbers of muskrats evicted, there can be a tremendous amount of vulnerable wandering. Coyotes were fairly numerous, and Low had found conspicuous representations of muskrat remains in their scats at times. This is quite to be expected, for muskrats must occasionally travel about on dry land by hundreds. In addition, cattle pastured about the springs in winter are said to trample and flatten the lodges.

One other factor is in the muskrat equation at Locomotive Springs: tularemia. Quortrup and Sudheimer (1942) reported this disease in the muskrats on the Bear River Delta, and Quortrup later wrote (letter, July 14, 1944) that "the losses here were noted during the hot summer months only. . . . [ The ] disease is very prevalent in this area. ... It may interest you that the winter following the summer losses noted here, there was no appreciable reduction of the muskrat population." At Locomotive Springs, the outstanding vectors must be the abundant and ferociously pestiferous tabanid flies (Jellison, 1950b). Low told me that when the CCC boys worked there years ago, about 20 contracted tularemia nearly simultaneously, and at the time of our visit in 1949, dead jackrabbits (Lepus californicus deserticola) were strewn all over the desert immediately surrounding the water, their remains being undisturbed except for decay. These rabbits could not have died through human agency, for ours was the only sign of human visitors laid down for months at least. Those swarming tabanids loaded with tularemia made the place one of singular menace, and hardly any local mammals that would be about during hours of fly activity could escape being bitten. I do not know what tabanidmuskrat relations might be, but even were the muskrats almost entirely nocturnal, they still should suffer bites now and then, and with so much tularemia apparently in the vicinity, might well be exposed to it in other ways.

No one seems to know of muskrats ever having been planted at Locomotive Springs, and it looks as if they arrived there naturally. Springs other than the above occur north of Great Salt Lake, and they are visible as green spots for long distances. Two were seen within 20 or 30 miles of Locomotive Springs, of which one was looked at and found to have no muskrat signs. Great Salt Lake itself had caked brine beaches, and the only clear-water spring seen there during the trip had a salt content of about 13 per cent. 
In the extreme northwestern part of Utah were many streams that started in mountains but dried up in the desert. One of these was looked over carefully and found to have beaver workings but no muskrat signs. To the north, the tributaries of the Raft River had muskrats. Stretches that I saw were mostly of steep-banked small streams in sagebrush desert, but higher up in the foothills were some willowgrown places of sorts that might have had either beavers or muskrats.

The streams of west central Wyoming are typical of badlands and sagebrush desert, but some impounded waters had bulrushes and other emergent vegetation when visited in 1949. A large tributary of the Big Horn River near Shoshoni had recently been in flood when seen on July 13, yet most of the stretch looked at had no surface water except for some of whitish color remaining in shallow pools of the silted bed. It appeared about as uninhabitable for muskrats as a stream could be. In general, I saw few places where muskrats might live away from dam reservoirs. The Wind River Canyon between Shoshoni and Thermopolis was full of very muddy, very rough water, and I doubted that muskrats could even travel through. North of the Wind River Canyon, the stream smoothed out and ran through country in which a few muskrats might have lived.

One of the most interesting places was a tract of about an acre of cattail in a pond formed by a warm spring at the northern outskirts of Thermopolis. It reeked of sulfides, and the spring flows were barren of cattails, but to the sides were heavy growths of vegetation and some muskrat signs. Fringing willow thickets along the Big Horn River between Thermopolis and Greybull and cattail seepages in the irrigated lowlands afforded some muskrat habitat. In the hills were gullies with heavy localized growths of cattails, mostly merely damp but of sorts that would have some attraction for muskrats during wet seasons. A fair-sized alkaline lake had scattered patches of bulrushes and cattails, an abundance of carp, but no muskrat signs.

Gray's Lake, in southeastern Idaho, was in 1949 the site of an intensive muskrat investigation by Roger M. Williams, of the University of Idaho (Williams, 1950; Reeves and Williams, 1956), and I spent a few days with him there in early July. This is a big bulrush and cattail marsh lying at an altitude of 6,386 feet and used as a reservoir for irrigation water. Its normal marshy area covered about 32 square miles, and the surrounding lowlands fully as much more. At the time of my visit, following unusual spring rains, its water level was the highest in the memory of the people living about its edges. About 10 per cent of the marsh had open water full of pondweeds and bladderwort, and this was mostly in the south end; the rest was covered by an almost solid stand of emergent vegetation growing in about two feet of water - tracts of hardstem bulrush stretching away for miles, in almost unbroken stands except for strips of cattail. Williams had observed that the muskrats preferred bulrushes to cattails, the latter being mostly narrow-leaved. The muskrat population was rather low. 
Williams seldom found lodges with young nearer than 100 yards of each other.

Old-timers said that they had known of die-offs of muskrats in the past for which tularemia was believed responsible. One trapper had nearly died of tularemia evidently contracted from a muskrat.

Williams wrote (letter, January 18, 1950) that the water level of the marsh dropped possibly 18 inches in the weeks following my visit in early July. "It reached its lowest level [ for 1949 ] in late August or early September, but there was still plenty of water for muskrat habitation" in the observational areas. Rain and snow water later in the year "raised the level more than a foot above what it was at its lowest point."

In another letter (December 17, 1949), Williams wrote of the data obtained from 176 muskrats taken as specimens in the fall of 1949. These were close-trapped to give a cross-section of a population of a comparatively small area. Of the 176 muskrats, 16 were adult females, and of these, one had not conceived in 1949, 5 had placental scars indicating one litter each for 1949, and 10, two litters each. The mean litter size shown by the placental scars was 7.04, compared with the mean of 6.97 young found in 35 litters examined during the breeding season in lodge nests. The average adult female had conceived 11 young, whereas a ratio of 8.75 juveniles to each adult female was found in the sample trapped. At Dingle Swamp, 55 miles away, the mean conceived per breeding female was 19 and the mortality rate of the young was 47 per cent from birth to their first fall (Reeves and Williams, 1956).

The natural outlet flowing northward from Gray's Lake was, when seen in July, a shallow stream 40 to 50 feet across, with fringing growths of sedge and grass and much yellow water lily and some emergent vegetation in places. It flowed through a heavily pastured valley in sagebrush desert. Muskrat densities were not high at this place, but some animals were present. The irrigation diversion, a rather swiftly flowing ditch stream about 15 to 20 feet wide and a couple of feet deep, led off through more sagebrush desert.

The marsh edge varied considerably in affording possible burrowing sites for muskrats away from the flowages. The whole east side had shallow water grading off into wet meadow, but in places along the western and southwestern edges, muskrats could dig bank burrows without much trouble. Beavers were so abundant as to be a nuisance - plugging ditches - in lowland willow tracts, and some muskrats were associated with these beavers.

Between Gray's Lake and Bear Lake (the north half of which lies in the southeastern tip of Idaho and the rest in Utah) were other extensive marshlands, consisting mainly of large tracts of hardstem bulrushes with variable amounts of open water. One marsh of several hundred acres, looked over from shore and surrounding hills, was found to have muskrats in low densities, as at Gray's Lake. The im- 
mense flats north of Bear Lake at Montpelier looked like a great seepage area having alternate patches of grassy meadow and stands of bulrushes or cattails; for most parts, the water looked too shallow to winter many muskrats. Nearer Bear Lake, the marshy stands became more and more extensive, stretching away mile after mile for nearly the width of a wide valley. Bear Lake, itself, a large body of open water, had a fringe of bulrushes about 100 yards in width along its northwest shore, and a single, weed-grown muskrat lodge was seen from the road.

The Snake River makes a roughly semicircular loop from south of Yellowstone Park westward and southwestward through southern Idaho, then northwestward and northward along the Oregon-Idaho boundary. The main stream, all across Idaho, is "western-type," often cutting between steep bluffs or canyons or meandering through silted valleys. Above irrigation impoundments in southeastern Idaho, it was full of water up to the fringing willow growths of its divided channels in early July, 1949. In south central Idaho, dams had widened the river to form Lake Walcott (having attractive bulrush fringes in places) and the big American Falls Reservoir. South of Hagerman, in the Thousand Springs area, springs came out of rock faces for miles along the river, and the river here had very substantial bulrush fringes with muskrat signs. Downstream toward the Oregon line, Snake River became increasingly unattractive for muskrats as its course led through canyons and desert. The real muskrat habitat of the Snake River Valley in southern Idaho is in the tributary streams and irrigation waters, where the animals may be very abundant locally.

The Malheur Lake area of southeastern Oregon has been noted since presettlement days for its abundance of marsh life, especially muskrats and water birds. The flat land having extensive marshes near its center comprises about 600 square miles, at an elevation of 4,100 to 4,200 feet and surrounded by mountains of 8,000 to 9,400 feet. Geographically, the marshes and watercourses leading into them are isolated in a desert, though tributaries of the Malheur River (which joins the Snake River at the Idaho boundary) approach it from the east.

As muskrat habitat, the Malheur River, as I saw it, was nothing special. It was creeklike in size in most places where irrigation waters had been drawn off, and its best stretches from the standpoint of muskrats had willow and bulrush fringes. Some bulrush-filled pools occurred at the bases of springs or where the ground was wet from irrigation seepage. Whether this stream provided much of a connection between the muskrats of Malheur Lake and vicinity and those of the Snake River Valley was not clear. Bailey (1936, p. 215) referred specimens from the Malheur Valley to osoyoosensis rather than "to mergens of Nevada, while those south of the Malheur Valley are perhaps nearer to the pale mergens, although not typical. For the present purposes, all of the specimens examined from east of the Cascades in 
Oregon can be treated under the single form osoyoosensis." Davis (1935, pp. 329-30) considered specimens from the Snake River Valley in southern Idaho to be "intergrades between osoyoosensis . . . and mergens. ... Other specimens which I have examined from southern Idaho are light in color like mergens."

The last week of July, 1949, was spent on or about the Malheur National Wildlife Refuge in company with Dr. Ray C. Erickson of the U.S. Fish and Wildlife Service.

The approach to Malheur Lake was one of miles of dusty sagebrush-covered dry lake bottom surrounded by steep hills. On the outskirts of the wet area were occasional shallow or partly dry ponds. Malheur Lake and neighboring Harney Lake were but remnants, without outlets, of a lake that once covered the vast flat lands. The Silvies River entering Malheur Lake from the north and the Blitzen River from the south were practically the only sources of water for months or even years at a time in the dry climate prevailing. Irrigation demands reduced the flow from Silvies River, although in years of heavy snowfall this river contributes more water to Malheur Lake than does the Blitzen River, which arises from melting snowbanks of the Steens Mountains to the south.

John C. Scharff, the Malheur Refuge superintendent, told me that there had been many muskrats in the Blitzen Valley during the early forties, but later they all but disappeared. Only a few signs were seen along the creeklike Blitzen River at the time of my visit, but larger numbers lived in some of the shallow, food-rich marshes lying off to the side. South of Frenchglen, the river took on more and more of the appearance of a swift mountain stream.

Malheur Lake's main body of water was perhaps 10 miles in length when Erickson and I worked over a representative part of it. What I saw consisted of large acreages of rather shallow marsh dominated by hardstem bulrush and a large Juncus, which occurred in clumps and in more or less solid stands. The wettest parts that we looked over by wading and by canoe had from a few inches to a foot and a half of water. Much of the emergent growth had been heavily cut by muskrats the previous year, but the cutting had served mostly to clear away the top growths and did not appear to have injured the 1949 stand. Current muskrat densities were estimated at possibly a family group per one to two acres.

A shallower bulrush marsh in which muskrats had been badly drought-exposed in other years was in process of going dry again, with the driest part of the summer being ahead. A notorious "botulism flat" had fringing growths of bulrush clumps and some muskrat lodges, but the muskrats remaining here were largely concentrated along a wet channel - which also had prospects of going completely dry in the weeks to come. Ditches along dikes were partly dry, and the usual sign of muskrat adjustments between the dry and the wetter parts was evident. In places, heavily used muskrat trails ran for 
hundreds of yards from dry or drying marsh into wetter areas, yet at the same time, it could be seen that occupants of other parts were confining their detectable activities to established territories.

Muskrat movements of impressive magnitude have been witnessed. Bailey (1936, p. 217) wrote that most of the muskrats left Malheur Lake in the winter of 1914-15 and scattered for miles over the sagebrush. "They were poor and possibly diseased, but more probably starving, as their regular food supply had been destroyed by unusually high water that summer. . . Many thousands were estimated as killed outside of the lake, and as many more died that were not recovered. The next summer the writer saw their carcasses in the sagebrush over the valley and the animals were scarce in the lake." Stanley G. Jewett (letter, September 17, 1949) observed in the early spring of 1917 a big movement of muskrats traveling over the snow-covered desert to the east of Malheur Lake. "During a two day trip . . . I saw evidence of where not less than 20 were killed by coyotes and rough-legged hawks."

Scharff described some of the mass movements taking place across the desert. One winter in the mid-thirties, school children at Crane clubbed large numbers of muskrats along a travel route about 10 miles from the lake, making more money at this, it is said, than their teachers were receiving in salaries. He thought that this migration was a result of overpopulation rather than of drought or perceptible food shortage. Wanderers have also been seen during more ordinary years scattered all over the desert west of Refuge Headquarters, three or more miles away from water.

Some idea of the productivity of Malheur Lake for muskrats may be gained from the vertebrate remains to be seen about the middens of an old Indian campground near a big spring at the present Refuge Headquarters. Bones of ungulates and large birds are abundantly mixed with the broken arrowheads and stone utensils, but what one really notices are the literally countless skulls of muskrats.

There is reason to think that the hemorrhagic disease may have some importance in the population dynamics of the Malheur area muskrats. Dr. M. P. Chapman, of Oregon State College, sent me (letter and enclosures, April 2, 1947) necroscopies on two muskrats that had been sent to him in February from Malheur Lake. The lesions described were similar to those often observed in Iowa victims. In submitting the specimens to Chapman, Scharff had written:

During the last month or six weeks there has been a considerable "die-off" of muskrats on Malheur Lake. . . . At first this "die-off" was noticed only over a small area but later it seems to have spread to most of the rat inhabited waters. As many as 14 dead rats have been found in one house.

Scharff and other refuge personnel at Malheur told me that trappers there regard digging into lodges by coyotes as indicative of dead muskrats within. This digging may occur on a considerable scale dur- 
ing years of known disease losses, and some of the local residents even asserted that a coyote would not dig into lodges unless it were after dead muskrats.

Buena Vista marsh, one of numerous marshes within the refuge south of Malheur Lake, was the site of a suspected die-off, and Erickson and I worked it by canoe. It had a good water level and well-dispersed islands and clumps of cattail, bulrush, and burreed but very few muskrats. About 1942, the muskrat population had been very heavy but had since declined to the extent that neither the shore zone nor some solid blocks of the best-looking emergent vegetation showed recent muskrat signs. While a few tracts of about six to eight acres had possibly a family group per acre, there was over most of the marsh (including parts having 1949 spring lodges) no fresh or recent signs, as of late July, except of what seemed to be scattered subadults.

The decline of the muskrats was ascribed by the public to an abundance of minks, but I do not see how that could have been. Wintering conditions had been favorable, and in summer, muskrats lived in lodges that minks should rarely have gotten out to. Along the shore, mink as well as muskrat signs were conspicuously absent at the time of my visit. Minks were frequenting to some extent - much less than I had been prepared to expect - the more accessible small islands, where they were preying rather severely upon nesting water birds. On the principal island having mink signs, we examined about 100 scats from winter or early spring, of which 3 scats contained muskrat remains. The staple prey consisted of mice. None of about 168 later scats contained muskrat remains; the food items were mostly avian (blackbird and some waterfowl), with some mice and invertebrates.

No one knew of disease losses among the Buena Vista muskrats, but the population symptoms were those of a continuing epizootic. In the case of dense stands of wet vegetation not penetrated by canoe, the view from a high rimrock nearby revealed a decided lack of lodges, of muskrat openings or trails, or of anything indicative of the species. Some of the parts of the marsh that were muskrat-vacant in July had been well used in the spring.

Harney Lake receives water at times from Silver Creek (rising in the Blue Mountains to the north) and from Malheur Lake, which lies about 15 miles to the northeast. When Erickson and I visited Harney Lake in late July, 1949, it had some springs with marshy vegetation but was otherwise a salt-flat desert surrounded by miles of sagebrush. We walked out to a series of springs - surrounded chiefly by alkali bulrush clumps, the largest about four acres in area - about a mile from the nearest recent shoreline. Here, at the largest bulrush clump, we found an old dead muskrat, bones intact.

Ex post facto "reading of sign" indicated that this same lone animal had lived in a small lodge built of the 1949 growth of vegetation and, before then, in another small and flattened lodge dating back at least to the fall of 1948. Erickson had seen the drying body in 
much fresher condition in June, and we judged that it had probably died early in that month from old age. As wintering habitat, the bulrush clumps with their spring water looked quite good. Erickson said that the springs remain wet and that snow collects over the bulrushes, so that an animal living here should be able to reach rootstocks without difficulty. The place was diligently hunted over by coyotes, but the muskrat had taken care of itself in this restricted niche for about a year.

Scharff told me that, in 1942, when the water had been higher in Harney Lake, he had seen 20 to 30 lodges in the bulrush clumps. Maximum depths of water in the bulrushes (not counting the depths of the springs) had been about a foot and a half in recent years. It may be significant that this isolated colony was noted during a year of high muskrat populations in the Malheur area.

Other isolated wet valleys lie to the west and southwest of Malheur and Harney lakes and the Blitzen Valley, and some of these afford excellent habitat for muskrats. The animals have been introduced at Summer Lake, about 90 miles WSW of Malheur Lake. They occur in the Warner Valley lakes and marshes about 50 miles southwest of Malheur Lake, though local residents are not in agreement as to whether muskrats were there at the time of settlement or were introduced. Other suitable places in south central Oregon are still muskrat-vacant and for obvious reasons, with 40 to 50 miles of desert separating isolated watersheds.

In Washington, Dalquest (1948, pp. 362-63) depicted the range of osoyoosensis as including all of the state except that occupied by occipitalis in the southwestern part and the crests of the Cascade Mountains. To quote from his pages 361-62:

In the extensive marshes along Lake Washington, King County [ east of Seattle], muskrats are abundant. They occupy sluggish water, often water polluted by garbage and sewage. In these marshes, banks suitable for the construction of burrows are absent and houses are made of cattail stalks and leaves. . . .

Near Richmond Beach, Snohomish County, muskrats took up residence in a small tidal pool along Puget Sound. The nearest fresh water stream large enough to support a muskrat was two miles away. Two muskrats were trapped here. Investigation of a tidal pool a mile to the north disclosed unmistakable muskrat signs. Traps set in the culvert connecting the pool with Puget Sound at high tide took several specimens. Study showed that the muskrats were not living in the pool but among the large boulders forming the breakwater for the Great Northern Railroad, along the sound itself. They were feeding on marine mussels (Mytilus). These mussels lived in the salt water of the sound, not in the tidal pool.

At Peavine Pass, Blakely Island, in the San Juan Islands, muskrats were living in the swift tidal current and deep, marine waters. Several were seen in late afternoon. All were swimming parallel to the shore about 50 feet out. Here also they fed on Mytilus, but their homes were not discovered. . . .

In the interior of Blakely Island a colony of muskrats was discovered living in a marsh of about one acre. In the rainy season the ground of the marsh was covered with less than one inch of water. Residents said that in the dry season springs kept the ground moist. Muskrats were living in burrows whose 
entrances descended at a 45-degree angle and were filled with water. The ground about some occupied burrows was dry, the only water visible being in the burrow itself. A variety of marsh vegetation provided food.

Minks (Mustela vison energumenos) may be abundant over some of the muskrat range of the northwest Pacific states, some trappers taking, according to Dalquest, as many as 100 in a winter. From Dalquest's pages 200-201:

In the San Juan Islands minks have forsaken the shoreline and roam over the uplands, feeding on the abundant, feral domestic rabbits. ... Along Puget Sound, minks spend part of their time on the beaches, feeding on dead fish and other marine animal life. These animals, however, seem to live along the rivers and streams flowing into the sound. Along the ocean coast, some minks seem to live exclusively in the marine shoreline habitat. . . The muskrat forms an important item of diet near the larger lakes and streams. Muskrats trapped near Seattle were often attacked by minks.

Dr. Ian McTaggart Cowan, of the University of British Columbia, told me in conversation, March 9, 1949, that osoyoosensis occurs right down to the seashore in British Columbia. Later, he wrote (letter, March 16, 1951) that "it is abundant on the delta of the Frazer River in the vicinity of Vancouver, but north of this on the coast, it is of only sporadic occurrence."

The many glacial waters of eastern Washington, northern Idaho, and southeastern British Columbia present various grades of muskrat habitats. I traveled over part of the region in 1938, inspecting in particular the Palouse country of Washington and the vicinities of the Pend Oreille and Coeur d'Alene lakes of northern Idaho. There was muskrat habitat, along with muskrats, in bays and seepages grown to emergent marsh vegetation, in the quieter streams of forest and farmland, in potholes and beaver ponds and backwaters of rivers. There, too, as elsewhere, wave-beaten rocky lake shores and rapids-filled canyons were largely muskrat-vacant.

Farther north, in the Kootenay National Park of British Columbia, Munro and Cowan (1944) reported muskrats in expected types of habitats. I would judge, however, that the area is more suited to beavers than to muskrats, though the presence and activities of the beavers surely must make some of the smaller streams more habitable for muskrats than would otherwise be the case. This park, which lies just inside of the British Columbia boundary about eighty miles west of Calgary, Alberta, and about an equal distance southeast of Jasper National Park, may be close to the northern edge of the range of osoyoosensis. Soper (1947) wrote that muskrats from Jasper Park and north are undoubtedly referable to spatulatus.

It may well be that genuine osoyoosensis extends much farther north in British Columbia than in Alberta - possibly northward from its known range in the Columbia River Valley far up into the Cariboo Parklands. The lakes and marshes of this area are known as waterfowl 
breeding grounds, as is illustrated by many papers by J. A. Munro, and they have muskrats. This author (1945) described the

territory ... [ lying between the 51st and 53rd parallels ] as one of shallow east and west valleys from which grasslands and aspen-covered slopes ascend to forested ridges. One of the notable features is the multitude of water areas of varied extent ... from small, shallow ponds and sloughs to deep, usually narrow lakes up to 12 miles and more in length.

Also:

the lakes are not connected with the main drainage systems and hence not subject to flooding so that the water level is fairly well stabilized during the course of any one season. None of the marshes is of great extent; they vary in size from a few acres to 100 acres or more. Some are in the form of a series of discontinuous shoreward strips between open areas of boulders or soft bog. Others encircle the circumference of small lakes or ponds. . . . [Still others ] cover relatively large areas in which open water is restricted to a few narrow channels. Certain small lakes in narrow valleys have their main areas of marsh at the outlets.

The disease complex in muskrat populations of western United States may be most involved, and with tularemia, hemorrhagic disease, and fungus diseases dominating local situations, one might wonder to what extent they may depress or keep depressed the numbers of muskrats over significant areas. (See Appendix M for a résumé of disease studies centering upon Montana muskrats.)

Over much of Montana where good, naturally formed marshes are scarce, I saw during the late forties many cattail-grown irrigation seepages that furnished fair ecological equivalents of natural marshes. Those were seen from main highways in many parts of the state. Some particularly fine marshes originating from irrigation seepage - two or three acres in size, or larger - were noted, together with those of presumably natural origin, between Missoula and Flathead Lake. South of Flathead Lake were the Nine-Pipe marshes, having obviously excellent muskrat habitat in places. Jellison told me of a trapper who took about 1,000 muskrats per year from these, mainly seepage, marshes and sloughs.

Toward the mountain foothills, typical small streams were bordered by dense growths of willows, sufficient both to catch drifting snow (thus affording protection against the deep freezing of the ground and water so detrimental to wintering muskrats) and to attract beavers. Waters impounded by beaver dams were not always grown over by cattails and bulrushes, but those having marshlike aspects were almost certain to have muskrats unless the animals happened to be generally scarce. Sometimes, large acreages of creek lowlands were flooded by complex series of beaver dams, which resulted in extensive willow thickets being interspersed by plant growths of marshes and meadows and by open or debris-filled pools. The pools were from an acre or two up to perhaps 40 acres or more in size. In these ecological 
blends of meadow, marsh, bog, and willow swamp, with clear streams trickling through, the muskrats naturally stood some chance of finding suitable living quarters, whether with the beavers or away from them.

No precise figures as to population densities of muskrats in the waters of foothill "beaver meadows" are at hand. The view of local trappers and ranchers seemed to be that muskrats seldom became as abundant there as along the streams of lower altitudes. Drying of snow-fed flows in winter surely must have affected the habitability of considerable areas of foothill country for the muskrats, despite the beaver impoundments.

Field work in the Flathead area of northwestern Montana was centered in 1948 about two localities. One locality included the valley of the Clearwater River north of Seeley Lake, along the west side of the large wilderness or roadless area of the Flathead National Forest. Inez Lake, at slightly over 4,000 feet, was one of a string of five narrow lakes connected by the Clearwater River. It was a trout and perch lake with deep, clear water and little vegetation, but the muskrats were about as abundant along its shores in early July as they usually were along the shores of open-water prairie lakes - perhaps the equivalent of a family group about every 500 to 800 yards. At the north end of the lake, where the river came in, were rather extensive border zones of yellow water lily, pond weeds, bulrushes, and fringing willow growths. Here, both beaver and muskrat signs were evident, especially in the food-rich places. The river between lakes was shallow and had many willow-grown bars and banks, much driftwood litter and many old beaver dams. Muskrat signs suggested (on the basis of known fall catches from Iowa streams of similar size and appearance) populations of around 40 to 60 per linear mile. George W. Roskie, a veteran resident outdoorsman (retired forester and Boy Scout executive) regarded the parts of lake and river that I inspected as being fairly typical for the lake chain. He said that muskrats occurred in numbers in suitable places all along the stream.

The second locality worked over was the east side and the south end of Flathead Lake, a large (about 7 by 35 miles), deep (over 100 yards maximum depth), oligotrophic lake having an altitude of about 3,000 feet. It had a waveswept cobble beach, with a water level artificially lowered by about 10 feet in late winter. Those stretches of lake shore that were looked over were so unsuitable for muskrats as to arouse questions if the animals could live there at all and, if so, how. Dr. Gordon B. Castle, Director of the Biological Station of Montana State University at Yellow Bay, made available the facilities of the Station during a four-day stay, and the Station personnel discussed with me the ecological problems that resident muskrats would be up against.

Dr. Philip L. Wright of the Station's staff, through inquiries of year-round residents, established that muskrats were seen from time to time along the lake shore, but rarely except in spring. One had been 
observed trying to winter in a boathouse, which it had partly filled with miscellaneous debris. Away from the lake, several places were seen where muskrats lived or had lived. A beaver pool in the woods about 50 yards from the lake had had a muskrat (seen by students) earlier in the summer, though no signs remained by mid-July. An open pasture type of slough of about six acres had many old sunken muskrat burrows, as well as some in current use. The evidence indicated about three breeding territories, including one in a lodge built on a rock pile out in the water. This slough was appraised as being short of food, like many midwest pasture sloughs having little emergent vegetation. Wright spoke of there being many sloughs like this one scattered through woods and meadows between the lake and the mountains to the east.

The highest, really good, extensive muskrat habitat observed, with substantial numbers of muskrats resident, was at Lower Red Rock Lake, about 3,500 acres, at 6,800 feet, 40 miles west of Yellowstone National Park. It had in 1948 about 6 feet of water in the deeper parts, which were mainly of open water except for bulrush (Scirpus occidentalis) islands. The shallows - especially those grading off into meadow around the edges - were dominated by the sedge, Carex rostrata. Dr. Ward M. Sharp, in describing the winter status of the muskrats, said that the muskrat lodges are then distributed both in the bulrush islands and in the sedges of the shallows. The winters are long and cold, and the muskrats here are doubtless confronted with obstacles to survival much as are the muskrats living at lower altitudes a thousand miles to the north.

A small sample of the sedge margin was looked over in mid-July, 1948. A mink den with four or five active young was found, and in its vicinity were two recognized breeding territories of muskrats. The muskrats at existing densities seemed quite secure, as no muskrat remains were seen in a collection of about 300 mink scats, the contents of which were mostly of avian material. In one of the above muskrat territories, a litter of muskrats of about three and one-half weeks was being kept under a boat only about ten feet from the mink den.

Good stream-dwelling populations of muskrats were noted in suitable habitats of the Red Rock Creek and the Beaverhead River into which the Red Rock lakes drain. (The Beaverhead River is one of the streams along which beavers and muskrats were reported by Jellison, Kohls, Butler, and Weaver (1942) as dying of tularemia in the spring of 1940.) These streams at altitudes of 4,500 feet, or higher, had many of the features of good muskrat habitats of the lowlands, especially willow-hung eddies, oxbows, and old beaver pools. Exposed sand or mud bars were often packed by muskrat trails and sitting and feeding places, and scattered about was the plant litter characteristic of the activities of high densities of muskrats. Smaller creeks and irrigation flows had many muskrats. One typical 150-yard stretch examined in 1948 had the equivalent of two territories. Local stands of cattail 
furnished attractive muskrat environment, and the animals occurred abundantly in meandering waters choked with bittercress.

Hegben Lake, lying just west of Yellowstone National Park and north of the Idaho-Montana boundary, had considerable marsh area, sluggish streams, willow parkland, and fair numbers of muskrats.

The Gallatin River, at the northwestern tip of Yellowstone Park, had muskrats even in some of its higher source waters. Here, streams angled off through wide, grassy valleys, where a few beaver pools and quiet eddies fringed by sedges could be seen. Downstream, where the river had quite swift water running through a deep channel, muskrats were restricted to the less turbulent stretches having mossy or grassy banks.

Because they are protected from human exploitation or persecution, the muskrats of Yellowstone National Park should represent one of the most "natural" high altitude populations of the species to be found in the United States. Their status in the Park has therefore been a matter of exceptional interest from the standpoint of the investigations. Although pressure of time in mid-July, 1948, permitted my inspection of muskrat habitats only in the northern third of the Park, David de L. Condon, Chief Park Naturalist, contributed a very useful summary of his observations on distribution and numbers over the Park area as a whole. The statements immediately following are based upon an interview with Condon and personal notes taken shortly afterward in the field.

The highest altitude at which Condon observed muskrats was at 9,400 to 9,500 feet, at Mariposa Lake on Two Ocean Plateau, in the southeast corner of the Park. Some glacial ponds near Mammoth in the northwest corner have muskrats, but the altitude there is only 6,200 feet. Muskrats occur at about 7,800 feet all along the Yellowstone River between the Grand Canyon and Yellowstone Lake, in quiet waters where the river meanders and has much vegetation. Alum, Trout, and Sour creeks, tributaries of the Yellowstone in Hayden Valley, have generally more attractive vegetation for muskrats than do the Firehole and Gibbon rivers on the other side of a plateau; and the muskrats, while present on both sides of the plateau, are more abundant on the ecologically better side. Some of the willow parks bordering small streams have many muskrat lodges in fall.

In 1949, I looked over the southern part of the Park and the approaches from the south, including Jackson Lake. Here, there are marshy places or quiet waters with muskrats, but the good habitat is very limited. Beaver pools near Moose, Wyoming, had some muskrats; and, from what Dr. O. J. Murie told me of wintering conditions, the species should be able to maintain itself in such niches. Muskrat signs were also to be seen about some of the oxbows of the upper Snake River, but the main channel was too swift to be attractive. Yellowstone Lake, as seen from its west and northwest shores, offered few attractions for muskrats. Its altitude of 7,731 feet, its 100-mile shore line, and 
approximately 139 square miles of surface area gave me somewhat the impression of a large lake in the Pre-Cambrian Shield of the Canadian North.

Dr. Adolph Murie, in studying food habits and prey relations of coyotes in Yellowstone National Park, observed (1940, pp. 124-25) that:

Muskrats are not very numerous but are generally distributed along the water courses and ponds. During the fall and spring they are especially vulnerable to coyote attack when they wander out over the snow. Should a muskrat be discovered by a coyote when journeying on land, its chances of escape are, of course, slight. Journeys of more than 100 yards on the ice were noted. . . . Coyotes have been found to investigate a network of tunnels along a stream but it seems probable that muskrats are generally captured accidentally, for it would hardly be profitable for the coyote to spend a great deal of time hunting them.

This sort of behavior on the part of muskrats in winter is so indicative of individual insecurity that one may suspect that either the food situation was bad or that numerous transients were moving. If the animals tracking up the snow were truly wanderers, they might represent either or both the drifters from habitats occupied in summer but untenable in winter or the harassed surplusage of overpopulation - overpopulation in the sense of there being too many muskrats for the habitat even though numercial densities may not have been high. While Murie wrote further that "Coyote pressure upon muskrats does not appear to be great," and while the probability is that the elimination by coyotes of essentially doomed surplusages had little or no net effect on population levels maintained by the muskrats, his finding of remains of 98 muskrats in 5,086 coyote scats might mean quite a pronounced vulnerability of muskrats, considering their relative scarcity.

In short, it would be strange if, in muskrat environment as marginal as most of that of the Park, winter did not ordinarily bring about lethal crises. Repeated pruning back in winter of the ranges expanded in summer would seem to be the big natural regulator of numbers, with a fairly secure population nucleus left here and there to perpetuate the process.

One of the superior muskrat habitats in the Park is the Lamar River valley. Trumpeter Lake in this valley has muskrats the year around, and these are a probable source of the muskrats that occasionally reach the high and inhospitable Beartooth Plateau, lying northeast of the Park. (See Appendix N for discussion of special study of muskrat movements and distribution centered on and about the Beartooth Plateau.)

At the higher altitudes where muskrats were found, where the streams became rockier, swifter, more intermittent in flow with change of seasons, and more lacking in vegetation of the sorts eaten by muskrats, the muskrats tended to be restricted to beaver ponds. 
The close association of muskrats with beavers in many parts of the mountainous Northwest is readily understandable. Where streams are fed by melting ice and snow and dry up in winter, there is often virtually no place except in water impounded by beavers in which muskrats could winter. Individual beaver ponds may or may not have nutritious vegetation available for muskrats under the ice. If not too high, some beaver ponds take on marshlike aspects, with variable stands of cattails, bulrushes, water lilies, and other well-known muskrat foods. An example seen next to East Rosebud Creek, at about 6,500 feet, had in early July, 1948, no fresh beaver signs, but one of its two old beaver lodges had been taken over by a family group of muskrats. The pond was about one-half acre in area, with maximum depths of four feet and much water one and one-half to two feet deep. Heavy growths of yellow water lily, besides good herbaceous swamp growth (no cattails nor bulrushes) and thickets of willows, were growing in or near the water.

At altitudes exceeding about 8,000 feet in south central Montana, such few muskrats as were able to maintain themselves in stream habitats fed on much the same kinds of foods that the beavers ate among other things, upon the terminal branches of willows and aspens cut down and dragged to the ponds by the beavers. Moreover, the muskrats lived in both the lodges and bank burrows of beavers, including some occupied by beavers at the time. And muskrats living in the beaver colonies after freeze-up would have for their own feeding some of the food stored by beavers for winter use-sometimes available in huge piles under the ice.

The highest habitat so far observed that appeared to be occupied on a year-round basis by muskrats was a beaver pool in the Big Horn Mountains of north central Wyoming at an altitude of approximately 10,000 feet. At lower levels in the Big Horns, the beaver ponds were also the main habitats of muskrats. These included extensive flats of willow parklands as well as little trickling headwaters dammed in numerous places to create a series of ponds.

A possible indirect role of disease in the population fortunes of the mountain-stream muskrats should here be brought out. In the spring of 1946, both forks of Rock Creek and some neighboring tributaries were all but depopulated of beavers, evidently through the agency of tularemia. Apart from the deaths of muskrats from tularemia itself, the loss of beavers could well reduce very decidedly the amount of livable habitat that the muskrats might have. Except for beaver floodings so old that they have become truly marshlike, with natural growths of cattails and Cyperaceae, the usual beaver impoundments of mountain streams in the above locality have little food suitable for wintering muskrats after the beavers no longer bring it in from outside.

Winter food shortage certainly must be a foremost limiting factor for muskrats in south central Montana far below the altitudes of the 
mountains. Residents of Red Lodge have described muskrat trails in the snow about the willow parks and old beaver pools upstream along Rock Creek, at about 5,600 feet. In here, a strong flow of water continues in the main channels of the stream throughout the winter, and early snows usually prevent the boggy parts from freezing deeply. Bernt Egenes, of Red Lodge, who one winter trapped 45 muskrats from a place nearby, noticed that they were much smaller than the muskrats with which he had been familiar as a central Iowa trapper years before; the largest specimens of his Red Lodge catch were graded medium size by the fur buyer. But if these muskrats happened to have been cinnamominus, or intergrades therewith, their smaller size need not be ascribed wholly to difficult environmental conditions.

A few data on what may be classed as lone muskrat pioneers in mountain-stream habitats west of Red Lodge should be worth presenting. One animal lived throughout most of the summer of 1935 (it had left by late August) under a wagon bridge across a canyon brook at about 6,000 feet; the nearest place where muskrats were found to be living during close inspections in six later summers was in a series of beaver pools over a mile downstream. Another animal appeared about a half mile farther upstream in 1949, though there were not any in maintained residence for at least three miles downstream, or along the entire length of this particular brook valley. All of the old beaver pools were by then washed out, dry, and weed-grown, having signs of neither beavers nor muskrats. Summer and fall wandering of muskrats up and down this stony brook might be expected from time to time, but, without the beavers, the stream seemed to lose all the habitability it ever did have for muskrats.

Another muskrat pioneer - a big animal - moved about late May, 1948, into a spring-fed beaver pool to the side of the West Fork of Rock Creek, at an altitude something less than 9,000 feet; it was still around by late July, living in the main set of beaver burrows with the beavers and feeding chiefly on beaver-carried vegetation. This particular pool was 20 to 25 yards wide, from 8 to 21 inches deep, and with a considerable area of sedge meadow around it. Adjoining it was a 20 by 65 -yard pool with a maximum water depth of about one and one-half feet, impounded by a very old but still functional beaver dam about 80 yards long, and surrounded by sedge meadow having an area roughly twice that of the open water. Between the latter pool and the creek lay about a half acre of willow and cutgrass swamp and old beaver pools. No muskrats were known to be living farther upstream (though they had occurred at least six miles farther up in 1939), nor were other sites of residence known for nearly seven miles downstream - which meant one known muskrat along the entire 20-mile stretch of the West Fork of Rock Creek. In 1949, I could find no muskrat signs along the West Fork.

The comparable 20 miles of the South Fork of Rock Creek had many more muskrats than the West Fork in the summer of 1948, 
but it, too, was seemingly devoid of the species in 1949, despite better looking environmental conditions than in 1948. The highest point known to have been occupied by muskrats here at any time was at an altitude of about 8,500 feet. In 1948, an apparent family group lived in an old beaver lodge in the midst of about four acres of beaverflooded creek valley. Downstream were several other places where muskrats lived, notably in a wide area of beaver floodings above the junction of the West Fork and South Fork. The South Fork has the wider valley along much of its course and consequently many more places of superior attractiveness to beavers and muskrats alike.

\section{THE EASTERN CANADIAN MUSKRATS, obscurus and aquilonius}

I have been unable to find in the literature more than fragmentary information on the Newfoundland muskrat, obscurus, but learned much from correspondence with $\mathrm{H}$. W. Walters, of the Newfoundland Department of Natural Resources, and Austin W. Cameron, of the National Museum of Canada.

Walters (letter, April 11, 1949) wrote that the

marsh areas in Newfoundland suitable for muskrat are small and it is only on rare occasions that one would see a muskrat house. Generally they burrow within the banks of ponds or small lakes. From personal observation I would say that their food consists of various types of grasses and weeds and I believe the leaves and roots [ of the yellow waterlily]... Short lengths of the yellow waterlily root can always be found stored near the burrows of muskrats.

Cameron very generously undertook to record for me any observations he might make on obscurus in connection with a field program he had planned in Newfoundland for the summer of 1949, and, along with a letter of September 24, 1949, he sent me the following notes:

The Newfoundland muskrat (Ondatra obscura) is a rather small, dark insular species differing from continental forms in a number of morphological characters. Local furriers contend that pelts of this species are of less value for fur purposes, due to the thinness of the skin.

This species is widely distributed over the island, occurring in ponds, streams, and in the bays of the larger lakes. The greatest concentrations are to be found on the Avalon Peninsula and in the river valleys along the west coast. Much of the interior consists of barrens or semi-barrens dotted with numerous rocky, largely unvegetated ponds and lakes. Here a few muskrats manage to subsist on the scanty vegetation.

(Appendix O contains Cameron's notes as to the localities in which he found obscurus.)

Jean Duguay, of the Department of Fish and Game, outlined for me the distribution of aquilonius in the Province of Quebec (letter and enclosure of April 1, 1949). The forty-eighth parallel is the approximate dividing line between that subspecies and zibethicus to the south, but both subspecies occur in places on either side of this line. 
On a detailed map, it can be seen that, in western Quebec, this line follows roughly the height of land between the Hudson Bay and St. Lawrence drainages. Probably there is a big area of intergrading south and southeast of James Bay: "The trappers divide the aquilonius in different types. They call it Lake St. John type, Mistassini type, Abititi type. . . One thing is sure: the more you go north the less you meet zibethicus."

Anderson (1934), after writing of zibethicus being "found around both sides of the southern end of James Bay, ranging from thence southeast to the St. Lawrence," described the recorded range of aquilonius as from the Strait of Belle Isle (between Newfoundland and Labrador, at about the fifty-second parallel) to Fort Chimo, which lies south of Ungava Bay above the fifty-eighth parallel. "There is still a wide area from James Bay to Chimo and the northeast end of the gulf of St. Lawrence where the muskrat is known to occur but no scientific specimens are yet available."

It is rather clear from present information that the main range of aquilonius extends northwestward from the Gulf of St. Lawrence to the vicinity of the fifty-fifth parallel.

I know of two records of extreme northern occurrence of aquilonius in Quebec. Dr. O. J. Murie told me in 1949 of having collected a specimen in 1915 at the Nostapoka River, along the east coast of Hudson Bay. This place is between the fifty-sixth and fifty-seventh parallels, beyond the timber, characterized by many little clear lakes in granitic hills. Concerning the northernmost record in the Carnegie Museum, J. Kenneth Doutt wrote (letter, April 14, 1949):

The specimen was obtained at the mouth of the Kikkerteluk River which is between Great Whale River and Port Harrison on the east coast of Hudson Bay at approximately a point where the 58th parallel crosses. ...

I got the specimen from an Eskimo boy on July 28, 1945. . . From him I was led to believe that muskrats were not abundant, but were not uncommon at that point.

The sparseness of aquilonius populations over Quebec is illustrated by a statement in Duguay's letter to the effect that, despite the much larger geographic range of aquilonius, it comprises on the average only about 30 per cent of the muskrats caught for fur in the province. And, included in the range of aquilonius is a famous muskrat-producing area about Lake Mistassini, lying in the James Bay (Rupert River) drainage but nearly half way between James Bay and the mouth of the St. Lawrence River. The Lake Mistassini "rice rats" are considered by the fur trade as among the choicest in Canada.

\section{THE HUDSON BAY MUSKRAT, albus}

In the summer of 1948, I had opportunities to inspect representative parts of the eastern range of albus, largely through the cooperation of the Hudson's Bay Company and the Manitoba government. In 
addition to transportation and facilities furnished by these agencies, D. E. Denmark (Manager of the Company's fur preserves) and G. W. Malaher (Director of the government's Game and Fisheries Branch) gave me access to many years of records on the management and fur yields of celebrated muskrat-producing areas of southern and central Manitoba and east central Saskatchewan. In wilderness regions, the usual investigative procedure was to look over wetlands from aircraft, then cover them by canoe. The main reliance in gathering data was placed upon firsthand "reading of sign" and questioning of competent observers familiar with local situations. Between trips with personnel of the Hudson's Bay Company and the Manitoba government, I headquartered at the Delta (Manitoba) Waterfowl Research Station at the invitation of the Station Director, H. A. Hochbaum.

The eastern edge of the range of albus may be imperfectly traced. Anderson (1934) wrote of it being "found on part of the west coast of Hudson Bay, at least as far south as York Factory, but is not definitely known to occur as far east as James Bay coast." Near York Factory, in northeastern Manitoba, is a tract of Barren Grounds comprising the edge of muskrat range.

Among the other troubles to which muskrats of the Barren Grounds are said to be subject is the eating of their lodges by caribou, which apparently can well clean up the plant material within their reach above the ice. The significance to the muskrats of this molestation is not clear from information at hand. The species, nevertheless, does exist hundreds of miles to the northwest and north of York Factory, though in here the range of albus should be grading off into that of spatulatus. John S. Tener, of the Canadian Wildlife Service, sent me a record (letter, February 22, 1955) of a muskrat having been "shot in a pond at Eskimo Point, Keewatin District, N.W.T., in September, 1952."

Clarke (1940) wrote concerning his investigation of the Thelon Game Sanctuary, which lies in the Northwest Territories almost due north of the Province of Saskatchewan and west of the north part of Hudson Bay:

According to Mr. A. J. Knox, muskrats [ which could be albus, or intergrades with spatulatus ] are found regularly in the ponds on Crystal Island, Artillery Lake, at the extreme edge of timber, and he once found a wanderer at Ptarmigan Lake. In the eastern end of Great Slave Lake there are few marshes suitable for large numbers of rats, and there is only one record.

Southward from the Barren Grounds near York Factory, the terrain becomes more typical of the timbered rocky formations of the Pre-Cambrian Shield. Some of the country south of James Bay (which I remember from a canoe trip in 1921) had lakes with shores that were more precipitous than the lakes of the Whiteshell area of southeastern Manitoba. There was also more about northern Ontario south of James Bay that reminded me of the near-timberline woods, waters, and 
rocks in the western mountains and, conversely (if this be not taken too literally), more about southeastern Manitoba to be likened to the lower slopes and valleys of the mountains. The undersized muskrats reported trapped in the high altitude streams east of the Beartooth Plateau of south central Montana and from the Barren Grounds at York Factory would strengthen these analogies. Still, the Pre-Cambrian Shield about James Bay is known to have fine muskrat country yielding the choice "rice rats." These muskrat-producing areas - whether in the actual ranges of albus, zibethicus, or aquilonius or intergrades thereof - have bays grown with emergent vegetation, including almost pure stands of wild rice.

In southeastern Manitoba, Soper (1946) believed, lacking museum specimens, that the muskrats possessed chiefly the characteristics of albus, perhaps showing intergradations with zibethicus in the extreme southeast corner. Examples of living and dead animals that I saw in the Netley marshes south of Lake Winnipeg in 1948 certainly agreed with albus in size, if not in coloration. Toward the southwestern part of its range, albus seems to come close to or to intergrade with cinnamominus in the vicinity of Touchwood Hills, northwest of Regina, Saskatchewan (Hall, 1938).

Of its general range, Anderson (1937) wrote that the Hudson Bay "muskrat is found in waters draining into Hudson Bay from the west and which arise in northern Manitoba, northern Saskatchewan, and Keewatin District north to the limit of trees." Preble (1908) considered specimens from Athabaska and Great Slave lakes to be "somewhat intermediate between [spatulatus and hudsonius (=albus)] and might without impropriety be referred to hudsonius."

Beginning at the middle of Lake Manitoba and extending 500 miles northward and 700 miles northwestward is a triangle of wilderness wetlands, largely of bogs and shallow limestone lakes and marshes. The view from the air varied in 1948 from that of tremendous expanses of willow and scraggly tamarack bog, with an occasional pond or a low ridge of spruce-covered limestone, to equally extensive, interconnected open water separated by crooked and narrow fringes of shore vegetation. In August of that year, the water level in many places was still two or three feet above normal, as a consequence of spring floods. Dr. J. A. McLeod of the University of Manitoba said that many of the lakelike areas then to be seen were nothing more than mud flats in late summer of ordinary years. This is a country of moose and woodland caribou, of breeding waterfowl, and of muskrats, too; but the last found good environment only locally. Indeed, in the vastness of this triangle, the really attractive muskrat marshes may be likened to islands in the waters and bogs.

Looked over only from the air in 1948 were innumerable generally small - marshes along the west side of Lake Winnipegosis. These had alternating strips of water and vegetation, and irregular "feather-edge" shores. Many had open centers surrounded by bulrush 
rings; others had scattered bulrush clumps. (I had seen some of these, or at any rate some like them, at the height of the drought in 1934, and, even then, a surprisingly large number had remained in attractive condition for marsh-dwelling life.)

A celebrated muskrat marsh, Plummer's Island, was mainly open bog dominated by strips and clumps of coarse grasses, but there were also substantial bulrush growths in places. This lease of 21,145 acres (A. G. Cunningham, letter and enclosure, June 2 and 4, 1938) had 40 lodges in the fall of $1933 ; 1,554$ in $1934 ; 4,053$ in $1935 ; 4,793$ in 1936; and 4,361 in 1937. The spring catches following the falls having more than 4,000 lodges fell off from 10,891 muskrats in 1936 to 8,426 in 1937 and 5,055 in 1938. I do not have any information as to the mechanism of the decline. Fur managers with whom I talked at The Pas in 1948 felt that the muskrat habitat on this lease had greatly deteriorated because of high water.

The east half of the Hudson's Bay Company's Steeprock lease, near Dawson Bay of the northwest end of Lake Winnipegosis, was worked by canoe and on foot. This was the site of Butler's (1940) study of muskrat foods, in which he calculated that the existing stands of marsh vegetation could have furnished sufficient food for an average of 15 muskrats per acre. Between then and 1948, the emergent vegetation had evidently deteriorated somewhat, though it had not been subject to the excessive flooding prevalent over much of the region.

Management of the muskrats through manipulation of water levels has been singularly effective. An anonymous article (1943) reported that the 1,400-acre marsh on the Steeprock River had once been

famous for muskrats. The drought years around 1930, combined with heavy trapping, reduced the muskrats to nearly the vanishing point. In 1934 the marsh with its surrounding area, comprising a total area of 4,830 acres, was leased ... and a control dam ... . below the marsh, was completed. . . . Water levels were raised and have since been kept at the desired level.

Muskrats were protected from trapping for nearly three years. Under protection and with the right depth of water, their increase was rapid.

The raising of water levels increased the acreage of marsh suitable for muskrats. In the newly flooded sections, it was some time before muskrat food grew, but there is now much more than before. Care is taken to reduce water levels in spring to allow the growth of vegetation. As it grows, the water level is raised until the best level for winter is reached. . . .

Trapping during the last seven years [1937-43] has produced 20,144 muskrats, an average of 2,878 per year. Before development and with uncontrolled trapping, 100 muskrats was an average crop.

\section{(See also Appendix P.)}

During my 1948 visit, I looked over parts of about a 20-mile stretch of the west shore of Dawson Bay of Lake Winnipegosis near the road between Mafeking and The Pas. The visible shore for many miles was irregular in outline, marshes and "feather-edges" alternating with rocky banks rising up one and one-half to three feet above the mid- 
August high water level. Side marshes, connected by channels with the lake, had fair to good stands of bulrushes, and there were some muskrats about these. Wintering conditions could have been expected to be difficult for the muskrats except in the very best of the marshes adjacent to the lake and near the wide-channelled, sluggish mouths of streams entering the lake.

Among the once-good muskrat marshes west of The Pas that I saw in 1948 were Saskeram and Pasquia lakes. Pasquia Lake was inspected by canoe and on foot, and the following description applies more or less to a great many of the flooded marshlands of the region. In early August, 1948, the water was two or three feet above the normal level, and it had been three to four feet higher earlier in the year. Stalks and fruiting bodies of dead cattails protruded from the deeper parts-drowned tracts of a half square mile or more extending out in places, with practically all of the still-living cattails growing next to shore. On the other hand, great areas of former haylands were then grown up to river bulrushes and sedges. Muskrats were extremely scarce on the main bodies of water. They were present at low densities along the shore, which, though rocky, had flooded willow growths of varying thickness. Some of these willow growths extended for many yards into the marsh waters; others grew on both sides of rocky shore reefs; and in these muskrats lived at densities of the equivalent of about a breeding pair per quarter of a mile. Young were found in a low nest on the base of a tipped-over willow. It was apparent that essentially the entire muskrat population had taken refuge in the willows all summer up to that time. An adjacent marsh had island-like clumps of willows in extensive growths of river bulrushes. Here the muskrats were still living in the willows at the time of the visit, though beginning to forage out in the bulrushes.

A local concentration of muskrats was observed along The Pas River, a sluggish stream about 40 yards wide cutting through the flooded marshlands. Muskrats of all sizes were seen actively swimming in the fringing willow growths, and these muskrats were using very shallow, but in some cases very complex, systems of burrows in the low banks. Several muskrats had earlier established themselves in the yard about some flooded Indian cabins. They had renovated a small haystack, hollowing out and heaping vegetation over one side to make a lodge of it, besides building nests on a woodpile, on the floor of one of the cabins, and on top of a hay rake. Stretches of river bank were treeless, grown only to weedy herbaceous vegetation, and the shallow burrows here were thinly roofed over with cut plant materials. The muskrat densities of this stream ran about the equivalent of one pair and their season's young per 100 yards. Trappers' catches during fall "salvage trapping" in 1948 were reported as poor (memo, November 18, A. C. McMillan to Malaher): As of that date, four of six trappers had been checked in and these had a total of 150 muskrats, classified as 51 adults to 99 young. 
The Thomas Lamb lease of 54,120 acres - also not far from The Pas - was truly a pioneering venture in northern muskrat management. A. G. Cunningham (letter and enclosure, June 2 and 4, 1938) summarized the data on lodge counts and spring catches: 40 lodges in the fall of $1931 ; 840$ in $1932 ; 4,163$ in $1933 ; 5,633$ in $1934 ; 8,356$ in 1935 ; 4,599 in 1936; and 2,153 in 1937. Plotted on coordinate paper, the 1931-35 figures define a passable lower asymptote and slope of a Verhulst-Pearl-Reed logistic curve. When the decline came, some of the spring catches fell off even more sharply than did the lodge counts, and the fact that the largest spring catch preceded the largest fall lodge count would seem to rule out possible overtrapping as a major cause of the decline. The spring catches were 12,257 for 1934; 23,780 for 1935 ; 17,792 for 1936 ; 15,179 for 1937 ; and 1,739 for 1938. Lamb found dead muskrats with liver lesions ("white spots") on his lease as early as the spring of 1934 and in what would appear to have been considerable numbers in 1938 (letter, A. G. Cunningham, January 11,1940 ).

Lamb flew me over his lease at the time of my work in the vicinity of The Pas in August, 1948. It then had a very limited amount of good muskrat marshes, with bulrush, sweet flag, reed, and cattail growths usually occurring over about a third of the surface water. Feeding beds of muskrats were seen at from 50- to 100-yard intervals, but the muskrats seemed to have been living in surrounding willows. Probably most of what formerly had been the best marshes had been reduced to the status of open water lakes, the willow fringes of which harbored about all of the remaining muskrats in their vicinities. The brush-fringed outline of a small river could be distinguished amid the flood waters, and Lamb said that he had caught in some years as high as 400 to 500 muskrats along a six-mile stretch.

A special effort was made in the summer of 1948 to study effects of wind tides from very large lakes. Preliminary observations had been made in the summer of 1934 about the south ends of Lake Manitoba and Lake Winnipeg, where rises in water levels up to several feet sometimes accompanied strong winds from the north.

The south and southwest shores of Lake Manitoba were separated from much of the roughest water by low sandy ridges. Between these ridges and shore growths of vegetation extended a border zone of relatively quiet water having variable, sometimes thick, stands of bulrushes and reeds and with occasional long fringes of willow thickets. One of the best lakeshore habitats for muskrats lay out from the breakwater near the village of Delta. Between the 1948 sand bar and the permanent shore, the water was two to three feet deep (less in ordinary years) and was well-grown to cattails, bulrushes, and reeds. Some lodges and numerous feeding platforms of muskrats were seen, representing two breeding territories in a 150 -yard sample examined. Provincial Conservation Officers William Newman and D. J. McIntosh said that some muskrats usually wintered here, though wintering along the lake shore generally would be difficult. 
More typical shore (for 1948) had willow growths extending out into shallow water, but enough wave action carried past the sandy reef on which the waves broke to wash sand from the roots of the willows. Muskrat burrows in such places could not be expected to hold their form very well until protected by ice from the washing. But, with snowdrifts in the willows preventing deep freezing and the push of the thickening lake ice being held up by the outlying sand bars, some few animals could doubtless get through a winter on the available foods, including willow roots.

The marshes near Delta, south of Lake Manitoba, were connected with the lake, though sufficiently protected from wind tides by engineering devices to have relatively stable if shallow-water habitat for muskrats. Provincial Conservation Officer C. Batten said that, two years before, the water in most bays had been only about one and onehalf feet deep, with emergent vegetation standing exposed on mud bars, and muskrat lodges constructed of mud. Much winter mortality of muskrats had followed. The 1948 water level was decidedly higher but not up to the three-foot depths of the otherwise similar marshes extending off to the east, near Lake Francis. Batten found through regular measurements of the thickness of the ice that the water two and one-half to three feet deep, or even shallower, seldom froze to the bottom in the reedy growths - in part because of insulation by snow but also in part because of the nature of the bottoms. With the advance of winter, the layer of ice almost disappeared under the snow and vegetation at certain of his sampling stations.

During the summers of 1955 and 1956, Olsen (1959) made a special study of the ecology of the muskrat on about 2,500 acres of the Delta marsh. He also presented a paper on effects of high water levels and low breeding populations on reproduction of the local muskrats at the eighteenth Midwest Wildlife Conference (Lansing, Michigan, December 10, 1956), which is excerpted in part in Appendix Q.

The Delta and Lake Francis marshes both had good interspersion of water and emergent vegetation in 1948. For a long time, neither marsh had been very productive of muskrats, however, except during a short period a few years before. According to $\mathrm{H}$. A. Hochbaum, the 1948 muskrat population was greatly reduced over what it had been. The major losses at Delta apparently had been due to winter-killing in shallow habitats; those at Lake Francis, to the hemorrhagic disease. This disease had swept local areas of the Lake Francis marsh in the spring of 1948. During my inspection of the epizootic sites in August, I saw evidence of a continuing, practically annihilative die-off. On other parts of the marsh, the populations were low - estimated at the equivalent of about a breeding pair and associated season's young per five acres - but these seemed well situated.

The Netley marshes south of Lake Winnipeg are broadly the ecological and geographical counterparts of the Delta and Lake Francis marshes south of Lake Manitoba, except insofar as the Netley marshes 
are not only influenced far more by wind tides but also by changes in the flow of the Red River, which sends three main and several lesser channels running through the marshland into Lake Winnipeg. The Red River's floods are notorious, particularly in spring, when the melt waters from the south pile up on the Netley ice.

About eight square miles of the Netley marshes between Netley Lake and the southwest corner of Lake Winnipeg were looked over personally in company with Malaher a few days after one of the celebrated wind tides. A rise of nearly four feet was indicated by the fresh water marks seen along the main channel of the Red River, where the north wind had backed up waters seven miles south of the lake. Malaher said that this was about what could be expected from a big wind tide. Ordinarily, big wind tides are said to occur only once or twice a year and to last only a day or two.

A 15-inch rise that reached some of the irregular peripheries of the west side of the Netley marshes was enough to start some lodges floating across open spaces; it was enough to flood lodges solidly anchored on bottom mud; and it put muskrats on shore and into nests built under the foundations of hunting lodges, on boat landings, and such higher locations. The four-foot rise along the channel of the Red River had completely evicted the occupants of bank burrows, and these muskrats had sat out the high water in the riverbank willows. Doubtless, helpless litters had been drowned, drifting of lodges had brought territorial complications, and other upsets in the lives of the Netley muskrats had resulted from the wind tide. Malaher said that, in some years, great numbers of muskrats were forced by wind tides to move up a sluggish stream, Netley Creek, having its mouth seven and one-half miles south of the lake.

Muskrats were scarce over all but the west shore zone of the eight square miles of the Netley marshes that Malaher and I covered. Only one lodge that looked like headquarters of a functional breeding territory was seen in the extensive islands of reed and bulrush of the central parts, and that lodge was about a half mile from shore. A representative sample of the rush-and sedge-grown west shore had what looked like breeding territories at about 150-yard intervals. These were centered about lodges, as the banks were too low and flat even at normal water levels to invite burrowing. The effective muskrat habitat of the eight square miles totaled about ten miles (map estimate) of this sort of shore zone. Its muskrat population, as estimated prorata, should have been the equivalent of about 120 pairs and their season's young.

McLeod worked with me on the Netley marshes and told of a situation brought on by a freeze-up during a high wind tide. The resulting exposure of the muskrats to bad weather at the height of the wind tide could well have meant mortality, but the stratification of ice and air spaces following withdrawal of water to the lake was not without advantages for those remaining alive. After the relative sta- 
bilization of the water by the ice covering on the lake, the muskrats beneath the stratified marsh ice built nests and lodges at different levels and established labyrinths of partly dry, partly wet trails and tunnels, plugged and unplugged holes, and littered vegetation and mud.

Aside from the vicissitudes accompanying violent fluctuations of the water, the muskrats of the Netley marshes may have lost as severely from hemorrhagic disease as from any single factor. Like the Lake Francis muskrats, they had suffered from an epizootic attaining its greatest observed destructiveness during the spring of 1948 and also, from an evidently continuing die-off through the summer. (A single dead animal picked up on the marsh on August 6 had no positively recognized lesions, but possible hemorrhages may have been masked by decomposition.)

Later, McLeod (letter, February 12, 1949) prepared a summary of the recent history of muskrats of the Netley marshes. The area had been subject to extremes of flooding and drying several times within the memory of local residents. By the mid-thirties, the water levels of the marsh, the Red River, and Lake Winnipeg were very low, and in 1940 , the marsh

was almost completely dry except for pools in the low places. . . The water level began to rise in the autumn of 1941 and ... [ continued rising] with slight but steady increases until August 15, 1944. At this time a terrific storm from the north-west raised the south end of Lake Winnipeg and piled an additional four feet of water into Netley marsh. The water level has remained high and erratic ever since with the first appreciable recession in the fall of 1948.

From McLeod's letter and one from Alex J. Reeve (March 26, 1951), the following muskrat catches may be listed for the Netley Fur Block of about 56,000 acres. After closed seasons in 1942 and 1943, 69,677 were taken in the spring and 25,171 in the fall of $1944 ; 119,634$ in spring and 4,300 in fall, 1945; 24,432 in spring, 1946; 9,870 in spring and 364 in fall, 1947; 1,151 in fall, 1948; 25,896 in spring, 1949; 14,980 in spring, 1950. In addition, Reeve furnished figures on the annual catches from a 640-acre tract of Netley Marsh known as Warner's Ranch: 1943, 306; 1944, 6,197; 1945, 2,954; 1946, 1,013; 1947, 834; 1948, 1,330; 1949, 1,292; 1950, 743 .

Continuing the quotation from McLeod's letter:

In the fall of 1944 muskrat houses were very abundant and there were some signs of destruction of the habitat. . . . [ Severe flooding from the Red River occurred in late fall, and] muskrats began migrating out of the marsh in hundreds mainly to the north-west. Dozens were killed crossing the Winnipeg Beach highway a couple of miles to the west and muskrats were abundant in grain stooks and hay coils as far west and north as Lundar about forty miles away. They also became plentiful in sloughs and pot holes over this area where they had previously been scarce. Another large scale migration occurred in the spring of 1945 following an early breakup and severe flooding 
of the marsh. At this time muskrats were found as far north on Lake Winnipeg as Hecla Island and they were abundant around cottages at Winnipeg Beach.

McLeod (1950) "estimated that the two migrations involved at least 50,000 muskrats."

In 1948, when I saw it, the main channel of the Red River leading into the Netley marshes from the south was about 200 yards in width, with a variable, generally narrow, fringe of bulrushes and other quietwater vegetation, as well as overhanging willow thickets. Its banks in August were about four feet above the water. Though scarce in 1948, the bank muskrats were reported to have been fairly abundant in some years.

Netley Creek had variable muskrat habitat. Near its junction with the Red River, its banks were the same height as those of the river, or about four feet above the water level observed in 1948. Within about a mile and a quarter upstream, the creek banks gradually became lower until they disappeared in a wide, reedy marsh. Farther upstream about three miles, where the creek meandered through cultivated lands, its banks were better defined, though cattails, bulrushes, sedges, and reeds still covered much of the channel. The banks between the reedy marsh and the Red River had five recognized muskrat territories or about one per quarter mile. Only two territories were found in the reeds in about an hour of cruising with a canoe. The few muskrats present had selected what were rather clearly the choicer habitats in ordinary terms of food, cover, and water, in addition to refuge from the wind tides.

The largest and richest "muskrat country" in Canada with which I can claim any familiarity comprises the Saskatchewan River delta and adjacent lands and waters - especially those extending both upstream and downstream from The Pas and managed for fur production by the Hudson's Bay Company and the Manitoba government. The Company's Cumberland lease and the government's Summerberry Fur Rehabilitation Block have yielded too much information over too many years to facilitate condensing without losing a great deal of what a serious population student might wish to refer to, so treatment of these two areas is reserved for Appendix R.

\section{THE NORTHWESTERN MUSKRATS, zalophus and spatulatus}

The subspecies zalophus has a restricted range about the base of the Alaska Peninsula, in the area of Cook Inlet south of the Alaska Range. It is spatulatus that is really the muskrat of northwestern North America. As Anderson (1937) wrote, it

inhabits all suitable streams, ponds, and marshy areas in the Mackenzie River drainage of the Northwest Territories, north to Richards Island [ which is just below the seventieth parallel] in the Mackenzie delta and on lower Anderson River [ which lies to the east of the Mackenzie delta]. It is not very common in the lakes of the rocky districts bordering the "barren grounds" and the rats 
in such areas are more apt to live in holes in banks instead of building houses. The best muskrat areas in the Northwest Territories are in Slave River delta and Mackenzie River delta, but many marshy areas also produce large crops of rats, which form an important part of the fur returns in those districts.

Banff National Park in southwestern Alberta seems close to the southern limit of range of spatulatus. Dr. Ian McT. Cowan, who has studied the mammals of National Parks of the Canadian Rockies, found muskrats not much higher than 4,000 feet in Banff Park and not above 3,600 feet in Jasper Park (to the northwest of Banff Park), although beavers were noted as high as 7,000 feet in certain areas (letter, February 11, 1948). A Canadian engineer, Alex Campbell, mentioned in chance conversation in July, 1948, that he had watched a muskrat in close association with a beaver, near Banff, at an altitude of about 4,600 feet.

Henderson (1923) referred to heavy winter losses in muskrats, especially in 1915-16 in the Peace River District. There had been thousands of muskrats present in the fall, but a prolonged hunt in the spring yielded fewer than 100. Cowan wrote me (letter, June 20, 1951) that the "die-off this year has been particularly severe and seems to have extended from British Columbia and the Upper Mackenzie right across the Prairie Provinces to southern Manitoba. . . . I know one trapper here who estimates that the disease took two thousand rats from his anticipated crop."

Soper's $(1939,1941)$ descriptions of the Wood Buffalo Park (northern Alberta and adjacent Northwest Territories south of Great Slave Lake and west of Lake Athabaska) are of the greatest value in appraising the immense delta of the Peace and Athabaska rivers as muskrat habitat. This delta is reminiscent of that of the Saskatchewan River except for much higher elevation, including low mountains, in its vicinity. Soper referred to the Park as lying "some 270 miles southwest of the nearest Arctic tundra." He (1942) found spatulatus commonly distributed throughout the region and of "amazing abundance" in parts, especially in the great marshes. Except on the larger, swiftcurrent streams such as Peace and Slave rivers, the muskrats also abounded in many stream habitats. He gave figures of from 70,000 to 90,000 muskrat skins being traded at Chipewyan alone during a peak year, the majority from the Peace-Athabaska delta. I would also suspect that the activities of the numerous beavers of the Park (Soper, 1937) might provide some habitable environment for muskrats away from the extensive marshlands. At the time of Soper's residence within the Park, 1932-34, he saw evidence of recent expansion of beavers in numerous localities. "Thus, in places where beavers had not been seen for a decade or more, they are now established in ponds and insignificant streams which ordinarily would be ignored by a smaller beaver population."

Dr. W. A. Fuller, who made a special study of muskrats of the Park, described about half an area of roughly 6,000 square miles as 
ideal for muskrats. However, he found (letter of September 17, 1947) that the muskrats had

declined ... in recent years to an exceedingly low point. The chief causes are probably: 1. Series of dry years with a steadily lowering water table in the marshy area. This was undoubtedly aggravated by excessive forest fires and a serious depletion of the beaver population. [ He had written earlier in the letter: "From my own travels this summer there appears to be an abundance of plant material available for food, lodges and cover. There are extensive stands of Typha latifolia, Scirpus spp., Carex spp., Potamogeton spp. and Nymphoxanthus variegatus, as well as numerous other grasses and sedges as yet unidentified."] 2. The heavy hunting pressure which probably did not injure the population in "normal years," but which should have been regulated during the period when environmental conditions were unfavorable. [Also from earlier in his letter: "The chief difficulty centres about the Indians who have shown themselves to be notoriously poor conservationists. They are invariably opposed to restrictions of any nature and since they were granted hunting and trapping rights in the park, in lieu of the reservation, their protests in most cases carry a great deal of weight." ] 3. Probably cyclic fluctuations. 4. Disappearance of other forms of game used both as food and fur which caused the trapper to devote even more attention to muskrats. There appears to be no evidence that disease or predation have played any significant role.

A year ago conditions were so serious for the natives that they would have accepted any restrictions in the hope of restoring fur. This spring, however, there was excessive flooding of the entire area and sufficient precipitation and inflow from the major rivers to preserve a high water level and the trappers are convinced that in a year or two there will again be an abundance of fur. They are unable, therefore, to see the value of any positive conservation programme.

There is no doubt that Indian hunting of muskrats for food may be, especially in the vicinity of large camps, the severest type of predation and one at times capable of depressive influence on local muskrat populations. I have observed evidence of depleted muskrat populations on Indian lands in both the United States and Canada, and from Preble (1908, p. 191) the following about northwestern muskrats may be quoted:

At Fort Smith they were common in the marshes to the south of the post, and on the lower part of Slave River and in its delta they were abundant. While crossing Great Slave Lake to Fort Rae I found them inhabiting the islands and shore of the Northern Arm wherever marshy inlets occurred, Trout Lake, 25 miles south of Fort Rae, evidently being a favorite locality. In the immediate vicinity of Fort Rae, though conditions were favorable, I found the animals very rare, doubtless owing to the presence of a large band of Indians then congregated about the post.

Fuller (1951), reporting on his studies in the Athabaska-Peace River delta, discussed the types of shallow or food-poor habitats in which muskrats get along during the warmer but not necessarily during the colder months. However, if "frosts are light and snowfall heavy, even shallow lakes may be so well insulated that they do not 
freeze solid and the muskrats may survive in them through most or all of the winter."

East of Great Bear Lake are tracts of Pre-Cambrian that Robert H. Smith, who has done much flying over the area for the U.S. Fish and Wildlife Service, described to me (conversation, August 18, 1948) as being nearly all bare rock and shallow waters without vegetation other than occasional patches of Carex. He has seen a few muskrat burrows in the Barren Grounds at least 150 miles northeast of Aklavik. Although the Mackenzie delta opens up about the first of June, the Barrens do not thaw until about a month later. Many of the lakes are so shallow that muskrats could winter only in the deeper lakes. They had sedge growths along shore and coontail in the water, but nothing of the emergent vegetation to be found about typical northern muskrat marshes. Smith had also seen muskrats on the Anderson River, about 150 miles northeast of the Mackenzie delta, and thought that they probably extended in limited numbers all the way across the lakes lying just south of the Beaufort Sea.

Clarke (1944), who spent three months in late summer and early fall, 1942, in field work on reindeer between Aklavik and Burnside River (which is about half way between Aklavik and Hudson Bay), "learned with some surprise of the population of muskrats to be found beyond the limit of trees in tundra ponds, whether fresh or brackish, throughout the unglaciated coastal region . . . which extends east to beyond Horton River [ north of Great Bear Lake]. They have certainly increased in recent years."

Porsild (1945) wrote that in

the untimbered country, to the east of the [Mackenzie] delta, some rats are found in most of the large lakes and in the deep creeks and lakes that are tributary to the Eskimo lakes basin. . . . The northward and eastward range of the species is largely governed by the depth of lakes and the thickness of their ice-cover in winter. Rats, therefore, are not found in all lakes in the barren grounds, but only in those that are deep and enclosed by high banks. Due to the shelter afforded by high banks such lakes generally have an abundant snow cover in winter and the ice, consequently, does not get as thick as on lakes where, due to lack of shelter, no snow accumulates.

The local distribution of the muskrat is also closely tied up with its food supply and only in lakes that have an abundant aquatic vegetation and a depth of over 12 feet of water do rats winter successfully. Such lakes also are relatively rich in other aquatic life. The realistic Mackenzie delta Eskimo, who told the writer that "Lake with plenty of rats got plenty of fish too," was aware of this, if not of the underlying cause.

The food of the muskrat, at least during autumn, winter and spring consists of the fruits, rhizomes and winterbuds of pondweeds (Potamogeton spp.), rhizomes and tubers of horsetail (Equisetum arvense), the rhizomes and fruits of water arum (Calla palustris), and duck weed (Lemna trisulca). The roots, rhizomes, stems and fruits of a number of other plants, notably sedges and grasses are, no doubt, eaten as well. The Eskimo, who are keen observers, deny that rats eat fish, but say that rats, when "frozen-up" in their houses, often resort to cannibalism. 
The mountainous country west of the Mackenzie delta has muskrats in expected types of places. Murie (1944, p. 228) found them scarce in and about Mt. McKinley National Park, and his descriptions of the terrain remind one of the high altitude habitats in which the species barely maintains itself in western United States.

The Mackenzie River delta is the most northerly important muskrat habitat in North America. Here, strong populations live hundreds of miles north of the places about Hudson Bay where the ranges of both albus and aquilonius grade off into uninhabitability. The Mackenzie delta muskrats will be further treated in Appendix S.

\section{THE MARYLAND MUSKRAT, macrodon}

In early March, 1949, Francis M. Uhler, of the U.S. Fish and Wildlife Service, showed me typical habitats of macrodon in eastern Maryland. An example of about six and a half acres of heavily populated marsh dominated by Scirpus olneyi had an estimated 25 muskrats per acre. In general appearance, this sample was almost meadow-like, with most of the bottom being covered by very shallow water or exposed except for the muskrat channels. It was subject to but a few inches of tidal flow. I could easily see how cold weather could mean a crisis for the muskrat occupants, and Uhler said that cold snaps freezing about four inches of ice were fairly common, though usually of brief duration. By northern standards, this choice Maryland sample would be, at best, of marginal habitability during cold weather, an important distinction to remember in considering population dynamics of the muskrat in different parts of its geographic range.

The impression that I gained from conversation was that cattails became more important as the range graded off into that of zibethicus from New Jersey northward along the Atlantic Coast. Uhler did not regard Typha latifolia, that great favorite of north central muskrats, as being anywhere nearly as important to muskrats as Scirpus olneyi in Chesapeake tidal marshes.

The effects of ditching for mosquito control on habitats and populations of macrodon have been sometimes inconsequential, sometimes ruinous. Viewpoints thereon may be most divergent (see, for example, the symposium by Cottam, Bourn, Bishopp, Williams, and Vogt, 1938). Problems and consequences of action vary with localities as well as with methods. Compared with the Long Island operations described by Taylor (1938), the vegetational changes brought about by ditching may be much greater on Delaware tidewater marshes (Stearns, MacCreary, and Daigh, 1939, 1940; Bourn and Cottam, 1950). (See Appendix $\mathrm{T}$ for further treatment of ditching.)

Muskrat populations in Delaware appear to have been seriously affected, in recent years, at least locally, by what is almost certainly the hemorrhagic disease. In a letter of March 24, 1950, Robert A. Beck of the Delaware Game and Fish Commissioners described some of his observations: 
We are writing in regard to the severe mortality rate of muskrats of different areas in Delaware.

With the help of the University of Delaware, we have made many experiments on the various carcasses with very little success in determining the disease.

At the beginning of my survey in these areas, in October 1949, I trapped muskrats for experimental purposes. . . . [With five traps] I caught from two to three muskrats daily with very little effort. This indicated the muskrat population to have been normal at that time. However, the number of dead muskrats found increased. By December 1 when the trapper of this same area set his line ... of sixty-five traps . . . the muskrat population had decreased so badly . . . [ that he ] caught only six muskrats on the first day of the season.

The only external symptom found on the dead muskrats was a severe bleeding of the anus.

Hardy (1950) has compiled a list of trappers' opinions concerning the great decline of muskrats on the Dorchester County marshes. These opinions are remarkable for their variety and scope and cover the whole distance from inbreeding to environmental changes, ectoparasites to predation and trapping methods. But the following quotations may have special pertinence:

Some trappers contend that a disease struck the muskrats ten or fifteen years ago and has subsequently killed off the young. They state that they have opened the tops of muskrat houses and found from four to nine young muskrats, seemingly from three to four days old, all dead; and for no reason which they can explain except "that dreadful disease." In this connection, trappers have expressed the belief that the reconditioning and reuse of old beds by the muskrats have served to perpetuate the disease. . . .

"There seems to be [Hardy quoting E. Lee Le Compte] an epidemic of some sort on the marsh, for dead animals (muskrats) are to be found in considerable numbers. This is probably partly to blame for the scarcity of the muskrat [as of the mid-thirties ]. . . . To date no bodies fresh enough to permit examination have been found, so the nature of the disease is not known."

Hamilton (1943) wrote that macrodon is said to occur in the southeastern corner of Pennsylvania. From here southward through Maryland are a couple of large rivers (Susquehanna and Potomac) and their tributaries, as well as other small streams. Years ago (1928-29), I lived in Washington, D. C., and became quite familiar with these streams during field trips and also revisited them in the spring of 1949. They have little muskrat habitat except in certain places. Some streams have fairly rich stands of such food plants as a burreed (Sparganium americanum) and water starwort (Callitriche heterophylla). Uhler told me that the muskrats feeding on these plants were as fat as those feeding on Scirpus olneyi. He thought that the muskrats of the streams were almost certainly macrodon, comparable in weights with those of the Chesapeake Bay marshes. Roadside ditches may also have cattail stands, and I remember a canal that had good growths of both emergent and submerged muskrat foods. On the Patuxent Research Refuge of the U.S. Fish and Wildlife Service were impound- 
ments having at times, according to Uhler, high concentrations of muskrats living without recourse to marsh types of vegetation.

Uhler showed me one of the few natural ponds in the WashingtonBaltimore area. It was a backwater from the western branch of the Patuxent River, of about seven or eight acres and having its center filled with the smartweed, Polygonum portoricense, and bordered by cattail clumps and sedge. A tract of about two acres of cattail lay near the junction with the river.

Uhler and Llewellyn (1952) carried on a study of the fur productivity of submarginal farmland on a 1,000-acre tract of the Patuxent Refuge for the three trapping seasons, 1943-46. They took 12 to 40 muskrats per season, a total of 79 , of which 65 were taken from marshy lake borders and the others from along the forest-bordered Patuxent River. Cattails, bulrushes, burreeds, and arrowheads were particularly valuable muskrat foods.

Since the acquisition in 1933 of over 8,000 acres of timbered land and marsh for the Blackwater National Wildlife Refuge in Dorchester County, Maryland, the Federal government has carried on a long-term research program to obtain data on the natural history and management of the Maryland muskrat. Over 5,400 acres of the refuge consisted of marshland yielding up to 31,000 muskrat pelts in peak years. Dorchester County, on the Eastern Shore Peninsula, long has been celebrated for its muskrat production, and the well-known W. A. Gibbs marsh was the site not only of some pioneering experiments by the owner but also of some of the preliminary studies by the U.S. Biological Survey (Smith, 1938).

Dr. H. L. Dozier, late director of the U.S. Fur Animal Field Station on the Blackwater Refuge, 1937-49, and his colleagues have published many informative papers on the life history and ecology of macrodon; and the supplementary treatment in Appendix $\mathrm{U}$ will relate largely to their work.

Down the coast from Maryland, Handley and Patton (1947) gave the range of macrodon in Virginia as all counties east of the Blue Ridge Mountains, where it was rated as abundant. Statements applying to Virginia muskrats probably could be extended to cover northern North Carolina, but, somewhere in the western part, the ranges of macrodon and zibethicus must come together. In the eastern part of North Carolina, the range of macrodon fades out into the muskratvacant Southeast.

In the mid-thirties, W. A. Gibbs made what appears to have been a highly successful planting of Maryland-raised muskrats in a 3,000acre, improved marsh in Currituck County, North Carolina (Anon., 1938). This location, in northeastern North Carolina, is well north of the stated southernmost limit of macrodon's range. In his letter of January 28, 1949, from which extensive quotations were made with reference to the muskrat-vacant region of the Southeast, William E. Baldwin, Jr., wrote: 
The coastal marsh form, O.z. macrodon, comes south to midway of the North Carolina coast; perhaps the populations in our impoundments at Pea Island and Mattamuskeet National Wildlife Refuges represent southernmost concentration points for this subspecies, although I know that it extends a few miles farther south of those points.

In Baldwin's opinion, the extreme daily fluctuations in tide and the lack of sustaining habitat are among the major reasons for the absence of muskrats along the Carolina coasts south of the existing range of macrodon. The combination of hurricane salt tides followed by fresh water flooding of the streams surely would impose emergency conditions upon muskrats and, when suffered by populations confined to small and scattered tracts of livable habitat, might well be expected to push back the little extensions of range occurring southward during relatively favorable years.

\section{THE LOUISIANA MUSKRAT, rivalicius}

O'Neil (1949) showed the northern limit of range of rivalicius in Louisiana as running west from north of Lake Pontchartrain past Baton Rouge, then running irregularly northwestward and westward from Baton Rouge, to dip southwestward toward the Texas border at about the latitude of Lake Charles and Sulphur; its maximum width, as thus shown, is about 90 miles, narrowing down to about 30 miles in the southwestern corner of the state. It may be recalled that Lowery (1943) found that muskrats taken from fresh-water lakes were intergrades between rivalicius and zibethicus.

The southern coastal marshland is fairly continuous from north of Galveston Bay in southeastern Texas eastward nearly to Mobile Bay in southwestern Alabama. At the western edge of rivalicius range, the limiting factors look more obvious than at the eastern edge, which approaches the mysterious muskrat-vacant area of the Southeast. Earl Atwood told me (March, 1949) that the range gives out north of Galveston Bay, and this is also shown by Lay and O'Neil's (1942) distributional map. Aransas Refuge, approximately 225 miles southwest of Galveston Bay, has no muskrats but Atwood appraised its habitat as suitable. The intervening coast has few protected bays in which marsh vegetation could develop, and the area southwest of Galveston Bay is semiarid, with mostly intermittent streams, all the way down to the Rio Grande Valley.

Bailey (1905) did not mention rivalicius in his biological survey of Texas. Daniel W. Lay wrote (letter, January 6, 1949) that

Local marsh residents don't remember seeing them prior to about 1914 when a Beaumont rancher put a bounty on them because of the holes they dug in his marsh pasture. However there is no barrier or significant difference in habitat between the Texas and Louisana coastal marshes.

In March, 1949, Lay told me that he thought Bailey must have missed the muskrats along the Texas coast, which were living in places 
that would have been difficultly accessible before the years of automobile transportation. Lay has observed evidence of what he thought were ancient "eat-outs" on his regular study areas between Galveston Bay and the Louisiana state line.

The eastern edge of the range is Mobile Bay, Alabama, where muskrat populations have fluctuated greatly and not always with any apparent reason. This is more fully discussed in Appendix V.

Of a total of 70,000 acres of coastal marsh in southeastern Mississippi, Freeman (1945) appraised nearly 48,000 acres as being suitable for muskrats, chiefly on the basis of the presence of Scirpus olneyi. He reported that muskrats were found on about 13,500 acres of marsh along the Pascagoula River but that not all of this was good habitat for them. Ecological changes apparently resulting from floods were pronounced, and declines of $S$. olneyi were accompanied by population declines of the muskrats. Trappers' catches of 18,000 to 23,000 per year dropped to averages of about 3,500.

Freeman reported much movement on the part of the coastal marsh muskrats, some of which was patently the result of adjustments following destructive utilization of local stands of Scirpus olneyi. The Mississippi animals showed strong tendencies to congregate in favored areas and to leave other areas vacant - the instances specifically recorded took place during the fall, winter, and spring of 1942-43.

Freeman considered the abundant raccoons to be

the greatest limiting factor in the Pearl River marshes and certain parts of the Pascagoula marshes. Thirty houses examined in the Pearl River marshes had been visited by raccoons the previous night. . . . Evidence of the raccoons digging into muskrat nests had been found at all seasons of the year. . . One hundred and twenty-nine stomachs [ of winter-trapped raccoons] were examined. Ninety-one had remains of muskrat. . . To get some idea of their predations [during other than the trapping months], droppings were collected in March, May, and October. One hundred and twenty-seven scats were examined -31 , or $24.4 \%$ of them had muskrat remains.

Minks and alligators were scarce on Freeman's areas, but the remains of nine muskrats were reported from the stomach of an eightfoot alligator. Muskrat remains were found in an unspecified number of horned owl pellets, but not in a collection of over 100 otter (Lutra canadensis) scats from all seasons, though the otter is regarded as a muskrat enemy by trappers. Freeman did not know of any serious disease of muskrats on his study areas. Many dead muskrats had been found in 1933, before Freeman's investigations, 1942-45, but the observers attributed it to poison sprayed in connection with mosquito control measures.

Perhaps I may be reading into Freeman's data some things that are not there, but the "between the lines" picture I see is one in which disease as well as environmental deficiencies and emergencies must be considered.

The main range of the Louisiana muskrat is, appropriately, in 
Louisiana, and this state has been the site of so much work on the subspecies that the principal treatment in this book will be reserved for Appendix W. Let it be made clear, however, that rivalicius was undoubtedly much less numerous and still more localized in its distribution in Gulf Coast marshes a century ago than it is today. Nobody seemed to notice these muskrats in what later became choice habitat, though Dr. Leslie L. Glasgow, of Louisiana State University, described recent finds of rivalicius remains in Indian mounds (letter of March 12, 1956). O'Neil (1949) attributed the extensive growths of Scirpus olneyi, upon which the muskrats are so dependent, to the burning of marshes by alligator hunters, beginning in about the second decade of the present century. But even when rivalicius populations are at their peak, only a minor fraction of the Louisiana wetlands - comprising as they do nearly a third of the state - is real muskrat marsh. O'Neil (1949) wrote that 80 per cent or more of the normal muskrat catch of $5,000,000$ to $6,000,000$ is produced on approximately 1,000,000 acres of olneyi marshes.

The living habits of rivalicius resemble those of macrodon particularly in the way that both subspecies attain their highest densities in very shallow marshes or meadows dominated by Scirpus olneyi. From my own limited observations, I would say that these two subspecies come as close to being habitual land-dwellers as any that I have observed in North America.

THE SOUTHWESTERN MUSKRATS, ripensis, pallidus, goldmani, and bernardi

Bailey (1905) wrote of the Pecos River muskrat, ripensis, which occurs 400 to 500 miles west of the westernmost edge of the range of rivalicius: "This small, dull-colored muskrat lives apparently in suitable places along the whole length of the Pecos River and on some of its tributaries, and along the Rio Grande near the mouth of the Pecos."

In late years, however, the population status of ripensis has changed a great deal, and Dr. W. B. Davis, of Texas A. and M. College, has expressed a fear that it may even be doomed because of irrigation drawing off the water from its best habitat (conversation, March, 1949).

I have never been in the part of the country referred to but, from correspondence with Davis, Dr. W. Frank Blair of the University of Texas, E. G. Marsh, Daniel W. Lay, and O. F. Etheredge of the Texas Game, Fish, and Oyster Commission, I think that I now have a workable concept of the present situation.

Lay (letter, January 6, 1949) wrote that ripensis in Texas

occurs on the Pecos and Rio Grande rivers from Del Rio to New Mexico and is most numerous in the irrigation canals near El Paso. Although we estimated several years ago that the annual catch around El Paso might be as much as 50,000 , I feel sure that the catch has dropped more than half. Irrigation programs have removed all except flood water from the Rio Grande channel at 
El Paso, the ditches are cleaned of vegetation regularly, and flash floods are increasingly severe in their damage of streamside habitat on the two rivers and their tributaries.

I am very grateful to Etheredge for the trouble to which he went in investigating for me the status of ripensis in the vicinity of Fort Stockton, Texas. He wrote (letter of April 5, 1949) that "it looks like the muskrat populations in this area are definitely decreasing." However, land practices on the San Pedro Ranch in Pecos County were favorable for the maintenance of existing muskrat habitat, so that there should "continue to be at least some muskrats on this ranch. We found no one who would attempt to give us a population figure but it is agreed that there could not be more than 2000 animals in the entire district."

This subspecies probably is subject to fluctuations in much the same way as are the others, and it may well increase again in the years to come, but, as muskrats go, it does not seem to have a very strong hold on existence. A series of adverse years, a prolonged emergency like that afflicting cinnamominus of western South Dakota in the thirties, and ripensis might be all but gone; with no really big reservoir of animals anywhere, the difference between depletion and extinction during a crisis might not be so great, especially with human water use in an arid climate as a complicating factor.

The subspecies pallidus, goldmani, and bernardi have not always been clearly distinguished. The genuine pallidus, or Arizona muskrat, as nearly as I can judge from the literature, appears to be rather restricted to the Gila River and tributaries in southern and central Arizona and southwestern New Mexico. It would seem that the subspecies referred to by Barnes (1927) in southwestern Utah as mergens must have been goldmani, and Hall (1946) depicted the range of goldmani in Nevada as a little stretch of the Virgin River above Lake Mead in the southeastern corner of that state.

Dr. S. D. Durrant had just completed a study of the mammals of Utah when I visited the University of Utah on July 22, 1949, and from him I learned that goldmani seems limited in Utah to the Virgin River drainage upstream from a series of precipitous gorges starting at about the state line in the southwestern corner. He thought that these gorges may be an effective barrier, as downstream from these the range of bernardi begins (Durrant, 1952). Still, Hall examined specimens of goldmani from downstream sections in Nevada, including one that had characters intermediate between goldmani and bernardi.

Before the reclamation engineering in southeastern California, the Colorado River muskrat, bernardi, was confined to the valley of the lower Colorado River, but "recently," to quote Grinnell, Dixon, and Linsdale (1937, p. 731), "found conditions in one restricted section extremely favorable to its needs, and has thrived accordingly .... [ The ] great expansion in the population ... has come about as a 
result of the metamorphosis of a previously arid desert through man's agency." (For further information, see Appendix X.)

Storer (1937) generalized concerning the muskrat as a species:

In the arid west it is discontinuous in distribution, by reason of the localization of suitable habitat. It probably reached some of these now isolated waters during a period when aquatic and palustrine habitats were more widespread, in late Pleistocene or postglacial times. With subsequent contraction of habitat, stocks were reduced and isolated, since when limited subspecific differentiation has occurred. Parallel cases are known among amphibians and fishes in the western states.

The subspecies bernardi is the only one of which I know positively to occur, free-living, in Mexico, though ripensis should surely reach Chihuahua or Coahuila, at least as occasional strays, from its known range along the Rio Grande. In Lower California, Mearns (1907, p. 496) saw what he thought was a muskrat in 1894 near Seven Wells, and the following is from Grinnell, Dixon, and Linsdale (1937, p. 733): “On March 22, 1921, at a point five miles south of Mexicali, Lower California, an observer (D.) saw a large muskrat come to the entrance of its burrow."

Upstream, along the Colorado River, bernardi extends into southeastern Nevada up to the Lake Mead area and then eastward into northwestern Arizona. I do not know how far this subspecies goes into Arizona, but I should think that the Grand Canyon would be an effective barrier to movement upstream. 
Chapter 14

\section{The Muskrat Over the World}

The ChIEF PURPose of this chapter is to generalize on the biogeography of Ondatra zibethicus, in its constituent subspecies, over its native and acquired range. Its range by now includes most wetland areas of the northern hemisphere.

\section{THE MUSKRAT IN ITS RACIALLY NEW RANGE IN EURASIA}

There are many accounts of the introduction and initial spread of the muskrat in Europe, of which one of the best and most accessible for American readers is Storer's (1937). (See also Mohr, 1933.) Prince Colleredo-Mannsfeld released five animals (two males and three females) at Dobrisch, southwest of Prague, in 1905. By 1914, the whole of Bohemia had been colonized, and the population of muskrats in that country was estimated at two million. The spread of the species had been at the rate of four to thirty kilometers yearly. "For more than one and one half decades," as Mohr wrote, "the muskrat, starting out from Bohemia, has been a middle-European calamity." Storer explained that, under the more rigid economic limits of life and sustenance for central European peoples, the interpolation of any new element arouses concern. As early as 1912, the potentialities of the muskrat for harm had been publicized. Damage was principally through burrowing in canal banks, railroad grades, and earthen dams, though some could occur through raiding of gardens and fish ponds.

To me, the various references to the muskrat's piscivorous habits (see Ahrens 1921, as well as the two papers by Mohr and Storer and the bibliographies of Mohr and Storer), with implications of shortages of muskrat foods, may explain certain observed phenomena: 
higher densities of the muskrats at the periphery of the expanding range and scarcity of animals in parts that had been colonized earlier. From what I have read and what I have seen of northwestern Europe, I would suspect that central European muskrat habitats may have a rather low supporting capacity, at least as concerns the choicer types of food. At the time Storer prepared his manuscript, muskrats in Bohemia were "believed to have reached an equilibrium as to numbers."

I should not expect the muskrat to thrive in the rugged Balkan region, though there would seem to be localities in which the species might live if it reached them. Hoffmann (1952) mentioned its occurrence in the cool waters of high mountains of Germany, and he showed its range extending into Yugoslavia and at least to the northern boundary of Bulgaria. Muskrats apparently straggled into Switzerland from Alsace, and from 1942 through 1957, many thousands were reported killed (Hoffmann, 1958, p. 109). Muskrats were still being caught in fish traps in the Vierwaldstätter See of Switzerland, originating, according to Hoffmann, from escapes from muskrat farms legally closed in 1929 .

The following quotations from Bourdelle (1939) illustrate the situation in France.

The relative ease with which breeding stock could be procured, the prospect initially of rearing them in captivity, and the remarkable fecundity of these animals were the factors which encouraged many to undertake the raising of Ondatra. Numerous centers of propagation were established, but serious difficulties were quickly encountered. Whereas the nutria bred well when closely confined, the muskrat, on the contrary, showed little inclination to live under the same conditions, and did not reproduce well in captivity. To satisfy the biological requirements of this ungovernable rodent it was necessary to give it semifreedom. . . . Still more easily than the nutria, and in far greater numbers, the muskrat escaped from the parks where it was propagated and invaded the neighboring regions. . . . From this time on the importation and breeding of muskrats in France was rigidly forbidden, and an active campaign was organized against the wild populations by trapping and by the use of virus.

What the French refer to as "virus," used against the muskrats (Chappelier, 1933), is the bacterium, Salmonella typhimurium.

In northern France there have been four areas of infestation (Chappelier, 1948): (1) the north area in the region of the Somme, (2) the northeast area, Ardennes, (3) the east area in the region of Belfort near the Rhine, and (4) the west area in the region of Normandy, occupying four river basins and extending almost to the English Channel. Within these areas, the distribution of muskrats may or may not be continuous, depending both upon natural facilities for dispersal and upon numbers and sites of introduction.

The spread of the muskrat into Holland from northern Belgium, 1941-52, is well shown by a series of maps in a report by van Koersveld (1953). That the species was continuing to gain ground throughout the forties and into the fifties despite intensive campaigning is illustrated by the following figures. From 1941-46, the number of 
animals taken was reported as 23; in 1947, 74; in 1948, 164; in 1949, 537; in 1950, 337; in 1951, 569; and in 1952, 659. The size of the area occupied by muskrats was about 10 square kilometers in 1946, 30 in 1947, 70 in 1948, 500 in 1949, 650 in 1950, 750 in 1951, and 1,000 in 1952.

Dr. F. W. Braestrup, of the Museum of Zoology at the University of Copenhagen, wrote (letter, March 6, 1951) that the muskrat has not spread to Denmark and that the Danes "have very strict regulations forbidding any import of live muskrats on any pretext whatsoever." I heard of no reports of muskrats in Denmark while visiting there in the spring and summer of 1959.

To quote from Storer (1937):

The entrance of the muskrat into Germany was a natural consequence of the spread from Bohemia. There are no sharp biological barriers and the waterways crossing international boundaries afforded every opportunity for spread of muskrats. Ulbrich's (1930) chart shows clearly that the increase of territory occupied was a natural spread. By the time control measures were instituted in Bavaria the species already occupied a wide extent of waterways. ... It now seems impossible that the countries of central Europe can ever hope actually to rid their lands of the muskrat. The species will not only hold much of the territory already occupied, but may continue to spread and, in time, to occupy most of continental Europe suitable for its existence.

In connection with their campaigns, the Germans did a substantial amount of work on the biology of the muskrat, and Ulbrich's (1930) book has been especially useful to me in my own investigations. Later, Hoffmann (1952; 1958) summarized the German findings, especially the data acquired after Ulbrich's publication.

Ulbrich emphasized foxes and polecats (Mustela putorius) as enemies of the muskrat in central Europe. The habits he described for the polecat were rather minklike, and polecats used muskrat burrows as dens. Many instances were noted of house cats preying upon young muskrats that came to shore, also of predation by raptorial birds. The latter included small or weak owls - 11 of 57 pellets of Asio spp. contained remains of young muskrats.

The muskrat was first introduced in the British Isles in the middle and late twenties as a fur-farm animal. Then, as in France, some escaped to establish themselves as free-living muskrats. Within a few years, there were five centers of infestation (three in England, one in Scotland, and one in the Irish Free State). The rapidity with which the animals spread and the lessons provided by central European experience resulted in effective action, and the species was extirpated from England and Scotland in about five years (1932-37), at the respective costs of $\$ 28.29$ and $\$ 52.43$ per muskrat taken (Storer, 1937).

Of the best English habitats, Warwich (1940) wrote:

Shrawardine Pool, near Shrewsbury, where Musk-rats were originally enclosed in the autumn of 1929, has low banks, consequently few land burrows were made, and the animals lived mostly in houses. The increased population after the breeding season of 1930 so cut the dense growth of Typha that by the 
end of 1931 the pool was a clear sheet of water. . . The Severn [ which flows close by ] is a very suitable river for Musk-rats, as, although its banks are rather bare and do not support much rank vegetation, there is an abundance of aquatic plants in the river itself. The banks are high, in many place overhung with willows, and of a tough boulder clay, which becomes sandy below Shrewsbury. . . . After the first escapes from Shrawardine in 1930-31, a dense population was established on the adjacent ponds and ditches.

The catches, from June, 1932, to December, 1933, varied up to 147 per square mile and averaged around 35 per mile within a radius of about two miles of the point of introduction, on land lying near the Severn.

While the Germans and other peoples of central and western Europe regarded the value of muskrat pelts as little compensation for the damage the species did there, the Finns and Russians intentionally spread the muskrat, as a wild fur-bearer, over a large area of their northern lakes and marshes. From the German summary of Lavrov (1936), I would judge that, in the more thickly peopled parts of western Russia, the muskrat may do damage as in central Europe, though to a less serious degree.

Dr. Lauri Siivonen, of the Game Research Institute, Helsinki, Finland, sent me a list and notes on the contents of sixteen Russian publications on the muskrat of which he knew (letter and enclosures of March 1, 1947). The subject matter covered principally the ecology, introductions, food habits, enemies, parasites, and fur values of the species. N. P. Lavrov (or Lawrow, according to the German spelling) has carried on a great deal of the Russian investigations of muskrat biology, and I have had access to several of his papers and a book (1957). Dr. Teodor Juszkiewicz, of the Polish Veterinary Research Institute, Pulwy, Poland, was very helpful in translating for me "key" passages from Lavrov's book. Another account of muskrats in the U.S.S.R. that I found especially informative was in Artimo's (1949) comprehensive paper on the muskrat in Finland, which Dr. Thomas A. Hippaka of Iowa State University translated for me, along with other material, from the original Finnish.

The introductions best known to Artimo were in areas neighboring Finland, especially Solovetsk Island. There are over 400 lakes on this island, most of which have a very rich plant life, and the muskrats soon populated all of the lakes. From 1927 to $1955,160,000$ muskrats were introduced in the Soviet Union (Lavrov, 1957). According to a 1941 publication by S. P. Naumov and N. P. Lavrov cited by Artimo, trapping was initiated in 1935, with a catch of 5,000; in 1939, the catch was 300,000 . Hoffmann (1958) gave a 1956 figure of three million.

Lavrov's (1955a; 1957) distributional maps and one reproduced in Hoffmann (1958, p. 125) show a vast region of the central U.S.S.R. as occupied by the muskrat, extending east from the Urals to the Lena drainage in eastern Siberia, and from Outer Mongolia north toward the Arctic Circle - a region greater in size than all of Europe. In addition, there is a large region extending from Finland east to the 
Urals, and many scattered localities in the southwestern U.S.S.R., especially north and northeast of the Black Sea and in some of the headwaters of tributaries leading north to the $\mathrm{Ob}$ River, within a relatively few hundred miles of India. I learned (through Mrs. Olga Garner's translation of the Russian text for me) that Lavrov (1955a) considered the area lying south of the present main range of the muskrat in central Asia to be unfit for the species and that it cannot be expected to occur there. The muskrat-less area referred to is principally that lying between 40 and 50 degrees of latitude and between 80 and 120 degrees of longitude. On the other hand, Lavrov's (1957, p. 184) curve plotting increase of the Russian muskrats from 1937 through 1955 conforms in a rough way to a lower asymptote of a Pearl-Verhulst-Reed logistic curve, with the 1955 population suggesting the beginning of a steep climb; it could be that the upper asymptote is still far off and at a level that would be hazardous to predict.

From Artimo's English summary, it may be seen that the muskrat was, beginning in 1922, transplanted to at least 216 places in Finland, from Hankoniemi in the south to Inari in the north. By 1931, possibly a fourth of the south half of Finland was occupied range for the species; by 1937, the spread had included possibly two-thirds of the south half, plus areas in the north half, nearly up to the northern tip of the country; by 1948, practically all of the south half of Finland was occupied, as well as what seemed to be the habitable environment of the north half.

The species is shown in Artimo's paper as occupying the Aland Archipelago of southwestern Finland. Introduced on Åland, itself, in 1926, the muskrat has apparently spread over thousands of the smaller islands by natural means. Muskrat populations, however, have not thrived on the sea islands to the extent that they have on the inland waters of southern Finland. From what I have seen of Finnish archipelagoes, I should not rate much of this type of habitat very high from the standpoint of the muskrats - possibly about the same as our Quetico-Superior region.

Artimo showed that the muskrat had by 1948 lost some of the range in northern Finland that it had occupied in 1937. The Finns were considering trying the introduction of zalophus, spatulatus, albus, aquilonius, and obscurus into the places in Lapland that seemed too uncongenial for zibethicus or other of the more southernly subspecies or strains thereof. But, it is understandable why the muskrat should build up dense populations locally and be virtually unrepresented in the open-water, food-poor lakes and ponds and the "north woods" terrain characterizing much of Finland. The heaps of muskratopened mollusk shells on the rocks of lakes, the water lily pads, the fringing Cyperaceae of open waters, the wooded backgrounds bespeak ecological counterparts of, let it be repeated, the Quetico-Superior region.

Artimo wrote that "North Finland is less productive than South Finland and East Finland less productive than West Finland. The 
best cultivated districts are also the best muskrat areas." The hydrographic district of Kokemäenjoki in southwestern Finland includes some of the most productive habitat, its yield being "considerably larger than in the greater part of the country." In visiting (spring of 1959) some of the best muskrat-producing wetlands of southwest Finland, I was especially aware of the great local differences in habitats. The muskrats were living in places and at about the same densities that I would expect for comparable North American habitats, but in general, I thought that the accommodation capacity of Finnish wetlands for muskrats must be rather low.

Artimo found that the muskrats had done considerable leveling off in Finland between 1940 and 1945. He indicated that too few observations had been made over too short a time to permit very definite conclusions as to "cyclic" behavior of the species in Finland. The gross fluctuations of North American muskrats (see Elton and Nicholson, 1942) and the Finnish muskrats do not, however, agree very well chronologically. This might be in part explainable in terms of weather conditions, as the winters of 1939-42, which coincided with a "high" phase of the "10-year cycle" in central North America, were in Finland exceptionally severe. The meaning of the gross fluctuations of muskrats can surely be as badly obscured by climatic emergencies in Finland as they can be in North America. The same also applies to the U.S.S.R. (Lavrov, 1955b - see the newly available Canadian translation).

Artimo discussed biotopes occupied by muskrats in Finland and the quantitative investigations of the species carried on in the Kokemäenjoki district, 1946-48. On the basis of his results and known fur catches, he figured that "the catch of muskrats in our country in peak-years may possibly amount to 250,000." The maximum catch of 240,000 , made in the spring of 1947 , is approximately the same as his calculated maximum and far below the predictions of some earlier workers on Finnish muskrats. According to Hippaka's translation notes, Artimo indicated in the Finnish text that the attainment of peak catches of even 250,000 would require better management than had been practiced up to the date of the writing. Actually, I did not see during my visit what kind of management short of expensive, large-scale manipulation of biotopes could stand much chance of greatly increasing the Finnish muskrat populations. It should be pointed out, however, that according to Hoffmann (1958, p. 117), the Finnish catches for two years exceeded the 1947 figure of 240,000: 262,000 for 1950 and over 600,000 for 1955, the latter catch following a closed season in 1954. In 1956, the catch was down to about 212,000; in 1957 , to about 128,000 .

In his English summary, Artimo reported that the "most important enemies of the muskrat in Finland are the fox, the dog, and the birds of prey. The fish traps levy an annual tax of about 10,000 muskrats from the muskrat population of the country."

Little information is available on disease in Finnish muskrats, 
though animals have been found dead at times (Lampio, 1946). Lampio, who had done much work on diseases of Finnish game, spent some time with me in late spring, 1952, in connection with an extensive survey he was making of wildlife research in the United States; and after inspecting the sites of recurrent die-offs at Little Wall and Goose lakes (Chapters 8 and 9) he volunteered the comment that disease could well be a more important factor in Finnish muskrat populations than had been recognized. What the possibilities are cannot yet be appraised, but on the occasion of my 1959 visit to southwestern Finland, I saw some evidence of mortality that could have been due to disease, and the Russians have many records of tularemia in their muskrat populations (Tcherkasski, 1951).

A question that keeps recurring to me is: Do the Finns really have predator-prey relationships on their muskrat marshes that differ greatly from those studied long and intensively on the Iowa observational areas?

What, for example, is the basis for the emphasis that the Finns place upon repression of predatory enemies of the muskrats as a management measure (Artimo, 1949, 1952; Brander, 1951)? Specifically, just what is behind Brander's (1951) designation of canids as, next to man, the most serious enemies of muskrats because of their tendency to attack muskrats through the latter's biologically weakest point, winter habitations? In Finland, as in northern United States and Canada, the quality of habitations varies with location and construction material; similar types of freezing and water fluctuations occur, and I see no reason to believe that wintering security or lack of security should differ in comparable parts of the Old and New Worlds. Admittedly, I have no first-hand knowledge of canids and other predators or scavengers exploiting muskrats in Finland, but the Iowa areas have often yielded data that looked much like what the Finns described, yet which, in detailed analysis, proved to reflect something very much different from simple predation by foxes and minks upon a favorite prey animal. I have in mind the case history after case history of epizootics of the hemorrhagic disease in which responses of flesh eaters could have been so easily misinterpreted. Scent-hunting predators may be adept at smelling dead muskrats lying inside of habitations, and when these dead are dug out, eaten, and remains scattered, the signs certainly can resemble those of predation. Other faulty appraisals rather frequently arise through the propensity of sick muskrats to spend their last days or hours on top of the ice, wandering around or burrowing into the sides of lodges. When a predator takes one of these, the resulting sign is that of a direct and bloody kill that may not be further diagnosed unless one obtains enough of the carcass to reveal identifiable lesions.

Or, are the views of the Finns toward muskrat enemies but a carryover of the anti-"vermin" traditions that have long been strong in European game management? Or, have the Finns really observed more significant predation upon muskrats than I have? 
Brander repeatedly referred to a sensitivity toward disturbance shown by Finnish muskrats that far surpasses anything I ever detected in Iowa, South Dakota, and northern Minnesota - or ever heard of in the course of my travels over other parts of North America, including the Canadian North. He reported serious consequences to muskrats driven out of their lodges by horse traffic over the ice, muskrats becoming sufficiently affrighted to wander when disturbed by hunters, trappers, predatory enemies, or anything breaking into their habitations, and abandonment of lodges even because of noisy human activities in rowboats.

One possibility that comes to my mind is that such sensitive muskrats may have been very ill-situated, compared with the Iowa and South Dakota populations with which I have had the most experience. When I consider the trapping in lodges, the mink intrusions, and the variety of disturbances to which the muskrats of north central United States may readily adjust, I feel that there must be a most special reason for the Finnish muskrats behaving as described. Our north central muskrats may at times engage in movements for not wholly apparent reasons, but $I$ have seldom attributed any of this to disturbance by man, livestock, or predatory mammals, except when the muskrats were suffering from overpopulation tensions, acute food shortage, or drought exposure.

Brander did explain (conversation, May, 1959) that muskrats that had newly colonized an area were the ones displaying the greatest inclinations to move when disturbed. The importance that he ascribed to clams in the diet of the Finnish muskrats further strengthens my view that many of the Finnish waters offer muskrats poor habitat in which only a relatively few muskrats could be expected to live, conceivably whether they may be disturbed or preyed upon by enemies or not.

By the early forties, it was apparent, from articles and editorial comments in Svensk Jakt, that the muskrat had become a controversial animal among Swedish outdoorsmen, with opinions sharply differing as to whether introduction of the species into Sweden would result in economic benefits or a new pest problem. Then, the question of whether Sweden should or should not have muskrats became outdated in 1954. Velthuysen (1954) considered that the muskrat would sooner or later come over to Sweden across the Torne River and that it had already been reported as established within the Swedish boundary. Six months later, Liljeström (1954) definitely confirmed this report and added that the species had been established for at least a decade after illegal introduction into the Torne River Valley. Curry-Lindahl (1955, p. 102) wrote that the muskrat had spread through large parts of Norrbotten (through which the Arctic Circle runs) and also to islands south of Haparanda at the mouth of the Torne River. The 1955 range of the muskrat in Sweden appeared to be well over 150 kilometers in length along and adjacent to the Torne Valley.

The strongest muskrat population that $I$ found in Sweden was in 
the lower reaches of the Torne River and neighboring streams. Here, signs could be seen generally distributed about sluggish, vegetationgrown waters within a comparatively short radius - 50 kilometers? of Haparanda; my estimate for this local population was about 1,000. I was unable to find signs of the species elsewhere in this region during two days (mid-July, 1959) of stopping to investigate likely places along the roadsides, though the species was reported at the Pite River, about 150 kilometers southwest of Haparanda.

As muskrat habitats go, I would rate the best that I saw in the Haparanda area as only fair - similar, again, to those occurring in the Quetico-Superior area of Minnesota and Ontario. The landscape of many places in the lower Torne River is rather lakelike, with oxbows, islands, meadows, and other features in a wide, flat valley; but, unless the abundant growths of Equisitum are a staple sustaining food (which can be the case for $E$. fluviatile in northern Canadian waters), I hardly could see how the species could winter at all with no more food than it appeared to have. Yet, by its presence, it proved that it must be able to take care of itself passably well during long, cold winters.

The upper stretches of the Torne River that I saw looked still less hospitable. From the Torne River southward, muskrats spreading from their focus of relative abundance would have a wide zone of inferior or inhospitable environment to pass at the higher levels, across wide stretches of mountain and forest, and I am not sure how well they could spread along the coast, once they got away from the flatlands in the vicinity of Haparanda. Except for the human help that one has reason to suspect that they get illegally, they might well have remained essentially restricted to the waters of the Finnish-Swedish boundary for decades.

There are several places south of the Pite River where muskrats might get along fairly well if they reached them - extensive wetlands including marshes - and the Pite River is about a third of the way to Jämtland, the center of public agitation to introduce muskrats into central Sweden. Jämtland has some wetlands in which muskrats would find livable habitat, but in my opinion, it is much overrated as muskrat habitat by the enthusiasts. The muskrats could well do better in parts of Jämtland than in the Torne River, but I saw no place in Sweden where they could be expected to thrive as well as on the best North American marshes.

I am reluctant to make predictions as to the future status of muskrats in Sweden, but it would seem reasonable to expect something comparable to the situation in Finland, where the better marshes have good populations and where vast areas of inferior muskrat waters have few if any muskrats. Hornborgasjön-far down in southern Sweden - is the most attractive place from the muskrats' point of view that $I$ saw in any part of Scandinavia.

The drainage of marshes that has taken place in southern Sweden and the concentration of remaining water in open, vegetation-poor 
lakes has gone to extremes that I never saw over wide areas in North America. In the Kävlinge River valley of Skåne (where I did most of my field work during a six-month association with Lund University, 1958-59), marsh and lake waters had covered about 29 per cent of the surface 150 years ago, but by now the wet area has been reduced by artificial drainage to 3.4 per cent (Wolf, 1956; cited also in Rodhe, 1958). Rodhe considered this the typical fate of marshy areas in Skane. Granted that the muskrats sooner or later will reach all waters of the Scandinavian Peninsula that can support the species, I do not see how they would ever become sufficiently numerous there to be either a serious pest or a more than locally important fur resource.

\section{SOME COMPARISONS OF MUSKRATS AND MUSKRAT HABITATS}

It may seem surprising how little can be said of the living habits of any subspecies of muskrat anywhere in North America or Europe that cannot be said to some extent of the type subspecies, zibethicus, in its native or naturally acquired range.

There are differences. The reputed helplessness of rivalicius under ice (O'Neil, 1949) has no counterpart of which I know among the other subspecies, and some of the western muskrats of restricted geographic range apparently do not build lodges under any conditions. Both macrodon and rivalicius attain consistently higher densities in very shallow marshes or in meadow-like habitats than does zibethicus, but the latter may occur in great local abundance in similar places, as may also cinnamominus and osoyoosensis. In general, there is less difference between the habitats of zibethicus and macrodon in New Jersey coastal marshes than between those of zibethicus and rivalicius in Louisiana.

A greater tendency may exist on the part of macrodon and rivalicius to increase up to densities destructive of their food supply than on the part of zibethicus and other of the more northern subspecies - even though macrodon and rivalicius have decidedly smaller litters and have great expanses of some of the most food-rich marshes on earth.

Possibly zibethicus, with the rather special storage habits it exhibits on occasion in the Corn Belt and in certain duck potato marshes, may have a trait somewhat peculiar to itself, but genuine storage can occur in muskrat populations living outside of the range of zibethicus - in Saskatchewan, for example (Carter, 1922). The Louisiana subspecies seems to fall in a special category with respect to its avoidance of stream habitats, whereas all of the others may be frankly stream dwellers. Of the other subspecies living most nearly like rivalicius, macrodon on Maryland streams lives about as any northern muskrat would under like conditions.

Mountain or mountain-like habitats of zibethicus in eastern United States, northern Minnesota, and northern Ontario differ little in essentials from those occupied by albus and spatulatus in parts 
of the Canadian wilderness or from those of the real "mountain muskrat," osoyoosensis. The latter occupies a good deal of range that is much higher above sea level than any area in North America in which I know that zibethicus lives, but that does not prove that osoyoosensis has a unique specialization for high altitudes. At the edge of the Rockies, cinnamominus may get up just about as high as osoyoosensis and so, I think, may mergens and spatulatus, if comparisons between the subspecies be restricted to comparable latitudes and terrain. In its strongest habitats, osoyoosensis is as much of a marsh dweller as any muskrat.

Although zibethicus does not get near true deserts in the sense that osoyoosensis does - unless it now may in its new range in the U.S.S.R. - it certainly has had racial experience with droughts. For that matter, cinnamominus is a drought-tested subspecies if this can be said of any muskrat, not excluding from consideration the minor subspecies of the arid American Southwest.

Brackish-water macrodon and rivalicius notwithstanding, osoyoosensis has as much demonstrated ability as one might expect in a muskrat to live in a seaside or saline habitat. The Pacific Coast or the salt flats east of Great Salt Lake offer their own physiological obstacles to muskrats trying to maintain themselves, and one may think it astounding what the animals can tolerate and stay alive, yet the white-rimmed alkali lakes of the northern high plains must be no more congenial for cinnamominus during drought crises. Nor does zibethicus display any notable lack of tolerance when living in pollution-foul streams, ponds, and puddles.

At the southern end of its North American range, zibethicus is not exposed to winter conditions more severe than those to which rivalicius is subject, except insofar as the habitat of zibethicus is more marginal in the South than is that of rivalicius. At the northern end of its range, zibethicus may have to winter under several feet of ice. East-to-west extremes vary from a few inches of ice over macrodon marshes to alpine depths in the upper retreats of osoyoosensis. It may be that the muskrats of the American Far North do have more in the way of adaptations for wintering than do zibethicus, cinnamominus, or even osoyoosensis, though I know that the air temperature has fallen as low as 58 degrees below zero Fahrenheit in western South Dakota; and eastern Montana and northern Ontario have cold winters, at either high or low altitudes. The Torne River between northern Sweden and Finland surely is not one of the most hospitable of places for muskrats of probable zibethicus stock, with its long winters and a cold getting down to the vicinity of 50 below zero Fahrenheit. Lavrov's maps show considerable muskrat range extending north of the Arctic Circle in Siberia as well as in western Russia, and, I suppose that these muskrats of the Soviet Far North must also be largely of zibethicus stock. The runty albus in the Barrens near York Factory has its own problems of winter survival. Of the range of spatulatus, Soper (1941) wrote that in the Wood Buffalo 
Park "Ice normally appears to attain a maximum thickness of about 5 or 6 feet, though it has been known to reach seven feet at Great Slave Lake"; and above the Arctic Circle lie deep-freezing waters of the Mackenzie delta, in which life for the same subspecies has its restrictions.

Winter-killing of muskrats in northern wilderness and western high plains has many of the characteristics of the winter-killing studied in detail in Iowa. Whether the period of unendurable exposure or starvation lasted a day or three-quarters of a year, whether brought on by an accumulation of 5 inches of ice or by 5 feet or through extremes in air temperature of 15 degrees above or 50 degrees below zero, or colder, it reflected the state of the food, shelter, and unfrozen water available to the muskrats. Losses from droughts or losses from floods similarly had their community of aspects, whether in a stream running through a sagebrush semidesert in the western Dakotas or in the delta of the Saskatchewan River or in agriculturally lush central Iowa.

In other words, the muskrats, whatever the subspecies, live like other living things, where, when, and if they can, in any way that they can; and this certainly is true even in the South and Southeast where, as yet, marginality of range of macrodon, zibethicus, and rivalicius cannot in all cases be satisfactorily defined.

With recognition that we are concerned with essentially the same animal confronted by specific problems of survival differing according to locality and region, we may see that the status of the species in marginal and submarginal habitats becomes of fully as great interest as its status in optimum habitats. The desirability of learning more about why the muskrat or any other animal may maintain itself in a marginal habitat, and how the marginal grades off into the utterly uninhabitable, may at first glance seem merely of "academic" importance. The implications of marginal habitat may be much greater than that, however, insofar as even superb habitat may become, actually or in effect, marginal or worse in consequence of emergencies or deterioration. The fine differences between what a thin-spread, edge-of-range population can endure and what it cannot endure are not only scientifically informative but also contribute significantly to our practical understanding of populations. 


\section{Part 4}

Concerning Population Dynamics of the Muskrat 



\section{Chapter 15}

\section{Self-limiting Trends and Intercompensatory Adjustments in Muskrat Populations}

MaN HAS NO DOUBT OBSERVED throughout most of his thinking career that there must be limits to the numbers of animals able to maintain themselves in a given area at a given time. Malthus' (1798) essay on populations greatly influenced Darwin (1872) and can still be recommended (with reservations) to modern students. The final paragraphs of a review by Davis (1950) may here be quoted:

Malthus of course did not completely anticipate our present concepts about populations. He did not recognize the difference between densityclependent and density-independent factors. While he was dimly aware that social structure of the population was important he apparently did not consider the possibility that a change in social structure may result in a change in population in a given environment. . . Similarly, Malthus was not aware of the need of animals for space as such (territory) and neglected this limiting factor. Finally, Malthus did not clearly state the consequences of predator (disease) control as such. However, from his statements about the means of subsistence limiting the redundant population it is certain that Malthus realized that a reduction of the mortality due to predation would be matched by an increase in the mortality due to other causes in a stable environment.

In conclusion it may be said that Malthus shrewdly analyzed many aspects of the principles of game management. He found that the gain of a population was inversely proportional to the population and that mortality factors constantly act to keep a redundant population within its means of subsistence.

Malthus' views as to populations being limited by the means of subsistence seem to have prevailed in oversimplified form in scientific thought until about the time of Raymond Pearl - though awareness of the phenomenon of self-limiting territoriality had been shown by occasional writers long before Pearl and even long before Malthus (Nice, 1941). In his book on natural regulation of animal numbers, Lack (1954) certainly emphasized food as a basic limiting factor. It 
is wholly apparent that many academic people as well as the lay public continue to regard populations as increasing up to the limits of their food supply unless prevented by obvious types of mortality.

It may now be emphasized, without belittling the genuine influence of food and other environmental essentials on animal life, that something not improperly called self-limitation may also operate to prevent a considerable variety of natural populations from increasing up to - or even very near - the literal limits of their food supply.

Pearl's $(1925,1937)$ demonstrations that many populations tended to follow a sigmoid growth curve (the Verhulst-Pearl-Reed "logistic") focused much scientific attention on a major pattern in population behavior. Allee, Emerson, Park, Park, and Schmidt (1949, pp. 301-15) presented an instructive discussion of the logistic curve and its significance, together with some more recent examples; and still later, other authors, including Andrewartha and Birch (1954, pp. 347-97) further discussed the curve.

In my own treatment of data from both original investigations and the literature, I have usually learned less from plotting on coordinate paper the population changes against time (as one does in looking for evidence of the logistic curve) than from plotting annual rates of gain (or loss) against adult or breeding densities. On the whole, the more complete records from long-term studies of higher vertebrates reveal strong tendencies for spring-to-fall (or breeding to post-breeding) populations to conform to mathematical formulas that differ with species and areas but which for a given species in a given area may remain apparently unchanged for years at a time (Errington, 1946). At one extreme, very low breeding densities often show low rates of increase, about as one might expect from the discussion of underpopulations by Allee, Emerson, Park, Park, and Schmidt (1949, pp. 399405). Nevertheless, the lower of the breeding densities that still permit efficient mating and living relations tend to show the higher rates of increase.

Whenever it occurs, the lining up of a string of data points either along a curve of inverse gains in relation to adult densities or along the familiar logistic curve of population growth implies not only the self-limiting influence of the density factor but also compensating adjustments in rates of gain or loss and a stability of what Pearl (1925, p. 20) called the absolute base from which the law operates. Whenever the data points line up along neither curve in a definite way, the operation of something besides a density pattern may naturally be looked for.

\section{THE IOWA MUSKRAT DATA AND DENSITY PATTERNS}

In my work with the mainly stream-dwelling muskrats of Boone and Story counties in central Iowa, I have been impressed by the yearto-year extremes in population behavior.

First may be considered the spring and fall (pre-trapping) population levels of the muskrats over those parts of the Keigley's Branch 
and Squaw Creek drainages that were kept under regular observation from approximately the beginning of the Iowa muskrat investigations. Combined, these areas total about twenty square miles, with data on fall densities and rates of summer gain lining up as in Figure 15.1.

In the above treatment of data, the responsiveness of muskrats to patterns may show more definiteness for the twenty square miles considered as a single land unit than for most of the component areas separately, but the rates of spring-to-fall gain are still much less welldefined than for Iowa as a whole (Figure 15.2). However, if we just add the data from Goose and Little Wall lakes and vicinities to the data from the Keigley's Branch and Squaw Creek drainages, we get a much better conformity to what look like basic patterns for a 23 -squaremile land unit (Figure 15.3). For both figures 15.2 and 15.3, the upper series of clata points in the lower sections of the figures represent periods when the areas most nearly approached full habitability for the muskrats. Conversely, the data points lining up or grouped more in the lower left parts of both figures represent mainly the effects of drought years.

Although figures 15.2 and 15.3 have sufficient features in common to suggest capacities for adjustments of muskrat populations that may go far beyond local boundaries, it was not until the last decade of the field work along central Iowa streams that the magnitude of the upstream and downstream adjustments of late summer and early fall became apparent. I refer here to the orderly adjustments occurring in years of normal rainfall and stream-flow as well as during droughts.
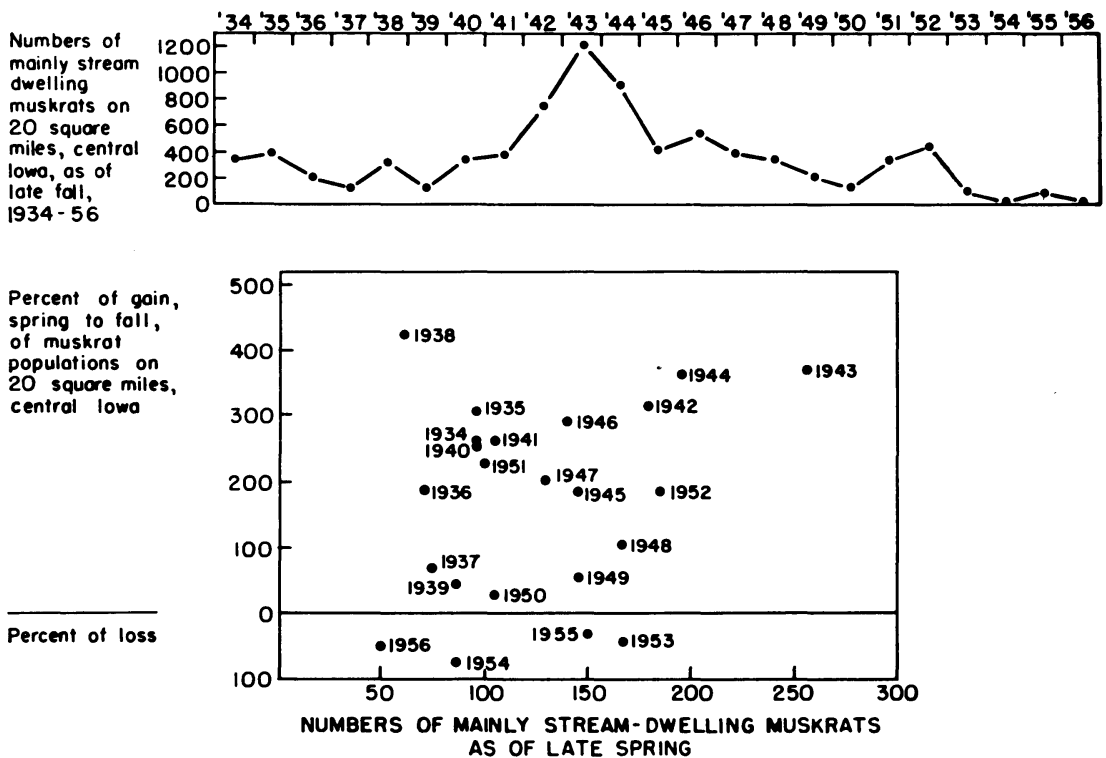

Fig. 15.1. Population changes of mainly stream-dwelling muskrats in central lowa, 1934-56. (After Errington, 1957-Cold Spring Harbor Symposia on Quantitative Biology.) 

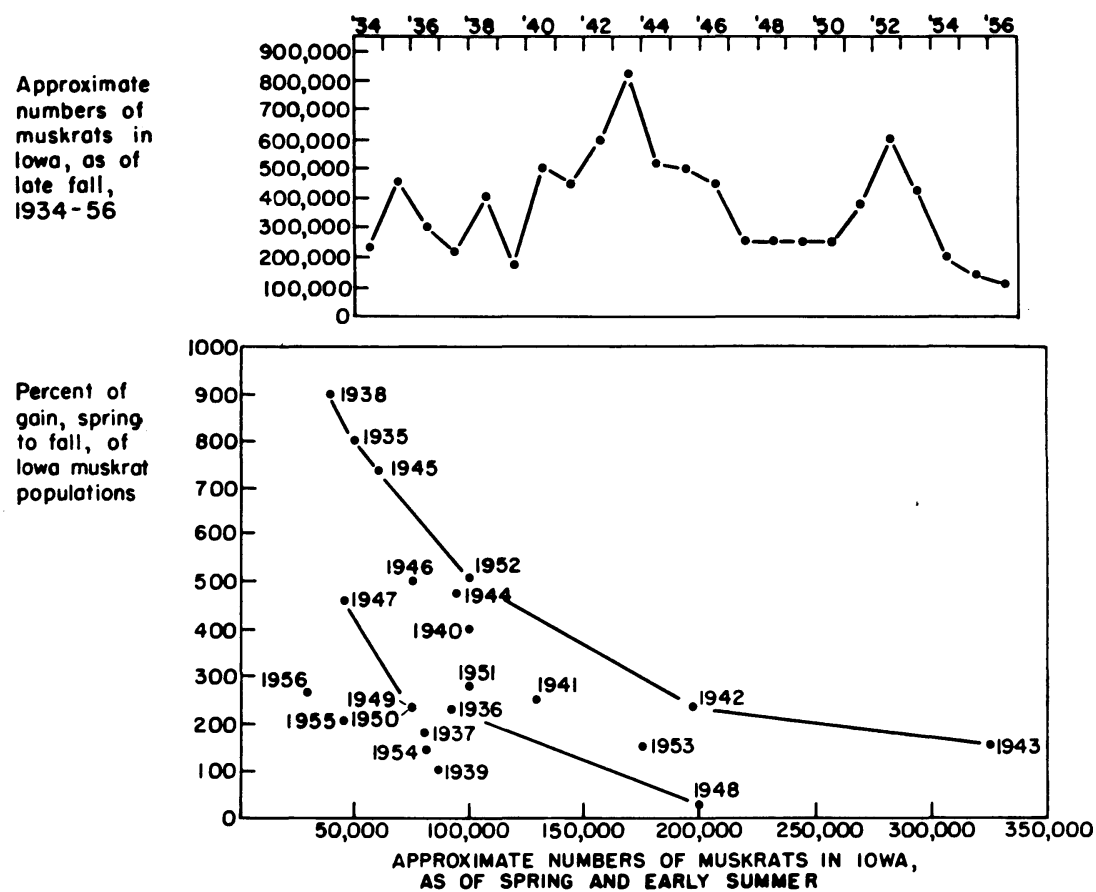

Fig. 15.2. Population changes of muskrats over the state of lowa, 1934-56. Connecting lines in the lower part of the figure chiefly indicate population responses during normal and drought years. (After Errington, 1957 -Cold Spring Harbor Symposia on Quantitative Biology.)

At first, as in the late summers of 1947 through 1950, these adjustments seemed to have been mainly downstream and in response to drought conditions. Except for a few upstream drifters, the muskrats gave the appearance of almost flowing downstream, following the last of the water. Then, it was rather surprising to find a notable amount of much the same sort of adjustments in 1951, a year of favorable water conditions. In 1953, the movements could have been precipitated by low-water stages, but in 1954, the muskrats clearly abandoned most of their stream habitats at about their customary time, despite the fact that substantial flows of water continued over the stream beds at the height of this period of adjustment.

In 1955, of 28 trails of individual muskrats that were traced along stream channels far away from places with which the animals could have been familiar, 21 led in upstream directions. Even so, there was no evidence of congregating in upstream habitats, and late fall observations indicated that a large proportion of the adjusting muskrats finally arrived at Skunk River. In 1956, I failed to trace the destinations of most of the adjusting muskrats along the central Iowa stream areas, though massing was discovered in late fall in one upstream area. This latter area was characterized by its attractive con- 
dition for muskrats. However, it did not look any more attractive to my eyes than many of the places that the muskrats had passed through or abandoned.

Changes in local food supply and in traditions of response of the muskrats were surely influential. I would say that the extensive postbreeding movements along watercourses during the past decade have been linked more with food than with water and that the greatest variable in sight has been in the utilization of ear corn by the local muskrat populations.

In some of the earlier years of the Iowa investigations, streamdwelling muskrats wintered at high densities, sometimes despite considerable drought exposure. The populations of those years, however, were corn-storers. It was routine behavior for muskrats to establish burrow systems next to corn fields and to pack their burrows with ear corn and to live far more sedentary lives than they did after the midforties.

By the early fifties, many stretches of streams were consistently occupied by highly productive breeding muskrats in early summer and

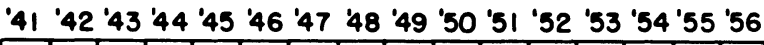

Numbers of stream- and morsh-dwelling muskrats on 23 square miles, central lowa, os of late fall, $1941-56$

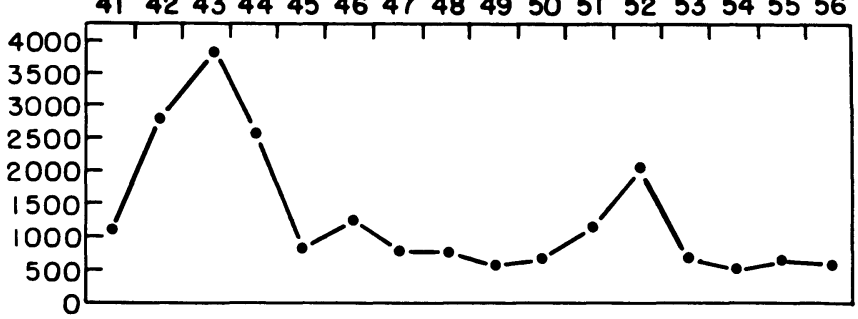

Percent of goin, spring to foll, of muskrat populations on 23 square miles, centrol lowa

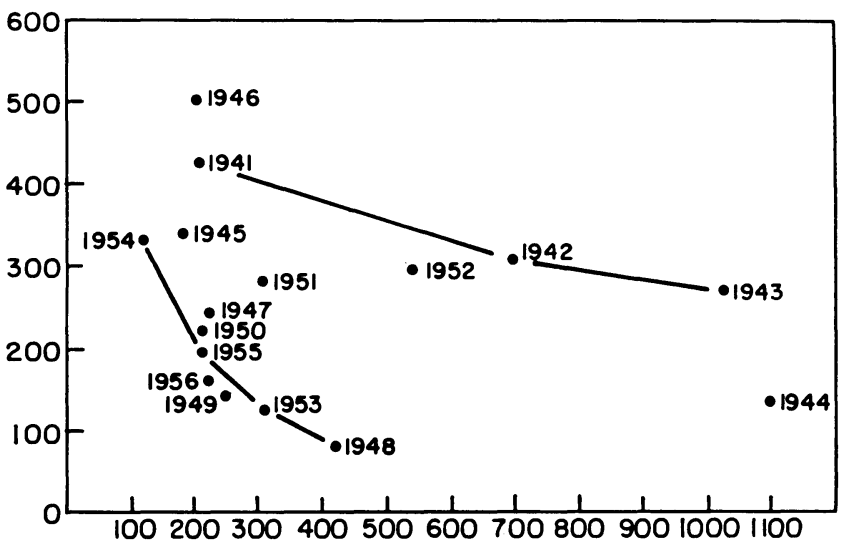

NUMBERS OF STREAM-ANO MARSH-DWELLING MUSKRATS ON 23 SQUARE MILES, CENTRAL IOWA, AS OF LATE SPRING

Fig. 15.3. Population changes of central lowa muskrats, 1941-56, all regularly observed habitats combined. The 1941-43 series of data points may be compared with those for the mainly drought years in the extreme lower left. (After Errington, 1957 - Cold Spring Harbor Symposia on Quantitative Biology.) 
as consistently muskrat-vacant by late summer, yet they had corn fields in as close proximity to the water as they had when they were favored retreats for the muskrats the year around. The differences were not in the presence or absence of corn fields but in whether or not the muskrats discovered and utilized the corn.

Without the corn, central Iowa stream habitats had scant attractiveness or habitability for muskrats during the colder months, though as habitats, they were satisfactory for moderate densities of muskrats from late spring through midsummer. From the standpoint of the muskrats, the corn fields that they did not visit added nothing to otherwise foodpoor habitats. In view of the regular raiding of corn fields and the storage of ear corn that in the thirties and early forties almost characterized the muskrats living along the stretches of central Iowa streams that later were regularly abandoned, it seems to me that decided changes in local behavioristic traditions occurred.

For all of what we still do not know about these late-summer and fall adjustments, they have given us a better understanding of the mechanisms behind the known tendencies of populations of the larger land units or combinations of units to conform to patterns. At times, such conformities were evident more or less irrespective of a wide range of local conditions and local behavior. Some muskrat populations remained essentially sedentary throughout the lives of their members, whereas other populations engaged in seasonal movements over astonishingly long distances. Exclusive of the cross-country wandering that the desperate and the geographically lost may have done, some of the movements of late summer and fall occurred along practically the whole length of small and medium-sized creeks. One may conjecture that migrants having inviting travel routes of great length - and nothing more attractive than the habitats they abandoned to cause them to establish living quarters on the way - may travel much farther than the movements actually traced along Squaw Creek and Keigley's Branch.

Of the three major marsh areas kept under regular observation in central and north central Iowa, Goose Lake was the only one having an outlet along which adjusting muskrats traveling upstream were likely to move - and fall movements along this outlet occasionally were heavy. Fall movements of stream-dwellers into Little Wall Lake had to be overland and, so far as I was usually able to judge, from a drainage ditch lying to the north. Field evidence suggested that the usual route of travel here was quite narrow, apparently to one corner of the marsh.

The third marsh, Wall Lake, being sufficiently isolated to preclude anything more than irregular discovery by cross-country drifters, has not been involved in the sort of counterbalancing with neighboring stream habitats to the extent that Goose and Little Wall lakes have been. It patently drew many muskrats from outside areas in both 1943 


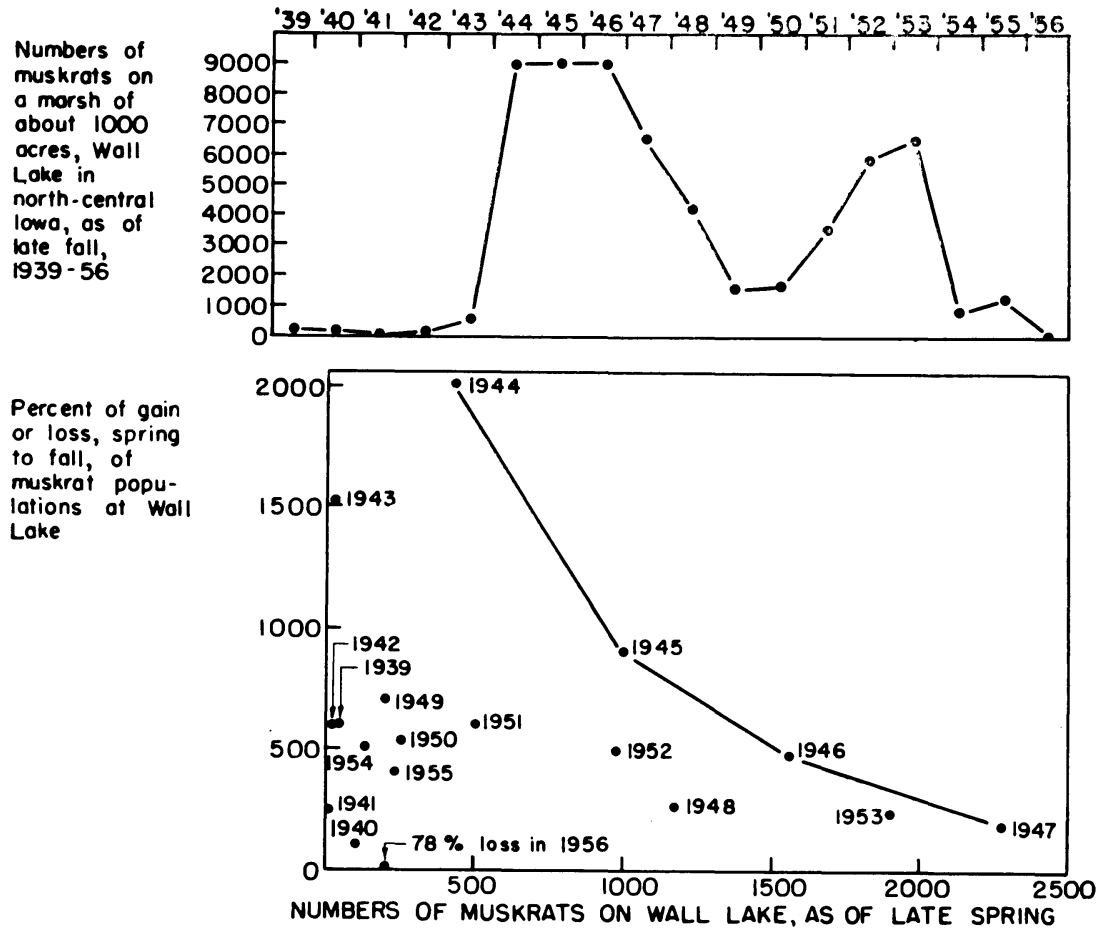

Fig. 15.4. Population changes of muskrats on a marsh in north central lowa. The upper series of data points - connected by lines - in the lower part of the figure represent the period when the marsh most nearly approached full habitability for muskrats. (After Errington, 1957 - Cold Spring Harbor Symposia on Quantitative Biology.)

and 1944. In 1943, the year of Iowa's peak muskrat population, muskrats went just about everywhere in the course of their postbreeding adjustments. In 1944, the over-all population of central and northern Iowa not only was still high but the exceedingly wet season also left an unusually great number of water connections to serve as travel routes for adjusting muskrats. But, for the other years of our records, Wall Lake has had muskrat populations that were essentially self-contained during the spring-to-fall periods for which data have been plotted in Figure 15.4.

As in figures 15.2 and 15.3 , the data points for spring-to-fall gains in Figure 15.4 lined up chiefly according to the degree that the marsh was in habitable condition. For most years, the fall population averaged about ten muskrats per acre of marsh having water covering the bottom, but this may not be correctly stated as a formula. In 1947, 1951, and 1952, the average was closer to fifteen per acre, and in 1957, the marsh was practically unpopulated, irrespective of its substantial amount of food, cover, and water. 


\section{THE IMPACTS OF EMERGENCIES}

The broad subject of adaptations and distribution of organisms is one of great complexity, and where the muskrat may live or thrive depends more than anything else upon the advantages afforded it by climate and habitat. Emergencies imply the opposite of advantages, and sometimes they have terrific impacts upon the muskrat populations affected.

For muskrat populations living under edge-of-range conditions in high plateaus, in isolated desert waterholes, in arctic or subarctic tundra, in the mysteriously unfavorable southeastern states - a minimum of resilience under the impacts of emergencies may be expected. When one of these muskrats dies, it is dead, and its death may mean one less animal in the population without any compensatory improvement of the chances of another one for living. Edges of range may often have many apparent vacancies that are to some extent habitable by muskrats yet perhaps seldom even discovered by them.

Well within its established geographical range, the muskrat may have much poor or marginal habitat - the brooks, the temporary field ponds, the out-of-the-way places where the species may now and then be found. Habitability of many of these places may vary with the year, so they have muskrats chiefly during years of general abundance. As the sorts of places into which overflow animals tend to drift, they are often sites of mortality involving large proportions of the muskrats taking up quarters. The existence of better habitats in the neighborhood of the marginal ones does not necessarily mean that muskrats may adjust to emergencies by leaving the poorer places for the better - especially if the better are occupied to capacity by intolerant residents - but it may be presumed that such adjustments stand somewhat more chance of being successful than would attempted adjustments on a mountain top or over a waterless plain.

Muskrat habitats are notably subject to changes, insofar as shallowwater zones are among the more ephemeral geological features. It is apparent that about the only thing likely to interrupt the deterioration of many glacial marshlands would be another glaciation, but of course, the different stages of filling and the unevenness with which filling occurs leave attractive waters for muskrats somewhere at almost any given time over the greater part of the muskrat's North American range. Oxbow marshes along large streams and delta marshes may come and go over short periods of years. Stream habitats, in their broader aspects, are perhaps as geologically permanent as any major habitats the muskrats have, though the flows in silted channels vary from year to year, and silting itself can progress to the point of practically making long stretches uninhabitable for muskrats. Soil erosion is an inexorable factor, even when occurring without human acceleration; and so also are climatic cycles and the constant adjustments of plant and animal communities, collectively.

Muskrats, being more dependent upon the intermediate successional stages occurring in shallow waters than upon either the earlier 
or the climax stages, would have limited prospects for attaining any long-term stability of population in their better habitats if only for the reason that the better habitats usually do not retain their superior food resources indefinitely. Heavy stands of cattails or bulrushes may persist for a series of years, to be killed out by high water, plant diseases, or insects, or simply to deteriorate from unknown causes. Then, particularly after low-water years, the emergent vegetation may again grow in profusion. Neither of the extremes represented by food-poor open-water lakes or ponds or by dry lowlands choked with vegetation is conducive to high populations of muskrats in northern regions.

O'Neil's (1949) descriptions of muskrat "eat-outs" and damage to marshes from concentrated feeding by wild geese in Louisiana surely bespeak drastic lowering of the habitat for muskrats of the areas affected. When an excessive muskrat population denudes an area of its better food plants, the plant growths may not recover for a long time, and the muskrats are left with little alternative except to decline. They may attempt adjustments by moving out of the denuded area, but their chances of successful adjustments are dubious unless they find suitable vacancies elsewhere. An extreme case of unsuccessful adjustment is afforded by the mass movements out in the desert away from Malheur Lake, as described in Chapter 13.

I have never known northern marshes to suffer anywhere near the damage from overuse by muskrats that seems to occur regularly in Louisiana, but the activities of carp seem to be very detrimental to some north central marshes. Rooting by hogs in dry or nearly dry marsh bottoms may eliminate duck potatoes, cattails, and other of the better muskrat foods. Cattle may damage a vulnerable marsh for muskrats by their trampling and feeding. The digging out of bank burrows by farm dogs falls in one of the lesser categories of emergencies but still is illustrative. In appraising the effects of these changes, consideration should be given to the question of how much remains of livable habitat in relation to the muskrat population after the damage has been done. With excellent areas of deep marsh remaining for low to moderate resident populations to live in, what happens to the shore zone may be rather immaterial from the standpoint of the muskrats. Disturbances or exposure of bank burrows may not impose any particular handicap on muskrats that can easily establish themselves in suitable places elsewhere in their home ranges. But, if a habitat is crowded to begin with and suffers pronounced deterioration from any cause, one need not expect adjustments to such deterioration to be fully compensating.

Human engineering may ruin or create muskrat habitat, depending upon what is done and where. The drainage of a fine marsh may be a virtually complete loss for the muskrats. If generally uninhabitable wetlands are drained, the new habitat offered by food-rich, wet ditches may represent gains for the muskrats. Flood control projects may result in a multiplicity of consequences - ranging from disastrous to highly beneficial - for muskrats. Some of the agricultural drainage 
that channels the water of small marshes into lakes are almost wholly detrimental to muskrats, in contrast with water manipulation for the primary purpose of muskrat management, as on the great "rat ranches" of and about the Saskatchewan River delta (Chapter 13). Irrigation diversions may lower the habitability for muskrats of original streams or marshes, create seepage marshes of varying quality, and sometimes make available to the muskrats new frontiers for expansion.

The lighter of the emergency losses suffered by muskrats may be easily absorbed in population adjustments at practically any time of year, especially during the breeding months. The drowning of a few animals in a local cloudburst, or as a result of some other special circumstance, is nothing compared with over-all effects of density on population patterns and usually may be thought to improve the life expectancy of the survivors. So also may be classed miscellaneous minor losses of accidental nature. A limited amount of drying of ditch pools, field ponds, and marshy shallows, of trampling of burrow systems by cattle, evictions through human agencies, and freezing of subsurface retreats may, of course, be of so little consequence that they could not affect populations appreciably even were the losses therefrom quite uncompensated.

It is true that the numbers dying during severe emergencies may be so great that almost no survivors remain. This is illustrated by virtual depopulation of large expanses of muskrat range in the North American Great Plains during the droughts of the thirties and by terrific winter-killing of muskrats under five feet of ice in northern Manitoba and Saskatchewan in 1949-50. Hurricanes may be drastically lethal to muskrats in southern marshlands. The net impacts of the more severe emergencies depend chiefly upon what happens to the habitat of the muskrats. Of the examples given in this paragraph, the droughts of the thirties were followed by a period of lush marshy growths in former open-water lakes, and the muskrat populations recovered with spectacular rapidity where breeding stock remained in improved habitat; but, over much of the "West River Country" of the Dakotas, the populations of marginal stream habitats did not recover in fifteen years. Presumably, once the crisis was over, the deepfreezing of 1949-50 did not affect one way or another the real attractiveness and habitability of the Canadian marshes. On the other hand, the southern hurricanes that flooded vast tracts of choice muskrat habitats with salt water sometimes did damage that would not be repaired naturally for many years.

The often deadly local emergencies studied on Iowa streams and marshes have shown wide gradations in net population effects. From the area case histories presented in Part II of this book, it can be seen that most observed crises suffered by the muskrats were in one way or another associated with droughts, some with floods, and relatively few with other causes.

At times, there may be some slight survival of muskrats in places all 
but losing their habitability, and a given place may prove to be more habitable than expected, such as the dry Northeast Marsh of Cheever Lake in 1940, the dry Christianson's Pond in the winter of 1943-44, and the remaining puddles in the upper part of the Keigley's Branch observational stretch in the winters of 1949-50 and 1950-51. Still, under conditions such as these, death or departure of the ill-situated muskrats almost become certainties if the emergencies last long enough.

Departure of muskrats from drought-exposed habitats may or may not function as an agency compensating for local reductions, depending in part upon whether the emigrants succeed in re-establishing themselves elsewhere without detriment to other muskrats. The movement of juveniles from the shallower to the deeper zones of Round and Cheever lakes in 1939 seemed to represent a satisfactory adjustment, as did the southward drift across the east side of Wall Lake in 1949. The pronounced October ingress into nearly vacant Goose Lake in 1950 of animals that had been moving along the watercourses offset some of the partial depopulation of stream habitats then going on. Much the same appraisal might be made of the ingress into the wetter central area of Cheever Lake, probably from Four-Mile Lake, in 1947. The late summer and early fall drifting of 1947, 1948, and 1949, from the shallower south half of Goose Lake into the north half, had its aspects of temporarily successful adjustments, though in the end the advantages were lost in the winter-killing that followed.

On the other hand, a great deal of the overland drifting away from drying marshes and stream beds in the falls of 1936, 1937, 1939, and 1940 was attended by conspicuous mortality and complications, en route or at the remaining waters about which the wanderers tended to congregate. The failure of the dam at Four-Mile Lake in 1944 surely had a real depressive effect on the population, without corresponding gains elsewhere. Lesser-scale reductions attributable to mere lowering of water levels in late summer occurred prominently in what may be called outlying waters in the central Iowa areas, as at the Rainbolt Ponds in 1942 and along Onion Creek during most of the years when the observed tracts were occupied by muskrats - along Onion Creek even during the most favorable years. But, in some years (as in 1941), the muskrats of outlying waters were often less affected by emergencies than were those of the ordinarily more attractive and habitable streams.

In 1943, floods in late July and early August probably killed young muskrats along Squaw Creek, but without real depressive effects, considering the top-heavy fall population that was reached anyway. Midsummer flood losses on Onion Creek in 1947 were evidently compensated by later production of young, until the biological advantage of the compensation was finally lost through drought exposure. The losses of early-born young muskrats of central Iowa streams in the May-June floods of 1942 and 1944 were offset biologically by com- 
pensatory reproduction later in the summer and by better survival of the late-born young.

High water brought about emergency conditions at Goose Lake in 1943 and at Little Wall Lake in 1944 primarily through destructive flooding of the once-splendid stands of cattails. The net consequences of this loss of food resources were pronounced, in terms of year-to-year habitability as well as for the duration of the initial crises. Superimposed at Little Wall Lake were a number of lesser emergencies, as when windstorms washed the occupants of the more centrally located home ranges ashore. There the evicted animals were forced into contact with intolerant resident animals, forced to frequent strange and dangerous grounds, or forced to leave the vicinity of the marsh as wanderers. Goose Lake had a lethal situation in the winter of 1945-46 when flooding temporarily evicted muskrats from safe quarters and increased their vulnerability to minks.

For a ditch near Wall Lake, the relatively benign effects of dredging upon some old burrow systems in 1941 (Area E in Chapter 10) may be compared with the trampling of lodges by livestock in the pasture slough near Cheever Lake in July, 1939 (Chapter 6). In the first case, the animals having partly functional burrow systems and a trickle of water adjusted to the upheaval of dredging to at least some extent, whereas those in less favored sites were evicted. The livestock trampling at the pasture slough evicted the muskrat occupants decidedly ahead of the eviction schedule shown by similarly dry but undisturbed shallows in the neighborhood.

The disturbance from dog-digging endured for weeks by some muskrats of the brooklike county drain in Tract F of the Squaw Creek area in August, 1942, and the extensive digging noted in 1938 at the Story City drainage ditch obviously had less lethal effects because of the continued presence of water. At Goose Lake, digging farm dogs did the muskrats more real damage when burrow entrances were dry than when the burrow entrances had water in them. In 1947, the dogs dug out and killed muskrats in dry lodges, whereas, in wet 1951, the muskrats were clearly able to adjust to a great deal of the dogdigging of the peripheral burrows. Still more illustrative, the annihilative fox pressure upon young muskrats of drought-exposed tracts of Wall Lake in 1940 and the frequently observed responsiveness of minks to newly available muskrat prey after the disappearance of protecting waters contrast with the usual security displayed by the muskrats living under nonemergency conditions.

In combination with the effects of emergencies and of disturbance of desperate muskrats by enemies (including man), we may have the factor of disease also operating to accentuate the deadliness of the emergencies, especially where it may be borne by drought-concentrated remnants.

\section{THE IMPACTS OF EPIZOOTICS}

The muskrat is doubtless subject to a very wide variety of more or less lethal infections. Infectious diseases known (or suspected on 
good grounds) to kill large numbers of muskrats on occasion include: (1) pathogenic fungi, including Trichophyton and Haplosporangium, (2) protozoa, including coccidia of the genus Eimeria, (3) bacteria of the genus Salmonella, (4) plague-group bacteria, especially Pasteurella tularensis, the causative organism of tularemia, and (5) the hemorrhagic disease of imperfectly determined etiology with which the Iowa studies have been concerned since 1943.

The "ring-worm" fungus, Trichophyton mentagrophytes, is known to occur at least in muskrats of Iowa (Errington, 1942b) and Maryland (Dozier, 1943), and there is no reason to think that it may not be quite widespread over much of North America. In Iowa, observed clinical symptoms have been restricted to very young animals, which would reduce the chances of its recognition in nature. Few people have occasion to handle very young muskrats compared with those handling adults, subadults, or "kits" during the fur season.

The highest incidence of infection noted in the Iowa studies was at Round Lake. There, 35 or 9.6 per cent of 364 litters handled during the summers of 1935, 1936, and 1938 suffered from disease attributable chiefly to this fungus. Quoting from Errington (1942b):

Ninety-eight . . of 134 members of infected litters were recorded as contracting the ailment and, of the $98,90 \ldots$ apparently died. In general, incidence and severity of infection alike rose as the breeding season (mid-April to late August) progressed. The population significance of the disease, however, was conditioned by intercompensatory trends both in reproductive rates of the adults and in loss rates of the young. Not only were some losses of young - from disease as well as predation and miscellaneous agencies - offset by prolongation of breeding and production of extra litters, but, under given circumstances, losses of young through intraspecific friction had ways of increasing about in proportion to the extent that other types of losses diminished.

Jellison's (1950a) report of heavy infestations of Haplosporangium in muskrats near Charlo, south of Flathead Lake in northwest Montana (Appendix $M$ ), arouses currently unanswerable questions as to how serious this disease may be as a population depressant, either locally or throughout western North America, if not elsewhere.

Typical fungus cells were found in 23 sets of lungs, or in 18 per cent of the [ 126 ] animals [obtained, December 6, 1949, from fur trappers ]. Infestations varied from single cells to almost complete consolidation of the lungs by masses of fungi and their surrounding tissue nodules.

Parasitism of muskrats by coccidia has long been known, but the evidence suggests that this ordinarily is of little consequence to the muskrats. Under special circumstances, however, coccidiosis may attain greater severity, notably, as Shillinger (1938) indicated, during periods of low water.

The coccidial oocysts passing from the digestive tract with the feces of affected individuals become very numerous in the mud of the runways and former canals frequented by the animals. Massive infestations develop, and great 
mortality has been noted after several weeks of drought on a marsh. Trappers report a decrease of three-fourths in the muskrat population within a few weeks from this cause.

The latter certainly hints of coccidiosis in epizootic form, but the population effects thereof may not be clearly dissociated from other effects of drought or possibly other diseases.

The long history of paratyphoid infections in mouselike rodents (Elton, 1942), the substantial incidences of carriers reported for certain populations of Norway rats in the United States (Meyer and Matsumura, 1927), and Chappellier's (1933) advocacy of the use of artificial cultures in controlling muskrats in France should quite prepare a reader for reports of Salmonella in free-living muskrats of either their original North American range or their new range in Eurasia. In fact, the first really good specimen obtained as the muskrats started to die of epizootic disease at Goose Lake in 1943 yielded a fine culture of $S$. typhimurium, to which organism was attributed the general dying that followed on that marsh until it became clear from continued study that such could not have been true. Armstrong (1942) found S. typhimurium in Maryland muskrats during a period of mortality, but Dozier (1947) considered the main decline due to an unidentified disease. At any rate, Salmonella can occur in muskrats, whether or not it may be responsible for large-scale mortality or population depression.

The plague-group bacteria include a number of organisms of proven or possible significance in the epizootiology of muskrats. In a mimeographed report on Minnesota wildlife disease investigations for May, 1935, Green and Shillinger referred to their previous isolation of Pasteurella pseudotuberculosis from two muskrats; and Green had once told me (about 1933?) that the collapse of a top-heavy muskrat population of a big marsh in south central Minnesota may have been due to this disease. Despite the high degree of infectiousness of pseudotuberculosis noted by Green and Shillinger in a variety of animals and their feeling that "it would appear to play an important part in the destruction of wild life," I know of no other report of its occurrence in muskrats.

Neither do I know of any actual die-offs in muskrats that were due to Pasteurella pestis, or plague, though sylvatic plague is established in western parts of the muskrat's range in North America (Miller, 1940), in

ground squirrels, marmots, prairie dogs, tree squirrels, chipmunks, several of the native rats and mice, and the cottontail rabbit. ...

Sylvatic plague occurs periodically in epizootic form, with very large numbers of rodents dying of the disease. This has been noted in every area where sylvatic plague occurs. As in rats, the infection is transmitted from one animal to another through the bite of fleas, and many observers believe that a flea may retain its infection and transmit it a considerable length of time after 
the host has died. . . . It appears as if sylvatic plague may exist in some rodents as a latent infection, and that those rodents act as reservoirs of the infection which occurs in an epizootic form only when the resistance of the rodent population is lowered.

Holdenried's experience with plague in California ground squirrels (Evans and Holdenried, 1943), along with preliminary accounts of the epizootiology of the hemorrhagic disease in Iowa muskrats, gave him the basis of the following comparative statements (letter, August 9, 1950):

Both diseases under proper circumstances seem to be efficient in reducing the host populations. Both diseases seem to vary tremendously in virulence. Another similarity is that there may occur times (frequently of several years duration) when it is very difficult and even impossible to demonstrate its presence; yet, when conditions are right, up it flares in its former destructiveness.

The near absence of fleas on muskrats (Fox, 1940, p. 37) must confer some protection against plague, but considering possible ways of transmission other than flea bites in an area having the disease established in its rodents, I certainly would not be surprised to learn of the finding of plague some time in muskrats of western United States. The related Pasteurella tularensis can sweep through populations of muskrats and beavers at times when transmission through arthropod vectors would be most improbable (Parker, Steinhaus, Kohls, and Jellison, 1951).

According to Parker, et al. (1951), spontaneous infection of muskrats by tularemia was first recognized by R. G. Green and J. E. Shillinger. The specimens came from northeastern Iowa (Allamakee County), and from Green and Shillinger's report, it may be seen that transmissions of tularemia to laboratory animals were obtained from two of the five muskrats necropsied. These specimens were submitted after death during what may have been a considerable die-off in southeastern Minnesota as well as in northeastern Iowa in late October and November, 1933, but in my opinion, it is far from certain that this die-off took place even mainly through tularemia. The hemorrhagic disease is also known to kill muskrats on a variable scale in the area, and both tularemia and the hemorrhagic disease are known to occur over such a great deal of central and west central North America that their impacts on muskrat populations are difficult or impossible to dissociate accurately. Tularemia has inflicted the severest detected losses on muskrats of western United States.

According to Parker et al. (1951), tularemia was known to occur in muskrats in Maine, New York, Ontario, Indiana, Michigan, Wisconsin, Iowa, Minnesota, Manitoba, Alaska, Montana, Idaho, Wyoming, Washington, Oregon, Utah, and Nevada. (It also occurs, to my knowledge, in Saskatchewan, on the Cumberland Lease of the Hudson's Bay Company.) To quote from the discussion section of these authors: 
The localities and streams in Northwestern United States in which either beavers or muskrats or both are known to have died within the period covered by this report [1942-50] lie within an area which includes central and western Montana, northern Wyoming, southern Idaho, northern Utah, and most of Oregon. That tularemia was at least partially responsible for fatalities in Montana, Idaho, Wyoming, Utah, and the Klamath Lake region of Oregon is indicated by the recovery of $P$. tularensis from dead beavers or muskrats, and/or the occurrence of human cases resulting from skinning or handling one or the other of these animals trapped or found dead in the streams concerned.

Surprising contaminations of natural waters with $P$. tularensis have been reported from the western states (Jellison, Epler, Kuhns, and Kohls, 1950), and Parker, et al. (1951) summarize:

In general, the results and data gained from the field observations and laboratory experiments indicate that water and mud contamination, and the occurrence of tularemia in muskrats and beavers are wide-spread phenomena in the Northwestern States. Water and mud contamination may be present at any season of the year and may persist for at least 16 months. It is improbable that persistence of contamination can be attributed to factors resident in land-frequenting animals. Present information suggests that the factors governing persistence are resident in the water or mud or both, and suggests the hypothesis that the organism multiplies in the water-mud medium.

The epizootiology and population effects of muskrat tularemia observed by the U.S. Public Health people in the West are well illustrated by two publications. Jellison, Kohls, and Philip (1950) estimated the 1950 spring mortality at over 500 muskrats for a marsh bordering Utah Lake west of Provo, Utah. In June of that year, one marsh had only two muskrat lodges where it had had dozens in previous years. Prior to this die-off, local trappers had seen only an occasional dead muskrat in the course of many years of experience. Then, from the comprehensive bulletin by Parker, et al. (1951) on tularemia in muskrat waters of northern United States the following may be quoted:

Of 668 guinea pigs used to test water samples from the Cattail Creek area during the warmer months of June, July, and August, 1948, 168 died of tularemia. ... Of 848 guinea pigs used to test water samples taken from September 1942 through March 1943, 645 died of tularemia. [ This work was done on an area of which it had earlier been written: "No muskrats were present after this date [March 16, 1942] although 60 had been trapped in the marshes during the preceding year." Also: ] Hundreds of muskrats along the course of Gird Creek died during the early months of 1943. . . .

The recoveries of $P$. tularensis reported above and in earlier sections of this paper convey no adequate idea of how extensively the beaver and muskrat populations of the north half of the Bitter Root Valley were affected by epizootic tularemia during the period covered by this report, especially during the winter of 1942-43 and the following spring when the populations of these animals were virtually annihilated in numerous localities. Reports of dead beavers were numerous and some trappers reported having seen hundreds of dead muskrats. The assumption that the deaths of these animals were at least in part due to tularemia is supported by the occurrence of at least 
eight cases . . . among local trappers who had skinned dead muskrats. River sloughs, marshy areas, ponds along the courses of creeks, and other habitat areas known to have been populated by numerous muskrats in the fall of 1942 and the early winter of 1943, and marked for trapping operations in the spring, were found completely depopulated when the trapping season opened in March. It is probably safe to assume that deaths of muskrats from tularemia numbered in the thousands and those of beavers at least in the hundreds. . . .

It is apparent that late in 1942 and early 1943 considerable numbers of beavers and muskrats died in ... . [ Big Spring Creek, central Montana ] and its tributaries. One report stated that " 1,500 dead muskrats were found" along a few miles of the main creek above Lewistown between March 1 and 24, 1943. Early in the same month a trapper reported that he found more dead beavers than he caught live ones. . . The local game warden has informed us that most of the tributaries south of Lewistown were populated to capacity with beavers and muskrats prior to the epizootic under discussion and that the loss approximated 80 per cent. . . .

Information from various sources, including a questionnaire sent to over 2,000 trappers, indicates that beavers and muskrats have been found dead in at least 150 Montana streams in 40 of the 56 counties during the period 1939 to March 1943. While smaller streams predominate, all the main rivers are included. For some streams there have been reports of dead animals having been found only in restricted areas, while for others there are reports that animals have been found dead over long stretches of the water courses and that in some instances mortalities occur nearly every year. On the other hand, men who have trapped along certain streams for many years report never having found a dead beaver or muskrat.

Such a range of variation in mortality would insure much variation in population effects of tularemia, even if we ignored compensations in loss rates. The data available from outside Iowa give us very limited grounds for appraisals of the intercompensatory trends that may exist in the more severe disease losses of any type, but the tularemia losses in western muskrats surely seem to have their population counterparts in the hemorrhagic losses we have studied in detail in Iowa.

The disease entity designated in this book as the hemorrhagic disease of muskrats is referred to in the literature and veterinarian's reports chiefly as "Errington's disease" and may possibly occur over the entire occupied range of muskrats. The chief publications that have so far come out concerning this disease are those of Wisconsin workers (Lord, Todd, and Kabat, 1956; Lord, Todd, Kabat, and Mathiak, 1956).

Epizootics positively traced or attributed on good circumstantial evidence to the hemorrhagic disease have been reported from, in addition to Iowa and neighboring states, the marshes of Maryland and other states of the central Atlantic Coast, from Michigan, Ohio, and Ontario, from the Prairie Provinces and northwestward to the Mackenzie delta, from British Columbia to southern Oregon and eastward through Montana, Idaho, and Wyoming. I do not know if it occurs about wherever tularemia does but suspect that it does, including California, Nevada, Utah, and Colorado. No proof of its occurrence in the coastal marshes of the Gulf States seems to exist so 
far, but those marshes have had extensive die-offs of undetermined nature, some of which might have been due to hemorrhagic disease. Apparently, no proven cases of the disease have been recognized in the muskrat's new range in Eurasia.

Outside of Iowa, the most sweeping recent epizootics in muskrats that were assigned to the hemorrhagic disease have been at Malheur Lake in southern Oregon, in parts of Montana, Idaho, southern British Columbia and Alberta, in the Mackenzie River Delta of the Northwest Territories, in the Saskatchewan River Delta of Saskatchewan and Manitoba, in the marshes south of lakes Manitoba and Winnipeg, in North Dakota, eastern South Dakota, and the Nebraska Sand Hills, in southern and northeastern Minnesota, east central Wisconsin, eastern Michigan, southern Ontario, northern Ohio, parts of New York and Pennsylvania, and in the brackish marshes of Maryland, New Jersey, and Delaware. Some of these epizootics have been of relatively short duration; others have dominated muskrat populations to the extent of allowing little population recovery for years.

Once a deadly epizootic of the hemorrhagic disease gets started on a marsh, its course may be quite unpredictable. It may depopulate the whole area of muskrats, leaving no survivors, and it may do this either in cold or warm weather. It may depopulate only part of a marsh, then inexplicably subside for weeks or for years. It may advance over a marsh on a single front or on several fronts. It may or may not advance in several places simultaneously. Animals may die locally now and then without real epizootics getting started. Some areas or parts of areas in a region may appear essentially free of infection and others may be saturated with it, but freedom from infection should never be thought to be absolute, in view of the known inclinations that diseased muskrats may show for wandering. The hemorrhagic disease probably gets around ultimately about wherever there are muskrats, however much its manifestations may vary after it gets there or however long it may remain a lethal agency.

The many years of detailed studies of the hemorrhagic disease on central Iowa streams and at Goose Lake, Little Wall Lake, and Wall Lake have yielded data that surely must typify much to be expected of the disease over the geographic range of the muskrat. The known die-offs, occurring in such widely separated parts of North America as the Malheur marshes of Oregon, the Sand Hills of Nebraska, the marshes south of lakes Winnipeg and Manitoba, the Saskatchewan River Delta, the marshes of the Lake States and those of the East Coast are so similar to those of the closely studied Iowa areas that it may be assumed that the findings from the Iowa studies probably apply to these other places, also.

The best Iowa example of severe, locally uncompensated disease mortality is from the first real study of a hemorrhagic epizooticthe collapse at Goose Lake in fall and winter, 1943-44, with no evidence of any muskrats surviving on the marsh. Not only did the 
disease leave the marsh depopulated after that epizootic but it also impaired the habitability of the marsh for muskrats for the next several years because of the thorough "seeding" of infection that took place during the die-off. However, the population effects of the disease mortality on very much lower populations of succeeding years are not so easily appraised. Of what real signficance was the annihilative disease mortality of the summer of 1946, when fall ingress brought back the population to about what seemed to have been the current supporting capacity of the marsh for muskrats? Or, the partial subsidence of the epizootic of 1947 , only to leave the survivors to winter-kill? But the depopulation of the north half in the fall of 1944, the substantial losses of the central part in the fall and winter of 1945-46, and the dying in scattered places in the fall and winter of 1946-47 almost certainly resulted in a net lowering of the numbers of muskrats wintering, whether or not the habitat was actually filled to capacity by breeding animals again in the spring.

At Little Wall Lake, the population effects of the sweeping spring and summer epizootic of 1945 seemed to have been quite well offset through fall ingress, and by winter the marsh may have had about as many muskrats as could have been comfortably accommodated. The epizootic at Little Wall Lake having the clearest population effect was that occurring in the summer of 1951, and this certainly did leave fewer muskrats present by late fall than should have been there otherwise, thus bringing about a reduction of the muskrat population at least by half. On the other hand, the dying of about 200 (or far more than survived) in the spring of 1947 still left a fair breeding stock for the marsh in its existing condition.

Likewise, the numerically severe losses on most of the disease-swept parts of Wall Lake in the spring of 1948 left a great adequacy of breeding stock for the marsh as a whole. Except for the parts dominated by a continuing warm-weather die-off, even the depleted tracts soon refilled to capacity. This afforded a good example of losses substituting for each other within the framework of a larger pattern. But the epizootic that did continue kept an otherwise suitable tract effectively depopulated during the breeding season, and the spreading autumnal die-off of the same year among animals otherwise favorably situated had a net depressive influence in terms of the population present by freeze-up.

The 1949-50 losses at the main Wall Lake disease foci may not have done much more than to have given the populations a better fit with respect to the drought-restricted carrying capacity of the marsh in 1949 and 1950. In 1951, when Wall Lake was in excellent condition and the survival rates of young were very high, the spring losses of adults through disease probably did result in some net lowering of the population present by fall, if only through reduction of the numbers of young born in a habitat that was far from being filled to capacity with the species. 
The extensive population adjustments frequently shown by muskrats of the central Iowa stream habitats greatly complicate efforts to appraise population effects of disease mortality. A big question to consider is whether declines in some tracts were or were not counterbalanced by gains in others. Disease losses of central Iowa streamdwelling muskrats appeared to have had as much net influence on population levels in 1945 as in any single year of investigation, with the possible exception of 1949. The disease losses suffered by muskrats of the stream habitats during late summer and fall of 1949 substituted in part for drought losses, and in some places such as the Story City ditch, it may be judged that the muskrats probably would not have gotten along much better if the habitat had been diseasefree. In contrast, the disease was quite evidently depopulating long stretches of Skunk River south of Cambridge in a way scarcely suggesting substitution phenomena or any sort of compensating gain.

Numerically light disease losses may have their confusing aspects. It is hard to assign much population effect to the dying of a muskrat here and there over the observational areas, when nothing like a sweeping epizootic may be in progress. Yet, when only a small proportion of the animals infected may be dying, when light mortality may belie widespread prevalence of infection, then may we wonder about the lethal potentialities of seemingly rather innocuous infections. Considering the thoroughness with which Wall Lake appeared to be "seeded" with hemorrhagic disease by the fall of 1951 - even though very few muskrats were actually dying - might not deadly epizootics be expected there if for any reason the collective resistance of the population were drastically lowered? 


\section{Chapter 16}

\section{Predation and Muskrat Populations}

IN THIS CHAPTER, I shall try to avoid unnecessary duplication of subject matter and discussions already published (see especially Errington, 1943, 1945, 1946, 1954b, 1956; Errington, Hamerstrom, and Hamerstrom, 1940; Errington and Scott, 1945). I shall here consider what, if any, are the population effects of predation upon muskrat populations. In my view, population effects of predation cannot be arrived at by merely counting the numbers of prey animals killed. Unless a prey population is reduced by predation below the levels that would evidently be reached or maintained in the absence of predation, I do not consider that the predation has population effects on the prey.l

ConventionaT ideas as to population effects of predation are frequently erroneous because of unwarranted assumptions. A standard thought-pattern is that if a predator kills a prey animal, the prey population must then be lower by one animal than it would have been had the predation not occurred. This would seem an obvious conclusion, but a great many natural relationships do not work out in ways that are always obvious or predictable.

Any conclusions as to the population effects of predation require critical appraisals of the factors conditioning predation, understanding of the circumstances promoting capture of prey by predators, detailed information on just what individuals of prey populations are most vulnerable to predation, and most important, long-term data on basic patterns of the prey populations living in definite areas hunted over by predatory faunas of varying densities, habits, and prowess. 


\section{HAZARDS OF USING DATA TABULATIONS IN APPRAISING POPULATION EFFECTS OF PREDATION UPON MUSKRATS}

I do not mean to imply that tabulated data on muskrat populations cannot be used advantageously. Accurate and voluminous data on reproductive and mortality rates may indeed be extremely useful - provided that no greater population significance be ascribed to them than they have, that no undue concreteness be assumed for values that keep changing in reference to each other. Tabulated data may not, in themselves, insure the proper appraisal of the conditioning effects of values upon the meaning of other values.

There may be, for example, little real definiteness in a figure on reproductive potential or number of young produced by a muskrat female or a population sample. Extremes of underpopulation and of overpopulation, alike, may be manifested by decided irregularities in the reproductive performances of an area's muskrats. With males scarce or poorly distributed, inefficiencies in mating may result in many females conceiving only once or remaining unbred during a breeding season. With disturbances and complications of living accentuated by top-heavy densities, breeding may terminate several weeks or even two or three months ahead of the normal seasonal schedule. Or, populations of females either living in somewhat (not grossly) underpopulated habitat, or those losing heavily of their earlyborn young, may continue breeding much later in the season than those having good success in rearing their early-born young - even conceiving twice as many litters during the breeding season as their counterparts living under acute population tensions.

The latter phenomena emphasize the linkages between reproduction and mortality that can introduce error into calculations from tabulated data. Mortality may not have anything even suggesting a net depressive role in those cases where it serves to stimulate reproduction, more young being born simply because more die. This sort of compensation occurs widely and influentially among mammals and birds. Whether appraisals relate to a litter of young muskrats killed by a mink or dead of disease, or to the loss through floods of half of the young born to a whole population of muskrats, the possibility of compensatory reproduction should never be overlooked.

Mortality data may be tabulated on the bases of about anything from local investigations to continental averages. If we try to consider separately the various categories of muskrat mortality, we find ourselves confronted by values that, when expressed numerically, operate more along a sliding scale than after the manner of gradeschool arithmetic. They may or may not interact predictably with each other. A value assigned to a mortality factor that merely substitutes for another - a frequent occurrence - is not the same as one that exerts a bona fide depressive influence on the population.

What, specifically, would be justifiable grounds for rating mink predation numerically? Mink predation has in the north central 
studies accounted for more muskrats than predation by all other native predators together, yet it appeared but to have taken the place of losses from other agencies that, in the absence of minks, probably would have done about an equal amount of eliminating. Suppose that it were demonstrable - and under some conditions it might be - that mink predation increased (or its lack decreased) the total mortality suffered by a muskrat population, we can still find ourselves wondering how to weigh compensatory reproduction in the situation.

Of further bearing upon the matter of how seriously mortality figures, per se, should be taken are data on predation by canids. Although the numbers of muskrats killed by members of the dog family added up barely to a modest fraction compared with the number killed by minks, canid predation could have greater net effect on muskrat populations exposed to it. The distinction here is that enterprising, adaptable, and occasionally selective canids tend to be more capable of tactics permitting them to cut into populations that otherwise would not be vulnerable to wild enemies. Still, canid predation does not invariably fall in a class apart from general predation. The ordinary red fox, for example, may reveal little more originality in its day-to-day hunting than may the ordinary mink - or the ordinary cat, the ordinary horned owl, or the ordinary higher vertebrate of any species responding mainly to the chance availability of whatever it may recognize as food.

Man can be by far the most efficient of predators upon muskrats, but the population effect of even his predation may not be satisfactorily reckoned merely in terms of the numbers of animals he kills. Let us suppose that he depopulates hundreds of acres of excellent muskrat marsh in a couple of weeks' time, killing hundreds or even thousands of muskrats in so doing. How much of a biological impact would this represent? In the event of the human exploitation taking place in the autumn and leaving the best part of the marsh muskrat-vacant for many months, the mortality could be largely noncompensatory for that period. Perhaps because of the continued severity of human exploitation, the marsh might remain underpopulated, or virtually uninhabited by muskrats for years. That would have population significance. On the other hand, the depressive influence of brief though sweepingly lethal exploitation may later be more or less nullified if the depopulated tract functions as a refuge for otherwise insecure or doomed population overflows from surrounding areas.

\section{GENERALIZATIONS AS TO PREDATION BY MINKS UPON IOWA MUSKRAT POPULATIONS}

The mink has been both the outstanding nonhuman predatory enemy of the muskrat on the Iowa study areas and one studied with special care throughout the investigations. For consideration of the more technical aspects of the Iowa findings on mink-muskrat re- 
lationships, the reader may be referred to Errington (1943, 1954b).

From the latter publication the following conclusions are quoted as to categories of mink predation upon muskrats:

(a) Adult muskrats having regular home ranges on Iowa areas during the breeding months were practically safe from mink predation as long as their habitats remained in good condition. However, when put to overwhelming disadvantage, as through drought exposure, these same muskrats could suffer severe mink predation, to the extent of local annihilation in extreme cases.

(b) For adult muskrats that did not enjoy the normal security of bona fide residents during the breeding months, severity of mink predation was mostly a matter of the larger minks encountering land-active muskrats that were neither able to defend themselves nor to escape. Habitual transients of late spring, the surplus individuals that are attacked and injured by defenders of established territories and driven into the poorer grades of environment, had a tendency to congregate along the edges of marshes and lakes, directly in the lines of travel of minks.

(c) Mink predation upon young muskrats during the breeding months could be heavy whenever circumstances made large numbers vulnerable to predation. The main factor other than drought exposure to promote predation losses was overpopulation of habitats by the muskrats themselves. Minks preyed upon overproduced young muskrats particularly when the latter were forced into hazardous ways of life in consequence of attacks of other muskrats, as when forced ashore from the crowded wetter parts of marshes. Infection by a fungus skin disease (Trichophyton mentagrophytes) was another factor predisposing victims to mink predation. Young muskrats of well-situated populations ordinarily were not subject to much mink predation; many substantial muskrat populations having physical and psychological odds in their favor lost few or no young to minks during entire breeding seasons, the presence of even high densities of minks in their midst notwithstanding.

(d) Mink predation upon muskrats during the post-breeding months of late summer and fall tended to be negligible unless droughts, storms, etc., brought about crises, or large numbers of muskrats started wandering crosscountry or invading habitats already occupied to capacity by other muskrats. Although these may be among the drier months of the year, an abundance of food combined with diminished breeding-season tensions often meant very favorable living for the muskrats. Furthermore, with most of the natural "shaking down" of population surpluses having already taken place by late summer, survivors had rather good prospects for continuing to survive for a time.

(e) Early-winter mink predation upon muskrats tended to be light and sporadic and centered upon the homeless, the restless, and the droughtexposed.

(f) From mid-winter through early spring, any sinking of frost lines that sealed off the food supply of muskrats in the shallower habitats and made the muskrats increasingly subject to general winter mortality also made them increasingly subject to mink predation. When muskrats frequently or regularly came out on the surface of the ice or snow to seek food in cold weather, some minks could kill them in large numbers. Late winter mink predation was often centered upon muskrats becoming restless or forced out of secure wintering quarters with the approach of the muskrat breeding season. The special targets for this predation were the individual muskrats that kept coming out on the ice during thaws, weeks before the beginning of the real spring dispersal. Severe predation upon these vulnerable individuals was followed in well-studied cases by notable absences of battered, ha- 
bitual transients in late spring, and it would appear to have been the same individuals - social misfits? - that behaved in these ways, whether long before the ice broke up or long afterward.

The fundamental role of intraspecific intolerance in limiting muskrat populations was apparent by the end of the first decade of field work. Herein lay the big rigidities in the population behavior of the muskrat, those dependent upon the muskrat's own psychological make-up. On the whole, annual increases and upper levels of maintenance of muskrat populations conformed to mathematical patterns set by the species itself in relation to the supporting capacity of its environment.

Conformation to these self-limiting patterns nevertheless implied much resilience in rates of gain and loss, much natural substituting and compensating especially in the loss rates. Higher rates of loss from one agency of mortality had ways of being offset, partly or completely, by lower rates of loss from other agencies, with the totality of the seasonal or annual losses being more or less predetermined by how much a population consisted of wastage animals. With that part of a population in excess of the secure level for a given area being doomed to die, the exact fate of wastage animals made scant difference biologically.

When losses from mink predation were considered from this perspective, the severest observed had doubtful net effect on the muskrat populations of the Iowa areas as long as the habitats remained in good condition for the muskrats. During the breeding season of the muskrats, which was typically the period of severest nonhuman predation, nearly all that the minks ever were able to do as muskrat predators was to prey upon some of the more expendable parts of the populations.

In analysis, more than 70 per cent of the closely studied feeding by minks upon muskrat flesh appeared to represent scavenging, mostly upon victims of the hemorrhagic disease.

Of the feeding that represented proven or highly probable predation, about half involved victims "that had been vulnerable to mink predation chiefly for reasons of their troubles with other muskrats." About a third of the predation victims were "young muskrats caught under varying conditions of physical disadvantage, at ages at which they could have realized only a small degree of the inherent abilities of grown muskrats to take care of themselves." Most of the other victims were adults or subadults killed during acute drought or freezeout crises.

\section{GENERALIZATIONS AS TO PREDATION BY MISCELLANEOUS PREDATORS UPON IOWA MUSKRAT POPULATIONS}

Other than minks, the nonhuman predators that have been studied with more or less intensiveness on the Iowa study areas included great horned owls, red foxes, domestic dogs, and raccoons. In addition, data were obtained from certain marshes that supported thousands of snapping turtles at times when the muskrat populations were well demonstrating their ability to increase and maintain high densities according to patterns that bore no relation to abundance or scarcity of the turtles.

Horned owl predation on the muskrats of the study areas could be negligible, even when the owls were living in the midst of great 
abundances of muskrats. Formidable predators that the horned owls were, they behaved in an unimaginative manner, and their food habits were mostly determined by relative availability of prey within their hunting ranges (Errington, Hamerstrom, and Hamerstrom, 1940). The principal recorded instances of owl predation upon muskrats were of the owls responding to parts of muskrat populations made vulnerable through environmental deficiencies or evictions. Ordinarily, the presence or absence of horned owls made no perceptible difference in the fortunes of the local muskrats.

Only on drying Wall Lake in 1940 were red foxes known to have preyed heavily on muskrats, and this represented a most special case of concerted effort on the part of the foxes (Errington and Scott, 1945). The other fox predation upon muskrats was a little here and there in response to drought exposures or to muskrats coming out on ice or traveling overland.

Several examples of rather severe local "sport-killing" of muskrats by domestic dogs were noted, mostly at Goose and Little Wall lakes. These dogs often showed persistence and ingenuity in their muskrat hunting, and they seemed, on occasion, to have killed muskrats that probably would have been secure from practically all other nonhuman predators on the areas. Nevertheless, this sort of killing occurred on too much of a restricted scale and too infrequently to have had any more than trifling population effect. In some cases, depredations of dogs upon Iowa muskrats were a fair equivalent of those noted for coyotes in western United States.

I feel that raccoon predation upon young muskrats is as little understood as any type of predator-muskrat relationship worked with on the Iowa study areas. The raccoon depredations upon nestling muskrats at Wall Lake in 1953 may be compared, up to a point, with those reported from Atlantic Coast marshes (Harris, 1952; Wilson, 1953); but the fact that the Wall Lake raccoons confined their nest raiding to shallow water zones in disease foci is hard to explain. Granted that dying of muskrats from disease may have been what started the raccoons digging into lodges and then raiding the nests in certain tracts, why did not the raccoons raid muskrat nests in similarly accessible but disease-free shallows once they acquired the nestraiding habit in the disease foci?

Other nonhuman predators upon Iowa muskrats include practically anything that, under conditions favoring predation, is capable of killing prey larger than a mouse. Even meadow mice may prey upon helpless young muskrats in nests, and it is not too exceptional to find newly weaned young muskrats preying upon young muskrats of the more helpless sizes.

\section{CHIEFLY CONCERNING SOME DISTINCTIONS}

In contrast with situations often found in the Far North or in desert regions where predatory vertebrates may have difficulty finding much to eat, agricultural Iowa is ordinarily rich in food for minks, 
foxes, raccoons, birds of prey, and almost anything predatory that would be likely to prey upon muskrats. Although muskrats may be preyed upon by these predators, I do not know of a single instance of predators actually being forced by desperation to prey upon muskrats - though sometimes the predation was patently a result of predatory choice as well as in response to ready availability of the muskrats as prey. The mere fact that muskrats might serve as staple prey for some predators at some times does not necessarily imply that the muskrats were obligatory prey, even for short intervals. It is true, as the north central trapping public has long believed, that minks tend "to follow the muskrats," to increase as the muskrats increase, but, insofar as that reflects responsiveness to muskrats, the responsiveness is to the muskrats as den-makers for the minks more than to the muskrats as food animals.

Not only do we have the shifting of dietary trends of the predators in response to changes in relative availability of many types of prey, but the food consumption of many common predators is not by any means expressible as a definite quantity that has to be extracted somehow out of a prey population, the year around, good years and bad. Some predators, like the snapping turtles, do not even have to be very predatory in their habits and may keep themselves stuffed with submergent vegetation supplemented by invertebrates and carrion. Other species may feed heavily or lightly, and, for the minks, pronounced extremes have been shown by field data.

From Errington (1943):

At one extreme . . . a large mink ate adult-sized muskrats . . at the rate of about two in 24 hours. This mink was gorging to the extent that its fresh excrement consisted of pale red, raw meat. More commonly . . minks on a straight diet of muskrats in spring consumed two or three per week. . . [ At another extreme, for minks wintering on a dried-up marsh, a ] consumption rate of less than one muskrat per nine days per mink on essentially a straight diet was arrived at, and there was no reason to suspect that the minks ... . were not maintaining themselves in normal health and flesh despite thorough scavenging reflected by the dirt and heavy bone contents of many fecal passages. . . . Straight-diet rates of consumption showing all intergradations between two adult-sized muskrats per day to one per nine days alone are enough to invalidate the assumptions underlying many hypothetical considerations - and even greater differences may very likely exist in the minimal nutritional requirements of minks and the amount of food they may eat when they have opportunities.

In the region of my greatest familiarity, predatory faunas have shown both remarkable stability and remarkable variation over considerable periods of years. While food is certainly important in the ecology of predator populations, and human persecution or exploitation can be influential, I should say that central Iowa populations of able "general practitioners" among predatory species - minks and horned owls, for examples - are more apt to be limited in numbers by the intolerance they show toward crowding by their own kinds. 
On the Iowa study areas, the principal native predators upon muskrats, and the muskrats, themselves, would therefore both seem to have intraspecific intolerances as their ultimate population checks - though always within the frame of reference of their habitat requirements. In other words, these predators and these prey animals are as they are with some degree of independence of each other, at least as relates to one killing and the other feeding the other. And, in still other words, much happens in these relationships between predators and prey that really does not count in population dynamics under the conditions prevailing on the Iowa study areas.

Craighead and Craighead (1956, pp. 306-10) considered "that the role of predation as a population depressant has been underestimated" and that I, in particular, underestimated its importance because of having seen it replaced by other regulating forces, of which I believed intraspecific strife to be dominant. Also:

It is likewise questionable if we can say accurately, as Errington (1943) has indicated [ with reference to muskrats], that a large proportion of the victims of predation are doomed anyway, regardless of the presence or absence of predators, and therefore predation is ineffective in controlling population levels. There is no question that a certain proportion of an annual population is doomed. The important thing is not that the individuals constituting that proportion are doomed, but how they die, and that by their removal nature contrives to maintain population levels in harmony with the environment. Predation is extremely effective as a force operating in conjunction with other resistance forces to bring about this harmony. Numerous cases in which the forces of predation, intraspecific self-limiting mechanisms, and habitat limitations exerting tremendous pressure have all been necessary to check an expanding population could be cited; therefore we cannot assign a basic role to any one. It seems clear, however, that the continual pressure, governed by relative densities, that is exerted by a population of predators on prey populations is a force so powerful and so accurately meshed with all of life that it cannot be dismissed as ineffective. We almost surely shall fail to see the function of predation if we approach it from the standpoint of predation on a single prey species or predation by a single predator species, but we need only to visualize an animal community with predation eliminated to grasp immediately how important this force is and how intricate and widespread its ramifications.

We have seen that the pressure exerted by a raptor population tends to be in proportion to the relative densities of the various prey species. Thus the raptorial pressure on the prey population of an extensive area tends to depress the various species more or less simultaneously toward the threshold of security. . . Observations of predation by a single raptor species at times will show marked pressure on one or a few prey species and will at other times show little or no pressure on the same species. In evaluating such data we should keep in mind the fact that they are only part of the pertinent information. On such a basis we could, according to the partial data at our disposal, judge predation to be either nearly annihilative or ineffective. The mechanics of predation are such that no single species in a multiple prey population can under normal environmental conditions draw sufficient predation pressure to keep its population level dangerously depressed. This we should naturally expect, and this fact cannot be used as an argument against the effectiveness of predation as a controlling or regulating factor. The killing of a prey animal by a predator does not necessarily mean a lower prey population than would have existed had the act of predation not oc- 
curred; but the continual killing of prey animals in a prey population means a continuous proportional loss of animals, which tends to keep the population within limits, The argument that other regulatory forces would become operative in the absence of predation or that intercompensation (Errington, 1946) would offset the forces tending to lower populations has no bearing on the role of predation as a force regulating and at times limiting populations. The same could be argued for any other limiting factor.

As a matter of fact, if predation frequently can act as a limiting factor, and if as we have shown it becomes most effective in late winter and early spring reducing the over-wintering populations (breeding stock) then we could expect to find a reproductive mechanism evolved to counterbalance it and other depressants simultaneously operative. Compensatory breeding would appear to be such a mechanism. Just as predation or intraspecific strife are responses to high density levels, so compensatory breeding is a response to low density levels. This response is exhibited when spring to fall prey population gains show an inverse ratio to spring breeding densities. It does not indicate the ineffectiveness of predation but rather the complexity of population producing and destroying mechanisms.

It should be noted that food supply, for example, is sometimes a factor limiting populations and when this factor has a strong depressing effect, predation naturally will tend to regulate prey levels only within the limits imposed by the food supply. In such cases, predation cannot be considered the limiting factor.

Although predation can be the limiting factor, we should perhaps have a truer concept of it if it were thought of not in terms of when and how it may assume this role, but rather as a regulatory force continually operating to lower prey increase in proportion to prey density and to do this before more drastic but less steadily functioning forces become effective. These other forces seldom, if ever, affect the total prey population simultaneously, but are confined to specific prey only. Disease may strike one prey, while food shortage may regulate another. In contrast, predation strikes all components of the collective prey simultaneously and continually. ... .

As a suppressive force, predation does not reduce populations to very low numbers, as do epizootics or starvation. Moreover, the number of any single prey species accounted for may be far less than the number killed by a hard winter or a wet spring. Sudden drastic reduction in numbers temporarily releases a population from the pressure of control forces, thus allowing population densities to be again increased. This creates a type of control characterized by excessive fluctuations in numbers. Where predation is dominantly operative, however, control is characterized by continuous and proportionate reduction that tends to keep population levels near a mean. The fact that predation operates as a steadily functioning force throughout the seasons and year after year, in spite of continually changing physical and biotic conditions of the environment, gives it a great advantage, in comparison with regulators that operate intermittently or only under special conditions, in harmoniously regulating animal populations with one another and with the rest of their environments.

Although my conclusions as to population effects of predation upon muskrats were what elicited the Craighead comments, their own conclusions were drawn on the basis of experience with predation not upon muskrats but upon meadow mice. To quote again from their book:

It would appear that on any area of land, animal populations tend toward stability of interrelationships and that predation in greater or less degree 
plays an important role in establishing and maintaining such a state of balance.

In this chapter, I am not undertaking any general critique of the Craighead work or philosophy concerning predation. The questions involved in a broader philosophical discussion of predation are much too complex to be treated at any length in this book, devoted so largely as it must be to muskrats. The scope of the present chapter nevertheless not only permits but also requires some discussion of the Craighead criticisms of my interpretation of the Iowa muskrat data.

I do not deny that I have different interpretations of the overall meaning of the predation borne by the Iowa muskrat populations that have been so long kept under close observation. Nor can I help questioning the validity of the Craigheads judging the population effects of predation suffered by the Iowa muskrats from no better perspective than an investigation of other animals - and from population data on prey species that collectively must be less exact than the population data that I have on my long-term specialty, the muskrat of the Iowa study areas. (See also Hamerstrom's 1958 critique of the Craighead prey data.)

I really do not know how much disagreement exists between the Craigheads and me, and the disagreement may be less than it seems. They intimated in various places that superior habitat afforded superior protection even to high prey populations, that emergency conditions could precipitate severe predation upon vulnerable prey populations, and that thresholds of security could operate in ways reminiscent of many data from the muskrat areas.

The Craigheads, in the parts quoted, wrote of the "continual pressure, governed by relative densities, that is exerted by a population of predators upon prey populations," of predation "as a regulatory force continually operating to lower prey increase in proportion to prey density," of predation as striking "all components of the collective prey simultaneously and continually." "Where predation is dominantly operative ... control is characterized by continuous and proportionate reduction that tends to keep population levels near a mean." And, "predation operates as a steadily functioning force throughout the seasons and year after year."

Whatever may be the possible validity of the Craighead objections to my reasoning concerning other aspects of predation or other predator-prey relationships, I do not see that their idea of continuous operation of the predation factor fits in with the available data from the muskrat case histories.

It was only in 1943, that "peak" year for Iowa muskrats, that I ever observed anything having even a superficial resemblance to steady month-by-month attrition. When muskrats were then to be found in poor or good habitat generally, and appearing at times almost anywhere, the predation upon them seemed most to conform 
to the Craighead concepts of predation upon the meadow mice. It was then that I was seldom surprised at finding muskrats being preyed upon, wherever they were and at any time. Still, the predation suffered by those widely distributed and abundant muskrats was by no means random nor in direct proportion to their populations. Nor do I interpret the evidence I saw as indicating that the predation was a primary limiting or regulating factor. The real limiting factor I should say was the muskrats' own nature together with the limitations of the habitat available to the muskrats. The badly-situated muskrats of 1943 could not maintain themselves indefinitely in the absence of predators, and the obviously well-situated animals got along despite the presence of minks and other formidable predators. High thresholds of security were operative in 1943 as well as in years of far fewer muskrats.

In general, our closely studied Iowa populations of muskrats did not show steady attrition after the breeding season. During the breeding season, and for a few weeks after weaning, much wastage of immature animals might occur; and predation was one of the agencies of the mortality suffered by the overproduced or vulnerable young. When this biological shaking-down was over, the rest of the population might be remarkably secure from native predatory enemies for months. Moreover, this period of security from ordinary predation may be prolonged into the winter, until the social intolerances of the next breeding season or environmental crises again increased the vulnerability of certain members of the muskrat population.

Substantial or, at times, very high muskrat populations may live the year around in the presence of heavy mink or fox or raccoon or horned owl or snapping turtle populations without suffering more than trifling losses from any kind of predation. Local populations may level off and maintain themselves according to about the same patterns when predation losses are light, moderate, or heavy, whether predation occurs through the agency of one predator or many.

I doubt if I can advance any all-comprehensive formula by which the role of predation in the population dynamics of muskrats or meadow mice, of vertebrates or invertebrates, may be expressed. Never have I maintained that predation cannot be at some times and places a limiting factor with some prey populations. Nevertheless, the following point of view has nothing in it that seems illogical to me: The more a prey population is basically limited by nonpredacious factors, including its own intolerances of crowding, the less it can be basically limited by predation. To this may be added the corollary that the "less that strong territoriality or other self-limitation enters population equations, the more something else may do the limiting" (Errington, 1956).

Exact details relating to the differences between security of muskrats from, and vulnerability to, minks and other subhuman predators are rarely available. In part, security of the muskrats appears 
to be a matter of predators not readily finding prospective victims; in part, to active defense by muskrats that are themselves formidable enough, singly or through concerted attack, to drive off or keep at bay enemies, including fully functional minks; probably mostly, to adeptness in utilizing escape facilities offered by familiar grounds and suitable combinations of water and shelter. The comparative safety of daily routines of individual muskrats is linked not only with environmental features, such as the position and quality of food resources with reference to dwelling quarters, but also with the psychological status of the animals.

There are two periods when thresholds of security for adult or grown muskrats may clearly be recognized from the Iowa case histories: one in the fall and the other in the spring. The fall threshold determines the number that can then be accommodated on a given area under nonemergency conditions without undue losses from nonhuman predation or from departures, and the population tends to reach and to level off at this threshold value. The spring threshold has a decidedly lower numerical value than the fall threshold, at a time when social tensions among muskrats reach their maxima. A third possible threshold seems to be determined by the numbers of young that adults and large young, collectively, will tolerate on an area at the height of the breeding season; it may permit much higher densities of muskrats to be reached on a given area during the breeding months than can be maintained there later in the year. I am not sure, however, that this third type represents a very definite value at any given time or place; but the values for the other two may show a fair degree of uniformity from year to year as long as environmental and psychological changes affecting muskrat populations do not become too pronounced.

\section{OF PREDATION AND MATHEMATICAL MODELS}

Much laboratory experimentation has been devoted to the mathematical expression of predator-prey relationships (Andrewartha and Birch, 1954), and there have also been a great many efforts to express these relationships mathematically on purely theoretical grounds. No one has, to my knowledge, succeeded in constructing a mathematical model that adequately reflects predation upon muskrat populations. Of the population students I know, I think that Nicholson (1954) and Cole (1954a) have come, to quote from my paper (Errington, 1956),

the closest to depicting relationships that I personally have observed in nature - particularly the mathematical expressions of thresholds of security, overflows from favorable into unfavorable habitats, and compensatory trends.

Ideally, perhaps, everything that happens should be expressible mathematically, but, in the matter of population equations, I would say that the mathematicians have some distance to go. They have an imposing array of analytic pitfalls to avoid, and some of my mathematician friends confess that they do not see how anyone is ever going to put down on paper true-to-life 
mathematical expressions of the sorts of population relationships that are commonplace among higher vertebrates. But the potentialities of mathematics as an analytic tool in population studies should be far from exhausted at the present time. What I am stating here is not intended to discourage mathematicians from going ahead with any promising approaches that they might have. My purpose is only to emphasize that, to be true to life, the mathematical expression of a population equation must not assume constancies that are not constant or more randomness than exists, and that it must not fail to take into minimal account the capacities for adjustments that living species have acquired during the millions of years that they have lived their lives in their own ways.

And thus, at the end of this chapter, which deals with some of the most carefully studied phenomena in the whole field of population dynamics of the muskrat, I find my thoughts tending to be dominated by what our knowledge of predation lacks rather than by what the studies have so far accomplished.

At any rate, we still have as subjects for our attention animals that are quite disinclined to serve as prey for anything, and which, under favorable living conditions, may not need to let themselves be preyed upon by much of anything - that is, except by that distinctively special enemy, man. The muskrats themselves have nothing to prove, disprove, rationalize, or explain, and, being to some extent free agents, they do not necessarily have to do things one way if another way will suffice. Their job is living, and they work at it full time. 


\section{Chapter 17}

\section{The Muskrat and Population Cycles}

The more or less periodic or cyclic of population fluctuations have drawn the attention of literate observers for centuries. Primitive peoples dependent for their livelihood upon violently fluctuating food or fur animals, or agricultural communities subject to devastating abundances of rodents or lagomorphs, doubtless have been aware - in a very personal sense - of the reality of great fluctuations since long before languages were written. The consequences of these changes to human economics may be tragic under extreme conditions, particularly in northern regions where events such as the famine in Longfellow's Hiawatha have had their many counterparts in actuality.

The past quarter-century has been one of especially pronounced scientific interest in the so-called "cyclic" fluctuations of wild species. A great diversity of viewpoints exists as to whether population cycles can be explained by chance variations, by climatic variations, by variations in food supply or habitat niches, or by variations in predator pressures. In the tremendous mass of existing literature on animal fluctuations, the reader may find a bewildering array of statistics, miscellaneous facts, hypotheses of all shades of credibility, and, as Cole $(1951,1954 b)$ has emphasized, interpretations that may be subjectively colored. There have been disagreements as to whether fluctuations are or are not species characteristics. Some authors have looked for a single underlying master factor, and some, for a multiplicity of factors. Some have felt that the phenomena classed as "cyclic" are explainable in very commonplace terms and others that we are here confronted by unknowns that are among the greatest in biology, perhaps beyond human comprehension. 
My own attitude is one of suspicion for the easy answers. I consider that two symposium papers (Errington, 1954a, 1957) have summarized my thoughts on cyclic phenomena about as well as anything I am currently prepared to write, and I shall quote and cite them at length in this concluding chapter.

First, from Errington (1954a):

The resulting literature [on population cycles] has become so voluminous in the English, German, and Scandinavian languages alone, that I doubt that any one person could now truly master it in a lifetime, even if he were competent in all of the fields of science contributing. Its scientifically reputable authors include not only biologists of many fields but also economists, meteorologists, astronomers, and mathematicians. The subject matter so treated is sufficiently complex and lacking in first-class data to make it extremely diffcult to judge whether we are on the trail of the truth or not, or what the truth may mean if we have it before us.

For persons wishing to have a background of modern thought, I would recommend the symposium edited by Hewitt (1954) and, further, the books, review papers, and discussions by Elton (1942), Bump, Darrow, Edminster, and Crissey (1947), Allee, Emerson, Park, Park, and Schmidt (1949), Grange (1949), Solomon (1949), Franz (1950), Rowan (1950), Christian (1950), and Frank (1957). These illustrate the major differences in viewpoints among biologists studying population cycles, and, to resume quotation from my 1954a paper, the

reader should be prepared for divergent and conflicting opinions, without interpreting them as meaning that anyone is necessarily all right or all wrong.

My own views concerning population "cycles" have changed ... and very probably they may change some more, very probably also in ways that I cannot now predict. As one investigator, I do not in any way claim to have the answers to the ancient mysteries of "cyclic" or like fluctuations of species, my own research specialties among these species included. But, since I have long attributed some of the outstanding confusion in the literature on population "cycles" to undue preoccupation of scholars with numerical fluctuations, per se ..., my hope is that a presentation of data from a different approach may help reconcile some of the controversies that are currently so apparent. Better progress toward what are (or should be) mutual objectives in studying population "cycles" might be possible if the more distracting areas of disagreement could be reduced. I think that they can be.

This chapter, which is submitted neither as a comprehensive review nor as a solution to cyclic mysteries, is intended to be a factual presentation and discussion of evidence obtained from the muskrat investigations. By restricting its scope to the north central region of my greatest familiarity, I think that I can lay the most accurate groundwork for the following treatment. There are complexities and apparent contradictions enough in our knowledge of population cycles without here attempting approaches on a global scale at this time. 


\section{INTRODUCTION TO SOME CHRONOLOGICAL SIGHTING POINTS}

Of all of the different cycle-lengths assigned by modern investigators to animal fluctuations (Wing, 1951-57), those occurring approximately with three-to-four-year and with 10-year rhythms seem to show the greatest likeliness of validity as applying to common mammals and birds. Insofar as the shorter-term fluctuations are considered by some authors (Vinogradov, 1934; Siivonen, 1948) to be related to and a part of the 10-year, I have no intention of trying to dissociate them with more finality than is scientifically proper; but the muskrat field data have had much more of an evident relation to the 10-year cycle than to the three-to-four-year. The latter is manifested especially by vole and lemming fluctuations (Elton, 1942).

Before proceeding, I should emphasize that the actual population levels reached or maintained even by species labelled "cyclic" can be resultants of numerous factors, among them some factors that operate most irregularly in ordinary time scales: the big emergencies and epizootics, plant successions following disturbances, changes due to human land uses, the letting out and taking up slack by the density factor. The more synchronous of the recorded fluctuations of vertebrate populations have been almost a property of regions lying in northern parts of the northern hemisphere (Rowan, 1950), but not exclusively so (Elton, 1942; Bodenheimer, 1949; Wodzicki, 1950, pp. 139-41).

In the "North Woods" parts of the north central region, to quote Errington (1957),

the ruffed grouse (Bonasa umbellus) and snowshoe hare (Lepus americanus) are not only characteristic species but they are also notable for their fluctuations. They go through periods of abundance and scarcity at approximately 10 -year intervals. While such periods may not be exactly synchronous in all parts of the grouse and hare range even within the region (or even locally), the over-all effect is close to a rhythmic pattern. The ruffed grouse and snowshoe hares are among the "classically cyclic" species, if any may be so designated. ... .

Neither the ruffed grouse nor the snowshoe hares are animals that I am entitled to refer to as specialties, but I can claim some familiarity with their habits and ecology, and I have had much discussion and correspondence with field biologists who have made special studies of these and related species. The picture that shapes up from all sources is that at least the ruffed grouse and snowshoe hares of central and northern Minnesota and Wisconsin have generally been reaching peak population levels in or near the years ending in ones or twos and minimal populations in or near the years ending in sixes or sevens.

It should be made clear that an occasional abundance peak may carry over into the years ending in threes or fours or even later, and an occasional period of scarcity may be apparent in a year ending in a five or even considerably earlier in a decade. The grouse and hares need not fluctuate in complete agreement with each other, and the impacts of emergencies or environmental changes may be so great as to overwhelm populations, seemingly irrespective of any particular time schedule. Year-to-year differences in populations may not be great even when a high phase is shifting 
to a low phase. Superimposed on the trends in annual fluctuations may be the long-term population trends of either the ruffed grouse or the snowshoe hares in a given area - as human land use and plant succession bring about their changes over the decades.

Yet, throughout these interplays of variables, something that might be called a master pattern does seem to dominate; and the one-two and the sixseven year-groupings are worth paying attention to. If there is a significant chronology in the grouse and hare fluctuations of the north-central region since the turn of the century (I am refraining from making statements about other regions), it would seem to be linked with the above year-groupings.

In Iowa and southern Wisconsin, my own long-term research specialties, the bobwhite quail (Colinus virginianus) and the muskrat . . may at times show fluctuations as pronounced as those of the grouse and hares of the northern parts of the north-central region. Sometimes, the quail or muskrat fluctuations line up with those of the grouse and hares; sometimes, they do not. If fluctuations alone were all we had to compare, we would have scant grounds for expecting to find any common time schedule in the "cyclic" manifestations of the grouse and hares and of the quail or the muskrats.

The quail and the muskrats have adaptations and habitat requirements differing greatly from those of each other and little resembling those of either grouse or hares. Both quail and muskrats are far more vulnerable to certain types of emergencies than are the grouse and hares.

In this region, the staple winter food of the quail consists of grains of cultivation and other seeds that have proteins, carbohydrates, and fats in concentrated and readily available form. By midwinter, almost all of this quail food remaining in fields, pastures, and woodlots is on the ground, and, if snow covers the ground, it also covers much if not most of the food. Insofar as the quail have no aptitudes for digging or scratching down through deep snow to reach food, a winter of heavy snowfall may all but annihilate them from the more northerly parts of their geographic range.

A wintering population may collapse within a couple of weeks, whenever a foot or two of snow-covering persists as long as that. The quail, which lose weight fast after the first two or three days of a hunger crisis, begin dying of starvation after about a week - or even before the end of the first week. Contemporaneously, the ruffed grouse and snowshoe hares of the "North Woods" may winter well-fed on the plant foods that they are adapted to eat and accustomed to find above the snow. . . .

The muskrat, a semi-aquatic rodent, is naturally susceptible to drought emergencies. Factors other than drought may influence the population levels reached or maintained by the species, but it should be safe to say that there is nothing like a series of drought years to reduce the north-central muskrats and keep them reduced. In extreme cases, droughts may leave entire counties devoid of muskrats, and an experienced field observer may then need no refined measurements of environmental changes to identify the dominant factor.

For the 24 years - 1934 to 1957 - that intensive muskrat studies have been carried on in Iowa, 17 have been years of severe droughts for muskrat populations of the study areas. Only 1935, 1938, 1942, 1943, 1946, 1951, and 1954 may be rated as drought-free years for the muskrats. Whether anyone would argue that the drought years are the normal years for this series, the droughts came at intervals that look more irregular than regular; and the lack of close agreement between the fluctuations of Iowa's muskrats and the more rhythmic 10-year pattern of Minnesota's and Wisconsin's ruffed grouse and snowshoe hares should surprise no one.

During my first decade of association with Aldo Leopold, and despite the interest that I felt in the work he was doing on population cycles, I did not see how the bobwhite quail and the muskrats could have any real tie-up 
with the "10-year cycle" of the grouse and hare fluctuations. If, as of the late Thirties or the beginning of the Forties, I may be charged with having biases concerning the "cyclic" status of quail and muskrats, they were the biases of skepticism.

I still make no claims that "cyclic" tie-ups between the grouse and hares and the quail and the muskrats are proven to exist. I do not know for sure whether they do or not.

By the early and middle Forties, the data from the quail and muskrats were revealing synchronies that might suggest physiological and psychological responsiveness to some common denominator. If there is a common denominator behind these synchronies, I should not expect it to be definable in ordinary climatic or environmental terms. Such a possibility would seem to be ruled out by the differences in behavior, adaptations, and habitat requirements of the species with which we are concerned.

Let us then go on to consider the evidence of synchronies we have from the quail and muskrat studies and, while doing so, keep in mind the onetwo and the six-seven year-groupings that seem most meaningful from the standpoint of the grouse and hare fluctuations of north-central United States.

Both my 1954a and 1957 papers illustrated how imperfectly the fluctuations in numbers of the Iowa muskrats synchronized with the fluctuations in numbers of ruffed grouse and snowshoe hares, even within a geographical radius of a few hundred miles. While the synchronies that do exist between the muskrats and the grouse and hares in the above respects may have useful biological meaning, I question that they should be given so very much weight in our exploration of possible cyclic phenomena shown by the muskrats.

I recognize the confusion into which this may lead a reader. If, according to my reasoning, more muskrats were present during the cyclic low year of 1946 than during the cyclic high year of 1941, just what may be the basis for assigning a given year to one cyclic phase or another? What may we then expect to be in chronological agreement, to show meaningful correlations?

There are still other synchronies to consider, those relating to evident changes in the physiology of the muskrats, whether such changes resulted in population changes or not. Unless otherwise indicated, the following quotations are from Errington (1957).

\section{CYCLIC PATTERNS IN REPRODUCTION}

The main reproductive data tabulated in connection with the Iowa muskrat studies related to: (1) mean sizes of litters conceived by or born to fully adult females, (2) proportions of young females breeding precociously during the calendar year of their birth, (3) proportions of adult females conceiving young during the breeding season, (4) mean numbers of litters per adult breeding female during a breeding season, (5) proportions of adult females conceiving their usual Iowa maxima of four litters during a breeding season, (6) proportions of litters born later in the summer than the middle of July, and (7) proportions of late-born young among the young of the year surviving up to late fall or early winter.

The high and low values for the above categories 3 to 7 showed little or no correlation with either the one-two or the six-seven year-groupings. This 
may be seen in the data tabulated in my 1954 paper, and the subsequent data are similarly non-committal. It is still possible that changes in reproductive vigor could result in changes in mean numbers of litters conceived, in prolonged or retarded breeding seasons, and in increased or decreased survival rates of late-born young, but year-to-year variables having no visible relation to patterns in year-groupings afford likelier explanations for the observed differences.

For example, the proportions of adult females passing through an annual breeding season without conceiving depend principally upon the chance isolation of females outside of the usual travel routes or home ranges of prospective mates. We have good field data illustrating this. Many other differences in breeding performances depend upon situations that vary from year to year. Either severe early-season losses of young or a state of underpopulation of muskrat habitats may be accompanied by the birth of more litters per adult female, by prolongation of the breeding season and by increased survival of late-born young (Errington, 1951). These differences are not wholly without their evidences of some synchronizing with year-groupings, but the naturally compensating adjustments that one may expect in almost any year leave most of the reproductive data too obscured for "cyclic" correlations.

Our reproductive data on muskrats that seem most independent of compensating adjustments and the usual types of environmental influences relate to mean sizes of litters of adult females and to the precocious breeders among the young females.

Of these latter two categories of data, the mean sizes of litters seem to be influenced the least by drought, by local differences in food supply, and by population tensions among the muskrats. The litter sizes of a droughtexposed, hungry, or crowded population may average a half muskrat smaller than the litter sizes of a well-situated neighboring population, but that is about as much difference as the case histories of our Iowa study areas show in a given year. At their greatest, such differences look inconsequential compared with the differences shown between the chronological "highs" and "lows" of the "10-year cycle." Between the one-two and six-seven year-groupings of ... [ Figure 17.1], the difference in mean size of litters can be about two muskrats.

Our central and northern Iowa data on a total of 2,656 litters over a period of 22 years have a mean value of 7.49 young per litter. The minimal figures for each of three decades - 6.35 to 6.42 - came 10 years apart, in 1936, 1946 , and 1956, but I do not regard that as signifying any absolute periodicity. The high-value means for the early Forties reached more of a peak, with 8.19 for 1941 and 8.41 for 1942 than did the high values coming later: 8.09 for $1949,7.95$ for $1950,8.17$ for $1951,8.01$ for 1952. The mean for 1.951 was almost the same as the mean for 10 years earlier, but there seemed to have been less conformity to anything resembling periodicity in the peaks than in the years of minimal values. The mean that breaks most the smoothness of the wave-like pattern of . . . [ Figure 17.1], the 7.29 for 1937, is statistically the poorest in our 22-year series.

Seventy-four, or 1.5 per cent, of samples totaling 4,785 young female muskrats examined in November and December of the calendar year of their birth had conceived young during the second half of the summer. Except for an animal giving birth to two litters during its own birth year, all of the above precocious breeders were one-litter females conceiving small (averaging 5.3 young) litters.

The data on precocious breeding ... [Figure 17.1] lack the correlation with the one-two and six-seven year-groupings shown by the changes in mean sizes of litters conceived by adult females, but precocious breeding appears to have been rather restricted to the years centering about the chronological 


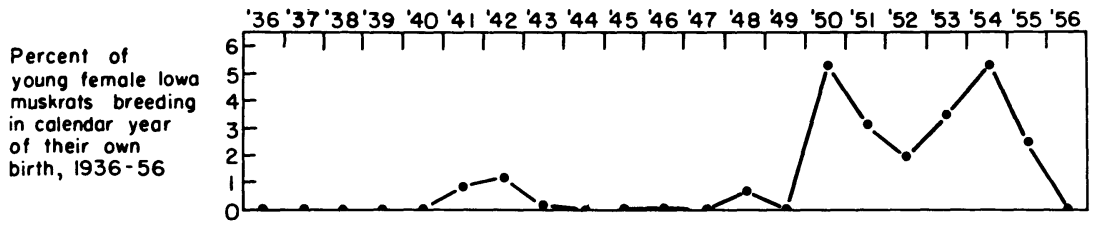

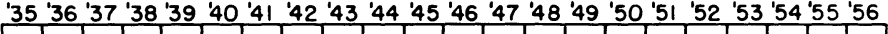

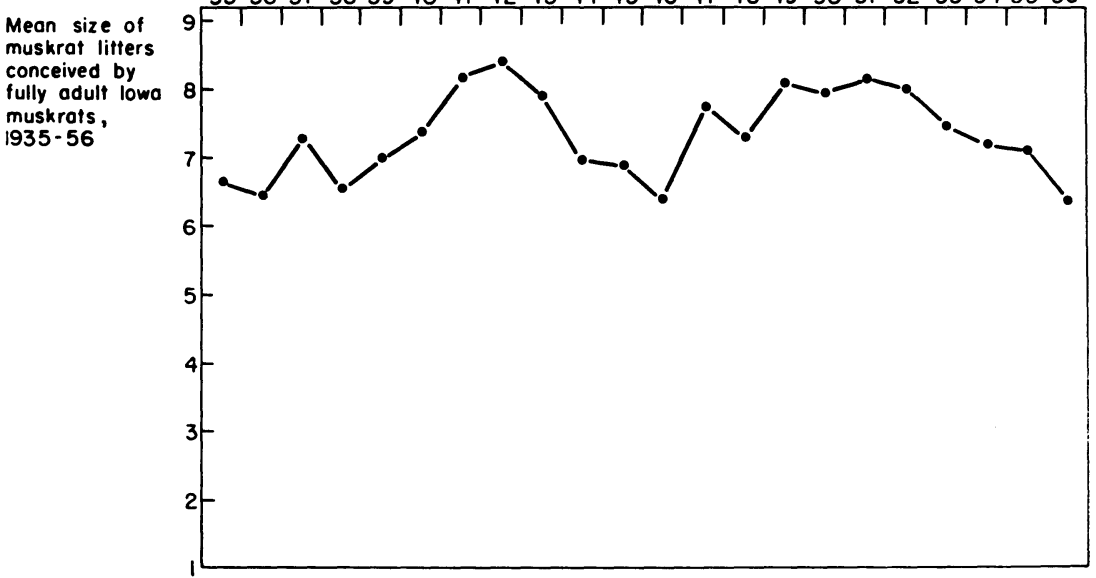

Fig. 17.1. Alignments with year-groupings shown by certain changes in reproductive performances of lowa muskrats, 1935-56. (After Errington, 1957 - Cold Spring Harbor Symposia on Quantitative Biology.)

"cyclic highs." It is true that the incidences of precocious breeders in the samples are much higher for the 1950 to 55 year-grouping than for that of 1941 to 43 , besides reflecting a greater year-to-year prolongation of the phenomenon.

Late summer droughts, population crises, and possibly other factors than "cyclic" chronologies can be expected to have had irregular effects on precocious breeding among Iowa muskrats, but something a bit special may have been required to damp or to stimulate the reproductive physiology of the young. A substantial amount of late breeding or what might be called fullscale breeding by bona fide adults occurred during the "cyclic low" years of 1946 and 1956, when no precocious breeding was recorded from our specimen series.

Anyone wishing to do so may bring Figure 17.1 up to date by adding the 1957 values presented in Chapter 1: 2.0 per cent precocious young females (Table 2.3) and 7.58 mean size of litters conceived by adult females (Table 2.4). It may be of some significance that the litter sizes for 1937, 1947, and 1957 - the years immediately following the lowest-value years for each decade - rose as abruptly as they did, and that, at least following 1937 and 1947, the curve dropped down again before resuming the upward trend. 


\section{CYCLIC PATTERNS IN SYNDROMES OF THE HEMORRHAGIC DISEASE}

A great many attempts have been made to link cyclic declines of animal populations with disease, and while disease has often been prominent among the population symptoms observed, it has not invariably been so. Neither have many specific diseases played any uniform roles in these population declines, even over relatively short periods of years.

Before introducing our data on disease in muskrats in relation to "cyclic" chronologies, I should like to clarify one point: With the approach of the chronological "cyclic low," we do not necessarily find that more muskrats, or larger proportions of muskrat populations, are contracting or dying from disease. The spread of epizootics in muskrat populations varies so much with chance and with local situations that I should not expect changes in incidence of infection to be among the better criteria for judging stages of the "10-year cycle."

On the other hand, changes in mortality rates of the animals that are infected with a serious contagious disease could fit in with year-to-year changes in the physical well-being of populations. . . .

On less than 27 square miles of our regularly observed study areas in central and northern Iowa ... [ the hemorrhagic disease ] has killed a calculated total of about 8,500 muskrats of larger than suckling sizes since our intensive disease work was begun in 1943. Some data were acquired on upwards of 1,400 individuals among the victims, and, of these, 568 were found in passable to excellent condition for postmortem examination. . . .

First, from the 568 specimens, let us subtract 70 having lesions dominated by pneumonitis or lung hemorrhages. There seemed to be no year-groupings, either at high or low phases of the "10-year cycle," when pneumonic syndrome epizootics might not sweep through a muskrat population if such an epizootic got started under conditions favoring its spread. We have had locally annihilative mortality from the pneumonic syndrome on Iowa marshes during years when the muskrats had practically stopped dying from the other syndromes.

The lesions of the remaining 498 specimens diagnosed as victims of the hemorrhagic disease were mostly necrotic foci in livers and intestinal hemorrhages, together with minor hemorrhages in other parts of the body, including lungs. Victims might have few if any gross lesions in their viscera yet be members of local populations patently collapsing from the hemorrhagic disease in the space of a couple of weeks; or as much as a quarter of the volume of the victim's liver might be necrotic, with lesions in all stages of onset and healing.

These differences were discussed at some length in my 1954 paper, and I believe that they mainly reflected differences in resistance of the muskrats to the disease - or, at any rate, differences in length of time that victims were able to stay alive after becoming infected. For purposes of this presentation, I therefore feel justified in taking the short-cut of referring to superior, intermediate, and inferior resistance on the basis of lesions shown by hepatic-enteritic syndromes.

It is true that all of the animals of . . . [ Figure 17.2] died, whether dying after a month's struggle with the disease or staying alive only a few days, but the apparent differences in resistance still line up with "cyclic" chronologies....

The syndrome data . . . show their first big change as of about mid-year, 1944. Most of the 38 specimens posted from fall, 1943, through the summer 


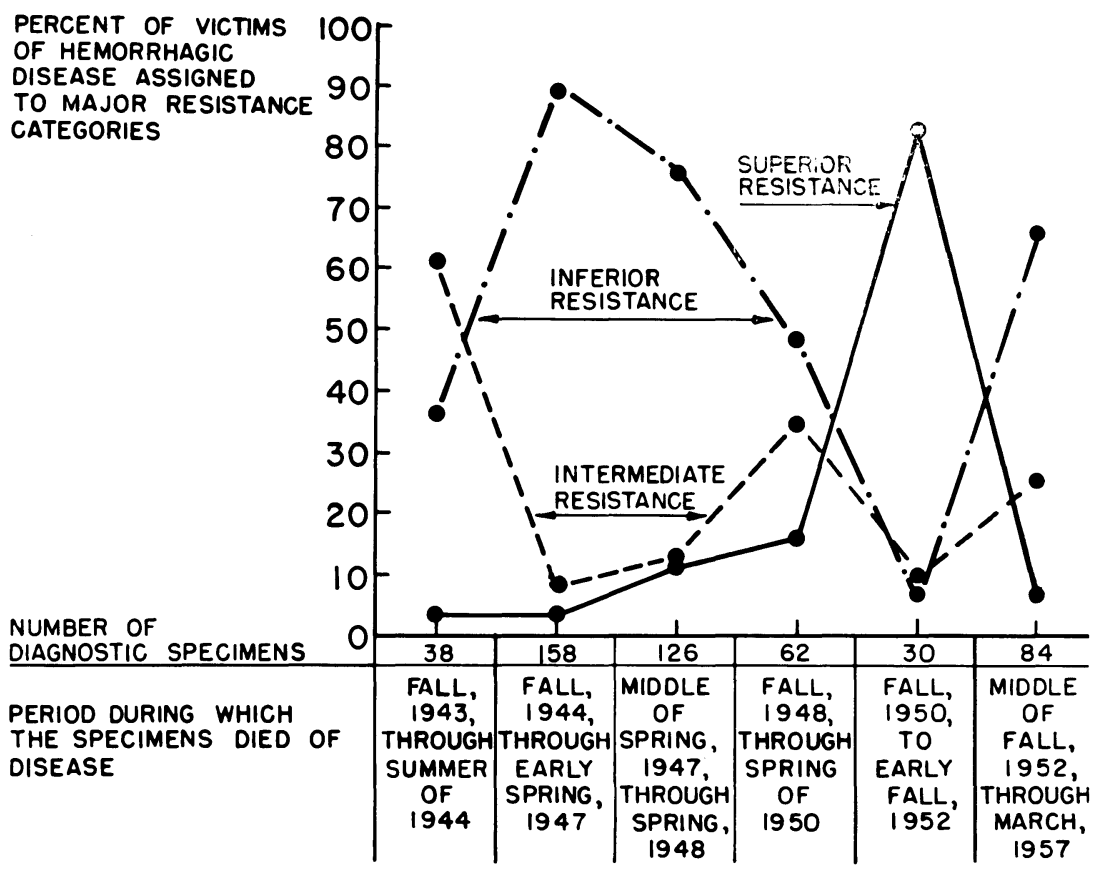

Fig. 17.2. Alignments with year-groupings shown by changes in disease syndromes in lowa muskrats, 1943-57. (After Errington, 1957 - Cold Spring Harbor Symposia on Quantitative Biology.)

of 1944 had the liver lesions that we usually found in animals known to have stayed alive a week or longer after exposure to the infection, but a series of 85 specimens for fall and early winter, 1944 to 1945 , was made up largely of victims that evidently had died before liver lesions had time to form. Thereafter, until about half-way through the spring of 1947, the lesion syndromes for 73 more specimens followed a similar pattern, seemingly indicative of lowered resistance.

For a brief period in late spring and early summer, 1947, the victims included a number having the massive liver necrosis that undoubtedly took more than a week or so to build up, but there were only nine specimens in this sample, and the influence of these ... was swamped by the 117 other postmortems from the middle of the spring of 1947 through the spring of 1948. From the middle of the spring of 1947 through the spring of 1950 , the over-all trend of 188 postmortems showed a gradual increase in proportions of victims that evidently succeeded in staying alive longer.

The hepatic-enteritic syndrome changes of the early Fifties were the most pronounced. Although the postmortems for a series of only 30 specimens may leave doubts as to the adequacy of the sample, the field data from other sources supplement very well the postmortem data from these disease victims.

During this period of the fall of 1950 to the early fall of 1952, muskrats could still die on a large scale from the pneumonic syndrome. They could still contract the disease on a large scale when it was manifested by lesions other than the pneumonic - but without dying from it except in tracts of marsh that were persistent foci of infection.

Even in the foci of infection having the deadliest of past histories, rela- 
tively few of the animals living there between mid-year, 1950, and mid-year, 1952, succumbed to the disease. Specimens found at the latter places rather typically had liver lesions in conspicuous quantities and in various stages of healing, all suggesting prolonged and repeated infections. The syndromes usually to be seen in the postmortems were those to be expected for unlucky individuals that put up good fights for their lives before dying.

Other data were appraised as pointing in the same direction. Fur trappers on our Wall Lake study area found only two dead from probable disease while trapping about 800 in the late fall of 1950, but 30 of the sample of 446 trapped carcasses that I posted had liver lesions. In the fall of 1951, the trappers found only four probable or verified disease victims while trapping about 1,850 , but 45 of my posted sample of 450 had liver lesions. In this connection, it should be mentioned that incidences of one or two per cent of the trapped carcasses with liver lesions would not have been surprising, but incidences of six to 10 per cent for the above samples were astounding and, in these cases, interpreted as signifying both an unusual occurrence of the disease in the marsh population and unusual proportions of infected animals remaining alive and sufficiently active to be caught in traps.

Of the 75 posted specimens having liver lesions among the Wall Lake carcasses trapped during the falls of 1950 and 1951, most were of animals less than four months of age. This itself was significant. During years when muskrats were suffering locally annihilative mortality from hepatic-enteritic syndromes of the hemorrhagic disease, the very young victims seldom had anything more than the slightest of gross lesions in their viscera; but, in 1950 to 51 , it was clear that even the highly susceptible young were coping with their infections. Their livers had extensive necrosis in many cases, but such animals were rarely dying in the field.

After this two-year period of wide-spread contagion and little mortality except for the irregular flare-ups of pneumonic-syndrome epizootics, animals started dying again from hepatic-enteritic syndromes about as they had been doing in the late Forties. The syndrome changes were about as expected, and, as the mid-Fifties came on, the specimens became increasingly reminiscent of those of the mid-Forties. As of the spring of 1957, an epizootic has almost wiped out the main population the last drought left us on our study areas, and the lesion syndromes suggest low resistance on the part of the muskrats.

The standard questions regarding immunology of the muskrats or possible changes in virulence of the infectious agent that naturally come to mind are partly answered by what data we have.

The Wall Lake muskrats that almost stopped dying from the disease when they contracted it in the fall of 1950 - and showed such changes in lesion syndromes when they did get fatal dosages - were members of the same local population groups that died readily in the spring and early summer of the same year. The converse in 1952 would seem to eliminate any hypothesis that the population had merely built up resistance through contact with the disease. In 1952, the population groups of muskrats that were resisting the disease on a large scale in spring and early summer included the same ones that were dying from it, with changed lesion syndromes, in the fall.

Furthermore, these changes in syndromes and mortality in the early Fifties were not peculiar to Wall Lake nor to any one study area. At about the same time that the syndromes and mortality patterns changed at Wall Lake, they also changed on our other study areas. Field data - including those from marked animals - indicated that at least certain population groups were essentially self-contained during the seasons when the more abrupt changes took place in 1950 and in 1952. In the fall of 1952, the changes were noted 
more or less simultaneously in areas situated as the points of a triangle eight, 22 and 29 miles apart and all well isolated from major routes of travel of adjusting muskrats.

In my opinion, the observed changes in syndromes were due to changes in resistance of the muskrats rather than changes in virulence of the infectious agent - though the possibilities of changed virulence should never be ignored. The concept of changed resistance makes much more sense when considered along with the other "cyclic" manifestations, along with the increasing and decreasing of mean sizes of litters and the behavioristic changes that presumably accompanied changes in the physiology of the animals.

\section{CYCLIC PATTERNS IN BEHAVIOR CHANGES}

If changes in muskrat physiology are linked with "cyclic" year-groupings, then it would seem likely that changes in muskrat psychology might have similar chronologies.

Nothing much that is new about toleration of muskrats to crowding by their own kind has come out of the Iowa studies since preparation of my 1954 paper, but the trends of our data may here be reviewed.

For marshes dominated by ... choice food plants, spring densities of muskrats frequently exceeding the equivalents of five or six pairs per acre were tolerated during the year-groupings of 1941 to 43 and 1951 to 52 . Observed concentrations approached the equivalents of eight pairs per acre over sizable blocks of marsh in 1943 and 10 pairs per acre in 1952.

Maximum breeding densities for the same or the same types of marshes generally leveled off at the equivalents of two or three pairs per acre during the 1936 to 1937 and 1946 to 1947 year-groupings, even though much higher muskrat populations were present in 1946 to 1947 than in 1936 to 1937. (Actually, the spring of 1947 was one in which the muskrats showed less intraspecific tolerance than in 1946.) Intermediate concentrations occurred during the years intermediate in chronology between the one-two and the sixseven year-groupings.

It should be emphasized that the maximum spring concentrations shown during the above year-groupings are not explainable merely in terms of more muskrats being present in some years than in others. In the spring of 1936 , despite the low populations existing on the better Iowa marshes kept under regular observation, maximum breeding densities the equivalents of two or three pairs per acre still meant conspicuous numbers of battered transients working the marsh edges. Such transients represented a biological surplus in that animals in residence did not permit them to establish territories in the kinds of places that would be most attractive to muskrats, the relative abundance of favorable environment and the low populations of the muskrats, notwithstanding. When large numbers of muskrats remained on an area at times of acute intolerance toward crowding, breeding territories might be distributed with striking uniformity throughout good and poor environment, alike. The muskrats then seemed much more disposed to try to maintain themselves in inferior places than to try to crowd into the attractive places maintained and defended by their better-situated fellows.

In contrast, at times of the higher tolerances to crowding, the muskrats of observed marshes packed their breeding territories into the most attractive cattail and bulrush stands to such an extent that wide expanses of less attractive-but more or less habitable-environment remained sparsely occupied. The animals patently did not accept the poorer grades of environment when they could choose the better with no more trouble from antagonistic fellow muskrats than they usually had during the two chronological "cyclic highs" that I have studied.

These differences in social tolerances of muskrats of course affect the net habitability of a marsh or stream for the species. No greater numbers of the 
animals can be expected to maintain themselves than will be tolerated by their own kind, irrespective of whether, for example, sufficient food may exist to feed several times the numbers that are able or willing to stay there and face trouble to utilize it. The manifestations of overpopulation (including unrest, withdrawals, and fighting) have looked the same to me for the "cyclic low" maxima of two or three pairs per acre as for the "cyclic high" maxima of eight to 10 pairs.

I think it would be accurate to say that the muskrats feel crowded when they act crowded, at levels that are numerically low as well as numerically high; and that their population tensions during the breeding season differ with the year-groupings in ways that do not seem to be correlated with the more obvious climatic and environmental differences.

Three years of our Iowa studies - 1936, 1945, and 1946, all at or near chronological "cyclic lows" - were notable for cross-country movements of muskrats in summer and fall. Cross-country movements at this time of year are much more indicative of panic or desperation than the orderly adjustments up- and downstream or from shallow to deeper parts of marshes that may be expected in any year when muskrats become dissatisfied with the places in which they are living. Footloose wandering is one of the most hazardous of activities for muskrats and it ordinarily is not resorted to on any large scale unless something is very much wrong.

While 1936 was a year of great drought crises, the drought of 1945 was only of moderate intensity from the standpoint of central Iowa muskrats. There were several other years of our period of study in which drought conditions were as bad as, or worse than, in 1945 and during which no comparable cross-country movements occurred. And 1946 was not a drought year, nor a year of any events that seemed, to my eyes, unfavorable for muskrats; but entire study areas in central Iowa were abandoned by the muskrats in late summer and early fall, to the accompaniment of large-scale crosscountry movements and massing of new-comers in a few bodies of water. The year most comparable to 1946 in muskrat populations and in environmental conditions for muskrats was 1951, in the chronological "cyclic high," but practically no cross-country movements of muskrats were then detected.

The data we have on lengths of time that muskrat populations of foodrich marshes remained in their regular home ranges despite severe drought exposure in summer and fall also suggest big differences in behavior. Our best comparisons are provided by case histories, 1936 to 1952, of 44 local populations. Twenty-four populations remained an average of about five weeks after disappearance of the surface water before abandoning their home ranges to wander, and the other 20 remained an average of about three months. All except three of the 24 populations in the less tenacious group dated to years of chronological "cyclic lows" or impending "lows." Only four of the 20 populations of the more tenacious group dated to or near years of "cyclic lows," and three of these four showed the lesser degrees of tenacity for the group.

With the beginning of the Fifties, separation of populations into more tenacious or less tenacious groups became less satisfactory. The fall of 1952, which lined up with or surely came not long after a chronological "cyclic high," was a time of conspicuous abandonment of food-rich shallows on one of our marshes. During the droughts of 1953 and 1955, some populations abandoned food-rich home ranges and some did not.

Another fact that introduces doubt as to how good these observed differences in tenacity toward home ranges may be as criteria of "cyclic" influence is the lack of differences in behavior shown by populations wintering in drought-exposed though food-rich places. Data in hand relating to 36 local populations do not seem to reveal greater tendencies for abandonment under such conditions during years of chronological "cyclic lows" than dur- 
ing "cyclic highs" or any other years. The majority of the animals usually held on to their accustomed home ranges in winter as long as they could stay alive.

The chronological "cyclic low" year of 1956 was not, except in one respect, a year of distinctive behavior of muskrats in central and northern Iowa. However, the one population symptom that did stand out during the summer was so pronounced as to be without counterpart during the other years of our studies.

By early summer, the drought had left only two of our long-studied areas with substantial numbers of muskrats - Wall Lake with about 200 adults maintaining about 80 territories and Little Wall Lake with about 170 adults maintaining 67 territories. Both marshes were rich in muskrat foods, but, by September, Wall Lake was drought-exposed and so was more than half of Little Wall Lake.

The remarkable thing is that Wall Lake became nearly abandoned by its muskrats before the surface water disappeared. As early as the middle of June, while the deeper parts could still be navigated by canoe, I found evidence of territorial abandonment; and, within the next two weeks, abandonment continued to the extent that I could find only two maintained breeding territories left on the marsh. Following this period of abandonment, a population estimated at about 45 (consisting chiefly of very large animals) maintained itself in the dry cattails and bulrushes with slight further change until late fall.

At Little Wall Lake, only 20 of the 67 territories maintained in mid-June were exposed by drought in late June, July, and August, but most of these and at least 20 additional territories were abandoned without the appearance of corresponding numbers of animals elsewhere on the marsh. This occurred at the same time as the large-scale abandonment at Wall Lake. The remainder of Little Wall Lake's 67 territories (or about 25 scattered over about 100 acres of wet marsh) were productive, and the early fall population of muskrats was about 220. In late fall, a heavy ingress totaling about 330 muskrats from outside sources resembled the fall ingress of the "cyclic low" year of 1946 .

For one abandoned territory after another, at both Wall and Little Wall Lakes, the 1956 story was similar: Residents not only failed to show any tenacity in maintaining their territories during the drought but they did not even begin to await drought-eviction before departing. The food was abundant and of superior types, inches of water still covered the marsh bottoms, and the territories were not sufficiently crowded anywhere to promote much friction. The animals simply left, to take their chances trying to get along in strange environment, living for variable periods of time in places that were usually far less attractive than their old familiar ranges, and otherwise engaging in activities that had little pleasant future for the majority of the participants. Theirs was a special kind of mass recklessness.

\section{WHAT CAN THE SYNCHRONIES MEAN?}

Of course, the first question to consider with respect to cyclic phenomena in muskrat populations is the extent to which we are dealing with actuality.

To quote again, now from Errington (1954a):

Palmgren (1949) and Cole ... have discussed random series of numbers that fall in patterns similar to those of some fluctuations of animals. For one as doubtful of the validity of most population fluctuations as "cyclic" criteria as I have become ... their writings naturally leave me with heightened 
distrust of conventional methods of exploring "cyclic" possibilities in wild populations. . . .

So far as the Iowa muskrat data in my possession are concerned, I would say that straining to prove or to disprove their connections with the fluctuations of "North Woods" hares and grouse by concentrating on mere parades of numbers has scant prospect of getting anywhere unless it be farther toward analytical chaos. But, emphasis transferred from changes in numbers of muskrats to the synchronies in population symptoms that are not necessarily tied up with gross fluctuations of the muskrats seems to me most rewarding. At any rate, from the modest start we have thus made, we are entitled to say that the newer evidence as to "cyclic" changes or synchronies in muskrat physiology and psychology is worth considering.

Of population fluctuations of north-central animals, those of snowshoe hares and ruffed grouse may logically be suspected of reflecting extramundane influence if any may be - though it is apparent (Grange, 1949) that some of the more ordinary of environmental and climatic factors are important in the life equations of hares and grouse, as well. Of the known year-to-year fluctuations of animal life in this region with which the Iowa muskrat data here treated show synchronies, none would seem to be more indicative of a common denominator than the fluctuations of hares and grouse. I do not know what such a common denominator might be, whether it be labelled cosmic, astronomical, solar, extramundane, or something else.

I do not see how environmental or climatic changes, as usually defined or interpreted, can explain the synchronous decreases or increases in populations of hares and grouse of northern Minnesota and Wisconsin and the decreases or increases in litter sizes of central Iowa muskrats, nor why a series of peak years for hares and grouse should be the years during which young Iowa muskrats were found to be breeding during the calendar years of birth. Nor why peak years of hares and grouse should be the only ones during which any substantial proportions of central Iowa muskrats were known to recover from infections of the hemorrhagic disease, nor why the apparent resistance of central Iowa muskrats collapsed about the time that hares and grouse went into their declines hundreds of miles away.

And, among the population symptoms on which it has been more difficult to obtain quantitative data (but which have been prominent enough to deserve attention), we have Iowa muskrats adjusting to drought exposures, maintaining themselves in definite home ranges, tolerating crowding and trespasses on the part of neighboring muskrats, and living what could be called much more normal and peaceful and secure lives during the upgrade and peak years of hares and grouse. During the downgrade and low years of hares and grouse, Iowa muskrats behaved as if highly restless and irritable and living under a decided, if not wholly definable, handicap.

How could it be, for example, that exceptionally well-situated central Iowa muskrat populations of late summer and fall, 1946, engaged in spectacularly footloose wandering without visible incentive as the "North Woods" hares and grouse reached their "cyclic low," whereas, at more favorable "cyclic" stages, the muskrats at similar or substantially greater densities engaged in practically no footloose wandering, at times even despite drought exposures? Or that, in spring of 1947, the Wall Lake muskrats were so intolerant of crowding as to distribute themselves with notable uniformity at densities of about a pair per acre, throughout poor and excellent habitat, alike - and on Wall Lake and comparable marshes during the "cyclic high" of 1951-52, breeding populations congregated in the choicer habitats at densities up to 10 pairs per acre, at the same time that adjacent habitats having less attractiveness were almost or wholly unpopulated by muskrats?

I do not believe that these alignments are due to chance. If we had only 
one set of data that so lined up, I would not feel so confident about this, but, when several whole categories synchronize as well as they do over the period of study, the probabilities of chance being the explanation become sufficiently remote to encourage looking for something else. If we were to leave hare and grouse fluctuations completely out of our calculations, we would still have far too much of a residuum of synchronies in the Iowa muskrat data to dismiss on grounds of randomness. Surely, several of these phenomena must be tied up together, whether occurring with true periodicity or not.

\section{Once more, back to Errington (1957):}

As I see them, the year-to-year changes in physiology and psychology suggested by the muskrat data are changes only in degree - neither all this nor all that at any chronological "cyclic" phase. Some individuals had large litters and several of them, some few tenaciously hung on to their established territories or home ranges, and some others were resistant to the hemorrhagic disease during the six-seven year-groupings; but the prominence with which some trends stood out for the different year-groupings affords a basis for concluding that bona fide changes occurred.

Probably about a decade after becoming acquainted with Green and Larson's (1938) findings on hypoglycemia in snowshoe hares, I began thinking that the population symptoms I had been seeing in the mid-Thirties and mid-Forties might be those of overstimulation followed by exhaustion. Selye's work (1949) strengthened in my mind the exhaustion thesis in possible relation to "cyclic lows," and so did papers by Christian (1950) and Frank (1953; 1954; 1957).

Christian and Frank emphasized the role of stress in declines of highdensity populations. They have undoubtedly dealt with valid phenomena phenomena that may dominate population equations when intraspecific tensions become extreme. It is very conceivable that such stress reactions may be a principal agency of population collapse in the three- or four-year fluctuations of the vole, Microtus, which is phylogenetically the muskrat's closest living relative.

We cannot, however, stop with the stresses of population peaks if we are to search for any satisfying explanation for the chronologies and changes that are presented by the Iowa muskrat data. There is a lot more in sight than muskrat populations reaching peaks, to decline in consequence of builtup stresses.

If we again consult ... [ figures $15.1,15.2,15.3$ and 15.4], we may see how little the high- and low-density years of the muskrats are in uniform agreement with the years in which we see the most evidence suggesting either relieved or intensified stress - the one-two and six-seven year-groupings, respectively. Plenty of stress can occur in muskrat populations, not only at high numerical densities - as in 1943 - but also at other times when population densities are not and have not been very high numerically, nor high in relation to visible qualities of the occupied habitat.

To reiterate: Our Iowa muskrats living in superior types of marshes may be said to have acted crowded when they felt crowded, whether their breeding densities were two or 10 pairs per acre, or whether their fall populations leveled off at 10 or 20 or 35 animals per acre over sizable tracts. Whatever may be the reasons, when our nearly a quarter-century of data lined up according to certain year-groupings, the muskrats could show much intolerance at low densities and much tolerance at high densities.

I have been asked, many times, what I thought my data signified and 
many times have answered that I did not like to conjecture. My reluctance to theorize is partly due to a disinclination to flounder around outside of my fields of competence and partly, I am ready to admit, to a fear of perhaps making too good a case for something that might not turn out to be true.

I am willing to say that I think my data could be consistent with something like changes in ultraviolet radiation, as such investigators as Rowan (1950) and Shelford (1951) have proposed. As dwellers within our solar system, the muskrats may not spend much time in the direct rays of the sun or even outside of their burrows and lodges during daylight, but the possibilities of their being affected by radiation changes deserves more exploration than anyone, to my knowledge, has given them to date.

If the combination of synchronies to which I am calling attention can be explained with recourse to nothing more extraterrestrial than ordinary sunlight, they are still not explainable in terms of the meteorological changes customarily reported by Weather Bureau stations.

Nor are they explainable in terms of quantities of staple foods available to the muskrats.

There remains, however, the possibility that changes in quality of food may have underlain some of the population symptoms associated with cyclic year-groupings shown by the Iowa muskrat data. I know of no place in the literature where I have felt that this foodquality concept had been thoroughly developed with respect to any population cycle but have come to feel least surprised when finding it advanced by Finnish and Scandinavian authors - such as recently by Svärdson (1957).

Braestrup's (1940; 1942) hypothesis was that cyclic die-offs may be due to lack of availability of essential minerals in plant foods. He noted similarities in the cyclic symptoms of wild species and some of the deficiency ailments of domestic cattle. In his 1942 paper, he cited the Swedish investigator, T. Hedlund, as having found no potassium deficiency in the soil, though bacterial action resulted in great variation in the amount absorbed by the plants. "It may be possible therefore to account for the regularity of the cycles in numbers [ of wild species ] by oscillations in the biological and chemical processes in the soil regulated by or adjusted to climatic cycles" (Braestrup, 1940).

Braestrup's hypothesis is reflected in Kalela's (1941) careful study of lemming fluctuations in Finnish Lapland, the latter author's introduction mentioning climate-dependent variations in quality as well as quantity of food. Somewhat later, Kalela (1944), after considering evidence on fluctuations in different parts of the world and the hypotheses concerning vitamin and mineral deficiencies (including Braestrup's), formulated a hypothesis of his own to the effect that meteorological cycles may through influencing plant metabolism exert in turn an influence on animal life. His main new concept was one of critical periods during the growing season when adverse influences might profoundly depress plant metabolism and thus indirectly the animal life dependent thereon. One big theoretical advantage of Kalela's concept is that it might explain some of the regional differences to be 
seen in cyclic manifestations. Kalela properly recognized the limitations of his hypothesis, but it has features that serious students of biological cycles should carefully think over.

Shelford (1951) also emphasized possible critical periods in his studies of physical factors in relation to animal populations of the Upper Mississippi Basin, concluding, among other things, that a wide variety of both vertebrates and invertebrates were especially sensitive to changes in short-wave radiation during the spring months. Moisture appeared to be paired with intensity of ultraviolet light as population factors for several species that he studied. He did find such a number of decided contrasts presented by some of the species that generalizations become very difficult, indeed, and there are variables in the data needing more accurate dissociation than currently looks possible, including behavioristic responses of animal life to weather conditions and sunlight. Then, too, some of the correlations of population phenomena (for example, of the bob-white quail) with density or emergency factors seem to me of greater over-all significance than the correlations of the data plotted in Shelford's ultraviolet hydrograms - though, in so writing, I do not wish to minimize the possible significance of the ultraviolet hydrograms.

Rowan (1950) considered the likelihood very strong that the unknown factor behind the "10-year cycle" in Canada "might be ultraviolet radiation (or some as yet undetected factor of analogous nature) exerting an influence on animal health in general." His grounds for reasoning include the following:

(f) That the cycle is especially developed in the arctic and subarctic, where winter shortage of ultra-violet supply has been demonstrated;

(g) That migratory birds, evading the northern winter altogether, appear to remain immune from the effects [that is, in terms of violent synchronous fluctuations];

(h) That at times of crash numerous diseases are on record, predisposition to disease suggesting itself as the cause;

(i) That large-scale decimation at the crash may be due to a deficiency condition or nutritional imbalance. ...

Those facts, added together, would indicate at least a reasonable experimental approach to the ten-year cycle on a nutritional basis. Such an attempt is now under way.

What any one person can expect to do in arriving at the answer to the 10-year cycle I cannot say. The efforts of the rather numerous people who believed that they had done so in the past have all left plenty of major questions. No one person has in my estimation accounted for anywhere nearly the full range of phenomena that $I$ at least think are related, and this perhaps may always be the case.

Still, it seems to be realistic to think that such a tremendous amount of work in connection with cyclic problems may profitably be done in the future that population students should be stimulated by potentialities rather than discouraged by the difficulties in sight. 
Appendices 



\section{Appendix $A$}

\section{Taxonomy and Phylogeny of the Muskrat}

For ADVICE IN THE PREPARATION of this Appendix, I am indebted especially to Dr. E. Raymond Hall, University of Kansas, who critically read and worked over for me one of the preliminary versions; to Dr. George Gaylord Simpson, American Museum of Natural History, for very informative earlier correspondence; and to personnel of the U.S. National Museum for suggestions helpful to me in winnowing a formidable literature that was largely outside my accustomed reading.

\section{THE LIVING MUSKRATS}

Hollister's (1911) systematic synopsis of the muskrats listed three full, living species, but Davis and Lowery (1940) have shown that two of these are only subspecies of one species. This would leave one species native to the mainland of North America and another for the island of Newfoundland. Hall (letter, January 10, 1949) considered the Newfoundland muskrat as but

an allopatric species - one which owes its characters in large part to isolation and which differs from the mainland species in a degree scarcely more than some of the mainland subspecies ... differ from one another. The muskrat, then, in recent time may conveniently, and perhaps correctly, be thought of as comprising a single species.

On the basis of the more modern literature, sixteen variants recognized by students of geographic variation and evolution may be distinguished. If the muskrat of Newfoundland be retained as the separate species, Ondatra obscurus, in this classification, it should be with some expectation that this form ultimately will be assigned as a sub- 
species to the mainland species, Ondatra zibethicus. The spelling that is used here is that of Davis and Lowery (1940), instead of the Ondatra zibethica of most authors, on grounds of Ondatra being "a French Canadian word of Iroquois Indian (= Huron) derivation and masculine in gender."

No attempt will be made to incorporate a taxonomic critique of the muskrats in this book. For reviews of the technical characters of the first 14 of the 16 forms to be described, the reader may consult Hollister (1911) or the usually more readily accessible condensed accounts of Anthony (1928, pp. 442-46); the other two of the sixteen may be conveniently referred to in Hall (1946, pp. 567-69).

The known living forms, following the order given by Miller and Kellogg (1955, pp. 615-19):

1. Ondatra obscurus (or Ondatra zibethicus obscurus?) (Bangs), a rather small, dark muskrat, is isolated in its Newfoundland range by the Strait of Belle Isle and the Gulf of St. Lawrence from the nearest mainland forms, $O$. $z$. aquilonius to the northwest and $O$. z. zibethicus to the southwest.

2. Ondatra zibethicus zibethicus (Linnaeus), of large size for a muskrat, dark brown in color except when pelage is bleached or otherwise atypical. It is the common muskrat of the eastern half of the United States and southeastern Canada and the one with which the intensive Iowa studies have dealt.

3. Ondatra zibethicus macrodon (Merriam), the largest of the muskrats, with black and brown color phases and much variation in appearance of pelage. It is the muskrat of Maryland and Virginia coastal marshes and some adjacent parts of the Middle Atlantic coast.

4. Ondatra zibethicus albus (Sabine), is a small muskrat, paler than $O$. z. zibethicus, centering its range in Manitoba.

5. Ondatra zibethicus aquilonius (Bangs), similar to O. z. zibethicus in many ways but described as having a brighter and richer coloration. It occurs in Labrador and adjacent parts of Ungava and Quebec.

6. Ondatra zibethicus spatulatus (Osgood), a dark muskrat, covers much of northwestern North America. It is usually described as small, but Fuller (1951) considers that it "compares favorably in size" with typical $O$. z. zibethicus.

7. Ondatra zibethicus zalophus (Hollister), small like the usually described $O$. z. spatulatus but more reddish in color. It is of restricted distribution about the base of the Alaska Peninsula.

8. Ondatra zibethicus osoyoosensis (Lord), like the usually described spatulatus but larger. It is the principal muskrat of the Rocky Mountains of western United States and the southwestern corner of Canada.

9. Ondatra zibethicus occipitalis (Elliot), like O. z. osoyoosensis 
but paler and redder. It has a very small range along the Oregon coast.

10. Ondatra zibethicus mergens (Hollister), paler and smaller than $O . z$. osoyoosensis but still a fairly large muskrat. This subspecies centers its range in northern Nevada and parts of adjacent states.

11. Ondatra zibethicus goldmani Huey, a light-colored mediumsized muskrat,

\section{and}

12. Ondatra zibethicus bernardi Goldman, another pale but smaller muskrat, are both subspecies of very restricted range in the southwestern tip of the United States.

13. Ondatra zibethicus pallidus (Mearns) is a small reddish muskrat of extreme southwestern United States.

14. Ondatra zibethicus ripensis (Bailey) has a darker pelage than its neighboring subspecies $O . z$. pallidus but is similar to it in size. Its range centers in southern Texas and southeastern New Mexico.

15. Ondatra zibethicus cinnamominus (Hollister), a pale and reddish subspecies smaller than either $O . z$. osoyoosensis or $O . z$. zibethicus. It has a range covering much of the Great Plains lying between the ranges of the latter two.

16. Ondatra zibethicus rivalicius (Bangs), somewhat smaller and darker than $O . z$. zibethicus. It has a restricted though densely populated range in the coastal marshes of Louisiana and neighboring states.

A certain amount of intergrading between the subspecies of $\mathrm{On}$ datra zibethicus occurs where subspecific ranges are not separated by effective natural barriers. Hall's (1946, p. 566) reference to the muskrats of the northern edge of Nevada is illustrative: "Considering all features, the animals are intermediate, and I think, intergrades between mergens and osoyoosensis, but show greater resemblances to the latter." Sometimes, wide areas are noted where specimens prove to be intermediate between two subspecies but are assigned to whichever subspecies they resemble most closely-for example, see Preble's (1908) comments on a number collected from Athabaska and Great Slave lakes of northwestern Canada. Even for O. z. zibethicus and the southern coastal $O$. $z$. rivalicius, the ranges of which were once thought of as not overlapping, intermediate specimens from Baton Rouge, Louisiana, have been reported (Hamilton, 1943).

The round-tailed muskrat or Florida water rat (Neofiber alleni True) is related to the muskrat and is intermediate in size and appearance between living muskrats and the meadow mice of the genus Microtus. It lives in suitable habitats of Florida and the southeastern extreme of Georgia, outside the range of any living member of $\mathrm{On}$ datra. 


\section{THE FOSSIL MUSKRATS}

The oldest known species of muskrat seems to be Ondatra idahoensis Wilson, about the same size as Neofiber alleni, described from the Grand View and Hagerman deposits of southern Idaho. Wilson (1933) wrote of the containing deposits:

In the present state of our knowledge, an exact determination of age based on the relationships of the Idaho rodent fauna cannot be made. However, available evidence indicates a stage of development not earlier than upper Pliocene or later than middle Pleistocene. Presence of Mimomys primus in the Hagerman points to an upper Pliocene or lower Pleistocene age, more probably to the former.

Upon the advice of Dr. Edwin C. Galbreath, University of Kansas, our foremost student of fossil muskrats, five other named and described extinct species may be listed in order of geological age, from the oldest to the youngest:

Ondatra hiatidens (Cope), from Pennsylvania.

Ondatra annectens (Brown), from Arkansas.

Ondatra kansensis Hibbard, from Kansas.

Ondatra nebrascensis (Hollister), from Nebraska.

Ondatra oregonus (Hollister), from Oregon.

All of the latter five are from Pleistocene deposits and all except $O$. nebrascensis are of small size, like Neofiber or slightly smaller. $O$. nebrascensis agrees in size with the living $O$. zibethicus and appears closely related to it, whereas the smaller species may comprise a separate line of ascent.

\section{THE ANCESTRY OF THE MUSKRATS}

I was informed by Galbreath (via Hall's letter and enclosures of January 10, 1949) that the fossil record has not yielded the undoubted ancestor of Ondatra. This affords us no strong reality to anchor to, but, for whatever interest such may hold for the reader, we might go a little into the more reputable speculations and discussions to be found in the literature.

While inquiring many years ago of staff members of the U.S. National Museum concerning the phylogeny of the muskrats, I had been referred to Hinton's (1926) monograph on the Microtinae as the best source of information of that time. On his page 50, he had stated: "The North American genus Phenacomys appears to represent, in its essential characters, the common stock from which two of the most important groups; namely, Pitymys and its associates and Microtus and its closest allies, have descended."

Then, relative to the muskrats (his pp. 70-74):

Notwithstanding its high specialization for aquatic life Ondatra, peculiar to North America, is apparently more closely related to Phenacomys than to any other Microtine genus, and it has descended from some primitive 
Phenacomys-like stock. In one respect, the palate, it is even a little more primitive than any known Phenacomys. .. .

Apart from the primitive characters above mentioned, the skull is highly specialized, it is very large and massive, and in general form and structure closely resembles the skull of the more highly specialized species of Microtus.

Some of the difficulties of tracing back ancestral forms of Ondatra may be surmised from reading Wilson's (1937) paper on the upper Pliocene rodent faunas of southern Idaho, from which he described the oldest known species of muskrat, $O$. idahoensis. Among other things, he referred to a sharp "faunal break from the middle Pliocene as evidenced by: (a) decided increase in myomorph population; (b) decided decrease in number of extinct genera; (c) first appearance of many modern types." The sharpness of the faunal break is further emphasized by his statement that few of the upper Pliocene genera, including Ondatra, have known ancestors in the earlier Pliocene.

\section{Appendix B}

\section{Information on the Biotopes and Muskrat Populations of Round Lake, 1945-58, Contributed by James G. Sieh}

From Sieh's mimeographed REPORT of June 14, 1949, to the Biological Department of the Iowa State Conservation Commission (Biological Briefs - Round Lake, Clay County):

During the summer of 1945 little ... vegetation remained. ... In an effort to re-establish vegetation ... the area was partially drained during the summer of 1946. . . Drainage continued throughout the summer of 1947 until both Round and Trumbull Lakes were almost dry (muddy conditions prevailed). This lowest level continued from the last week of September through the first three weeks of October. . . The present lake levels were established by placing stop logs at the outlet structure of Trumbull Lake before the spring thaw of 1948. Soon after the spring thaw ... crest level of the outlet was reached and the lake levels have remained approximately constant since. . . The stands of emergent species are [by 1949] becoming more dense. . . Sago pondweed is exceedingly abundant which was not the case during the summer of 1948 . Other pondweeds are numerous and increasing.

According to Sieh's remarks as to the status of certain marsh plants, hardstem bulrush was "along shore everywhere; some patches throughout marsh and continuing to spread." Narrow-leaved cattail had "large stands along shore and some stands throughout marsh," but broad-leaved cattail was probably present only in limited 
amounts. Reeds were present as small stands but apparently spreading, and the same was said of burreed. Sweet flag (Acorus calamus) was common among stands of burreed. Duck potatoes were "common along north and east margins of the shore at the edges of bulrush and open water."

To quote from a letter (July 9, 1958) from Sieh: "The muskrat population continued at satisfactorily high levels through 1951 and 1952; however, my estimation is that it started downhill during the extreme drought years [of 1954-57] . . . and the muskrat population for all practical purposes reached zero. During these dry years the emergent vegetation has become very dense and abundant."

\section{Appendix C}

\section{Calculations of the 1950 Fall Population of Muskrats at Wall Lake}

The Wall Lake trapped carcasses for late fall, 1950, may be classified in two groups that are nearly enough equal to be called equal: 471 and 481. The 471-specimen group in turn is divisible into nearly equal series: 236 taken during the first part of the week-long trapping season and 235 in the second part. For the early-caught 236, the adult:young ratio was 40:196, or 17.0 per cent adults; for the later-caught 235 , the ratio was 26:209, or 11.0 per cent adults. Our figures from large series of datable Iowa specimens support a rule-of-thumb generalization that about two-thirds of the adults of a muskrat population will be trapped by the time that about half of the entire population is trapped by efficient methods.

The first 90 muskrats of the datable sample of 471 consisted of 25.6 per cent adults; when 170 were caught, the sample then consisted of 18.2 per cent adults; at 236, it was 16.8 per cent adults; at 271 , it was 14.8 per cent adults; and, at the full 471 , it was 14.0 per cent adults. The other 481 of the trapped carcasses, the data for which could not be segregated in any order of trapping, had 12.1 per cent adults compared with the 14.0 per cent in the 471 , so it may be assumed that the falling off in percentages of adults progressed in about the same way in the whole collection of 952 carcasses. Both major subdivisions - the 471 that could be split up chronologically and the 481 that could not be - were actually trapped at comparable rates.

The age ratio obtained for the first 90 muskrats of the 471-group should therefore apply fairly well to an equivalent number in the 48l-group, so the figure of about 25 per cent adult should be appli- 
cable to twice 90 or to about 180 muskrats. Carrying this on, there should be about 18 per cent adults for twice 170 , or for the first 340 taken; about 17 per cent adults for twice 236, or for the first 472 taken; about 15 per cent adults for twice 371 , or for the first 742 taken; about 14 per cent for twice 471 or for the catch at 942 . In actuality, the entire sample of 952 contained 13 per cent adults. This falling off in percentage of adults with continuation of the trapping gives, when plotted on coordinate paper, a useful curvilinear regression.

The population of adult females maintaining territories at Wall Lake figured out at about 100, as of July, 1950, plus associated males and plus, possibly, some females not living in regular territories. No evidence of significant mortality of adults was found after midsummer, and the sex ratio of adults in the trapped carcasses may be accepted as representative of that existing in July.

The adult females under suspicion of living away from established territories were, of course, those not conceiving young, or else conceiving irregularly, in 1950. All together, 24 of the 79 adult females in the trappers' catches fell in the latter categories, but of the 24,11 unbred females and two having single litters in early July came from places where territories were known to have been well maintained despite shortage or absence of males. This would leave 11 adult females of the trapped sample that might not have had established and recognizable territories, but some of these females were surely maintaining territories, as well. About a half dozen adult females may be estimated as the number living in other than established territories up to midsummer.

A 106-female base applied to the observed sex ratio in adults would give 60 males, or a total of 166 adults after the known period of adult mortality had passed. Subtraction of the 124 adults recorded in 952 trapped carcasses would then leave a figure of 42 adults in the remainder of the population - assuming that the population at Wall Lake was a self-contained unit in 1950, which all evidence indicates was true.

According to rule-of-thumb formula, about two-thirds of the adults must have been taken at Wall Lake in 1950 when the trappers' catches reached the vicinity of 800 . If 800 be accepted as the half-way mark, twice 800 would give a figure of about 1,600 muskrats of all ages for the whole marsh. The 1,600-figure thus arrived at may be tested by extrapolating to 1,600 the previously mentioned curvilinear regression defined by the age ratios in the Wall Lake specimens. If 1,600 had been taken, the adults theoretically should have comprised around 11 per cent of the entire population at Wall Lake in the late fall of 1950. The total population figure of 166 adults arrived at through the field data would comprise 10.3 per cent of a total population of 1,600 .

From the sample of 79 adult females conceiving 1,474 young in 1950, it may be calculated that the approximately 106 adult females 
living through the whole breeding season conceived about 1,980. To these must be added the number conceived by adult females that were lost in the early summer period of mortality, plus the number conceived by precocious young.

Somewhere between 28 and 35 adult females were judged lost through hemorrhagic disease, etc., from spring to midsummer, of which 10 were lost between late April and the last of May and 18 to 25 (the best evidence suggests about 22) during June. These lost females were mostly occupants of parts of the marsh characterized by efficient breeding, and there is no reason to think that they had not been normally active as breeding and nursing mothers almost up to the times of their death. Thirty-seven of their surviving neighboring females each conceived a mean of 9.2 young in the time that the April-May victims had been alive, so those dying may be calculated to have conceived about as many young individually before their deaths as did the others in the same period. As nearly as this can be figured out from the data at hand, the 10 early-doomed ones conceived about 90 young and the approximately 22 late-doomed ones about 313 young, or between them, in rounder numbers, a total of about 400 . Perhaps half of these young stood fair to good chances of being reared past weaning, whatever happened to them later.

If 1,600 be accepted as the figure for the total late fall muskrat population at Wall Lake, in 1950, and 166 as the number of adults therein, a figure of 1,434 young of both sexes could be arrived at. A ratio of 53.4 per cent males in the trapped sample of 828 young of the year would mean a total of about 670 young females in the total population of 1,600. Prorating of the 22 precocious young females in a sample of 386 females born in 1950 would give about 38 late-breeding, single-litter young females in the population. These, at a mean of 5.3 young per litter, should have conceived about 200 young in 1950 .

Addition of the figures of 1,980 conceived young assigned to adult females that were still present in the fall, 400 young assigned to adult females dying before midsummer, and 200 young assigned to precocious young females of the year would give a grand total of about 2,580 young muskrats conceived at Wall Lake during the breeding season of 1950. No basis exists for calculating the number of fetuses resorbed, but resorption can be here ignored.

Of the 204 litters represented by placental scars for 1950 in the 79 adult and 22 precocious young females of the 952 trapped specimens, 61 litters averaging 7.3 per litter and totaling 439 were born from late July through September. This represented 27.6 per cent of the young conceived by the whole trapped sample. But the 111 young classed as "kits," or those born during much the same late-season period, comprised only 13.4 per cent of 828 young of the year and only 25.3 per cent of their age-class conceived!

Compared with the poor survival of the late-born young, those born from April to mid-July obviously did much better, but even so, 
heavy losses of early-born young were noted during the field studies.

Of $61 \mathrm{Wall}$ Lake litters handled during the field investigations of spring and early summer, 57 yielded sufficient data to justify statements as to known or probable fates. Thirty-two or 56 per cent of the sample of 57 litters were judged to have gotten along well, rearing a mean of perhaps 6 young of a mean of 7.1 born; 8 or 14 per cent of the litters suffered severe losses, being reduced to a mean of about 3 by weaning time; and 17 or 30 per cent of the litters were classed as lost. The few young that may have survived in the "lost" litters may be assumed to have been offset by postweaning mortality among the 8 litters having severe but not complete early losses. This would give us a mean of 3.8 young, or 54 per cent reared to more or less independent ages for the mean of 7.1 young born per early summer litter. In this case, the rate of postweaning juvenile mortality was probably relatively low - perhaps about enough to bring the survival rate of animals conceived down to about 45 per cent.

The 45 per cent survival rate should apply to a total of 650 young known to have been conceived in early-season litters by the adult females in the sample of trapped carcasses examined, which amounts to 293 early-season young in the sample. The total number of 828 young also included, it may be recalled, 111 late-born, or "kits." Subtraction of 293 early young and 111 "kits" from the total number of 828 young in the sample would leave 424 young of the year in the midseason age class.

The mid-season breeding was by far the most successful, not only in terms of net productivity of numbers of young on the marsh but also in proportions of conceived young that were reared. The figures from the population sample for mid-season would give a survival of 424 or 84 per cent of the 502 mid-season young conceived, which is an exceedingly high rate but not at all out of reason for a productive and well-situated population. Accordingly, the mid-season segment of 502 (31.2 per cent of the 1,591 young conceived by the breeding females of the trapped sample in 1950) grew up to represent 424 or 51.2 per cent of the 828 young in the sample. The early-season segment of 650 or 40.9 per cent of the 1,591 young conceived gave only 293 or 35.4 per cent of the 828 young. The late-season segment of 439 or 27.6 per cent of the 1,591 young conceived gave only 111 or 13.4 per cent of the 828 young of the year in the sample.

Precocious young females of the trapped sample conceived a total of 117 young or 26.7 per cent of the 439 late-season young conceived. The same ratio would credit about 30 of the 111 late-born young to the precocious females, or 3.6 per cent of the total of 828 young of the year that were examined.

The appearance of the placental scars of precocious young females at Wall Lake suggests later breeding than that done by the fully adult females. Compared with forty-two, nineteen, and two litters of adult females assigned to late July, August, and September, respectively, 
five, nine, and eight litters for the precocious young may be assigned to these periods. The excessive lateness of many of the litters born to the precocious young females further reduced the population significance of their slight contributions to the productivity of the marsh, for the life expectancy of very young animals entering an Iowa winter is substantially less than for the young of more nearly "normal" development.

\section{Appendix $\boldsymbol{D}$}

\section{Descriptions of Central Iowa Stream Areas and Outlying Waters}

The Story City block lies in T.85N. and R.24W., in the northwest corner of Story County. Keigley's Branch is a medium-small creek, varying in appearance from an open pasture stream to a woodland stream and having a bed about 10 feet wide on the tracts (sections 26 and 36 and a corner of Section 35) kept under regular observation. It is joined near the southeast corner of Section 36 by a smaller creek not much larger than a brook, the upper part of which is a drainage ditch appearing above the ground at the mouth of three big tiles. The regularly observed parts of the smaller creek consist of a two-thirds of a mile stretch of largely unditched creek (Section 25) lying downstream from and draining the small, artificial, artesian-fed Lake Comar and upstream, a three-mile stretch of the ditch (sections 3, 10, 15, and 22). The drainage ditch, being tile-fed, not only at its source but in places along its length (and also having a small artesian drain at the upper edge of Section 22), has a more uniform flow than Keigley's Branch.

With the exception of Lake Comar and its ponds, the brooks, gravel-pit pools, field ponds, and miscellaneous muskrat habitats in sections 25 and 26 were observed along with the designated stretches of the Keigley's Branch drainage. Of these, a wet gully and associated small bog in the southeast corner of Section 26 and scattered hay-field ponds in the east half of Section 25 yielded especially interesting data at times. All together, an area of six square miles of land drained by Keigley's Branch and the ditch was kept under regular observation.

Some years after studies were begun on the above six square miles, a stretch of a mile and a half of relatively untampered Skunk River (including about a half square mile of bottomlands in sections 18, 19, and 30, T.85N., R.23W., southeast of Story City) was added to complete what may be called the Story City block. 
Less regularly observed were stretches of Keigley's Branch in sections 22 and 27 lying upstream from the main area; sections 30 and 31 of T.86N., R.24W., west of Randall, Hamilton County; the headwaters of Keigley's Branch and a series of wet gravel pits lying about four miles southeast of Stanhope in Hamilton County; and a mile and a half of brook near the headwaters of Indian Creek, sections 16 and 21 of T.85N., R.22W., west of McCallsburg, Story County. The Indian Creek area is eight miles east of the Story City block but handled in connection with the latter for convenience. It was put under observation because it exemplified a very small stream along which muskrats could at times live in fair abundance. Muskrat habitats in the vicinity of Story City that were sometimes visited included the impounded artesian Lake Comar, two miles south of Story City; brooklike Long Dick Creek in sections 17 and 18, T.85N., R.23W., upstream from the place where it enters Skunk River southeast of Story City; and various stretches of Skunk River and environs between Story City and Ellsworth and between Story City and Ames, especially those lying about three miles east and southeast of Gilbert. A mile and a half stretch of drainage ditch south of Wall Lake in Wright County (sections 14, 22, and 23, T.90N., R.24W.) was also studied for a few years; it is included here, although it lies many miles north of the Story City block.

The Ames-Gilbert block is more extensive than the Story City block. The data presented were largely obtained from a nine-mile stretch - exclusive of minor windings - of the more permanent channel of Squaw Creek, and outlying waters in sections 7, 18, 19, 20, 29, 32, 33, and 34, T.84N., R.24W. of Story County and sections 35 and 36, T.85N., R.25W., and 1, 2, and 12, T.84N., R.25W. of Boone County. The Squaw Creek area was subdivided into tracts A-F (Figure 10.2) to facilitate reference. Its area encloses ten square miles of land. Squaw Creek is larger and usually has more favorable water conditions than Keigley's Branch.

Tracts D-F have the most outlying waters, though there is a short string of oxbow pools occasionally used by muskrats east of Squaw Creek in lower Tract C. The oxbows of Tract D west of Squaw Creek form a complex series of more or less shallow pools extending through most of the tract, generally parallel to and within 250 yards of the course of the main stream. These furnish marginal habitat for muskrats from both standpoints of food and water.

In Tract $\mathbf{E}$ are several places that tend to be deficient in water, but the disadvantages thereof for muskrats are partly offset by the usual availability of that splendid food, corn, which is raised year after year in the fertile bottomlands. The two Rainbolt Ponds of the southwest quarter of Section 7 of Tract $\mathrm{E}$ may have no muskrats or may be crowded with them, depending upon the year. A pasture brook lying to the southeast of the Rainbolt Ponds may likewise have many muskrats, especially at a pool in front of a big tile at the head of the brook. 
Another pool, this one at the head of a short ditch along the BooneStory County line near the upper middle of Tract E, may or may not have muskrats. Then, there is a large, food-poor pasture pond known as Hutchinson's Lake in the northwest part of Tract E, which is connected by a ditch with the smaller York Pond in lower Tract F.

York Pond goes dry more quickly but is much more favorably situated with respect to food than is Hutchinson's Lake. In Section 1 of lower Tract F, in addition to York Pond, there are numerous oxbow pools in the woods and pastures bordering the upper part of the creek, of which only two sets are important enough to list. One is near the west center of the section, and the other is west of Squaw Creek in the line of drainage of some roadside ditches between sections 1 and 36.

Upper Tract $\mathrm{F}$ has (1) a county drain with a pool near the middle of Section 36, (2) a small creek running through the northwest quarter of the same section to join Squaw Creek, (3) an oxbow series east of the junctions of Squaw and Montgomery creeks in the east center of Section 35, (4) an oxbow north of Squaw Creek near the north boundary of the observational area, (5 and 6) two series of gravel-pit pools in the northwest quarter of Section 35, (7) a roadside culvert near the northwest tip of Section 35, (8) a series of pasture ponds near the west center of Section 35, (9) a stretch of the small Montgomery Creek lying less than 100 yards south of the above ponds, and (10) an intermittent tributary of Montgomery Creek running northeastward from near the southwest corner of Section 35. All of these places have muskrats at times, and some constitute fair habitat, especially in moderately wet years when raidable corn fields are planted nearby.

Three miles north of the boundary of the Squaw Creek observational area and about a mile and a half east of Squaw Creek at its nearest place is a pasture pond on the land of J. H. Turner, near the north central edge of Section 14, T.85N., R.25W. Boone County. It became spectacularly productive of muskrats during a wet-year period. The part of this pond occupied by the muskrats is a two-acre tract dominated by duck potato, whereas about a half acre of the same pond extending west of the Turner property into a neighbor's hog lot is only a mud hole with neither emergent vegetation nor muskrats. Overflow and seepage from the pond drains into smaller ponds and boggy ravines, but these are far less attractive to the muskrats.

Tracts $\mathbf{G}$ and $\mathbf{H}$ of Figure 10.2 are observational areas along Onion Creek north and northwest of Ontario and east of Jordan. Tract G, of sections 19 and 30, T.84N., R.24W., Story County, actually includes a small part of Boone County adjacent on the west. Its outlying waters are a county drain just north of the creek along the BooneStory County line, roadside ditches near the northwest corner of Section 30, and a series of marshlike ponds covering possibly two acres near the middle of Section 19 (which is only about a half mile from Squaw Creek in the middle of Tract C). Onion Creek in Tract H runs 
mostly through the south halves of sections 27 and 28 and through the northeast and northwest corners of sections 33 and 34, T.84N., R.25W., Boone County. Of the two Onion Creek tracts, Tract $\mathrm{H}$ has a smaller creek running through open pasture but with corn fields planted within 25 to 50 yards of the water's edge at several places that are used by muskrats. The creek in Tract $\mathrm{G}$ is more food-poor, running through much woodland pasture.

Southeast of Ames and upstream and downstream from the junction with Squaw Creek, a mile stretch (Section 12, T.83N., R.24W.) of straightened Skunk River was kept under regular observation during the early years of the muskrat investigations. Downstream, Skunk River and some oxbow pools in what was once the bed of Squaw Creek in Section 13 were sometimes visited. A much wider stretch of straightened Skunk River, three miles in length and beginning in Section 34, T.82N., R.23W., south of Cambridge and extending two miles farther south into Polk County, yielded supplementary data for years. This stretch is bordered by many corn fields and willow thickets.

\section{Appendix $E$}

\section{Central Iowa Weather, 1932-57}

The SUMmer AND FALL of 1932 antedates our period of regular muskrat investigations, but the weather at those times was not without influence on the muskrat populations later worked with. A wet August (7.68 inches), followed by rains of 1.80 and 1.42 inches for September and October and an above-normal 2.42 inches for November, left central Iowa muskrat habitats in good condition. The winter was mild (January had an average temperature of 32 degrees Fahrenheit), with close-to-normal precipitation. Very low raw fur prices (muskrat pelts averaged $\$ 0.30$ ) discouraged exploitation of the muskrats by fur trappers, so a substantial muskrat population was still present in the spring.

April, 1933, was dry, with 1.08 inches; May, wet with 6.11 inches; June was hot (average of 77.4 degrees) and distinctly dry (1.02 inches). The months from July through December were, except for September with its 4.86 inches, more or less drier than normal but not enough to make much difference to the muskrats. A generally abundant muskrat population wintered on the central Iowa stream areas that I most frequently visited.

In 1934, March and April each had less than 0.75 inch; June, 
TABLE E. 1

Some Monthly Averages and Extremes Shown by 82 Years of Weather Records (Through 1957), Ames, Iowa*

\begin{tabular}{|c|c|c|c|c|c|c|c|}
\hline Month & $\begin{array}{c}\text { Average } \\
\text { Temper- } \\
\text { ature }\end{array}$ & $\begin{array}{c}\text { Highest } \\
\text { Temper- } \\
\text { ature }\end{array}$ & $\begin{array}{c}\text { Lowest } \\
\text { Temper- } \\
\text { ature }\end{array}$ & $\begin{array}{c}\text { Average } \\
\text { Precipi- } \\
\text { tation }\end{array}$ & $\begin{array}{c}\text { Highest } \\
\text { Precipi- } \\
\text { tation }\end{array}$ & $\begin{array}{l}\text { Lowest } \\
\text { Precipi- } \\
\text { tation }\end{array}$ & $\begin{array}{c}\text { Greatest } \\
\text { 24-Hour } \\
\text { Precip. }\end{array}$ \\
\hline January . . . . . . & 20.0 & 63 & -37 & 0.90 & 3.57 & 0.00 & 2.07 \\
\hline February....... & 23.2 & 76 & -31 & 1.00 & 3.09 & 0.00 & 1.72 \\
\hline March ........ & 35.6 & 89 & -18 & 1.62 & 4.49 & Trace & 1.90 \\
\hline April . . . . . . & 49.2 & 95 & 7 & 2.67 & 6.35 & .0 .40 & 2.21 \\
\hline May. & 60.3 & 104 & 18 & 4.28 & 12.28 & 0.32 & 4. 54 \\
\hline June. . & 69.8 & 104 & 36 & 4.69 & 13.42 & 0.87 & 3.71 \\
\hline July. . . & 74.7 & 109 & 39 & 3.25 & 16.31 & 0.04 & 4.16 \\
\hline August . . . & 72.4 & 107 & 36 & 3.81 & 14.67 & 0.53 & 5.95 \\
\hline September. & 64.2 & 102 & 22 & 3.82 & 12.07 & 0.16 & 4.30 \\
\hline October... & 53.0 & 91 & -7 & 2.36 & 6.24 & 0.03 & 3.45 \\
\hline November..... & 37.5 & 81 & -19 & 1.46 & 7.71 & 0.02 & 2.44 \\
\hline December...... & 24.4 & 68 & -29 & 1.02 & 5.29 & 0.02 & 2.00 \\
\hline
\end{tabular}

* Temperature in degrees Fahrenheit; precipitation in inches.

with 1.24 inches, was far below normal. May and June also had temperatures averaging nearly 8.5 degrees above normal. July had 3.27 inches of rain, still slightly below normal, and an average temperature 4.2 degrees above normal. The drought really broke with rains of 1.09 inches on August 30, 1.58 inches on September 3, 1.06 inches on September 25, and 2.00 inches on September 26, and a total of 5.61 inches, or about 1.75 above normal, for September - which also had an average temperature 4.2 degrees below normal. October was again dry, with 0.84 inch, and November was wet with 4.33 inches. From December, 1934, through March, 1935, the weather varied from wet to dry within rather ordinary limits, but the streams were subject to two severe winter floods. One of these floods, in late January, was accompanied by the greatest cold of the winter, 19 degrees below zero.

April, 1935, was dry, with only 0.80 inch of rain; May, a little drier than normal, with 3.35 inches; June, very wet, with 10.50 inches. These three months had temperatures averaging about 4.3 degrees below normal. After some hot, dry weather in July and more in August, the autumn had above-normal, well-distributed rainfall and somewhat subnormal average temperatures. January and February, 1936, were months of the greatest sustained cold in the Ames records averages of 8.6 degrees (11.4 degrees below normal) for January and 5.0 degrees (18.2 degrees below normal) for February. On the other hand, above-normal winter precipitation and accumulation of snow gave muskrat habitats much protection against the cold.

The spring and summer of 1936 went to the other extreme. Starting with March, the year was one of generally above-normal temperatures and subnormal rainfall through August. April had 1.04 inches of rain and May had 2.04 inches. June was the wettest month, with 3.81 inches. July had 1.04 inches and also an average temperature 
of 82.2 degrees, or 7.6 degrees above normal. (This really dried things up.) August had 1.41 inches and an average temperature of 78.2 degrees, or 5.8 degrees above normal. The drought was broken by rains of 4.30 inches on September 5, 2.65 inches on September 15, and 1.28 inches on September 26. October, November, and most of December had less than half of their normal precipitation. Precipitation for January, February, and March, 1937, was above normal but lay over ground and muskrat habitats mostly in the form of a thick ice glaze; average temperatures for these months were about four degrees below normal.

Rainfall and temperatures did not depart greatly from normal in April and May, 1937. June and July had somewhat deficient rainfall, with 2.86 and 1.38 inches. August was both a hot month (average temperature of 76.6 degrees, or 4.2 degrees above normal) and a wet one (5.00 inches, or 1.19 inches above normal). September had only 0.98 inch of rain; October, 1.16 inches; and November, 0.81 inch, all adding up to a long, dry Indian summer that had pronounced effects on muskrat habitats. Moreover, the drought crisis was little alleviated during the winter of 1937-38, except by February's average temperature of 28.5 degrees (5.3 degrees above normal). March was both warm (average temperature of 43.4 degrees, or 7.8 degrees above normal) and wet (3.05 inches, or 1.43 inches above normal).

April, 1938, had 4.06 inches, or 1.39 inches above normal; May, 8.24 inches, or 3.96 inches above normal; June and July were not so far from months of average rainfall, with 3.50 and 4.04 inches. The next three months had subnormal rainfall - August with 1.87 inches, September with 3.19 inches, and October with 0.42 inch - but the October dryness was relieved by a total of 1.58 inches falling on November 3-4. From then on through January, 1939, only a total of 1.25 inches of precipitation fell. January was also a mild month, with an average temperature of 28.1 degrees, or 8.1 degrees above normal. February's coldness (20.0 degrees, or 3.2 degrees below normal) was accompanied by the decidedly above-normal precipitation of 3.04 inches. In mid-February, some habitats were severely flooded and froze over while flooded, to the accompaniment of at least local mortality among the muskrats.

The spring of 1939 became progressively drier, March until June. March had 0.89 inch, April had 1.45 inches, and May had 1.03 inches, the latter being 3.25 inches below normal. May was a warm month, averaging 66.2 degrees, or 5.9 degrees above normal. After a somewhat wetter (5.61 inches) June than normal, July and August had near-average rainfalls of 3.03 and 4.47 inches. September was both warm (68.4 degrees, or 4.2 degrees above normal) and dry (0.83 inch, or 2.99 inches below normal). October had a subnormal 1.53 inches, of which 1.09 inches fell on October 9. November was very dry, with 0.39 inch, of which 0.32 inch fell on November 9. Like 1937, 1939 was a year of another long dry Indian summer, so drastically affecting 
the muskrats that the State Conservation Commission gave them the legal protection of a closed trapping season. Temperatures for the first half of the winter of 1939-40 changed from mildness in December (average of 31.8 degrees, or 7.4 degrees above normal) to severity in January (average of 8.2 degrees, or 11.8 degrees below normal).

Precipitation started catching up in February and March, 1940, with 1.89 and 2.10 inches. April had nearly normal rainfall, with 3.27 inches; May and June, somewhat subnormal, with 2.43 and 3.93 inches; July and August had 6.38 (3.13 above normal) and 6.67 (2.86 above normal). Rains of 4.16 inches on July 29, of 0.81 on August 11, 1.13 on August 13, 1.10 on August 16, and 2.15 on August 24 resulted in some bad flooding of stream habitats of the muskrats. September was dry, with 0.44 inch, or 3.38 inches below normal, and October had a somewhat subnormal 1.84 inches. November precipitation was an above-normal 2.67 inches, mostly falling during the famous Armistice Day Blizzard, which, among other things, imposed great hardship upon the fur trappers just after the trapping season opened and undoubtedly reduced the catch of muskrats. December and January had both above-average precipitation and temperatures; February and March, both subnormal precipitation and temperatures.

The spring of 1941 was warm and fairly dry, April and May with average temperatures of 53.8 degrees and 65.9 degrees and rainfalls of 1.88 and 2.06 inches. June was very wet, with 9.53 inches, or 4.80 inches above normal, and during the rainy period (which covered the first half of the month), temperatures were mostly subnormal. July and August had 3.49 and 2.88 inches. September and October were wet, with 9.55 ( 5.73 above normal) and 5.44 inches (3.08 above normal). December was warm (31.8 degrees, or 7.4 degrees above normal).

Except for a warm April (54.4 degrees) and a fairly wet June and July (6.98 and 5.57 inches), and a cold December (19.0 degrees), the year 1942 had close to average weather. On paper, the June and July rainfall figures do not look excessive, but the summer was one of repeated, sometimes severe, floods - highly lethal to stream-dwelling young muskrats of the more helpless sizes. The June rains were unevenly distributed, varying within a short radius of Ames from less than three inches to over fourteen inches.

The spring and fall months of 1943 were cool (May and September having average temperatures of 57.4 degrees and 59.4 degrees), with generally subnormal precipitation. The summer was somewhat warmer and considerably wetter than normal. June had 6.74 inches of rainfall, and August had 5.32 inches. Streams were badly flooded in early August from rains of 3.58 inches on July 31 and 2.00 inches on August 3. The subnormal precipitation of fall led up to a state of winter drought, which was broken by a rain of 2.06 inches on January 27 , 1944. January was also notable for an average temperature of 29.5 degrees, or 9.5 degrees above normal. A warm February (average of 27.0 degrees) was followed by a cold March (29.4 degrees) and April 
(45.2 degrees). March and April were also months of somewhat above-normal precipitation.

May, 1944, had a rainfall of 12.28 inches, or 8.00 inches above normal, including 4.53 inches on May 19, 3.68 inches on May 20, 0.85 inch on May 22, and 0.75 inch on May 26. Floods following the rains of May 19-20 were among the worst on record for the vicinity of Ames, and the waters stayed high for so long that even minor rains often put streams over their banks again. Flood after flood occurred while helpless young muskrats were in bank burrows. June and July had somewhat above-normal rainfalls of 4.97 and 4.58 inches, and August had 6.83 inches, or 3.02 inches above normal. The heavier of the June-July-August rains were 1.71 inches on June $8,1.21$ inches on June 11, 1.38 inches on July 25, 1.40 inches on July 26, 1.98 inches on August 4, 2.12 inches on August 26, and 1.04 inches on August 27. The fall was fairly dry, September, October, and November having $2.23,0.89$, and 0.92 inches, respectively. December was a cold month, with an average temperature of 18.6 degrees, but otherwise the weather for that month, as well as January and February, 1945, differed little from the normal.

March, 1945, was warm, with an average temperature of 45.0 degrees, or 9.4 degrees above normal. Thereafter, the rest of the calendar year was one of subnormal temperatures - May and June with averages of 55.2 degrees (5.1 degrees below normal) and 63.6 degrees (6.2 degrees below normal), and December with 17.6 degrees (6.8 degrees below normal). Precipitation departures were not especially noteworthy except for a dry (0.12 inch) October, which had varying effects on muskrat habitats kept under observation. For the winter of 1945-46, February was mild (28.6 degrees) and dry (0.08 inch), followed by a warm (46.0 degrees) and wet (4.46 inches) March and a warm (54.0 degrees) and rather dry (0.97 inch) April.

Beginning with May, 1946, the summer was cool, but not excessively so, through September; then the fall and early winter, through January, 1947, was somewhat above normal. February and March were cold, with average temperatures of 17.2 degrees and 31.9 degrees. Precipitation from April, 1946, through March, 1947, usually was more or less subnormal, except for a wet June (8.68 inches, or 3.99 inches above normal) and a rainfall of 5.12 inches in October. During the rather dry months of July, August, and September, stream flows were restored by timely rains whenever they began to approach unfavorable levels for muskrats; and on the whole, the more permanent types of central Iowa stream habitats remained in good condition even during the driest weather of 1946.

April, May, June, and July, 1947, had temperatures averaging about 3.5 degrees below normal, then a hot August (80.3 degrees), a warm September (67.8 degrees), and an unseasonably warm October (61.2 degrees, or 8.2 degrees above normal) furnished the opposite extreme. A cold November (32.6 degrees), followed. Rainfall was 5.44 
inches for April, 4.46 inches for May, and 13.42 inches (8.73 inches above normal) for June. The excessive wetness for June resulted in severe floods, especially following rains of 2.75 inches on June 1, 3.17 inches on June 12, 1.22 inches on June 13, 1.06 inches on June 21, and 2.30 inches on June 23. After June, the summer turned dry: July had only 0.59 inch, and August had 1.18 inches. September was wetter but with still subnormal rainfall -2.29 inches, practically all falling on September 11-12. The drought was broken in October by 5.67 inches, of which a total of 5.09 inches fell on five days toward the end of the month.

Near-normal temperatures almost characterized the calendar year of 1948, except for a cold March (average of 31.0 degrees and the coldest weather of the winter of 1947-48, including a minimum of 18 degrees below zero) and a warm April (54.0 degrees). Precipitation, February through April, was somewhat above normal. June and July, considered together, had about normal rainfall, and August had a subnormal 3.02 inches, with most of that coming late in the month. September was dry, with only 1.19 inches, of which over half fell on September 20. October had 1.81 inches, virtually all falling on two days, October 6 (0.95 inch) and October 30 (0.83 inch). Then, November had 3.01 inches, mostly falling on November 5 (1.48 inches) and November 19 (1.29 inches). Precipitation for the winter months of 1948-49 (December through March) totaled 7.23 inches, or 2.61 inches above normal.

In 1949, a dry spring (April with 1.14 inches and May with 1.36 inches) was terminated by near-normal (3.91 inches) rains in June. July was dry (1.93 inches, of which 1.24 inches fell on July 18-20), and so was August with its 1.98 inches, of which 0.83 inch fell on August 11-12 and 1.13 inches on August 19. September had 4.36 inches, of which 1.10 inches fell on September 3 and 3.10 inches on September 11-12. October had 2.69 inches, well distributed over the month. Precipitation for November and December was somewhat below normal; for January and February, 1950, somewhat above normal. In many ways, the weather pattern of 1949 paralleled that of 1948, except that the 1949 drought crisis progressed farther and thus the season, so far as the muskrats were concerned, became progressively drier until late fall. The rains of mid-August and the first half of September briefly restored some flow in the streams, but the water quickly sank into the bottom, leaving the drought-exposed state of the water courses little changed after a few days. Except for a cool (58.9 degrees) September, the summer and fall temperatures were more or less above normal, those of October (55.6 degrees) and November (41.6 degrees) being most so.

For the fourth consecutive year, stream habitats of central Iowa muskrats were subject to late-summer and fall drought in 1950. Following a dry March and April (with 0.53 and 1.40 inches), May and June had 7.14 and 7.55 inches, and were thus much wetter than nor- 
mal - still without accompaniment of severe floods. The rest of the calendar year was dry, with a total precipitation of 6.98 inches, or 8.74 inches below normal. July had 1.92 inches; August, 1.79; September, 1.22; October, 1.39; November, 0.30; and December, 0.36. The consequences of the drought for the muskrats were mitigated to some extent by the exceptional coolness of the year. Only October, with an average of 58.1 degrees, had an above-normal temperature, and the summer was one of the most consistently cool on record. From midJune to mid-September, there were 13 consecutive weeks of subnormal temperatures. In parts of northern Iowa, the temperature on August 20 dropped to 30 degrees.

The year, 1951, was one of exceptionally favorable water levels resulting from frequent and well-distributed, though not excessive, rains. Days on which rainfall exceeded a quarter inch during the rearing season for the muskrats were April 6, 11, 12, 20, 21, 24, 25, and 29, May 1, 9, 10, 25, and 31, June 1, 2, 7, 15, 19, 26, and 27, July 3, 8, 11, 18, and 21, August 2, 13, 14, 15, 17, 20, and 28, September 9 and 12, and October $3,4,18$, and 21 . The summer was again cool, though not quite as cool as that of 1950 .

Following above-normal rainfall in May, June, and July, late summer and fall of 1952 was very dry. September, October, and the first half of November were nearly rainless. Conditions generally remained favorable for stream-dwelling muskrats of central Iowa, however. While Squaw Creek, Keigley's Branch, the Story City ditches, and Skunk River had low levels much of the time, their flows never ceased over the greater part of the channels observed. The outlying pools and smaller streams that did dry up had few muskrats trying to live in them anyway.

The period from late spring, 1953, through the first half of February, 1954, was one of generally subnormal precipitation. Starting with May, 1953, and ending with January, 1954, a total of 13.81 inches fell, or 11.78 inches below normal; and 4.99 inches of the 1953 precipitation fell in June. It was a hard year for muskrats, though a warm February (37.1 degrees, or 13.9 degrees above normal) surely permitted more survival in drought-exposed habitats than otherwise would have been possible.

In 1954, early-summer floods following 4.68 inches of rainfall in May (mostly coming late in the month) and 7.58 inches in June (2.85 inches above normal) did not result in serious mortality of helpless sizes of stream-dwelling muskrats. July was dry, with 0.69 inch. Extremely heavy rainfall in August - 14.67 inches, or 10.86 inches above normal - gave rise to more floods, but these came at a time when they had little effect on the known fortunes of the muskrats. The rains contributing to the greatest flooding fell as 2.51 inches on August 17, 5.95 inches on August 22, 0.52 inch on August 23, 0.57 inch on August 24, 3.05 inches on August 25, and 0.88 inch on August 27.

The summer of 1955 started out with nearly normal rainfall - a 
total of 14.18 inches for April, May, June, and July, compared with an 82-year average of 14.98 inches for this period. The heavier rains were of 0.94 inch on April 13, 1.37 inches on April 23, 1.86 inches on May 9, 1.22 inches on June 29, 0.87 inch on July 1, and 2.10 inches on July 10. August through the rest of the calendar year had a total of 5.05 inches, or 7.42 inches below normal. At the same time, the temperatures for the months of April through September averaged over two degrees above normal, with July and August being hot months averaging over four degrees above normal. November and December were cold, with average temperatures of 30.5 degrees and 19.9 degrees. Drought conditions continued throughout the winter: January had 0.51 inch precipitation, February had 0.25 inch, and March had 0.79 inch. All together, central Iowa muskrats had a hard fall and winter, 1955-56.

The severe drought continued with little interruption through 1956. Only August, with 4.25 inches, and November, with 1.99 inches, had above-normal precipitation. For the year, the total precipitation was about 10 inches below normal, with a hot (4.7 degrees above normal) June being also one of the drier months.

This particular drought may be said to have broken with a rain of 1.93 inches on April 26, 1957. May, June, and July had abovenormal rainfall of $6.19,6.50$, and 3.48 inches, respectively; then, the rainfall averaged about normal for the fall. There were, during 1957, no special weather conditions adversely affecting central Iowa muskrats after the breaking of the drought in the spring.

\section{Appendix F}

\section{The Varying Fortunes of Muskrats in Eastern South Dakota, Particularly in the Oakwood-Tetonkaha Lake and Marsh Chain of Brookings County Over a Period of Nearly 30 Years}

My Regular home Range in my native Brookings County, South Dakota, included most of the Oakwood-Tetonkaha area.

For this area (of which our family farm was a part), I have sufficiently good data from fur catches and field observations to piece together a fair equivalent of a long-term case history, beginning with the fall of 1921. My trapping experience there actually began in 1917, but I have no data from those earlier years that I would consider of quantitative value.

Water levels of the Oakwood-Tetonkaha area were moderately 
high during the summer and fall of 1921. Outlying marshes and sloughs had up to three feet of water in their deeper parts, but usually about two feet. Some were densely grown to cattails, bulrushes, burreeds, and sedges, while some had much open water or were dominated by duck potato or submergents. The lakes had open water except for bulrush fringes and shallow bays and connecting channels grown to typical marsh emergents. Of Lake Tetonkaha and its ramifying waters and outlying marshes, potholes, and sloughs, about 1,725 acres of a five-section block of land were under water: about 75 acres too shallow or otherwise deficient to be muskrat habitat, about 250 acres of marshes or sloughs representing marginal habitat for muskrats, about 175 acres of good muskrat marsh, and about 1,225 acres of open-water lakes having muskrats only along the shores.

During the fur season of 1921-22, I trapped over most of the Lake Tetonkaha block, with the exception of some of the choicer privately owned marshes that were not accessible to me. My catch of muskrats in the block was 201, and the numbers caught in different places well illustrate local differences. The best populated muskrat habitat to which I had access was a duck potato slough of five and a half acres, and here I took 56 muskrats out of a total population estimated at 70 to 75 . From a fifteen-acre, rather food-poor marsh-grown chiefly to smartweeds and some hardstem bulrush - I caught 45 muskrats and supposed, after the trapping, that about 5 had escaped. Of the other 100 muskrats of my Tetonkaha catch for that season, approximately 20 were taken from seven acres of a cattail-grown bay, but those taken from the bay probably did not represent more than a third of the actual population living there.

I think that my catch of around 80 muskrats from eight and threequarters miles of lake shore represented about three-fourths of the muskrats of that stretch. A stretch of about two and a half miles was left untrapped, and this was judged to have had a somewhat higher muskrat density per mile than the eight and three-quarters miles from which the 80 had been taken. The population of muskrats living along an additional mile and a quarter of shore line bordering the open water lake was negligible. The pre-trapping population of a total of twelve and one-half miles of lake shore in the Tetonkaha block should figure out at about 145 .

In the above block of five square miles were two cattail bays other than the one I had trapped lightly, and these showed evidence of having had a total of perhaps 110 muskrats between them. All three of the above cattail bays had been trapped hard enough by the public so that all of their lodges were dead by mid-December, or a couple of weeks after the opening of the fur season.

Of the privately-owned marshes and sloughs in the Tetonkaha block that I did not have access to as a trapper, 1921-22, only three had substantial numbers of muskrats. One, of about 230 acres known as Mortimer Slough, had over a fourth of its area visible densities of 
muskrats comparable to those of the 5.5-acre duck potato slough from which I had taken 10 per acre and estimated the population at about 13 per acre. This would give 800 for the most heavily populated part, and I would say that somewhat fewer, or perhaps 700 , lived on the other three-quarters, bringing the total up to 1,500 .

Populations and habitats were highly variable for a ramifying series of marshes, the Oldencamp Sloughs, lying to the northwest of the open waters of the Tetonkaha series and totaling about 60 acres. Some parts were understandably nearly muskratless and some had concentrations probably reaching 20 to 25 per acre. I should say that the densities probably averaged about eight per acre, giving a total of about 500 .

The third privately owned marsh was of about 15 acres at the inlet to the Lake Tetonkaha series. Its fur yield disappointed its owner, who suspected poaching before the legal opening of the trapping season. The numbers of muskrats to be seen there just before the freezeup, however, indicated a total of about 130 .

The figures of the preceding paragraphs added to an estimated 50 living in the scattered potholes, and such habitats, of the five square miles would give a grand total in the vicinity of 2,600 muskrats for the Tetonkaha block, as of late fall, 1921, prior to human exploitation for fur. Of this grand total, the number surviving the trapping to try to winter may be estimated from various bases at between 400 and 660 , probably nearest to 600 .

The Tetonkaha block afforded little really good wintering habitat for muskrats. The deeper waters tended to be food-poor and, even by December, the lake-dwellers living away from the cattail bays were in lean condition and a month behind the fur-priming schedule of the fat marsh-dwellers. They fed mainly upon animal matter, such as bivalves and fishes, along with occasional bulrush rootstocks and miscellaneous submerged vegetation that they could reach. They wintered badly and, with the coming of spring, all that I could see of them were old snowdrift nests and tunnels, frozen water holes littered with food particles, and their mink-eaten remains near the sites of their lake shore burrows.

The food-rich marshes and cattail bays were generally too shallow for comfortable wintering. Such places, nevertheless, and in particular the Mortimer Slough, were where muskrats did winter in the area. Practically no live lodges could be found after mid-December or later and it may be concluded that the marsh-dwelling muskrats then still alive were in burrows, channels, and air spaces under thick ice. As the ice of marshes and sloughs on my family's farm softened in the spring, muskrats could be seen coming out and sitting about patches of open water in places where the frost line had been known to sink far into the bottom mud.

The only Tetonkaha marsh of which I know (other than the deeper parts of the cattail- or rush-grown bays) where the water did 
not freeze to the bottom was that of the rather food-poor 15 acres where I caught the 45 muskrats. It continued to have "push-ups" with unfrozen water beneath, and I think that the muskrats escaping my trapping wintered satisfactorily on the limited food they continued to have available. Their usual food debris consisted of bulrush particles.

Any estimate of the muskrats entering the breeding season of 1922 on the Tetonkaha block must necessarily be a rough one: the equivalent of the survivors at the Mortimer and Oldencamp sloughs, at the inlet marsh, and at scattered minor wintering sites, totaling between 325 and 550 , or more likely about 450 .

Rainfall on the Tetonkaha block was deficient in the summer of 1922, and the shallower marshes dried up and stayed dry except for temporary wettings. This partly eliminated as livable muskrat habitat the inlet marsh and a good deal of the Oldencamp Sloughs. The surface area of the Mortimer Slough was reduced, but the muskrats there readjusted effectively, and this place (the site of the most successful wintering of 1921-22) had the highest muskrat density in the Tetonkaha block by late fall, 1922. New and thriving growths of emergent vegetation in bays and shallows partly offset, from the standpoint of muskrat habitat, the drying of outlying waters.

During the fur season of 1922-23, my muskrat catch was about 185, including over 40 from a bulrush-grown bay of about five acres. An unknown illegal take before the trapping season introduced a big variable in computing the Tetonkaha muskrat populations. At this time, illegal practices by poachers living outside the area became intensified. I know, for example, that one man, stalking muskrats lying in piles on lodges at the Mortimer Slough, killed 13 with two charges from a shotgun, and I have no means of guessing how many more he and his associates may have removed.

Comparison of visible evidences of muskrats with those of other areas of known densities afforded the best basis for estimating the late fall population of the Mortimer Slough in 1922. I do not recall ever having seen elsewhere quite as much bunching of muskrats on resting places over a sizable area as was to be seen there on sunny fall days. The most equivalent spectacles were those witnessed in Iowa on the part of 20 to 30 per acre local populations. The Mortimer Slough muskrats were, in short, just about as abundant as they allow themselves to become on a good duck potato slough, or probably 1,200 on a tract of 60 acres.

Over the rest of the Tetonkaha block, I think that my catch of 170 should have represented most of the muskrats taken, except for a stretch of three-quarters of a mile of rush-bordered lake shore known to have been worked over by the same party of poachers that had shot muskrats on the Mortimer Slough. The three-quarters of a mile of poached lake shore was somewhat more than the equivalent of the bay from which I had taken about 40, so the suspected illegal take may have been about 60 . In addition to the 40 that I took from the 
above bay and a trifling 15 from a few days of trapping on a small corner of the Mortimer Slough, my catch included remnant animals occupying several partly dry marshy potholes - usually from one to four or five from a pothole and totaling fewer than 20 from this sort of habitat. My catch from the same eleven and one-quarter miles of shore line covered in 1921-22 (excluding the three-quarters mile that had been poached out and the best bay that had yielded the 40) was about 110, mostly taken from the lesser concentrations of muskrats found on minor cattail or rushy bays.

After consideration of my trapping methods and the criteria by which I decided when enough trapping had been done, I would say that my 1922-23 lake shore catches probably accounted for four-fifths of the muskrats originally present there in the fall. Allowing for somewhat more animals escaping the poachers along the three-quarters of a mile (which I did not bother to trap), about 60 should have escaped exploitation, to have been present by midwinter as the shoredwelling population of Lake Tetonkaha.

The greater number of these shore-dwellers seemed to winter safely. Most of them lived in bank burrows in rather sheltered places having fair to good food resources in the form of bulrush rootstocks. The numerous dry or nearly dry outlying marshes, potholes, and sloughs had no wintering muskrats of which I was aware, but there was again, as in 1921-22, a fair wintering population at the Mortimer Slough. Such shallow-marsh animals had access to an abundance of duck potatoes, and there was sufficient deep water and unfrozen mud to afford at least some of the muskrats a livable winter habitat. I lack the most satisfactory basis for estimating the numbers surviving either the trapping or the winter at the Mortimer Slough, but think that the survival may have averaged three per acre for an area of about 70 acres, or a total of about 210 muskrats. This might give us a grand total in the vicinity of 275 wintering on the Tetonkaha block out of an original late fall population of about 1,600.

I did not live much at our lake side farm after the spring of 1923 and saw the Tetonkaha block only briefly during that summer. My catch of muskrats during the 1923-24 fur season was only 130, and I worked hard for it. There were not many muskrats by late fall except along the better stretches of shore. The Oldencamp and Mortimer sloughs were nearly dry, though with some fair muskrat habitat remaining. The lesser outlying potholes and sloughs were either dry or with water restricted largely to the food-poor deeper parts. The practice of before-season poaching did not appear to be serious in the block in the fall of 1923, and I camped in the best muskrat area to reduce further the competition from fellow trappers. My own catch probably accounted for the majority of muskrats on the five square miles, and I think that a late-fall, pre-trapping estimate of 200 muskrats should be fairly accurate.

I do not know exactly what went wrong at the Tetonkaha block between spring and fall, 1923, but I would guess that the then-un- 
recognized hemorrhagic disease would partly explain the decline. Crowded, muddy Mortimer Slough offered favorable conditions for a die-off, and something special almost certainly did happen there. While hunting ducks in late fall, I saw some dead muskrats but assumed that they had been killed by predators. The fact that I did not find clear evidence of disease mortality is quite consistent with the known failures of hunters and trappers to notice even highly lethal epizootics under ordinary circumstances. At that time, I had neither college training nor suspicions that muskrats died from anything important other than deliberate attacks of minks and humans.

By the fall of 1924, the muskrat situation was so unfavorable in eastern South Dakota that the trapping season on the species was closed for that part of the state lying east of the Missouri River. It was still so unfavorable by the fall of 1925 that the trapping season for muskrats was kept closed, and the years of closure were extended up through 1928, when I left the state to establish residence elsewhere.

Legal protection of these years notwithstanding, the Tetonkaha block muskrats, which were still largely restricted to the shores and shallows of the lakes, did not then regain more than about the densities of the fall of 1922. Conspicuous bubble signs were to be seen after the freeze-ups of 1926 and 1927 in the likeliest habitats along the lake shore, but the muskrat occupants were subject to a variable amount of poaching during both falls. (The poachers also may be suspected of having operated during the falls of 1924 and 1925, but I was not around the lakes enough to know this with certainty.) The observed poaching should not be overrated, for it was surreptitiously done and rather localized along stretches of shore that were conveniently accessible to the poachers. I am sure that something else was a more effective population depressant for the muskrats of the Tetonkaha block.

For one thing, the amount of habitable environment available to muskrats in the block remained limited, though the improved state of the shore zones as a result of increased growth of emergent vegetation partly offset the deterioration of the outlying wetlands. The shallower of these outlying wetlands had been dry and muskrat-vacant since 1922, and the others were sometimes occupied by muskrats and sometimes not. The continued closed seasons also resulted in unusual numbers of animals attempting to winter in very marginal habitats.

The winter of 1926-27 was notable for outside activities on the part of muskrats living about Lake Tetonkaha. In the fall of 1926, the muskrats had been observed at low to moderate densities in a number of widely separated potholes and outlying bodies having a little water in the deeper places. By midwinter, the muskrats of these marginal habitats were betraying great unrest. Strife-torn individuals gnawed holes in lodges, mud, or ice, to wander over the countryside. They sat around in weed patches or ice-heaves, leaving blood where they went, finally dying of hunger, exposure, or mink predation along the lake shores. In the spring, I found twelve dead muskrats along about three miles of lake shore. In several instances, individuals were identi- 
fied as those previously known to have broken out of shallow potholes - their remains found at places where trailed wanderers had last been observed to have sought refuge under ice-heaves or to have tracked up the shore while trying to forage.

The dead also included some residents of the shore zone. Soon after I had made a December camp near one of the Tetonkaha lakes, and had chopped a hole in the lake ice for cooking water, a muskrat began to take advantage of the shelter of the snow-heaped wooden box used to keep the water hole from freezing. For weeks, what was almost certainly a single individual sat and fed under the box, despite successive moves of the box to new water holes as the old ones became befouled with litter, including bloody remnants of aquatic prey. In late January, at the time of the last use of the box, a muskrat came out from beneath the edge of the ice at the lake shore. On the last day that I saw it alive, it ran along shore for about a quarter of a mile and returned to enter the ice shelf at the place where it had come out. A few days later, it was found dead under the shelf, body intact and in fair flesh. The signs indicated that the muskrat had been unable to return to the water. Its original passageway had been frozen or cut off by the creep of the ice.

The winter of 1926-27 was the next to the last of my South Dakota trapping winters and the first one during which I carried on field studies under the scientific direction of faculty members of South Dakota State College, at which school I was intermittently in attendance. Of 100 large muskrat lodges opened for examination in March, only two were in use, and both of these were in water that had been more than three feet deep at freeze-up. The occupants of the lodges of the shallower waters had largely withdrawn to bank burrows. Snowdrift tunnels were either temporary retreats of wanderers or adjuncts to bank burrows, sometimes used by both minks and muskrats and filled with mink-cached frozen fishes that served as food for both species. The muskrats frequenting the same snowdrift tunnels as the minks sometimes were eaten by the minks, sometimes were still alive there by spring.

Most evidence of mink predation upon muskrats under the above circumstances was noted in places where the muskrats of the snowdrifts were known, or strongly suspected, to have taken refuge there as wanderers. Most occupants of regularly used burrows appeared to have had a much better chance of staying alive, even though feeding on the mink caches in the drifts. It also happened that the main sites of the mink caches (other than adjacent to springs) were in drifts over used muskrat burrows, for many of the latter were the sites of fish concentrations.

Fall and winter, 1927-28, was a period of continued manifestations of restlessness and wandering by the muskrats of the Tetonkaha block. Water levels of the lakes were much as they had been for the previous few years and were considerably improved on the outlying marshes and sloughs. The muskrats themselves seemed to be somewhat less 
numerous than they had been in 1922-23, though still at a relatively moderate rather than a high level of abundance, despite the years of legal protection.

Oldencamp Slough probably had, 1927-28, an average of about three muskrats per acre (or perhaps about 200 in all), with some animals being found almost anywhere on it. Mortimer Slough, on the other hand, had much deteriorated through loss of vegetation, and most of its muskrats lived in the banks. Its periphery had fewer muskrats than the better stretches of rushy lake shore, and some of its main burrows were mink-opened and vacant-appearing by early winter. Judging from the signs left by known Iowa populations of later years, I would estimate that there had been perhaps 60 muskrats at Mortimer Slough by the late fall of 1927 but doubt that many got through the winter.

Lake Tetonkaha showed moderate to heavy signs of muskrats only along about a mile of lake shore at freeze-up, 1927 - probably of about 100 muskrats. For the $11 \frac{1}{2}$ miles of shore covered in addition, the 1927 fall population was estimated at no more than 10 per mile, or about 110. The total lake shore population of the Tetonkaha block then figures out at about 210 .

Fall and winter wandering was noted on a considerable scale. One field note of December 4, 1927, relates to a muskrat with a frozen tail living in a corncrib at the family farm. It had been there many days but stayed less than a week longer and probably died as a wanderer.

After leaving South Dakota in 1928, I revisited the Tetonkaha block on several occasions during the droughts of the thirties. In late May, 1934, no traces of muskrats were found in the entire block, nor about what remained of dried-up Lake Oakwood. Only a few inches of water covered the very deepest parts of the lakes. The bottom of the westernmost lake of the Tetonkaha series (Johnson Lake, of about 115 acres) was a barley field - the only field of thriving grain seen for miles. Along the dry channel of the Big Sioux River in four sections of land west and southwest of Brookings, I found a single pool having what seemed to have been a single muskrat. This sort of situation prevailed in adjacent counties of east central South Dakota. Lake Albert - one of the great waterfowl and fur marshes of my youth - was a hay field in 1934. Water could be seen far out from the shore of 8,205-acre Lake Poinsett, but only the deeper bodies had surface water left.

Nor did the emergency soon pass; 1935 brought back some water, but 1936 was another drought year. Of the three main subdivisions of Lake Tetonkaha, the west-lying Johnson Lake was still dry in late August of 1936, but the second in the series (Upper Tetonkaha) had turned into a marsh with a 50- to 150-yard fringe of hardstem bulrushes. The water extended about half way into the rush fringe but was no more than a few inches in depth except in the deeper center. I looked over the west side and found signs that a muskrat was fre- 
quenting an old spring near shore. The third subdivision in the series (Goodfellow Lake) had very shallow water and little vegetation over most of the bottom.

By October, 1937, the Tetonkaha series of lakes looked much as described above except that Goodfellow Lake, the wetter subdivision, had perhaps six inches more water. No sign of muskrats was seen about Upper Tetonkaha, the new marsh.

By late August, 1938, Johnson Lake (the shallowest main subdivision of Lake Tetonkaha) had water over two-fifths of its bottom and a wide, heavy growth of young willows around the edge. The new marshy growths of adjacent Upper Tetonkaha looked about the same in 1938 as in 1936-37 except that there were several muskrat lodges in sight from almost any high place on the shore. Christian Berg, the tenant on our farm, said that there had been about 15 lodges on Upper Tetonkaha in the winter of 1937-38. My view is that this local recovery had its beginning with animals moving in naturally via the Big Sioux River.

The next winter, Berg (letter of February 13, 1939) counted 34 very large lodges along three-quarters of a mile of the rushy shore zone of Upper Tetonkaha. If allowance be made for less favorable stretches, these lodges should have comprised about a third of the dwelling-type lodges on that lake, which might have meant a wintering population in the vicinity of 500 muskrats.

Twice in August, 1939, I thoroughly worked the Tetonkaha block. Early in the month, the water of Upper Tetonkaha came to within 50 feet of the old shore line, and the thick fringe of bulrushes extended out from 175 to 250 yards from shore. At the far edge of the rushes out in the marsh, the water was three to four feet deep. Lodges could be seen a few yards from the water's edge at average distances of perhaps 50 yards. Johnson Lake had a few inches of water about 150 yards out from shore, and this wet bottom was surrounded by dense growths of willow and hardstem bulrush.

By late August, 1939, the water of Upper Tetonkaha had gone down about six inches, thus exposing about five yards more of mud margin. Freshly built muskrat lodges were to be seen but none farther out than 40 yards from shore. There were a few bank burrows, including some partly caved in by hogs and other livestock. The distinguishable breeding territories were centered an average of about 200 yards apart. The 1939 breeding density would appear to have been the equivalent of about 40 pairs, or but a small fraction of the estimated 1938-39 wintering population. The spring of 1939 had been a time of natural restocking of formerly muskrat-vacant waters over all the Tetonkaha block and probably surrounding areas as well, and Upper Tetonkaha may be judged to have been the immediate source of most of the newcomers.

The Johnson Lake subdivision had water covering 10 acres in late August, 1939, and heavy stands of bulrushes greatly enhanced the attractions of the place for muskrats living away from the wetter parts. 
Sites of eight breeding territories were distinguished, these being situated from less than 100 to several hundreds of yards apart. One territory had been completely abandoned in July, and, in late August, evidences of wandering individuals were seen in two places. The other territories appeared to be well maintained, though showing typical adjustments as their occupants moved toward deeper water and built new lodges or deepened channels.

Signs noted about two neighboring territories on Johnson Lake illustrated the adjustments taking place. The initial sites of what may be designated territories " $\mathrm{A}$ " and " $\mathrm{B}$ " had been about 300 yards apart, on opposite sides of the wetter center. As territory "A" dried up, its occupants moved 90 yards toward the center to erect two new lodges; the occupants of territory "B" built two new lodges about 50 yards apart and about 75 and 100 yards from their initial territorial site. By late August, the territorial sites of "A" and "B" were about 250 yards apart. Animals of the adjusted territory "A" regularly worked along a main trail leading about 150 yards somewhat in the direction of the adjusted territory " $\mathrm{B}$," but the animals of " $\mathrm{B}$ " worked only about 40 yards in the direction of "A." A trail showing a few passages connected the outermost fringes of the adjusted territories " $\mathrm{A}$ " and "B," but, on the whole, it could be seen that the muskrats of each territory were staying where they belonged.

The dryness of the fall of 1939 meant more crisis to at least the muskrats of the shallower marshes such as Johnson Lake, but the crisis could not have been excessively deadly. By the fall of 1940, the new marshes were full of muskrats, and thousands were trapped on what formerly had been open water lakes of the Oakwood-Tetonkaha chain. The principal trapper, Dean Goodfellow, took 1,100 from the parts of Lake Oakwood and Lake Tetonkaha that were accessible from his farm (Mrs. Hortense Goodfellow, letter, August 9, 1950), and the numbers must have been similar to those of my childhood years in the first clecade of the century, when the lakes had also been in marshlike condition. (In particular, I remember a tale of the exploits of two men who in three mornings had speared a total of 600 muskrats through "rubber ice," to sell the pelts for three cents each!)

As of the fall of 1940, 3,000 acres of the Oakwood-Tetonkaha lake chain could be classifiable as marshland, including open water centers of some rush-bordered bodies. Lake Oakwood had perhaps 400 acres of thickly covered shallow water, and Lake Tetonkaha perhaps 900 acres more of this type of habitat, which would add up to 1,300 acres of bona fide muskrat marsh. I would judge that the local muskrat densities varied from a few per acre upward to 30 per acre in "fur pockets," averaging somewhere around six per acre or a total of about 8,000 muskrats for the 1,300 acres, or about 5,500 for the Lake Tetonkaha parts.

The main lake beds were a series of marshes in 1941, and the carrying capacity of the Tetonkaha block for muskrats was obviously much greater than it had been during the best of my own fur trapping 
years. Although the outlying low areas were still dry in 1941, the wetlands that were then productive muskrat marshes on the block amounted to much more than the approximately 425 acres of marginal to good muskrat marsh of 20 years before.

By the time that I next saw the Tetonkaha block in early June and late July, 1946, the intervening wet years had brought some big changes. The parts that had been marshes, 1939-41, were in 1946 passing into open water stages, but the lake levels were not anywhere near high water marks. The Oldencamp Sloughs looked similar to what they had been in the early twenties. Muskrat breeding densities in the cattail and bulrush marshes were equivalent to about a pair per two acres, or about 210 pairs on the five-section block.

Much variability in the status of other eastern South Dakota wetlands was noted in 1946. Lake Albert was an open water lake, after having passed through hay field and marsh stages after the droughts of the thirties. The region was on the whole in attractive condition for muskrats, rather comparable to what it had been about 1922 . Muskrat breeding densities over the better marshes averaged about a pair per two acres, as on the Tetonkaha block.

Trappers of both the Tetonkaha block and of eastern South Dakota marshes, generally, were disappointed in their muskrat catches during the 1946-47 fur season, so the net population recovery during the 1946 breeding season evidently had not been very good. Considering the appearance of the better marshes, a pair per two acres in early summer on something over 400 acres of the Tetonkaha block should have been a highly productive breeding density. Fall densities of between 5 and 10 muskrats per acre on these favorable wetlands should have been entirely within reason, yet such densities were seldom present even locally about the block in the fall of 1946 .

By the latter time, all of the main subdivisions of Lake Tetonkaha were in a high, open water stage. The thick fringes of willows and other trees that had been growing since the drought years along the dry or marshy edges were flooded and dead. The vegetation of the Oldencamp Sloughs looked thinner, with more open water in the centers, than it had in June, but bulrush growths were massed in places.

By 1947, the muskrat habitat of the Tetonkaha block had deteriorated still more. Breeding densities possibly averaged the equivalent of a pair per 2 to 10 acres for good marshes. Substantial tracts of habitable but not choice marshes had few if any muskrats. The breeding population for the five-section block would seem to figure out at the equivalent of between 40 and 65 pairs on the 130 acres of fair to good marshland.

By early summer, 1948, muskrats were scarce in the Tetonkaha block, even in choice-looking places, including the Oldencamp Sloughs. A few marshes - usually small and isolated ones - had signs of one or two breeding territories, but few signs were to be seen on the five-section block as a whole. This may be in part attributed to the dryness of the preceding fall, in part to disease, and, conceivably, in part to overtrapping. After the summer's breeding, there was a 
low to moderate muskrat population distributed in the better habitats, including heavy stands of cattails over the lake bays and the smaller and shallower marshes. My estimate would be five muskrats per acre on 20 acres and perhaps three per acre on 60 acres more, or a total fall population of about 300 .

I took a brief trip in late September, 1948, through familiar lake and marsh areas of Hamlin and Codington counties, north of the Oakwood-Tetonkaha chain. Lake Poinsett, Lake Albert, Lake Norden, Dry Lake, and most wetlands of substantial acreage were in open water. The good marshy areas were rather limited in extent, but there were a few excellent ones and a great many marshy potholes. Muskrat densities in most marshes appeared to be quite low. At this time, a cross-country movement of muskrats was in progress in eastern South Dakota and southwestern Minnesota. On the basis of numbers seen killed on the highways during over 500 miles of driving in these areas, I thought that the highway mortality ran much in proportion to the local densities of the muskrats, irrespective of whether the local water levels were high or low. For example, fully as many highway victims were seen near attractive marshes of Brookings and Codington counties, South Dakota, as about the drying marshes and sloughs near Heron Lake, Minnesota, where the muskrats might be thought to have had real incentive for moving. In the vicinity of some good marshes, fresh highway victims were seen at the rate of one or two per mile.

In early June, 1949, the Tetonkaha block had a tremendous amount of open water and lacked cattails and bulrushes except about bays, shore zones, and shallow marshes. Breeding densities of muskrats on bays and potholes varied from equivalents of a pair per acre to a pair per five acres. On the Oldencamp Sloughs, the estimate was a pair per three or four acres or about 20 pairs. On the rest of the block, I think that there were probably enough muskrats to bring the total up to an equivalent of 60 pairs, these living on perhaps 180 acres of marsh. By late August, localized rainfall and general drought had left some of the wetlands of eastern South Dakota in good condition for muskrats and some dried up. The lakes of the Tetonkaha block had considerable shore zone exposed. The shallow outlying poiholes and sloughs were dry. The Oldencamp Sloughs were in attractive condition, though the water was a little low in places.

Whether due to the continuing drought of 1949, or to something else, the muskrats of the Tetonkaha block had all but disappeared by the spring of 1950. By early June, the water had come back, and the environmental conditions for muskrats were roughly comparable to what they had been in 1949. But, I saw muskrat signs in only two places during a half day spent with Maurice Anderson of the South Dakota Department of Game, Fish, and Parks. One after another of the old lodges in the best looking marsh of the lake-chain showed no current sign at that time. It should be safe to say that the muskrats had not been so scarce locally since the droughts of the mid-thirties. 


\section{Quotations From a Letter (January 28, 1949) From William P. Baldwin, Jr., in Explanation for the Absence of True Muskrats in Florida and Adjacent Georgia}

In eastern North Carolina, where macrodon exists, the daily tidal fluctuation on the protected Sound marshes is slight, often only wind tides of a few inches to a foot. This, coupled with low salinities, has permitted the growth of marshes of Scirpus-Typha and associates that are suitable for muskrat feeding ... and the proper water levels exist for daily rat activity. There are few large rivers bringing extremely high freshet waters into the region. The same is true for the Eastern Shore of Maryland, where large rat populations exist. In Virginia one does find the larger rivers but the vegetative types are more favorable than on the large rivers of the Southeast.

As one progresses southward from the southern limits of macrodon the daily fluctuation increases, and on such rivers as the Santee and the Savannah, and the coastal salt marsh, the daily tidal fluctuation may vary from four to nine feet, with a complete cycle every twelve hours. . . Presumably muskrats cannot persist in habitat subject to such extreme daily variations of water level. One might ask, however, if lack of extreme fluctuation is favorable for rats, why there are none on the Gulf Coast of Florida where water levels resemble those on the Sounds of eastern North Carolina. . . . It would appear that other factors of the complex are at work in Florida. . . This section of the coast, by reason of its close location to the source of hurricane storms, receives more severe water damage than areas to the north. . . If one of these storms passes inward the period of several days of high saline waters is followed, within one to two weeks, by extreme freshets on the major river systems, causing inundation a second time. Rivers rising in the Coastal Plain exhibit crests of shorter duration, but the large "yellow" rivers, rising in the uplands, are capable of devastating floods in the deltas after prolonged rains. . . .

One might ask... how... [rivalicius] flourishes on the Louisiana coast, subject to just as many devastating hurricanes and output from the greatest freshet-carrier of them all, the Mississippi? This would seem possible because there is a large expanse of sustaining habitat, thousands of acres of marsh possessing an abundance of good food plants and exhibiting slight daily water fluctuation. In this habitat storm-damaged rat populations are able to "come back" quickly, or if actually extirpated [locally] . . spread into the zone again from adjacent habitats.

The South Atlantic and Florida coast . . does not possess this wide buffer belt of sustaining rat habitat. When flood waters cover our marshes and wooded lowlands they cover them all the way to high land, and after subsidence the remaining muskrats of a normally small population would find themselves miles from their best habitat. . . A brief resume of the coastal ecology clarifies this.

The outer narrow band of saline marshes ... . [ is of ] tall Spartina alterniflora on soft muds, with extreme daily fluctuation - poor for rat feeding or movement. The inner saline marshes are short S. alterniflora, S. cynasuroides, Juncus roemerianus on higher firmer soils; these are subject to only slight tidal flooding on the highest zones . . . [ but ] I do not consider these species to be good rat foods. Even in North Carolina the rat population is low on this type of vegetative and water cover. Unfortunately, these two types of marsh comprise the bulk of the habitat along the Southeastern Atlantic and the upper Gulf Coast of Florida. . . . The next, highest zone is brackish, sup- 
porting Scirpus americanus . . . [and] olneyi and Typha spp. - all excellent rat foods. Here ... [ these latter plants] occupy only very small acreages compared to the total acreage of marsh (along much of the salt marsh strip this zone may be entirely lacking or a few inches wide). It is of greatest development only in the river deltas. Such a condition is far different from that existing in Maryland, Virginia, upper North Carolina, and Louisiana, where rats are present.

Passing up the river deltas beyond this narrow band of bulrush-cattail one comes to the fresher delta zones of giant cutgrass (Zizaniopsis); this can be considered of poor value for rat food, although throughout its range are found intermingled species [ of plants] existing on the loam, clay or peat soils, which might be considered capable of supporting rat colonies. This type dominates the thousands of acres of old "rice-fields" which were largely cleared from the virgin swamp forest and, now abandoned, are slowly reverting through the brush stage to the forest type again. . . . Prior to the start of widespread rice planting about 1700 , the uncleared delta forests extended well down through the tidal zone toward strongly brackish water, and there must have been only a minute portion of natural marsh capable of supporting the better rat foods or which had the proper balance of water levels favorable for rat activity. And here were working against them the storm-tide factor . . and in those days probably a critical predator population (mammals) for such small hypothetical colonies. . . . [ It should be indicated that Baldwin does not accept the popular thesis that alligator pressure is responsible for the lack of muskrats in the Southeast, which thesis, to quote another part of his letter, "is not borne out ... by observations in Louisiana areas where alligators and muskrats thrive on the same marshes." ] In Florida, on the South Gulf Coast, it is presumed that the mangrove-sawgrass vegetation, the narrow band of coastal marsh, and frequency of hurricane tides repeat the unfavorable picture described above, even though the daily tidal fluctuation may be favorable for rats. . . .

If our region possessed large expanses of adequately-watered rat habitat the successful colonization would have occurred by now. No doubt this species wanders down the rivers from the uplands, or attempts to move southward along the coast just as do many species. We recently discovered on the isolated Cape Island, Charleston County, S.C., a colony of Microtus, the only known record for coastal South Carolina. The presumption is that it came down the Santee River in floods or is a remnant of earlier populations connected with the coastal North Carolina form. At any rate, there are large gaps in the range between this colony and the nearest Microtus population in upland South Carolina or coastal North Carolina; in fact, the analogy with muskrat distribution is striking. To date, however, we know of no successful colonization in this section by muskrats. There now exist on the south Atlantic and to a lesser degree on the upper Gulf Coast of Florida thousands of acres of impounded marshes that appear to be capable of supporting muskrats. These are principally along the salt marsh . . . which under impoundment for waterfowl usage rapidly converts to a Typha-Scirpus type. . . . It must be presumed that these artificial ponds and marshes have not been invaded by numbers of migrating rats sufficient for colonization. . . . [ The ] impoundments at Pea Island, N.C., which support muskrats, had the same origin and vegetation types as many in our South Carolina-Georgia area, where rats do not exist.

In summarizing, it might be stressed again that the major factor for the absence of rats in this region appears to be the extreme daily water fluctuation. This cannot explain their absence entirely. . . . Of course, the entire complex of temperature, soils, parasites and disease would have to be considered along with the ones I have discussed, but I believe they would be secondary, and I am not qualified to develop the topic further. . . . There are no natural barriers to keep rats out of the Coastal Plain, other than the differences in stream and marsh habitat. 


\section{Appendix $\boldsymbol{H}$}

\section{Special Local Studies of Upper Mississippi River Muskrats}

INTENSIVE STUDIEs were carried on for a few weeks in June and July, 1940, on three Upper Mississippi observational areas: (1) about 280 acres of what was selected as a cross section of "ordinary" river's edge habitat about three and one-half miles north of Lansing, Iowa, (2) about 50 acres of a very low and irregular peninsula out from the mouth of a creek about three miles south of Lansing, and (3) a shallow oxbow marsh of three or four acres dominated by burreed about nine miles north of Lansing.

The tract of 280 acres at the river's edge consisted of samples of sandbar islands having heavy herbaceous growths and willow thickets, stump areas, and some virgin timber. It had four evident breeding territories, of which one was located at a bayou in virgin timber. All territorial burrows were in banks that extended about three feet above the early-June water level. Many old unused burrow systems were seen, including one appraised as the site of a territory that had been lost in May. The shallowness of some of the burrows was offset by refuge cavities under stumps. The muskrats of the virgin timber were feeding upon tree seedlings and presumably having some difficulty obtaining enough to eat, whereas the other three family groups fed mainly on burreed. The general population of this tract was getting along well at the last visit in mid-July.

The 50-acre peninsular tract had many stumps as well as vegetative covering varying from grasses to scrub willows and typical marshy emergents. It had nine (or possibly ten) territories, as of early summer. The ground was a foot or less above the surface of the water in early June and undercut by old muskrat burrows - I broke through every few steps along whole stretches of shore line. None of the many remnants of stump lodges - made up of sticks, ax chips, smartweed stems, and grass - showed current use. The entire population of muskrats lived in the shallow, partly-caved burrows. Opening up some of these, I found that they rarely extended more than 25 feet from the water's edge and that their interiors were littered with burreed fragments and other food debris, as were root tangles under stumps. I was out on the peninsula one day after the water had risen about seven inches and was still rising. Familiar burrow systems had from two to four inches of air space over the water, and the muskrat occupants were sitting or lying in the water.

The burreed-grown three or four acres of oxbow north of Lansing had, in early June, the aspect of a typical north central marsh during drought exposure except for the greater quantities of dead and dying fishes that one is more likely to find in a drying oxbow of a big river. 
A single breeding territory was centered about an exposed bank burrow, and out of this, young and old muskrats ranged into the shallow water and burreeds of the center. By mid-June, recent rains had refilled the oxbow, and the muskrat occupants, if not the fishes, were spared an acute drought crisis. In early July, the oxbow was again dry, then a heavy rain put it under flood for several days. On July 16 , the water had gone down about 20 inches, but the greater part of the bottom was still covered. The water went down about an inch a day until my last visit, July 20.

Scarcities of muskrats about the deep water impoundments and many of the medium-sized or wooded channels may be due not only to the comparative unattractiveness of the habitats but also to hazards resulting from commercial fishing operations. In a letter dated October 1, 1940, E. C. Volkert, a veteran riverman of Dubuque, Iowa, described the incidental killing of muskrats by

the so-called "fiddler net" or wooden fish trap now in use in enormous numbers by commercial fishermen, outlawed by Iowa but legal in Illinois. Muskrats have disappeared along all banks where these nets have been used all summer. . . Single traps often produce 4 or 5 or even more [ drowned muskrats ] each time they are lifted. ... I have learned of one such commercial fisherman fishing such nets who admitted that he alone had destroyed hundreds of muskrat in a single season by this process carried on during the muskrat reproducing season and it is obvious that others have like results.

Snead's (1950) live-trapping study was characterized by exceptional technical proficiency, and he obtained data from hundreds of eartags placed on family and local population groups of muskrats. All together, he made 2,348 in-the-hand examinations of 1,741 muskrats tagged at various ages, and he obtained 191 additional records from tagged animals trapped by the public for fur. The results of his work are still largely unpublished, but I learned something about them through conversation and correspondence and from mimeographed progress reports coming out in the Quarterly Reports of the Iowa Cooperative Wildlife Research Unit, October-December, 1946, to January-March, 1948. In addition, he obligingly sent me in August, 1950, a copy of his newly written final report to the Iowa State Conservation Commission, summarizing his live-trapping and tagging data.

In his published paper, he referred to captures of 476 muskrats in family traps during 44 nights between July 7 and September 13, 1947. $\mathrm{He}$ noted loose family relationships and localized shifting around, especially on the part of older subadults. At a den site, the catch would typically consist of members of a single family group - one or both adults and commonly members from two successive litters. As. many as 18 muskrats of various ages were caught in a single trap in: one operation. This especially informative group consisted of survivors of several litters, plus an adult male and two adult females. One' of the adult females was pregnant, and the other was lactating. Two 
more juveniles were caught at the same time in another part of the same burrow system.

Snead found that fluctuations in water levels - whether occurring as a result of variations in rainfall or manipulations at the dams forced shifts in living quarters of the muskrats. These quarters varied from temporary flood shelters to bank burrows having chambers and openings at different levels. There were periods during which his live-trapping area was covered by two or three feet of water; and once in the summer of 1947 , the waters receded so abruptly that many actively used den openings and runways were exposed on the mud flats. A local flood in late February, 1948, temporarily evicted the muskrats from bank dens and all but the very largest houses. A covering of surface ice remained anchored to trees and stumps as the water drained away beneath, leaving an air space up to a foot or more in thickness. The air space afforded the muskrats considerable protection, and many continued to stay there a week or so after the main population had returned to the banks and lodges.

Minks were abundant on Snead's areas in 1946, and he made observations on mink-muskrat relationships when he had opportunities. Twenty of 99 mid- and late-summer mink scats from a family den contained muskrat remains, and so did 28 of 52 scats for the winter of 1946-47. Appraisal of this predation (or feeding) of minks upon muskrats requires consideration of the hemorrhagic disease (Errington, 1954b). Snead first discovered the disease on March 10, 1947, but believed that muskrats had been dying from it on his area much earlier. Six of the March disease victims were found in two groups about two-thirds of a mile apart, and six others were found in three lodges situated approximately three miles from the sites of the other mortality. Following the spring flooding of 1947, the disease appeared to subside for a time.

Snead wrote in his progress report for October-December, 1947:

From limited data available regarding the current muskrat epizootic disease it would appear to be operative over a considerable area along the Upper Mississippi River bottoms. . . . No instances have come to the writer's attention wherein mass die-offs occurred, although it is suspected that disease foci have existed accompanied by heavy localized mortality. Aside from a report in the fall by a local commercial fisherman of numerous dead muskrats seen in a particular locality during the summer all authenticated disease victims or reports of dead animals were of but one or two individuals occurring over a considerable time period and dispersed for the most part over a wide area. [In his final report, Snead mentioned] that at no time during the project did anything approaching a sweeping die-off occur on the investigational area. And, whereas mortality within localized vicinities was sometimes severe, the disease was not considered to be a controlling factor.

Snead (1950) also referred to what seemed to be the same lethal fungus disease of young muskrats with which I had worked in northwestern Iowa (Chapter 5 and Errington, 1942b). 


\title{
Appendix I
}

\section{Kent Island (New Brunswick) Muskrats}

\author{
TO QUOTE FROM GROSS (1947):
}

In 1941 muskrats, the first mammals, made their appearance. . . . These individuals probably came from nearby Hay Island (connected at low tide) where they arrived a few years before. Just how the muskrats reached Hay Island over the six miles of water, the shortest distance from Grand Manan, remains an unsolved question. Because of the excessive tides and strong currents this stretch of water is never frozen even during the most severe winters, hence they could not have crossed on a bridge of ice. It is difficult to conceive that they were able to swim that distance against the hazards of strong tides, even if they took advantage of floating debris. We are reasonably sure that they were not introduced by man. The fact remains the muskrats are there, they are prospering and increasing in numbers under the new environmental conditions. Evidence of their presence can be seen in all parts of each of the 3 islands, Kent, Hay and Sheep which comprise the group designated on charts as Three Islands. The muskrats are especially abundant in the iris and alder swamps where one may see an intricate network of runways and tunnels. . . .

On Hay Island there is a fresh water pond in which the muskrats build their characteristic mound houses which are occupied during the summer. They remain until the ice forms and for a time maintain open holes in the ice. But when the pond becomes solidly frozen in December they retreat to the high ground where they live in burrows until the pond is again freed of ice in early spring. No constructed mound homes are found on other parts of Hay Island or on Sheep and Kent Island. . . Mr. Joy [ Ernest A. Joy, the warden ] was given permission to trap the muskrats during the trapping season in 1943 and during each year since that time. The results of his catches offer a rough index of the steady increase of these mammals. [ A later report (Gross, 1949) gave the Joy catches as 13 for the spring of 1943; 35 for 1944; 75 for 1945; 101 for 1946; 191 for 1947; and 203 for 1948. ] Mr. Joy states that since the muskrats have become so numerous many hawks . . . have been seen on the island. He has found many muskrats that have been killed and partially eaten by the hawks. He has also found it necessary to conceal his traps so that the trapped animals cannot be found and mutilated by the hawks.

During the following decade, the muskrat population apparently increased to the point of dominating the habitat. Daniel McKinley, after what he referred to (letter, July 21, 1959) as "a very superficial examination of an introduced muskrat population ... in early May of this year," wrote:

Anyway ... the animals ate and dug out the only few square rods of really suitable-looking (to me!) habitat - it is now a perfect honeycomb of eroded burrows, caving in from the top. They then spread to every foot of the island [ of about 115 acres], and most of it is high, dry, barren and hilly under spruce forest, old grass-raspberry meadow, or dead forest where herring gulls have killed the trees within the past 20 years or so. The muskrats seem to be perfectly at home there: their burrows, their trails, their conical latrines may be found everywhere. There seems to be no sign that they eat each other, nor kill birds (petrels and herring gulls especially abound there, and eiders, too)... There is no fresh water over most of 
the island; what there is is concentrated on one end, and the island must be nearly a mile long.

The present director of the Bowdoin Scientific Station on Kent Island, Dr. Charles E. Huntington, wrote (letter, January 19, 1960) that, following a closed trapping season in 1951, the trappers took about 1,400 in 1952 and 675 in 1953. In 1959, the catch was 850. The intensity of the trapping varied with the prices of muskrat pelts, which had been rather low in recent years.

\section{Appendix J}

\section{Concerning the Nebraska Sand Hills and Especially Sather's Muskrat Study}

I SPENT June 11 and 12, 1949, with Dr. J. Henry Sather, then of the Nebraska Game, Forestation, and Parks Commission, inspecting the fur and waterfowl lakes and marshes lying south of Valentine.

Typical marshes of the Sand Hills varied as much as those of the eastern Dakotas. They were small or large, with much open water or covered with vegetation. Sather seldom found muskrats at an alkalj lake having little vegetation except a bordering growth of sedges. There were extensive areas of grassy meadow and other areas resembling the willow swamps of northern wetlands - the willows sometimes being mixed with cattails and bulrushes. Arrowhead patches as well as heavy stands of cattail and hardstem and river bulrushes were the choice feeding grounds of the muskrats, as in the typical glacial marshes lying hundreds of miles to the east and northeast.

The muskrats did much burrowing in the sandy soil, but of course, the thin sod above could be easily broken through by livestock.

One of Sather's study areas was a cattail, bulrush, and burreed marsh of about 33 acres in 1949, about 43 acres in 1950, and about 51 acres in 1951. In 1949, at the time of my visit, it had eight recognized breeding territories in the banks in addition to the muskrat territories situated out in the emergent vegetation. Badgers had dug out the upper parts of some of the territorial burrow systems of the banks and in one case, had exposed a nest of the sort in which young muskrats are kept. The badger digging seemed to be rather general, doubtless centered to a considerable extent upon muskrats, but by no means entirely, as meadow mice were also sufficiently abundant in those places to draw much attention. I did not see why the muskrats would need to remain in the burrows if excessively troubled by the badgers, 
for the marsh had an abundance of emergent vegetation suitable for lodge building and a total breeding popualtion not much over 30 pairs. Some muskrats plugged up their burrows with vegetation or sand after the visitations of the badgers.

Sather's (1958) account of his Sand Hills study, while especially strong on muskrat life history and behavior, also includes quotable information on the ecology and population dynamics of cinnamominus:

During early spring the first green plant appearing above water was a sedge, and simultaneously, feeding platforms appeared in this plant community. When other aquatics emerged, feeding in the sedge community dropped off.

During summer muskrats apparently fed on any plants growing near their dwellings; however, on Rice Lake they apparently preferred burreed in early July. Other plants heavily utilized in summer were cattail, river bulrush, hardstem bulrush, various sedges, duckweeds, arrowhead, and smartweed.

Materials in feeding houses on Rice Lake in winter indicated that muskrats were eating primarily river bulrush and hardstem bulrush. The housesper-acre figures somewhat indicated a winter preference for river bulrush. Though dwellings in hardstem bulrush and river bulrush were of about equal density during the 1949-50 winter, there were about twice as many feeding houses per acre in the river bulrush. ...

Analysis of coyote scats collected during this study revealed that muskrat ranked second only to meadow mouse (Microtus pennsylvanicus) in the coyote's diet. There was an inverse relationship between the occurrence of meadow mice and muskrats. The degree of coyote predation upon muskrats is probably related to emergency conditions. Fichter, Schildman, and Sather (1955) found a close correlation between the occurrence of "muskrat disease" and damage to houses by coyotes during winter. . . .

Of 74 mink scats collected on Ballard Marsh during 1949 (December, January and February) 41 (56 percent) contained muskrat. No muskrats had been harvested from Ballard Marsh for several years, and great surpluses must have been produced annually only to fall to mink and/or other natural mortality. Under such conditions, muskrat could be expected to occur frequently in the mink scats.

The role of the badger in predation upon muskrats is unknown. Badger scats are rarely found. The only evidence available is circumstantial. Badger work frequently occurred near muskrat burrows in spring, summer, and fall, and muskrat-nesting material often was found at badger burrow entrances. Badgers probably do take nestling young, but the fact that most muskrat burrows entered by badgers remained active indicates that the activities of older muskrats were not disrupted. . . .

I found little evidence of raccoon predation upon muskrats. Raccoons were not abundant, and excep $\hat{\imath}$ in local areas probably preyed very little upon muskrats. The only raccoon seen had torn apart a muskrat house: But of the hundreds of houses examined each summer, only two appeared to have been torn apart by raccoons. During winter trapping, trappers often stated that raccoons had been digging into muskrat houses but many of these may have been scavenging upon dead muskrats. . . .

A fungus skin disease, presumably that noted by Errington (1942) in Iowa, was found on Rice Lake muskrats during the 1949 summer. Two muskrats three to four weeks old, live-trapped on the same house, had hairless ears with a dandruff-like scurf. They were emaciated and had difficulty in coordinating their movements. Nestling young on other lakes were similarly affected, especially after litters were moved to less suitable houses be- 
cause of disturbance by the investigator. In these cases, the disease seemed to be associated with the wetness of the new nests.

The most spectacular disease noted was the hemorrhagic disease apparently peculiar to muskrats (Errington, 1946 and 1954). It has not been previously reported in Nebraska. The characteristic symptoms are hemorrhagic intestines and/or rectum and lungs. Liver lesions also occur. The disease is highly lethal and may annihilate entire populations. In this study it was first observed in the winter of 1949-50. A trapper had found seven dead muskrats in two houses on Vanderline Marsh on January 26. Dissection of the seven revealed clear-cut symptoms of the hemorrhagic disease. The trapper said that no muskrats had been harvested from this lake the previous winter.

On February 15, 1950, a trapper brought in a muskrat found dead in a house on West Long Lake. Examination revealed hemorrhagic intestines and rectum, and liver lesions. The lake was examined on the same day. The west half had the most houses and appeared to support much the heavier population; but upon closer examination few, if any, muskrats were found. Most of the houses were frozen and had been entered by coyotes; however, four dead animals were found in unmolested houses and all had the characteristic symptoms of the disease. Their small size indicated death had come during the fall. The muskrats of this lake also had not been harvested the previous winter.

Die-offs of muskrats were reported from other sandhill lakes during each winter of the study, but they could not be inspected. Landowners stated that the muskrats of all of these lakes were either unharvested or very lightly harvested the previous winter. A definite relationship between the occurrence of this disease and over-population is apparent. ...

Fluctuating water levels profoundly affect muskrat habitat in the sandhills region. Rising levels in the past few years flooded out extensive areas of emergent aquatic plants used as food and shelter by muskrats. The greatest changes occur on lakes without surface drainage, but carrying capacity is also reduced on lakes with surface drainage.

\section{Appendix K}

\section{Excerpts from Glass (1952) Concerning Muskrats and Muskrat Habitat in Modern Oklahoma}

In the past in Oklahoma the muskrat has apparently been a streamdweller. Prior to the last two decades, ponds and lakes had been virtually non-existent. ...

Recent development of large and small impoundments has made much new muskrat habitat available. Today muskrats are more often found in ponds, lakes, and strip-pits than along stream margins. Streams that maintain flow still harbor some animals, and provide routes of travel for many more, but the greater number occur in the new impoundments.

As a rule ponds and small lakes provide better habitat for muskrats than large bodies of water. . . . Large impoundments usually are equipped with outlet works, and the water levels vary from season to season through manipulation for flood control, power development, municipal water supply, and in some cases irrigation. Consequently much of the margin of these bodies of water is bare mudflat over which water floods and recedes at varying 
intervals. Under these circumstances food plants have difficulty becoming established. . . .

The practice of building fish-rearing ponds below the dams of large impoundments is frequent in Oklahoma. These ordinarily have steep grasscovered sides and have depths varying from two to six feet. Unlimited supplies of clear or nearly clear water are usually available by siphon from the lake above. In such ponds food plants nearly always grow in profusion, and muskrats thrive... .

Regarding muskrat foods in Oklahoma impoundments, Glass wrote:

Cattails (Typha latifolia and T. angustifolia) do occur, but usually in small patches, and scattered, never in extensive areas such as occur in northern muskrat marshes. Rushes of the genus Scirpus are more uncommon. In certain impoundments the American Lotus (Nelumbo pentapetala) is well established. However the local people regard it as undesirable because of its tendency to choke entire bodies of water. . . . In ponds where turbidity is absent, Najas guadalupensis often becomes extremely abundant. . . Najas, Typha, and Nelumbo are the principal aquatic foods available to muskrats for winter food, the former as green leafy vegetation, the latter two as starchy tubers.

Many other plants are available for food during the warmer parts of the year, and evidence of use has been noted in Cyperus, Jussiaea, Ceratophyllum, Eleocharis, Polygonum and Potamogeton. Other plants that may furnish food include Dianthera, Juncus, Sagittaria, and Heteranthera. . . . They are less common, or are abundant only in very restricted localities. In this category should also be placed the introduced waterlily, Nymphaea. In some lily ponds muskrats have been known to eliminate these plants.

In ponds where only plants of these two groups occur muskrats may establish themselves and thrive until the onset of cool weather. If plants that provide winter food are not present, however, the first killing frost will cause the pond to be abandoned. This was observed in the fall of 1947 on a small lake north of Stillwater. On November 5 five occupied holes were observed in the banks. Food plants in the vicinity consisted almost entirely of Jussiaea and Cyperus. Both showed evidence of heavy use. By December 1 , when the area was visited a second time, frost had killed all of the plants in the vicinity. There was no evidence of muskrat activity, and the rats remained absent all winter.

Two species of exotic plants have come to occupy a significant position in the winter diet of the muskrat in Oklahoma. One is Johnson Grass, Sorghum halepense, a native of South Africa, which has become characteristic of field borders, roadsides, and stream banks. Where this grass occurs in proximity to water inhabited by muskrats the animals dig out the large rhizomes for food. In many places along streams this grass seems to be the sole item of food during the winter. It is probable that this introduced plant is responsible for the continued existence of muskrats along the streams in Oklahoma. The other is Bermuda Grass, Cynodon dactylon, a European grass that is widely used in Oklahoma for lawns, pasture, and as an erosion-resistant cover on dams and embankments. When used in the latter capacity it will spread to the water's edge, and may even trail into the pond itself. Muskrats resort to these places, especially in winter, and scratch out the rhizomes. Where this occurs over successive years the whole embankment may be undercut as much as 18 or 20 inches.

One of the ponds used for fish culturing at Lake Carl Blackwell leaked, and the margins became "grown up with small cottonwood 
trees, Populus deltoides. When the leak was partially repaired in 1946 the water level was raised so that these trees stood in approximately three feet of water." While these trees were submerged, wintering muskrats stripped the bark from every tree between the water level and bottom of the pond. At this time, "the whole pond border was sodded with Bermuda grass, and in the adjoining pond was an ample supply of Najas."

This pond provided an opportunity to observe the carnivorous tendencies of muskrats. When the water receded following the siphon failure raccoons dug about forty hibernating turtles, Pseudemys scripta troosti, out of the mud. As the water receded it was possible to keep track of successive finds, and to determine the manner of usage by both raccoons and muskrats. Only in one or two instances were the racccons able to eviscerate the turtles completely. In other cases the limbs and heads were eaten off and the shell and its contents discarded. Muskrats would find the carcasses, gnaw them open, and feed on the contents. The shells were completely cleaned and chewed to varying extents.

Of muskrat responses to emergencies in the fish ponds below Lake Carl Blackwell in the winter of 1946-47, Glass wrote:

When the siphon burst water levels quickly lowered, and the den openings, normally a foot or so below the surface, were exposed. As soon as one opening was exposed the animals would plug it with earth and trash, mainly dead stems of Polygonum, and open a new entrance at a lower level. When this in turn was exposed the whole process was repeated. Often openings at three levels could be detected. As the lowering water reached the foot of the embankment and receded across the bottom of the pond the muskrats would extend canals to the edge of the water. As the water receded further, these would be extended, until ... some of them attained a length of approximately 30 feet. At this point it became impossible for the canals to be lowered deep enough to keep water in them. When this occurred the holes were usually abandoned.

\section{One more quotation from Glass:}

In the fish culture ponds below the dam at Lake Carl Blackwell an attempt was made to effect a clean-up count in the winter of 1947-48. The arrangement of these ponds is such that there are approximately 10.3 surface acres of water, and 8,000 feet of shoreline. In these ponds there were located 14 den sites, each possessing from one to three openings. This gives approximately one den per 750 feet. Trapping was carried on in November and December until several successive nights yielded no results. In this manner twelve muskrats were obtained, one per 667 feet of shore, or a little more than one rat per surface acre of water. Yost Lake, a lake north of Stillwater where conditions in most years are very favorable to muskrats, has an area of about 30 surface acres, of which a considerable amount (approximately one fifth) is grown up with cattail and lotus. The farmer who lives on land adjoining this lake traps muskrats every winter, and in average years takes between 30 and 40 . This again amounts to just over one rat per acre. Both Yost Lake and the culture ponds are considered to be the best muskrat habitat seen in this study. 


\section{Concerning the Exceptionally Life-rich Marshes Along the East Side of Great Salt Lake}

The Bear River Marshes have long been known for their muskrat populations. My own inspections, carried on chiefly with the invaluable assistance and company of Dr. Jessop B. Low of the U.S. Fish and Wildlife Service, were almost confined to Unit 2 of the Bear River Migratory Bird Refuge, which Marshall (1937) described as having

an area of approximately 5,000 acres. Vegetative type areas in this unit . . were roughly as follows: Submerged aquatics (Potamageton spp., Ruppia spp., and Chara), 3,000 acres; emergent vegetation (Scirpus paludosus, S. occidentalis and Typha spp.), 1,500 acres; and Distichilis spicata, 500 acres. In general, muskrat signs, such as houses, feeding stations, bank dens, and canals, were adjacent to the strips of $S$. occidentalis and Typha, which extend along channels through the unit and total roughly 400 acres in area.

The view over Unit 2 was, to my eyes in July, 1949, one in which the area of barren-appearing shallow-water flats greatly exceeded the area grown to emergent vegetation. Numerous bayous were full of carp, but these seemed to be making little impression on the almost solid mats of submerged plants, such as Potamageton.

Some places were seen that were then barren of emergent vegetation but having remains of old muskrat lodges in them. The local opinion was that these were the result of muskrat eat-outs, but this upon examination proved not to be true. The lodges were in sight merely because they were exposed by collapse of the vegetation, and there were dead patches to be seen in the midst of essentially unbroken tracts of bulrush and cattails showing no damage by muskrats. One of these so-called eat-outs was closely examined on foot - a stand of alkali bulrush (Scirpus paludosus), which characteristically did not thrive in this part of the marsh, though it was a dominant plant in other parts. The affected area consisted of about an acre in the center of a patch of about four acres, with the emergent vegetation dead except for a tongue of $S$. acutus (= occidentalis) extending into it. Muskrat lodges were exposed there, but the entire four-acre patch had a similar distribution of lodges concealed by vegetation, including the living stands of $S$. paludosus. The alkali bulrushes that were still alive were conspicuously afflicted by something resembling a virus disease of river bulrushes observed on central Iowa marshes.

Surrounding the ailing stand of $S$. paludosus were extensive growths of $S$. acutus and cattail, together with some reeds - all having muskrats in good numbers but not damaged by overuse. In the living $S$. paludosus were occupied muskrat lodges, exposed on the mud ex- 
cept for wet channels. About the lodges, the vegetation had been cleared for lodge-building materials, but, farther than about fifteen feet from the lodges, the stands appeared to be unaffected by the muskrats.

The main channel of Bear River on the higher ground did not have a heavy flow, for much water was diverted upstream for irrigation. In the marsh, the channel had variable growths of willows and marshy plants and very considerable numbers of muskrats. The latter were coming out in late afternoon and early in the evening about as do populations of midwestern small rivers reaching densities of 80 to 100 per mile. Deeper in the marsh toward Great Salt Lake, the river banks disappeared in places and stuck out a foot or so from the water in others. Artificial islands, dating back to an old CCC program, afforded more banks for muskrats to burrow into. Bulrushes and cattails lined the banks or extended off to the sides as typical marshy growths. Muskrats occurred everywhere in the above bulrushes and cattails, but their local densities varied rather inexplicably.

The dikes enclosing Unit 2 were found to have some signs almost everywhere, varying in part with the neighboring vegetation. Although the food supply near the more barren of the dikes was not very attractive, I would say that even here the muskrat breeding territories occurred about every 50 to 75 yards. Some of the better-vegetated parts of the dikes had currently used territories 25 to 30 yards apart. Many lodges could be seen in the cattail and bulrush growths out from the dikes; these were generally in very shallow water.

In most parts of the impoundment, there were, however, several inches of water in the cattails and bulrushes having the heaviest muskrat signs. The abundance of muskrats along channel banks having limited amounts of the better food types probably reflected as much as anything the generally high densities of muskrats in the Refuge. Some of the ditchlike channels had signs indicating populations equal to if not greater than any drainage ditch populations worked with in Iowa. Heavy stands of emergent vegetation lying 30 to 50 yards away from the channels were also full of muskrats, and substantial areas just did not seem to have room for more of the animals.

The beginning of a botulism die-off among ducks, coots, and shorebirds was noted on July 11, 1949, in one place having high densities of muskrats. The muskrats were feeding upon some of the fresher victims, but I did not see any dead muskrats among the dead birds. Upon returning to this site on July 20, I found the place strewn with hundreds of dead birds but with no dead muskrats. The current muskrat signs seemed fully as heavy as they had been before.

Dr. E. R. Quortrup, formerly in charge of the U.S. Fish and Wildlife Service's disease studies at the Bear River Migratory Bird Refuge, has done a tremendous amount of work with botulism. In reply to an inquiry, he wrote (letter, December 13, 1950), in part: 
The problem that puzzles you now also made me wonder when I was at Bear River - why do we not find sick muskrats during a severe outbreak among waterfowl? I have killed muskrats by inoculating the toxin, but I have never found a muskrat poisoned naturally with the botulinus toxin. I am inclined to believe that they have developed a natural immunity as have foxes, coyotes, and dogs. As a comparison I might mention that although mice are excellent test animals when the toxin is injected they are quite refractive to oral exposure, although they will die from large oral doses.

The fact that you observed muskrats eating the flesh of duck and coot victims would indicate that they are at least partially immune. . . . It is, however, possible that muskrats in Iowa might not have the same degree of refractive ability as muskrats inhabiting an area where botulinus toxin is constantly present.

Between the Bear River Migratory Bird Refuge and Brigham, Utah, were cattail-grown seepages along irrigation ditches, and these had muskrats. There were numerous bulrush marshes on private land; while these were said to have a fair amount of water in winter after irrigation ceased, they tended to go dry in summer, and, when looked at in July, 1949, had few muskrats. Bear River, itself, had the appearance of a western-type stream. Oxbows showed a wide range of water levels and emergent growths, with those most favorable for muskrats having fairly high banks and stands of bulrushes and cattail.

Near Hooper, Utah, along the east central shore of Great Salt Lake, lies the Ogden Bay Migratory Bird Refuge of 12,000 acres. It had an area of fresh water (water from the Weber River held in by dikes) and natural expanses of wet flats extending off to the lake. Low gave me the following figures on its muskrat harvests in late years: 270 in $1944 ; 1,681$ in $1945 ; 3,022$ in $1946 ; 3,362$ in 1947 ; and 1,542 in 1948.

Unit 1 of the Ogden Bay Refuge has roughly 1,025 acres, mostly salt flats. Heavy stands of cattail and alkali bulrush grow in sizable tracts on the flats and along the wide ditches that have been dredged in this area. The mid-July muskrat sign along the ditch banks was light, and I was told that this was typical for summer. By fall, after the water had risen, muskrats usually appeared in large numbers along the ditches and dikes. No one had, as of then, demonstrated the main sources of these newcomers, but there were indications that they came from both cattail and bulrush clumps in the vicinity and from big tracts of alkali bulrushes lying miles out on the flats.

Unit 2 of the Ogden Bay Refuge exemplified a peculiar type of muskrat habitat to be found far out on the flats. Noland Nelson, of the Utah Fish and Game Association, took Low and me in an airboat out on the flats within a half-mile of Great Salt Lake, where there were large patches of thriving alkali bulrush. (This was where alkali bulrush really grew, in contrast with the stunted, blighted, and dying stands inspected on the Bear River Refuge.) In mid-July, the flats were drying, with immense acreages of hard bottoms exposed. 
This exposure was of seasonal occurrence, with the water commonly covering the bottoms again in late September or later.

One tract of alkali bulrush was essentially continuous over about 1,200 acres and had breeding densities of about the equivalent of a pair of muskrats per acre. Most of the little outlying islands of alkali bulrush also had muskrats. The muskrats out here were restricted to the vicinity of this species of bulrush, for it was the only emergent to be seen for vast distances. Within the alkali bulrushes, the muskrat signs were those of animals living in early drought stages. Traces of water covered the bottoms in the vicinity of the lodges, but the muskrats had not as yet deepened their burrows to any appreciable extent. Possibly what I consider the tardiness of the muskrats in responding in an expected way to the loss of surface water might be due to the hardness of the bottoms; beneath a slippery superficial layer of gumbo-like mud, the bottoms were quite unyielding to a man's weight.

The remarkable gradualness with which changes in water levels occur on the flats might also have a bearing upon the responses of the muskrats. On July 23, after days of exceptionally hot weather for that part of Utah, with maximum temperatures of between 90 and 100 degrees Fahrenheit, I revisited Unit 2 of the Ogden Bay Refuge to find that the flats had dried up hardly at all since a first visit on July 12. There may be almost no water over them for much of the time, but what there is seems to have a way of lasting.

In the summer of 1948, Low and others had observed a heavy drift of muskrats along a main trail leading up one of the fresh water streams that trickled over the flats. Many muskrats were then reported to have been in dead or in dying condition. Some that were picked up alive died soon after from undetermined cause.

\section{Appendix M}

\section{Montana Muskrats and Contagious Diseases}

Jellison, Kohls, Butler, and Weaver (1942) found tularemia to be highly lethal to muskrats in Montana, and Brown (1944) cited a personal communication from Dr. R. R. Parker, of the U.S. Public Health Service at Hamilton, Montana, as stating "that when an epizootic started in a colony it would kill all of the animals present." Parker wrote (letter, August 9, 1944) that the "frequency with which natural waters are contaminated in Montana is surprising but the source of contamination is a real mystery."

In the summer of 1946, I visited the Rocky Mountain Laboratory 
of the U.S. Public Health Service at Hamilton, Montana, where Dr. William L. Jellison made available to me the records of proved occurrences of tularemia in muskrats and beavers in that region. The disease seemed to be about everywhere. However, there was evidence that the hemorrhagic disease was about as widespread among muskrats as tularemia, and, even in Montana, the deadlier agency. Jellison told me of a spectacular late fall die-off that was almost certainly due to hemorrhagic disease, though first, before negative results were obtained from good specimen material in the laboratory, it had been ascribed to tularemia. These specimens had shown the bleeding from the anus so often found in the Iowa victims of hemorrhagic disease. Mortality from either or both tularemia and hemorrhagic disease has been reported in recent years from other parts of western Montana, as may be illustrated by a letter (August 30, 1946) from Robert F. Cooney of the Montana Department of Fish and Game:

I was discussing the matter of muskrats with our Deputy Game Warden, Kenneth Fallang in White Sulphur Springs, yesterday. He ... had found a number of dead muskrats in his area, that is in Meagher County along the Smith River drainage, during the past several years. This situation seemed particularly pronounced early last spring or late in the winter. $\mathrm{He}$ said that several trappers had brought dead muskrats in to him and that he had opened them up and found the livers containing . . . lesions . . typical of tularemia.

Of course, insofar as liver lesions of tularemia are similar to those of the hemorrhagic disease, the latter could well have been the disease from which the muskrats had died, especially in view of the time of year of the losses.

In February, 1950, I received from Jellison a slide and fixed ma. terial of Haplosporangium obtained from a muskrat in Lake County, which includes most of Flathead Lake in northwestern Montana, and the same investigator later (1950a) published an account of his findings on this fungus in muskrats:

Muskrats ... trapped on the Wall farm, 11/2 miles north of Charlo, showed such extremely heavy infestations that considerable areas of the lungs appeared consolidated. Cultures of Haplosporangium sp. were established from three of four muskrats from this farm and from one muskrat on the Morris farm near Charlo. This would tend to confirm the suspected findings of Haplosporangium sp. in muskrats in British Columbia as reported by Dowding. . . .

Arrangements were made . . . to save in cold storage the lungs of a series of muskrats to be trapped when the regular season opened [ in 1949 ]. On December 6, frozen lungs were obtained from 126 muskrats which were trapped in the general vicinity of Charlo. No attempt was made to culture these lungs, but they were examined microscopically before and after partial digestion in 2 per cent $\mathrm{NaOH}$ solution. Typical fungus cells were found in 23 sets of lungs, or 18 per cent of the animals. Infestations varied from single cells to almost complete consolidation of lungs by masses of fungi and their surrounding tissue nodules. 
From papers by Ashburn and Emmons (1942, 1945), it would seem that Haplosporangium (or coccidioidal) infections in rodents might be rather much a phenomenon of western North America. At the time of this writing, I know of no instances of Haplosporangium having been found in muskrats elsewhere, though Erickson (1949) reported $H$. parvum from a beaver trapped in Aitkin County, Minnesota. The population significance of the disease in muskrats is unappraisable on the basis of our present information. My guess is that it must be extremely variable locally.

\section{Appendix $N$}

\section{Studies of High Altitude Muskrats on and About the Beartooth Plateau, South Central Montana and North- western Wyoming}

I MADE A SPECIAL EFFORT to gain insight into the ecology and distribution of muskrats at an extreme edge of their habitable range in about four townships (144 square miles) of mountain wilderness in south central Montana and adjacent Wyoming, just northeast of Yellowstone National Park. Field work was done during the summers of $1935,1936,1938,1939,1941,1946,1948$, and 1949, chiefly in connection with personal vacation trips.

Numerous small bodies of water are distributed over the Beartooth Plateau at altitudes between 9,000 and 11,000 feet. The timberline lakes and ponds are ice covered for most of the year and furthermore are swept by strong winds during the brief growing season for emergent plants. Dr. R. F. Daubenmire of the State College of Washington expressed the view in conversation that the winds were responsible for the scarcity of marsh-type emergents more than were the other adverse factors. Where rather dense sedge growths were occasionally seen to occur, they were rather well restricted to sheltered zones, particularly along the west borders.

Foresters, trappers, fishermen, and other persons having had experience on the Beartooth Plateau were asked if they had ever known of muskrats about any of the higher waters there, and their invariable reply was that they had not. It is easy to see why muskrats would have almost no chance of surviving nine months of alpine winter, with the best food plants, the sedges, seldom growing in water more than a foot deep. Yet, during the warmer months, muskrats might conceivably straggle up from altitudes at which they could have wintered. Indeed, during the 1948 investigations, what certainly looked like an old caved-in muskrat burrow (of a temporary type) was 
seen in the sod bank of the sedge-fringed west side of one of the higher, shallow lakes of the plateau.

Information from other sources indicates that occurrence of muskrats in this sort of place is unlikely though not impossible. Dr. O. H. Robertson of the University of Chicago spent "approximately ten weeks during the months of August 1942, 1943, and 1944" at the No Name Lakes (about 10,500 feet - several hundred feet above timberline) in the Wind River Mountains of western Wyoming without observing any muskrats (letter, August 4, 1947). Yet, Dr. John W. Scott of the University of Wyoming told of having seen in midsummer of about 1929 a large muskrat practically under his feet at a similar altitude, at the outlet of Telephone Lake, Medicine Bow National Forest, near the south central boundary of Wyoming.

Just east of the Beartooth Plateau, I saw muskrat tracks in July, 1939, only a few hundred feet below timberline on a sand bar of the West Fork of Rock Creek. In 1948, when muskrats were in fact not found higher than 8,000 feet along this same stream, the upper parts were explored to find out whether muskrats might ever within reason go on up to the plateau; and the ruggedness of the canyons toward the end was judged to constitute an impassable barrier. A like situation existed in the upper parts of the South Fork of Rock Creek, also lying east of the plateau. North of the plateau, East Rosebud Creek and East Rosebud Lake were looked over and found to be devoid of muskrat signs above 7,000 feet, many miles downstream from places where the canyons became sufficiently precipitous to prevent upstream travel by these animals.

The best high-altitude muskrat habitat in the West Rosebud drainage was an old beaver pool at the upper part of West Rosebud Lake, at about 6,300 feet. This pool was seldom over a hundred yards wide and only a few hundred yards long and may be described as a widening of the stream. There were in the terraced series of beaver pools substantial growths of sedges and plain evidence of a muskrat breeding territory on June 24, 1949. Muskrats were using both an abandoned beaver lodge and a series of bank burrows, the main retreat being in the burrows.

Emerald Lake is separated from West Rosebud Lake by several hundred yards of torrent. It had some muskrat signs when visited, but little livable habitat other than a stretch of overhanging mossy bank. Old muskrat signs were seen in two places off to the side of the stream: one place was a very old set of abandoned beaver pools, and the other was a shallow, rock-lined flooding with an old beaver dam. The latter place was barren of food plants except for one end, where an extensive growth of sedge covered the exposed mud and shallow water. It was about a quarter-mile from the main stream and connected with it by a small, trickling brook.

The main stream below West Rosebud and Emerald lakes was creeklike and turbulent, but, farther down in the foothills, it had quiet stretches and muskrats. Rough water, however, extended for miles in 
places, and muskrats using the stream as a travel route must be forced to do much climbing over rocks and banks. Above the Montana Power Company's plant, the terrain looked impassable for muskrats. I was unable to find out whether muskrats had ever been known to occur in the two rather large lakes (Mystic and Island) lying above the power plant but still at an altitude of less than 7,000 feet.

To the south of the Beartooth Plateau, accessible parts of the upper reaches of Clark's Fork of the Yellowstone River were visited in search of possible avenues of travel between muskrat-occupied stretches and the plateau waters above. The species occurred downstream from Clarke, Wyoming. Upstream from Clarke, miles of steep canyons and swift water were sufficient to serve as a barrier. Between Cooke, Montana, and Painter, Wyoming, were several stretches that appeared to have a minimal habitability, with sod banks and overhanging willows, but no muskrat signs were seen in the likeliest places. On the other hand, a long stretch of gorge must surely have been impassable to muskrats. The roughest part of the river in here was a good 25 miles long, probably longer, and samples that I saw were cataracts and rapids pouring over solid rock.

Swamp Lake, an irregularly shaped marsh, lay a couple of miles south of, and connected by a creek with, Upper Clark's Fork. The muskrat-habitable area was of perhaps 200 acres, mostly grown heavily to round bulrushes, but with stands of sedge, river bulrush, and cattail, as well as tracts of open water of varying depth. A few muskrat lodges were in sight from shore, and the periphery had typical signs when inspected on June 19, 1949. This was said to have been the site of a muskrat farm, and my guess is that the local stock had been artificially planted, insofar as it was surrounded by mile after mile of what would seem to have been impassable barriers of mountains and rough waters.

Beartooth Lake lay only about 10 miles north of Swamp Lake but on much higher ground and separated from Swamp Lake by several miles of plateau and steep canyon. Beartooth Lake had beaver workings, and some parts looked as if muskrats could live there, but no actual signs of muskrats were ever seen there during any of my visits. Four miles east of Beartooth Lake and in the same drainage, Long Lake had some sedge-grown places that could attract a stray muskrat if one got over there. It was to the south of Long Lake that I saw the only probable muskrat burrow - the old, caved-in one previously mentioned - on the plateau.

Along the western edge, the headwaters of Clark's Fork had muskrats. Norman Cowger, a rancher living near Red Lodge, Montana, had seen muskrats while fishing at Kersey Lake, which lies about five miles east of Cooke, Montana, or about nine miles east of the northeastern tip of Yellowstone National Park. This was described as a fair looking place for muskrats, at about 8,500 feet, with rushy fringes, etc. Rock Island Lake and Broadwater Lake (a shallow widening of an upper part of Clark's Fork) might also afford some muskrat habi- 
tat. These waters were about 20 miles $\mathrm{WNW}$ of the caved-in burrow seen south of Long Lake.

How do muskrats reach such places in mountainous regions? In view of the Lamar River populations of northeastern Yellowstone National Park and the nearness of several Lamar tributaries to tributaries of Clark's Fork across a narrow and not always excessively high or rugged divide, invasions from the Clark's Fork headwaters to the west should repeatedly have taken place whenever population pressures in the Yellowstone muskrats induced much up-stream movement.

Gordon Watson, of the U.S. Fish and Wildlife Service, considered view of the Lamar River populations of northeastern Yellowstone NaNational Park) too precipitous to invite passage by muskrats. $\mathrm{He}$ thought that animals could more easily move northward up Slough Creek, then eastward along Lake Abundance Creek to Lake Abundance, which lies four miles north of the northeastern tip of the park. From Lake Abundance, muskrats getting across a hump would find themselves in the Clark's Fork drainage, and within five to eight miles of the Kersey-Broadwater-Rock Island series of lakes.

\section{Appendix $O$}

\section{Austin W. Cameron's Notes on Localities Occupied by Ondatra obscurus in Newfoundland}

The Port-aux-Basques area consists of extensive barrens largely vegetated with ericaceous plants (Ledum, Kalmia). Sphagnum and reindeer moss are also plentiful. The trees are usually less than $3^{\prime}$ high except in the ravines. Numerous rocky ponds dot the barrens. Vallisneria, Potamogeton and Nymphaea are the chief aquatic plants with a few sedges and grasses comprising the littoral vegetation. Old tunnels were noted here, although no muskrats were actually observed.

Tompkins lies in the fertile Codroy Valley, which in contrast with Portaux-Basques, 15 miles away, is heavily wooded with white spruce (Picea glauca), black spruce (Picea mariana), mountain maple (Acer spicatum), and numerous other species characteristic of the Canadian Zone. Evidence of muskrats was apparent along the banks of the Codroy River and in small ponds in the valley. Local residents reported them abundant. Again, Nymphaea, Vallisneria, and Potamogeton natans were the common aquatics.

Salmonier on the Avalon Peninsula is rather low, undulating country showing evidence of glacial scouring. The soil is rather infertile and apparently acidic, as well as being very rocky. Of sixteen ponds (locally called "lakes") examined, only one was occupied by muskrats at the time, although all showed evidence of previous occupation. Several active burrows were located on the rocky bank of a small point jutting out into the pond. Cuttings of Vallisneria were noted at the entrance to the burrows. Nymphaea and Potamogeton also occurred here. ...

In all cases, heaps of fresh water clam shells were noted at intervals along the shores. 
The large number of unoccupied ponds may be due to (1) excessive trapping or (2) frequent emigration from pond to pond. I am rather inclined to favor the latter explanation because (1) the scarcity of available food appears to be such that the supply would be quickly exhausted; (2) trapping, no matter how intensive, probably would not remove all the muskrats from so many ponds. The inaccessibility of most of the ponds seems further to confirm my suspicion. The only fresh water fish observed in ponds occupied by muskrats were brook trout . . . and sticklebacks. . . .

South Brook in the interior is located in the fertile Humber Valley. Muskrats were found in the still water of the river and in beaver ponds. Here again, the quantity of available food appeared to be rather scanty. The vegetation in and around one beaver pond in particular consisted of: - Vallisneria americana, Potamogetan natans, Nymphaea advena, Carex intumescens, Carex diandra, Sparganium sp., and Scirpus rubritinctus. Cuttings of Vallisneria, Potamogeton and Sparganium were noted. Typha, which constitutes the main food plant of Ondatra, was not observed in Newfoundland. This absence, combined with a general scarcity of other food plants, may account for the poor condition of the pelts.

It seems significant that the Newfoundland Muskrat almost never builds lodges but is primarily a bank muskrat. . . . Here again the absence of suitable plants (such as Typha) seems to be a contributing factor.

\section{Appendix $P$}

\section{Supplementary Information on the Hudson's Bay Company's Steeprock Lease, Manitoba}

IN 1948, when I visited the Steeprock lease, muskrats were scarce, in splendid appearing stands of cattails as well as in the rather open center. No convincing explanation for the scarcity of the muskrats may now be advanced. The trapping had been discreet. The water and plant balance seemed favorable. William Blowey, the manager of the lease, had seldom found dead muskrats he suspected of having been disease victims - though he had found many dead beavers.

The beavers at Steeprock often lived out in the marsh, instead of merely in the shore zone. Three of their lodges were noted in deepmarsh locations, one being near the middle. These did not differ greatly in appearance from neighboring muskrat lodges, except in over-all size and the sizes of some of the dead sticks incorporated along with green marsh vegetation in the lodges. The beavers lived as muskrats did in other respects, feeding on miscellaneous submerged and emergent growths. Here, in their own unquestionably favorable habitat, the muskrats displayed no propensity to live in close association with the beavers, as they had in the Montana and Wyoming 
streams. Nevertheless, the Steeprock muskrats did not particularly avoid the beavers.

Enlargement of the marsh as a result of artificial damming in the early thirties was accompanied by interesting ecological changes. Considerable dying of willows, tamarack, and black spruce occurred in the swampy areas, and much of the dead wood had just become rotten enough by 1948 so that the roots were breaking off. These flooded swampy areas furnished some of the heaviest cattail stands of the marsh, or rather a tangle of cattails and woody debris. Here were old muskrat clearings and mostly old dead muskrat lodges. The peat bottom of the former swamp, after fifteen years submergence, lay as a tough undulating blanket about five inches thick, mostly unbroken but with occasional holes in it, sometimes lying on the mucky substratum under four feet of water, sometimes floating on the surface like an algal mat.

A high (about 30 feet) limestone bank bounding the east side of the Steeprock marsh was well tunnelled by muskrats. Most of the burrow systems were old and little used, but those in the more attractive looking places showed fresh muskrat signs. Blowey considered the east bank one of the best places for muskrats in a normal year.

The company records for the Steeprock lease (D. E. Denmark's letters of January 20, 1949, and January 9, 1951) show lodge counts of 290 for November, 1934; 600 for 1935; 670 for 1936; 1,000 for $1937 ; 1,000$ for 1938; 979 for $1939 ; 609$ for $1940 ; 670$ for $1941 ; 509$ for 1942; 1,149 for 1943; 521 for 1944; 390 for 1945; 700 for 1946; 593 for 1947; 401 for 1948; 640 for 1949; and 670 for 1950.

When these fall lodge counts are plotted against time on coordinate paper, the first five points define what could be called the slope and upper asymptote of the Verhulst-Pearl-Reed logistic curve except that the point for 1936 fell considerably below its expected place on the curve. This slowing down of the rate of population growth in 1936 occurred cluring a season of good rainfall - in contrast with the drought of that year on the north central prairies and plains. In 1938, when the lodge count fell a little below the expected line of the upper asymptote, flood losses had been heavy - estimated at about 1,000 muskrats. In 1939, when the lodge count fell still a little more below the expected upper asymptote, the rainfall had been light, and the winter of 1939-40 had been one of severe losses (estimated at 2,000) from freeze-out. The summer of 1940 had been one of drought, and no lodges appeared in the frozen-out areas of the preceding winter. The season of 1941 had been favorable and the slightness of the gain over 1940 (609 to 670 lodges) may perhaps reflect overtrapping in March and April, 1941, when 3,119 muskrats were taken an above-average catch following a drought summer and a severe winter-kill. Events in 1942 were most imperfectly appraisable. Among other possibilities, it might be that the trapping catch of 2,585 for March and April, 1942, had been excessive for the population under the circumstances. 
The peak population of 1943 followed complete protection of muskrats from trapping in the spring. Denmark wrote in his letter of January 20, 1949:

You will note that we stopped trapping in 1943. This was in part an experiment to determine the capacity of the marsh which I think is about 7,000 . The surplus estimated at about 500 migrated in the fall of ' 43 and built their winter houses about three miles away at the mouth of the Steep Rock River on Lake Winnipegosis.

Exactly what happened to hold the Steeprock populations down, 1944-48, may hardly be figured out with complete satisfaction. On coordinate paper, the increase from 1945 to 1946 looks like a segment of the same Verhulst-Pearl-Reed logistic curve indicated by the earlier statistics. Could the low populations for 1944 and 1945 have been in consequence of the peak population of 1943? Or do we have influence of a cyclic low entering either in here, or in the depressed level for 1947, if not that of 1948 ?

The 1950 spring catch was 2,657, and in his letter of January 9 , 1951, Denmark considered the situation at Steeprock to be one of the most favorable in Manitoba and Saskatchewan.

\section{Appendix $Q$}

\section{Excerpts From a Paper on Muskrats at Delta, Manitoba, Presented by Peter F. Olsen at the 18th Midwest Wildlife Conference (Lansing, Michigan, December 10, 1956)}

The water table of the Lake Manitoba drainage basin undergoes periodic wet and dry phases. The low of the last dry cycle was in 1944 after which a wet cycle began. From 1949 to 1952 water levels were stabilized at a foot above the long term average. Beginning in 1953 there followed a rapid and continual rise in the lake level which reached a peak in June, 1955 at a level 3.5 feet above average. This surpassed the previously recorded high and any others recalled by the oldest residents.

Formerly, in years of normal water levels, the sloughs of the marsh proper contained water to a depth determined solely by spring rainfall and snowmelt and were not affected by water fluctuations in the lake and bays; often these sloughs would be dry by mid-August. The high water of 1955 flooded this entire portion of the marsh to the same level as the bays. Five or six breakthroughs occurred in the narrow, wooded, shore ridge which separates the marsh from the lake allowing a direct connection between the two. As a result, throughout the greater part of the summer, wind tides from the lake caused fluctuations in the marsh levels of from 6 inches to over a foot within a 24-48 hour period. . . . 
In addition to the direct effects upon the muskrat population of these high and fluctuating water levels, the indirect effects through changes in the vegetation should be noted. The picture to be gained from a comparison of the present vegetation with that existing prior to the current wet cycle is one of degeneration. The species composition of the flora has been greatly altered to the point of eliminating, for practical purposes, those emergents which were least tolerant of the increased water depths, such as the once lush stands of cattail and white-top grass. Species which managed to survive, such as hardstem bulrush and phragmites, the latter being the dominant emergent on the marsh, were greatly reduced in density, distribution, and quality. ... This degeneration greatly reduced the food and cover supply, resulting in a lowered muskrat carrying capacity.

In 1955 the first peak of litter production occurred during the week of May 29. As things developed, this was a very unfortunate time for the young to be born. During this period and the week following, violent north-west storms caused wind tides, which, with almost continual heavy rainfall, produced a 1.5 foot rise in the already high water levels on the marsh. In the 24 hour period between June 8 and 9 , when the first litters were still less than one week old, an 8.4" rise was recorded. In addition, the weather was cold, with temperature averaging 54 degrees - about 10 degrees below normal. All these factors combined to produce very poor conditions for survival of nestling muskrats. On June 10 a trip was made through part of the marsh to see how the muskrats were faring. Several litters were found exposed on the top of flooded-out houses; some of these were being brooded by the female. Many of the young were cold and in poor shape and showed very little inclination to move about.

The distribution of litter birth dates for 1955 shows . . . instead of a progressive decline in the number of litters . . . born in each succeeding peak, there is an increase. ... I believe that this departure from the normal is the result of a virtual wiping out of the first litters by drowning and chilling. Furthermore, I believe that the high late peaks of litter production and the extended period of production represent what has been termed by Errington as "compensatory breeding," being stimulated by the poor success in raising early-born young. The evidence . . . is as follows:

First, the breeding season was extended well into August and, instead of about $13 \%$ of the total production occurring after July 15, which is normal, about $43 \%$ occurred after that date in 1955 .

Second, it was found that on the basis of placental scar counts, each breeding female had produced an average of 19.4 young or 2.8 litters during the season, a full litter more than normal. Also, it was observed that $100 \%$ of the adult females had produced at least 1 litter, $96 \% 2$ litters, $67 \% 3$ litters, and $10 \% 4$ litters, more than doubling the percentage of $2 \mathrm{nd}$, 3rd, and 4 th litters produced in a normal season.

Finally, there was the factor of survival of the young to the trapping season. It was found by comparing the total seasonal productivity with the ratio of adult females to juveniles in a sample of approximately 2000 animals taken during the harvest, that of the 19.4 young produced per female, 10.55 had survived. This is a survival value of $54.2 \%$ which is just about normal. Thus, it seems that the compensatory production of an extra litter during the summer brought about a normal survival of the young. Had the compensatory breeding not taken place a much lower adult female:juvenile ratio would have prevailed and the survival would probably have been in the neighborhood of $30 \%$.

Evidence that it was late litters which survived was obtained from the results of the examination of over 700 skulls from a random sample of the harvested muskrats. A method utilizing tooth measurements was developed by which juveniles of early litters and late litters could be quite definitely separated. This work indicated that $75 \%$ of the surviving juveniles were 
born in the latter half of the breeding season while only $25 \%$ were born in the first half.

In summary, it appears that in 1955 the Delta muskrat population was able to offset a severe mortality of the early born litters by prolonged breeding and greater average individual productivity. . . .

During the winter of $1955-56$ the muskrat population at Delta was cut back by nearly $90 \%$. The pre-trapping season population was estimated at 8200 animals. Trapping and a severe epizootic of Errington's Disease accounted for about 7000 animals leaving a total of approximately 1200 breeders or 1 pair to 4 acres of marsh, a relatively low breeding density even when the reduced carrying capacity of the marsh is considered.

The water level receded during the winter so that by breakup in spring 1956 the level was $1.5^{\prime}$ lower than the preceding year. The weather during April and May was considerably cooler than in 1955 and, as a result, the breakup and start of breeding was one week later, with breeding commencing about May 8 and the first peak of litter production coming during the week of June 3 .

Conditions were ideal for litter survival with no pronounced water level fluctuations, fair weather with very little rain, and above average 70 degree daily temperatures during the period of peak production and the week following.

The distribution of litter birth dates for 1956 shows that there were again, as in 1955, some major variations from the "normal" distribution. . . . There were 3 well defined peaks with the middle rather than the first [ peak being the highest ] . . . . Also there was a good deal of litter production between the peaks. There was strong evidence that the explanation for both of these divergences from the normal was the presence among the breeders of an abnormally large proportion of the preceding year's late born juveniles. Autopsies of 200 muskrats during April, 1956, indicated that these late born young would not be capable of sexual response to the triggering action of a weather factor in early May as would be the juveniles produced in the early part of the 1955 season and the two year olds. Thus, these animals did not commence breeding until later and were "out of phase," so to speak, in terms of peak periods of production throughout the summer.

In 1956 the breeding season was again extended into late August with $23 \%$ of the litters being born after July 15. This is somewhat lower than the 1955 figure but still significantly greater than the normal.

The breeding females continued their high rate of production giving birth to an average of 20.4 young or 2.7 litters each during the season. Of the entire sample of adult females examined, $3 \%$ were barren, 97\% had produced [at least] 1 litter, $95 \% 2$ litters, $71 \% \quad 3$ litters, and $5 \% 4$ litters much the same distribution as noted in 1955 .

Survival was somewhat greater in 1956 than in 1955 with an age ratio in the fall trapping season of 12.9 juveniles per breeding female, indicating a $64.5 \%$ survival. Although the dentition method of determining the percentage of early vs. late litter juveniles among the harvested rats was not used on the 1956 sample, examination of the frequency distribution of weights of harvested juveniles indicated a higher percentage of early-born young, which was more in proportion to the actual production.

It appears that the 1956 reproduction conformed to the "inversity principle," i.e., there is an inverse relationship between the density of the spring breeding population and the production. . . . Thus, the extended breeding period and the high individual productivity noted in 1956 are thought to have resulted from: 1) the stimulation inherent in low-density breeding populations; 2) from diminished population tension; and 3) from increased opportunity for young to disperse from foci of adult activity.

These same factors may also have been operative in the 1955 breeding season combining their influence with the stimulation of early litter mortal- 
ity. However, survival data and the distribution of litter birth dates substantiate the original contention that the high productivity noted in 1955 was primarily the result of excessive early litter mortality and compensatory breeding.

\section{Appendix $R$}

\section{The Hudson's Bay Company's Cumberland Lease and the Manitoba Government's Summerberry Fur Rehabilitation Block}

DenMark (1940) Wrote of the Hudson's Bay Company's 303,000-acre lease in east central Saskatchewan:

The Cumberland House District has always been good country for muskrats. The lakes are shallow, and the marshes full of cattails and bulrushes. ... But in recent years, overtrapping and continued low water have caused serious depletion there. . . . The worst factor was the series of dry years following 1930, which resulted in the lowering of water levels in the marshes. The Saskatchewan River was very low in 1936, and in 1937 the usual summer high water on the river did not materialize. . . .

In September, 1938 [ after leasing by the Hudson's Bay Company], work was started on a small canal to carry water from the Saskatchewan River, in high water, to the marshes. [ More engineering improvements followed, and Denmark wrote later (1946) ]: The flow of water is controlled by a system of dams and dykes so that the water diverted from the river in June does not reach the lower end of the area until August. In its course the water keeps the marshes fresh and maintains the water levels at the desired depth for muskrats, three to four feet. A large lake at the upper end serves as a storage reservoir which feeds water to the marshes through the winter.

This irrigation has not only restored water levels in the marshes but has created new marsh areas which in the preliminary survey were not considered suitable for muskrats. Some 50,000 acres now produce muskrats, and the recent construction of a large rock crib control dam near the lower or east end of the lease will bring into production an additional 30,000 acres.

What I saw of the Cumberland lease in 1948 showed great fundamental extremes because of differences in major environmental types. There were vast bogs and swamps having little value for muskrats, but there were also some very fine large marshes. In mid-August, I looked over three of the latter - Big, Waterhen, and Egg lakes - in company with Denmark and Russell Robertson, the manager of the lease.

Most of this inspection trip was centered on Egg Lake, of roughly 4,000 acres, which then had a water level about a foot above normal, after a level that had been about one and one-half feet higher earlier in the season. Fine stands of bulrushes grew in the deeper water (about four and one-half feet), and varying growths of cattail, reed, and bulrush occurred near the margin of the willow swamp surrounding the marsh. The swamp also had much cattail, considerable bur- 
reed and sweet flag, besides reed. Many muskrat lodges were seen at the swamp edges, mostly built in the willows. Feeding signs of muskrats extended out to about 300 yards into the marsh from the willow swamp. Most lodges in the deep-water bulrushes were of very recent construction, but there were a few that had been there for months and in which young had been raised.

The marsh had signs indicating possibly about the equivalent of a breeding pair and their young per 10 acres and about a pair and associated young per 100 yards along the swampy margin.

Dr. Leonard Butler, of the University of Toronto, has done much work on the biology of the Hudson's Bay Company's muskrat marshes. He said that, in dry years, the peat of the bogs and swamps provided sufficient insulation to prevent the frost line from sinking very far. Hence, some catches of muskrats were made in the boggy zone during springs following dry summers and falls. The muskrats apparently had been able to dig in unfrozen peat for food even at times of not much snow.

So far as wintering conditions were concerned, Denmark rated cattail lower as a marsh plant valuable for muskrats than the "goose grass" (Equisetum fluviatile), which occurs in heavy stands in wetlands over a great deal of the North. Not only was the "goose grass" extensively utilized both as food and for lodge building, but the muck in which it grows was said to be resistant to freezing. The roots and rhizomes were described as growing as deep as six feet below the surface of the water and the plant (the upper parts of which remain green under the ice in winter) as having remarkable powers of regeneration when heavily eaten by muskrats.

Big Lake had thicker stands of reeds about the edge than had Egg Lake, and as much bulrush in the deeper parts, but not anywhere nearly as many muskrat signs. There were more signs along the channels - of both natural and artificial origin-connecting Big Lake with Egg Lake. To the sides of these channels were willow swamps having six inches to a foot of surface water. Several muskrat nests at the bases of willows were seen in the swamp, and it was expected that the occupants would soon be moving into Big Lake, itself. Waterhen Lake, one of the steadiest producers of muskrat pelts on the lease, had few muskrats in large tracts of reeds, but where the reeds were mixed with cattails, bulrushes, burreeds, sweet flag, and "goose grass," the muskrat signs were conspicuous. In mid-August, muskrats were moving into the bulrush patches of this marsh from the willow swamp. Deeper in the marsh were some old lodges, including focal points of regularly occupied breeding territories, mostly restricted to floating clumps of cattails or reeds.

In the Old Channel of the river and its offshoots leading to the Hudson's Bay Company Post of Cumberland House, muskrats were all but lacking. I found them living at only one place along stretches of about a mile and a half looked over carefully and about ten miles looked over casually. 
Epizootics have quite evidently become a major problem in muskrat management of the Cumberland lease. During the winter and spring of 1946-47, the estimated losses from epizootics exceeded 100,000 muskrats. The hemorrhagic disease that has shown such destructiveness in regions to the south seems to have been the main agency, but Butler had contracted tularemia a few years before in the course of his handling muskrat specimens from the Cumberland marshes, so tularemia also may have contributed to the mortality. Denmark (letter, January 9, 1951) wrote of substantial disease losses in the fall of 1949, as well. "We were able to spot these areas by the number of ravens that were hanging around." Also: "There was very little snow in the early winter of $1949-50$ and the frost penetrated five feet in the marshes. It was still there two feet below the surface in some places in August [ 1950 ]. Damage [ from this 1949-50 freezing ] was terrific and we reduced our 1950 spring catch accordingly. The surviving muskrats were in poor shape in the spring after a hard winter and a very late break-up. In the summer there was little sign of increase."

Denmark made available to me the Company records on December lodge counts and muskrat catches for the Cumberland lease and its constituent subdivisions. The annual lodge counts are given in Table R.l.

The lodge counts for the entire 303,000-acre lease, plotted against time in the usual way on coordinate paper, show a modest increase between the falls of 1939 and 1940 that may reflect the recency of the water manipulations and the 1940 drought conditions. The decline in 1941 followed another season of drought; in the spring of 1942, 4,315 muskrats were trapped (a light catch but one conceivably quite heavy for the drought-reduced stock), and the survivors were subjected to a bad marsh fire. Then, after protection from trapping in the spring of 1943 and restored water levels, the lodge counts for 194346 line up like the slope and part of the upper asymptote of the Verhulst-Pearl-Reed logistic curve. The spring catches were 24,765 in 1944; 63,212 in 1945; and 94,111 in 1946 .

The drastic decline occurring between the fall of 1946 and the 1947 spring trapping - when the catch was only 38,475 - seems to me classifiable as a possible cyclic manifestation, coming when and as it did. Much loss evidently took place through the agency of disease, which should be considered both in connection with a possible cyclic low and independently of it. Environmental deterioration may not be blamed for the muskrat decline, for not only was much of the habitat that I saw in 1948 still in good condition despite high water but 30,000 acres more of marsh also had been brought into production through the construction of a new control dam in 1946. Moreover, the increase in lodge counts between 1947 and 1948 has its mathematical counterpart in that from 1943 to 1944, so it would seem that the over-all population was still responding in conformity to the same logistic curve defined by the earlier data. 


\section{TABLE R.1}

Annual December Counts of Muskrat Lodges Made by the Hudson's Bay Company on Its Cumberland Lease, 1939-50, by Area and Agreage

\begin{tabular}{|c|c|c|c|c|c|c|c|c|c|c|c|c|}
\hline Year & $\begin{array}{c}\text { Cut } \\
\text { Beaver } \\
2,000 \mathrm{~A} .\end{array}$ & $\begin{array}{c}\text { Blood } \\
\text { Sucker } \\
3,700 \mathrm{~A} .\end{array}$ & $\begin{array}{c}\text { Swan } \\
2,600 \mathrm{~A} .\end{array}$ & $\begin{array}{l}\text { Junction } \\
1,300 \mathrm{~A} .\end{array}$ & $\begin{array}{l}\text { Water- } \\
\text { hen } \\
2,200 \mathrm{~A} .\end{array}$ & $\underset{\text { 4,600 A. }}{\text { Egg }}$ & $\begin{array}{c}\text { Big } \\
\text { Lake } \\
2,400 \mathrm{~A} .\end{array}$ & $\begin{array}{c}\text { Bog } \\
7,000 \mathrm{~A} .\end{array}$ & $\begin{array}{l}\text { Gull } \\
2,000 \mathrm{~A} .\end{array}$ & $\begin{array}{c}\text { Deep } \\
\text { 1,200 A. }\end{array}$ & $\begin{array}{c}\text { Number } \\
\text { Three } \\
\text { 1,300 A. }\end{array}$ & $\begin{array}{c}\text { Entire } \\
\text { Lease } \\
\text { 303,000 A. }\end{array}$ \\
\hline $\begin{array}{l}1939 \ldots \ldots \\
1940 \ldots \ldots \\
1941 \ldots \ldots\end{array}$ & $\begin{array}{l}487 \\
682 \\
784\end{array}$ & $\begin{array}{r}911 \\
1,135 \\
0\end{array}$ & $\begin{array}{r}1,116 \\
1,173 \\
742\end{array}$ & $\begin{array}{r}617 \\
1,790 \\
808\end{array}$ & $\begin{array}{r}556 \\
648 \\
25\end{array}$ & $\begin{array}{r}2,014 \\
3,878 \\
978\end{array}$ & $\begin{array}{r}143 \\
359 \\
0\end{array}$ & $\begin{array}{l}0 ? \\
0 ? \\
0 ?\end{array}$ & $\begin{array}{l}0 ? \\
0 ? \\
0 ?\end{array}$ & $\begin{array}{l}0 \\
0 \\
0\end{array}$ & $\begin{array}{l}360 \\
574 \\
296\end{array}$ & $\begin{array}{r}9,194 \\
14,331 \\
4,267\end{array}$ \\
\hline $\begin{array}{l}1942 \ldots \ldots \\
1943 \ldots \ldots \\
1944 \ldots \ldots \\
\end{array}$ & $\begin{array}{r}113 \\
823 \\
1,261\end{array}$ & $\begin{array}{r}56 \\
394 \\
3,526\end{array}$ & $\begin{array}{r}57 \\
558 \\
1,261\end{array}$ & $\begin{array}{r}66 \\
725 \\
1,015\end{array}$ & $\begin{array}{r}182 \\
437 \\
1,198\end{array}$ & $\begin{array}{r}755 \\
2,738 \\
4,330\end{array}$ & $\begin{array}{r}4 \\
435 \\
979\end{array}$ & $\begin{array}{r}0 ? \\
0 ? \\
548\end{array}$ & $\begin{array}{r}0 ? \\
27 \\
174\end{array}$ & $\begin{array}{r}14 \\
218 \\
1,567\end{array}$ & $\begin{array}{r}3 \\
263 \\
837\end{array}$ & $\begin{array}{r}1,519 \\
10,211 \\
23,080\end{array}$ \\
\hline $\begin{array}{l}1945 \ldots \ldots \\
1946 \ldots \ldots \\
1947 \ldots \ldots \\
\end{array}$ & $\begin{array}{r}1,622 \\
959 \\
51\end{array}$ & $\begin{array}{r}3,592 \\
2,169 \\
244\end{array}$ & $\begin{array}{r}1,471 \\
1,359 \\
98\end{array}$ & $\begin{array}{r}1,484 \\
1,476 \\
142\end{array}$ & $\begin{array}{r}787 \\
1,218 \\
557\end{array}$ & $\begin{array}{r}2,542 \\
800 \\
450\end{array}$ & $\begin{array}{r}1,200 \\
805 \\
129\end{array}$ & $\begin{array}{r}2,240 \\
7,194 \\
139\end{array}$ & $\begin{array}{r}1,118 \\
3,185 \\
237\end{array}$ & $\begin{array}{r}1,888 \\
944 \\
75\end{array}$ & $\begin{array}{r}1,412 \\
1,898 \\
168\end{array}$ & $\begin{array}{r}28,532 \\
31,795 \\
3,132\end{array}$ \\
\hline $\begin{array}{l}1948 \ldots \ldots \\
1949 \ldots \ldots \\
1950 \ldots \ldots\end{array}$ & $\begin{array}{r}526 \\
142 \\
0\end{array}$ & $\begin{array}{r}1,412 \\
334 \\
384\end{array}$ & $\begin{array}{r}874 \\
758 \\
4\end{array}$ & $\begin{array}{r}1,234 \\
392 \\
49\end{array}$ & $\begin{array}{r}1,903 \\
401 \\
579\end{array}$ & $\begin{array}{r}1,188 \\
1,145 \\
243\end{array}$ & $\begin{array}{l}354 \\
233 \\
181\end{array}$ & $\begin{array}{r}1,346 \\
80 \\
386\end{array}$ & $\begin{array}{r}1,288 \\
1,631 \\
272\end{array}$ & $\begin{array}{l}319 \\
183 \\
118\end{array}$ & $\begin{array}{l}928 \\
669 \\
132\end{array}$ & $\begin{array}{r}16,823 \\
14,160 \\
3,950\end{array}$ \\
\hline $\begin{array}{l}\text { 12-year } \\
\text { means }\end{array}$ & 621 & 1,180 & 789 & 815 & 708 & 1,755 & 402 & 994 & 661 & 444 & 628 & 13,416 \\
\hline
\end{tabular}


The lower lodge count of 1949 could have been due to the local epizootics that the Company personnel observed in the fall (see earlier quotation from Denmark's letter of January 9, 1951). Possibly, the 1949 spring catch of 54,908 may have been sufficiently heavy to have had a net depressive influence on the population. In appraising the trapping, it should be considered that some of it had been made as nearly annihilative as possible on certain marshes as an experiment in disease control (Denmark, letter of April 12, 1949). Also considerable "salvage trapping" had been done early in the winter of 1948-49 to harvest muskrats from areas where conditions had been unfavorable for their successful wintering (Denmark, letter, May 16, 1949). Yet, the 1949 period of effective spring trapping had been shortened by unusually mild weather, and the 1949 status of the marsh for muskrats appeared to have been excellent, with breeding starting early and trappers reporting large litters.

The poor wintering conditions in 1949-50 alone would be a convincing explanation for the great reduction of the muskrats implied by the fall lodge count of 1950; and the 1950 spring catch of nearly 25,000 , although representing an intentionally lowered quota to allow for wintering losses, may still have been somewhat high for the surviving population. It should also be mentioned that 10,225 muskrats had been "salvaged-trapped" earlier in the winter of 1949-50 from shallow water and disease areas (Denmark, letter of January 9, 1951).

If the lodge counts for the principal units of the Cumberland lease be plotted separately, much irregularity may be seen in the ways that the clata line up, whether unit be compared with unit or with the lineup for the entire lease. Denmark (letter, February 15, 1949) explained:

The irregularity of the population in certain Cumberland areas may be accounted for at least in part by a change in environment. For instance, Muskeg, Deep, and Blood Sucker lakes were slowly drying up from 1938 to 1942 when canals were excavated to irrigate these lakes. During that period Swan Lake had a bountiful (sometimes too much) supply of water. Then, there has been considerable migration from Fgg Lake to nearby areas such as the Bog. On several occasions Egg Lake has raised a lot of rats which for some reason leave what looks like attractive ground to go off and winter in some place where they get into difficulties.

It was the combination of marshlands comprising the whole Cumberland lease for which populations responded so well according to the pattern outlined by the Verhulst-Pearl-Reed logistic curve. If allowance be made for the effects of droughts, epizootics, and probably a depressed phase of the 10-year cycle, evidence can be seen of a biological base level remaining essentially unchanged over a considerable period of years despite local differences. The idea should not be gotten, however, that all of the environmental changes taking place at Cumberland were without influence on the underlying biological base level ordinarily manifested by conformity to the logistic curve. A pronounced change in the base level was seemingly brought about by the management measures initiated on their lease by the Hudson's Bay 
Company in 1939, as may be seen by comparing the muskrat catches for the entire Cumberland area of 735,000 acres $(=432,000$ acres in a Community lease plus the 303,000-acre Company lease) .

The spring catch figures sent to me by Denmark (letters, March 1, 1949, and March 12, 1951) for the 735,000 acres were derived from the actual records of furs collected by the Hudson's Bay Company and estimates of those purchased from the area by competing buyers. The figures: 13,548 in the spring of $1927 ; 24,970$ in $1928 ; 20,927$ in 1929 ; 12,954 in $1930 ; 13,771$ in $1931 ; 18,354$ in $1932 ; 26,091$ in $1933 ; 44,460$ in 1934; 46,365 in 1935; 16,015 in 1936 ; 5 ,221 in 1937; closed season, 1938 ; 19,218 in $1939 ; 50,901$ in 1940 ; 43,503 in $1941 ; 12,214$ in 1942; closed season, 1943; 59,056 in 1944; 76,668 in 1945; 127,419 in 1946; 49,902 in 1947; closed season, 1948; 79,105 in 1949; and 69,910 in 1950.

Plotted against time, the earlier catches for the 735,000 acres lined up along the slope and both asymptotes of a Verhulst-Pearl-Reed logistic curve, followed by the severe 1936-37 drop. The latter may be tentatively ascribed to either or both cyclic decline or drought emergencies. After the Company's engineering operations to improve water levels on its 303,000-acre lease, the catches for the 735,000-acre area continued to show, when not depressed by droughts and other similar crises, a tendency to line up along the slope of a logistic curve, but of a curve having a decidedly higher base than the one operative in the early thirties. This higher base could hardly be credited to anything other than the bringing into production of a substantial acreage of marshland that had not been in production during the preceding decade. The 12-year total catch before development (1927-38) was 242,676, and the 12-year catch after development (1939-50) was 587,976 .

The great delta of the Saskatchewan River, lying east of The Pas, was once, like the marshes near Cumberland House, a celebrated trapping ground that had been badly dried out during the early thirties. Like the Cumberland marshes, those of the delta were put under management - by the Game and Fisheries Branch of the Manitoba Government in this instance - and a system of canals, dikes, and dams was installed. These measures restored to productivity a tremendous amount of muskrat habitat, which came to be known as the Summerberry Fur Rehabilitation Project. From Allan (1941), it may be learned:

that in 1902 approximately 800,000 rat pelts . . . were marketed from the Saskatchewan Delta alone. In 1934, 50,000) would be a high estimate. In 1935, due to preliminary experiments in muskrat management through water control, some 27,000 rats had been harvested from 54,000 acres, and from an area which in $1932 \ldots$ had produced only 120 pelts.

McLeod (1948) reported on the results of field studies carried on in 1944, 1945, and 1947 for the Manitoba Government, as well as on the 1937--47 records from lodge counts, etc. The area he had under in- 
vestigation was described as "a large flood plain involving approximately a million acres bordering on the Saskatchewan River and its branches." His paper is a valuable source of quotations:

The Saskatchewan River in Manitoba shows two flood periods per year, the first representing the local spring run-off with the peak occurring on the average somewhere between April 18 and May 6, and with an average rise over the past ten years of twelve feet six inches. The second flood period normally occurs sometime between June 12 and August 9, representing the run-off from melting snows in the Rocky Mountains and showing an average rise of ten feet five inches.

At the present time under peak flood conditions, the Saskatchewan River spills over its banks in many places in the delta region and fills the numerous depressions with water. There is a tendency toward dyke formation along the banks of the channels and also some silting-in of channels and depressions where currents are reduced. . .

The study of the responses of the plants to flood conditions was greatly facilitated by the fact that a portion of the delta area had been under flood for ten years while other portions had been under flood for various lesser periods ranging down to one year. It was observed that shortly after flooding there is a general drowning out of the existing vegetation and a recession of all emergent plants toward shallower water or drier soil. Thus, for about two years, the usual marginal zonation of plants is somewhat confused and young marsh plants are found establishing themselves amongst meadow forms which are in the process of dying out and becoming re-established beyond the water's edge. Providing conditions remain reasonably stable, and particularly if the water level does not rise, zonation of plants again becomes apparent and a maximum growth is obtained in four or five years following flooding. It was found that emergent forms normally did not occur in water in excess of thirty inches in depth and that signs of drowning appeared when the water depth exceeded two feet.

The predominants of the marsh, or emergent-plant zone, were listed as Phragmites maximus, Typha latifolia, Scirpus validus, and Equisetum fluviatile, with the predominants of the meadows being Agropyron pauciflorus, Agrostis alba, Carex rostrata and lacustris, and Alisma plantago-aquatica.

Usually the Phragmites zone is relatively broad and extends from above the water's edge out to a depth of one foot or eighteen inches. . . . If the water level was allowed to rise appreciably after the plants had become established, uprooted masses of plants of various species occurred along the outer margin as a result of what appeared to be drowning and wave action.

\section{The same author mentioned the}

water control measures that have been undertaken in order to increase or maintain the supporting capacity of the habitat [ for muskrats]. However, in spite of these measures, the sustained high production desired has not always been achieved, but rather it was found that while the results were often gratifying they were extremely unpredictable and occasionally disappointing. The disturbing feature was that it was impossible to explain why enormous variations should occur in an area where environmental conditions remained reasonably stable from year to year. 
From his treatment of the marsh in relation to the ecology of the muskrat:

Because of the very level nature of the terrain and the high water of the delta region, very limited areas are available for burrowing where muskrats are able to make nests above the high water mark . . . ; it is apparent that the muskrat has a very specific habitat which includes only the marginal strip of vegetation around each lake or slough from the water's edge out to open water. Here the animal makes its house and must find most of its food and coverage. Thus, the supporting capacity of the marsh is dependent upon the size of the marginal strip of emergent plants and on their quality and quantity.

Large molluscs, crayfish, and larger insect naiads are practically absent from the area so the muskrat is restricted largely to a vegetable diet. In summer, from June 10 to September 15, fresh stalks, shoots, and leaves are abundant so that the food supporting capacity of the area . . . is usually adequate unless a very large muskrat population is present. However, at this time coverage appears to be the most critical requirement and may often be the limiting factor. ...

Any plant material within reach of the muskrat may be utilized as winter food but those of greatest importance in descending order are as follows: Typha latifolia, Scirpus sp., Phragmites maximus, Carex sp., and Sagittaria sp. There can be little doubt that for quality and quantity of muskrats supported per acre Typha latifolia is without a near rival as a native plant type. . . .

As previously pointed out, shortly after initial raising of the water level a shift in the distribution of the plants to a new margin is seen, and under suitable water level conditions a new zonation is established in two or three years, and a maximum density is reached in about five years. One would expect this to continue in an unaltered state almost indefinitely but under conditions of consistent high water a deterioration sets in, and in about ten years the area has reverted to open water.

The general opinion is that the land "sours" in time and its productivity is reduced. The one soil element very essential for plant growth and the one most likely to be absent in soils of low fertility is nitrogen. It was thought that the so-called "sour" condition of the soil might refer to a nitrogen deficiency. There are two possibilities here: either the total nitrogen content of the soil is low, or if nitrogen is present in reasonable quantity it may all be taken up during the first four or five years of growth and become bound up in organic form. In the absence of complete decomposition of plant material in the water and mud by bacteria and animal organisms the nitrogen would be found in no simpler form than amino acids. It might be noted that there was an almost complete absence in the water of animal forms such as Cladocera and Copepoda, and bottom dwelling forms such as chironomid larvae were quite rare.

Other possibilities are suggested by Wilde, Youngberg, and Hovind's (1950) discussion of effects of impounded water on the fertility of soils flooded for more than five years by beaver clams in Wisconsin:

From an ecological viewpoint, the most important outcome of deoxidation is saturation of the soil with toxic "swamp gases," including the ill-smelling hydrogen sulfide. The action of hydrogen sulfide on the ferric compounds enriches soil in soluble ferrous iron. . . The accumulation of ferrous iron leads to fixation or "tie-up" of phosphorous in insoluble form. This is sub- 
stantiated by the pronounced deficiency of available phosphates in practically all flowage soils analyzed. The extremely low base exchange capacity in mineral soils reflects the destructive hydrolytic action of water.

\section{To continue quotation from McLeod's 1948 paper:}

The present study, based on observations of areas which had been flooded for various lengths of time up to ten years, indicates that there is a general rise in the muskrat-supporting capacity of a marsh up to the fourth or fifth year following flooding. This is then followed by a gradual decline until at the end of about ten years the supporting capacity is again low. Other factors being equal it is natural to expect the muskrat population to follow closely the supporting capacity of the habitat but a consideration of census figures based on winter house counts over a period as long as ten years shows that this is not the case. . . These data indicate that the maximum population is governed largely by the supporting capacity of each zone, but that a definite increase and decrease in the population occurs in five years and shows a tendency to be repeated in a cyclic manner. For purposes of comparison, zones as far removed as forty miles and in different stages of flooding and plant development were taken. While the rises and falls in population numbers are not exactly synchronous there appears to be sufficient similarity to indicate a general trend. Some increases are known to have continued in the face of heavy trapping, while decreases also have been known to occur in the absence of any trapping.

Such sharp declines in population might be explained on the basis of lowered reproduction or increased mortality due to starvation or predation, but information from field observers indicated that the decline may occur under very favourable conditions as regards food when the animals are in good nutritional condition. Such information states that periodically a pronounced die-off occurs, and that dead animals are found in great abundance. These specimens are reported to be fat and to have been feeding normally but to have died suddenly without evidence of sickness or distress. What small amount of material has come to hand for post-mortem examination strongly indicates a virus enteritis, first reported by Errington . . . and referred to in many quarters as "Errington's disease" [ referred to in this book as hemorrhagic disease ]. . . . Why the die-off should recur with regularity regardless of food conditions or population density is a matter for speculation. It seems probable that the virus may be present all the time and that the variable is host resistance resulting from a vitamin or trace element deficiency in the diet.

\section{In a later paper, McLeod (1950) wrote that the}

epizootic type of disease has been found locally only during the winter and early spring months but a similar disease in enzootic form has been found to persist at all times of the year and particularly during the reproductive season....

Evidence gathered to date indicates that Manitoba muskrats tend to show cyclic fluctuations in abundance but the peaks and depressions recur at intervals of from 4 to 5 years rather than at intervals of 9.5 to 10 years. In addition, the population data from definite marshes or areas over a period of 14 years show that the fluctuations are often more pronounced than a study of over-all pelt returns would indicate. Many of the fluctuations are synchronous in widely separated areas but the time appears to be determined by the date of initial flooding of the marsh which is invariably followed by an upswing of the population. 
In August, 1948, McLeod and Norman McKenzie (then Deputy Chief Warden resident in the area) showed me part of the Saskatchewan River Delta. It was still much flooded. Most of the relatively few muskrats in the vicinity of Baptizing Creek, about which our field inspection was centered, were living - as they had lived all summer - in nests and flimsy lodges in the willow thickets fringing the oxbows and main channels. By mid-August, muskrats were just beginning to return to remnants of marsh-type habitats, to build lodges and to rear late-season litters. The better of the existing marshes had, besides floating cattails, variable blocks of "goose grass," reed, and bulrushes; but, unfortunatcly from the standpoint of muskrat management, the best vegetation commonly occurred on marshes that would be nearly dry as soon as the water receded to normal levels.

McKenzie told of the small creeklike lagoons often having substantial numbers of muskrats in fall but hardly any alive by spring. Samples of the lagoons that I examined were 30 to 40 feet in width. Their banks were as high as one and one-half feet above the August water levels, grown heavily to river bank willows, and marked with as many muskrats (and mink) signs as I saw anywhere in the delta. The sluggish waters flowed through water lilies, pond weeds, arrowhead, coontail, some cattail and bulrushes, and other usual quietwater plants. McKenzie said that the water would be about three and one-half feet deep at freeze-up and that a little water would usually remain unfrozen beneath the ice all winter.

The main channels of the Saskatchewan River, and of its delta branch, the Summerberry River, were yellow with silt and could easily be distinguished from the other waters of the delta. No sign of muskrat was seen along these rivers, despite the occurrence of attractive looking willow bars. Lying parallel to the main channels were some marshy strips that did have muskrats, and muskrats were said to come out of the "bush" at times to congregate about the banks. (Denmark and Robertson had mentioned that, during drought years, muskrats had come to the banks of the Old Channel of the Saskatchewan River bordering the Hudson's Bay Company's Cumberland lease, to wander about by the hundreds but apparently not to take up definite living quarters anywhere.) After freeze-up, the water level of the Saskatchewan River is said to drop four or five feet, which should make the stream itself essentially uninhabitable for wintering muskrats, except for what individuals happened to be living with beavers or were otherwise exceptionally situated.

Director Malaher of the Game and Fisheries Branch of the Manitoba government lent me the detailed office records of the Summerberry Project, which I abstracted for use in preparing this appendix. The government's program of muskrat management was much expanded in the years following the establishment of the original Summerberry area in 1936, and by 1942 eight other areas had been added, bringing the total area in the Summerberry Fur Rehabilitation Block 
TABLE R.2

Annual Fall Counts of Muskrat Lodges Made by the Manitoba Government on Its Summerberry Fur Rehabilitation Block, 1937-50, By Area and Acreage

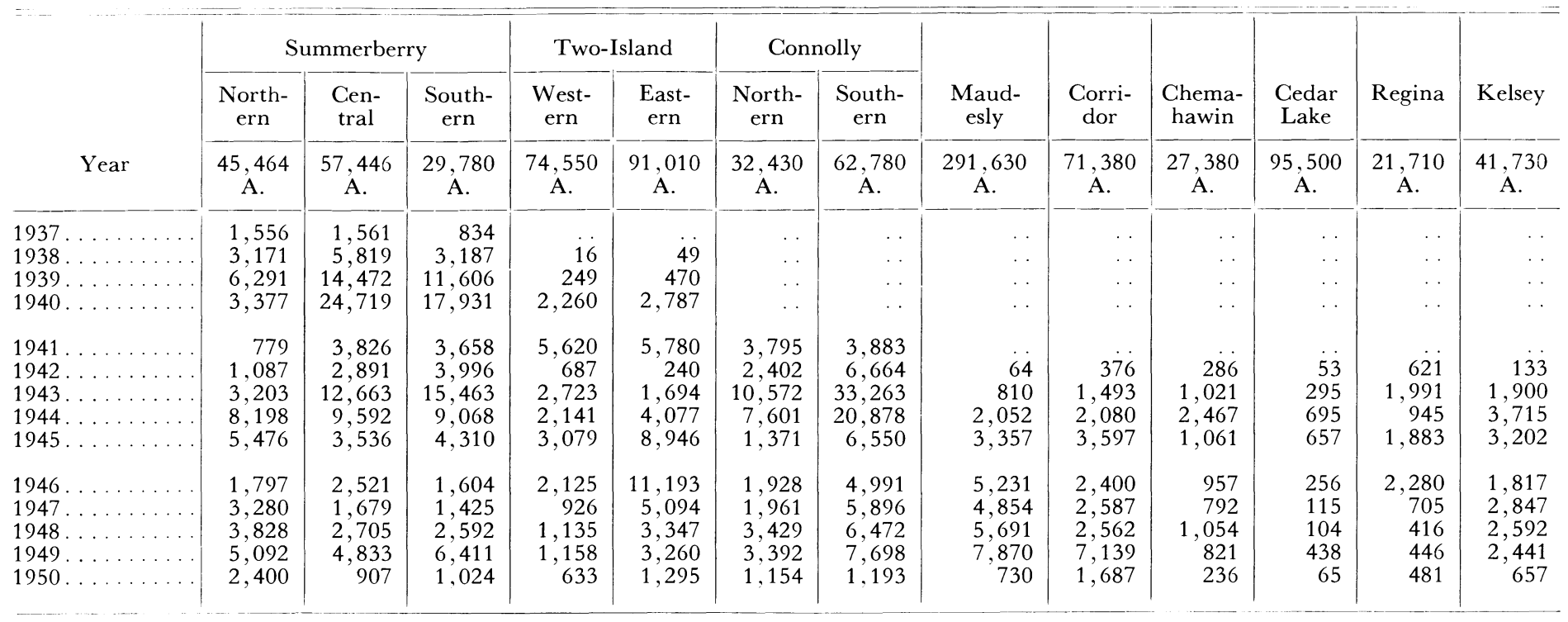


up to nearly 950,000 acres. Table R.2 summarizes the data on lodge counts, 1937-50, according to each area or major subdivision of areas.

The records show just about all conceivable variations in environmental conditions and muskrat populations of local areas from year to year, but, in their broader aspects, they delineate important trends.

The first big decline in fall lodge counts on the three subdivisions of the Summerberry area marshes after they were put under management - the decline of 1941-42-agreed in general chronology with that described for the Hudson's Bay Company's Cumberland lease. On the Two Island area, however, the population had reached a peak in 1941 and was very low only in 1942. These differences look explainable mainly in terms of local variations in habitat. The office records of the Manitoba government for the Summerberry area (dated December 14, 1941) refer to two years of near drought having reduced the productive acreage. A view was also expressed that the productive acreage remaining should have supported more muskrats than it was carrying. Overtrapping was given as a possible cause of the decline. Also, "some muskrat carcasses and organs showing lesions of disease have been preserved and held for laboratory examination."

The general case history of the Fur Rehabilitation Block for 1942 is expressed in the wording of the report:

The annual census returns were disappointing with very few zones showing any increase in house count and in many zones, especially on the Two Island Area, the decrease was astounding. . . .

There are several factors, taken together, which would account for this very marked decrease: (1) Water levels in the marsh were very low in the fall of 1941 due to very light precipitation and the absence of flood waters in the Saskatchewan River during the summers of 1940 and 1941. (2) Though water was low, there would have been sufficient in many of the lakes to carry the rats through a normal winter. However, snowfall was extremely light and nearly all lakes froze to the bottom. (3) The 1942 [spring] trapping programme was based on the [1941] fall census and did not allow sufficiently for winter freeze-out. In trying to obtain their quotas the trappers practically stripped many zones. . . . (4) Trappers did not get their quotas on their allotted zones and had to be transferred in some cases to zones which it had not been intended to trap. This left these zones very low in breeding stock. (5) The effect of the water let into the marsh during the flood period was abnormal. Lakes were so low that a rise of several feet took place before any water would flow out at the outlet point. Lakes nearest the intake point were affected first and each succeeding lake was similarly affected as the flood progressed. Thus, Lake 14 on the Two Island raised approximately three feet before flooding over the banks and leveling off. In most cases, this rise was rapid. It occurred during the breeding season and, in some places, breeding houses were flooded and washed away.

Following favorable wintering conditions and a closed trapping season, 1942-43, the muskrat populations of the Summerberry Rehabilitation Block began a pronounced ascendancy over nearly all of the managed marshland. The ascendancy terminated quite soon on some areas; after several years on others. 
The declines of the mid- and late-forties over different parts of the Summerberry Rehabilitation Block were not without their mixed variables. The general decline on the block was not overly severe by 1944, the losses on the Summerberry and Connolly areas being partly offset by gains on Two Island and on five of the six areas that were first reported upon in 1942.

Possible explanations advanced were: (1) that losses from winter freeze-out were higher than anticipated when trapping quotas were set (the early snowfall in the winter of 1943-44 had melted away and the later snow drifted badly, causing excessive frost penetration in many areas), and (2) overtrapping as a result of a quota of four muskrats per lodge in areas of concentrations, which quota appeared to have been too high for a sustained yield.

Notable freezing occurred in 1943-44 in the southern section of the Connolly area. "The [ 1944 spring ] catch amounted to 51,950 muskrats. The poor conditions in the marsh were reflected in the grades. There was a larger percentage of medium, small, kits, and damaged pelts than on other sections." The western part of the Corridor area "is deteriorating each year" because of water failure; elsewhere on the block, water conditions were little changed in 1944 from what they had been in 1943. Frequent references were made in the 1944 report to food being "good in the aggregate and well distributed."

For 1945, the "census returns on the whole were very disappointing." A letter from A. G. Cunningham (March 10, 1945) quotes a report from the Game and Fisheries pathologist, Dr. H. C. Collins:

During routine post-mortem examination ... of muskrats during the spring trapping season a few specimens revealed an indication of enteritis. Field equipment did not permit of extensive bacteriological tests, but routine inoculations in all cases resulted in mixed cultures. Later carcasses were submitted to the laboratory. Attempts failed to isolate a specific organism but test feeding of liver and spleenic suspensions, to a test muskrat, proved fatal and was diagnosed as acute hemorrhagic enteritis with septicoemic indications. Parallel test animals succumbed to intraperitoneal injections of suspensions made from infective livers and spleens. Acute peritonitis and death of muskrats, guinea pigs, and ferrets occurred within three to six days approximately, with no specific organism being isolated as the causative agent.

For 1946, the office records "have again shown an overall drop in the house count - only Maudesly, Two Island, and Regina areas showed increases. . . . The decrease in the house count cannot be accounted for by blaming it on overtrapping, as so many zones which were not trapped and had good water and feeding conditions only increased an infinitesimal amount or in some cases had less houses. ... Water levels are better than they have been in the past six years." As for the previous year, many references were made to food being good, diversified, and well distributed. On the Summerberry area, north section, the "census was very disappointing. The zones which were not trapped last spring have a small increase of $38 \%$, 
while those which were trapped ... decreased $80 \%$." In the south section of the Summerberry area, decreases occurred "in all zones except North Bluff, which held its own after having 4.5 muskrats per house trapped off it." Concerning one zone where there was freezing out if not disease loss: "The trappers were not able to get their quotas and ... about 2 per house were trapped. A large number of houses had been damaged by coyotes and foxes and some dead muskrats were found."

The Kelsey area was the only one showing a strong increase by the fall of 1947. Food and water conditions were very good. Food and water conditions likewise were very good in some of the areas and parts thereof showing continued declines of the muskrat populations. These declines were often quite baffling in particular zones of the central section of the Summerberry area and in some other places. In certain cases, environmental deterioration was apparent, but this was often counterbalanced by improved conditions on other parts of the same areas.

The decrease in the house count may be partially accounted for by the long cold winter of 1946-47. Conditions in the marsh started to deteriorate in the early part of November. There was a heavy wet snow in the latter part of October and the weight of the snow on the marsh vegetation knocked a good portion of it down into the water. In November we had very little snow ... [ [with] hard frost and the ice thickened very quickly. When we did get snow it was followed by high winds and, instead of catching in the marsh vegetation around the houses, a big percentage of the snow drifted into the willows. . . . Following the adverse conditions in November, we had a very cold and long spring. The usual mild weather in the latter part of March did not materialize and it was May before there was enough runoff to flood the houses. It was felt that muskrats were confined under the ice for almost a month longer than usual and many were lost.

The 1948 census returns, after a summer of floods, were better than anticipated. Four areas showed increased lodge counts over those of 1947; two gave practically the same counts; and three had fewer lodges. One of the two areas showing the greatest declines had good food and water conditions, but the food on the other had greatly deteriorated, "with some lakes which were solid with cattail a few years ago being almost barren of this type of food." The 1949 spring muskrat catch on the Summerberry Block was very satisfactory, with a take of nearly 80,000 muskrats. Malaher (letter, May 18, 1949) wrote: "Judging by the weight of the pelts per thousand they are not as good as usual but this could well be expected in view of the flood conditions last year."

Evidences of fairly general late breeding had been seen during my visits to the Canadian marshes in August, 1948, so there may have been considerable numbers of "kits" in the wintering population. In late December, 1948, and early January, 1949, 33 muskrats were trapped by the Manitoba government for specimens from a sample of six lodges on one of the North Connolly lakes where conditions 
permitted making a representative catch: six were clearly adults on the basis of their moult patterns, 25 were clearly immatures, and two others of questionable determination were probably immatures, thus giving a probable age ratio of one adult to 4.5 young (A. C. McMillan, letter and enclosures, February 17, 1949).

Six of the nine areas of the block showed increases by the fall of 1949, and the declines on the other three were rather unimportant and attributable mostly to drowning of food plants (particularly cattails) during the floods of the previous year. Greater concentrations of muskrats were noted, and food and water conditions varied with the locality.

Winter-killing in 1949-50 proved to be terrific, much as Denmark had described for the Cumberland lease. Except for the Regina area, all major divisions of the Summerberry Block had decidedly lower populations in the fall of 1950 than in the fall of 1949. Malaher (letter, January 22, 1951) referred to "a quite drastic reduction in muskrat populations" as having taken place over the whole Saskatchewan River Delta.

No numerical data are available as to muskrat populations on the constituent areas of the Summerberry Block before these were put under management. This would leave hiatuses in the data for six areas between 1937 and 1941, for one area between 1937 and 1939, and for one area for 1937, but McMillan (letter, January 23, 1951) wrote "that the lodges in the respective areas [for these periods] would be few and far between and that the water levels were low and in cases whole marshes were dry." We may then, without risking much distortion of facts, use the figures for the Summerberry area for 1937 as nearly the equivalent of the lodges for the whole Summerberry Block of 942,790 acres; those of the Summerberry and Two Island areas for 1938 as nearly the equivalent for the whole block; and those of the Summerberry, Two Island, and Connolly areas in 1940 and 1941 as nearly the equivalent for the block.

Such data, plotted on coordinate paper against time, reflect a distinctly lower supporting capacity or biological base level for the muskrats during the first years of increase, 1937-40, than between 1942 and 1943, when nearly the whole block was in an excellent state of productivity. In contrast, the late increase between 1948 and 1949, while impressing observers on the block as being astonishing, actually seems to reflect less favorable environmental conditions for the block than existed before the greater part (seven areas totaling 644,540 acres, including nonproductive habitat) was put under management. In other words, it looks as if the excess of water in 1948 may then have imposed a greater handicap upon the muskrats than had lack of water in the late thirties.

All of the principal muskrat waters that $I$ inspected in Manitoba and Saskatchewan in 1948 were "jackfish" (Esox lucius, northern pike) waters, and this species has a reputation throughout the Canadian North for preying upon young muskrats (Solman, 1945). Regarding 
the Summerberry marshes, Allan (1942) referred to 11 young muskrats having been taken from a single lot of 25 northern pike gill-netted during the last of June, 1939. In the discussion following the paper, Dr. Victor E. F. Solman stated that he had examined 3,000 pike from the same area and found no muskrats in the stomach contents, at a time of year when young muskrats were both plentiful and "of the greatest availability." And from a letter from H. E. Beresford dated November 19, 1943: "This summer one of my game guardians, in feeding our sledge dogs, has opened over 3,000 pike and has found no traces of young rats."

When plotted against time on coordinate paper, the Summerberry figures, 1935-40, line up in the form of a large segment of what looks like a typical Verhulst-Pearl-Reed logistic curve, which is so widely applicable to courses followed by growing populations of organisms (Pearl, 1937). The lower asymptote is as well defined as one might expect from the data points of the first four years, but the points for 1939 and 1940 only suggest the beginning of the leveling off toward the upper asymptote.

The lining up of the data points to define the celebrated logistic curve is, in my opinion, significant so far as concerns the biology and management of the Saskatchewan delta muskrats. Mathematically, this is something of an equivalent way of stating that rates of spring to fall gain had been in inverse ratio to the breeding densities for a steadily growing population. The equation certainly must have reflected intercompensations and automatic adjustments in rates of population gain and loss, these being determined primarily by the density factor in relation to the capacity for accommodation of the habitat as then existing. Despite the lack of many types of desirable data, the configuration of this logistic curve may be interpreted as meaning that, on the whole, variations in losses from specific predatory agencies such as the pike, or the usual avian and mammalian predators, or for that matter, the trappers, were taken in stride; that whether natural predation or trapping pressure was heavier or lighter in particular years, it did not effectively retard the growth of the population, which in the end merely conformed to what had the aspects of a rather set formula, at least for the 1935-40 period.

\section{Appendix $S$}

\section{Muskrats of the Mackenzie River Delta}

From Porsild's (1945) DESCRIPTION:

The delta of the Mackenzie River occupies an isosceles triangle which includes not only the delta of the present day, but also the basin of the Eskimo lakes through which, at one time, when the sca stood higher, at least part of the waters of the Mackenzie flowed.

From Point Separation, in latitude $67^{\circ} 35^{\prime}$, at the head of the delta to the 
Arctic coast the delta is approximately one hundred miles deep while its waterfront along the Arctic ocean is nearly two hundred miles long. The area comprises approximately 10,000 square miles. . . .

While entirely within the Arctic circle, the southern and forested portion of the delta faunistically and floristically belongs to the Hudsonian zone, while the northern and treeless part, as well as the Eskimo Lake basin and the foothills and mountains west of the delta, fall within the Arctic zone. . . .

A short distance below Point Separation the Mackenzie delta spreads out into a great fan-shaped maze of rivers and channels. A great profusion of small rivers and streams, some navigable and some mere sloughs, interconnect the three main branches of the delta. Extensive lakes and swamps occupy the space between the river channels, almost to the exclusion of dry land. The course of most of the main channels is changing rapidly due to river erosion and in some places the river cuts into delta islands at the rate of 50 feet or more in a season. . . .

In the delta the rivers are generally clear of ice by the first of June, but already in early April, the swelling of the Mackenzie a thousand miles to the south is felt. In May, the pressure of the water breaks the ice along the banks and water commences to flow into the lakes and swamps bordering the river banks ... [ but] in the larger lakes some ice may remain until the end of June.

By the time the river ice has disappeared, practically all land in the delta, with the exception of the higher river banks, is completely inundated. In a few days the water commences to drop, and during early June gradually recedes from the swamps and meadows.

The climate of the Mackenzie delta is continental, with low winter temperatures only slightly tempered by the proximity of the ocean. The summers are short, but surprisingly warm in the delta proper and in the Eskimo Lake basin. In the delta the summer temperature is greatly influenced by the great mass of warm water carried by the river from the south. By the end of August the summer is over and sharp frosts frequently occur at night. The river generally freezes during the first week of November. . . .

Lakes and river channels probably occupy more than two-thirds of the Mackenzie delta and more than half of the surface on the low, marshy plain which separates the Eskimo lakes from the sea. Most of the lakes in the delta support an astonishingly rich plant and animal life. During summer the water temperature, even in the larger lakes, may reach $68^{\circ} \mathrm{F}$. . .

To the estuarial waters of the region should be counted the mouths of the main river channels, the very shallow sea adjacent to the delta, the shore waters east of the delta and Liverpool bay and the brackish Eskimo lakes. During the early part of the summer the shore waters remain fresh or but slightly brackish. The amplitude of the tide is small everywhere in the region, the largest spring tide measured being about three feet. In the Mackenzie delta the tide may be felt to about twenty miles above the mouth, and in the Eskimo lakes to the very head.

\section{Quoting from the same author's discussion of $O$. z. spatulatus:}

Muskrats are very common in the Mackenzie delta, particularly in the timbered parts where life conditions are very favorable . . . and where, therefore, the greatest density of the rats is observed. . . .

In the delta, the water level, in lakes connected to river channels, does not remain stationary throughout the winter and towards spring may be much lower than at the time of freeze-up. In such lakes, rats do not depend on burrows in the lake banks but make houses on floating "rafts" or on the ice itself. Large numbers of "push-ups" are seen on all lakes frequented by rats. Often the "push-ups" are very large and undoubtedly sometimes take the place of regular muskrat "house" or "lodge," and are kept open throughout the winter. For this reason it is important for the rat that an abundant 
snowfall covers the lake and the push-ups. The principal material used in the push-ups is the leafy-stemmed Richardson's pondweed (Potamogeton Richardsonii) and water-milfoil (Myriophyllum exalbescens).

Fluctuations in the Mackenzie delta muskrat populations during the years 1926-27 and 1931-36 were not as marked as were, for example, those of the rabbits, lynxes, mice or lemmings, nor did the writer during these years observe instances of diseased muskrats.

However, Mr. Lang [ K. H. Lang, for many years a resident trapper and fur trader ] informs me that, in the winter 1933-34, he saw many dead rats in feeding houses on the ice in the upper part of the delta. The following spring very few rats were seen in many of the lakes that in the autumn had had large populations of rats. He thinks that the rats had died from some kind of disease. In the winters of low water level in the delta many muskrats "freeze out." This is apt to happen also in years when the snow comes late and when, therefore, some of the lakes freeze to the bottom. . . .

Some large lakes, 3 to 4 miles long, in the timbered parts of the delta have been known to yield over 1,000 rats in one spring hunt, but it is by no means certain that these rats were all produced on that particular lake, since muskrats travel extensively during the spring flood.

The writer . . . has estimated the area covered by the alluvial part of the Mackenzie delta at about 4,000 square miles. With an average catch of 200,000 , this gives an approximate maximum yield of 50 rats to the square mile.

\section{Clarke (1944) wrote that around}

Tuktoyatuk and Anderson River an excellent harvest is reaped and the skins are large and of good quality. . . . There is no sign that the rat population has changed much in recent years, although the catch was lower than usual in 1943.

There have been low years in the past, in 1925 and 1935. The catch during the years preceding these two low years was not as high as it has been lately. It may be that these low years are corresponding phases of a ten year cycle, and that another low may be expected in 1945. . . A great many people in the Delta believe that there is a cycle, and the possibility must be admitted. It is likewise believed by some that a decline should have set in by this time [Clarke's field work was done in 1942], but this has been prevented by a large annual catch. ... .

Along Slave River muskrats are reported to be increasing. On the Mackenzie River above the Delta they have been scarce for several years. At Simpson a dramatic reduction from abundance in 1939 to scarcity in 1940 is reported. In the intervening fall they were observed wandering overland.

MacFarlane (1905) reported that when the Mackenzie River muskrats are "very numerous, epidemic liver disease appears and carries off many thousands."

A. W. F. Banfield, of the Canada Department of Mines and Natural Resources, wrote (letter, October 3, 1947) of finding tapeworm (Taenia sp.) liver cysts that laymen might confuse with disease lesions in muskrats but considered it "extremely unlikely that this Taenia infestation would assume the proportions of a lethal disease" (letter, October 28, 1947).

Preble (1908) reviewed earlier observations of muskrats of the Mackenzie region and presented his own concerning local differences: 
In this vicinity [ Fort Simpson in 1904] the species is common in the muskegs back from the main river. . . . During my voyage down the Mackenzie in the summer I found the species abundant in the numerous ponds in the valley of the Nahanni, but seldom observed the animal elsewhere, though it is common in suitable places throughout the region. ... At Fort Good Hope the species was said to be common in the numerous ponds on Manito Island. . . . On the lower reaches of the Mackenzie and Peel rivers muskrats are excessively abundant.

Elton and Nicholson (1942) wrote in their treatment of muskrat fluctuations in Canada:

We have a practically complete series of fur returns for Mackenzie River District for the years 1821-1927. . . . The "ten-year" cycle is very plain after about 1866 [ early fur-trade practices made muskrat catches a poor index of natural fluctuations ], with peaks in $1870,1878-9,1889,1899-1900,1909$ and 1921. This illustrates the cycle shown by a fairly homogeneous large district within the Northern Department.

A breakdown analysis of the Northern Department muskrat fur returns into separate regions will not be given here, as the main object of the present paper is to show the existence of a general ten-year cycle in muskrats, without going into a detailed regional analysis for early years.

To sum up: The Northern Department as a whole after 1849 had peaks in 1852, 1862, 1872, 1880 (probably around 1890), 1901, and about 1912. The minimum years were in 1849, 1858, 1866, 1876, 1887, (around 1898?), and 1906. The doubtful years in the Nineties are confirmed in a general way by the sales figures.

A great deal of work has been done in recent years on the muskrats of the Mackenzie delta, especially by Dr. Ward E. Stevens. Some of his most interesting findings concerned movements, survival rates, longevity, and particularly relationships of animals beneath the ice - the work was done by means of winter live-trapping and tagging. The following may be quoted from a letter of May 19, 1951:

The Mackenzie delta is about the extent of the northward spread of the species and here the animals are often much at the mercy of the environment and the climate. Climate, I am convinced, is the limiting factor in population growth since it has an important bearing year-long on the animals. In summer it regulates the growth of plant food and the levels of the water, in winter the amount of ice and snow on the lakes and thus the area of lake bottom with its food stores which are available to the animals. Because of the depth of ice which is often encountered ... the lakes have to be about 5 or 6 feet deep in order to support a secure population of muskrats. Many of the lakes are deeper than this but it was found that anything over 10 feet was too cold (or something else) at the bottom to encourage growth of adequate amounts of submerged plants. Habitat, therefore, is often narrowly restrictive. The upper half of the delta is much more suitable than the lower half for the raising of muskrats. One reason for this is the protection of lakes by adequate spruce growth in the upper half and the disappearance of this growth toward the coast.

\section{Excerpts from Stevens (1953):}

In northwestern Canada the muskrat reaches its greatest abundance in the maze of lakes and waterways of the Mackenzie Delta. . . . The following con- 
centrations, other than that of the Mackenzie Delta, may be briefly noted.

At Fort Norman there was, in the past, a considerable source of muskrat fur in the lakes feeding Brackett River, especially those below Brackett Lake. Ten or fifteen years ago it was possible for a single hunter in that area to take up to 1,000 pelts in one season. At the present time he is very fortunate to get one-third as many. Reports . . . indicate that overtrapping together with rapid deepening of some of the channels, and consequent draining of the lakes, has contributed to this reduction. . . .

Another source of muskrat fur, and one which seems to be holding its own fairly well, is ... the Ramparts River near Fort Good Hope. In this area muskrats co-exist with beavers and the relationship appears to be a favourable one for the smaller animai. Approximately 10,000 muskrat pelts have been exported yearly from Good Hope and most of these came from the lakes and channels comprising the Ramparts and Hume River drainage systems.

North of Fort Good Hope there are no more areas of muskrat abundance until the Mackenzie Delta is reached. In the delta the muskrat populations reach extraordinary size, and they are forced out to less favourable habitats. The various streams flowing into the delta furnish waterways for these local movements. . . .

Most of the tundra lakes bordering the lower delta, especially those connected with the delta by small streams, have signs of muskrat use. Viewed from the air there appear to be deep runways dug from muskrat dens in the banks as a means of access to sources of food during winter. Because this region is exposed to the wind ice forms to great depths and the muskrats have a precarious existence. These lakes open late and freeze up early. The number of muskrats is restricted by the rigours of the climate and the very slow growth of vegetation. The amount of trapping is negligible.

There are very few muskrats in the lakes and streams bordering the Arctic Coast from the vicinity of Herschel Island on the west to at least Darnley Bay on the east. In the vicinity of the settlement of Paulatuk a "rat lake" is one in which muskrats may be found, and which may yield to the Eskimo hunter five to ten pelts a year. . . .

The vast hinterland from Fort Good Hope on the south to the delta of the Anderson River on the north, and westward to the Mackenzie River, shows evidence of muskrat activity. Concentrations that can be trapped profitably have been reported in some localities. . . .

The Mackenzie Delta has somewhat the same character as the delta of the Old Crow River in Yukon Territory. The latter area, known locally as "Old Crow Flats," has a population of muskrats that is economically important and furnishes a means of subsistence to the people there. . . .

The feeding station or pushup is maintained even above several feet of ice. In autumn, small holes may be found in the ice after it is formed. . . . These do not close readily, as bubbles of gas rising to the surface seem to keep them open. If a hole does freeze, it forms a dome-shaped space filled with gas and the ice above it remains thin. Pushups are usually built at such locations. The gas apparently comes from the decomposition of organic matter. A considerable mound of vegetable debris - a by-product of feeding - accumulates below each pushup. The generally slow rate of decomposition in northern lakes produces a slow continuous release of gas, and in this way pushups are perpetuated year after year in the same location.

Muskrats may open holes in the ice in other ways. Pushups are often placed in a straight line between the den and feeding areas, but how the animals space their pushups at appropriate sites is not clear. It was observed that a muskrat could enlarge a hole in the ice if it could get its muzzle and upper incisors through the hole, but that it could not chew upward or downward through solid ice. . . The native trappers stated that when muskrats are frozen out of their shore dens they must try to live in the pushups and 
usually end by freezing or starving there. One Indian reported taking sixty dead muskrats from frozen pushups in a single lake. . .

A disadvantage of snow cover, which is considerable in some years, is its weight. The weight of very deep snow can cause the ice to sink and force water to flow out through cracks in the ice and through the plunge holes of pushups. This water freezes quickly and, if enough of it escapes, the pushups are sealed by ice and thus are useless to the muskrats. . .

It would be safe to say that for the most part the lakes in the upper twothirds of the delta are adequate habitat for muskrats, or can be made so. In the lower delta, north of latitude $68^{\circ} 30^{\prime} \mathrm{N}$., the situation is much less favourable. Because this area was so recently formed, there has not been so much deposition of silt, and as a consequence the banks of the channels are lower and the lake areas relatively larger than in the upper delta. There is also a decidedly greater fluctuation of water levels during the summer. . . .

The nature of the country made it difficult to check the depredation of foxes on muskrats in summer. During the winter, when there was a good snow cover and the lakes were frozen, the foxes were much more in evidence. Trappers made use of their presence on the lakes to find buried pushups. A fox would locate, and visit, most of the pushups on any lake it came to, especially if the pushups were in active use. The trappers said that pushups visited and used by foxes, as scent stations or for voiding droppings, were invariably in active use by muskrats. This was generally the case.

There were two winter periods, of about a month each, when foxes had good success in taking muskrats. During October and early November, when the pushups were being built, the foxes were still able to dig into them. Later, when the pushups froze solidly, they were sealed against such attack. In late April, warmer weather again allowed foxes to dig into the pushups.

\section{Appendix $T$}

\section{Concerning Effects of Ditching on Muskrats of Tidewater Marshes, Especially Delaware}

Stearns, MacGreary, And Daigh (1939) summarized results of a ditching program in Delaware. There was

a substantial lowering of the water table and a marked change in vegetation of the ditched portion of the experimental area accompanied by a general movement of the muskrat population to the unditched portion of the same. When this work commenced (season of 1935-36), there was a vigorous, waisthigh, and moderately pure stand of Scirpus olneyi throughout the central portion of the ditched area, with frequently as many as four or five muskrat houses in the individual study units $\left(75^{\prime} \times 100^{\prime}\right)$ of 7,500 square feet each. At this time (season of 1938-39), with the passing of but three summers, this same area is covered with a tangled, almost shoulder-high growth of Hibiscus oculiroseus, Kosteletskya virginica, Solidago sempervirens, Aster novi-belgii, and Bidens trichosperma. . . . The original stand of Scirpus olneyi has practically disappeared, and the few muskrat houses remaining are located in close proximity to the ditch banks in the very wettest sections of the 
area. . . The movement of the muskrat population . . . was directly correlated with the rapid disappearance of . . S. olneyi upon which this animal so largely depends.

Then, from a 1940 paper by these authors:

Much of the marshland bordering the Delaware River and Bay is adapted by nature to support a sizeable muskrat population. . . . The muskrat has long been recognized ... a as one of the most important of the natural resources of Delaware, and good muskrat marshes are fully as valuable as any farm land... The Delaware City area is considered the best from all standpoints - quantity, size and quality of pelts. Primehook Neck, where conditions are much the same, rates second due to the present smaller acreage involved. This district has become increasingly less productive during recent years, the decrease being attributed to vegetative changes occasioned by the flow of salt water through many breaks in the dunes along the bayshore. . . .

Both the Delaware City and Primehook Neck areas have extensive cattail (Typha, mostly angustifolia) ... marshes ... while those intervening are characterized by mixed vegetation with considerable three-square (Scirpus $o$ lneyi)... . Practically all of this region is subject to tidal action with the higher sections producing more and better muskrats. . . .

With slight increases in elevation, the dominant growth is first big cordgrass (Spartina cynosuroides) . . . then three-square. . . Both of these plants are preferred as food and are utilized about equally in the construction of houses. . . . The more favorable situations here and in the embanked or "stillwater" marshes about Delaware City, where the water supply is subject to artificial regulation, emphasize the importance of this particular environmental requirement of both the muskrat and the plants upon which it depends for its livelihood.

Bourn and Cottam (1950) summarized a 12-year study (1935-47) of the biological effects of ditching tidewater marshes in Delaware for mosquito control. Experimental work on the Bombay Hook National Wildlife Refuge indicated "that breeding of mosquitoes on a tidal marsh may be controlled effectively by the impoundment of water to provide stable levels, and by proper swamp drainage that removes sheet water without lowering ground water levels. Control of mosquito breeding by these methods can be practiced without detrimental effects on wildlife habitat, provided the systems are adequately constructed, operated and maintained." Some idea of the magnitude of changes brought about by mosquito control operations is afforded by the statement of these authors that "by the end of 1938, some 90 per cent, or 562,500 acres, of the total original acreage of tidewater marshland along the Atlantic coast from Maine to Virginia had been ditched."

\section{A quotation from Dozier (1947a) illustrates the}

many changes, both natural and man-made, that have influenced . . muskrat abundance. Chief among these, perhaps, has been the effect left by occasional hurricanes and storms of unusual violence. . . Excellent examples of the latter are the so-called "break-throughs" that have occurred along the Delaware Coast, where tidal ingress of salt water through new breaks 
along the coast line... has greatly affected marsh vegetation types and muskrat production. One of the more important of these breaks took place in the Woodland Beach area just above the Bombay Hook National Wildlife Refuge, near Smyrna, Delaware, during the record-breaking storm of October, 1878. Prior to this, much of the area is said to have consisted of excellent cattail and Scirpus olneyi. Through a period of years, as this break enlarged, the marsh changed slowly from a fresh to a more brackish water condition. This was hastened by the digging of Sluice Ditch at the southern end of the area about 1890. Today, most of the muskrats taken in this area come from the upland borders where the freshest water is present.

\section{Appendix U}

\section{Concerning Muskrat Studies on the Blackwater National Wildlife Refuge, Dorchester County, Maryland}

FOLLOWING ARE QUOTATIONS from a recent discussion of muskrat population changes and their associated ecological complexities on the Blackwater Refuge (Dozier, 1947a):

Very heavy rains occurred during all of the late summer of 1934 [ following great emergencies brought on by a hurricane in 1933 ]. Heavy rains in 1935 caused a small flood that raised the water levels about one to two feet, but without any attendant tide. With an abundance of fresh water, Scirpus olneyi made excellent growth, crowding out the Spartina patens, and by 1936 the older trappers were saying that conditions for muskrats looked the best in some 25 years.

A steady rise in the muskrat population took place up until a peak in 1938-39. The trapping records show a peak catch from January 1 through March 15, 1938, of 26,286 for the refuge, but the largest [ number ] of houses was counted in the fall of 1939 , in spite of a minor drought the same summer.

During the 1940 trapping season, however, intense cold prevailed and ice and snow covered the marshes. The heaviest snowfall in 40 years closed roads and schools. A few days of trappable weather from January 15 to 22 , was then followed with a record-breaking snow blizzard on January 23. . . Only a comparatively few traps were set . . . the catch dropping to 19,310, a figure that did not represent a true picture of the actual population. Observations made just prior to the second snow blizzard showed that the muskrats had started to "cut out of the ice." There was evidence that many animals perished in the snow and also inside of their nests in the houses. Some of these were in badly emaciated condition, due apparently to a lack of food in badly eaten out areas. Others perished inside their nests in good flesh, possibly through some virulent form of disease. . . .

During the fall of 1940, a serious epizootic of disease that produced a virulent septicemic condition occurred in our experimental pens and marsh enclosures and this carried through into the following summer. Apparently the same disease occurred in the open marsh and, although Armstrong (1942) attributed this outbreak principally to infection by Salmonella typhimurium, 
possibly several organisms, including a virus, may have been involved. The radical drop in numbers of muskrat houses from 30,578 in 1940 to 11,175 in 1941, and a corresponding drop in actual catch from 19,310 to only 9,895 would tend to support the writer's contention that this unidentified disease was a major factor that started the decline.

In early March, 1949, Dozier expressed in conversation his view that the Maryland epizootics probably had been largely due to the same hemorrhagic disease that had proved to be so destructive elsewhere in North America. An indication that the disease may long have been operative on the Maryland marshes is afforded by Smith's (1938) reference to septicemia causing deaths of muskrats in Dorchester County.

In another paper, Dozier (1948a) wrote of outbreaks of disease occasionally occurring following construction of lodges in the fall and greatly reducing populations over widely scattered areas:

On certain units of the Blackwater Refuge in Maryland in the fall of both 1946 and 1947, numerous large dwelling houses that had been counted as freshly constructed "active" ones at that time, had assumed a deserted, straw-colored appearance by the first of January, when trapping was started. ... As there was no evidence of any migration or serious predation at the time the most plausible explanation appeared to be that a particularly virulent form of disease had struck, even though few dead muskrats could be found when trapping commenced.

To continue the quotation from Dozier (1947a) regarding the fortunes of the Blackwater Refuge muskrats:

The downward trend has been continuous since 1940, accelerated by the years of drought and heat with corresponding increased salinity, to a new low in 1944. This decline has not been confined to the Blackwater Refuge, but has been general over the entire Delmarva or Eastern Shore Peninsula.

The Weather Bureau's Baltimore Office reported the summer of 1943 as a whole the second hottest since 1872, with an official average of 79.1 degrees for the months of June, July and August. The heat was terrific with a total of 24 days of 90 degrees for the period July through September. Water levels dropped so low that the large fresh-water ponds near refuge headquarters dried up almost completely, with a total loss of fish.

The summer of 1944 saw a continuation of the drought of the preceding year and the muskrat reached its lowest ebb on the lower salt marshes. . . .

The summer of 1945 was the wettest on record and resulted in a conspicuous decrease in salinity. There was an over-all increase of 23 percent in the number of houses. It became evident that the low had been definitely passed and that the population had increased on over half of the 27 trapping units. There was a remarkable improvement also in the vegetation, starting on the lower brackish marshes as well as on those units affected by the abundant rainfall and fresh-water runoff. . . .

With high precipitation and cooler temperatures prevailing, the muskrat has continued to show a rapid "come-back." A total of 5,185 houses was counted in the fall of 1946, as against 3,055 the preceding year, an increase of 70 percent.

Dozier's Table 1 and Fig. 5 of his 1947 paper present the following data on lodge counts for the Blackwater Refuge: 1,254 lodges counted 
prior to trapping in 1933; 1,377 in 1934 ; 2,048 in 1935 ; 5,269 in 1936; 4,652 in $1937 ; 27,373$ in $1938 ; 29,893$ in $1939 ; 30,578$ in $1940 ; 11,175$ in $1941 ; 6,601$ in $1942 ; 6,250$ in $1943 ; 2,575$ in $1944 ; 2,481$ in 1945 ; 3,035 in 1946; and 5,185 in 1947.

As plotted in Dozier's aforementioned Fig. 5, these data give a fair outline of the Verhulst-Pearl-Reed logistic curve for the population growth between 1933 and 1940, or up to the beginning of the big decline of the forties. Allowance must be made for the fact that, prior to 1937, only large lodges were counted and that, from 1937, the counts included both the large or "nesting" lodges and the feeding shelters. This, however, would shorten the slope of the sigmoid curve defined rather than to alter much the appearance of the lower asymptote, which represents the earlier or ascending phase of the growth of the population after the hurricane of 1933. The upper asymptote begins to level off about as one might have expected before the onset of the epizootics and the adverse environmental changes. The upper and lower asymptotes look like parts of a definite curve having, for the span indicated, but a single "off-point," that for 1937.

In contrast with the "off-point" of 1937, the fidelity with which the other data points, 1933-40, conformed to what seems like a definite growth curve is a strong indication that intercompensatory trends in rates of gain and loss were operative, despite much variation in trapping toll, predator pressures, impacts of emergencies, and environmental conditions. Then, as I see it, the combination of events from the fall of 1940 to 1945 proved too much for the muskrat's limits of tolerance.

Heit's (1944) finding of muskrat remains in 37 of 95 scats of red foxes gathered about the Blackwater marshes, March through August, 1939 , could be interpreted as symptomatic of the state of the population and the increasing vulnerability of its "overflow" animals rather than as a substantiation of "the reports of trappers and marsh owners that foxes in the Blackwater area are a menace to the muskrat population." The muskrats did, foxes notwithstanding, attain a very high density from which leveling certainly could have been expected somehow or other, and the configuration of the upper asymptote of the curve of population growth testifies to the fundamental role of densities of the muskrats themselves in bringing about the leveling off.

In this connection, it may be brought out that Smith's (1938) treatment of predation no doubt reflected both emergency vulnerabilities and what may be interpreted as normal responsiveness of miscellaneous predators to the vulnerability resulting from high densities of muskrats. He found that almost everything carnivorous that frequented the Maryland marshes seemed to eat muskrats, whether as scavengers or predators. Approximately half of 62 bald eagle pellets contained muskrat remains. Trappers regarded horned and barred owls as equally harmful, and 6 of 315 food items in a barn owl nest were muskrats. Remains of both young and old muskrats occurred at practically all fox dens reported upon by trappers. A fox den 
examined by Smith had remains of more than twice as many muskrats as of all other prey animals combined. Individual raccoons sometimes habitually broke into muskrat lodges, and one mass of raccoon scats consisted largely of muskrat fur. One trapper found two partly eaten young muskrats at a weasel den.

That outstanding predator of the north central marshes, the mink, was essentially lacking from the good coastal marshes of macrodon, but its absence did not seem to result in any increased security of muskrats living under conditions favoring predation.

The drastic decline of the early forties seems convincingly accounted for in terms of disease losses and adverse environmental changes. With the rains of 1945 and improved conditions of the marshes, the upward trend of the population lined up again along what might be the same (or a similar) lower asymptote as that defined from 1933 to 1936 . Hence, it might be that the former base governing the curve of population growth had been restored, with possibly slight modification through the impacts of epizootics or the cyclic low centering about 1946-47. However, I learned from Dr. Van T. Harris of Johns Hopkins University (letter, May 19, 1950) that the "population dropped during 1940 and $1941 \ldots$. [and ] is still at a low ebb. The low population thus seems to be more than a periodic cycle phenomenon. The blame is, of course, placed on predators. As a matter of fact, raccoons and foxes do tear into many of the houses."

Harris (1952) referred to the Blackwater muskrat populations of 1938, 1939, and 1940, as having been excessively high. A trapper who lived in a shack on the marsh during the trapping season said that he could kill muskrats with a stick in the vicinity of the shack before breakfast. This high population damaged the marsh by its "eat-outs," and the evidence suggests that the lowered capacity of the marsh to support muskrats was partly responsible for the lowered populations of later years. Although Harris did not consider raccoons responsible for the decline of the muskrats, he did express the possibility that the heavy raiding of nests by the raccoons may have operated in combination with habitat deterioration to prevent rapid recovery of the muskrat populations.

Harris did find much evidence of raccoons and foxes feeding upon muskrats. Five of 150 food-containing raccoon stomachs and 106 of 551 scats contained muskrat remains. Of the 117 individual muskrats represented in the 106 scats, 44 per cent were half-grown or smaller. Ten of 17 red fox stomachs and more than half of the 132 fox droppings reported upon contained muskrat remains. These remains were almost entirely those of adult-sized muskrats. Small mammals serving as important foods of the local predators were mice of the species Microtus pennsylvanicus and Oryzomys palustris, which were found living in nearly half of the muskrat lodges.

Even though Harris found "no evidence of epidemic disease" during the period of his study, the described phenomena are, to me, most 
suggestive of continued disease losses. The Wall Lake case history for 1953 in Chapter 7 (see also Errington, 1954b) illustrates what may have been a comparable situation. Nevertheless, the high proportion of Maryland lodges located in very shallow water could have its special aspects, if lodge-digging became traditional behavior among the raccoons and foxes.

Dozier (1948b) paid a good deal of attention to color mutations in macrodon and summarized his findings on their inheritance. Concerning the principal brown and black phases, Dozier, Markley, and Llewellyn (1948) had written that "kits" showed a slightly higher ratio of black to brown individuals, as compared with the combined subadult and adult population. During the five-year study, black "kits" outnumbered the brown in a ratio of 54 to 46 per cent, and varied from 52 to 59 per cent in different seasons. According to Dozier (1944) there is a belief among Maryland trappers who have handled large numbers of live muskrats that the brown phase is hardier than the black. Both the annual catch data and the five-year summary would seem to indicate a slightly higher survival rate for the browns.

Quoting from Dozier, Markley, and Llewellyn:

On many units, the population density was so great that the trapper simply could not cover the assigned area thoroughly enough in the allotted time with the average number of traps available to him. This under-trapping resulted in some very bad "eat-outs." . . . It will take many more years for the vegetation to come back to its former state of luxuriant growth and muskrat production. . . .

There appears to be a direct correlation between the degree of marsh salinity and the growth and abundance of the preferred food plants of the muskrat. The vegetation of the Blackwater Refuge is typical of tidal marshes that border the lower Chesapeake Bay, ranging from those of a fresh or slightly brackish ecological type, such as cattails, Typha spp., three-square sedges, Scirpus americanus, olneyi and robustus, and tall reed, Phragmites communis, along the upland wooded borders and the upper reaches of the creeks and rivers, into a more brackish salt marsh of needlegrass, Juncus roemerianus, saltmarsh cordgrass or "blade grass," Spartina alterniflora, and saltmeadow grass, Spartina patens. Extensive stands of big cordgrass, Spartina cynosuroides, occur particularly along the banks of the meandering rivers. . . .

Data given ... [ [show ] that the Scirpus olneyi-Typha formation ... produced muskrats of the highest average weight. . . These marshes also were the freshest or least brackish ones to be found on the Refuge. . . .

It is evident from the above comparison that there is a direct correlation between size and weights of muskrats and the quality and abundance of their food supply. This is further substantiated by a study of several badly "eatenout" marshes that have shown a most significant progressive decrease in muskrat weights as the supply of food plants diminished. . . .

Units 17, 18, 19 and 23 have produced the smallest adult muskrats on the entire Refuge during the period of study. It is quite evident that this was due to over-population which resulted in a radical reduction in available food supply and consequent serious "eat-outs.". . . [ The ] vegetation was so badly eaten out during the summer of 1940 that Unit 18, especially, became nothing but shallow ponds and mud flats. Muskrats were forced to migrate in large numbers elsewhere to survive. 


\section{The Muskrat at Mobile Bay, Alabama}

From Correspondence with Francis X. Leuth of the Alabama Department of Conservation, I learned (letter of January 20, 1949) that on the western shore of Mobile Bay there "is no sharp break . . . that divides the 'rats. They are found from the Delta area south and west to the Mississippi. The marshes, all tidal, are more brackish in that direction and near Bayou LaBatre-Grand Bay are predominately Juncus - a black rush."

George C. Moore had written (letter, December 31, 1941) :

We have an unusual situation existing in the Mobile Bay Delta. Up until 1928, there were no muskrats of any kind found in the Mobile Bay area east of Mobile Bay and the Mobile River. The northern 'rat zibethicus was found at least one hundred miles north of this area. . . . About 1928, reports indicate that there were twelve pair of the Louisiana 'rats released in this area. These 'rats multiplied so fast that by 1934 , approximately twenty or thirty thousand were removed. By 1936, the peak year, reports show that there were at least one-hundred thousand 'rats removed from this area. During the 1937 trapping season, those 'rats had fallen off to a point where it was found unprofitable to trap. The trapping season in this area was closed in 1938, and has been closed ever since.

When the trapping season was closed, there were at least several hundred 'rats left on the area for breeding stock. In each successive year, thereafter, the 'rat population has steadily decreased and a close check in December of this year revealed that there were probably less than fifty 'rats in the entire marshes. . . . At present we are still unable to put our finger on any one definite limiting factor or any group of factors that would cause such a sudden drop in the 'rat population in the area. . . . It seems to me that the disease factor could cause a sharp decline in the population but after it had reached such a low level, this should play out. We have checked food, predators, water levels and everything that we can think of.

Moore wrote further on July 2, 1943, that he had

made a trip to the Delta recently and found that 'rats are present but very scattered. Apparently, there has been very little or no change in the 'rat population during the last three or four years. As far as we have been able to tell, there have been no 'rats entering the Delta from surrounding areas, as the Mobile Bay and the City of Mobile lie on the west which would act as a barrier. If the Louisiana 'rats entered this area they would have to swim the Bay which would be seven or eight miles of open water, or pass through the City of Mobile. The northern 'rat, of course, could migrate down the Tombigbee and Alabama rivers, but as far as we have been able to find out, there is an area of approximately seventy-five miles between the Delta region and the present known range of the northern muskrat. There are no 'rats found to the east or south.

We realize that the Mobile Delta is not considered an excellent muskrat marsh, but we do think that since they were so abundant at one time there is some reason for the drastic decline. . . .

A well-known marsh ecologist from Louisiana spent several days in the Delta with me and he agrees that food is certainly not an important limiting factor. 


\section{Howell (1921) wrote of rivalicius in Alabama:}

The small, dark-colored Louisiana muskrat is found at present in Alabama only in the coast region west of Mobile Bay. . . . The animal has apparently extended its range into the state within very recent times, since it is unknown to most hunters and trappers in the region where it is now found, and many of those who are acquainted with it state that it first appeared there after a big storm in 1906. . . . [ Although it] is not as yet widely dispersed ... there seems to be no reason why it should not extend its range into the big marshes of the Delta region and along the eastern shore of the Bay.

At Bayou LaBatre, residents reported a number of muskrat houses on the marshes between the mouth of the bayou and Little River, but a storm and high tide in the fall of 1915 apparently broke up this colony. . . . A considerable colony, however, was located close to the town in a little marsh between the public road and the pine woods.

Leuth (letter of January 20, 1949) mentioned a planting of muskrats

between 1926 and 1929 - probably in 1928. The supposition is that the present population [ of the Mobile Delta, his main study area for the previous two years ] is due to that planting. However, a marsh resident and trapper (John Lewis) tells of his father taking an animal to a local buyer "about 1910 or 1912." This animal proved to be a muskrat. Other trappers also apparently took an occasional muskrat prior to the construction of the Cochrane Causeway (1926) and therefore prior to any known planting.

Six specimens taken in April, 1947, from Hog Island in the Mobile Bay Delta were sent by Leuth to Dr. Remington Kellogg of the U. S. National Museum, who referred them to rivalicius.

Continuing quotation from the letter from Leuth:

Since I shipped the above specimens, I have examined over 1,000 muskrats [ of which nearly all fell in the common size and color categories of rivalicius ]. . . . The 'rats taken on the Mobile Delta and those taken at nearby Dog River are considered better, both in size and fur quality than those taken in Bayou LaBatre and the Grand Bay area. The latter are considered nearer the type found in the majority of the salt marshes of Louisiana. Differences are probably due to environment. Those of poorer quality are from the salt marshes.

The Mobile Delta marsh is a tidal marsh. There is variation as to brackishness from year to year. Chief plants are Phragmites communis, Spartina cynosuroides, Panicum virgatum, Zizaniopsis miliacea, Typha angustifolia, Typha latifolia, Scirpus spp., and Alterathera philoxeroides. Juncus is present but not extensive.

The 'rats of the Delta have supposedly stayed in the treeless areas and not gone to the swamps until recently. .. . I personally believe that some 'rats have been in the swamp but are now being taken because they now bring more than the previously trapped raccoon. If there is any separation between the northern 'rat and the Louisiana 'rat on the Tombigbee River it is less than 60 miles. . . .

On the eastern shore there is a sharp line beyond which the 'rats do not go. Between Daphne and Fairhope, or from two to eight miles from the southern end of the Delta marsh, there are no muskrats. As far as I know there are none from there to the Florida coast. On this eastern shore there are about twenty miles of coast without a marsh. Steep banks and sand 
beaches predominate. However, in the vicinity of Bon Secour, Ala., there are marshes that resemble those of the western shore.

On March 27, 1948, Leuth found a diseased muskrat on his study area and sent it in to the Iowa Veterinary Diagnostic Laboratory, where it was examined by Doctors E. A. Benbrook and Leon Z. Saunders. It had visceral nodules, especially about the lungs. From a memorandum sent me by Saunders (April 26, 1948):

Cultures were made from the fluid in the cysts mentioned above and some of the fluid was examined microscopically; both examinations were negative for fungus or bacterial organisms and it is believed that the process was entirely neoplastic in nature.

\section{Appendix W}

\section{Concerning the Louisiana Muskrat in Its Main Range}

William P. Baldwin, JR., considered (letter, January 28, 1949; see also Appendix $\mathrm{G}$ ) that the ability of $O$. $z$. rivalicius as a subspecies to withstand the gulf hurricanes and Mississippi River floods could be due to the large expanses of sustaining habitat existing away from the areas of greatest crisis. While the coastal marshes comprising the main range of rivalicius occur in the form of a strip extending from southeastern Texas through southern Louisiana and southeastern Mississippi into southwestern Alabama, this strip varies considerably in actual width. Many places having good muskrat habitats and high populations may be found as far as 15 to 20 miles from the coast, itself; and others exist still farther away from the open gulf (see Lynch, O'Neil, and Lay, 1947, for maps of the southern Louisiana marshes). Lay and O'Neil (1942) wrote of the approximately

260,000 acres of marshland on the southeastern Texas coast between Galveston Bay and Louisiana.... [at ] the westernmost range of the Louisiana muskrat. . . One important characteristic is that almost all the marsh area lies behind beach ridges of sufficient size to prevent direct influx of seawater except when hurricane winds blow directly in shore. The marshes overlie a heavy mineral soil and the peaty layer is often only a few inches thick. The formation of peat is apparently limited by the frequent droughts which allow rapid oxidation of plant remains. . . .

The general topography is level. There are about 20 lakes with an average size approaching 500 acres. An intracoastal canal, two rivers, and many bayous drain the marshes.

The mean annual rainfall at Port Arthur is 51.81 inches, extremes from 1911 to 1930 being 66.07 and 30.52 inches. The mean annual temperature is $68.9^{\circ} \mathrm{F}$., with an average of only six days a year when the minimum is below freezing.

Penfound and Hathaway (1938) have discussed thoroughly the plant com- 
munities of southeastern Louisiana and their major classifications apply to the Texas marshes. . . The brackish marshes . . . the most productive of muskrats, are marked by smooth cordgrass (Spartina patens), saltgrass (Distichlis spicata), black rush (Juncus romerianus), bayonet rush (Scirpus olneyi), and three-cornered rush (Scirpus robustus)... The fresh marsh ... includes cattail (Typha angustifolia and $T$. latifolia), giant bulrush (Scirpus californicus), square-stem spike rush (Eleochris quadrangulata), duck potatoes (Sagittaria spp.).

Lynch, O'Neil, and Lay (1947) wrote of rivalicius using various habitats but that

About 80 percent of the annual muskrat catch of Louisiana and eastern Texas is produced on two types of brackish marsh, the most important being "three-cornered grass marsh," an association of Olney's three-square, salt meadow, and cordgrass. . . . Three-square marsh is found at the head of the normal gulf tide action ... and is extensive throughout the coastal range of the muskrat. The plant grows on highly organic peat soils. Muddy peats subject to admixture of clay from storm tides are taken over by "coco" or saltmarsh bulrush [Scirpus robustus ], saltgrass, and "wiregrass." In southeastern Louisiana "coco-marsh" is usually along the edges of or mixing with three-square marsh. In southwestern Louisiana and east Texas "coco-marsh" forms extensive pure stands. . . . "Coco-marsh" produces many muskrats but cannot sustain high populations for long periods as does three-square marsh. "Coco" grows little during the winter and cannot keep pace with the winter food demand of heavy muskrat populations. Three-square has a year-round growing season, retarded only temporarily by winter frosts. . . .

The Louisiana muskrat is strictly a marsh animal. Unlike the bank and pond rats in other parts of the country, this animal depends on the marsh for all of its food, shelter, and living space. . . . As the ponds and bayous of the Gulf Coast abound with alligators, gars, turtles and other enemies, the muskrat shuns open water and confines normal movement to the marsh. The animal has surface trails for some of its feeding and a system of underground tunnels and plunge-holes for feeding in warm weather and during low tides. The muskrat makes exhaustive use of this habitat: its food and shelter decrease the supply of marsh vegetation; its trails and burrows cut up the marsh floor. Fortunately marsh plants grow rapidly in this latitude and usually are able to keep pace with the normal food demands of the muskrat and to repair the damage caused by its burrowing. . . . The loss of muskrats during floods and tropical storm tides is not so great as might be supposed, and canes, brush, and other tall vegetation enable many rats to weather storm tides and high water. Muskrats are subject to certain diseases, but these are usually the result of overcrowding and apparently do not assume epizootic proportions until populations threaten to exceed the carrying capacity of the marsh.

The carrying capacity of the muskrat marshes of this region varies greatly. Some lands may produce one or two per acre. First-class marshes have produced 50 rats per acre each year for several successive years, and their carrying capacity must be considered in excess of this figure. Other lands have proluced an even greater number, but on many of these the population had already exceeded carrying capacity. The present authors do not intend to deal with the intricacies of carrying capacity, but only to consider the obvious fact that rat populations tend to increase beyond the capacity of the marsh, regardless of what that might be.

These authors discussed some of the population complications attending overuse by muskrats of occupied habitats and outlined the ecological consequences of damage from "eatouts." Plant succession was 
important, and trends toward unfavorable climax vegetation were notable on marshlands protected from burning. Geese as well as muskrats, by their intensive local exploitation of food, brought about profound modifications of wetland habitats.

Readers interested in the ecology of Gulf Coast marshes might profitably consult not only the above paper but also various writings of Lynch, Penfound, O'Neil, et al. - for examples, Penfound and Hathaway (1938), Lynch (1941), Penfound and Schneidau (1945), and a semi-popular book by O'Neil (1949). The latter book emphasizes both the tremendous importance of Scirpus olneyi to these coastal muskrats and the tendency of olneyi stands to be ruinously exploited by the overpopulations of muskrats that they build up.

From Penfound and Schneidau (1945):

In general, marshes (with emergent plants) are valuable primarily for the production of fur animals. Relatively open water, such as streams, bays, lagoons and ponds (with submerged plants) are most valuable for fisheries. Landing strips (and food) for waterfowl are provided in the open water areas and shelter (as well as food) is afforded by the marsh areas. It is obvious, therefore, that a marshland threaded with streams or dotted with lagoons would provide more variety and probably a greater volume of wildlife than either marshes or open water.

The wildlife potential of a marsh depends not only on the proximity of open water, but also on the nature of the substratum and the predominant species of plants. In general, the fresh marshes have a low muskrat potential because the peaty materials are decomposed too fast to provide the soft fibrous substratum so desirable for the construction of muskrat runways and nests. In many of the fresh-water marshes (Zizaniopsis miliacea and Mariscus jamaicensis types) there is insufficient food for good muskrat production. In the brackish marshes, the muskrat potential is usually high because of the deep peaty substratum, but may be moderate to low if the marsh succession is well advanced and the dominant species are Spartina patens, Distichlis spicata, and Juncus roemerianus. The muskrat potential of salt marshes is low not only because they contain very little peat but also because the dominant species (Spartina alterniflora) has little food value.

It is obvious from the above statements that marshes have their highest muskrat potential only when the marsh succession is arrested short of the climax. In this connection, Lynch states (1941) that "climax marsh . . . usually contains little wildlife of any kind." Firing of the marshes has been practiced regularly as a tool in muskrat production. The primary objectives have been to prevent destructive fires [i.e., uncontrolled fires, occurring at the wrong times of year or under the wrong conditions], to facilitate trapping, to accelerate spring growth and to promote development of muskrat food plants (especially Scirpus olneyi, S. americanus, and S. robustus).

Lynch (1941) introduced a widely-cited discussion of fire as a very important ecological agent:

Fire always has been a factor in the ecology of the Gulf Coast marshes. Natural fires have been caused even recently by lightning, and spontaneous combustion has been advanced as another cause. Before the advent of man, natural fires must have been much more severe than at present. The subtropical climate of this region provides a year-round growing season. The resulting growth of marsh vegetation is so luxuriant that an unburned marsh becomes a veritable tinder box within three or four years. 
Despite the abundant rainfall of the region, droughts are frequent in late summer. During this same period, squalls accompanied by lightning are almost an everyday occurrence on the coast. Fires started by lightning in recent drought years have lasted for days, even on marsh regularly burned. It is not difficult to visualize the consequences of such fires in former times, before regular marsh burning was practiced. Fed by the accumulated vegetable litter, these natural fires may have raged for weeks at a time.

Man has taken a lesson from these natural fires. Cattlemen, trappers, and operators of hunting clubs burn their marshes regularly. The time and method of burning varies with the result desired ... . and the condition of the marsh at the time of burning. . . . Cover burning accelerates production of food for waterfowl, muskrats, and cattle. Removal of the dense canopy of vegetation gives many important waterfowl food plants a chance to mature. On muskrat marshes, the growth of three-square (Scirpus olneyi), an important food for both muskrats and geese, is accelerated with removal by fire of dense wire grass (Spartina patens). . . .

Cover burns, when handled properly, are a practical means of fire protection in the marsh. . . . They do not affect the structure of the marsh, since they do not reach the basal parts of perennial plants which are protected by standing water. In times of drought, however, it is possible to alter the vegetation of certain marsh types by fire. Root burns or deep peat burns will result from dry fires, depending on the depths to which the water table has dropped below the surface of the soil. . . In times of extreme drought, fires not only destroy existing vegetation, but may burn out marsh peat down to the clay subsoil.

The dry burns may at times be directly lethal to muskrats and associated animals, but such marsh dwellers show a certain resourcefulness by taking refuge in holes, remaining under cover of the muskrat lodges, etc. With the protection of dense growths gone, the muskrats undoubtedly are more vulnerable for a time to such enemies as raptorial birds, but their losses through most fires would seem inconsequential compared with their future advantages resulting from improved environmental conditions. Without the background of fire, it is unlikely that Louisiana trappers could have harvested $10,000,000$ muskrats in a single year from a 300-mile strip of coastal marshes, as they did during the fur season of 1922-23 (Arthur, 1931).

A prevailing view has long been that the presence of alligators (Alligator mississippiensis) kept the muskrats out of the streams and bayous of the Gulf States. It is true that the alligators prey heavily upon muskrats on occasion. Arthur (1931) listed muskrat remains in the stomachs of 6 of 22 alligators, three to seven feet in length, that had been killed on the Rainey Refuge June 27 to July 4, 1925, but I am not convinced that this signifies depressive influence on the muskrat population. Almost everything that is carnivorous seems to eat muskrats on the Louisiana coastal marshes, and, considering the muskrat densities, it would be most surprising if such were not the case.

Lay and O'Neil (1942) wrote of alligators on a productive Texas marsh, purposefully managed for muskrats and other fur-bearers:

The alligators ... on this marsh serve muskrat management in at least two ways. Their holes retain fresh water in dry periods, and the movements of alligators in the pools prevent stagnation of the water. There are musk- 
rat beds close to almost every alligator hole, indicating the attractiveness of these pools to muskrats. The predation of alligators on muskrats is a controversial question, but here the alligators apparently do more good by improving the habitat than harm by possible predation. A second benefit is the scouring of ditches, along which the alligators travel and thereby reduce clogging by vegetation and obstructions.

The 142,000-acre Sabine National Wildlife Refuge in southwestern Louisiana was a site of a recent investigation of the alligator by Giles and Childs (1949). As of late 1946, the refuge had an estimated 15,000 alligators, of which about two-thirds were animals less than three feet in length. "So far as mammal foods are concerned, the dividing line between large and small alligators is at about the 5-foot length. .. . The same relationship between size and mammalian foods was noted by O'Neil. Muskrats were more important as food where his investigations were made but were not found in specimens less than 5 feet long."

Giles and Childs rated practically all of the Sabine Refuge as alligator range, but the species was not evenly distributed. It tended to concentrate in the more favorable habitats - along canals and bayous, and about lakes. The largest concentration was in an area of deep marsh where ponds and lakes developed after loss of marshy vegetation. Muskrats did provide the most important mammalian food for the alligators and were found in 55 of the 318 stomachs reported upon by Giles and Childs - still, muskrats were not considered

important as prey because most of the alligators inhabit marsh that is not muskrat habitat, or marsh areas "eaten out" by muskrats and no longer productive of these furbearers. . . .

Predation on muskrats of the Sabine Refuge conceivably would actually reduce the population only during extreme drought, when muskrats must abandon their usual marsh habitat and concentrate along the bayous and other available waters in alligator habitat. There they would be extremely vulnerable and the alligators could take a terrific toll. Under drought conditions, however, losses might be expected with or without alligator predation as dwindling food supplies, intra-specific strife, disease and parasitism, and increased predation from all sources would tend to reduce the population to a level commensurate with the carrying capacity of the remaining environment.

Concluding their account of food habits, Giles and Childs wrote of the diet of the alligators including

about every type of animal of edible size found in the environment [ with the possible exception of gar fishes (Strongylura) and frogs ]. . . . In suitable marshes, they may feed extensively upon muskrats . . . [ but ] it is questionable whether they do or can seriously deplete the muskrat population. In the early 1920's, when the marshland was first opened up for extensive exploitation of fur resources, there were tremendous numbers of alligators and, at the same time, muskrats were produced in numbers probably never again to be equalled. 
From the short section on predation in O'Neil (1949):

Muskrats are preyed upon probably as much as any species of wildlife known. Their rate of reproduction is so great that they can withstand this predation without damaging effects when in their better habitats. However, when in habitats not having the qualities of three-cornered grass, 'rat colonies often seem to struggle to keep the race going, and this is largely due to predation. The following is a list of predators in order of their predation upon muskrats. Mink, raccoon, barn and barred owls, alligator, ants, marsh hawk, cottonmouth moccasin, bullfrog, garfish, bowfin, snapping turtle, black bass, crabs, hogs, house cats, and dogs.

A new variable in the ecology of the Gulf Coast muskrats has been introduced in the form of the nutria (Myocastor coypus), a native of South America (Ashbrook, 1948). The habits of this exotic rodent are rather similar to those of the muskrat, though it is much larger in size and apparently ill-adapted to cope with severe winter conditions. Its possible impacts upon the muskrat as a competitor are being kept in mind by biologists, but, to my knowledge no one as yet feels like predicting exactly what is going to happen. Atwood (1950) carried on an investigation of the nutria on the Lacassine National Wildlife Refuge in southwestern Louisiana, from which report the following may be quoted:

The original habitat of the nutria or coypu is in marshes, swamps and along margins of rivers and lakes in fresh-water plant associations. In Louisiana its range is limited to the coastal marshes which may be roughly divided into brackish and fresh-water plant associations. The former are good muskrat marshes while the latter, with the exception of the Terrebonne area, are poor producers of muskrat.

The fresh-water marshes are of two types. The first, producing many muskrats and known as the Terrebonne area, extends eastward from the Atchafalya River almost to the Mississippi River. The other marsh extends westward from the Atchafalya River to the Texas state line. This marsh produces few muskrats and supports populations estimated at 1 pair per 40 acres in the better, to 1 pair per 400 acres in the poorer producing portions. It is in this latter fresh-water ecological niche that the coypu has become most firmly established in Louisana. In this marsh the most common association is composed of saw grass (Cladium jamaicense), giant cut-grass (Zizaniopsis miliacea), southern bulrush (Scirpus californicus) with 15 to 20 percent a pure stand of maidencane (Panicum hemitomon).

Atwood listed the staple foods of the nutria as including cattails, bulrushes, arrowheads, and other familiar items of muskrat diet, besides the saw- and cut-grasses and miscellaneous submergents that muskrats may or may not eat in quantities.

In the discussion of a recent paper, Harris (1956) brought out that the ecological impact of the nutria on the Louisiana marshes "has been quite a problem." $\mathrm{He}$ also wrote, regarding competition with muskrats, that there is evidence of nutrias relishing that outstanding food plant of Gulf Coast muskrats, Olney's bulrush. 


\title{
Concerning the Colorado Muskrat in Its New Range in Southern California
}

\author{
From Grinnell, Dixon, and Linsdale (1937):
}

Along the Colorado River, the original habitat of this race [bernardi] the muskrats dwell both in the main river and in the old channels which are numerous in the adjacent bottom lands and which are connected with the river at least at high water. Near Palo Verde, on April 1, 1910, the animals were found ... inhabiting the lower end of a tule-bordered slough near its confluence with the main river. There, they were living in burrows in a bank where the current was sluggish and were feeding on "green tule stems." ...

In May, 1910, muskrats were found to be common in the vicinity of Pilot Knob, just north of the Mexican boundary, and at the site of the present intake of the main Imperial irrigation canal, where the dense overhanging canebrakes and high bank on the west side afforded the animals good places for breeding dens and refuge burrows opening under water. ... In February, 1912, it was first recorded . . . that muskrats had invaded the Imperial Valley along the irrigation canals leading from the Colorado River. . . .

By 1920 , muskrats were found ... to be inhabiting all the main irrigation canals as well as the cattail areas along the Alamo and New rivers, from the southern shore of the Salton Sea south into the delta region of lower California. Between the Eastside Highline and Number Seven Highline canals of the Imperial Valley, there is a depression that averages 50 feet in width between the canals where the earth was excavated to form the canal banks. This depression soon became filled with seepage water from the adjoining canals and now supports a luxurious growth of cattails. . . Such a pond forms a veritable paradise for muskrats, since in such places they have abundant food and are little disturbed. . . .

Animal food is rarely eaten. . . . Nothing was found which would indicate that the Colorado River muskrat stores food. Snow, ice, frozen ground, and the associated rigors of winter existence are practically unknown to this race of muskrat. Because open water and green vegetation are to be had all winter long in the habitat of this subspecies, the regular activities of the animal are scarcely even slowed down during the winter months. . . . [ Muskrats] in the Imperial Valley rarely, if ever, eat any cultivated crop. It was found that there these animals live almost entirely within the canals, where they feed upon root stalks of Bermuda grass, sprouts of cattails, and other vegetation that grows up voluntarily and tends to clog the canals.

Dixon (1922) carefully estimated average bernardi populations in the Imperial Valley as follows, per mile: "Large main canals, 40; small mains, 20; Alamo River, 20; New River, 40 (and in places up to 200 per mile). In 1920, 67 muskrats were actually trapped during a single night in a distance of one mile along New River, and at least twice as many were left untrapped." 
Literature Cited 



\section{Literature Cited}

Ahrens, T. G. 1921. Muskrats in central Europe. J. Mammal., 2:236-37.

Aldous, S. E. 1946. Live trapping and tagging muskrats. J. Wildl. Mgt., $10: 42-44$.

- 1947. Muskrat trapping on Sand Lake National Wildlife Refuge, South Dakota. J. Wildl. Mgt., 11:77-90.

Aldrich, J. W. 1943. Biological survey of the bogs and swamps in northeastern Ohio. Am. Midl. Nat., 30:346-402.

Alexander, M. M. 1951. The aging of muskrats on the Montezuma Nationaly । Wildlife Refuge. J. Wildl. Mgt., 15:175-86. and M. RADwAY. 1951. The distribution and production of muskrats on the Montezuma National Wildlife Refuge. J. Wildl. Mgt., 15:360-67.

Allan, D. J. 1941. New fur trails. Civil Serv. Rev., June:104-7.

. 1942. Marsh management for fur production. Trans. N. Am. Wildl. Conf., 7:263-69.

AlleE, W. C. 1942. Group organization among vertebrates. Science, 95:289-93.

A. E. Emerson, O. Park, T. Park, and K. P. Schmidt. 1949. Principles of Animal Ecology. W. B. Saunders Co., Philadelphia and London. xii+837 pp.

Anderson, J. M. 1947. Sex ratio and weights of southwestern Lake Erie muskrats. J. Mammal., 28:391-95.

Anderson, R. M. 1934. Mammals of the Eastern Arctic and Hudson Bay. In Canada's Eastern Arctic: 67-108. Department of the Interior, Ottawa. 1937. Mammals and birds of the Western Arctic District, Northwest Territories, Canada. In Canada's Western Northland: 97-122. Land, Parks, and Forests Branch, Ottawa.

Anderson, W. L. 1948. Level ditching to improve muskrat marshes. J. Wildl. Mgt., 12:172-76.

Andrewartha, H. G. And L. G. Birch. 1954. The Distribution and Abundance of Animals. Univ. Chicago Press. xv+782 pp.

Anon. 1934. Musk rats in Scotland. Scottish J. Agr., 17:94-98. 
Anon. 1938. An experiment in muskrat farming. N. Carolina Wildl. Cons., $2(5): 3-5$. 9-10.

Anthony, H. E. 1928. Field Book of North American Mammals. Putnam's, New York. xxv+625 pp.

Arant, F. S. 1939. The status of game birds and mammals in Alabama. Ala. Dept. Cons. 38 pp.

Armstrong, W. H. 1942. Occurrence of Salmonella typhimurium infection in muskrats. Cornell Veterinarian, 32:87-89.

Arthur, S. C. 1931. The fur animals of Louisiana. La. Dept. Cons. Bull., 18 (revised). 444 pp.

Artimo, A. 1949. Suomi tuottavana piisamimaana. With English summary: Finland a profitable muskrat land. Suomen Riista, 4:7-61.

- 1952. Piisamituoton tehostaminen. With English summary: How to increase muskrat production. Suomen Riista, 7:22-38, 183-84.

Asнвrook, F. G. 1948. Nutrias grow in United States. J. Wildl. Mgt., 12:8795.

Ashburn, L. L. And C. W. Emmons. 1942. Spontaneous coccidioidal granuloma in the lungs of wild rodents. Arch. Path., 34:791-800.

AND - 1945. Experimental Haplosporangium infection. Arch. Path., 39:3-8.

Atwood, E. L. 1950. Life history studies of nutria, or coypu, in coastal Louisiana. J. Wildl. Mgt., 14:249-65.

BAILeY, V. 1905. Biological survey of Texas. N. Am. Fauna 25. 222 pp. pp.

1931. Mammals of New Mexico. N. Am. Fauna 53. 412 pp.

1933. Cave life of Kentucky, mainly in the Mammoth Cave Region. Am. Midl. Nat., 14:390-635.

. 1936. The mammals and life zones of Oregon. N. Am. Fauna 55. $416 \mathrm{pp}$.

Barkalow, F. S., Jr. 1949. A game inventory of Alabama. Ala. Dept. Cons. $\mathrm{x}+140 \mathrm{pp}$.

Barnes, C. T. 1927. Utah mammals. Bull. Univ. Utah, 17 (12) (revised). 183 pp.

Baumgartner, L. L., And F. C. Bellrose, JR. 1943. Determination of sex and age in muskrats. J. Wildl. Mgt., 7:77-81.

BeER, J. R. 1950. The reproductive cycle of the muskrat in Wisconsin. J. Wildl. Mgt., 14:151-56.

- AND R. K. MEYer. 1951. Seasonal changes in the endocrine organs and behavior patterns of the muskrat. J. Mammal., 32:173-91.

- And W. Truax. 1950. Sex and age ratios in Wisconsin muskrats. J. Wildl. Mgt., 14:323-31.

Bellrose, F. C. 1950. The relationship of muskrat populations to various marsh and aquatic plants. J. Wildl. Mgt., 14:299-315.

-—— AND L. G. Brown. 1941. The effect of fluctuating water levels on the muskrat population of the Illinois River Valley. J. Wildl. Mgt., $5: 206-12$.

Bellrose, F. C., Jr. and J. B. Low. 1943. The influence of flood and low water levels on the survival of muskrats. J. Mammal., 24:173-88.

Bennett, L. J. 1938. The Blue-winged Teal; its Ecology and Management. Iowa State Univ. Press, Ames, Iowa. $144 \mathrm{pp}$.

Bennitt, R. and W. O. Nagel. 1937. A survey of the resident game and furbearers in Missouri. Univ. Mo. Studies, 12 (2). $215 \mathrm{pp}$.

Beshears, W. W. and A. O. Haugen. 1953. Muskrats in relation to farm ponds. J. Wildl. Mgt., 17:450-56. 
Bissonnette, T. H. 1936. Sexual photoperiodicity. Quart. Rev. Biol., 11:37186.

. 1938. Experimental control of sexual photoperiodicity in animals and possible applications to wildlife management. J. Wildl. Mgt., 2:10418.

ANd A. G. Csech. 1937. Modification of mammalian sexual cycles. VII. Fertile matings of raccoons in December instead of February induced by increasing daily periods of light. Proc. Roy. Soc. London, B, 122:246-54.

Black, J. D. 1938. Mammals of Kansas. 30th Biennial Rept. Kansas State Bd. Agr.: 116-217.

Blair, W. F. 1939. Faunal relationships and geographic distribution of mammals in Oklahoma. Am. Midl. Nat., 22:85-133.

- And T. H. Hubbell. 1938. The biotic districts of Oklahoma. Am. Midl. Nat., 20:425-54.

Bodenheimer, F. S. 1949. Problems of vole populations in the Middle East. Report on the population dynamics of the Levant vole (Microtus guentheri D. et A.). Research Council of Israel. $77 \mathrm{pp}$.

Bogart, R., G. Sperling, L. L. Barnes, and S. A. Asdell. 1940. 'The influence of reproductive condition upon growth in the female rat. Am. J. Physiol., 128:355-71.

Borell, A. E. ANd R. Ellis. 1934. Mammals of the Ruby Mountains region of northeastern Nevada. J. Mammal., 15:12-44.

Bourdelle, E. 1939. American mammals introduced into France in the contemporary period, especially Myocaster and Ondatra. J. Mammal., 20:287-91.

Bourn, W. S. And C. Cotтam. 1950. Some biological effects of ditching tidewater marshes. Fish and Wildl. Serv., U.S. Dept. Int., Res. Rept. 19. 30 pp.

Braestrup, F. W. 1940. The periodic die-off in certain herbivorous mammals and birds. Science, 92:354-55.

1942. Om Svingninger i Antallet af Raeve og andre Dyr i Arktis ...deres Aarsager og Virkninger. Gronlandske Selskabs Aarskrift. pp. 12951.

Brander, T. 1951. Om bisamråttan ur jaktvårdssynpunkt. With English summary: On muskrat from the point of view of game management. Suomen Riista, 5 B, 84-142.

Bridges, W. 1935. They say the Kankakee is coming back. Bull. N. Y. Zool. Soc., 38:205-12.

Brown, J. H. 1944. The susceptibility of fur-bearing animals and game birds to tularemia. Canad. Field-Nat., 58:55-60.

Brown, L. G. And L. E. Yeager. 1943. Survey of the Illinois fur resource. Bull. Ill. Nat. Hist. Surv., 22:435-504.

Bump, G., R. W. Darrow, F. C. Edminster, and W. F. Crissey. 1947. The Ruffed Grouse. N.Y. State Cons. Dept., Albany. 915 pp.

Butler, L. 1940. A quantitative study of muskrat food. Canad. Field-Nat., $54: 37-40$.

Calmoun, J. B. 1945. Diel activity rhythms of the rodents, Microtus ochrogaster and Sigmodon hispidus hispidus. Ecology, 26:251-73.

Carter, T. D. 1922. Notes on a Saskatchewan muskrat colony. Canad. FieldNat., 36:176.

Cartwright, B. W. 1944. The "crash" decline in sharp-tailed grouse and Hungarian partridge in western Canada, and the role of the predator. Trans. N. Am. Wildl. Conf., 9:324-29.

Cary, M. 1911. A biological survey of Colorado. N. Am. Fauna 33. 256 pp.

Chappelier, A. 1933. Destruction du rat musqué (Fiber zibethicus Linne) et du campagnol d'eau (Arvicola terrestris amphibius L.) par le virus (Bacillus typhimurium). Annales des Epiphytes, 19:185-206. 
Chappelier, A. 1948. Le rat musqué en France. Bull Français de Pisciculture, 20(149):137-58.

Christian, J. J. 1950. The adreno-pituitary system and population cycles in mammals. J. Mammal., 31:247-59.

Clarke, C. H. D. 1938. A study of the mammal population of the vicinity of Pancake Bay, Algoma District, Ontario. Natl. Mus. Canada Bull. 88:14152.

Natl. Mus. Canada, Bull. 96. 135 pp.

- 1944 . Notes on the status and distribution of certain mammals and birds in the Mackenzie River and Western Arctic area in 1942 and 1943. Canad. Field-Nat., 58:97-103.

Cockrum, E. L. 1952. Mammals of Kansas. Univ. Kansas Publ., Mus. Nat. Hist., 7:1-303.

Cole, L. C. 1951. Population cycles and random oscillations. J. Wildl. Mgt., $15: 233-52$.

- 1954a. The population consequences of life history phenomena. Quart. Rev. Biol., 29:103-37. 18:2-24.

Cottam, C. and W. S. Bourne. 1938. What's wrong with mosquito control. Trans. N. Am. Wildl. Conf., 3:81-87.

一, - F. C. Bishopp, L. L. Williams, and W. Vogt. 1938. What's wrong with mosquito control. Trans. N. Am. Wild. Conf., 3:81-98.

Craighead, J. J. and F. C. Craighead, Jr. 1956. Hawks, Owls and Wildlite. Stackpole Co., Harrisburg, Va., and Wildl. Mgt. Inst., Washington, D. C. xix +443 pp.

Curry-Lindahl, K. 1955. Djuren i Färg. Almqvist och Wiksell, Stockholm. $172 \mathrm{pp}$.

Dalquest, W. W. 1948. Mammals of Washington. Univ. Kansas Publ., Mus. Nat. Hist., 2:1-444.

Darwin, C. 1872. The Origin of Species by Means of Natural Selection, or the Preservation of Favoured Races in the Struggle for Life. 6th ed. John Murray, London. $458 \mathrm{pp}$.

Davis, D. E. 1950. Malthus - a review for game managers. J. Wildl. Mgt., 14:180-83.

- And J. T. Emlen, JR. 1948. The placental scar as a measure of fertility in rats. J. Wildl. Mgt., 12:162-66.

Davis, D. H. S. 1933. Rhythmic activity in the short-tailed vole. Microtus. J. Anim. Ecol., 2:232-38.

Davis, W. B. 1935. The Recent Mammals of Idaho. Caxton Printers, Caldwell, Idaho. $400 \mathrm{pp}$.

- ANd G. H. Lowery, JR. 1940. The systematic status of the Louisiana muskrat. J. Mammal., 21:212-13.

Dellinger, S. C. And J. D. Black. 1940. Notes on Kansas mammals. J. Mammal., 21:187-91.

Denmark, D. 1940. Conservation at Cumberland. Beaver, March:47-49.

- 1946. Muskrat conservation at Cumberland House. Moccasin Telegraph, November: 1-3.

Dice, L. R. 1938. The Canadian biotic province with special reference to the mammals. Ecology, 19:503-14.

Dixon, J. 1922. Rodents and reclamation in the Imperial Valley. J. Mammal., 3:136-46.

Dorney, R. S. AND A. J. Rusch. 1953. Muskrat growth and litter production. Wis. Cons. Dept., Tech. Wildl. Bull. 8. 32 pp.

Dozier, H. L. 1943. Occurrence of ringworm disease and lumpy jaw in the muskrat in Maryland. J. Am. Vet. Med. Assoc., 102(795):451-53. 
1944. Color, sex ratios and weights of Maryland muskrats, II. J. Wildl. Mgt. 8:165-69.

- 1945. Sex ratio and weights of muskrats from Montezuma National Wildlife Refuge. J. Wildl. Mgt., 9:232-37.

. 1947a. Salinity as a factor in Atlantic Coast tidewater muskrat production. Trans. N. Am. Wildl. Conf., 12:398-420.

99.

- 1948a. Estimating muskrat populations by house count. Trans. N.

Am. Wildl. Conf., 13:372-89.

- 1948b. Color mutations in the muskrat (Ondatra z. macrodon) and their inheritance. J. Mammal., 29:393-405.

- And R. W. Allen. 1942. Color, sex ratios and weights of Maryland muskrats. J. Wildl. Mgt., 6:294-99.

- M. H. Markley, ANd L. M. Llewellyn. 1948. Muskrat investigations on the Blackwater National Wildlife Refuge, Maryland, 19411945. J. Wildl. Mgt., 12:177-90.

Duck, L. G. AND J. B. Fletcher. 1945. A survey of the game and furbearing animals of Oklahoma. Okla. State Game and Fish Comm., 144 pp.

Durrant, S. D. 1952. Mammals of Utah. Taxonomy and distribution. Univ. Kansas Publ., Mus. Nat. Hist., 6: 1-549.

Eastman, C. A. 1902. Indian Boyhood. McClure, Phillips, New York. 289 pp.

Eble, H. 1955. Funktionelle Anatomie der Extremitätenmuskulatur von Ondatra zibethica. Beiträge zur Anatomie der Bisamratte. II. Wiss. Z. Univ. Halle, Math-Nat., 4:977-1004.

Elton, C. 1942. Voles, Mice and Lemmings. Problems in Population Dynamics. Oxford Univ. Press. $496 \mathrm{pp}$.

-_ AND M. Nicholson. 1942. Fluctuations in numbers of the muskrat (Ondatra zibethica) in Canada. J. Anim. Ecol., 11:96-126.

Erickson, A. B. 1949. The fungus (Haplosporangium parvum) in the lungs of the beaver (Castor canadensis). J. Wildl. Mgt., 13:419-20.

ERrington, P. L. 1937a. Habitat requirements of stream-dwelling muskrats. Trans. N. Am. Wildl. Conf., 2:411-16.

- 1937b. The breeding season of the muskrat in northwest Iowa. J. Mammal., 18:333-37.

- 1937c. Drowning as a cause of mortality in muskrats. J. Mammal., 18:497-500.

- 1938. Observations on muskrat damage to corn and other crops in central Iowa. J. Agr. Res., 57:415-21. 168-86.

. 1939b. Observations on young muskrats in Iowa. J. Mammal., 20:465-78. $4: 173-85$. muskrat. J. Wildl. Mgt., 5:68-89.

_. 1941b. An eight-winter study of central Iowa bobwhites. Wilson Bull., 53:85-102.

- 1942a. On the analysis of productivity in populations of higher vertebrates. J. Wildl. Mgt., 6:169-81.

Am. J. Vet. Res., 3:195-201. 
ERrington, P. L. 1943. An analysis of mink predation upon muskrats in north-central United States. Iowa Agr. Exp. Sta. Res. Bull. 320:797-924. - . 1944. Additional studies on tagged young muskrats. J. Wildl. Mgt., 8:300-306.

- 1945. Some contributions of a fifteen-year local study of the northern bobwhite to a knowledge of population phenomena. Ecol. Monogr., 15:1-34.

_ 1946. Predation and vertebrate populations. Quart. Rev. Biol., 21:144-77, 221-45.

-. 1948a. Environmental control for increasing muskrat production. Trans. N. Am. Wildl. Conf., 13:596-607.

- 1948b. In appreciation of Aldo Leopold. J. Wildl. Mgt., 12:341-50. widely distributed muskrat. Am. Nat., 85:273-92.

- 1954a. On the hazards of overemphasizing numerical fluctuations in studies of "cyclic" phenomena in muskrat populations. J. Wildl. Mgt., 18:66-90.

- - 1954b. The special responsiveness of minks to epizootics in muskrat populations. Ecol. Monogr., 24:377-93.

7.

- 1957. Of population cycles and unknowns. Cold Spring Harbor Symp. Quant. Biol., 22:287-300.

- - AND C. S. ERrington. 1937. Experimental tagging of young muskrats for purposes of study. J. Wildl. Mgt., 1:49-61.

—_, F. Hamerstrom, and F. N. Hamerstrom, Jr. 1940. The great horned owl and its prey in north-central United States. Iowa Agr. Exp. Sta. Res. Bull. 277:757-850.

- AND T. G. SCOTT. 1945. Reduction in productivity of muskrat pelts on an Iowa marsh through depredations of red foxes. J. Agr. Res., $71: 137-48$.

Evans, F. C. And R. Holdenreid. 1943. A population study of the Beechey ground squirrel in central California. J. Mammal., 24:231-60.

Fichter, E., G. Schildman, and J. H. Sather. 1955. Some feeding patterns of coyotes in Nebraska. Ecol. Monogr., 25:1-37.

Forbes, T. R. 1942. The period of gonadal activity in the Maryland muskrat. Science, 95:382-83.

AND R. K. ENDERS. 1940. Observations on corpora lutea in the ovaries of Maryland muskrats collected during the winter months. J. Wildl. Mgt., 4:169-72.

Fox, I. 1940. Fleas of Eastern United States. Iowa State Univ. Press. 191 pp.

Frank, F. 1953. Untersuchungen über den Zusammenbruch von Feldmausplagen (Microtus arvalis (Pallas)). Zool. Jb., Abt. Syst., 82:95-136.

․ 1954. Die Kausalität der Nagetier-Zyklen im Lichte neuer populationdynamischer Untersuchungen an deutschen Microtinen. Ein Zwischenbericht. Z. Morph. ökel. Tiere, 43:321-56.

- 1957. The causality of microtine cycles in Germany. J. Wildl. Mgt., 21:113-21.

Franz, J. 1950. Zyklische Massenvermehrungen bei Vögeln und Kleinsäugern. Vogelwarte, 15:141-55.

Freeman, R. M. 1945. Muskrats in Mississippi. Miss. Game and Fish Commission. 48 pp.

Frison, T. H. 1938. Advances in the renewable natural resources prograin of Illinois. Trans. Ill. Acad. Sci., 31:19-34.

Fuller, W. A. 1951. Natural history and economic importance of the muskrat in the Athabasca-Peace Delta, Wood Buffalo Park. Wildl. Mgt. Bull. Ser. 1(2), Ottawa. 82 pp. 
Gashwiler, J. S. 1948. Maine muskrat investigations. Bull. Maine Dept. Inland Fish and Game. 38 pp.

- 1950. Sex ratios and age classes of Maine muskrats. J. Wildl. Mgt., 14:384-89.

Gerstell, R. 1942. The place of winter feeding in practical wildlife management. Pa. Game Comm. Res. Bull. 3. 121 pp.

Giles, L. W. And V. L. Childs. 1949. Alligator management on the Sabine National Wildlife Refuge. J. Wildl. Mgt., 13:16-28.

Glasgow, R. D. 1938. Mosquitoes and wildlife as interrelated problems in human ecology. N.Y. State Mus. Bull. 316:7-20.

Glass, B. P. 1952. Factors affecting the survival of the Plains inuskrat, Ondatra zibethica cinnamomina, in Oklahoma. J. Wildl. Mgt., 16:484-91.

Gould, H. N. And F. B. Kreeger. 1948. The skull of the Louisiana muskrat (Ondatra zibethica rivalicia Bangs): I. The skull in advanced age. J. Mammal., 29:138-49.

Grange, W. B. 1949. The Way to Game Abundance. Scribner's, New York and London. xviii $+365 \mathrm{pp}$.

Green, R. G. and C. L. Larson. 1938. A description of shock disease in the snowshoe hare. Am. J. Hyg., 28:190-212.

Grimm, W. C. 1941. The muskrat in northwestern Pennsylvania. Pa. Game News, $12(2): 6-7$.

Grinnell, J., J. S. Dixon, and J. M. Linsdale. 1937. Fur-Bearing Mammals of California. Their Natural History, Systematic Status, and Relations to Man. Univ. Calif. Press. 2 vols., xii + 1-375 pp. and xiv + 377-777 pp.

Gross, A. O. 1947. The eighth annual report of the Bowdoin Scientific Station. Bowdoin Coll., Bull. 10 (mimeographed). 26 pp.

- 1949. The ninth annual report of the Bowdoin Scientific Station. Bowdoin Coll., Bull. 11 (mimeographed). 22 pp.

Gunn, C. K. 1933. Phenomena of primeness. Canad. J. Res., 6:387-97.

Hall, E. R. 1938. Mammals From Touchwood Hills. Canad. Field-Nat., 52: 108-9.

- — 1946. Mammals of Nevada. Univ. Calif. Press. xi +710 pp.

Hamerstrom, F. N., Jr. 1958. Hawks, Owls and Wildlife. (Review of John J. Craighead and Frank C. Craighead, Jr.) J. Wildl. Mgt., 22:212-13.

- AND J. Blake. 1939a. A fur study technique. J. Wildl. Mgt., 3:54-59. Nat., 21:514-20.

Hamilton, W. J., JR. 1943. Mammals of Eastern United States; An Account of Recent Land Mammals Occurring East of the Mississippi. Comstock, Ithaca and New York. 432 pp.

Handly, C. O., JR. And C. P. Patton. 1947. Wild mammals of Virginia. Va. Comm. Game and Inland Fish. 220 pp.

Hardy, J. D., JR. 1950. What is happening to the muskrat? Maryland Conservationist, $27(3): 8-9,27$.

Hargrave, C. W. 1950a. Age and sex ratios of muskrats in N.D. N.D. Outdoors, $12(9): 8$.

- 1950b. North Dakota fur harvest report 1949-1950. N.D. Outdoors, $13(4): 13$.

Harper, F. 1927. The mammals of the Okefinokee Swamp Region of Georgia. Proc. Boston Soc. Nat. Hist., 38:191-396.

Harris, V.T. 1952. Muskrats on tidal marshes of Dorchester County. Publ. 91. Chesapeake Biol. Lab., Dept. Res. and Ed., Solomons Island, Md. $36 \mathrm{pp}$.

- 1956. The nutria as a wild fur mammal in Loiusiana. Trans. N. Am. Wildl. Conf., 21:474-85.

Hayden, Ada. 1943. A botanical survey in the Iowa lake region of Clay and Palo Alto counties. Iowa State Univ. J. Sci., 17:277-416. 
Heit, W. S. 1944. Food habits of red foxes of the Maryland marshes. J. Mammal., 25:55-58.

- 1949. Muskrat weights and sex ratio in the Riverbend marshes of Wayne County, New York. J. Mammal., 30:122-24.

Henderson, A. D. 1923. Cycles of abundance and scarcity in ceriain mammals and birds. J. Mammal., 4:264-65.

Hendrickson, G. O. 1936. Observations on nests and young of the coot. Wilson Bull., 48:216-18.

Henry, C. J. 1939. Response of wildlife to management practices on the Lower Souris Migratory Waterfowl Refuge. Trans. N. Am. Wildl. Conf., $4: 372-77$.

Hesse, R., W. C. Allee, and K. P. Schmidt. 1951. Ecological Animal Geography. Wiley, New York. xiii +715 pp.

HewitT, O. H. 1942. Management of an artificial marsh in southern Ontario for ducks and muskrats. Trans. N. Am. Wildl. Conf., 7:277-82.

- ed. 1954. A symposium on cycles in animal populations. J. Wildl. Mgt., 18:1-112.

Highby, P. R. 1941. A management program for Minnesota muskrat. Proc. Minn. Acad. Sci., 9:30-34.

Hill, J. E. 1942. Notes on mammals of northeastern New Mexico. J. Mammal., 23:75-82.

Hinton, M. A. C. 1926. Monograph of the Voles and Lemmings (Microtinae) Living and Extinct. British Museum, London. 488 pp.

Hoffmann, M. 1952. Die Bisamratte. Neue Brehmbücherei, Leipzig. 44 pp.

1958. Die Bisamratte; ihre Lebensgewohnheiten, Verbreitung. Bekämpfung und wirtschaftliche Bedeutung. Akademische Verlagsgesell schaft Geest und Portig K.-G. Leipzig. 267 pp.

Hollister, N. 1911. A systemic synopsis of the muskrats. N. Am. Fauna 32. $47 \mathrm{pp}$.

Hotchkiss, N. ANd H. L. Dozier. 1949. Taxonomy and distribution of North American cat-tails. Am. Midl. Nat., 41:237-54.

Hovind, J. 1948. Beaver trouble. Wis. Cons. Bull., 13 (7) :15-18.

Howell, A. H. 1921. A biological survey of Alabama. N. Am. Fauna 45. 88 pp.

Huenecke, H. S., A. B. Erickson, and W. H. Marshall. 1958. Marsh gases in muskrat houses in winter. J. Wildl. Mgt., 22:240-45.

Huestis, R. R. 1938. Muskrats in Crater Lake National Park. Nature Notes, Crater Lake National Park, Oregon, 11 (2) :22-23.

Irving, L. 1938a. Changes in the blood flow through the brain and muscles during the arrest of breathing. Am. J. Physiol., 122:207-14. 123: 107 .

—. 1939. Respiration in diving mammals. Physiol. Rev., 19:112-34.

Jellison, W. L. 1950a. Haplomycosis in Montana rabbits, rodents, and carnivores. U.S. Publ. Health Repts., 65:1057-63.

_. 1950b. Geographical distribution of "deerfly fever" and the biting fly, Chrysops discalis Williston. U.S. Publ. Health Repts. 65:1321-29.

, D. C. Epler, E. Kuhns, and G. M. Kohls. 1950. Tularemia in man from a domestic rural water supply. U.S. Publ. Health Repts., 65:121926.

-, G. M. Kohls, W. J. Butler, and J. A. Weaver. 1942. Epizootic tularemia in the beaver, Castor canadensis, and the contamination of stream water by Pasteurella tularensis. Am. J. Hyg., 36: 168-82.

of human infection in Utah. Rocky Mt. Med. J., 48:594-97.

Jenkins, J. H. 1953. Game resources of Georgia. Georgia Game and Fish Comm. ix +114 pp. 
Johnson, C. E. 1925. The muskrat in New York. Roosevelt Wild Life Bull., 3:199-320.

Johnson, M. S. 1926. Activity and distribution of certain wild mice in relation to biotic communities. J. Mammal., 7:245-77.

Kalela, O. 1949. Uber Fjeldlemming-Invasionen und andere irreguläre Tierwanderungen. Ann. Zool. Soc. Zool. Bot. Fenn. "Vanamo." 13 (5) . iv $+90 \mathrm{pp}$.

KellogG, C. E. 1946. Variation in pattern of primeness of muskrat skins. J. Wildl. Mgt., 10:38-42.

KellogG, R. 1939. Annotated list of Tennessee mammals. Proc. U.S. Nat. Mus., 86:245-301.

KING, H. D. 1913. Some anomalies in the gestation of the albino rat (Mus norvegicus albinus). Biol. Bull., 24:377-91.

-1935. Birth weight in the gray Norway rat and the factors that influence it. Anat. Rec., 63:335-54.

Koersveld, E. van. 1953. De muskusrat, Ondatra zibethica L. in Nederland en zijn bestrijding. In Jaarboek, 1951-1952, Plantenziektenkundige Dienst, Wageningen, No. 120:229-49.

Komarek, E. V. And R. Komarek. 1938. Mammals of the Great Smokies. Bull. Chicago Acad. Sci., 5:137-62.

Koppanyi, T. And M. S. Dooley. 1929. Submergence and postural apnea in the muskrat (Fiber zibethicus L.). Am. J. Physiol., 88:592-95.

LAck, D. 1954. The Natural Regulation of Animal Numbers. Oxford Univ. Press. 343 pp.

Lampio, T. 1946. Riistantaudit Suomessa vv. 1924-43. With English summary: Game Diseases in Finland, 1924-43. Suomen Riista, 1:93-142.

Lavrov, N. 1933a. [ To the biology of the musk-rat (Musquash) Fiber zibethicus L.] Zool. Zhur., 12:86-100. (In Russian; summary in English) . - 1933b. [Einige Tatsachen über die Ernährung der Bisamratte (Fiber zibethicus L.).] Zool. Zhur., 12:67-79. (In Russian; summary in German).

- 1955a. [Dynamics of distribution and economic significance of muskrats in U.S.S.R.] Zool. Zhur., 34:441-53. (In Russian).

- 1955b. [Fluctuations and forecasts of muskrat numbers.] Translation from the Russian in Translations of Russian Game Reports, 2:20324, Canadian Wildlife Service, 1957.

- 1957. [Acclimatization of the Muskrat in U.S.S.R.] Izdatielstvo Centrosoyuz. Moscow. 530 pp.

LAY, D. W. 1945. Muskrat investigations in Texas. J. Wildl. Mgt., 9:56-76. 6:301-11.

LEedy, D. L. 1948. Some wildlife and land use relationships in Ohio. Ohio J. Sci., 48:151-60.

Ligon, J. S. 1927. Wild life of New Mexico. Its conservation and management. N. Mex. State Game Comm. 212 pp.

Liljestrom, G. 1954. Bisam i Norrbotten. Svensk Jakt, 92:341.

Ling, F. E. 1935. The Kankakee in the old days. Bull. N.Y. Zool. Soc., 38:197-212.

LinsDale; J. M. 1938. Environmental responses of vertebrates in the Great Basin. Am. Midl. Nat., 19:1-206.

Lord, G. H., A. C. Todd, And C. Kabat. 1956. Studies on Errington's disease in muskrats. I. Pathological changes. Am. J. Vet. Res., 17:303-6. disease in muskrats. II. Etiology. Am. J. Vet. Res., 17:307-10.

Low, J. B. 1945. Ecology and management of the redhead, Nyroca americana, in Iowa. Ecol. Monogr., 15:35-69. 
Lowery, G. H., JR. 1943. Check-list of the mammals of Louisiana and adjacent waters. Occ. Papers Mus. Zool. La. State Univ., 13:213-57.

Luppa, H.-W. 1956. Zur Morphologie und Histologie des Magens der Bisamratte (Ondatra zibethica). Wiss. Z. Univ. Halle, Math.-Nat., 5:64768.

LyNCH, J. J. 1941. The place of burning in management of the Gulf Coast refuges. J. Wildl. Mgt., 5:454-58.

-, T. O'NeIL, ANd D. W. LAy. 1947. Management significance of damage by geese and muskrats to Gulf Coast marshes. J. Wildl. Mgt., $11: 50-76$.

MacFarlane, R. 1905. Notes on mammals collected and observed in the Northern Mackenzie River District, Northwest Territories of Canada, with remarks on explorers and explorations of the Far North. Proc. U.S. Nat. Mus., 28:673-764.

Malthus, T. R. 1798. An Essay on the Principle of Population. London, Johnson. [Reeves and Turner, London. 9 th ed. $x v+551$ pp.]

Manville, R. H. 1948. The vertebrate fauna of the Huron Mountains, Michigan. Am. Midl. Nat., 39:615-40.

Marshall, W. H. 1937. Muskrat sex-ratios in Utah. J. Mammal., 18:518-19. 1940. A survey of the mammals of the islands in Great Salt Lake, Utah. J. Mammal., 21:144-59.

Mathiak, H. A. 1953. Experimental level ditching for muskrat management. Wis. Cons. Dept., Tech. Wildl. Bull. 5. 35 pp.

- 1954. Role of refuges in muskrat management. Wis. Cons. Dept., Tech. Wildl. Bull. 10. 16 pp.

- And A. F. Linde. 1956. Studies on level ditching for marsh management. Wis. Cons. Dept., Tech. Wildl. Bull. 12. 48 pp.

McCann, L. J. 1944. Notes on growth, sex and age ratios, and suggested management of Minnesota muskrats. J. Mammal., 25:59-63.

- AND P. Highby. 1942. Why December muskrat trapping. Conservation Volunteer (Minn. Dept. Cons.), 3(16):11-14.

McLeod, J. A. 1948. Preliminary studies on muskrat biology in Manitoba. Trans. Roy. Soc. Canada, V, 42:81-95.

- 1950. A consideration of muskrat populations and population trends in Manitoba. Trans. Roy. Soc. Canada, V, 44:69-79.

___ AND G. F. Bondar. 1952. Studies on the biology of the muskrat in Manitoba. Part I. Oestrus cycle and breeding season. Canad. J. Zool., $30: 243-53$.

Mearns, E. A. 1907. Mammals of the Mexican Boundary of the United States. Part I. Families Didelphiidae to Muridae. U.S. Natl. Mus. Bull. 56 xv + $530 \mathrm{pp}$.

Meyer, K. F. and K. Matsumura. 1927. The incidence of carriers of $B$. aertrycke ( $B$. pestis caviae) and B. enteritidis in wild rats of San Francisco. J. Inf. Dis., 41:395-404.

Miller, G. S., JR. AND R. Kellogg. 1955. List of North American Recent Mammals. U.S. Natl. Mus. Bull. 205. xii + 954 pp.

Miller, M. J. 1940. Plague: history and epidemiology. Canad. J. Comp. Med., 4:183-93.

Mizelle, J. D. 1935. Swimming of the muskrat. J. Mammal., 16:22-25.

MoHr, E. 1933. The muskrat, Ondatra zibethica (Linnaeus), in Europe. J. Mammal., 14:58-62.

Morris, R. F. 1948. The land mammals of New Brunswick. J. Mammal., 29:165-76.

Muller, G. 1952-53. Beiträge zur Anatomie der Bisamratte (Ondatra zibethica). I. Einführung, Skelett und Literature. Wiss. Z. Univ. Halle, Math.Nat., 2:817-65.

Munro, J. A. 1945. The birds of the Cariboo Parklands, British Columbia. Canad. J. Res., D, 23:17-103. 
And I. McT. Cowan. 1944. Preliminary report on the birds and mammals of Kootenay National Park, British Columbia. Canad. FieldNat., 58:34-51.

Murie, A. 1940. Ecology of the coyote in the Yellowstone. Fauna Natl. Parks U.S., Fauna Ser. 4. 202 pp. Fauna Ser. 5. 238 pp.

Nice, M. M. 1941. The role of territory in bird life. Am. Midl. Nat., 26:44187.

Nicholas, J. S. 1947. Experimental approaches to problems of early development in the rat. Quart. Rev. Biol., 22:179-95.

Nicholson, A. J. 1954. An outline of the dynamics of animal populations. Australian J. Zool., 2:9-65.

Odum, E. P. 1949. Small mammals of the Highlands (North Carolina) Plateau. J. Mammal., 30:179-92.

Olsen, P. F. 1959. Muskrat breeding biology at Delta, Manitoba. J. Wildl. Mgt., 23:40-53.

O'NeIL, T. 1949. The muskrat in the Louisiana coastal marshes. La. Dept. Wild Life and Fisheries. xii + 152 pp.

PARK, T. 1939. Analytical population studies in relation to general ccology. Am. Midl. Nat., 21:235-55.

- 1941. The laboratory population as a test of a comprehensive ecological system. Quart. Rev. Biol., 16:274-93, 440-61.

Parker, R. R., E. A. Steinhaus, G. M. Kohls, and W. L. Jellison. 1951. Contamination of natural waters and mud with Pasteurella tularensis and tularemia in beavers and muskrats in the northwestern United States. Natl. Inst. Health Bull. 193. 61 pp.

Pearl, R. 1925. The Biology of Population Growth. Knopf, New York. 260 pp.

- 1937. On biological principles affecting populations: human and other. Am. Nat., 71:50-68.

- - And S. L. Parker. 1922. On the influence of density of population upon the rate of egg production in Drosophila. Proc. Natl. Acad. Sci., 8:212-19.

Penfound, W. T., and E. S. Hathaway. 1938. Plant communities in the marshlands of southeastern Louisiana. Ecol. Monogr., 8:1-56.

And J. D. Schneidau. 1945. The relation of land reclamation to aquatic wildlife resources in southeastern Louisiana. Trans. N. Am. Wildl. Conf., 10:308-18.

Porsild, A. E. 1945. Mammals of the Mackenzie Delta. Canad. Field-Nat., $59: 4-22$.

Preble, E. A. 1908. A biological investigation of the Athabaska-Mackenzie Region. N. Am. Fauna 27. 574 pp.

Provost, M. W. 1948. Marsh-blasting as a wildlife management technique. J. Wildl. Mgt., 12:350-87.

Quortrup, E. R., And R. L. Sudheimer. 1942. Research notes on botulism in western marsh areas with recommendations for control. Trans. N. Am. Wildl. Conf., 7:284-93.

Rand, A. L. 1944. The recent status of Nova Scotia fur bearers. Canad. FieldNat., 58:85-96.

ReEves, H. M. AND R. M. Williams. 1956. Reproduction, size, and mortality in the Rocky Mountain muskrat. J. Mammal., 37:494-500.

Rensch, B. 1938. Some problems of geographical variation and speciation. Proc. Linn. Soc. Lond., 150 (4):275-85.

Rodhe, W. 1958. Aktuella problem inom limnologien. Svensk Naturvetenskap, 11:55-107.

Rowan, W. 1938. Light and seasonal reproduction in animals. Biol. Rev., 13:374-402. 
Rowan, W. 1950. Canada's premier problem of animal conservation. New Biol., 9:38-57.

Sather, J. H. 1953. The life history, habits and economic status of the Greai Plains muskrat. Univ. Nebr. Doctoral Abst. 3 pp.

- 1954. The dentition method of aging muskrats. Chicago Acad. Sci. Nat. Hist. Misc. 130. 3 pp.

- 1958. Biology of the Great Plains muskrat in Nebraska. Wildl. Monogr. 2. $35 \mathrm{pp}$.

Schwartz, A. 1953. A systematic study of the water rat (Neofiber alleni). Occ. Papers Univ. Mich. Mus. Zool., 547. 27 pp.

Scott, T. G. 1947. Comparative analysis of red fox feeding trends on two central Iowa areas. Iowa Agr. Exp. Sta. Res. Bull., 353:427-87.

- AND W. L. Dever. 1940. Blasting to improve wildlife environment in marshes. J. Wildl. Mgt., 4:373-74.

AND C. A. Sooter. 1937. Migrations of shorebirds at Goose Lake, Hamilton County, Iowa during the fall of 1936. Iowa State Univ. J. Sci., $11: 247-52$.

Sealander, J. A., JR. 1956. A provisional check-list and key to the mammals of Arkansas (with annotations). Am. Midl. Nat., 56:257-96.

Seamans, R. 1941. Lake Champlain fur survey. Vt. Fish and Game Serv. State Bull., 3-4. 34 pp.

Selye, H. 1949. Textbook of Endocrinology. Acta Endocrinologia, Inc., Montreal. 2nd ed. xxxii +914 pp.

Shanks, C. E. 1948. The pelt-primeness method of aging muskrats. Am. Midl. Nat., 39:179-87.

- And G. C. Arthur. 1952. Muskrat movements and population dynamics in Missouri farm ponds and streams. J. Wildl. Mgt., 16:138-48.

Sheldon, C. 1936. The mammals of Lake Kedgemakooge and vicinity, Nova Scotia. J. Mammal., 17:207-15.

SHelford, V. E. 1951. Fluctuations of non-forest animal populations in the Upper Mississippi Basin. Ecol. Monogr., 21:149-81.

Sherman, H. B. 1952. A list and bibliography of the mammals of Florida, living and extinct. Quart. J. Florida Acad. Sci., 15:86-126.

Shillinger, J. E. 1938. Coccidiosis in muskrats influenced by water levels. J. Wildl. Mgt., 2:233-34.

Sigler, W. F. 1948. Aquatic and shore vegetation of Spirit Lake, Dickinson County, Iowa. Iowa State Univ. J. Sci., 23:103-24.

Sirvonen, L. 1948. Structure of short-cycle fluctuations in numbers of mammals and birds in the northern parts of the northern hemisphere. Finnish Found. Game Res., Papers Game Res. 1. 166 pp.

Slonaker, J. R. 1929. Pseudopregnancy in the albino rat. Am. J. Physiol., 89:406-16.

Smith, F. R. 1938. Muskrat investigations in Dorchester County, Md. 193034. U.S. Dept. Agr. Circ. 474.

Smith, R. W. 1940. The land mammals of Nova Scotia. Am. Midl. Nat., 24:213-41.

Y SNEAD, I. E. 1950. A family type live trap, handling cage, and associated techniques for muskrats. J. Wildl. Mgt., 14:67-79.

SNyder, L. L. 1942. Mammals of the Sault Ste Marie Region. Trans. Roy. Canad. Inst., 24:105-20.

Solman, V. E. F. 1945. The ecological relations of pike, Esox lucius L., and waterfowl. Ecology, 26:157-70.

Solomon, M. E. 1949. The natural control of animal populations. J. Anim. Ecol., 18:1-35.

Sooter, C. A. 1946. Muskrats of Tule Lake Refuge, California. J. Wildl. Mgt., 10:68-70.

Soper, J. D. 1937. Notes on the beavers of Wood Buffalo Park, Alberta. J. Mammal., 18:1-13. 
1939. Wood Buffalo Park. Notes on the physical geography of the park and its vicinity. Geog. Rev., 29:383-99.

1941. History, range, and home life of the northern bison. Ecol. Monogr., 11:347-412.

1942. Mammals of Wood Buffalo Park, northern Alberta and District of Mackenzie. J. Mammal., 23:119-45.

- 1946. Mammals of the northern Great Plains along the International Boundary in Canada. J. Mammal., 27:127-53.

Sprugel, G., JR. 1951. Spring dispersal and settling activities of central Iowa muskrats. Iowa State Univ. J. Sci., 26:71-84.

Stearns, L. A. and M. W. Goodwin. 1941. Notes on the winter feeding of the muskrat in Delaware. J. Wildl. Mgt., 5:1-12.

, D. MacCreary, and F. C. Daigh. 1939. Water and plant requirements of the muskrat on a Delaware tidewater marsh. Proc. 26th Ann. Meet. N.J. Mosquito Exterm. Assoc. pp. 212-21.

— $\longrightarrow$, AND — 1940. Effect of ditching for mosquito control on the muskrat population of a Delaware tidewater marsh. Univ. Del. Bull. 225, Tech. 26. 55 pp.

Stevens, P. G. And J. L. E. Erickson. 1942. The chemical constitution of the musk of the Louisiana muskrat. J. Am. Chem. Soc., 64:144-47.

Stevens, W. E. 1953. The northwestern muskrat of the Mackenzie Delta, Northwest Territories, 1947-48. Wildl. Mgt. Bull., Ser. 1 (8), Ottawa. 40 pp.

Storer, T. I. 1937. The muskrat as native and alien. J. Mammal., 18:443-60.

Sumner, F. B. 1916. Notes on superfetation and deferred fertilisation among mice. Biol. Bull., 30:271-85.

Svihla, A. 1932. A comparative life history study of the mice of the genus Peromyscus. Misc. Publ. Mus. Zool. Univ. Mich., 24:1-39. 28.

Svardson, G. 1957. Kronåren. Svensk Jakt, 95:2-4, 38.

Swank, W. G. 1949. Beaver ecology and management. Cons. Comm. of W. Va. Div. Game Mgt., Bull. 1. 65 pp.

Takos, M. J. 1943. Trapping and banding muskrats. J. Wildl. Mgt., 7:400-7. $8: 307-11$.

1944. Summer movements of banded muskrats. J. Wildl. Mgt., Mgt., 11:331-39.

TAYlOR, N. 1938. A preliminary report on the salt marsh vegetation of Long Island, New York. N.Y. State Mus. Bull. 316:21-84.

Tcherkasski, E. S. 1951. [ Tularemia in muskrats and measures to be taken against it.] Translation from the Russian in Translations of Russian Game Reports, 2:40-73. Canadian Wildlife Service, 1957.

Tsygankov, D. S. 1955. [ A method of determining the age and length of life of the muskrat (Fiber zibethicus L.).] Zool. Zhur., 34:640-41. (In Russian).

Twining, H. And A. L. Hensley. 1943. The distribution of muskrats in California. Calif. Fish and Game, 29:64-78.

Uhler, F. M. AND L. M. Llewellyn. 1952. Fur productivity of submarginal farmland. J. Wildl. Mgt., 16:79-86.

Ulbrich, J. 1930. Die Bisamratte; Lebensweise, Gang ihrer Ausbreitung in Europa, wirtschaftliche Bedeutung und Bekämpfung. Heinrich, Dresden. 137 pp.

Velthuysen, H. 1954. Får vi förestalla bisamråttan. Svensk Jakt, 92:128-30, 146.

Vinogradov, B. S. 1934. [Materials for the study of the dynamics of the fauna of muriform rodents in the U.S.S.R.] People's Commissariat Agric., 
Assoc. Pest and Disease Control U.S.S.R., Leningrad. 63 pp. (In Russian; summary in English).

Warwick, T. 1934. The distribution of the musk-rat (Fiber zibethicus) in the British Isles. J. Anim. Ecol., 3:250-67.

- 1936a. Methods of detecting musk-rats. Ann. Appl. Biol., 23:165-74. 1936b. The parasites of the musk-rat (Ondatra zibethica L.) in the British Isles. Parasitology, 28:395-402.

- 1940 . A contribution to the ecology of the musk-rat (Ondatra zibeth$i c a)$ in the British Isles. Proc. Zool. Soc. Lond., Ser. A, 110:165-201.

Welter, W. A. and D. E. Sollberger. 1939. Notes on the mammals of Rowan and adjacent counties in eastern Kentucky. J. Mammal., 20:7781.

Wiebe, A. H. 1946. Improving conditions for migratory waterfowl on TVA impoundments. J. Wildl. Mgt., 10:4-8.

Wilde, S. A., C. T. Youngberg, and J. H. Hovind. 1950. Changes in composition of ground water, soil fertility, and forest growth produced by the construction and removal of beaver dams. J. Wildl. Mgt., 14:123-28.

Wildhagen, A. 1952. Om vekslingene $\mathrm{i}$ bestanden av smågnagnere $\mathrm{i}$ Norge 1871-1949. (With an English summary). Statens Viltunders $\phi$ kelser. 192 pp.

W'Illiams, R. M. 1950. Study shows improvement at Gray's Lake could triple present muskrat population. Idaho Wildl. Rev., 3 (2) :12-14.

Wilson, K. A. 1953. Raccoon predation on muskrats near Currituck, North Carolina. J. Wildl. Mgt., 17:113-19.

Wilson, R. W. 1933. A rodent fauna from Later Cenozoic beds of southwestern Idaho. Carnegie Inst. Wash. Publ. 440:118-35.

- 1937. Pliocene rodents of western North America. Carnegie Inst. Wash. Publ. 487:21-73.

Wing, L. W. 1951-57. Various articles. J. Cycle Res., 1-6.

WodzIcki, K. A. 1950. Introduced Mammals of New Zealand. An Ecological and Economic Survey. Dept. Sci. and Ind. Res., Bull. 98. x +255 pp.

Wolf, P. 1956. Utdikad civilization. Malmö, Sweden.

WraGG, L. E. 1955. Notes on movements of banded muskrats. Canad. FieldNat., 69:9-11.

YEAGER, L. E. 1937. Naturally sustained yield in a farm fur crop in Mississippi. J. Wildl. Mgt., 1:28-36.

1941. Trappers and fur animals of the original Delta Region of Mississippi. J. Mammal., 22:364-78.

- 1942. Coal-stripped land as a mammal habitat, with special reference to fur animals. Am. Midl. Nat., 27:613-35.

1943. Fur production and manage
Trans. N. Am. Wildl. Conf., 8:294-301.

. 1949. Effect of permanent flooding in a river-bottom timber area. Bull. Ill. Nat. Hist. Surv., 25:33-65. 


\section{Index}





\section{Index}

Age determined by

frequency distribution of weights, 596

pelage of adults, 95-96

pelage of "kits," 43

pelage of very young, 37,38

pelage second month, 40

skull size, 595

teeth, 50, 95, 595

Albinism, means of identification, 64,65

"Allee effect" of inefficient mating, 189-90

Alligator (Alligator mississippiensis) improves muskrat habitat, 629-30 population significance of predation by, 629-30

predator upon muskrat, 16, 471, 573, 629, 630

Anatomy

changes in tail during second month, 40

general, 3

morphological adaptation for eating, 14

for swimming, 4

uteri and testes of adult muskrat, 93-95

Ancestry of Ondatra, 544-45
B

Badger (Taxidea taxus), as predator on muskrat in Nebraska Sand Hills, 578-79

Baldwin, William P. Jr. re distribution of $O . z$. zibethicus in southern coastal states, 398 re muskrat absence in Florida and Georgia, 572-73

re $O$. z. macrodon in North Carolina, 469-70

Bear River Marshes (Utah), 583-85

effect of carp on, 583

muskrat densities of, 584

Behavior, 105-390 passim; see also

Cannibalism; and Intraspecific strife

adjustments to drought, 9, 26-28, 80,582

adjustment to emergencies (discussion), 496, 497, 500

burrowing, 19, 20, 21, 42, 43

conditioned by social intolerance, 81

cyclic patterns in behavior changes, 532-34

eating frozen material, 9

escape techniques, 6 
Behavior (continued)

female breeding season behavior, 23-24

during floods, 25, 26

food storage, 21-22, 493

generalizations, 31

gnawing, 6-7, 9, 616-17

lodge building, 19, 20, 21, 27

male breeding season behavior, 24

migration; see Mass movements

monogamy, 24

muskrat-mink fighting, 10, 30-31

overland travel, 8

related to reproductive physiology, 76

response to availability of food, 14

response to disturbance, 28-29, 294, $325,330,370,455,482$

response to predators, 10, 29-30

response to transients, 10

role of psychology in conflict between muskrats, 31

social relations causing spring dispersal, 74

submergence apnea of young, 37

swimming, 3, 4, 41

temperament, 22-23, 72

traditions, 79, 493-94

24-hour activity rhythms, 18

underwater breathing, 5-6

underwater digging, 6

use of scent, 3

of young, 37, 38, 39, 40, 43

Bergmann Rule

as applied to muskrats, 48

statement of, 47

Biogeography of muskrat

Balkan region, 475-76

Belgium, 476

British Isles, 477-78

Denmark, 477

Finland, 479, 480

France, 476

Germany, 476

Holland, 476

introduction and colonization in Europe, 475

Russia, 478-79

Sweden, 482-84

Switzerland, 476

Blackwater Refuge

color mutations of muskrats, 623

cyclic manifestations, 622

disease, 622-23 "eat-outs," 622, 623

food, 623

lodge counts, 620-21

population growth studies, 619, $620-21,622,623$

predation by great horned owl, 621

predation by red fox, 621-22, 623

predation by weasel, 622

relation between size and weight

Botulism of muskrats and food, 623

effect on muskrats, 584-85

mentioned, 435, 441

British Isles; see Biogeography extirpation of muskrats, 477 spring dispersal, 75

\section{C}

Cannibalism

mentioned, 41, 88, 110

Care of young, 105-390 passim; see also Behavior: male and female Carp during breeding season

damage to some north central marshes, 497

effect on Bear River Marsh, 583

Cat, house, as predator on young muskrats in Europe, 477

Central Europe; see Biogeography cat as predator on young muskrats, 477

economic damage of muskrats, 475 foxes as predators on muskrats, 477

future of muskrats in, 477

introduction and colonization of muskrats, 475

polecats as predators on muskrats, 477

quality of muskrat habitat, 475-76 size of muskrat litters, 60

Central Iowa streams and outlying waters; see Appendix D, 550-53, for description of

Ames-Gilbert block

brooks northwest of Gilbert, 379-81

county line ditch north of Squaw Creek, 383-85

Des Moines River west of Ledges State Park, 387-88 
ditch and brook habitats north of Onion Creek, 381-83

Hutchinson's Lake, 374-76

map of, 290

miscellaneous outlying waters of

Squaw Creek drainage, 38687

Montgomery Creek, 373-74

new gravel-pit pools on Turner estate, $378-79$

Nobel Christianson ponds, 36971

old oxbow series west of Squaw Creek, 376-77

Onion Creek, 360-66

pasture brook near Rainbolt ponds, $377-78$

Rainbolt ponds, 366-69

roadside ditches northwest of Gilbert, 385-86

Skunk River, 332-36

Squaw Creek, 336-60

Turner (Allen) estate oxbows, 373-74

Turner (J. H.) Pond, 371-73

York Pond, 374-76

Story City block

drainage ditch west of Story City, 310-24

headwaters, Keigley's branch, 325-27

Indian Creek area, 324-25

Keigley's branch, 297-310

Lake Comar, 312, 322

map of, 289

Skunk River, 290-97

small outlying waters, 327-31

Cheever Lake; see Estherville marsh area

\section{Climate}

central Iowa weather, 1932-1957, 553-60

depressive effect of severe winter (Cumberland Lease), 599

effect of thaw on spring dispersal, 77

as limiting factor (Mackenzie Delta), 615, 616

Colleredo-Mannsfeld, Prince, introduced muskrat in Europe, 475

Compensations, 105-390 passim

compensatory breeding in response to early losses (Manitoba), 595-97 in damaged habitat, 497, 498

discussion of, 498-500, 510-11

after disease loss, 437, 500-501, 502, $504,505,506-8$

in marginal habitat, 496

in response to severe loss, 498

Cotton rat (Sigmodon), 24-hour rhythms, 18

Coyote (Canis latrans), predation on muskrats by, 437, 442-43, 444, $450,579,580$

Craighead and Craighead, philosophy re predation, 516-18

Cumberland Lease (Hudson's Bay Company area)

annual lodge counts tabulated for 11 years, 600

cyclic evidence, 599, 602

depressive effect of severe winter, 599

disease control, 601

"goose grass," 598

habitat, 597-99, 601

hemorrhagic disease, 599, 601

overtrapping-effect on population, 601

population growth patterns, 599, 601-2

ravens indicate sites of mortality, 599

tularemia, 599

water manipulation, 597

Cycles, 105-390 passim; see also Territoriality

background discussion of, 522-24

breeding affected by cycle (Wiscon$\sin ), 52$

cyclic evidence on Blackwater Refuge, 622

cyclic evidence on Cumberland Lease, 599, 602

cyclic evidence on Mackenzie Delta, 614, 615

cyclic evidence on Steeprock Lease, 594

cyclic evidence on Summerberry Block, 605

cyclic fluctuations obscured by environmental changes, 525-26

cyclic fluctuations of grouse and hares, 524-25

cyclic fluctuations of quail, 525-26

cyclic patterns in behavior changes, 532-34 
Cycles (continued)

cyclic patterns in disease syndromes, 529-32

cyclic patterns in muskrat reproduction, 526-28

discussion of evidence of cycles in muskrats, 534-37

effect of cycles on dispositions of muskrats, 23

evidence of cycle in Finland, 480 fall dispersal influenced by, 78

hypotheses concerning, 537-38

number of litters per female affected by, 58

size of litters affected by, 61-62

spring dispersal affected by cyclic low, 78

\section{D}

Deer mouse (Peromyscus)

superfetation, 33

24-hour rhythms, 18

Development, 105-390 passim

condition of aged, 50

continuing changes in mature animal, 47

corn as affecting development, 45 description of "kit," 42, 44

differential development of male and female, 44-45

differential size of male and female at birth, 34

effect of food on growth rate of very young, 36

effect of food on sexual development, 45-46

effect of food on size of animals, $45,48-49,328,408,423,424$, 623

effect of food on size of litter, 61 during first month, 35-39

muskrat at birth, 34, 35

other factors affecting size of young, 34-35

during second month, 39-42

sexual state of "kits," 46

subadult weights and measurements, 44

during third and fourth months, 42-44

time of eye opening, 37-38

Dewey's Pasture; see Ruthven marsh area
Disease, 105-390 passim; see also Haplosporangium; Hemorrhagic disease; Salmonella typhimurium; Trichophyton mentagrophytes; and Tularemia

bacteria of genus Salmonella, 501, 502

disease complex in western U. S., 446

disease control (Cumberland Lease), 601

Fibricola (parasite in muskrat), 366 general comments, 500-501

pathogenic fungi Trichophyton and Haplosporangium, 501

plague-group bacteria (especially Pasteurella tularensis), 501, 502-5

protozoa (especially coccidia of genus Eimeria), 501-2

tapeworm (Taenia) in Mackenzie Delta, 614

Disease control; see Disease and Hemorrhagic disease

Ditching

effect on muskrats, 401-2, 403, 408, $409,467,617-19$

effect especially on movements, 68 irrigation ditches and seepages as muskrat habitat, 585

Dogs, 105-390 passim

damage to bank burrows by digging, 497

effect of digging on muskrats, 500 predation on muskrats by, 10, 16, $64,66,70,74,87$

predation marks by, 98

Drainage of wetlands

discussion of, 497-98

in Illinois, 405

in Iowa, 392

in Minnesota, 418

in Missouri, 394

in North Dakota (Lower Souris marshes), 423

in southern Sweden, 483-84

in Tennessee, 395-96

in Wisconsin, 401-2

\section{$\mathbf{E}$}

"Eat-outs"

on Blackwater Refuge, 622, 623

on Louisiana marshes, 627-28 
population significance of, 497

Economic damage

in central Europe, 475

to corn crop, 367, 381-82

to truck gardens, 14

Estherville marsh area, northwestern Iowa

Cheever Lake, 125-39, 140-50

Four-Mile Lake, 127, 139, 142, 143 , $144,145-46,147-48,149,150$

High Lake, 127, 139, 140, 142, 143, 144

Mud Lake chain, 127, 139, 140, 142, 143, 144

Spirit Lake, 127

Twelve-Mile Lake, 146

Extirpation of muskrats

cost of in British Isles, 477

how accomplished, 16

\section{$\mathbf{F}$}

Feeding habits; see Food and Behavior

Fibricola, parasite in muskrat, 366

Finland; see Biogeography

colonization of muskrats, 478-79

disease mortality, 481

effect of fish traps on muskrat population, 480

population growth, 480

predator-prey relations, 480, 481-82

quality of habitat, 480,482

sensitivity to disturbance, 482

Firing of marshes for muskrat management in Louisiana, 628--29

Florida, absence of muskrats, 398, 399

Food, 105-390 passim; see also Appendix G, 572-73; Cannibalism; Development: effect of food on; Food storage; "goose grass"; and Scirpus olneyi

analysis of muskrat food habits, 101 corn, 13,14

fish, 4,9

flesh of lower vertebrates, 14

food of flood evicted, 26

food plants on Bear River marshes, 583-84

food plants on Cumberland Lease, 597-98

food plants in Newfoundland, 591-92 food plants on Summerberry Block, 603,604

kinds eaten, 13-14

kinds stored, 92

oats (growing in oat fields), 312

of O. z. albus, 13

of $O$. z. cinnamominus in Oklahoma, 581-82

of $O . z$. rivalicius, 13

selection of, 14

soybeans, 383

storage in under-ice drought, 28

stored acorns, 359

turtles (scavenged upon by muskrats), 582

Food storage, 105-390 passim

corn and duck potatoes, 9, 22, 92

storage linked with lodge building, 21

_..survival value during winter drought, 28

Fossil muskrats; see also Appendix A, 544

during Pleistocene, 399

Four-Mile Lake; see Estherville marsh area

Fox (red), 105-390 passim

fox-mink relations, 155

predation on muskrats on Blackwater Refuge, 621-22, 623

predation on muskrats on Mackenzie Delta, 617

predation on young muskrats, 15455

as predator, $10,16,87$

as predator in central Europe, 477

as scavenger, 88

Fur, see Pelage

Fur refuges

on Cheever Lake area, 145, 146, 148

"sucking out" of muskrats from, 4 on Wall Lake, 157, 158, 159, 201

\section{G}

Georgia, muskrat absence, 572-73

Germany; see Biogeography

precocious breeding of muskrats, 59

sex ratios of adults in, 51

"Goose grass" (Equisetum fluviatile)

in Manitoba, 413, 598

preferred by $O$. z. albus, 13 
Goose Lake area, central Iowa, 24887 map of, 205

Gray's Lake (Idaho)

site of muskrat investigation, 43839

Great horned owl (Bubo virginianus), 105-390 passim

in Blackwater Refuge, 621

juvenile owl scavenging on dead muskrat, 213

muskrat security from, 300

predation during drought, 64

as predator on muskrats, 16, 30, $332,334,338,341,342,348$, 364,471

\section{H}

Habitat, 105-390 passim; see also Appendix D, 550-53; Appendix N, 588-91; Economic damage; Malheur National Wildlife Refuge; and Yellowstone National Park burrows, 14-15, 19, 42

cattle damage to north central marshes, 497

damage by carp to, 497

discussion re changes in, 496-98, 499,500

ditching as affecting, 401-2, 403, 408, 409, 467

drought conditions (Canada), 80

"eat-outs," 497, 622, 623, 627-28

effect of floods on, 24-25

effect of impounded water on soil fertility (Wisconsin), 604-5

effect of snow on freezing, 466

effect of tidal fluctuations on, 470

effect of vegetation on depth of freezing, 460

effect of wild geese on (Louisiana), 497

fire for habitat control (Louisiana), 628-29

food plants, 13

general comparisons, 484-86

generalizations, 17-18.

geographical variety, 11

impairment from disease, 507

importance of suitable water, 10 , $12,155,199$ irrigation ditches and seepages, 585 at Kent Island, New Brunswick, 577-78

lodges and burrows modified by drought, 27

at Mackenzie Delta, 612-14, 615, 617

in Manitoba, 594-95

material for lodges, 15, 267

at Mobile Bay, 625-26

mountain or mountain-like habitats, 484-85

-nature of lodges, 18, 19, 20-21

of O.z. bernardi, 632

of O. z. cinnamominus, 580-82

philosophy re marginal and submarginal habitats, 486

population significance of habitat selection, 15-16

quality of Swedish habitat, 483

selection conditioned by presence of other muskrats, 15

selection rarely influenced by presence of predators, 16

"sour land" at Summerberry, 604 at Steeprock, 592-93

at Summerberry, 602-3, 604, 605, 606-10

at Upper Mississippi, 399-401, 574-76

Haplosporangium

in Montana, 587-88

population significance of, 588

Hemorrhagic disease, 105-390 passim; see also Appendix H, 576;

Cycles; and Population dynamics characteristics of epizootics, 506 continuing infectiousness of old disease foci (examples), 268, $272,273,275,276,277$

on Cumberland Lease, 599, 601

distribution of, 503, 505-6

etiology, 501

experimental control at Goose Lake, 259

experimental control at Wall Lake, 166-67, 168, 170-71

field study of epizootics, 90, 92 infectiousness to man, 101

manifestations, 98-101, 102, 529

in Manitoba, 596

in Maryland, 620, 622

in Nebraska, 580 
raccoon with liver lesions, 160

on Summerberry Block, 605, 608, 609

time of epizootics, 90

Hogs

damage to marshes by, 497

root for duck potatoes stored in muskrat burrows, 372,373

as scavengers on muskrats, 318

Holland, growth of muskrat population despite effort to extirpate, 476-77

Horicon marsh

development studies, 44

nature of, 402-3

trapping and tagging studies, 6768

\section{I}

\section{Identification}

by albinism, 65-66

by behavior and appearance, 64

by deformity, 66

by isolation and behavior, 67

by live trapping and marking (Snead), 67

by tagging, $63-64$

by toe clipping, 63

Intraspecific strife, 4, 30, 31, 89-91, 105-390 passim; see also Behavior: breeding season; Population dynamics: self-limitation as population force

from disease, 183

during environmental crises, 26, 79 involving transients, $10,72,74,75-$ 76

involving young, 40-42, 43

linked with season, 22

as population check, 516

\section{$\mathbf{L}$}

Litters; see Population dynamics; Reproduction; and Cycles

Little Wall Lake area, central Iowa, 204-47

map of, 205

$\mathbf{M}$

Mackenzie Delta climate as limiting factor, 615, 616 cyclic evidence, 614,615

disease, 614

fox predation on muskrats, 617

habitat, 612-14, 615, 617

push-ups, 616

tapeworm (Taenia), 614

Malheur National Wildlife Refuge mass movements out of, 497

nature of muskrat habitat, 441-42, 443,444

Mass movements

behavior of mass moving muskrats, 78

of crowded population, 78

from deteriorating environment, 78,80

during droughts (Summerberry), 606

from Malheur Lake, 442, 497

mass migrations, 462-63

massing of muskrats along Iowa streams, 492

nature of, 78

of Scandinavian lemmings, 78

Meadow mouse (Microtus)

adaptations for living in marsh, 183

as affecting predation upon muskrats by coyotes, 579

Craighead and Craighead philosophy concerning predation upon, 517, 519

living in muskrat retreats, 52, 622 in North Carolina, 573

predation upon, 178, 182

as predators on muskrats, 182, 183, 188

prey of badgers, 578

24-hour activity rhythm, 18

Mink (Mustela vison), 105-390 passim

detailed account of mink predation on winter-handicapped muskrats, 265-66

mink-fox relations, 155

mink predation marks on muskrats, 98

mink predation on microtus living in muskrat lodges, 178

in Pacific Northwest, 445

predation on restless muskrats during late winter, 74 
Mink (Mustela vison) (continued)

as predator and scavenger in Nebraska Sand Hills, 579

as predator on muskrats, 10, 16, $87,511-13,576$

response to large numbers of muskrats, 154

as scavenger upon muskrats, 88

vulnerability of "kits" to, 43

vulnerability of second month, drought-exposed young to, 42

Mobile Bay area; see Appendix $\mathrm{V}$, 624-26

Montezuma National Wildlife Refuge, effect of food on size of muskrats, 48-49

Mosquito control

effect of ditching for mosquito control on muskrats, 467, 617-19 effect of poison spray for mosquito control on muskrats, 471

Movements of muskrats, $105-390$ passim; see also Mass movements; and Movements, special studies adjustments of stream-dwelling muskrats, 491-94

of adults, 65-71

as affected by population density, 64

caused by disease, 81

correlation of physiology with fighting and movement, 78-79 during drought, 64 during early independence, 64 effect of ditching on, 68 natural restocking of muskrats, 11 , 79

nonseasonal and emergency, 79-81 postbreeding and autumnal, 77-79 postbreeding movement affected by cyclic low, 78

postbreeding movements along streams, 493, 494

postbreeding movements, which animals involved, 78

sedentary nature of marsh dwellers, 4-5

size of spring dispersal, 77

spring dispersal affected by cyclic low, 78

spring dispersal affected by floods, 76-77

spring dispersal (British Isles), 75 spring dispersal, discussed, 73-77

spring dispersal in relation to the weather, 76

spring dispersal of $O$. z. rivalicius, 77

time of postbreeding movements, $77-78$

of trap cripples as wanderers, 81

under-ice movements, 5, 79

on underpopulated marsh, 64-65

winter wandering, 79

Movements, special studies

by Aldous in South Dakota, 68-69

by Dorney and Rusch in Wisconsin, 68

by Fuller in Athabasca-Peace Delta, 70-71

by Sather in Nebraska, 69

by Shanks and Arthur in Missouri, 69

by Stevens in Mackenzie Delta, 70

by Takos in Maine, 69-70

by Williams in Idaho, 69

by Wragg in Ontario, 70

Mud Lake; see Ruthven marsh area Muskrat, origin of name, 3

Muskrat-beaver association, 297, 388, $397,402,408,412,414,439,445$, $447,448,450-51,464,589,592-$ 93

Muskrat-mink association, 105-390 passim

fighting, 10, 30-31

muskrats as den makers for minks, 515

Muskrats: comparison of subspecies, 484-86

\section{$\mathbf{N}$}

Nutria (Myocastor coypus)

in France, 476

muskrat-nutria association, 631

\section{$\mathbf{O}$}

Oakwood-Tetonkaha lake and marsh chain (South Dakota), case history of muskrat population, 56071

Ogden Bay Migratory Bird Refuge, 585-86

Ondatra zibethicus albus; see Ap- 
pendix P. 592-94; Appendix Q. 594-97; and Appendix R, 597612

compared to other subspecies, 484 , 485,486

estrous cycle, 33

food preference, 13

habitat, 12, 455-62, 463, 484-85

population status, $457,458,459$. 461,462

range, $410,418,454,455,456$

response to caribou eating their houses, 455

size of, 48

size of litters, 59

taxonomy, 542

time of breeding, 53

Ondatra zibethicus aquilonius

habitat, 454

population status, 454

range, 410, 453-54

size of, 48

taxonomy, 542

Ondatra zibethicus bernardi; see Appendix X, 632

habitat, 632

population status, 473,632

range, 473,474

size of, 48

taxonomy, 543

Ondatra zibethicus cinnamominus: see Appendix J, 578-80

compared to other subspecies, 484 , 485,486

food of in Oklahoma, 581-82

habitat, 12, 422, 423-24, 425-30

intergrading with $O$. z. zibethicus in Kansas, 394

number of litters per female per year in Nebraska, 57

population status, 421, 424, 425 , $426,428,430$

range, 418-19, 422-24, 425, 427, $428,429-30$

range shifting, 391

size of, 48

size of litter, 59-60

taxonomy, 543

Ondatra zibethicus goldmani

range, 473

size of, 48

taxonomy, 543

Ondatra zibethicus macrodon; see
Appendix G, 572-73; Appendix T, 617-19; Appendix V, 624-26; and Blackwater Refuge compared to other subspecies, 484 . 485,486

compared to $O$. z. rivalicius, 472

eye opening time, 38

food, 13, 467, 472

food (Delaware marshes), 617-18

habitat, 467, 468-69, 470

independence of young, 38

lack of self-limitation in population, 484,627

mention of, 6

population status, 422, 467

range, 408, 467, 468, 469-70

resorption of embryos, 34

size of, 48

size of litters, 59

subject of experiment in respiration, 5-6

taxonomy, 542

Ondatra zibethicus mergens

compared to other subspecies, 485 , 486

habitat, 430, 431-32

population status, 432

range, 430-31, 441

size of, 48

taxonomy, 543

Ondatra zibethicus obscurus or Ondatra obscurus

behavior, 592

habitat, 453, 591-92

population status, 453, 591, 592

range, 453

size of, 48

taxonomy, 541-42

Ondatra zibethicus occipitalis

behavior, 433

habitat, 433

range, 421, 432-33

size of, 48

taxonomy, 542-43

Ondatra zibethicus osoyoosensis; see

Appendix N, 588-91

compared to other subspecies, 484 , 485,486

habitat, 12, 434, 435-40, 441-42, $443,444-51,484-85$

population status, 435, 437, 439 . $441,442,443,447-48,449,452$ range, 434, 438, 439, 440-41, 444 
Ondatra zibethicus osoyoosensis, cont. size of, 48

taxonomy, 542

Ondatra zibethicus pallidus range, 473

size of, 48

taxonomy, 543

Ondatra zibethicus ripensis

habitat, 472-73

population status, $472-73$

range, 472, 474

size of, 48

taxonomy, 543

Ondatra zibethicus rivalicius; see

Appendix G, 572-73; Appendix

V, 624-26; Appendix W, 626-31 adaptations, 627

age changes continuous, 47

"carrying capacity" on Louisiana marshes, 627

compared to other subspecies, 484, 485,486

disease (Louisiana), 627

effect of environment on size and fur, 625

food of, 13, 471, 472, 627, 628, 629

food preference, 13

habitat, 471, 472, 627-28

lack of self-limitation of population, 484

population status, $422,470-71,472$

range, 470-72

size of, 48

spring dispersal of, 77

in swimming experiment, 3-4

taxonomy, 543

Ondatra zibethicus spatulatus; see Appendix S, 612-17

compared to other subspecies, 484 , 485,486

habitat, 463-67, 484-85

population status, 463-64, 466, 467 population status on Mackenzie

River Delta, 613, 614-16

range, 455, 463, 464, 466, 467

size of, 48

taxonomy, 542

Ondatra zibethicus zalophus

range, 463

size of, 48

taxonomy, 542

Ondatra zibethicus zibethicus, 105390 passim; see also Biogeography compared to other subspecies, 484, 485,486

diversity of habitat, 12, 484-85

effect of environment on number of litters (Missouri), 57

estrous cycle, 33

geographic range, 419-20

in Alabama, 397-98

in Arkansas, 395

in Georgia, 398, and Appendix G, 572-73

in Illinois, 395, 399, 403-5

in Indiana, 399

in Iowa, 391-92, 393-94, 399-401, and Appendix $\mathrm{H}, 574-76$

in Kansas, 394, 429

in Kentucky, 395, 396

in Louisiana, 395

in Manitoba, 410, 413-14, 456

in Michigan, 405-6

in Minnesota, 401, 411-13, 41418, 419

in Mississippi, 396-97

in Missouri, 57, 393, 394

in Nebraska, 393

in New Brunswick, 409-10, and Appendix I, 577-78

in New England, 409

in New Jersey, 408

in New York, 408-9

in North Carolina, 396, 398

in North Dakota, 418-19

in Nova Scotia, 410

in Ohio, 399, 406, 407

in Oklahoma, 395

in Ontario (Canada), 406-7, 410, 413-14

in Pennsylvania, 407

in Quebec, 410, 453-54

in South Carolina, 398

in South Dakota, 392-93, 419, and Appendix F, 560-71

in Tennessee, 395-96

in Virginia, 408

in West Virginia, 408

in Wisconsin, 401-3

during Plẹistocene, 399

resorption of embryos, 34

size and weight of full adults, 47 , 48

size of litters in U.S., 60

taxonomy, 542, 543 
$\mathbf{P}$

Painted turtles (Chrysemys picta belli), as scavengers on muskrats, $111-12$

Pelage

color mutations (Blackwater Refuge), 623

description of, 3

effect of food on, 49

effect of food on priming, 46-47

as means of age classification, 46 , 95-96

Physiology; see Pollution of water

cause of differential development

in sexes of muskrats, 45

correlation between physiology, fighting, and fall movement, 78-79

effect of poison spray (mosquito control) on muskrats, 471

estrous cycle, 52

insensitivity to carbon dioxide, 78

of muskrat wanderers, 74-75

normal life span, 49-50

oxygen debt in diving animals, 6 placental scars, 53-54

predisposition to disease of young during first month, 39

reproductive, 76

respiration of diving animals, 5-6

sexual changes at time of spring dispersal, 74

tolerance of briny water, 436

tolerance of cold, 8

uterine changes in spring, 95

withstanding hunger, 14

withstanding thirst, 9-10

Pike (Esox lucius)

muskrat response to, 29-30

as predator, 16

predator on young muskrats (Summerberry), 611-12

Polecat (Mustela putorius), predator on muskrat in Europe, 477

Pollution of water, effect on muskrats, $333,364,365,369,404,407$

Population dynamics; see Compensations; Population growth studies; and Intraspecific strife

"Allee effect" of inefficient mating, 189-90, 490

climate as limiting factor, 615, 616 composition of winter mortality, 87

counterbalancing of marsh and stream populations, 494-95

differential mortality of young and adults, 9-10

discussion of Craighead philosophy, 518-19

effect of density on care of young, 23

effect of disease in combination with habitat damage, 500

effect of "eat-outs," 497

effect of "fiddler net" (fishing) on population, 575

effect of human predation, 465 , 511

effect of overtrapping on population, 16, 601

effect of population density on movement, 64, 78, 497

effect of predation combined with habitat deterioration, 622, 631 food as limiting factor, 451-52

general research objectives, 86-87 introductory discussion, $85-86$

lack of self-limitation (rivalicius and macrodon), 484, 627

Malthus' theory, 489-90

muskrat litter size affected by food shortage, 61

muskrat litter size affected by habitat, 61

muskrat litter size affected by population tension, 61

population density in relation to population growth, 490, 498

population effect of mink predation, 513

population effect of predation by miscellaneous predators (great horned owl, red fox, dog, raccoon, snapping turtle, coyote, alligator), 450, 513-14, 621, 629-30

population significance of transients, 11

quotation of Craighead and Craighead philosophy re effect of predation, 516-18

role of territoriality, 489

self-limitation as population force, 490

significance of population growth 
Population dynamics (continued) patterns, 490

size of home range affected by population density, 72

statement of principle of effect of predation, 519

Population growth studies

growth patterns of Iowa muskrat populations, 490-91, 492, 493, 494, 495

significance of population growth studies patterns, 490

in Finland, 480

in Holland, 476-77

on Kent Island (New Brunswick) 577-78

in Manitoba, 596

at Mobile Bay (decline), 624-25

in Nebraska Sand Hills, 579, 580

in Oklahoma, 582

on Steeprock Lease, 592-94

on Summerberry Block, 608-11, 612

Predation, 105-390 passim; see also

Alligator; Badger; Cat; Coyote;

Dog; Fox; Great horned owl;

Hog; Meadow mouse; Mink;

Mink-muskrat relations; Painted turtle; Pike; Polecat; Population dynamics; Raccoon; and Snapping turtle

affected by environmental crises, $17,26,42,265-66,500$

analysis of scats and pellets, 101-3 by California gulls, 435

conditions favoring security of prey, 300, 519-20

in Europe, 477, 481

generalizations about predators, 514-15

in Louisiana, 631

mathematical treatment of, 52021

by miscellaneous predators, 10, 297, 442, 513-14, 577, 621

in Mississippi, 471

muskrat response to predators, 10, 29-30, 627

by weasel, 622

$\mathbf{R}$

Raccoon (Procyon lotor)

on Blackwater Refuge, 622, 623 with liver lesions, 160

in Nebraska Sand Hills, 579

predator upon muskrats, 16, 160, $161,187-88,196-98$

"Rat-ranching," 402, 403

Rattus

in muskrat retreat, 52

physiological research on, 45

placental scar counts, 54

rats in competition with muskrats, 334

Reproduction, 105-390 passim; see also Physiology

environmental conditions for mating, 32

gestation period, 32-34

nonbreeding, 58

number and distribution of litters by placental scars, 58-59

number of litters during cyclic low, 58

number of litters in life span, 58

number of litters per female per year

from Iowa field evidence, 57-58

in Louisiana, 57

in Mackenzie Delta, 57

in Manitoba, 57

in northern U.S., 57

precocious breeding, 55-57, 59

in British Isles, 56

in Germany, 56, 59

in Louisiana, 56

in Manitoba, 57

in northern Canada, 57

reproductive physiology, 76

resorption of embryos, 34

scent during breeding season, 3

seasonal distribution of litters

in Iowa, 53, 54-55

in Manitoba, 53, 595-96

size of litters, 59-61

of $O . z$. albus, 59

of $O . z$. cinnamominus, 59-60

of O. z. macrodon, 59

of $O$. z. rivalicius, 59

of precocious breeders, 61

still births, 34

time of breeding

in California, 51

in Iowa, 52-53, 55

in Louisiana, 51

in Maryland, 51, 52

in southern Wisconsin, 52

in Texas, 51 
time of mating after birth of litter, 33-34

variation of litter size during breeding season, 61

Round Lake; see Ruthven marsh area

Round-tailed muskrat (Neofiber alleni)

range in Florida, 398-99

taxonomy, 543

Ruthven marsh area, northwestern

Iowa; see Appendix B, 545-46

Dewey's Pasture, 104, 115-16

Lost Island Lake, 139-40

map of, 105

Mud Lake, 104-6, 107-8, 114, 115, 119

Round Lake, 104, 106-7, 108-14, 116-18, 119-24

Trumbull Lake, 139-40

Russia; see Biogeography

colonization of muskrats, 478-79

economic damage by muskrats, 478

size and development of young muskrats in, 45

tularemia in, 481

\section{S}

\section{Salmonella typhimurium}

in Maryland, 619

used by French for control of muskrats, 476

"Salvage trapping," 601

Sand Hills of Nebraska; see Appen$\operatorname{dix}$ J, 578-80

Scandinavian lemmings (Lemmus lemmus)

mass movements, 78

overflow phenomenon, 63

Scent

anatomy of glands, 3

chemical properties, 3

Scirpus olneyi

food of $O$. $z$. macrodon and $O$. $z$. rivalicius, 13, 467, 471, 472.

617-18, 628, 629

in Georgia and Florida, 573

Self-limitation of populations; see Population dynamics

Sex ratios

of adults, 50-51

of adults in Germany, 51

at birth, 35

differential sex mortality, 50 differential sex mortality of wanderers, 76

of subadults, 47

Skunk River; see Central Iowa streams and outlying waters

Snapping turtle (Chelydra serpentina), predation by, 16,515

Social organization; see Intraspecific strife

Steeprock Lease (Manitoba, Hudson's Bay Company area)

evidence of cycle, 594

habitat, 592

population growth studies, 592-94

Summerberry Fur Rehabilitation Block (Manitoba government's area)

annual lodge counts tabulated, 607 cyclic manifestations, 605

food, 603, 604

habitat, 602-3, 604, 605, 606-10

hemorrhagic disease, 605, 608, 609

mass movements during droughts, 606

population studies, 608-11, 612

predation by pike on young muskrats, $611-12$

"sour" land, 604

Typha latifolia preferred plant, 604

Sweden; see Biogeography

future status of muskrat in, 483

introduction and colonization of muskrat, 482-83

quality of Swedish habitat, 483

\section{$\mathbf{T}$}

Tagging of muskrats

live-trapping and tagging, 575-76

summary statement, 63-64

Taxonomy; see Appendix A, 541-45

Techniques of study, 105-390 passim; see also Appendix C, 54650 , re calculation of fall population at Wall Lake

bubble "sign," 92

censusing from "signs," 92-93

censusing under-ice populations, 91

diagnostic marks from predation, 98

direct enumeration, 89

epizootics provide census data, 90 
Techniques of study (continued)

examination of mortality victims, 87, 91-92

examination of muskrat droppings and stomach contents, 101

examination of pathological material, 98

examination of scats and pellets, $87,89,101,103$

examination of trapped muskrats, 92, 93-97

field observations during crises, 90 91

late fall census methods, 90

limitations to tabulated data, 510, 511

mapping, etc., 86

mink predation as indicator of insecurity, 87

placental scars, 53-54, 55, 58, 9697

plotting annual rates of gain (or loss) against adult or breeding densities, 490

post-mortems for dating death, 89 post-mortems of hemorrhagic disease victims, 98-99

post-mortems of late summer and fall, 90

ravens indicate sites of mortality, 599

"reading of sign," $86,87,88,91$

spring census by territorial foci, 89

tabulation of annual lodge counts, 600,607

Territoriality, 105-390 passim; see also Cycles

adjustment in home ranges, 73

as affected by cycle, 71

during colonization, 71

fidelity to home range in winter flood, 77

home range mentioned, 71

selection of breeding territories, 76

size of home range, 72

size of territory, 71

territorial adjustments in response to environmental pressures, $72-73$

territorial responses of breeding female, 71, 72

territorial responses of male, 72 territoriality as affected by population density, 71-72

territoriality defined, 71

territoriality of free-living small rodents other than muskrats, 63

Trichophyton mentagrophytes, 110 , $111,112,118,121,136,194,337$. 579-80

geographic distribution, 501

re very young muskrats, 39

Tularemia, 437, 439, 501, 503-5; see also Appendix M, 586-88

on Cumberland Lease, 599

in Montana, 448, 586-87

in Russia, 481

in Wisconsin, 403

\section{$\mathbf{V}$}

Verhults-Pearl-Reed logistic curve

applied to muskrat populations, 407, 459, 479, 593, 594, 599, $601,602,612,621$

pattern in population behavior, 490

\section{W}

Wall Lake area, north central Iowa, 151-203; see also Appendix C, 546-50

map of, 152

Water manipulation

effect of flood control projects on muskrats, 497

effect of irrigation diversions on muskrat habitat, 498

effect of water manipulation on muskrat habitat, 498

water manipulation on Cumberland Lease, 597

Wind tides, effect on muskrat habitat

(Manitoba), 459, 460, 461-62. 594

Wounds, 105-390 passim

affecting value of pelt, 47

effect of wounds on young of one month, 39

intraspecific strife wounds during drought crises, 80

of "kits," 43

nature of, 10-11, 98 
scarred pelts of trapped adults, 46 from trapping, 11, 98 of very young, 35 of wanderers, 74-75
$\mathbf{Y}$

Yellowstone National Park, muskrat habitat, 449-50 